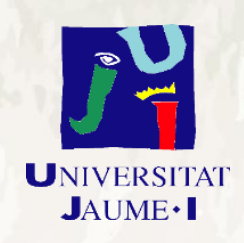

PROGRAMA DE DOCTORADO EN

LENGUAS APLICADAS, LITERATURA Y TRADUCCIÓN

Escuela de doctorado de la Universitat Jaume I

\title{
MULTILINGUAL EDUCATION: A CONTRASTIVE ANALYSIS IN HUMANITIES, SOCIAL SCIENCES AND HEALTH SCIENCES
}

La educación multilingüe: Análisis contrastivo entre las áreas de Humanidades, Ciencias Sociales y Ciencias de la Salud

Castelló de la Plana, October 2021

PhD candidate: Lucía Bellés Calvera PhD supervisor: Dr. Begoña Bellés Fortuño 


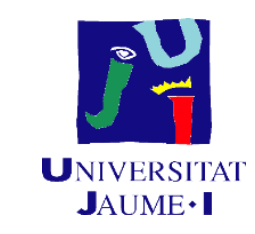

Programa de Doctorado en Lenguas Aplicadas, Literatura y Traducción

Escuela de Doctorado de la Universitat Jaume I

\section{Multilingual Education: A Contrastive Analysis in Humanities, Social Sciences and Health Sciences}

La educación multilingüe: Análisis contrastivo entre las áreas de Humanidades, Ciencias Sociales y Ciencias de la Salud

Memoria presentada por Lucía Bellés Calvera para optar al grado de doctor/a por la Universitat Jaume I

Lucía Bellés Calvera

BELLES Firmado digitalmente

CALVERA LUCIA LUCIA - 53787388W

- 53787388W Fecha: 2021.10.22
Directora: Begoña Bellés Fortuño

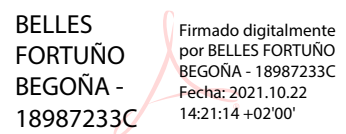

BELLES

Por BELLES FORTUNO

$18987233 C$ 


\section{Licencia CC Reconocimiento - No comercial - Compartir igual (BY-NC-SA).}

Se puede reutilizar contenido de tu tesis indicando expresamente que tú eres el autor/a, pero sin hacer un uso comercial. Sí que se pueden crear otras obras a partir de la tuya, siempre con la misma licencia que la de tu tesis.

\section{Financiación recibida}

Agencias financiadoras del doctorando/a

- Contratos predoctorales: 3. Programa de suport a la formació i incorporació de personal investigador. Acció 3.1. Convocatòria d'ajudes predoctorals per a la formació de personal investigador. Contrato predoctoral FPI de la UJI (Programa propio) PREDOC/2017/36

- Fundaciones o agencias que hayan contribuido a financiar gastos formativos o estancias de investigación: Pla de promoció de la investigació a I'UJI. Convocatòria de beques per a realitzar estades temporals en altres centres d'investigació per l'any 2019 (OCIT - Oficina de Cooperació en Investigació i Desenvolupament Tecnològic), Convocatòria Erasmus+ Práctiques 2018/2019 (OIPEP - Oficina d'Inserció Professional i Estades en Pràctiques) 


\section{ACKNOWLEDGEMENTS}

This $\mathrm{PhD}$ thesis would not have been possible without the advice and support I have received from a number of people, to whom I would like to show my gratitude. First of all, I would like to thank Dr. Begoña Bellés-Fortuño, who believed in my potential since I was an undergraduate student. Not only did she introduce me to the academic and research world but has also guided me throughout the whole process. Her supervision as well as her insightful comments on the earlier drafts of this study have been extremely valuable.

My gratitude extends to Professor Juan José Ferrer Maestro and Dr. Josep Benedito for giving me the opportunity to grow as a researcher within the ANTIQUA team as well as for their advice and encouraging words whenever I needed them. I am also indebted to Professor John E. Joseph and Professor Ruslan Mitkov for their warm welcome and assistance during my research stays at The University of Edinburgh and the University of Wolverhampton.

I am also grateful to the members and colleagues belonging to the CHLIOS group for inspiring me in my academic and professional endeavours. Without them, expanding my knowledge of Content and Language Integrated Learning (CLIL) initiatives would not have been the same.

All my gratitude goes to all the teachers and students that voluntarily took part in this research and allowed me to audio-record their oral outcomes in multilingual learning environments. Their generosity and cooperation were pivotal for the development of this research, where their anonymity has been preserved.

Last, I would like to thank my family for their love, support and patience, especially to my great-grandparents, Ángel and Pilar. Even though they passed away during this academic journey, I know they would be proud of my achievements. Thanks to my parents and my sister for taking such good care of me and being always by my side. Mamà, Papà, Noelia, gràcies per cuidar-me i estar sempre al meu costat. Vos vull molt. 


\section{Abstract}

Having a good command of additional languages has been valued as a positive asset in academic and professional spheres (European Commission, 2020b). Such influence has prompted the internationalisation of educational institutions, boosting the emergence of the Content and Language Integrated Learning (CLIL) approach, which implies the acquisition of curricular contents through a target language (Carrió-Pastor, 2013, 2019b; Ioannou-Georgiou \& Pavlou, 2011). Within the Spanish territory, different realities may occur in monolingual and bilingual regions implementing CLIL initiatives given that official, co-official and international languages are guaranteed in the education system.

Previous research on the CLIL approach has generally explored written and spoken outcomes, including areas such as grammar, vocabulary and pronunciation (BellésCalvera \& Bellés-Fortuño, 2018a, in press; Nikula et al., 2013; Uchihara \& Harada, 2018). Classroom interaction should also be approached as part of the learning process itself (Escobar Urmeneta \& Walsh, 2017; Martín del Pozo, 2014) by identifying metadiscoursal devices and translanguaging instances. Bearing this in mind, this dissertation focuses on the implementation of CLIL practices delivered at a multilingual Spanish university, more specifically at Universitat Jaume I. The programmes under study are offered within the degrees in History and Heritage, Humanities: Intercultural Studies, Tourism, Medicine, Nursing and Psychology. This study seeks to present a comparative analysis in the fields of Soft Sciences and Hard Sciences. The current research study examines the metadiscoursal traits employed by lecturers and undergraduate students in CLIL seminars.

As for the methodology, the data were retrieved from several research instruments: audio-recorded interviews, CLIL seminars and lectures, observation rubrics, students' questionnaires and placement tests. The interviews bring to light lecturers' and learners' concerns about the CLIL approach, including the command of the English language, anxiety levels, and the need for teacher training initiatives. Secondly, the data obtained from students' final surveys reveal that the respondents seem to be satisfied with their language learning experience, especially those belonging to the field of Health Sciences. Likewise, when dealing with attitudinal issues related to learning disciplinary knowledge through a foreign language, no objection is shown in the domains of Tourism and Medicine. From these questionnaires, it can be noted that actions devoted 
to disseminating institutional linguistic policies should be tackled. As to placement tests, participants in the area of Health Sciences appear to have an advanced communicative competence in the foreign language, with medical students outperforming undergraduates involved in other degrees.

Similarities and differences between Soft and Hard Sciences are not only limited to the interviews, surveys and placement tests conducted for the purpose of this study but also to classroom interaction. The findings indicate that there is not a big gap among the CLIL lectures and seminars allocated for the fields of Humanities and Social Sciences. There is a subtle tendency for History lecturers to produce a broader range of interpersonal markers in CLIL lectures. Similarly, the linguistic devices found in teacher discourse seem to be more predominant in the fourth-year module delivered in the History degree. It has also been illustrated that metadiscoursal features are more numerous in Health Sciences, where communicative exchanges occur at a higher rate. In fact, remarkable learner and teacher productions have been shown in the Medicine classroom.

This investigation sheds some light on the relevance of interpersonal markers in multilingual interaction practices delivered in higher education. Evidence may be used in future teacher training programmes in order to support meaningful CLIL experiences. 


\section{RESUMEN}

Últimamente se está valorando de manera muy positiva el dominio de otras lenguas en ámbitos académicos y profesionales (European Commission, 2020b). Dicha influencia ha propiciado la internacionalización de instituciones educativas, favoreciendo la irrupción del enfoque de Aprendizaje Integrado de Contenidos y Lenguas (AICLE), en el que la adquisición de contenidos curriculares tiene lugar a través de una lengua meta (Carrió-Pastor, 2013, 2019b; Ioannou-Georgiou \& Pavlou, 2011). Dentro del territorio español, pueden observarse diferentes realidades en regiones monolingües y bilingües en las que se implementan iniciativas AICLE, dado que la enseñanza en lenguas oficiales, cooficiales e internacionales está garantizada en el sistema educativo.

Las investigaciones anteriores sobre el enfoque AICLE han contemplado, por lo general, los productos escritos y orales en desde el campo de la gramática, el léxico y la pronunciación (Bellés-Calvera \& Bellés-Fortuño, 2018a, in press; Nikula et al., 2013; Uchihara \& Harada, 2018). La interacción en el aula también debe abordarse como parte del propio proceso de aprendizaje (Escobar Urmeneta \& Walsh, 2017; Martín del Pozo, 2014), identificando marcadores metadiscursivos y prácticas de translenguaje. Teniendo esto en cuenta, esta tesis se centra en la implementación de prácticas AICLE impartidas en una universidad española multilingüe, más concretamente en la Universitat Jaume I. Los programas objeto de estudio se ofrecen dentro de los grados de Historia y Patrimonio, Humanidades: Estudios Interculturales, Turismo, Medicina, Enfermería y Psicología. Este estudio tiene como objetivo presentar un análisis comparativo en las disciplinas de Ciencias blandas y Ciencias duras. El presente estudio de investigación examina los elementos metadiscursivos empleados por profesores y estudiantes en los seminarios AICLE.

En cuanto a la metodología, los datos se obtuvieron a partir de varios instrumentos de investigación: entrevistas grabadas en audio, seminarios y clases de AICLE, rúbricas de observación, cuestionarios de los alumnos y pruebas de nivel. Las entrevistas ponen de manifiesto las preocupaciones de profesores y alumnos en torno al enfoque AICLE, como son el dominio de la lengua inglesa, los niveles de ansiedad y la necesidad de iniciativas destinadas a la formación del profesorado. En segundo lugar, los datos obtenidos en los cuestionarios finales de los estudiantes revelan que los participantes parecen estar satisfechos con su experiencia previa en el aprendizaje de idiomas, 
especialmente los pertenecientes al ámbito de Ciencias de la Salud. Asimismo, cuando se trata de cuestiones actitudinales vinculadas al aprendizaje de conocimientos disciplinares a través de una lengua extranjera, no se muestra ninguna objeción en los ámbitos de Turismo y Medicina. De estas encuestas se llega a la conclusión de que deberían tomarse medidas destinadas a la difusión de las políticas lingüísticas institucionales. En cuanto a las pruebas de nivel, los participantes de Ciencias de la Salud parecen tener una competencia comunicativa avanzada en la lengua extranjera, siendo los estudiantes de Medicina quienes sobresalen por encima de otras titulaciones.

Las similitudes y las diferencias entre las disciplinas vinculadas a Ciencias duras y blandas no solo se limitan a las entrevistas, las encuestas y las pruebas de nivel realizadas para este estudio, sino tambien a la interacción en el aula. Los resultados indican que no existe una gran diferencia entre las clases magistrales y los seminarios de AICLE impartidos en las áreas de Humanidades y Ciencias Sociales. Existe una ligera tendencia por parte del profesorado de Historia a producir una gama más amplia de marcadores interpersonales en las clases de AICLE. De igual modo, los recursos lingüísticos encontrados en el discurso del profesor parecen ser más predominantes en la asignatura de cuarto curso impartida en el grado de Historia. También se ha puesto de manifiesto que los rasgos metadiscursivos son más numerosos en Ciencias de la Salud, donde los intercambios comunicativos se producen con mayor frecuencia. De hecho, se han mostrado notables intervenciones de alumnos y profesores en el aula de Medicina.

Esta investigación arroja un poco de luz acerca de la importancia de los marcadores interpersonales en las prácticas de interacción multilingüe que se llevan a cabo en educación superior. Los resultados pueden utilizarse para la creación de futuros programas de formación de profesores con el fin de respaldar experiencias significativas de AICLE. 


\section{TABLE OF CONTENTS}

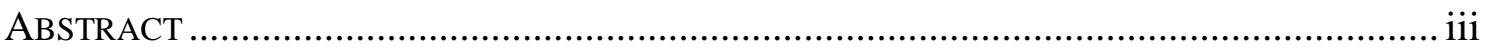

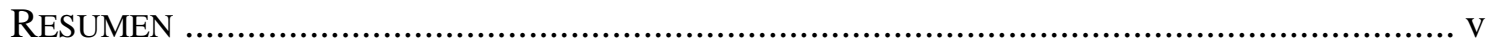

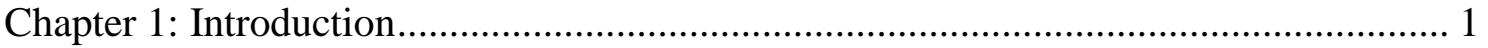

1.1. PRELIMINARY CONSIDERATIONS TO THE STUDY .............................................. 1

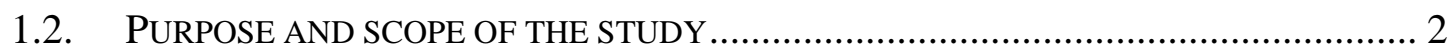

1.3. RESEARCH QUESTIONS AND METHODOLOGY ................................................... 4

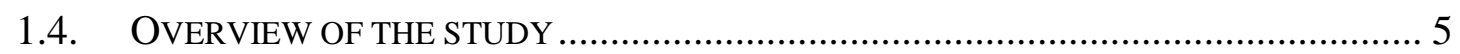

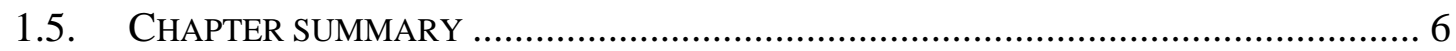

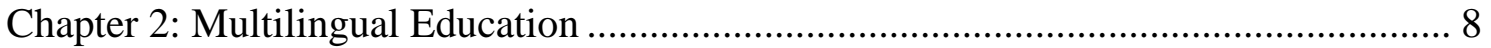

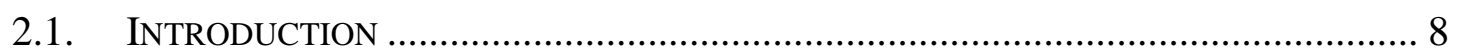

2.2. FROM MONOLINGUALISM TO MULTILINGUALISM .............................................. 9

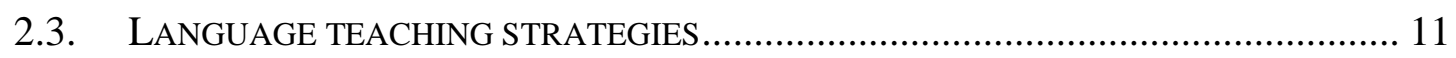

2.4. INTERNATIONALISATION OF THE HIGHER EDUCATION LANDSCAPE: A GLOBAL VIEW 14

2.5. The EURopeAn Higher EdUCATION ArEA (EHEA) ....................................... 18

2.5.1. Internationsalisation strategies in monolingual countries ...................... 21

2.5.2. Internationsalisation strategies in bilingual or multilingual countries...... 25

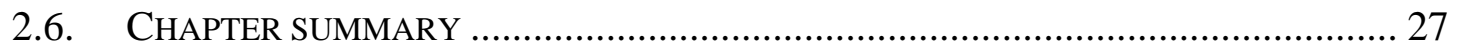

Chapter 3: The Content and Language Integrated Learning (CLIL) approach .............. 29

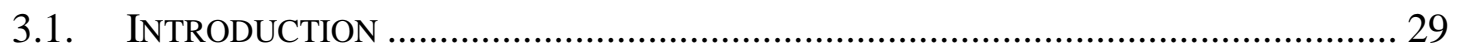

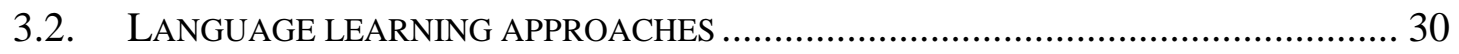

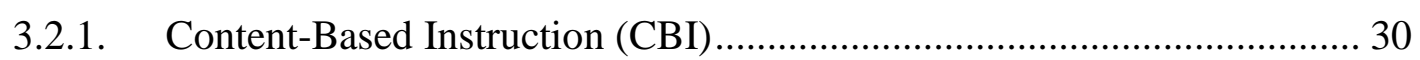

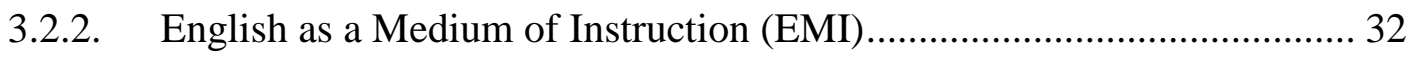

3.2.3. Content and Language Integrated Learning (CLIL) features ................... 33

3.2.4. CBI, CLIL and EMI: The concepts ..................................................... 36

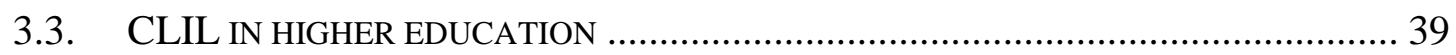

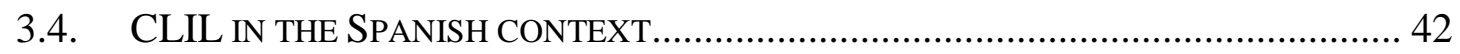

3.4.1. CLIL in monolingual and bilingual regions ....................................... 45

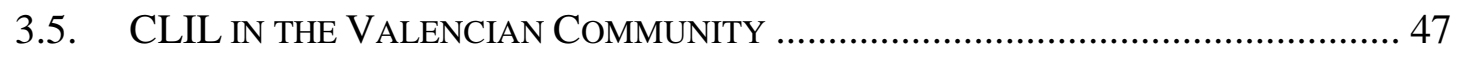

3.5.1. The case of Universitat Jaume I ........................................................ 48

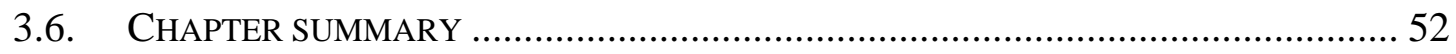


Chapter 4: Academic discourse

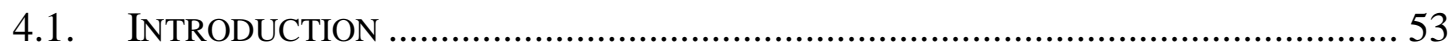

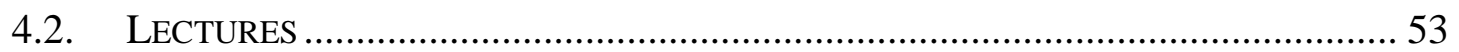

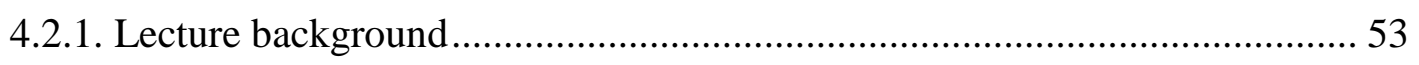

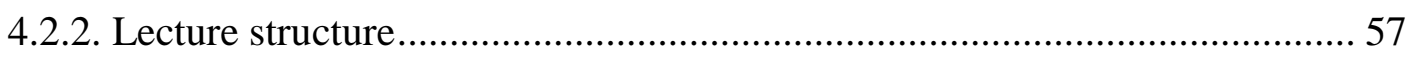

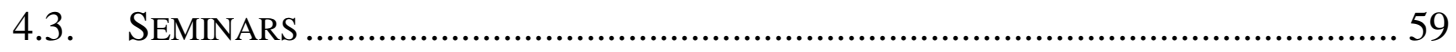

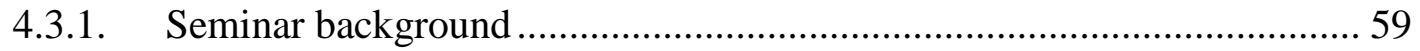

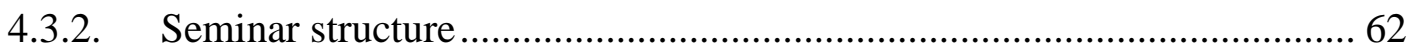

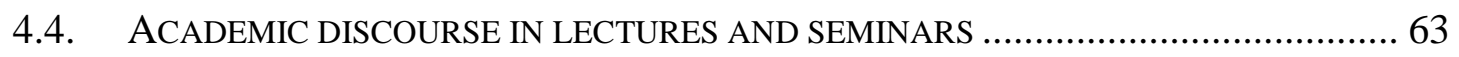

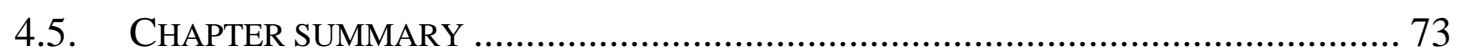

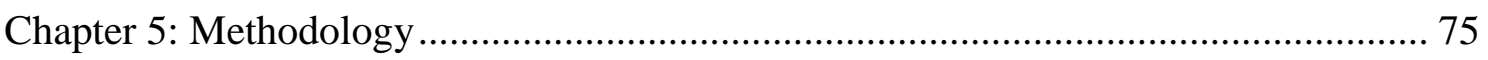

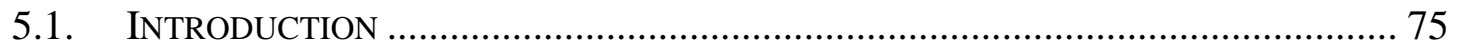

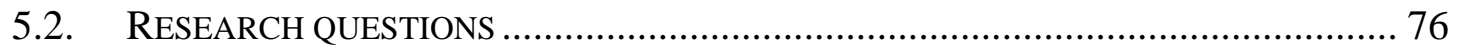

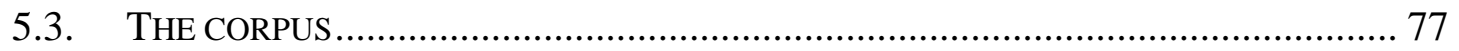

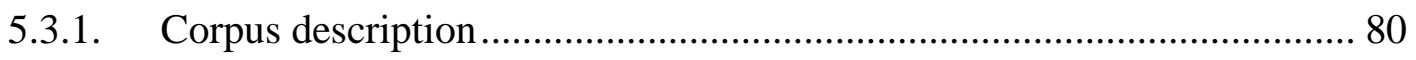

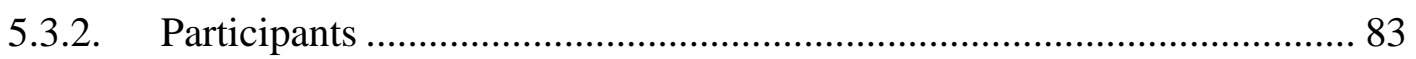

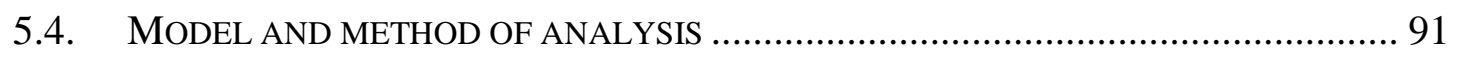

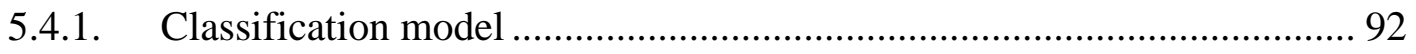

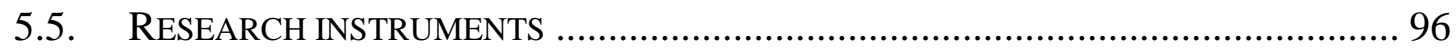

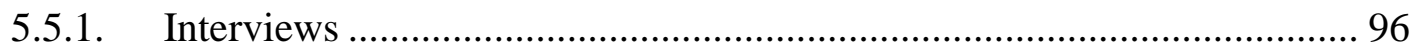

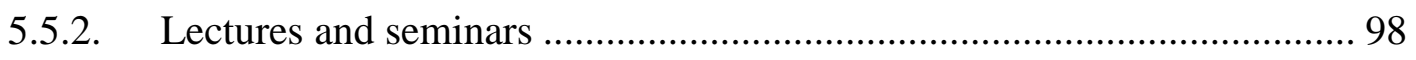

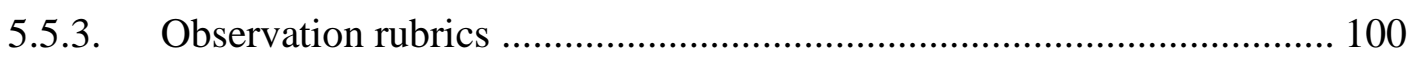

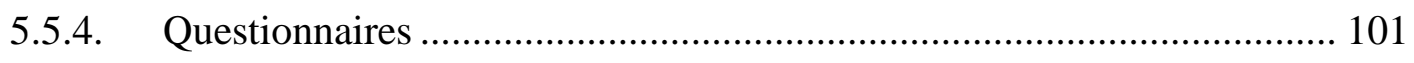

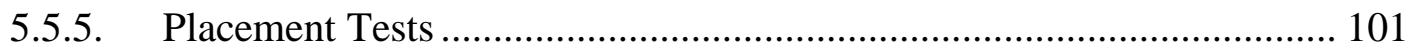

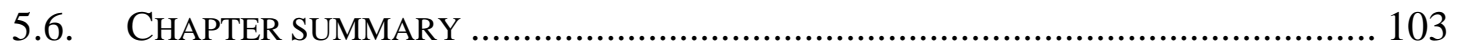

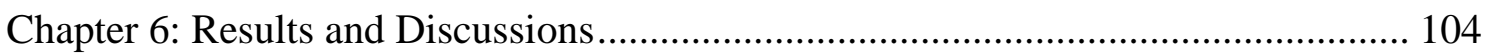

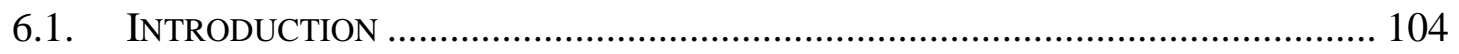

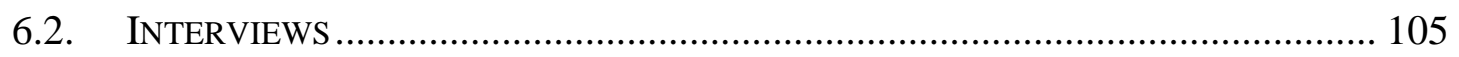

6.2.1. Lecturers' views on learners' concerns in the CLIL classroom ............. 106

6.2.2. Lecturers' concerns in the CLIL classroom ......................................... 110

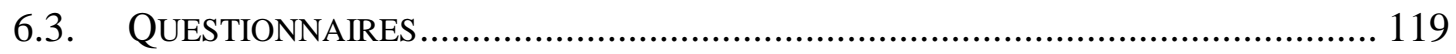

6.3.1. Humanities and Social Sciences ......................................................... 120

6.3.2. Health Sciences: The cases of Medicine, Nursing and Psychology ....... 127 
6.3.3. Humanities and Social Sciences vs. Health Sciences............................ 139

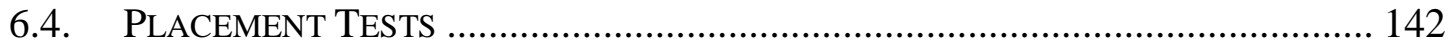

6.4.1. Humanities and Social Sciences .......................................................... 142

6.4.2. Health Sciences........................................................................... 143

6.4.3. Humanities and Social Sciences vs. Health Sciences ............................ 144

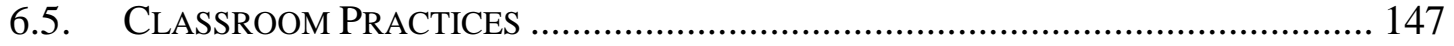

6.5.1. Humanities and Social Sciences ............................................................. 148

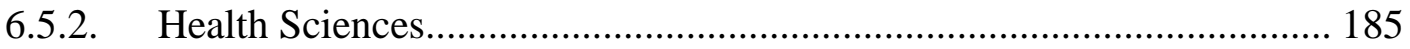

6.5.3. Humanities and Social Sciences vs. Health Sciences ............................ 220

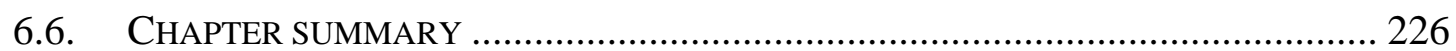

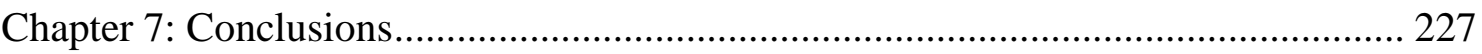

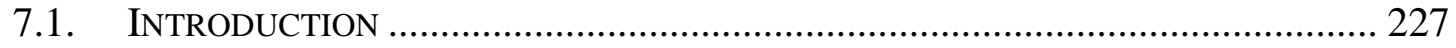

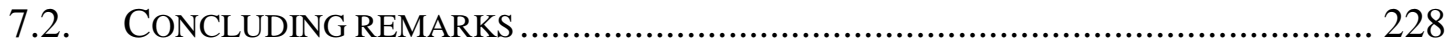

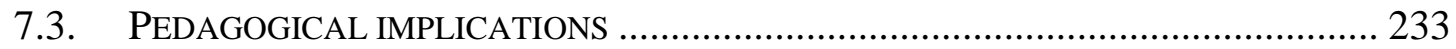

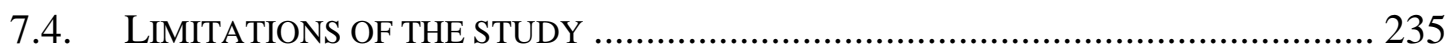

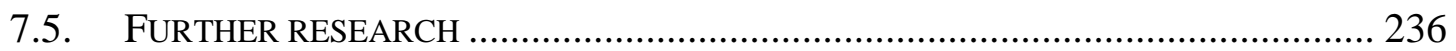

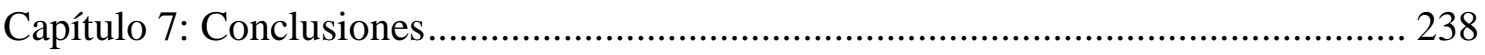

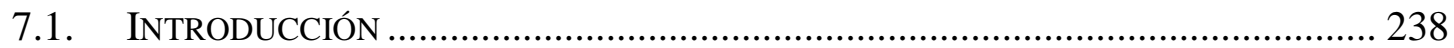

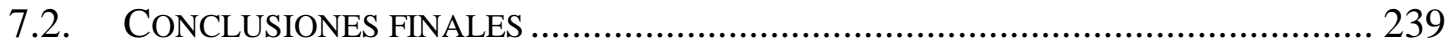

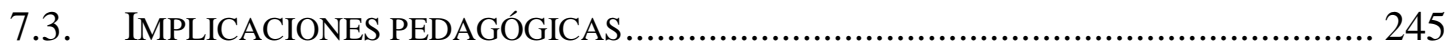

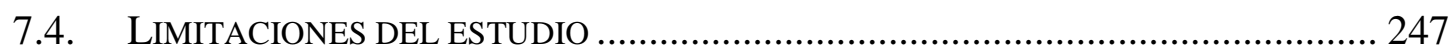

7.5. SUGERENCIAS PARA FUTURAS INVESTIGACIONES.......................................... 248

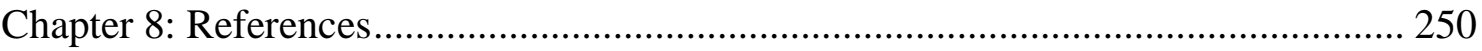

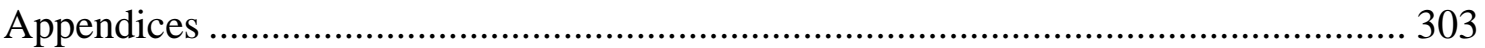




\section{LIST OF TABLES}

Table 1. Content-driven and language-driven CLIL programmes (Met, 1998)............. 31

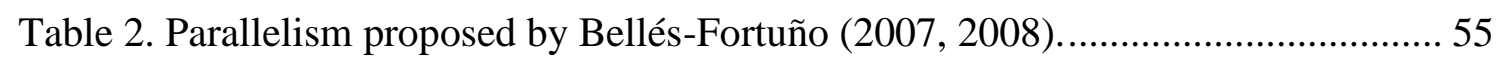

Table 3. Comparison of the structural phases of seminars based on Weissberg (1993)

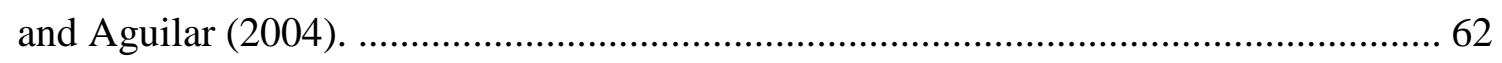

Table 4. The structural phases of lectures (Dafouz \& Núñez (2010, p. 218) ................. 65

Table 5. Phase analysis and metadiscoursal categories (Dafouz \& Núñez, 2010, p. 220).

Table 6. Phases and metadiscoursal categories for CLIL lectures (Martín del Pozo, 2014, p. 261).

Table 7. Framework for understanding the roles of language in CLIL (Llinares et al., 2012, p.15). 68

Table 8. Register dimensions and metafunctions of language (Halliday \& Matthiessen, 2004) 70

Table 9. Hyland's interpersonal model: interactive dimension (2005, p. 49)................ 71

Table 10. Hyland's interpersonal model: interactional dimension (2005, p. 49)........... 71

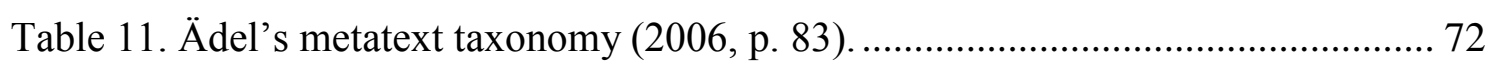

Table 12. Degrees and its corresponding modules included for the analysis of the study.

Table 13. Transcription codes. 79

Table 14. Corpus description of CLIL practices in the field of Humanities and Social Sciences. 81

Table 15. Corpus description of CLIL practices in the field of Health Sciences........... 82

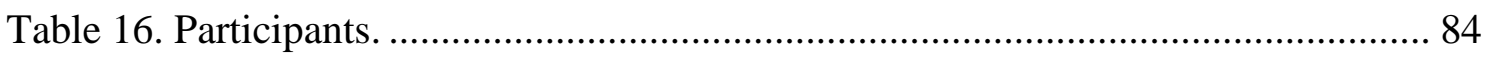

Table 17. First-year participants in the History and Heritage degree............................. 85

Table 18. Fourth-year participants in the History and Heritage degree. ........................ 86

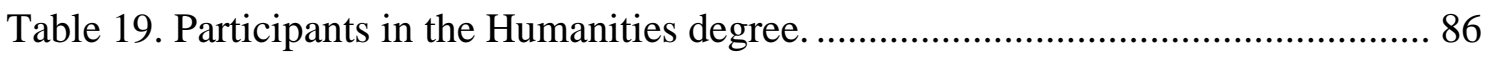

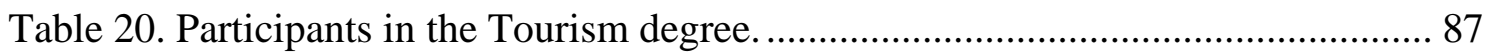

Table 21. First-year participants in the Medicine degree: English for Medicine seminars.

Table 22. Second-year participants in the Medicine degree: Anthropology and

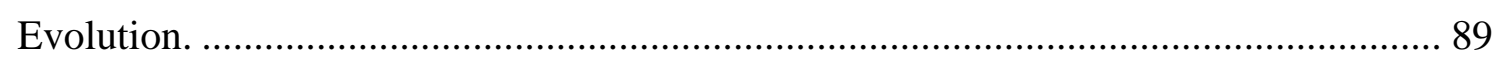

Table 23. Participants in the Medicine degree: Epidemiology and Public Health......... 89 
Table 24. Participants in the Nursing degree.

Table 25. Participants in the Psychology degree.

Table 26. Classification model for the analysis of interpersonal traits in CLIL discourse. Adapted from Martín del Pozo (2014). 94

Table 27. Summary of CLIL interviews and interviewees. 98

Table 28. Questionnaire: First variable (Q1-Q6).... 119

Table 29. Questionnaire: Second variable (Q7-Q12). 119

Table 30. Results from the placement tests administered in the fields of Humanities and Social Sciences.

Table 31. Results from the placement tests administered in the field of Health Sciences.

Table 32. Results obtained from the placement tests administered in the fields of Humanities, Social Sciences and Health Sciences. 146

Table 33. Metadiscoursal markers analysed in the fields of Humanities, Social Sciences and Health Sciences.

Table 34. Total number of metadiscoursal markers found in teacher discourse in Humanities and Social Sciences.

Table 35. Total number of metadiscoursal markers found in teacher discourse in Humanities and Social Sciences.

Table 36. Use of different markers in teacher discourse in Humanities and Social Sciences: Lecture / Lecture seminars. 152

Table 37. Use of different markers in teacher discourse in Humanities and Social Sciences: Seminars.

Table 38. Use of different markers in student discourse in Humanities and Social Sciences: Lecture / Lecture seminars. 154

Table 39. Use of different markers in student discourse in Humanities and Social Sciences: Seminars.

Table 40. Use of engagement markers in teacher discourse in Humanities and Social Sciences: Lectures or lecture seminars. 158

Table 41. Global use of engagement markers in teacher discourse in Humanities and Social Sciences: Lectures or lecture seminars. 158

Table 42. Use of engagement markers in teacher discourse in Humanities and Social Sciences: Seminars. 159 
Table 43. Global use of engagement markers in teacher discourse in Humanities and Social Sciences: Seminars.

Table 44. Use of engagement markers in student discourse in Humanities and Social Sciences: Lectures / lecture seminars.

Table 45. Global use of engagement markers in student discourse in Humanities and

Social Sciences: Lectures / lecture seminars. 166

Table 46. Use of engagement markers in student discourse in Humanities and Social Sciences: Seminars.

Table 47. Global use of engagement markers in student discourse in Humanities and Social Sciences: Seminars.

Table 48. Use of attitudinal markers in teacher discourse in Humanities and Social Sciences: Lecture / Lecture seminars. 171

Table 49. Use of attitudinal markers in teacher discourse in Humanities and Social Sciences: Seminars.

Table 50. Use of attitudinal markers in student discourse in Humanities and Social Sciences: Lecture / Lecture seminars.

Table 51. Use of attitudinal markers in student discourse in Humanities and Social Sciences: Seminars.

Table 52. Use of boosters in teacher discourse in Humanities and Social Sciences: Lectures and Seminars. 178

Table 53. Use of boosters in student discourse in Humanities and Social Sciences: Seminars 180

Table 54. Use of hedges in teacher discourse in Humanities and Social Sciences: Lectures and Seminars.

Table 55. Use of different markers in student discourse in Humanities and Social Sciences: Lectures and Seminars. 184

Table 56. Total number of metadiscoursal markers found in teacher discourse in Health Sciences. 185

Table 57. Total number of metadiscoursal markers found in student discourse in Health Sciences. 186

Table 58. Use of different markers in teacher discourse in Health Sciences: Seminars.

Table 59. Use of different markers in student discourse in Health Sciences: Seminars. 
Table 60. Use of engagement markers in teacher discourse in Health Sciences: Medicine seminars.

Table 61. Use of engagement markers in teacher discourse in Health Sciences: Nursing seminar.

Table 62. Use of engagement markers in teacher discourse in Health Sciences: Psychology seminar.

Table 63. Global use of engagement markers in teacher discourse in Health Sciences: Seminars

Table 64. Use of engagement markers in student discourse in Health Sciences: Seminars.

Table 65. Use of engagement markers in student discourse in Health Sciences: Nursing seminar.

Table 66. Use of engagement markers in student discourse in Health Sciences: Psychology seminar. 203

Table 67. Global use of engagement markers in teacher discourse in Health Sciences: Seminars. 204

Table 68. Use of attitudinal markers in teacher discourse in Health Sciences: Seminars. 209

Table 69. Use of attitudinal markers in student discourse in Health Sciences: Seminars.

Table 70. Use of boosters in teacher discourse in Health Sciences: Seminars.

Table 71. Use of boosters in student discourse in Health Sciences: Seminars. 215

Table 72. Use of hedges in teacher discourse in Health Sciences: Seminars. 216

Table 73. Use of hedges in student discourse in Health Sciences: Seminars. 218

Table 74. Results obtained from the placement tests administered in the fields of Humanities, Social Sciences and Health Sciences.

Table 75. Global use of metadiscoursal markers in teacher discourse: Lectures and Seminars

Table 76. Global use of metadiscoursal markers in student discourse: Lectures and Seminars. 


\section{LiST OF FIGURES}

Figure 1. Description of Dubois' continuum (1987, p.537), as in Aguilar (2004, p.62).61 Figure 2. Results from students' final questionnaire (Q1-Q6): First-year History and Humanities students.

Figure 3. Results from students' final questionnaire (Q7-Q12): First-year History and Humanities students.

Figure 4. Results from students' final questionnaire (Q1-Q6): Fourth-year History students.

Figure 5. Results from students' final questionnaire (Q7- Q13): Fourth-year History students.

Figure 6. Results from students' final questionnaire (Q1-Q6): Fourth-year Tourism students. 126

Figure 7. Results from students' final questionnaire (Q7- Q12): Fourth-year Tourism students.

Figure 8. Results from students' final questionnaire (Q1-Q6): First-year Medicine students. 128

Figure 9. Results from students' final questionnaire (Q7- Q13): First-year Medicine students.

Figure 10. Results from students' final questionnaire (Q1-Q6): Second-year Medicine students. 130

Figure 11. Results from students' final questionnaire (Q7- Q13): Second-year Medicine students

Figure 12. Results from students' final questionnaire (Q1-Q6): Third-year Medicine students.

Figure 13. Results from students' final questionnaire (Q7- Q13): Third-year Medicine students. 134

Figure 14. Results from students' final questionnaire (Q1-Q6): Third-year Nursing students.

Figure 15. Results from students' final questionnaire (Q7- Q13): Third-year Nursing students.

Figure 16. Results from students' final questionnaire (Q1-Q6): Fourth-year Psychology students. 
Figure 17. Results from students' final questionnaire (Q7- Q13): Fourth-year

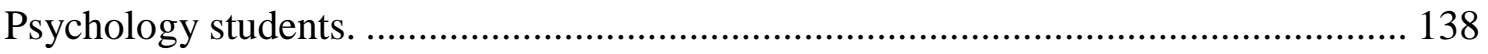
Figure 18. Total number of metadiscoursal markers in teacher discourse: CLIL lectures and seminars in Humanities and Social Sciences....................................................... 149 Figure 19. Total number of metadiscoursal markers in student discourse: CLIL lectures and seminars in Humanities and Social Sciences...................................................... 150 Figure 20. Teacher discourse in CLIL seminars: Health Sciences.............................. 186 Figure 21. Student discourse in CLIL lectures and seminars: Health Sciences. .......... 187 


\section{LIST OF ACRONYMS AND ABBREVIATIONS}

AICLE

ASEAN

BA

BICS

Bi-/multilingual

Bi-/multilingualism

CBI

CALP

CEFR

CIS

CEIL

CLIL

CLILiG

COVID-19

CRUE

EAP

ECOPOL

EFL

EHEA

ELFA

ELT

EMILE

ESP

EU

ECML

EGFSN

FL

HOTS

ICLHE

ICTs
Aprendizaje Integrado de Contenido y Lenguas

Association of South-East Asian Nations

Bachelor of Arts

Basic Interpersonal Communicative Skills

Bilingual and multilingual

Bilingualism and multiligualism

Content-Based Instruction

Cognitive Academic Language Proficiency

Common European Framework of Reference for Languages

Centro de Investigaciones Sociológicas

Content and English Integrated Learning

Content and Language Integrated Learning

Content and Language Integrated Learning in German

Coronavirus disease 2019

Conference of Spanish University Rectors

English for Academic Purposes

Strategy for the Coexistence and Promotion of Language

[Estratègia de convivència i promoció lingüística]

English as a Foreign Language

European Higher Education Area

English as a lingua franca in academic settings

English Language Teaching

Enseignement de Matières par l'Intégration d'une Langue Étrangère

English for Specific Purposes

European Union

European Centre for Modern Languages

Expert Group on Future Skills Needs

Foreign language

Higher Order Thinking Skills

Integrated Content and Learning in Higher Education

Information and Communication Technologies 
IELTS

IRF

ITC

L1

L2

LEL

LES

LOE

LOTS

LSP

MA

Mercator

MICASE

MDGs

MULTIMAT

NLP

ODL

$\mathrm{PhD}$

RGCL

SFL

TOEFL

UK

UN

USA
International English Language Testing System

Initiation-Response-Follow up

Institute of Ceramic Technology

First language

Second language

Large lectures

Small lectures

Organic Law on Education

Lower Order Thinking Skills

Language for Specific Purposes

Master

European Research Centre on Multilingualism and Language

Learning

Michigan Corpus of Academic Spoken English

Millennium Development Goals

Multilingualism Matters

Natural Language Processing

Open and distance learning

Doctor of Philosophy

Research Group in Computational Linguistics

Systemic Functional Linguistics

Test of English as a Foreign Language

United Kingdom

United Nations

United States of America 


\section{TRANSCRIPTION CODES}

\begin{tabular}{|c|c|}
\hline , & Short pause \\
\hline . & Pause \\
\hline : & Long pause \\
\hline- & Repetition, reformulation \\
\hline$\ldots$ & Unfinished utterances \\
\hline$[\ldots]$ & The speech of the speaker has been omitted. \\
\hline SX & Unknown student. \\
\hline Ss & More than one student. \\
\hline [unintelligible] & $\begin{array}{l}\text { Speech can be heard but cannot be understood because of phonetic } \\
\text { features. }\end{array}$ \\
\hline [inaudible] & $\begin{array}{l}\text { Indecipherable Passages. Speech cannot be heard due to sound } \\
\text { quality issues or noises. }\end{array}$ \\
\hline$\langle$ TLANG_Eng $>$ & Participants' speech occurs in English. \\
\hline$\langle$ TLANG_Sp $>$ & Participants' speech occurs in Spanish. \\
\hline$<$ TLANG_Cat> & Participants' speech occurs in Catalan. \\
\hline [laughs] & Non-verbals in italics. \\
\hline [applause $]$ & \\
\hline “...” & The speaker reproduces the speech of someone else. \\
\hline$[* \ldots *]$ & The speaker referred to something different. \\
\hline$<$ video $>$ & Used when a video or part of a video is played. \\
\hline$\langle$ READING $>$ & Used when short excerpts are read verbatim. \\
\hline$<\mathrm{PRON}>$ & $\begin{array}{l}\text { Used when a speaker makes a pronunciation mistake that appears } \\
\text { to affect the comprehension and transcription of academic } \\
\text { discourse. }\end{array}$ \\
\hline H1 & CLIL teacher in the History of the Classical module. \\
\hline $\mathrm{H} 2$ & $\begin{array}{l}\text { CLIL teacher in the Fundamentals and Theory of Artistic Heritage } \\
\text { module. }\end{array}$ \\
\hline $\mathrm{T}$ & CLIL teacher in the Valencian Art and Tourist Resources module. \\
\hline M1 & CLIL teacher in the English for Medicine: Skin cancer. \\
\hline M2 & CLIL teacher in the Anthropology and Evolution module. \\
\hline M3 & CLIL teacher in the Epidemiology and Public Health module. \\
\hline N1 & CLIL teacher in the Women's care module. \\
\hline
\end{tabular}



the Nursing degree.

N3

CLIL teacher in the Critical care module.

P1

CLIL teacher in the Affective and Social Neuroscience module.

$\mathrm{P} 2$

$\mathrm{PhD}$ student and CLIL teacher in the Affective and Social Neuroscience module. 


\section{Chapter 1: Introduction}

\subsection{PRELIMINARY CONSIDERATIONS TO THE STUDY}

Effective international communication has become of utmost importance in the $21^{\text {st }}$ century. The multilingual realities of our contemporary society have had a huge impact in academic and professional settings worldwide (King, 2018; Ruiz de Zarobe \& Ruiz de Zarobe, 2015). The development of language policies endeavoured by official organisations and the subsequent internationalisation of higher education are meant to refine the quality of the curricula and thus prepare future generations for the competitive labour market.

As it is clear that multicultural and multilingual skills have become a good asset in our current era (Edwards, 2004; King, 2018), institutional educations have adopted a number of bilingual and multilingual initiatives devoted to the acquisition of disciplinary knowledge through a foreign language (Brown \& Bradford, 2017; Valcke \& Wilkinson, 2017). This new landscape, where English serves as a lingua franca (Bellés-Fortuño, 2008; Cogo, 2010; Crystal, 2003), includes approaches such as Content-Based Instruction (CBI), English as a Medium of Instruction (EMI) and Content and Language Integrated Learning (CLIL) (Belles-Fortuño, 2021; CarrióPastor, 2021; Cenoz, 2015; Snow \& Brinton, 2017).

The CLIL phenomenon has been widely extended throughout the Spanish territory at all educational levels, but the higher education context is the core of this research. The fact that proofs of English language proficiency may not be required when enrolling in CLIL modules at undergraduate levels results in heterogeneous groups (Luján-García, 2012) where some participants may fail to perform in the target language. Given that both lecturers and students may resort to their mother tongues to (a) check comprehension, 
(b) include the audience in the speech event, (c) request and provide information (Pacheco, 2016), translanguaging instances occur. Accordingly, the analysis of interpersonal communication is decisive for the identification of participants' needs and language choice in the CLIL classroom.

This dissertation seeks to contribute to CLIL pedagogies by examining multilingual discourse patterns produced by both lecturers and students. In doing so, the present dissertation is devoted to defining the linguistic features that should be considered in the classroom setting, more specifically in seminars and lectures. Research on classroom interaction in the fields of Humanities, Social Sciences and Health Sciences will allow us to inspect and compare the extent to which these programmes seem to be profitable in a multilingual university. Knowledge transfer from this research can be useful for the adaptation or modification of the curriculum as well as for the design of teaching training programmes addressed to pre-service and in-service CLIL lecturers who need to learn how to integrate both language and content.

By focusing on classroom research and tertiary education initiatives, quantitative and qualitative data can be examined in depth with regard to classroom discourse in CLIL learning environments (Smit \& Dafouz, 2012). In fact, it should be noted that this thesis will pay attention to participants' language behaviour and concerns towards the target language, which may vary among the three areas of expertise under study.

\subsection{PURPOSE AND SCOPE OF THE STUDY}

The main purpose of this study is to explore the implementation of CLIL programmes at Universitat Jaume I, a Spanish university located in a bilingual region where multilingual learning is promoted in Spanish, Catalan and English. With this in mind, attention will be drawn to interpersonal markers that occur in classroom interaction. Within lectures and seminars - the genres under study-, an account of the most common linguistic traits will be given to compare their incidence in the domains of Humanities, Social Sciences and Health Sciences. Participants' concerns and attitudes towards the CLIL approach will also be considered. My interest here is to describe the similarities and differences encountered among these areas of expertise and help CLIL lecturers and students in classroom communication. 
The existing gap between teachers with appropriate linguistic skills and the lack of cohesive institutional policies across Spain may generate some problems when implementing CLIL modules. In addressing this issue, the theoretical framework has been committed to:

1. Define the notion of multilingual education, giving prominence to internasionalisation strategies around the globe, especially to the ones fostered in Europe.

2. Describe the CLIL, English as a Medium of Instruction (EMI) and ContentBased Instruction (CBI) approaches

3. Revise CLIL practices in higher education at European and Spanish levels, with a special emphasis on Universitat Jaume I.

4. Examine academic discourse research with regard to lectures and seminars.

5. Approach CLIL discourse traits in lectures and seminars, focusing on metadiscoursal devices.

Past research on bi-/multilingual programmes has conceived language as a product by focusing on grammatical, lexical and pronunciation elements (Bellés-Calvera \& BellésFortuño, 2018a, 2018b; in press; Nikula et al., 2013; Uchihara \& Harada, 2018). However, it is the conception of language as a process which may certainly illustrate challenging areas that take place during the implementation of this type of initiatives (Martín del Pozo, 2014), namely interaction or discourse comprehension.

By delving into non-linguistic modules delivered through a CLIL approach in English as a Foreign Language (EFL) environments, we can deepen our knowledge of the traits that foster interpersonal communication in academic discourse. The present study consists of a lecture and nine seminars addressed to non-native speakers. As observed from the number of CLIL seminar transcript samples, this study is mainly concerned with the metadiscoursal markers found in this academic genre. Nonetheless, some seminar sub-categories (e.g. slide talks, lecture seminars (Aguilar, 2004; Cañedo Iglesias, 2008) may share some similarities with plenary lectures.

The reasons why metadiscoursal elements have been the focus of this study lie in their relevance for interpersonal communication and speakers' linguistic awareness. Indeed, research on metadiscourse (Dafouz Milne \& Sánchez García, 2013; Lyster, 2007) has stressed that negotiations of meaning taking place in the classroom setting may enhance 
lecture and seminar discourse comprehension, especially among non-native speakers. Not only verbal exchanges are considered in these speech events, but kinesics and translanguaging appear to be crucial scaffolding strategies in the learning process (García Mayo \& Lázaro Ibarrola, 2015; Nikula et al., 2013).

Bearing in mind that a number of CLIL modules offered in the fields of Humanities, Social Sciences and Health Sciences take part in this research, the results of these teaching practices may be envisaged and applicable to other teaching and learning higher education contexts. This procedure may thus contribute to set out the basis of pedagogical initiatives aimed at disseminating discursive strategies that may be successful in multilingual university settings for both lecturers and students.

\subsection{RESEARCH QUESTIONS AND METHODOLOGY}

Having reviewed the key concepts from the theoretical background, the research questions addressed can be read as follows:

1. RQ(1). What are participants' attitudes and concerns towards the implementation of CLIL practices in higher education?

2. $\mathrm{RQ}(2)$. What interpersonal traits, such as engagement, attitudinal and evaluative markers, can be observed in CLIL programmes offered at higher education?

3. $\mathrm{RQ}(3)$. Are there any significant differences among the CLIL practices in the fields of Humanities, Social Sciences and Health Sciences?

The questions raised here correspond to the metadiscoursal, multilingual and attitudinal dimensions outlined in the literature review. An important premise of this study has to do with the idea that the analysis of metadiscoursal elements may raise awareness about the use of the English language in CLIL modules. With this in mind, we want to explore classroom interaction similarities and differences in the disciplinary areas of Humanities, Social Sciences and Health Sciences. The answer to these questions will contribute to increasing knowledge about linguistic needs and academic discourse produced in CLIL learning environments, particularly in lectures and seminars. 
Turning to the methodology of this research, a corpus has been compiled through the transcription of audio-recorded CLIL practices conducted in a variety of degrees, including History and Heritage, Humanities, Tourism, Medicine, Nursing and Psychology. The aim is to compare the results obtained in each of the disciplinary areas and explore their pedagogical needs. For the analysis of interpersonal features, a classification model deriving from that of Martín del Pozo (2014) has been devised in Chapter 5. Some modifications were introduced with elements from previous taxonomies (Ädel, 2010; Dalton-Puffer, 2010; Hyland, 2005; Llinares et al., 2012). Overall, the model for this research provides us with categories from which quantitative and qualitative findings can be reported, thereby helping us answer the research questions posed with regard to the CLIL initiatives available in the Spanish higher education context.

As for research instruments, qualitative and quantitative data have been gathered and examined. Qualitative results were interpreted by means of teachers' interviews, students' questionnaires, observation rubrics and descriptions of metadiscoursal markers. On the other hand, the incidence of these linguistic devices as well as the results obtained in the placement tests and some of the responses given in students' questionnaires were regarded as quantitative results.

\subsection{OVERVIEW OF THE STUDY}

To achieve the goals previously mentioned, this thesis is structured in two sections. The first part is constituted by Chapters 2, 3 and 4 which provide the main outline of this dissertation and delimit the theoretical foundations of the CLIL approach and academic discourse. The second part, which accounts for Chapters 5, 6 and 7, contains the methodological approach, the discussion of the results as well as the conclusions of the study.

Chapter 2 tackles the notions of monolingualism, bilingualism and multilingualism, which serve to introduce popular language teaching strategies in the field of education. The chapter concludes with a global view of internasionalisation trends in the higher education landscape and the policies arising from monolingual and bi-/multilingual European countries. 
Chapter 3 revolves around the CLIL, EMI and CBI approaches. A closer look at their features helps us to establish a clear distinction among these concepts. Since this study focuses on the CLIL approach, tertiary education initiatives in Europe have been described, with Spain and the Valencian Community at the heart of all of them.

Chapter 4 deals with academic discourse and stresses the role of lectures and seminars as instructional methods in higher education. Previous studies on metadiscourse are provided to ascertain the main linguistic elements that occur in these learning contexts, some of these patterns being displayed in different typologies.

Chapter 5 covers the research questions and the methodological procedure of the study. The corpus compilation process, the transcription conventions, the participants and other contextual factors are carefully explained. Likewise, the taxonomy used for the analysis of metadiscoursal data, based on previous classifications of discourse markers, and the research instruments employed are specified.

Chapter 6 shows the results of the research, which are analysed and discussed in order to answer the research questions posed in this study. On the basis of these results, a description of the lecturers' views and concerns with regard to the CLIL approach is given. The following sections are related to the responses obtained in students' questionnaires and placement tests, which are compared among the fields of Humanities, Social Sciences and Health Sciences. The same is true for classroom practices where interpersonal elements are classified. Consequently, the findings in this chapter are presented not only quantitatively but also qualitatively.

Chapter 7 summarises the main the contributions of the previous chapters and the conclusions of both the theoretical and empirical parts. The limitations derived from this study, linked to timing issues, and its pedagogical implications are considered. Finally, further research on academic discourse in CLIL settings is suggested.

\subsection{CHAPTER SUMMARY}

This introductory chapter aimed at providing a first glance of the thesis so that readers can familiarise with the topic. To do so, the preliminary considerations of the study were set out. Then, the objectives of the study and its theoretical foundations, consisting 
of research on the CLIL approach and the implementation of these programmes as well as on academic discourse uttered in lectures and seminars, were described. This section was followed by a preview of the research questions and the methodological approach, in which an account of the corpus, the participants, the classification of academic discourse, and the research instruments was given. The chapter ended with a brief overview of the study. In Chapter 2, emphasis will be placed on multilingual education and the emergence of internationalisation strategies in tertiary education. 


\section{Chapter 2: Multilingual Education}

\subsection{INTRODUCTION}

From early years, migrant networks boosted trade and communication between speakers of different languages. Building on these exchanges, this initial contact derived into a well-known globalisation era that has promoted interaction among companies, official institutions and individuals worldwide. This new landscape has had major implications for how education, and concretely educational programmes, is conceived since this contemporary era is facing new multilingual realities (Ruiz de Zarobe \& Ruiz de Zarobe, 2015). Most of the world's population are or have become bilingual and multilingual users (Bhatia \& Ritchie, 2014; Crystal, 2003; Lewis, 2009; Stavans \& Hoffmann, 2015). Therefore, the educational dimension is undergoing an internationalisation process where courses, modules or degrees are taught in a language other than students' mother tongue.

In light of these events, educational authorities can no longer ignore the need for embracing effective instructional models. From the range of language policies that exist in the field of education, several programmes can be identified -monolingual, bilingual, and multilingual systems, among others (Byram, 2004).

To better understand the different teaching approaches that are currently offered, in this chapter, I am going to review the notions of monolingualism, bilingualism and multilingualism. Then, a number of educational programmes and the policies being implemented at the moment in higher education institutions around the globe will be discussed. This last aspect will try to give some light on language planning within the field of education. 


\subsection{FROM MONOLINGUALISM TO MULTILINGUALISM}

From a sociolinguistic perspective, monolingualism can be regarded as the ability to know and use one language as a means of communication (Collins dictionary, n.d.). In countries such as the United Kingdom, France, Russia, China or Portugal, monolingualism is the norm. In this regard, Ellis (2008) argues that monolinguals' language proficiency should be considered as a continuum, ranging from those who are able to use some words in a foreign language to those who have been enrolled in foreign language courses but fail to communicate effectively.

Unlike monolingualism, bilingualism has been regarded as the "fluency in or use of two languages" (Lexico, n.d.). Nevertheless, this phenomenon has raised some concerns when comparing individuals' competence and performance (Chomsky, 1965). Scholars like Bloomfield (1933, p.56) refer to bilingualism as "the native-like control of two languages", which implies mastering two languages equally in all domains. Such perfection is rare. Instead, fluency in both languages may not be balanced (Hornby, 1977). Grosjean (1985) points out that bilinguals should not be conceived as the sum of two monolingual systems but as individuals who adapt their linguistic behaviour to suit their communicative needs in their social environment. Such conceptualisation can be clearly illustrated with all the language mixing phenomena that take place in early childhood (Meisel, 2012).

While it is true that multilingualism is related to the ability of an individual speaker or a speech community to interact effectively in three or more languages (Nordquist, 2019), other definitions seem to be closer to the notion of bilingualism. Cenoz and Gorter (2014) claim that multilingualism stands for knowledge of more than one language. Mackey (2006), on the other hand, highlights that bilingualism is an alternate use of two or more languages. Based on this perspective, the portrayal of a multilingual user is somehow assumed. However, international organisations, such as the Council of Europe, take into account individual and societal features by introducing a distinction between multilingualism and plurilingualism (Council of Europe, 2007). The former term calls for the coexistence of several languages in a given territory. In contrast, plurilingualism is regarded as the ability of speakers to use different varieties of the language and employ code-switching strategies. 
The whole spectrum of bi-/multilingualism can be examined from an individual or societal perspective (Edwards, 2006, 2012). As for individual bilingualism, individuals can be classified along a continuum displaying a number of proficiency levels (Hamers \& Blanc, 2000) in two languages. The same variables can be applied to individual multilingualism, also known as plurilingualism, so as to indicate how it differs from societal multilingualism (Aronin \& Laoire, 2004). Therefore, the profile of a bi/multilingual user who has developed reading skills in Portuguese but is unable to produce written and spoken outcomes would be placed at one end of the continuum, whereas the profile of a bi-/multilingual who is able to communicate in the target language using the four skills would be located at the other end of the continuum. In this sense, bi-/multilingualism, which relies on linguistic and psychological dimensions, may be classified as productive or receptive (Edwards, 2006). Productive bi/multilingualism accounts for the ability to comprehend and construct speech in two or more languages as opposed to receptive bi-/multilingualism. This receptive competence, also known as semibilingualism/semimultilingualism (Edwards, 2006), entails the comprehension of the discourse rather than the ability to produce meaningful utterances since there is a dominant language in their repertoire that may interfere in the acquisition process. This may be the case of speakers of a heritage language who have learnt their family's mother tongue at home but who have not received input from their social context. On that account, societal bi-/multilingualism -which embodies historical, educational and political dimensions- can be observed in speech communities using two or more languages. Thus, it seems logical that countries with more than one official language, such as Canada, Switzerland, Spain and Malaysia, or countries with an extremely high immigration rate, such as the United States, are of interest in the field of linguistics.

The role official institutions play with regard to language planning is paramount since the learning of a new language is highly valued all over the world. In this respect, the growing presence of bilingual and multilingual programmes does not only seek the preservation of citizens' local identity but also the shaping of new global identities (UNESCO, 2003). 


\subsection{LANGUAGE TEACHING STRATEGIES}

As commented before, our globalised society is facing a new reality characterised by international mobility and the need for technological and communicative skills in more than one language (Marsh, 2009; Pérez-Vidal, 2015; Rubio-Alcalá et al., 2019). In this context, bilingual and multilingual education programmes have proliferated worldwide (Hazelkorn, 2015; Stavans \& Hoffman, 2015), more precisely in higher education. However, such language learning initiatives do not only respond to the current internationalisation trends in education. Instead, language learning may be determined by the co-existence of languages in bilingual and multilingual communities. At this point, the differences between monolingual, bilingual and multilingual education should be noted.

Drawing on the characteristics of monolingual countries, mainstream education is dominated by programmes where there is only one language of instruction, which is usually the dominant language of the nation (Byram, 2004). Within this educational system, foreign language courses may be included as part of the curriculum, especially in primary and secondary education levels. Secondly, bilingual education indicates that two languages are employed as the language of instruction. These languages, which usually correspond to the dominant state language and a minority language, are stated within the syllabus of the educational institution. The basic premise of these programmes is that pupils are expected to have a good command of both languages (Byram, 2004; Cohen, 1975). However, the variety of teaching techniques will be determined by the position adopted by educational institutions. Thus, the traditional figure of a "mythical bilingual" (Valdes, 2001, p.40) has given rise to the learning of languages as two different systems. The foundations for a second learning practice have been based on the so-called Common Underlying Proficiency (Cummins, 1979), which argues that both learners' first (L1) and second language (L2) have a common ground that enhances the transfer of knowledge and communicative skills from one language to the other and vice versa. A third popular language learning practice in the bilingual classroom is that of code-switching, even though it has been "rarely institutionally endorsed or pedagogically underpinned" (Creese \& Blackledge, 2010, p.105). By switching from one language to another shared by the speakers, this strategy seeks to "scaffold the teaching of additional languages" (García \& Lin, 2016, p.2) by making meaning comprehensible through translation. Translanguaging pedagogies, however, 
are regarded as "the deployment of a speaker's full linguistic repertoire, which does not correspond to the socially and politically defined boundaries of named languages" (García \& Kleyn, 2016, p. 14). In other words, translanguaging is seen as a flexible process where bi-/multilingual speakers naturally integrate the resources that are available in their repertoire to convey meaning (Creese \& Blackledge, 2010). The adoption of this teaching technique may have an impact on the design of bilingual and multilingual education programmes. Research has suggested that learning becomes more effective if languages other than the language of instruction are used to explain contents that remain unclear and allow students perform their communicative tasks (Blackledge \& Creese, 2010). The integration of languages within learning practices can be embodied in a variety of bi-/multilingual approaches, which have also been labelled as immersion or content-based instruction in North America, as in Canadian immersion programmes (Macaro et al., 2018). The so-called Content and Language Integrated (CLIL) approach is preferably used in the European area, and English as a Medium of Instruction (EMI) is employed all over the world to mainly refer to programmes delivered in English in higher education. Finally, multilingual education involves "the use of at least three languages, the mother tongue, a regional or national language and an international language in education" (UNESCO, 2003, p.16). According to Coyle et al. (2010), it caters for the use of a second language for the learning of non-linguistic subjects through CLIL practices.

Even though there is a broader range of educational practices, it seems that bi/multilingual education programmes are to become the norm in our current educational panorama (Ruiz de Zarobe \& Ruiz de Zarobe, 2015), particularly in tertiary education. On that account, higher education institutions are meant to provide students with learning and employability opportunities (Bellés-Calvera \& Martínez-Hernández, 2021). Thus, the exposure to a variety of international, intercultural and global skills (Carrió-Pastor, 2009; Knight, 2004; Leask, 2015; Soria \& Troisi, 2014) will prepare them to face professional and social challenges in the near future.

Driven by this need of internationalisation, a growing number of students' mobility programmes, modules, degrees, summer courses and other academic projects are offered in English (Bellés-Calvera \& Martínez-Hernández, 2021; Bellés-Fortuño, 2021; Kirkpatrick \& Sussex, 2012; Lasagabaster, Doiz, \& Sierra, 2014; Veronesi \& Nickenig, 2009), the language of international communication (Jenkins, 2000; McKay, 2008), and 
other languages. The language to be learnt will be determined by language policy concerns (García, 2011; Tollefson, 2013). Generally speaking, the reasons underlying the choice of a second (L2) or foreign language (FL) are based on their international status (Cenoz, 2013). Other forces can be noted as human, cultural, economic, historical, social, political and educational, practical, intellectual and entertainment (Crystal, 2003; Dearden, 2014; King, 2018; Mauranen, 2003; McDougald, 2019; Schmitz, 2012; Sehoole \& Knight, 2013). According to Crystal (2003), English works as a lingua franca around the globe due to its prestigious status in the fields of business, commerce, science, technology, tourism and education. The combination of those areas has fostered the use of English as a contact language in multilingual contexts (Firth, 1996; Graddol, 1999, 2007). Accordingly, communication strategies can be established to foster understanding between speakers from different linguistic backgrounds (Jenkins, 2003; Seidlhofer 2009).

This English hegemony in all fields of daily life is a global trend that has been regarded as Englishisation (Boussebaa \& Brown, 2017; Phillipson, 1992, 2009; Piller \& Cho, 2013; Saarinen \& Nikula, 2012). A similar phenomenon can be observed in higher education with the growing use of English as the primary language of instruction (Bellés-Calvera \& Martínez-Hernández, 2021; Bellés-Fortuño, 2021; Doiz, Lasagabaster \& Sierra, 2012; Lanvers \& Hultgren, 2018). Official institutional and educational backing for the integration of foreign languages in the educational system has led to the proliferation of a variety of language learning approaches under different labels, including Canadian immersion programmes, EMI (Dafouz, 2018), and CLIL programmes (Bellés-Calvera, 2018; Bellés-Calvera \& Bellés-Fortuño, in press; Merino \& Lasagabaster, 2018; Nikula et al., 2016).

Notwithstanding, the use of English in these pedagogical practices and the materials to be used are some but only a few issues that may vary across countries belonging to the Inner, Outer and Expanding Circles (Kachru, 1992). These categories, included in Kachru's (1992) Three Circles Model of World Englishes, illustrate the extent to which the English language is relevant within a given society. Thus, the inner circle comprises countries where English is learnt as a first language. The Outer circle refers to nonnative regions characterised by the institutionalisation of the English language and the emergence of their own standard varieties (Kachru et al., 2006). In contrast, in Expanding circle countries English "is taught in schools, often widely, but it does not 
play an essential role in national or social life" (Broughton et al., 1980). Therefore, the role a target language plays is of utmost importance in learning environments since pedagogical practices may need to be adjusted or reconfigured in order to address the linguistic needs of Anglophone and non-Anglophone communities (Kachru et al., 2006).

\subsection{INTERNATIONALISATION OF THE HIGHER EDUCATION LANDSCAPE: A GLOBAL VIEW}

Attending to the need for internationalisation in tertiary education, contemporary universities around the world have adopted a set of strategies that focus on language planning policies, funding, research dissemination and academic mobility, among other institutional priorities (Liddicoat, 2016). The main issue educational institutions are confronting has to do with language planning, which has substantially responded to a marketisation process (Engwall, 2016). This concept suggests that curricular courses are envisaged as an investment intertwining the transfer of communicative and professional competitiveness in the workplace. Not only have these measures changed the linguistic profile of the learning and teaching communities, but also their academic curricula together with other educational initiatives (Källkvist \& Hult, 2014). The spread of the English language within the academic world has been partially attributed to the prominence of this language in journal publications, conferences, evaluation and university rankings (Curry \& Lillis, 2017, 2018; Liu, 2017; Hamel, 2013). In doing so, academic institutions seem to be going through a competition process (Engwall, 2016) that has favoured the creation of academic networks, including international and transnational associations or research groups. Such rationales have attracted overseas students and lecturers who acknowledge the economic value of the English language in our society (Carrió-Pastor, 2021; Lasagabaster \& Sierra, 2011).

To have a global view of the situation around the world, I am going to give a general overview of bi-/multilingual initiatives in higher education, which has posed some challenges to non-Anglophone regions located in Asia, Africa, and Latin America. Building on local and national requirements, the implementation of these international strategies may vary to a great extent. Thus, four modes of internationalisation can be identified, namely (a) Import of Ideas, (b) Outsourcing, (c) Insourcing and (d) Foreign 
Direct Investments (Engwall, 2016, p.223). The first mode of internationalisation, called Import of Ideas, entails that the programmes designed by higher education institutions in their home countries are mainly addressed to home students. The Outsourcing mode implies that the academic programmes offered in a host institution located in a foreign country are delivered to students enrolled in mobility programmes for a particular period of time. The Insourcing mode consists of providing foreign students with educational programmes in a home institution. Lastly, Foreign Direct Investments mode has to do with instruction being given in a host country to international students. Looking into these modes of internationalisation, the strategies devised by education policy-makers in the Asian, African, Latin American contexts will be explored.

Due to their colonial history, Asian and African countries witnessed the establishment of a language other than their home language(s) within their boundaries. Used as a lingua franca in these areas, today, English is perceived as a communication tool that allows for the establishment of international bonds (ASEAN Secretariat, 2013). It works as the official language of the Association of South-East Asian Nations (ASEAN) (Kirkpatrick, 2012). This "English language fever" (Le, 2007, p.172) has strongly influenced the language learning policies in the field of education. The rationales underlying the rising of English as the language of instruction in Asian countries account for the contribution of the nation's economy (Hamid \& Nguyen, 2016). Not surprisingly, the internationalisation of the curricula has embodied the introduction of bilingual programmes in primary, secondary and tertiary education occasionally resulting in the adoption of English as the only means of communication in tertiary education (Hamid et al., 2013; Kirkpatrick; 2017). By and large, differing national policies can be observed across countries. Successful programmes have been carried out in Singaporean educational settings where English is the sole medium of instruction (Bolton \& Botha, 2017). In most Malaysian universities, English has been accommodated as the medium of instruction in tertiary education, particularly those run by the private sector (Ali \& Hamid, 2018; Hamid \& Nguyen, 2016; Rahman et al., 2018). Being Outer Circle English-speaking countries (Kachru, 1992), Japan's and Korea's commitment to the use of the English language is based on competitiveness and funding. Even though it is not a mandatory subject, the Top Global University Project was launched to foster the learning of foreign languages in higher education (Rose \& McKinley, 2018). Both in Japan and South Korean, those educational institutions 
offering English-only programmes within the curriculum are granted governmental funding (Ikeda, 2013; Macaro et al., 2018; MEXT, 2006; Ministry of Education, 2016). The internal competition among universities in these countries is meant to be reflected in international rankings (Byun et al., 2011; Rahman, Singh \& Karim, 2018).

In addition to the Asian continent, the internationalisation of African higher education institutions is determined by the attainment of the Millennium Development Goals (MDGs) (Sehoole \& Knight, 2013). National and international partnerships have supported the African Network for the Internationalisation of Education in the dissemination of knowledge and research based on the role of higher education institutions as actors that can transform the African society (Jowi et al., 2013). These initiatives, which have resulted in the development of programmes in African universities, have been perceived as one of the primary internationalisation outcomes. Unfortunately, the existing curricula need to be reviewed to address the local and global needs of this multilingual and multicultural continent. In this sense, the application of language policies has upgraded or downgraded the use of their local languages in higher education at the expense of European languages such as English, French or Portuguese. The promotion of local and international languages can be observed in Senegal, where it is not English the language that holds an official status but French. The latter has been established as the primary medium of instruction, and reforms have been made to preserve local languages through bilingual programmes (Kaschula \& Kretzer, 2019a, 2019b). In a traditionally French-speaking country as Rwanda, English has become one of the two media of instruction in the educational system together with Kinyarwanda, delegating French as an optional subject (Trudell, 2016). Language policies in South Africa require the development of multilingual education programmes at higher education, where English, Afrikaans or Xhosa are languages of instruction (Madiba, 2013).

Shifting continents, multilingual practices in Latin America can be acknowledged due to the co-existence of indigenous and European languages (López \& Küper, 1999). Rather than crafting professionally-oriented policies, the Latin American and Caribbean higher education sector has endorsed initiatives that call for cooperation among cultures and nations (Pol, 2017). These priorities do not seem to reflect the actions undertaken by Latin American and Caribbean universities. The absence of an institutional plan for the internationalisation of their curriculum in more than half of the public institutions 
seems to be a reality as reported by a survey dealing with the trends in tertiary education Latin America (Gacel-Ávila \& Rodríguez-Rodríguez, 2018). Regardless of this poor progress in the internationalisation of the higher education space, their most frequent internationalisation activities are related to student mobility, academic mobility and participation in international cooperation projects for development. This implies that Outsourcing is the internationalisation model being promoted in these regions.

Other internationalisation concerns focus on the language policies developed by Latin American institutions. Since the mastery of a foreign language may not be required in their academic programmes, English proficiency seems to be one of the greatest limitations in these Spanish-speaking or Portuguese-speaking institutions. That being so, students' and faculty members' inadequate command of the English language may prevent them from making the most of professional and academic opportunities (GacelÁvila \& Rodríguez-Rodríguez, 2018). Some national strategies have been devoted to the regulation of foreign language learning in tertiary education, as in Peru and Colombia. In the Colombian model, known as Colombia Bilingüe, English has been included in the curriculum as a mandatory subject (Cronquist \& Fiszbein, 2017). This action may have positive effects considering that students are required to take an exam with an English component to graduate. Besides, access to the foreign language centres located at universities are open to the learning and teaching community as well as the administrative staff so that they strengthen their communicative competence in English (Hamel et al., 2016). Similar trends can be observed in the Peruvian education system, where the learning of a foreign language is a requirement for undergraduate programmes, as indicated in its national strategy called Inglés, puertas al mundo (Cronquist \& Fiszbein, 2017; Decreto supremo No 012-2015-MINEDU). The efforts made by other Latin American countries such as Mexico and Uruguay have not been sufficient to develop effective national strategies since actions that need to be accomplished are vaguely explained (Cronquist \& Fiszbein, 2017).

Another limitation is concerned with the visibility of these institutions on the net (Gacel-Ávila \& Rodríguez-Rodríguez, 2018). The languages displayed in most websites correspond to the local language (32\%), followed by those in which a second (19\%) and a third language are available $(9 \%)$ are available. These circumstances may harm the opportunities for cooperation among the members of the academic community. In recent times, the consolidation of networks, such as international cooperation agencies (e.g. the 
International Research Centre), bilateral programmes (e.g. the Academic and Professional Programs for the Americas) and government agencies (e.g. the IberoAmerican organisation for education, science and culture and the European Commission), have triggered collaboration among regional and international institutions. These actors have been key to set up research projects, mobility programmes, and grant and study awards in developing countries.

\subsection{THE European Higher EduCATION AREA (EHEA)}

I will revise now the situation in the European context since the current research has been conducted in Spain. To this end, I will look at the set of strategies prompted by the European Union (EU) that have had major implications in the higher education landscape of the continent. For instance, the building of a European Education Area has been placed to bring an international dimension to the higher education sector, (European Commission, 2020a; European Commission, 2018a). This vision, which may become a reality by 2025 , conforms to the EU's COVID-19 recovery plan referred to as Next Generation EU (European Commission, 2020a), and the UN 2030 Agenda (United Nations, 2015), where efforts have been devoted to supporting cooperation, innovation, competitiveness, quality education, inclusion and gender equality, among others. Through this process, European higher education institutions have collectively worked on transnational education agreements, the recognition of qualifications and a European student card. Because of the traditional linguistic diversity in Europe, attempts to generate successful multilingual practices have been made to promote foreign language learning from an early age (European Council, 2017; Mackiewicz, 2012). Based on the Council Recommendation on a comprehensive approach to the teaching and learning of languages (European Commission, 2018b), the communication on Rethinking Education (European Commission, 2012a) and other documents, the EU has supported several initiatives with the pursuit of generating successful multilingual experiences. For instance, widespread access to mobility programmes, such as Erasmus+, enhances participants' personal, linguistic and cultural growth. Through this Europeanisation process, students are meant to shape their identity as part of an international community (Jacobone \& Moro, 2015). 
Apart from cooperation and aid, strategies in Europe have moved towards the internationalisation of the curriculum since there is a need for adding at least two foreign languages to Europeans' repertoire (European Council, 2017; European Commission, 2002b). In collaborating with the European Centre for Modern Languages (ECML), and the European Research Centre on Multilingualism and Language Learning (Mercator), the European Commission supervises good quality and innovative practices in the field of foreign language education (European Commission, 2008).

Nonetheless, EU Member States follow their national guidelines to implement these policies effectively. It is the education authorities of each Member State the ones that handle the incorporation of foreign languages within the curriculum (European Commission, 2017). Although most of them have a preference for the English language, foreign language preferences may be conditioned by geographical and linguistic factors. Some countries are bilingual or multilingual in that they have more than one official language. Clear examples include bilingual countries with two official languages such as The Netherlands (i.e. Dutch and Frisian), Finland (i.e. Finnish and Swedish), and Ireland (English and Gaelic). As to multilingual countries, three languages can be found in Luxembourg (i.e. Luxembourgish, French, and German), and Belgium (i.e. Dutch, French and German). Thereafter, local administrative and education systems are tailored differently across Europe. Most EU countries offer educational programmes in several languages, English being a mandatory subject in 18 education systems so that learners can be independent multilingual users at the end of secondary education.

Unfortunately, statistics suggest that the initiatives to accomplish the multilingualism target are not working as fast as expected. So far, foreign language learning in secondary education has been characterised by a slow progress (European Commission, 2012b; Costa \& Albergaria-Almeida, 2015). The results of a test administered to lower secondary students revealed that nearly $42 \%$ of the subjects had an intermediate level (B1 or B2) according to the Common European Framework of Reference for Languages (CEFR) in the first foreign language, while $44 \%$ of the learners were basic users (A1 or A2) that could communicate using simple language. As to second language results, it is worth mentioning that $25 \%$ of the pupils could achieve an independent user level, whereas $55 \%$ had an A1 or A2 level. Curiously, the proportion of the participants who struggled to do the test is quite noticeable. Indeed, $14 \%$ of the students lacked basic knowledge of the first language, whereas $20 \%$ of the pupils could not attain an A1 level 
in the second language. Factors that contributed to these weak results are related to the policies implemented by authorities across Europe. Great efforts have been made concerning the learning of a first foreign language from an early age, but the fact that the learning of a second language is not compulsory in secondary education has a detrimental effect in the acquisition of multilingual skills (European Commission, 2017; Mackiewicz, 2009).

As to the higher education area, an updated survey on Foreign language skills statistics (European Commission, 2018c) reported that nearly 80\% of the participants could read and write in more than one language. Within this overall percentage, only $27 \%$ of the respondents have good reading and writing skills in three languages, whereas nearly $48 \%$ of those polled are able to comprehend and produce written discourse in two languages. Interestingly, $20 \%$ of the subjects are only communicatively competent in one language. There exist substantial regional disparities among EU Member States in terms of language proficiency. Citizens living in Luxembourg, Slovakia, Slovenia, Malta or Latvia stand out and can be regarded as multilingual users. In contrast, the data collected show poor foreign language skills in countries such as the UK and Hungary. Broadly, over $51 \%$ of the informants would course bilingual studies, but the proportion of students undertaking multilingual programmes (15\%) would be substantially reduced. The remaining percentage (33\%) corresponds to those young Europeans who would not be committed to enrolling courses or modules delivered in a foreign language at university.

As for the languages used in education, a small minority of Europeans have studied in a language other than their mother tongue (11\%) (European Commission, 2018c). Rather, most of them (89\%) have followed their studies in the national language of the country (89\%), either at school or university. That being said, English is by far the most widespread foreign language in the European Union being the main language of instruction in more than 7,000 degree programmes outside the UK and Ireland (European Commission, 2018c; Wächter \& Maiworm, 2014). Aside from English, other languages that are likely to be chosen as second or third foreign languages involve French (12\%), followed by German (11\%), Spanish (7\%), and Russian (5\%) (European Commission, 2018c). These languages can be used in the teaching of both linguistic and non-linguistic subjects, the latter being used in immersion or CLIL programmes. 


\subsubsection{Internationsalisation strategies in monolingual countries}

At a higher educational level, the European Union has an opportunity to take a leading position in this competitive educational landscape. Ease mobility inside the European Union, mutual recognition of degrees, cooperation, innovation and research as well as the availability of programmes in languages other than the local language are key elements to look at in an emerging EHEA (Ravinet, 2018).

In the context of multilingual education in Europe, the European learning environment has undergone a series of reforms, encouraged by the Bologna Process, to operate more efficiently at an international dimension. From a policy perspective, strategies for the internationalisation of EU universities account for funding and high-quality study programmes.

For instance, the proposal of the Swedish Government gives prominence to a new visa regime and grant scheme (European Commission, 2012c; Swedish Government Inquiries, 2018). In addition, international undergraduate and postgraduate programmes are taught in English or Swedish. Therefore, these policies have been implemented not only to attract skilled foreign students but also to enhance mobility across Europe and joint degrees. Internationalisation in the Romanian higher education sector is committed to take advantage of university fairs and provide talented international students with grants through the Ministry of Foreign Affairs (De Wit et al., 2018; Study in Romania, 2018). The national language is one of the vehicular languages at higher education courses, but other postgraduate or $\mathrm{PhD}$ programmes may be taught totally or partially in English or French (Extra \& Yağmur, 2012).

Traditionally, French higher education institutions' measures have addressed three main issues: prestige, cooperation and recruitment of international students (Ramanantsoa et al., 2016). Nowadays, strategies encompassing funding, a wider variety of e-learning programmes and transnational education initiatives, and the quality of education is at the core of France's vision. Based on the Swedish proposal, one of the factors underpinning the French Stratégie is bound to tuition fees (Ramanantsoa et al., 2016; Ministère de l'éducation nationale, de l'enseignement supérieur et de la recherché, 2014; Filliatreau \& Vidal, 2011). PhD students would be exempt from paying them as opposed to non-EU students, who would be charged with full fees of study. This money would then be invested to improve the quality of the French higher education system. 
Accordingly, the readjustment of the scholarship policy would award grants to international students. On average, these programmes are offered by the French Ministry of Higher Education, Research and Innovation, some institutes of higher education, and other regional authorities (Campus France, 2018; Ministère de l'éducation nationale, de l'enseignement supérieur et de la recherché, 2014; Ramanantsoa et al., 2016). Concerning the curriculum, French is the main language of instruction, although other languages may be taught at undergraduate and postgraduate levels.

In Denmark, more than 25\% of undergraduate and postgraduate programmes are taught in English and Danish (Extra \& Yağmur, 2012). Aside from the curriculum, other actions undertaken have to do with the availability of institutional and governmental grants for incoming students (Study in Denmark, 2018). Institutional grants are often addressed to international EU students, researchers or teachers who want to study in this country. As to the Danish government, long-term scholarships are offered under the Cultural Agreements Programme to non-EU highly qualified postgraduate students and researchers who are keen on learning about Denmark, whereas summer language courses can be applied by EU and non-EU citizens (Study in Denmark, 2018). Apart from that, local and regional authorities need funding for them to devise initiatives stimulating international competition and research. A clear example is the Student Incubator project, carried out at Aarhus University, where students from different fields share their ideas on entrepreneurship to disseminate basic knowledge on how to start a business.

As for the Czech Republic, the government's Foreign Development Assistance Programme supports talented international students coming from developing countries with scholarships (Study in the Czech Republic, 2018). Other well-known scholarships designed for EU and non-EU candidates involve Scholarship Awards Under Bilateral International Agreements, Visegrad Fund Scholarships, Scholarships of the South Moravian Center for International Mobility, Erasmus + Programme, CEEPUS Programme, and AKTION programme, among others.

Despite the Brexit, the United Kingdom (UK) remains a popular destination for international students. The measures being proposed in UK universities cope with academic excellence, innovation and research (Soliman, 2016). These factors are 
paramount to design an international curriculum, mobility and social programmes, as well as to establish strategic research partnerships with EU and non-EU governments, academic institutions and organisations (Soliman, 2016; The University of Edinburgh, 2018). From my own experience as an international $\mathrm{PhD}$ student in the UK, The University of Edinburgh and the University of Wolverhampton are two highlyrecognised universities undergoing internationalisation processes that have attracted thousands of overseas students. Thanks to my research stays in these higher education institutions, I could get acquainted with some of the internationsalisation strategies implemented there, this being the main reason why both of them have been selected and described in detail below.

\subsubsection{The case of The University of Edinburgh}

The University of Edinburgh is one of the world-leading public research universities in the UK and offers high-quality degree and postgraduate programmes in a number of academic disciplines (The University of Edinburgh, 2018). Building on the Times Higher Education (2020) ranking where it was placed sixth in the UK, this higher education institution has attracted 44,510 students from all over the world, about 16,375 of whom are international students coming from 180 countries, such as China, the United States of America, and Germany, among others (The University of Edinburgh, 2020). The fact that nearly $44 \%$ of the student body is from a non-UK region reinforces the global academic aspirations of the University of Edinburgh. Certain undergraduate and postgraduate programmes are popular among overseas students. This is the case of Issues in Applied Linguistics, a compulsory module delivered within the Master's degree programme in Applied Linguistics. As observed during my research stay at the University of Edinburgh, almost 90 out of 100 learners were geographically bounded to Asia. The linguistic profile of those postgraduate students comprised Chinese, Japanese, Korean and Vietnamese as well as English, which was learnt as a foreign language. The remaining participants were native speakers of English who came from the UK or the United States.

Such international focus also extends to a broad research agenda which has attracted funding thanks to internal and external collaborations (The University of Edinburgh, 2018). The leading outcomes in the fields of Humanities, Social Sciences, Medicine, Veterinary, Science and Engineering have been considered one of its strengths due to their impact in commercial, medical, political, social, environmental and cultural 
policies (The University of Edinburgh, 2015). For instance, the Bilingualism Matters centre, located in the school of Philosophy, Psychology and Language Sciences, has different branches all over the world exploring bilingualism and language learning issues, as noted during a talk given by the neuroscientist Thomas Bak as part of the Fringe Festival in 2019. Ongoing projects such as Bilingualism Matters in the Waterloo Region and Canada and Multi-Mind are particularly relevant to the current study as they work collaboratively with "schools, families, local authorities, cultural organisations, third sector groups and researchers at other universities" (Bilingualism Matters, 2020) to make informed decisions about multilingual learning practices.

Strategic partnerships and collaborative programmes with other higher education institutions, such as Peking University, the University of Sidney and the University of Granada, have contributed to shaping the quality of University of Edinburgh's projects (The University of Edinburgh, 2018), retaining the 'HR Excellence in Research Award' from the European Commission since 2010 (The University of Edinburgh, 2019). Due to its global vision, the University of Edinburgh has also become an active member in international academic networks, namely the League of European Research Universities, the Coimbra Group, Eurolife, Una Europa and Universitas 21 (The University of Edinburgh, n.d.).

\subsubsection{The case of University of Wolverhampton}

With four main campuses and 22,000 students, the Strategic Plan 2016-2021 outlined by the University of Wolverhampton has been committed to revitalising the economy and strengthening the development of workplace skills (University of Wolverhampton, 2016). With students from more than 130 countries, the University of Wolverhampton seeks to become a renowned educational institution that fosters knowledge exchange. For instance, the Research Group in Computational Linguistics (RGCL), founded by Professor Ruslan Mitkov in 1998, has become one of the major centres in the field of Natural Language Processing (NLP) (RGCL, n.d.). International and interdisciplinary collaborations have led to innovative research linked to the emergence and refinement of several NLP tools and resources.

Within this group, postgraduate students have the opportunity to expand their knowledge enrolling a Master's degree in Computational Linguistics, a Master's degree 
in Practical Corpus Linguistics for English Language Teaching (ELT), Lexicography and Translation or doing research in PhD programmes (RGCL, n.d.). It is these types of courses the ones that attract students from all over the world. The geographical background of both the group staff and Master (MA) students was quite heterogeneous as it included countries such as Spain, Greece, Macedonia, Germany, Italy, Slovenia, Bulgaria, Armenia, Russia, Turkey, Mexico, Tajikistan, China, Sri Lanka, Vietnam, and the UK. As part of my research stay plan at the University of Wolverhampton, attendance to modules such as Corpus Linguistics with $R$ and Machine Translation and Other Natural Language Processing Applications, incorporated within the study plan of the MA Computational Linguistics and the European Master's Technology for Translation and Interpreting was meaningful to learn the inner workings of a research group and have a truly multicultural experience.

\subsubsection{Internationsalisation strategies in bilingual or multilingual countries}

It is acknowledged that Ireland is a bilingual country where English and Irish are official languages. The international dimension of Irish higher education institutions is shaped by governmental and institutional actions. At a national level, Investing in Global Relationships: Ireland's International Education Strategy 2010-2015 was the first document where the Irish government are linked to the recruitment of international students (Clarke et al., 2018; Finn \& Darmody, 2017). Later on, forthcoming publications, such as Ireland's International Education Strategy 2016-2020 and the National Education Strategy for Higher Education to 2030 focus on economic ambitions by promoting cooperation plans between companies and academic institutions. Moreover, the government launched a new scholarship system to increase the number of students and researchers coming from other countries. At an institutional level, distance education courses are included in the teaching curriculum, but it is an important internationalisation component that requires more funding (Clarke et al., 2018). A study conducted by the Expert Group on Future Skills Needs (EGFSN) in 2012 pointed out that foreign language skills could be actively promoted by incorporating programmes delivered in Spanish, French, German, Arabic, Chinese or Russian (Ibec, 2014).

The Finnish Ministry of Education and Culture has developed an international policy for Finnish higher education and research (Ministry of Education and Culture, 2017a, 2017b). As in other Scandinavian countries, non-EU citizens will have to pay tuition 
fees. However, the design of science and research programmes, the incorporation of a Team Finland Knowledge network, and the cooperation between institutions with business life are meant to be international actions that can attract more students and researchers from all over the world.

In the Netherlands, the internationalisation agenda for Dutch universities has established a set of goals that need to be achieved (VSNU, 2018). These are committed to strengthen the quality of higher education and research, reinforce their international position and address the needs of the international market. To attain these goals, the efforts of the Dutch community are devoted to the creation of new instruments that allow the inflow of international students as well as social integration. As regards language policy, education at the tertiary level is guaranteed in English and Dutch.

With regard to the strategy for the Internationalisation of Spanish Universities, a simplified visa or residence system for international citizens has been suggested (Ministerio de Educación, Cultura y Deporte, MECD, 2016). Furthermore, this plan caters for a higher presence of English-medium courses and foreign language programmes in order to acquire intercultural, linguistic and leadership skills that can be useful when studying and working in multilingual and multicultural settings. Other policies boosting competitiveness have to do with the International Campuses of Excellence Programme, where funding is given to those higher education institutions implementing international events, mobility, excellence and research activities, and other actions. Another association that has played a decisive role in the internationalisation of Spanish higher education has been the Conference of Spanish University Rectors (CRUE, 2017). Some initiatives implemented in its member universities involve the creation of a language accreditation platform, known as CERTACLES and implemented in joint collaboration with other Spanish universities.

\subsubsection{The Universitat Jaume I}

In the Spanish context, the Universitat Jaume I is one of the the five public universities located in the Valencian Community. All the undergraduate and postgraduate courses offer students the possibility to participate in more than 700 exchange programmes with universities from Europe, North America, South America, Asia and Oceania (Universitat Jaume I, 2019b). Indeed, the number of incoming students in 2018/2019 
stood at 327, whereas the number of outgoing students which rose to 378 (Universitat Jaume I, 2019b).

Students can also benefit from training activities such as Erasmus + traineeship for companies in EU, Stella Junior, EU Careers Ambassador programme, Volunteer abroad internship programmes in developing countries or Vulcanus in Japan (OIPEP, 2014). Being part of these experiences will have an impact on their personal, academic and career development. These initiatives make it necessary to provide students with a wide range of CLIL programmes throughout their academic life so that they can build new knowledge and experience the reality of their professional area through the target language.

As for research, innovative actions have been undertaken in the domains of Medicine, and Technology to overcome the challenges posed by the COVID-19 disease (Universitat Jaume I, 2020, May 15). Evidence may be found in the cooperation between the Institute of Ceramic Technology (ITC for its Spanish acronym) and a German working group whose objective is to create a network of doctors, designers and entities that make the printing of 3D materials possible (Universitat Jaume I, 2020, May 15). In the linguistic area, the presence of interdisciplinary organisations, such as the Interuniversity Institute for Applied Modern Languages (IULMA for its Spanish acronym), has served to disseminate knowledge and bring together content and language specialists along the years.

The global vision of the EHEA landscape has called for collaborative initiatives embedding a range of disciplinary fields. In the case of CLIL pedagogies, joint collaboration between language and content specialists seems to be pivotal to select and adapt the scaffolding techniques that will allow students to understand and produce academic discourse in the target language (Carrió-Pastor, 2021). It has been found that content experts, who also happen to be non-native speakers, reformulate their utterances, slow or translate their speech, as occurs with our Italian counterparts (Crawford Camiciotolli, 2005, 2004). Therefore, it seems relevant to explore the notion of CLIL and its implementation in European and Spanish educational settings.

\subsection{CHAPTER SUMMARY}


Having looked at the notions of monolingualism, bilingualism and multilingualism, it has been possible to give an account of the internationalization strategies implemented in the higher education landscape. More specifically, this chapter has described the actions undertaken at a global scale in Latin American, Asian, African and European countries. Within monolingual countries, the strategic plans of The University of Edinburgh and the University of Wolverhampton in the UK have been reviewed. The same is true for bi-/multilingual countries with the case of Universitat Jaume I in Spain. Such internationalization strategies have had an impact in the upsurge of language learning approaches, such as CBI, CLIL and EMI, which will be reviewed in the next chapter. 


\section{Chapter 3: The Content and Language Integrated Learning (CLIL) approach}

\subsection{INTRODUCTION}

As seen in the previous chapter, the internationalisation of education has witnessed the spread of bilingual and multilingual programmes at a global scale, these being central on the agenda of higher education. Undoubtedly, the ability to communicate in more than one language has become an added value (Edwards, 2004) as it has forced countries to rethink their educational systems. At the moment, the number of courses where content is taught in a second or foreign language has witnessed a substantial increase (Brown \& Bradford, 2017; Valcke \& Wilkinson, 2017). This global trend is likely to be observed at educational institutions adopting a variety of teaching approaches, including CBI, EMI and CLIL (Bellés-Calvera, 2018; Bellés-Calvera \& Bellés-Fortuño, in press; Carrió-Pastor, 2019b, 2021; Dearden, 2014). These terms have been widely used as synonyms in the research community, given that their teaching goals and learning outcomes may be overlapped (Dearden \& Macaro, 2016; MacGregor, 2016).

Therefore, this chapter will explore the features of CBI, EMI and CLIL in order to try to provide a clear-cut distinction between these concepts. Very influential in Europe and the focus of this research, I will describe how CLIL programmes have been implemented across higher education institutions, with Spain at the core of all of them. This linguistically diverse country has embraced bilingual and multilingual initiatives through a set of policies that may differ in monolingual and bilingual regions. The Valencian Community, the region where this study has been conducted, falls in the second category. Given that this study is concerned with the implementation of CLIL 
programmes offered at Universitat Jaume I, a range of educational practices as well as the language planning policies approved over the last year will be outlined.

\subsection{LANGUAGE LEARNING APPROACHES}

Multilingualism has been at the heart of EU policies, and in this context, teaching approaches such as CBI, CLIL and EMI have been introduced in educational settings. What is interesting is that these approaches are not innovative practices in terms of pedagogical matters (Mehisto et al., 2008). For instance, the case of Canada, where there is a long tradition of French immersion programmes addressed to Englishspeaking communities, has served as a referent for the development of bilingual and multilingual education practices (Castro-García, 2017). These models will be presented in the following sections.

\subsubsection{Content-Based Instruction (CBI)}

While the mastery of a foreign language is clearly the key to global communication, the rise of foreign language approaches is one of the factors involved in the delivery of quality bi-/multilingual education. Shifting from traditional and structuralist models to a communicative model, the two theories supporting the advent of the CBI approach were drawn on Vygotsky's Scaffolding Theory (1978) and Krashen's Monitor Model (1982). Through his input hypothesis, Krashen (1985) pointed out that language acquisition can only occur if students are exposed to comprehensible input. On the other hand, Vygotsky's Zone of Proximal Development was concerned with the role of the teacher in helping students scaffold to the next level of the learning process. From these theories, it can be inferred that language and content should be accessible in bilingual or multilingual models following a CBI approach. French immersion programmes in Canada are one of the best-known examples of CBI (Brown \& Bradford, 2017).

CBI stands for an umbrella term comprising all the approaches where the instruction of a content subject takes place in a foreign language (Brinton et al., 2003; Lightbown, 2014; Stoller, 2008). Thus, it is a practical approach that advocates for the learning of meaningful content while developing communicative skills in the target language (Bellés-Calvera, 2018; Cammarata et al., 2016; Lightbown, 2014; Mesureur, 2012; Tedick \& Osborn, 2016). According to Wesche (1993, p.57), the scope of CBI is "the 
development of use-oriented second and foreign language skills". In this vein, content materials serve as a tool to determine the linguistic features that need to be mastered (Brown \& Bradford, 2017; Stoller, 2002).

For other scholars, the rationale of the CBI approach has been conceptualised with regard to the role of content and language within the academic curriculum. Stryker and Leaver (1997), for instance, introduced a three-model framework that contemplated the integration of content and language in varying degrees: a sheltered content model, an adjunct-CBI model, and a theme-based model. This proposal stressed language teachers' performance and their cooperation with content specialists, which are common in the sheltered and theme-based model.

The CBI approach has also been understood as a continuum covering content-driven and language-driven programmes (see Table 1). According to Met (1998), the balance between content and language would give rise to different categories labelled as total immersion, partial immersion, content courses, content courses and language classes, language classes with thematic units, language classes with content used for language practice (p.41).

Table 1. Content-driven and language-driven CLIL programmes (Met, 1998).

\begin{tabular}{|c|c|c|c|c|c|}
\hline ك5 & Content-driven & & ב & Language-driven & \\
\hline $\begin{array}{c}\text { Total } \\
\text { immersion }\end{array}$ & $\begin{array}{c}\text { Partial } \\
\text { immersion }\end{array}$ & $\begin{array}{l}\text { Content } \\
\text { courses }\end{array}$ & $\begin{array}{c}\text { Content } \\
\text { courses + } \\
\text { language } \\
\text { classes }\end{array}$ & $\begin{array}{l}\text { Language } \\
\text { classes with } \\
\text { thematic units }\end{array}$ & $\begin{array}{c}\text { Language } \\
\text { classes with } \\
\text { content used } \\
\text { for language } \\
\text { practice }\end{array}$ \\
\hline
\end{tabular}

Over the years curricular contents have been introduced through a language-driven perspective provided that language teachers have been responsible for the delivery of instruction based on thematic units (Banegas, 2019). Such teaching practices aimed at developing foreign language skills, as shown in Met's (1998) classification. It is clear, then, why assessment criteria have been usually tied to language learning rather than on content-specific outcomes (Brown \& Bradford, 2017). Content-driven programmes, on the other hand, would take place when instruction is held in a foreign language and 
assessment is mainly based on the subject matter. This can be a source of confusion in CLIL and EMI practices, which may sometimes be placed as areas within the CBI approach (Brinton \& Snow, 2017; Carrió-Pastor, 2021).

\subsubsection{English as a Medium of Instruction (EMI)}

EMI is an approach adopted by educational institutions offering courses delivered in English in regions belonging to the Inner, Outer and Expanding Circles, as referred to in the previous chapter (Kachru et al., 2006). It has been described as "an umbrella term for academic subjects taught through English, one making no direct reference to the aim of improving students' English" (Dearden \& Macaro, 2016, p.456). On this account, EMI courses can refer to academic studies in primary, secondary and tertiary education, but it is at the university level where there has been an increasing interest from scholars, policymakers and educational institutions. Looking at this definition, the role of international universities set in English-speaking countries should not go unnoticed. Undergraduate and postgraduate programmes are offered exclusively in English to recruit talented students who may not have English as their first language (Baker \& Hüttner, 2019; Tsou \& Kao, 2017). This multilingual context where English is the means of communication used by academic and international communities is reflected in Dafouz and Smit's (2016) conceptualisation of EMI as English-Medium Education in Multilingual University Settings (EMEMUS).

Unlike other bilingual education programmes, language learning is not a priority in EMI (Carrió-Pastor, 2021; Dearden \& Macaro, 2016). Instead, the focus is on content mastery and on building knowledge related to a given domain (Smit \& Dafouz, 2012; Unterberger \& Wilhelmer, 2011). EMI practices are conducted by content specialists in tertiary education (Baker \& Hüttner, 2018) and, through exposure to authentic input, language learning is acquired incidentally (Aguilar, 2015). The adoption of this approach has been examined in a variety of countries from different perspectives. For example, teacher training and team teaching are issues that stand out as they would help EMI educators teach content (Dearden, 2014; Lasagabaster et al., 2018). Other studies have reflected on teachers' and students' perceptions and attitudes towards EMI in Croatian, Japanese and Korean universities (Jiang et al., 2016; Margic \& VodopijaKrstanovic, 2018; Ng, 2017). Challenges posited by EMI instruction are related to teachers' confidence in their linguistic skills and reluctance to the use of translanguaging strategies in their pedagogical practices, as argued by Curry and Pérez- 
Paredes (2021). In Corrales, Rey and Escamilla's study (2016), the implementation of EMI was perceived as satisfactory in that students could develop international and intercultural competences. Aguilar (2021) has also explored the intercultural competence as an EMI outcome in Spain, whereas Carrió-Pastor (2020a, 2020b) has investigated the training of the pragmatic competence in EMI settings.

Research in the EMI area has also focused on the use of English as a lingua franca in academic settings (ELFA). Results have shown that multilingual speakers draw on their multilingual repertoire, thereby using different pragmatic and interactional strategies to achieve effective communication (Cogo, 2009, 2010; Jenkins \& Mauranen, 2019; Kaur, 2009; Mauranen, 2012). In fact, "when used as a lingua franca English is no longer founded on the linguistic and sociocultural norms of native English speakers and their respective countries and cultures" (Gnutzmann, 2000, p.358). Despite having a good command of the English used in the academic field, they rely on their cultural and linguistic knowledge to accommodate their speech rather than following the rules of Standard English (Jenkins, 2000, 2014). Therefore, ELFA may be characterised by the use of different communication strategies that, despite not being geographically located, may develop in monolingual-oriented or bilingual-oriented programmes (Liddicoat, 2016).

\subsubsection{Content and Language Integrated Learning (CLIL) features}

The CLIL approach, coined by David Marsh in 1994, was launched to meet the renowned EU's 2+1 goal, which fosters the learning of communicative skills in at least two additional languages (Eurydice, 2006). This vision was shared by the EU Member States in the White Paper on Education and Training, with the European Commission reinforcing the role of multilingualism in our society (European Commission, 1995). The CLIL phenomenon has been regarded as "a dual-focused educational approach in which an additional language is used for the learning and teaching of both content and language" (Coyle et al., 2010, p.1). This implies that disciplinary knowledge and communicative skills in the target language can be acquired simultaneously (BellésCalvera, 2018; Carrió-Pastor, 2008, 2009, 2011, 2013, 2019b; Heo, 2006; IoannouGeorgiou \& Pavlou, 2011). Other reasons for the promotion of this approach have reported satisfactory results in the development of foreign language areas classified as receptive, including reading, listening, vocabulary and morphology (Ruiz de Zarobe et al., 2011). As regards productive skills, students' risk-taking behaviour seems to boost 
fluency in both speaking and writing, especially when supported by Open Educational Resources (OERs) (Bellés-Calvera \& Bellés-Fortuño, 2018a, 2018b). Despite these positive outcomes, areas such as productive vocabulary, whether informal or nontechnical, pronunciation, accuracy and syntax do not seem to be favoured by CLIL (Gallardo del Puerto et al., 2009; Ruiz de Zarobe et al., 2011; Tedick \& Wesely, 2015). The role of tasks and individual affective factors, namely motivation, anxiety, age or self-esteem, seem to be crucial in CLIL settings (Bellés-Calvera, 2018; Bellés-Fortuño \& Ferrer Alcantud, 2016; Lasagabaster \& Doiz; 2015; Seikkula-Leino; 2007; Somers \& Llinares, 2018).

By and large, what makes CLIL different from other bi-/multilingual education programmes is that these courses can be implemented with contextual differences in terms of policy framework, teacher education, age of implementation, and exposure to the target language (Sylvén, 2013). When it comes to the policy framework, institutional actors, such as the European Commission, the European Parliament, the European Council, the Education Council and national governments, have worked together so that successful CLIL practices take place in primary, secondary and tertiary education (Dalton-Puffer et al., 2010). Such institutional collaborations have been decisive to render resolutions, declarations, regular reports and successful CLIL pedagogies in the EU context (Castro-García, 2017). Accordingly, policy documents are enforced by national governments to determine the guidelines that educational settings should adhere to. The number of languages and their introduction at earlier or later ages would fit in this category.

It is true that, even though any foreign, second or minority language can be used as the medium of instruction in CLIL initiatives, the preference for the English language is quite remarkable in the global educational sphere (Bellés-Calvera \& Bellés-Fortuño, in press; Eurydice, 2006; King, 2018; Lim \& Low, 2009; McDougald, 2019). Due to its role as the language of international communication (Jenkins, 2000; McKay, 2008), it works either as a foreign language in most European, Asian and Latin American countries or as a second language in some Asian and African regions (Cenoz, 2015; Eurydice, 2006; Marsh, 2002). As a result, CLIL has also been labelled as Content and English Integrated Learning (CEIL) (Dalton-Puffer, 2011; Dalton-Puffer, Nikula \& Smit, 2010). Notwithstanding, other languages can be used as the medium of instruction (Turner, 2013) as seen in Japanese, Chinese and Indonesian language teaching 
programmes in Australian educational settings (Baldwin, 2019). Other well-known acronyms for CLIL programmes offered in Spanish, French and German are called Aprendizaje Integrado de Contenido y Lenguas (AICLE), Enseignement de Matières par l'Intégration d'une Langue Étrangère (EMILE) and Content and Language Integrated Learning in German (CLILiG) (Pastor Martínez, 2011; Eurydice, 2006). What all these concepts have in common is that the introduction of bilingual communication in conventional monolingual educational settings can contribute to see Europe as a plurilingual and pluricultural territory (Coyle, 2013).

Another issue that needs to be tackled is the provision of teacher training courses since teaching content through a second or foreign language may be challenging for all the participants (Sylvén, 2013). Instruction is mostly carried out by content specialists (Dalton-Puffer et al., 2014) and the accommodation of authentic materials and teachers' discourse is decisive to provide students with comprehensible input in the content classroom (Bellés-Fortuño, 2021; Cenoz et al., 2014). On this account, formal instruction through pre- and in-service courses can help educators design an integrated curriculum (Sylvén, 2013), raising multicultural awareness (Coyle, 2009). A comprehensive learning pedagogy would seek to integrate both content and language through the 5C's framework (Agolli, 2013), which introduces context as one of the elements that should be considered in the teaching process. The remaining principles correspond to content, cognition, communication and culture, which were included in the 4C's framework (Coyle et al., 2010).

At this point, some sort of collaboration between content and language experts is highly desirable for an effective teaching procedure (Bellés-Fortuño, 2021, Bellés-Fortuño \& Belenguer Balaguer, 2006; Carrió-Pastor, 2008, 2019b, 2021; Doiz et al., 2019; Wozniak, 2013; Maljers et al., 2007), especially if content teachers feel that their proficiency level is not good enough to plan their lessons. Unfortunately, team-teaching practices where content and language instructors share their knowledge seem to be extraordinarily exceptional at university levels (Räisänen, 2009). External and internal indicators may be related to this lack of interaction between disciplinary lecturers (Zappa-Hollman, 2018). The former would depend on organisational aspects and institutional support, whereas the latter would involve the individuals' perceptions and the willingness to take part in collaborative projects. 
One of the attempts to unravel the wide array of CLIL practices in the field of education is that of Greere and Räsänen (2008), who listed five major variants. These models differed in terms of exposure to the target language and collaboration between content and language specialists: Non-CLIL, Language for Specific Purposes (LSP), Pre-CLIL, Adjunct-CLIL and CLIL (Greere \& Räsänen, 2008, p.6). The Non-CLIL model involves less than $25 \%$ of instruction in English, which is conducted by the content specialist. Similar to Met's thematic units (1998), LSP courses are meant to develop disciplinary language, but there is no cooperation between content and language educators. Pre-CLIL and adjunct-CLIL courses are somehow in between with higher exposure to the language and interdisciplinary team-teaching practices, yet communication and learning goals may be vague. The CLIL category implies a full integration of both content and language on the grounds of language exposure and explicit learning outcomes (Aguilar, 2015; Arnó-Macià \& Mancho-Barés, 2015; Greere \& Räsänen, 2008). Aguilar (2015), for example, referred to Non-CLIL and Pre-CLIL courses as EMI, whereas CLIL encompassed adjunct-CLIL and CLIL courses.

Far from being the unique model, Bentley (2010) classified three types of programmes known as soft-CLIL, modular CLIL and hard-CLIL. Soft-CLIL programmes are characterised by the introduction of curricular content in language lessons. In modularCLIL programmes, parts of the curriculum are selected to be taught in the target language. Finally, when the curriculum is totally or partially taught in the target language, we are talking about hard-CLIL programmes. Not only does the focus differ from language-driven to content-driven models, but also the number of hours exposed to the target language. Ergo, CLIL courses may be partially or entirely taught in the target language (Bellés-Fortuño, 2021; Coral i Mateu, 2013; Gené-Gil et al., 2012), which may result in bilingual and multilingual learning environments.

In light of the above, the most striking similarities and differences of CBI, CLIL and EMI will be described in the next section. The discussion of these features will attempt to shed some light on the blurred boundaries among the concepts of CBI, CLIL and EMI.

\subsubsection{CBI, CLIL and EMI: The concepts}

The variety of taxonomies arising from heterogeneous university practices integrating language and content across educational institutions and countries has presented fuzzy 
boundaries. Not without controversy, the terms CBI, EMI and CLIL have been used indistinctively; however, although these programmes share some features, they are pedagogically different.

Both CBI and CLIL have been described as umbrella terms and have thus been interchanged to depict similar realities (Krulatz, 2021; Ruiz de Zarobe, 2008; van de Craen et al., 2007), either in the United States of America (USA) and Canada with CBI being the most popular term or in Europe where the use of CLIL has been spread. For example, Cenoz et al. (2014) claimed that there are no substantial differences between CBI and CLIL in the Basque Country, which happen to be contextual (Krulatz, 2021; Paran, 2013). Nonetheless, even though these programmes share intrinsic features and can take place at all educational levels (Cenoz, 2015), the organisation of the curriculum and the implementation of content-oriented or language-oriented models (Genesee \& Lindholm-Leary, 2013; Met, 1998) have been decisive to provide clear definitions.

Some scholars have argued that CLIL differs from CBI with regard to the curricular role of the language (Genesee \& Lindholm-Leary, 2013; Pérez-Cañado, 2012). Within CBI, an additional or second language should be used as the means of communication during, at least, $50 \%$ of the teaching practice at early stages (Tedick et al., 2011). Exposure to the target language increases progressively in successive academic stages, where instruction and the learning goals are set by language specialists (Tedick et al., 2011). As can be noticed, these features cannot be found in all the alternative forms of CLIL, where both content and language are priorities. The fact that the curriculum can be partially taught in the target language does not guarantee that its presence in the classroom setting corresponds to 50\% (Bentley, 2010; Greere \& Räsänen, 2008). Despite this amalgam of bi-/multilingual programmes, and based on Met's (1999) continuum abovementioned, I here consider CBI as an umbrella term encompassing CLIL and EMI practices.

When it comes to differences between EMI and CLIL, it is evident that the EMI approach has been overlapped with CLIL in tertiary education. The latter has also come to be known as Integrated Content and Learning in Higher Education (ICLHE) (Aguilar, 2015; Arco-Tirado et al., 2016; Doiz et al., 2013), but I here use CLIL as the general and original term addressing primary, secondary and higher education practices. As aforementioned, the CLIL approach fuels the learning of content and language, both 
elements being considered in the assessment criteria (Aguilar, 2015; Bellés-Calvera, 2018). In CLIL settings, collaborative work between language and content specialists is highly desirable since both experts should be involved in the design of curricular materials (Bellés-Calvera, 2018; Carrió-Pastor, 2021; Taillefer, 2013). It is a fact that overt support exists for the use of the target language through the accommodation of teachers' discourse and methodological procedures (Aguilar, 2015; Aguilar \& Muñoz, 2014; Bellés-Fortuño, 2021). For instance, the integration of students' linguistic repertoire has proven to be useful in speaking, particularly when their command of the target language is likely to be heterogeneous (Guarda \& Helm, 2017; Lasagabaster, 2013; Martín-Macho Harrison \& Faya Cerqueiro, 2020; Nikula \& Moore, 2016). The main reason to include multilingual strategies in the classroom is linked to the perception of speaking as the most challenging skill for students (Curry, 2019). Hence, CLIL programmes are tailored to support the learning of any foreign, second or minority language through scaffolding strategies (Mahan, 2020; van de Pol et al., 2010).

While language and content mastery learning goals in CLIL classrooms, EMI programmes are only devoted to the learning of disciplinary knowledge (Aguilar, 2015; Carrió-Pastor, 2021; Smit \& Dafouz, 2012). We should not forget that English is the only language of instruction in EMI programmes in contrast to CLIL settings, where any language can be employed as the means of communication (Brown \& Bradford, 2016; Dearden, 2014). A good command of the English language is assumed before admission to EMI programmes, at least a $\mathrm{C} 1$ level according to the CEFR (CarrióPastor, 2021), on the grounds that linguistic outcomes are not considered for assessment (Aguilar \& Muñoz, 2014; Airey, 2016). Differences can also be observed in the perception and attitudes of teachers' role in CLIL and EMI settings. EMI teachers do not think of themselves as language teachers and appear to be reluctant to provide corrective feedback (Airey, 2011; Belles-Calvera, 2018). The circumstances are completely different in CLIL settings where teachers are aware of the need to raise linguistic and cognitive skills allowing the use of participants' first language (Dafouz, \& Núñez, 2010; Gené-Gil et al., 2012; Guarda \& Helm, 2017; Lasagabaster, 2013; MartínMacho Harrison \& Faya Cerqueiro, 2020; Nikula \& Moore, 2016). As a result, team teaching practices between language and content specialists are scarce in EMI programmes (Aguilar, 2015; Carrió-Pastor, 2021). In being able to understand academic lectures or seminars taught in English, little accommodations may be indispensable to 
assure content comprehension (Aguilar, 2015; Uchihara \& Harada; 2018). This phenomenon is unlikely to occur in some Asian countries where EMI practices seem to be challenged by students' poor skills, thereby making it necessary for teachers to equip students with linguistic resources and adapted materials (Jiang et al., 2016; Ng, 2017). This scenario, in my view, happens to be CLIL.

These differences are essential in order to understand the context in which the study presented here takes place, which is that of CLIL and its extension ICLHE. Therefore, an overview of the most recent research and findings related to CLIL in higher education is discussed in the sections below.

\subsection{CLIL IN HIGHER EDUCATION}

Policies endorsed by the EU's need for greater levels of multilingualism have nurtured approaches to foreign language teaching and learning. Perceived as an educational solution to foreign language teaching (Marsh, 2002), the so-called CLIL approach has been integrated into the curriculum of new university degrees. Not only do students have the opportunity to learn specific contents of a subject area, but they are also exposed to a foreign language on a regular basis (Bellés-Calvera, 2018; Lorenzo et al., 2009). Though early initiatives were mostly addressed to secondary education (Llinares et al., 2012), CLIL undergraduate and postgraduate courses have spread in the higher education landscape of non-Anglophone countries (Arnó-Macià \& Mancho-Barés, 2015; Bellés-Fortuño, 2021; Carrió-Pastor, 2009, 2021; Wei, 2013). Since the boom of CLIL programmes, research has delved into linguistic and non-linguistic issues, namely participants' attitudes towards the use of the target language, students' performance, teacher training support as well as the development of intercultural competences (Aguilar, 2021; Bellés-Calvera, 2018; Bellés-Calvera \& Bellés-Fortuño, 2018b, in press; Carrió-Pastor, 2009; Curry \& Pérez-Paredes, 2021).

As regards language learning outcomes, there has been an emphasis on the development of students' receptive skills in the target language through the design of a balanced curriculum (Brown \& Bradford, 2017). The rationales underpinning such concern are related to the instruction of academic literacies within a given discipline (Dafouz et al., 2007; Meyer et al., 2015), such as Nursing or Law (Arnó-Macià \& Mancho-Barés, 
2015; Garone et al., 2020; Stapel, 2016). In doing so, lecturers may be required to use Basic Interpersonal Communication Skills (BICS) and Cognitive Academic Language Proficiency (CALP) in their pedagogical practices since the language used may occasionally vary from formal to more informal registers (Cummins, 1984). The BICS a learner needs to interact with others on a daily basis are not sufficient in the CLIL classroom, but the formal language used in academic fields and the development of higher-order thinking skills need to be developed for successful learning experiences (Spratt, 2017).

In Greece, a project developed in an Accountancy degree revealed that exposure to comprehensible input in CLIL settings had positive effects on the development of reading skills (Chostelidoua \& Griva, 2014). Similarly, other studies carried out in Germany demonstrated that students who had access to bilingual education were eager to progress more rapidly in the target language (Bredenbröker, 2000; DESI-Konsortium, 2008). Agolli (2015) also stressed the benefits of CLIL programmes on students' receptive and productive skills. More specifically, their listening and cognitive abilities seem to be favoured. Students are able to understand and verbalise lexical items due to the exposure to comprehensible input, which, in turn, boosts content assimilation. The social factor has also been considered in CLIL practices that take place in Ireland (European Commission, 2004). Undergraduate students enrolled in a Business Ethics modules, offered in two degrees, those of International Business and Languages, and International Marketing and Languages, can gain linguistic skills in French while reflecting upon social and ethical challenges they can find in this area of expertise.

Individual and contextual variables play a significant role in the effectiveness of the CLIL approach. Teachers' and students' attitudes are closely linked to "self-perceived language competence as well as individual teaching/learning styles and expectations" (Dafouz et al., 2007, p.100). Their motivation and performance in the target language are highly dependent on language anxiety levels (Aiello et al., 2017; Rou-Jui, 2011); the higher the confidence, the higher the use of their oral skills (Romova \& Neville-Barton, 2007). A study conducted by Arnó-Macià and Mancho-Barés (2015) in Accounting and Law modules has proven lecturers' and learners' discourse to be inaccurate due to their low command of the target language, which also resulted in a limited provision of corrective feedback. Hence, comprehension problems may arise when the linguistic resources employed to explain and reformulate ideas are less clear (Dafouz \& Núñez, 
2010; Martyniuk, 2008). In this scenario, discourse analysis would allow for the identification of the communicative and interactional strategies used by the teaching and learning communities to convey meaning. To this end, the Systemic Functional Linguistics (SFL) framework, Pragmatics, Translanguaging and Scaffolding techniques could be combined to provide a deeper understanding of CLIL classroom discourse (Llinares et al., 2012; Dalton-Puffer \& Nikula, 2006).

The lack of an official CLIL in the European Higher Education landscape and the existing variety of language requirements for students and lecturers taking these courses may explain the assorted progress towards the EU target (Doiz et al., 2019). Published literature on institutional regulations have shown that there is no consensus about the language level for lecturers and students to get involved in CLIL pedagogies. In some institutions teachers need to prove they master the target language at a C1 level (BellésFortuño, 2021), but this is not a requisite in all universities (Doiz et al., 2019). Such miscellaneous measures may explain the shortage of qualified teachers who need support in terms of language provision and CLIL training (Sylvén, 2017; Aguilar \& Muñoz, 2014).

As stated by the Eurydice report (2006), the command of the language would range from a pre-intermediate to an advanced level of the target language. On the other hand, insights from research have suggested that teacher training courses are scarce (Dearden \& Macaro, 2016). These professionals, whose role is that of a guide or a facilitator (Foran \& Sancho, 2009), should be provided with scaffolding techniques and assessment procedures that ensure the integration of both content and language in their lesson plans (Bellés-Fortuño, 2021; Martín de la Lama, 2015).

The potential of OERs to complement classroom practices is beyond discussion in our technological era. These resources provide plenty of opportunities for interaction, autonomous and active learning in CLIL environments (Marsh et al., 2012). Research findings concerning technology-enhanced CLIL and EFL classrooms have shown new ways to strengthen students' communicative competence through online tools like Google My Maps, Escape rooms, Bombay TV, and Voki (Bellés-Calvera \& BellésFortuño, 2018a, 2018b, in press). The popularity of these devices has also resulted in new collaborative projects, such as LanQua Toolkit, CLILAU and CLIL Guide Book (Montalto et al., 2014). These have been carried out to collect and display online 
resources, materials and experiences that can be useful for both teachers and students at different educational levels.

In the Spanish context, the implementation of English as the vehicular language in CLIL programmes has been fruitful in monolingual and bi-/multilingual areas. The fact is that, in Spain, methodological approaches and adaptations have been subject to national and regional policies. The multilingual reality of Spain has thus been described for the purpose of this study.

\subsection{CLIL IN THE SPANISH CONTEXT}

Spain is a unique country culturally and linguistically speaking. This territory is divided into seventeen autonomous communities and two autonomous cities, those of Ceuta and Melilla. Within this southern European country, Spanish -the official language of the state - is not the only language of communication. Other minority languages, such as Galician, Basque and Catalan, have earned a co-official status in bilingual regions where each government is responsible for their preservation.

The linguistic landscape of Spain, which reveals the role languages play in certain domains (Bellés-Calvera, 2019; Shohamy, 2012), is truly unique. Thus, the presence of those languages is an indicator of multilingualism that reflects societal and linguistic changes (Luján-García, 2012). These changes can be produced in rural and urban sites due to the influence of the media or the language policies administered in a given territory, among other factors. Hence, language contact and language dominance phenomena can be observed as reported by Luján-García (2012) and Bellés-Calvera (2019). The prevalence of the English language has then raised some concerns among linguists who perceive it as a "killer language" (Skuttnab-Kangas, 2003, p.33) in the sense that it may lead to the death of existing minority languages.

As an EU Member State, the presence of the English language is also guaranteed within the education system, thus depicting bilingual and multilingual realities in Spain. In primary and secondary education, the curriculum is regulated by the Organic Law on Education (LOE for its acronym in Spanish) (BOE, 2006). Factors influencing the amount of input in the foreign language, which is compulsory in primary and secondary education, are conditioned by age and the autonomy of monolingual and bilingual 
regions to introduce instruction in other languages (Luján-García, 2012). This being the case, French or German may also be offered as part of the curriculum. However, no foreign language requirements are required to get their secondary education and Baccalaureate diplomas (BOE, 2017), but they are expected to have reached a beginner or a pre-intermediate level in English, which are equivalent to an A2 or a B1 level according to the CEFR (DECRET 9/2017).

At tertiary education, universities are expected to implement the National Strategy for the Internationalisation of Spanish Universities, developed by the Ministry of Education, Culture and Sport (CRUE, 2017; MECD, 2016). To do so, most of them adopt the criteria passed by the Conference of Spanish University Rectors (CRUE for its acronym in Spanish), the most influential higher education association in Spain. This means that exposure to the English language, which may become students' second or third language, varies throughout students' academic life. Admission to the university system is determined by the grade obtained in university entrance exams, with an average grade of 6.61 out of 10 in English (Ministerio de Ciencia, Innovación y Universidades, 2019). Nonetheless, foreign language requirements may or may not be included in degree programmes offered all over the country (Luján-García, 2012). The lack of cohesion in educational concerns among autonomous communities depicts a higher education landscape that is subject to change in every region. Following the premises of the Bologna Plan, Spanish universities have responded to the need for internationalisation by incorporating programmes in which English is the language of instruction (Bellés-Fortuño, 2021; Carrió-Pastor, 2020a, 2021). As a result, lecturers may find themselves in classrooms where the level of the target language is not homogeneous.

Several studies have revealed the poor skills of Spanish citizens when using the English language. According to a poll conducted by Spain's Centro de Investigaciones Sociológicas (CIS), a State research institute (2016), around 59.8\% of the population claimed that they were not able to speak, read or write in English. Of those who speak it (27.7\%), over $30 \%$ found it difficult to talk about everyday life topics. The fact that little time is devoted to speaking activities in the classroom and that TV series and films are dubbed in Spanish may explain this low command of the language. Interestingly, only $11.4 \%$ of the total number of respondents was learning a foreign language, and nearly $43 \%$ of those polled would like to learn English if they had the opportunity. 
These negative results are also shown in the Europeans and their identities document (European Commission, 2012b, p.58), where almost $41 \%$ of the surveyed stated that they had not learnt "any language other than their mother tongue". In a recent report carried out in the European Higher Education Area (European Commission, 2018c), about $85 \%$ of the participants noted that they could speak, write and read in two or more languages in contrast to those who could only use one language (15\%). Unpredictably, the proportion of students who would feel comfortable coursing bilingual or multilingual education programmes has dropped significantly (71\%). An in-depth analysis of the variables considered would help policymakers to understand these contradictory results since these may be related to the presence of minority languages in bilingual communities.

In light of these events, the implementation of language policies has committed to the generation of international and multilingual profiles within the Spanish university system (Wächter \& Mainworm, 2014). Noticeably, the incorporation of bi-/multilingual programmes, training courses and language accreditation procedures have proven to be effective internationalisation measures addressed to students, faculty members and administrative staff (CRUE, 2017). Nonetheless, there is still much to be done.

Currently, the number of bi-/multilingual undergraduate and postgraduate degrees offered in public universities during the 2016/2017 academic year was quite limited (7.5\%) (CRUE, 2018). By contrast, the proportion of bilingual programmes in private universities was significantly higher (17.8\%). Differences can also be observed in the area of expertise. Whereas in public universities bilingual programmes are more common in the field of Humanities (36.4\%), it is the field of Social Sciences the one that stands out in the private sector (53\%). These results are quite striking in the sense that research conducted in the field of Health Sciences is in English. Similar trends can be observed in bilingual courses offered in master degrees, as the proportion of these programmes in public universities $(10.4 \%)$ is lower than in private universities $(14.3 \%)$. In this case, the fields prevailing in private universities are those of Social Sciences and Engineering, whereas in public universities the areas of Hard Sciences and Humanities are more prominent.

Overall, being competent in a foreign language seems to be considered in university study plans by showing a positive trend towards bilingual and multilingual programmes. 
The higher education landscape in Spain has been devoted to the development of teachers' and students' academic skills in a foreign language. The quality of instruction is determined by the implementation of the CLIL approach, as it is directly linked to balanced lesson plans as well as to participants' attitudes (Aguilar \& Muñoz, 2014). Rather than having the same linguistic requirements, communities may ask their faculty members to hold a B2 or C1 level of the target language (CRUE, 2017). These linguistic requirements may also differ when it comes to undergraduates, who may need to prove their intermediate level at the end of their degree. Despite all these measures, the number of European Credit Transfer and Accumulation System (ECTS) credits allocated in the target language to content modules is scarce.

\subsubsection{CLIL in monolingual and bilingual regions}

Due to the decentralised higher education system, a number of multilingual plans and research projects have been implemented across Spanish universities set in monolingual and bilingual regions.

As regards monolingual communities, pioneering initiatives have been launched by Andalusian education authorities to promote the learning of foreign languages. Following the guidelines of the Plurilingualism Promotion Plan (BOJA, 2005), the new Strategic Plan for the development of languages in Andalusia seeks for the creation of teaching, research and audiovisual networks (Consejería de Educación, 2016). In this way, language learning becomes a useful tool that allows the transfer of knowledge to our society. Some measures that have been taken involve the funding of projects designed to develop bilingual learning materials, pedagogical tools as well as research on students' linguistic repertoire, among others. The research project known as Analysis and quality assurance of plurilingual Higher Education programmes in Andalusia was developed to analyse the quality of the plurilingual programmes run by the university as well as CLIL teachers' needs (Contero et al., 2018). Educators usually demand teacher training courses that do not only help them to improve their oral skills but also to design didactic materials (Contero et al., 2018; Sánchez Pérez \& Salaberri Ramiro, 2017). Cooperation with international networks has also been decisive in the dissemination of knowledge. This is the case of the University of Granada, which joined the Bilingualism Matters Centre, founded in Edinburgh, to share their expertise on the benefits of bilingualism and language learning (Bilingualism Matters, n.d.). 
Other actions related to CLIL have been undertaken in educational settings set in Madrid. A study carried out at the Complutense University of Madrid examined undergraduates' attitudes towards the implementation of CLIL programmes offered by the Economics and Business Administration school (Maíz-Arévalo \& DomínguezRomero, 2013). The findings suggested that students enrolled in this model improved their lexical, oral and comprehension skills, probably because they participated more actively in the learning process. Another experience developed in a Primary Education degree programme was intended to promote foreign language learning through literature (Llull, 2014). More specifically, comics can be used as a pedagogical resource that is helpful to introduce and reflect on curricular contents. As to interdisciplinary initiatives, training future CLIL schoolteachers has become one of the main assets of the Initial Teacher Education for CLIL: Interdisciplinary Innovation Project, conducted at the Autonomous University of Madrid (Pérez Murillo \& Steele, 2017).

In northern Spain, CLIL research has been conducted in Asturias and Cantabria concerning students' performance. At the University of Oviedo, a module common to the degrees of the Business Administration, Economics, Accountancy and Finance was key to carry out a comparative study between CLIL and non-CLIL groups (HernándezNanclares \& Jiménez-Muñoz, 2017). Results have shown that even though the CLIL programme was more challenging at the beginning of the academic year, there are no significant differences in terms of content learning. Despite being confident in their proficiency level, there seems to be a gap between students' expectations and CLIL lecturers' methodology at university (Hernández-Nanclares \& Jiménez-Muñoz, 2017; González \& Barbero, 2013). To overcome these limitations, a research initiative developed at the University of Cantabria was designed to enhance cooperation at all educational levels by sharing the perceptions of CLIL primary and secondary teachers about the best way to proceed at university.

With regard to bilingual communities, language policies have been traditionally devoted to the normalisation of minority languages, being used as institutional languages (Ramos-García \& Pavón Vázquez, 2018). Due to the internationalisation of higher education universities located in these territories, new regulations that foster the presence of national, regional and foreign languages have been devised. With its Plurilingualism Plan, the University of the Basque Country has offered an increasing number of modules taught in English and French (Lasagabaster, 2012). Nonetheless, 
students do not seem to be satisfied with the fact that they need to course compulsory modules taught in a foreign language as well as prove their proficiency in one or two foreign languages. A brilliant initiative that seeks to promote the use of foreign languages outside the classroom setting is the creation of a Monologue contest in English. This extra-curricular activity is an attractive strategy addressed to undergraduate and postgraduate students who have at least a B2 level in English.

In Catalan-speaking areas, the so-called Vives University Network has established a Language Policy Planning that should be followed by its member universities (Xarxa Vives d'Universitats, 2018). An example of the actions to be undertaken in the area of multilingualism involves the coordination of resources to boost English instruction. As for CLIL at tertiary level, the MULTIMAT (Multilingualism Matters) research group at the International University of Catalonia is an institute disseminating knowledge on language maintenance, teacher training and language learning in ICLHE contexts (UIC Barcelona, n.d.). The Sponsored Classroom for Innovation in English Language Teaching, created in collaboration with Richmond Publishing, has become a referent that brings universities and the publishing industry together through the development of academic, scientific and cultural events.

\subsection{CLIL IN THE VALENCIAN COMMUNITY}

Turning to the Valencian Community, the management of languages in higher education institutions is regulated by the Framework for the Language Policies of Valencian Public Universities (Comissió de Política Lingüística de les universitats Jaume I, de València, Politècnica de València, d'Alacant i Miguel Hernández d'Elx, 2011). As it is a bilingual region, the principles underlying the use of languages at tertiary education are intended to foster the learning of Spanish and, more explicitly, Valencian -a dialectal variety of Catalan- among the university community, including students, faculty members or administrative staff. Other linguistic priorities related to the internationalisation of higher education seek to boost individual plurilingualism and institutional multilingualism. The development of their plurilingual competence will allow university members to communicate effectively in personal, academic and professional settings. At the moment, the three main languages are Catalan as the region's official own language, Spanish as the national language, and English as a 
lingua franca. Two specific goals of this framework, which follows the path taken by the Vives University Network and the CRUE, are to guarantee instruction in the two official languages of the territory as well as increase the number of curricular and extracurricular courses taught in Catalan and English by qualified educators. Hence, trilingualism has been the main asset of the language policies developed in the Valencian Community to monitor and balance the introduction of English as a language of instruction. At present, the configuration of this trilingual plan is highly dependent on the Valencian higher education institutions. Each educational setting is responsible for the creation of its own language policy planning in which the measures that shall be implemented in terms of internationalisation and preservation of local languages are specified.

\subsubsection{The case of Universitat Jaume I}

The Times Higher Education World University Rankings 2021 placed Universitat Jaume I $601-800^{\text {th }}$ worldwide (Universitat Jaume I, 2020a). Occupying the $10^{\text {th }}$ position in the ranking of the best Spanish universities and the $2^{\text {nd }}$ in the Valencian Community, Universitat Jaume I has executed multilingual language policies over the past decades (Universitat Jaume I, 2019a, 2020a). Located in the province of Castellón, the members of this public higher education institution are as follows: 11,349 undergraduates, 1,523 MA students and $813 \mathrm{PhD}$ students (Universitat Jaume I, 2020a). The total number of students who do not come from the Valencian Community should be taken into account. Certainly, roughly $17.5 \%$ of undergraduates may not be familiar with the local language since they come from other parts of Spain (9.76\%) or are involved in Bachelor of Arts (BA) (7.60\%), MA degrees (23.30\%) and PhD degrees (28\%) as international students. On the ground of this complex reality, the priorities stated in the Language Policy Planning accounting for the normalisation of the local language and the promotion of English as the language of the academia (Xarxa Vives d'Universitats, 2018), have been adapted to the institutional needs of the university. Recent years have witnessed internationalisation strategies adapted to the needs of the institution which have encompassed the transfer of knowledge and the preservation of the local identity (Universitat Jaume I, 2016, 2019a, 2019b).

Following the lines approved in previous language policies, as in the Multi-Year Plan for Multilingualism (Universitat Jaume I, 2016), the current Strategy for the Coexistence and Promotion of Languages, known as ECOPOL Plan, has been committed to 
promoting Catalan, the local language, and English (Universitat Jaume I, 2019b, 2020a). Their presence in the curriculum as well as in other academic areas has thus been enlarged. Through a Guide for Multilingual Teaching, this Valencian university urged the incorporation of English as a language of instruction in content modules to enhance multilingualism (Bellés-Fortuño, 2021; Universitat Jaume I, 2017). According to this document, up to $5 \%$ of the total number of credits required in all degrees should be completed in the target language (Bellés-Fortuño, 2021), except for linguistic modules that have been generally comprised within the fields of English for Academic Purposes (EAP) or English for Specific Purposes (ESP). Each degree commission is responsible for the adaptation and configuration of the credits on a yearly basis, resolving which content modules are totally or partially administered in English. The ECOPOL Plan also emphasises the coexistence of this foreign language with the two official languages of the region, either in the design and use of teaching materials or in the methodological approach adopted in academic events such as lectures, seminars or workshops (Universitat Jaume I, 2019a). CLIL pedagogies at Universitat Jaume I are thus linguistically flexible, depicting the multilingual learning realities that take place in a bilingual region.

As for accreditation, in the document called Language Level Requirements for Researchers and Lecturers in Order to Enhance Teaching in English (Universitat Jaume I, 2020b) content lecturers who intend to teach their modules in English are imposed a certified $\mathrm{C} 1$ level according to the CEFR in order to guarantee quality education. Those who do not meet this prerequisite are given up to five years to attain this qualification. On this account, Universitat Jaume I has been committed to promoting initiatives devoted to the Incorporation of the English language in the classroom setting (Universitat Jaume I, 2021). Actions such as (a) free registration in a C1 English level course, (b) payment of the registration fees for the $\mathrm{C} 1$ level exams in English, (c) payment of the registration fees for an EMI course, (d) English language advisory services provided by the Language and Terminology Service, and (e) free registration in an advanced level conversation group, are addressed to lecturers participating in this programme. CLIL learners, however, are not required but recommended to have an intermediate knowledge of English, as can be read in the institutional Guide for Multilingual Teaching (Universitat Jaume I, 2017). More specifically, participants in first-year undergraduate modules should have a B1.2 level, whereas in subjects offered 
in subsequent years a B2.1 level would be necessary to understand lessons or teaching materials in English (Universitat Jaume I, 2020b). This investment on the progressive implementation of bilingual and multilingual education programmes has been materialised in degrees belonging to the fields of Health Sciences and Humanities through the CLIL approach. It is precisely those content modules totally or partially taught in English and the discourse produced in the classroom setting the object of this study.

\subsubsection{English as the language of instruction in Soft Sciences}

The CLIL teaching practices presented here are bound to the field of Soft Sciences with the domains of History and Tourism at the core. Within the field of History, the degrees in History and Heritage, and Humanities share a common curriculum. On the one hand, English is used as one of the vehicular languages in the modules that can be read as follows: History of the Classical World, Linguistics, English (Modern language), Fundamentals and Theory of Artistic Heritage, External Work Placement reports and Bachelor's Thesis. On the other hand, Humanities undergraduates can learn both content and language in subjects such as History of the Classical World, Linguistics, English (Modern language), Discourse and Society, Intercultural Citizenship, External Work Placement reports and Bachelor's Thesis. However, Linguistics and English (Modern Language) do not fall into the category of CLIL as they deal with academic uses of the English language. The content subjects under study correspond to History of the Classical World, basic training module delivered in the first cycle of both degrees, and Fundamentals and Theory of Artistic Heritage, a fourth-year elective module in the History and Heritage degree. Unfortunately, there is no opportunity to enrol CLIL modules until the fourth year of both degrees.

On the other hand, CLIL instruction in the Tourism degree is administered to second, third and fourth-year students in the modules that follow: Spanish Art and Tourist Resources, Information Systems Management in Tourism Organisations, and Valencian Art and Tourist Resources. The latter has been the chosen module for this analysis since a high number of international students get involved during their exchange programmes. In contrast to History of the Classical World and Fundamentals and Theory of Artistic Heritage, which are partially taught in English, Valencian Art and Tourist Resources is a fourth-year module students can enrol optionally. 


\subsubsection{English as the language of instruction in Hard Sciences}

When it comes to the domain of Hard Sciences, CLIL practices have been explored in the field of Health Sciences It is precisely in the Medicine, Nursing and Psychology degrees where the study has been conducted. The credits that need to be taught in the English language within the Medicine degree are distributed heterogeneously from the first year onwards. CLIL instruction occurs in modules such as Nervous System and Sense Organs, Cardiorespiratory and Renal Systems, Anthropology and Evolution, General Pharmacology, Epidemiology and Public Health, Cardiovascular, Renal and Urological Diseases, Toxicology and Legal Medicine, Diseases of the Endocrine and Digestive Systems, and Diseases of the Locomotor and Immune Systems and of the Skin. The CLIL practices examined in this degree involve Anthropology and Evolution, Epidemiology and Public Health, basic training and compulsory subjects taught in the second and third years, respectively. English teaching also occurs in English for Medicine, a first-year module taught during the first semester. Even though it is a linguistic subject, content seminars are allocated throughout the semester, resulting in CLIL learning environments that have also been considered.

As regards the Nursing degree, the choice of modules partially taught in English is limited to Human Physiology, Physiology Public Health, Mental Health Care, Women's Care, and Critical Care. English was mainly used in teaching materials, seminars or practical workshops from the first to the fourth year of the Nursing degree. The participants in this study were enrolled in Women's care, a compulsory content module delivered to third-year undergraduate students.

When it comes to Psychology, lecturers follow a CLIL approach during the fourth year of the degree in a number of compulsory and elective modules, namely Behavioural Neuropharmacology, Vocational Guidance and Career Development, Higher Cognitive Functions, Clinical Assessment and Intervention, and Affective and Social Neuroscience. As in the Nursing degree, teaching materials were available in the target language, which was also the means of communication in allocated CLIL workshops. In this area of expertise the chosen subject was that of Affective and Social Neuroscience. 
Chapter 3: The Content and Language Integrated Learning (CLIL) approach

\subsection{CHAPTER SUMMARY}

This chapter has delved into the features of the CBI, EMI and CLIL approaches to make these concepts clear and avoid confusion. Since CLIL programmes have taken a major role across the European higher education landscape, this chapter has explored a number of pedagogical practices conducted in a variety of countries, with Spain at the heart of the present study. It is precisely the Valencian Community the Spanish region that has been considered for analysis as this is the area where Universitat Jaume I, the higher education institution where CLIL initiatives have been examined, is located. The language planning adopted by the university promotes multilingual learning environments through the use of Spanish, Catalan and English. CLIL discourse will thus be influenced by such premises in different classroom genres. Chapter 4 will dig into lectures and seminars as the main spoken genres taking place in tertiary education by looking at their structure and linguistic features. 


\section{Chapter 4: Academic discourse}

\subsection{INTRODUCTION}

As has been argued in previous chapters, academic discourse is pivotal when learning content in a language other than participants' mother tongue. Written or spoken discourse is the main source of information to examine the effectiveness of CLIL programmes. The integration of content and language in multilingual settings calls for the use of multimodal strategies that help scaffold students' comprehension. Thus, speech events may involve kinesics and translanguaging processes that can be used as tools to negotiate meaning (García Mayo \& Lázaro Ibarrola, 2015; Nikula et al., 2013). Nonetheless, a great part of university discourse may be affected by differing instructional techniques, such as lectures, seminars or tutorials.

In this chapter I am going to review some research on academic discourse in relation to lectures and seminars. Teachers involved in the academic field adapt their discourse to the needs of their audience. The need for interaction may vary to a certain extent in the teaching and learning process of content modules, especially when it comes to the linguistic and discoursal features of CLIL lectures or seminars. Contextual variables and their influence on the structure and patterns of these teaching procedures are also aspects that need to be considered.

\subsection{LECTURES}

\subsubsection{Lecture background}

Lecturing has been regarded as the main instructional method used in tertiary education (Aguilar, 2004; Bellés-Fortuño, 2004; DeCarrico \& Nattinger, 1988; Deroey, 2015; 
Deroey \& Taverniers, 2011; Dudley-Evans, 1994; Dudley-Evans \& Jones, 1981; Flowerdew, 1994; Goffman, 1981; Lee, 2009; Lee \& Subtirelu, 2015; Morell, 2004; Morrison, 1974; McDonough, 1978). Former studies in lecture discourse have dealt with approaches to spoken and written modes (Baron, 2005; Biber, 1988, 2006; QuerolJulián \& Arteaga-Martínez, 2019), where orality and literacy were seen as two different systems when analysing language production. However, the advent of digital resources has given rise to mixed modes of communication ( $\ddot{\text { del }}, 2010$ ) that have reshaped pedagogical approaches to teaching and learning (Breuer \& Archer, 2016). More specifically, the integration of tools in CLIL programmes has had an impact on the use of English as an academic language. In this sense, it has been argued that multimodal practices help the audience construct meaning through the use of verbal and non-verbal elements (Kuteeva \& Mauranen, 2018; Morell, 2015). Given that mobility is highly promoted in tertiary education, either by attending international conferences or participating in exchange programmes (Alcaraz Varó, 2000; Carrió-Pastor, 2021; Flowerdew \& Peacock, 2001; Liddicoat, 2016; Rubio-Alcalá et al., 2019), speech events may be linguistically or culturally diverse (Crawford Camiciottoli, 2004). Therefore, a variety of traditional and interactive lecture taxonomies and styles will be revised.

By and large, delivering lectures has been conceived as a monologue (Morell, 2007). Early studies in the field of science only classified lectures as formal or informal (Morrison, 1974). More comprehensive categorizations can be found in Goffman's (1981) and Dudley-Evans' and Johns' (1981) proposals. On the one hand, Goffman (1981) identified three types of lectures, including (a) memorization, (b) aloud reading and (c) fresh talk. Memorisation is committed to a well-prepared lecture that has been rehearsed in advance; aloud reading has to do with the use of a script when giving an oral presentation; finally, fresh talk is related to a spoken academic discourse that has not been memorised, oral production being delivered with the help of some notes. As for Dudley-Evans and Johns (1981), three styles were established: (a) reading style, (b) conversational style and (c) rhetorical style. The reading style involves lectures being read, where the range of intonation patterns employed by the speaker is limited to falling intonation for the most part. The conversational style accounts for lecturers making use of an outline to help them introduce new contents. These improvised performances are characterised by a relatively informal discourse, thereby boosting 
interaction with the audience. Finally, the rhetorical style entails oral presentations with a wide range of intonation patterns, jokes and digressions.

As stated by Bellés-Fortuño (2007, 2008), there are some parallelisms between the classifications devised by Goffman's (1981), Dudley-Evans and Johns' (1981) and Morell's (2004) (see Table 2). Goffman's memorization may be close to conversational and no-interactive styles. In line with this, Goffman's aloud reading seems to resemble reading and interactive styles, whereas the fresh talk could be linked to Dudley-Evans and Johns' rhetorical style and Morell's (2004) interactive or no-interactive.

Table 2. Parallelism proposed by Bellés-Fortuño (2007, 2008).

\begin{tabular}{|ccccc|}
\hline Goffman (1981) & Dudley-Evans and Johns (1981) & Morell (2004) \\
\hline Memorization $\longleftrightarrow$ & Conversational style & No-interactive \\
\hline Aloud reading $\longleftrightarrow$ & Reading style & $\longrightarrow$ & Interactive \\
\hline Fresh talk $\longleftrightarrow$ & Rhetorical style $\longleftrightarrow$ & Interactive or no-interactive \\
\hline
\end{tabular}

Throughout the years, trends towards interactive practices have tailored mixed instruction methodologies to encourage students' participation and lecture comprehension processes. This shift means that two or event three modes of lecturing can be identified when analysing academic discourse, where the conversational style seems to be commonly encountered in both native and non-English speaking communities (DeCarrico \& Nattinger, 1988; Dudley-Evans, 1994; Ferris \& Tag, 1996; McDonough, 1978; Morell, 2007). Notwithstanding, it should be pointed out that the level of interactivity may have an impact on lecture comprehension due to the social norms of a given territory. Thus, some countries seem to be more familiar with conventional lectures, whereas others may opt for participatory lectures (Frederick, 1986) or open style lectures (Swales, 2004). These terms resemble the lecture categories included within Sander, Stevenson, King and Coates' framework (2000) which were seen as formal or interactive. Hence, two main functions can be identified in classroom discourse depending on the degree of interaction: monologic and dialogic. Monologic communication, which is said to be authorative, occurs when the voice of a speaker tends to dominate the speech event (Mortimer \& Scott, 2003; Nesari, 2015; Shirkhani \& Jamalinesari, 2015; Simpson et al., 2002; Wells, 1998). Dialogic, as opposed to monologic education, "the teacher shares his or her authority with the students; the voices of the students are heard and their opinions are valuable" (Shirkhani \& 
Jamalinesar, 2015, p.27). Therefore, dialogic interaction fosters participatory learning, which in turn contributes to build and acquire new knowledge and thinking skills (Alexander, 2008; Lyle, 2008).

Corpus-based has approached the analysis of academic genres such as lectures, being very useful at multiple linguistic levels, including syntactical, grammatical, phonetic or pedagogical uses (Campoy et al., 2007). Former studies in academic speech have mostly dealt with lexico-grammatical features and their functions (Deroey \& Taverniers, 2011). The emphasis on lexical bundles (Biber \& Barbieri, 2007), questions (Dafouz \& Sánchez García, 2013; García, 2007), personal pronouns (Dafouz, et al., 2007; Lee, 2009), and discourse markers (Bellés-Fortuño, 2007, 2008; Coulthard \& Montgomery 1981; Simpson, 2006) has allowed to ascertain whether lectures are more similar to oral or literate texts (Biber, 2006). Swales, for example, worked on similar and different interdiscoursal traits between spoken and written academic genres (Swales, 2004). Recent lines of research have revolved around organisational lecture cues (Thompson, 2003). Deroey and Taverniers (2011, p.1) recongnised six functions of lecture discourse, namely informing, elaborating, evaluating, organizing discourse, interacting and managing the class.

There is no doubt that students who come from different backgrounds may need to overcome some problems of cultural and linguistic nature when attending lectures (Carrió-Pastor, 2009; Carrió-Pastor \& Muñiz Calderón, 2012; Lee, 2007; Lin \& Scherz, 2014). This is the case of Asian countries where interaction is not as relevant as attendance due to the role and status university lecturers hold in the academic field (Lin \& Scherz, 2014). The premise of an authoritarian and demanding instructor (Ariza, 2018; Lee, 2007; Nakane, 1970) is not shared in the United States, the role of the lecturer being that of a guide (Benson, 1994) or a "co-manager of learning" (Lin \& Scherz, 2014, p.18) that generates interactive exchanges. In giving this type of lecture, active learning is expected. Due to the recruitment of international students and the proliferation of CLIL and EMI programmes in higher education, a more interactive lecturing style seems to be predominant in higher education (Dafouz et al., 2007; Lee, 2009; Lynch, 2011; Morell, 2004). Unfortunately, lecturers' may find themselves in a challenging scenario. Fears such as losing control of the lecture, adapting their discourse to their students' needs or over-presenting detailed information may prevent 
some educators from giving interactive lectures (McKeachie, 1994; Newble \& Cannon, 1994; Steinert \& Snell, 1999).

The expansion of digital resources in the educational dimension has supported the emergence of new educational and interactive models, facilitating the processing of lectures in real time or through virtual environments. To date, open and distance learning (ODL) has the potential to extend educational opportunities for students all over the world (Arkorful \& Abaidoo, 2015; Barajas, 2003; Carrió-Pastor, 2019a). Not only does it respond to economic, geographical or physical reasons that can make virtual mobility possible, but it also introduces a new distribution network that strengthens the transmission of information. The combination of those factors can help us rethink the notion of lecture since this academic event can be transmitted when it is being performed. At the same time, lectures can also be recorded and uploaded to a virtual platform, which may help students internalise knowledge as many times as needed. This practice may occasionally be regarded as flipped classroom, a studentcentred approach where the learning environment is rearranged. Lectures are delivered through online videos before the actual class in order to enhance students' engagement by means of discussions that will ultimately have a positive effect in their learning outcomes (Bossaer et al., 2016; Caviglia-Harris, 2016; Cavanagh, 2011; Day, 2018).

\subsubsection{Lecture structure}

Having portrayed these synchronous and asynchronous modes of communication, the structural and organisational patterns of lecture discourse need to be considered. Factors such as the lack of familiarity with the format, the distribution of information, the structure of the lecture, and students' command of the target language may pose some cognitive and linguistic challenges to CLIL and EMI students who are not used to these practices (Duszak, 1997; Flowerdew, 1994; Flowerdew \& Miller, 1992; Herington, 2019; Lin \& Scherz, 2014).

At this point, understanding the role interpersonal features and discourse markers have is likely to aid organisation, comprehension and interaction in the classroom setting (Hyland \& Jiang, 2016). Given that the macro-structure of the lecture may vary according to the discipline (Dudley-Evans, 1994), metadiscoursal strategies have been of interest to scholars and educators analysing lectures in a variety of disciplines (Aguilar, 2008; Bellés-Fortuño, 2007, 2008, 2016, 2018; Bu, 2014; D’Angelo, 2018). 
Certainly, recent research on metadiscoursal strategies has reported that using appropriate macro-structures and micro-features (van Dijk, 2019; Young, 1994), prosodic features of speech (Morell, 2007), discourse markers (Bu, 2014; Eslami \& Eslami-Rasekh, 2007), language functions (Bellés-Fortuño, 2018; Fraser \& MalamudMakowski, 1996), visual aids (D’Angelo, 2018), eye contact (Fiorella et al., 2019) and negotiations of meaning (Dafouz \& Sánchez García, 2013; Lyster, 2007; Walsh, 2006) are some of the variables that contribute to the quality of instruction.

Concerning the organisational patterns of academic lectures, Sinclair and Coulthard's (1975, 1992) model has served as a starting point for subsequent categorizations (Coulthard \& Montgomery, 1981; Swales, 1990; Young, 1994) as it established hierarchical levels that were used for both spoken and written texts. Within their rank scale, developed for the analysis of the discourse in primary classrooms, lessons can be found at the top of the hierarchy; these are made up of transactions, which are in turn made up of exchanges and moves that signal transitions from one section of the lesson to another; all of them are made up of acts, which are the smallest discourse units. Drawing on this model, Straker Cook (1975) introduced a new framework by adapting the elements previously mentioned to the internal structure of the lecture. Thus the macro-structure of a lecture consisted of expositions, episodes, moves and acts. Later on, Young (1994) concluded that university lectures are structured in six phases based on language choice: discourse structuring, conclusion, evaluation, interaction, content and examples. These phases are classified as metadiscoursal and non-metadiscoursal categories. Metadiscoursal phases stand for "strands which comment on the discourse itself" (Young, 1994, p.166) and include discourse structuring, conclusion and evaluation. In the discourse structuring phase, the lecturer outlines the direction of the speech event. The main points that have been covered throughout the lecture are summarised by the speaker in the conclusion, whereas in the evaluation phase the presenter evaluates the information that has already been transmitted or that will be the main focus in the near future.

The three non-metadiscoursal phases seem to be associated with the building of knowledge (Young, 1994, p.167). The interaction phase is characterised by the teachers' use of interpersonal features to engage the audience in the learning process and check comprehension. Within the content phase theoretical information is introduced to help 
the audience build new knowledge related to a given domain. Finally, the examples phase is devoted to illustrate theoretical concepts.

As for Bligh (2000), the planning of effective lectures is determined by a number of techniques that call for establishing key points, using hand-outs and obtaining feedback from students. In other models the focus is not on the lecture discourse as a whole but on introductions (Yaakob, 2014; Lee, 2009; Shamsudin \& Ebrahimi, 2012; Thompson, 1994). Thus, the internal structure of the lecture was conceived in three moves (Lee, 2009), namely Warming-up, Setting up the lecture framework, and Putting the topic in context.

\subsection{SEMINARS}

\subsubsection{Seminar background}

By examining academic discourse patterns, educators can benefit from effective teaching practices (Achugar et al., 2007). Apart from lectures, another popular source of knowledge acquisition in higher education has to do with seminars (Basturkmen, 1999). The main assumption of this instructional system is to get a better insight into an area of expertise by getting students involved in discussions dealing with topics that are generally more specific than those presented in lectures (Basturkmen, 1999).

Yet the notion of seminar may differ depending on contextual factors. Rather than merely presenting information as a monologue, seminars in the Anglo-Saxon academic culture have been understood as "an occasion when a teacher or expert and a group of people meet to study and discuss something" (Cambridge dictionary, n.d.). These academic events are progressively practised with smaller groups to support their academic progress (Basturkmen, 1999). It is through this instructional strategy that students are able to construct knowledge through self-reflection and the critical thinking (Aubrey \& Riely, 2016; Kraker, 2000; Curzon, 1990; Wilson, 1989). This has a great impact in their writing skills as they are exposed to a wide range of texts that need to be synthesised for the purpose of the seminar (Padgett et al., 2013). However, introducing new contents to a large audience may be daunting to undergraduate students, particularly to non-native speakers (Basturkmen, 1999; Hyland, 2009; Jordan, 1989; Mauranen, 1993, 1994, 2010, 2012). Indeed, in Furneaux et al's research (1991) it was 
evident that non-native speakers' performance in seminar sessions was characterised by high levels of anxiety. Al'Adawi (2017), for instance, explored students' perceptions of seminars as a valuable teaching and assessment method.

Based on previous literature, seminars may take different educational forms to further explore subject matter. These meetings have been referred to as Socratic seminars (Billings \& Roberts, 2003; Strong, 1996), discussion-based seminars (Bahar, 2003), graduate seminars (Northcott, 2001; Weissberg, 1993), peer seminars (Aguilar, 2004), colloquia (Weissberg, 1993) or even lab skills seminars (Sabanayagam et al., 2017). In this sense, this instructional practice can be framed as a classroom or as a research genre (Martín del Pozo, 2014). Socratic seminars have been defined as "collaborative, intellectual dialogue facilitated with open-ended questions about a text" (Billings \& Roberts, 2003, p.16). Because the emphasis is on questions and discussions, the purpose of this seminar is to construct and share knowledge through the examination of issues raised by the text. According to Weissberg (1993), graduate seminars are regarded as students' presentations of their original research, which belong to what Swales (1990, p.177) coined as "other research-process genres". Peer seminars encompass an expertto-expert meeting that can be understood as a spoken research genre within the academic community (Aguilar, 2004). This research talk, led by an invited speaker who is a specialist in a given research area, is addressed to other scholars interested in this field of study, be it lecturers or postgraduate students. This is why they may resemble conference presentations. Peer seminar and service learning models served as the basis of lab skills seminars, a new variant increasingly popular in the teaching of physical and health sciences across North American higher education institutions (Sabanayagam et al., 2017; Swales, 2004). Lab skills seminars are implemented to reinforce disciplinary knowledge and teach practical techniques through weekly theoretical workshops. These seminars are held in a collaborative learning environment, where teachers and their postgraduate fellows act as facilitators to actively involve students in the discussion.

As pointed out by Aguilar (2004), seminars, colloquia and lab meetings could somehow be placed within a continuum envisioned by Dubois (1987) that copes with biomedical academic communication (see Figure 1). 


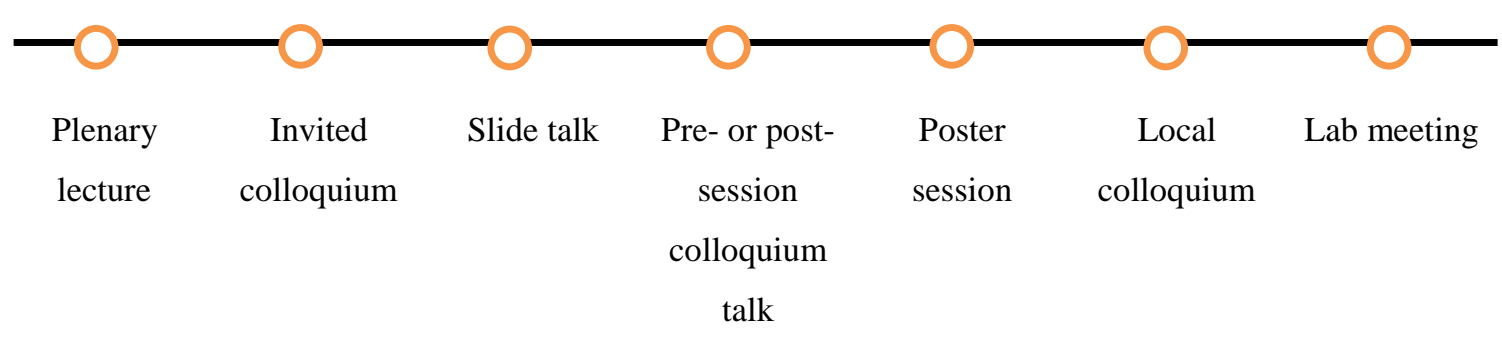

Figure 1. Description of Dubois' continuum (1987, p.537), as in Aguilar (2004, p.62).

Despite the fact that seminars are sometimes referred to as colloquia, Aguilar (2004) claims that both genres differ in terms of register, considering that peer seminars tend to be more formal than some of the aforementioned types of academic meetings, such as poster sessions or lab meetings. Along the years other categories have emerged. Barefoot and Fidler (1992) labelled these speech events as extended-orientation seminars, academic seminars with generally uniform academic content across sections, academic seminars on various topics, pre-professional or discipline-linked seminars, basic study skills seminars, and hybrid seminars. The first category, referred to as extended-orientation seminars, is tied to the introduction of the campus and other aspects of academic life to new students. The second category, academic seminars with generally uniform academic content across sections, is devoted to the learning of academic skills and curricular content through interdisciplinary or theme-oriented topics. Similarities can be found with academic seminars on various topics, but the latter are characterized by different content and topic sections. The fourth category, preprofessional or discipline-linked seminars address professional training issues for future workers. Last but not least, basic study skills seminars are meant to provide students with additional academic support, whilst features from several types of seminars can be spotted within hybrid seminars. A different taxonomy is that of Cañedo Iglesias (2008), who pointed out seven types of seminars that appear to be salient in Spanish-speaking countries. These included question and answer seminars (i.e. group discussions), dialogic seminars, presentation seminars (i.e. lecture seminar), presentation and opposition seminars, reading seminars, production seminars, debate seminars, board seminars, round table seminars, video-debate seminars and mixed seminars.

Among the tasks usually required of undergraduate students are academic presentations, where a given topic is meant to be presented individually or in groups in the classroom setting. In Martín del Pozo's view (2014), academic presentations are classified as a 
classroom genre other than seminars, assuming that these speech events present features that are typical in both lecture and seminar sessions. These correspond to monologic discourse as in lectures, and informal and conversational phrases that tend to occur in seminars (Hyland, 2009). For Baker (2000) oral presentations are understood as formal spoken events. Villar (2014) claimed that students' oral presentations are delivered within seminar sessions as part of the assessment of disciplinary modules. This is the vision I have considered for the identification of the different types of academic events that are presented in this study.

Yet interaction is central in all these types of university seminars. All the types of seminars mentioned earlier seek to negotiate meaning through the management of turns between the teacher and the students, both of them having the opportunity to exchange opinions and assessing knowledge comprehension (Soter et al., 2008). At the same time, seminars seem to a valid academic source to share recent research and present it to an audience that can provide you with corrective feedback through discussion (Al'Adawi, 2017), which allows the refinement of communication, management and presentation skills (Polly et al., 2012).

\subsubsection{Seminar structure}

In presenting the variety of seminar talks that can be encountered in higher education, it is worth mentioning that the internal structure of this speech event may differ depending on the academic context. As seen in Table 3, the main sequence patterns identified by Weissberg (1993) and Aguilar (2004) in graduate and peer seminars are as follows:

Table 3. Comparison of the structural phases of seminars based on Weissberg (1993) and Aguilar (2004).

\begin{tabular}{|c|c|}
\hline Graduate seminar (Weissberg, 1993) & Peer seminar (Aguilar, 2004) \\
\hline $\begin{array}{l}\text { Introduction of the academic advisor to the speaker } \\
\text { student. }\end{array}$ & \multirow[t]{2}{*}{ 1. Warm-up/Pre-introduction. } \\
\hline $\begin{array}{l}\text { Introduction of the student speaker led by the } \\
\text { academic advisor. }\end{array}$ & \\
\hline Student slide presentation & $\begin{array}{l}\text { 2. Body of talk: } \\
-\quad \text { Description and review of previous } \\
\text { literature. } \\
\text { - } \\
\text { Discussion of challenging issues posed } \\
\text { by the methodology implemented in past } \\
\text { research. } \\
\text { - } \\
\text { Presentation of the speaker's research }\end{array}$ \\
\hline
\end{tabular}




\begin{tabular}{|l|l|}
\hline $\begin{array}{l}\text { Questions and comments about the research } \\
\text { project. }\end{array}$ & 3. Conclusion \\
\hline
\end{tabular}

Having reviewed these types of classroom events, it can be noted that the main difference between graduate and peer seminars is related to macro-structure. Weissberg (1993) did not provide a deep analysis on talk moves and sections within graduate seminars. Actually, no details are offered with regard to students' presentations. In Aguilar's work (2004), however, several phases can be identified in the body of talk registered in peer seminars. In her study, it was reported that speakers felt the urge to delimit the different sections of their presentations, particularly because they follow similar patterns to those observed in conference presentations. Another major concern involves participants' introductions, which seem to be accommodated to the role of the speaker. In graduate seminars research is presented by a student who is introduced to a faculty member that will provide the presenter with feedback, whereas in peer seminars slide talk is conducted by an invited speaker.

Preliminary research in seminar talk has examined learners' discourse (Kraker, 2000; Basturkmen, 1999) and the competitiveness of the learning environment at a postgraduate level (de Klerk, 1995). Other corpus-based studies have analysed knowledge comprehension through the use of personal pronouns (Du Bois, 2007; O’Boyle, 2014), and participant intentions (Viechnicki, 1997). Little attention has been paid to the functions of metadiscoursal devices, such as attitudinal, engagement or personal markers (Flowerdew, 1992; Mauranen, 2002), in spoken corpora gathered in CLIL contexts and their prevalence across disciplinary fields.

\subsection{ACADEMIC DISCOURSE IN LECTURES AND SEMINARS}

Generally speaking, the time and effort invested in planning lectures and seminars as well as the asymmetrical relationship between the participants are somehow reflected in classroom discourse (Lapadat, 2000; Martín del Pozo, 2014) where one of the interlocutors organises and controls the topic and turn-taking processes. As seen earlier in the introduction of this chapter, Mauranen's taxonomy (2001) examined the varying degrees of classroom interaction, classifying spoken texts as monologic, dialogic and 
interactive. In monologic lectures the number of opportunities to negotiate meaning is scarce since students are required to take notes and listen to long spoken texts uttered by the lecturer (Mauranen, 2001; Mortimer \& Scott, 2003; Nesari, 2015; Shirkhani \& Jamalinesari, 2015; Simpson et al., 2002). On the other hand, dialogic lectures refer to verbal exchanges between the lecturer and the listener dealing with questions and doubts (Alexander, 2008; Lyle, 2008; Shirkhani \& Jamalinesar, 2015). In other words, in these communicative situations participants respond to the interlocutor's talk (Ädel, 2010). Interactive lectures are characterised by the elicitation of responses from the interlocutor by asking questions or choosing speakers, among others.

The field committed to the analysis of these talk-in-interactions is known as metadiscourse. According to Hyland (2005), metadiscourse is defined as an umbrella term for a number of resources that help "organize their texts, engage readers, and signal their attitudes to the material and the audience" (p. ix). Because language is highly dependent on the social context, the production and analysis of academic discourse has been of interest in the past decades. The analysis of discourse in CLIL settings has looked at the Systemic Functional Linguistics (SFL) theory featured by Halliday and Matthiessen (2004). Within SFL, language is described as a meaningmaking process that takes place in a given social context (Coffin, 2013). Adapting language is then crucial to make statements clear, especially when addressed to nonnative speakers of the target language. On this account, Martin and White (2005) devised the well-known SFL Appraisal theory, a model for the analysis of the interpersonal macro-function that focused on the linguistic resources used by speakers and writers to express evaluation, engagement and emotion. In the classroom context, SFL fosters the construction of knowledge through the selection of discourse markers (Dafouz \& Núñez, 2010).

Relying on these SFL premises and Young's (1994) phases, Dafouz and Núñez (2010, p.218) proposed a metadiscoursal model for the analysis of lectures as an educational genre. The way metadiscoursal and non-metadiscoursal phases were reconceptualised by Dafouz and Núñez (2010) can be observed in Table 4. 
Table 4. The structural phases of lectures (Dafouz \& Núñez (2010, p. 218).

\begin{tabular}{|l|l|}
\hline \multicolumn{1}{|c|}{ YOUNG (1994) } & \multicolumn{1}{c|}{ DAFOUZ AND NÚÑ̃Z (2010) } \\
\hline Metadiscoursal & Metadiscoursal \\
\hline Discourse Structuring & Discourse Structuring \\
Conclusion & Conclusion \\
Evaluation & Interaction \\
\hline Non-metadiscoursal & Discoursal \\
\hline Interaction & Evaluation \\
Content & Content \\
Exemplification & Exemplification \\
\hline
\end{tabular}

As can be seen from the table above, this classification is rooted in Young's (1994) macro-structure of university lectures, described in previous sections of this chapter. The categories adopted for the examination of lectures are labelled as metadisoursal and discoursal, thereby replacing Young's non-metadiscoursal phases (Dafouz \& Núñez, 2010). These terms are motivated by Hyland's concept of metadiscourse (2005), which reflects on the negotiation of interpersonal markers comprised in a text that to involve the audience and thus nurture interaction. On this account, it is reasonable to place interaction within the metadiscoursal dimension as it embraces the interpersonal function. Evaluation, however, seems to fit better at a discoursal level given that evaluative devices tend to signal the relevance of materials and content. Therefore, this model of metadiscourse is meant to be applied in spoken-based corpora of lecturing events taking into account the textual and interpersonal markers realised in the Discourse Structuring, Interaction and Conclusion phases (see Table 5). 
Table 5. Phase analysis and metadiscoursal categories (Dafouz \& Núñez, 2010, p. 220).

\begin{tabular}{|c|c|c|c|}
\hline Phases & Metadiscourse category & Function of metadiscursive devices & Examples \\
\hline \multirow{5}{*}{ 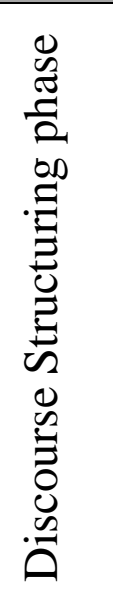 } & Openers & Signal the formal beginning of a class & $\begin{array}{l}\text { Today we are going to } \\
\text { talk about }\end{array}$ \\
\hline & Sequencers & $\begin{array}{l}\text { Mark particular positions within a } \\
\text { series }\end{array}$ & First, then, next \\
\hline & Topicalisers & $\begin{array}{l}\text { Indicate introduction of new topics / } \\
\text { topic shifts }\end{array}$ & $\begin{array}{l}\text { Another concept; what } \\
\text { are F1 cars made of? }\end{array}$ \\
\hline & Prospective markers & $\begin{array}{l}\text { Refer forwards to topics/sections in } \\
\text { the lecture/other lectures }\end{array}$ & We will see later \\
\hline & Retrospective markers & $\begin{array}{l}\text { Refer backwards to previous topics / } \\
\text { sections in the lecture/other lectures }\end{array}$ & As I mentioned before \\
\hline \multirow{4}{*}{ 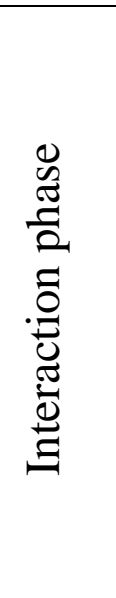 } & Questions & $\begin{array}{l}\text { Requesting student participation / } \\
\text { checking comprehension }\end{array}$ & Who can answer this? \\
\hline & $\begin{array}{l}\text { Commentaries (help to } \\
\text { establish speaker/listener } \\
\text { rapport) }\end{array}$ & $\begin{array}{l}\text { Direct address to the audience / } \\
\text { Inclusive expressions }\end{array}$ & $\begin{array}{l}\text { Remember; you know } \\
\text { well... We all know; it } \\
\text { is our decision }\end{array}$ \\
\hline & Apologetic comments & Apologise for some lack/deficiency & $\begin{array}{l}\text { I have to apologise for; } \\
\text { sorry... }\end{array}$ \\
\hline & Contextual comments & $\begin{array}{l}\text { Comment on situational features or } \\
\text { aspects outside the actual content of } \\
\text { the lesson }\end{array}$ & $\begin{array}{l}\text { We are going to be } \\
\text { recorded today; it is too } \\
\text { hot (in the classroom)... }\end{array}$ \\
\hline \multirow{4}{*}{ 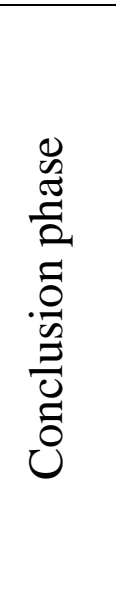 } & Closing markers & $\begin{array}{l}\text { Indicate the formal closing of the } \\
\text { lecture }\end{array}$ & I will finish here \\
\hline & Recapitulation & $\begin{array}{l}\text { Summarise the main ideas in the } \\
\text { lecture }\end{array}$ & Today we saw... \\
\hline & Prospective markers & $\begin{array}{l}\text { Refer forward to future topics to be } \\
\text { dealt within other lectures (placed } \\
\text { towards the end of the lecture) }\end{array}$ & $\begin{array}{l}\text { Tomorrow we will } \\
\text { cover... }\end{array}$ \\
\hline & Retrospective markers & $\begin{array}{l}\text { Refer backwards to previous topics/ } \\
\text { sections of the lecture (placed } \\
\text { towards the end of the lecture) }\end{array}$ & $\begin{array}{l}\text { What we learnt today } \\
\text { was... }\end{array}$ \\
\hline
\end{tabular}

Micro-linguistic devices are included in each macro-structural phase. The Discourse Structuring phase comprises openers, sequencers, topicalisers, prospective and retrospective markers. The Interaction phase entails the use of questions, commentaries, apologetic and contextual markers. Finally, the Conclusion phase encompasses devices 
such as closing, recapitulation, retrospective and prospective markers that signal the end of the academic event.

Within academic discourse, our main interest is on the oral outcomes produced in CLIL contexts, which is the core of this study. In this regard, the former taxonomy was revisited by Martín del Pozo (2014). In her classification, she introduced new categories oriented to the organisation of discourse and use of interactive patterns in CLIL lectures, namely non-verbal and visual topicalisers, referential, display, rhetorical and content questions (see Table 6).

Table 6. Phases and metadiscoursal categories for CLIL lectures (Martín del Pozo, 2014, p. 261).

\begin{tabular}{|c|c|c|c|c|}
\hline Phases & \multicolumn{2}{|c|}{ Metadiscourse category } & Function of metadiscursive devices & Examples \\
\hline \multirow{4}{*}{ 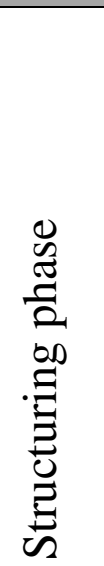 } & \multicolumn{2}{|l|}{ Openers } & Signal the formal beginning of a class & $\begin{array}{l}\text { In this lesson we will talk } \\
\text { about }\end{array}$ \\
\hline & \multicolumn{2}{|l|}{ Sequencers } & $\begin{array}{l}\text { Mark particular positions within a } \\
\text { series }\end{array}$ & $\begin{array}{l}\text { First of all } \\
\text { Then }\end{array}$ \\
\hline & \multicolumn{2}{|c|}{ Verbal topicalisers } & $\begin{array}{l}\text { Indicate introduction of new topics / } \\
\text { topic shifts }\end{array}$ & $\begin{array}{l}\text { Another possible model } \\
\text { Next concept is }\end{array}$ \\
\hline & \multicolumn{2}{|c|}{ Non-verbal topicalisers } & $\begin{array}{l}\text { Indicate introduction of new topics / } \\
\text { topic shifts without verbal } \\
\text { communication }\end{array}$ & (slide transition in silence) \\
\hline 岕 & \multicolumn{2}{|c|}{ Visual topicalisers } & $\begin{array}{l}\text { Indicate introduction of new topics / } \\
\text { topic shifts making reference to } \\
\text { visual aids }\end{array}$ & $\begin{array}{l}\text { Here we have } \\
\text { This is the index }\end{array}$ \\
\hline ○ & \multicolumn{2}{|c|}{ Prospective markers } & $\begin{array}{l}\text { Refer forwards to topics/sections in } \\
\text { the lecture/other lectures }\end{array}$ & We are going to see later \\
\hline & \multicolumn{2}{|c|}{ Retrospective markers } & $\begin{array}{l}\text { Refer backwards to previous topics / } \\
\text { sections in the lecture/other lectures }\end{array}$ & As you have heard \\
\hline \multirow{6}{*}{ 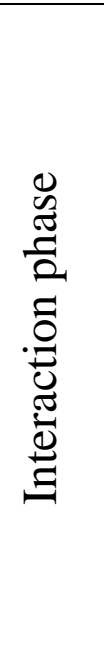 } & \multirow[t]{4}{*}{ Questions } & Referential & $\begin{array}{l}\text { Requesting student participation / } \\
\text { checking comprehension. }\end{array}$ & What is the result of? \\
\hline & & Content & $\begin{array}{l}\text { Indicating that the answer is not } \\
\text { known. }\end{array}$ & What do you prefer? \\
\hline & & Rhetoric & Asking and giving an answer. & What does this mean? \\
\hline & & Indirect & Requesting student participation. & $\begin{array}{l}\text { Could you raise your hand } \\
\text { if you agree? }\end{array}$ \\
\hline & \multicolumn{2}{|c|}{$\begin{array}{l}\text { Commentaries (help to } \\
\text { establish speaker/listener } \\
\text { rapport) }\end{array}$} & $\begin{array}{l}\text { Direct address to the audience / } \\
\text { Inclusive expressions }\end{array}$ & $\begin{array}{l}\text { As you can see } \\
\text { Let us consider }\end{array}$ \\
\hline & \multicolumn{2}{|c|}{ Apologetic comments } & Apologise for some lack/deficiency & Sorry \\
\hline
\end{tabular}




\begin{tabular}{|c|c|c|c|}
\hline & Contextual comments & $\begin{array}{l}\text { Comment on situational features or } \\
\text { aspects outside the actual content of } \\
\text { the lesson }\end{array}$ & $\begin{array}{l}\text { Temperature in any point } \\
\text { of this room. }\end{array}$ \\
\hline \multirow{4}{*}{ 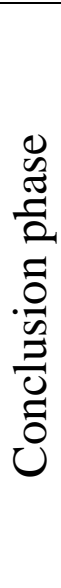 } & Closing markers & $\begin{array}{l}\text { Indicate the formal closing of the } \\
\text { lecture }\end{array}$ & $\begin{array}{l}\text { I finish the theoretical } \\
\text { lecture. }\end{array}$ \\
\hline & Recapitulation & $\begin{array}{l}\text { Summarise the main ideas in the } \\
\text { lecture }\end{array}$ & We have reflected that... \\
\hline & Prospective markers & $\begin{array}{l}\text { Refer forward to future topics to be } \\
\text { dealt within other lectures (placed } \\
\text { towards the end of the lecture) }\end{array}$ & $\begin{array}{l}\text { In the next lesson we } \\
\text { will... }\end{array}$ \\
\hline & Retrospective markers & $\begin{array}{l}\text { Refer backwards to previous topics/ } \\
\text { sections of the lecture (placed } \\
\text { towards the end of the lecture) }\end{array}$ & Here I talked about ... \\
\hline
\end{tabular}

Taking the SFL Appraisal theory as a basis, Llinares et al. (2012) also unveiled their own approach to the different roles of language in CLIL settings. In this model, three roles of language were identified when assessing classroom-based discourse, including subject literacies, classroom interaction and language development (see Table 7).

Table 7. Framework for understanding the roles of language in CLIL (Llinares et al., 2012, p.15).

\begin{tabular}{|c|c|c|c|c|c|}
\hline $\begin{array}{c}\text { SUBJECT } \\
\text { LITERACIES }\end{array}$ & & \multicolumn{2}{|c|}{ CLASSROOM INTERACTION } & & $\begin{array}{c}\text { LANGUAGE } \\
\text { DEVELOPMENT }\end{array}$ \\
\hline \multirow[t]{2}{*}{ Genre } & $\begin{array}{l}\text { A } \\
S\end{array}$ & $\begin{array}{l}\text { Instructional register } \\
\text { Regulative register }\end{array}$ & Focus & \multirow{3}{*}{$\begin{array}{l}\mathrm{A} \\
\mathrm{S} \\
\mathrm{S} \\
\mathrm{E} \\
\mathrm{S} \\
\mathrm{S} \\
\mathrm{M} \\
\mathrm{E} \\
\mathrm{N} \\
\mathrm{T}\end{array}$} & $\begin{array}{l}\text { Expressing ideational meanings } \\
\text { (content-related knowledge) }\end{array}$ \\
\hline & $\begin{array}{l}S \\
E\end{array}$ & $\begin{array}{l}\text { Communication } \\
\text { systems (approach) }\end{array}$ & Approach & & $\begin{array}{l}\text { Expressing } \quad \text { interpersonal } \\
\text { meanings (attitudes, evaluation) }\end{array}$ \\
\hline Register & $\begin{array}{l}S \\
S\end{array}$ & $\begin{array}{l}\text { Interaction patterns } \\
\text { Scaffolding }\end{array}$ & Action & & $\begin{array}{l}\text { Expressing textual meanings } \\
\text { (moving between spoken and } \\
\text { written modes) }\end{array}$ \\
\hline
\end{tabular}

As for subject literacies, two categories have been included: genre and register. The genre embodies those text types that are common in a discipline. For instance, some genres in the area of history would include historical recounts or historical explanations in contrast to descriptive reports or causal explanations, which correspond to the scientific area (Dalton Puffer, 2007). This implies that CLIL teachers need to know the 
characteristics of the discourse that should be produced. On the other hand, the notion of register stands for the lexico-grammatical features that typically occur in a given genre. Three dimensions are found at the level of register: (a) field, (b) tenor and (c) mode (Halliday \& Hasan, 1989). The field refers to the nature of the activity taking place in the communicative event; the tenor describes the roles of the subjects involved in the interaction process and their and relationships; and the mode is concerned with aspects related to the means of communication.

Turning to classroom interaction, the focus, the approach and the action taken to content communication are interactional features that enhance the integration of content and language learning (Llinares et al., 2012; Martin \& White, 2005; Mortimer \& Scott, 2003). The focus entails the planning of pedagogical objectives. As a result, discourse is articulated by means of instructional and regulative registers (Christie, 2002). The former stands for the skills and language structures related to the subject matter, whereas the latter refers to general academic language that is employed for classroom and social management purposes. Secondly, the way content is communicated and the degree of interaction have an impact in teaching practices. In this sense, the negotiation of meaning can take place through four teaching practices, these being dialogic and interactive, dialogic and non-interactive, authoritative and interactive, authoritative and non-interactive (Mortimer \& Scott, 2003). In dialogic and interactive practices, the teacher and the students would cover and share a variety of perspectives on a specific topic; dialogic and non-interactive practices would result in the teacher reviewing different impressions; a particular point of view would be presented in authoritative and interactive exchanges; in authoritative and non-interactive systems the teacher remains the only speaker who holds the floor to introduce a viewpoint (Mortimer \& Scott, 2003). Finally, a set of interaction patterns can be employed to exchange information. In this regard, the Initiation-Response-Follow up (IRF) pattern would allow for a controlled classroom discussion between educators and students since the teacher asks a question to monitor students' knowledge, students produce an output and then feedback is provided (Dafouz Milne, 2014; Dalton-Puffer, 2007; Nikula, 2007). Thus, after evaluating students' contributions, teachers can also get students to elaborate a particular task adapted to their needs (Llinares et al., 2012). 
As to language development, the aforementioned register variables seem to be closely connected to Halliday's and Matthiessen's (2004) metafunctions of language, namely ideational, interpersonal and textual (see Table 8).

Table 8. Register dimensions and metafunctions of language (Halliday \& Matthiessen, 2004).

\begin{tabular}{|c|c|}
\hline REGISTER DIMENSIONS & METAFUNCTIONS OF LANGUAGE \\
\hline Field & Ideational \\
\hline Tenor & Interpersonal \\
\hline Mode & Textual \\
\hline
\end{tabular}

Any CLIL student needs to become familiar with subject specific and general academic language of a given field. With the ideational metafunction they learn how to manage certain lexico-grammatical features that facilitate the comprehension of subject-specific matter and knowledge construction (Llinares et al., 2012; Nagao, 2019). Secondly, the interpersonal function serves four purposes in CLIL contexts, which have to do with socialisation, classroom performance, genre operation and personal experiences (Llinares et al., 2012). Syntactically speaking, the construction of this meaning can be observed through the use of different clause types. It is the variations in these syntactical structures the ones that determine how speech functions are realised. According to the Speech Function model presented by Halliday and Matthiessen (2004), there are four interpersonal functions based on the speech roles and the commodities exchanged (e.g. statements, questions, commands and offers), these being related to the Mood system (e.g. declarative, interrogative and imperative clauses). Finally, the textual function is concerned with the organisation of coherent texts consisting of theme and rheme (Halliday \& Matthiessen, 2014; Llinares et al., 2012).

Tied to interaction, metadiscourse analysis has been approached from interactive and reflexive perspectives. As to the interactive approach, Hyland (2005) argued that the functions of language can be analysed from an interpersonal model that is subdivided into interactive and interactional dimensions. The interactive model consists of a set of markers (e.g. transitions, frame markers, endophoric markers, evidentials, and code glosses) that are concerned with the organisation of the discourse (see Table 9). 
Table 9. Hyland's interpersonal model: interactive dimension (2005, p. 49).

\begin{tabular}{|l|l|}
\hline \multicolumn{1}{|c|}{ Category } & \\
\hline Transitions & In addition; but; thus; and \\
\hline Frame markers & Finally; to conclude; my purpose is \\
\hline Endophoric references & Noted above; see Fig.; in section 2 \\
\hline Evidentials & According to X; Z states \\
\hline Code glosses & Namely; e.g.; such as; in other words \\
\hline
\end{tabular}

These categories perform a special function throughout the lecture discourse. Transitions, which can also be referred to as logical markers, stand for additive, contrastive and consecutive conjunctions employed in the speech event. Frame markers involve the use of items to structure the items of the text. Endophoric references allude to information that has already appeared or that will appear in other parts of the text. Evidentials comprise sources from other texts that have been incorporated in the communicative event. Finally, code glosses facilitate comprehension by introducing reformulation and exemplification processes.

By contrast, the involvement of the producer and the audience can be found in the categories of the interpersonal model (e.g. hedges, boosters, attitude markers, selfmentions and engagement markers) (see Table 10).

Table 10. Hyland's interpersonal model: interactional dimension (2005, p. 49).

\begin{tabular}{|l|l|}
\hline Category & Examples \\
\hline Hedges & Might; perhaps; possible; about \\
\hline Boosters & In fact; definitely; it is clear that \\
\hline Attitude markers & Unfortunately; I agree; surprisingly \\
\hline Self-mentions & I; my; our; we \\
\hline Engagement markers & Consider; note; you can see that \\
\hline
\end{tabular}

As seen in Table 10 above based on Hyland's classification (2005), hedges reflect the commitment of the writer. Boosters express certainty in propositions. Attitude markers seek to display the attitude of the writer towards the information that has been provided. Self-mentions show the presence of the writer by means of first-person pronouns and determiners. Finally, engagement markers encompass interaction with participants through personal references, questions, and imperatives, among others. 
Criticism towards interactive approaches focused on the presence of categories that should not be considered as metadiscoursal devices. In an attempt to overcome the problems that entailed these "too all-inclusive" (Ädel, 2006, p.71) approaches, reflexive approaches (Ädel, 2006, 2010, 2017; Flowerdew, 2015; Mauranen, 2001, 2003, 2010, 2012; McKeown \& Ladegaard, 2020; Salas, 2015) which relied on Jakobson's (1960) functions of language emerged. A clear example is that of Ädel (2006), who identified three functions of language with the elements or participants involved in the communicative event. Thus, the metalinguistic, expressive and directive functions were associated with the discourse, the reader/listener and the writer/speaker respectively. In addition to these functions, metatext and audience interaction are established as metadiscoursal categories that should be looked at when analysing academic discourse. Metatext encompasses the organisation of the discourse, whereas audience interaction examines the use of personal references (see Table 11).

Table 11. Ädel's metatext taxonomy (2006, p. 83).

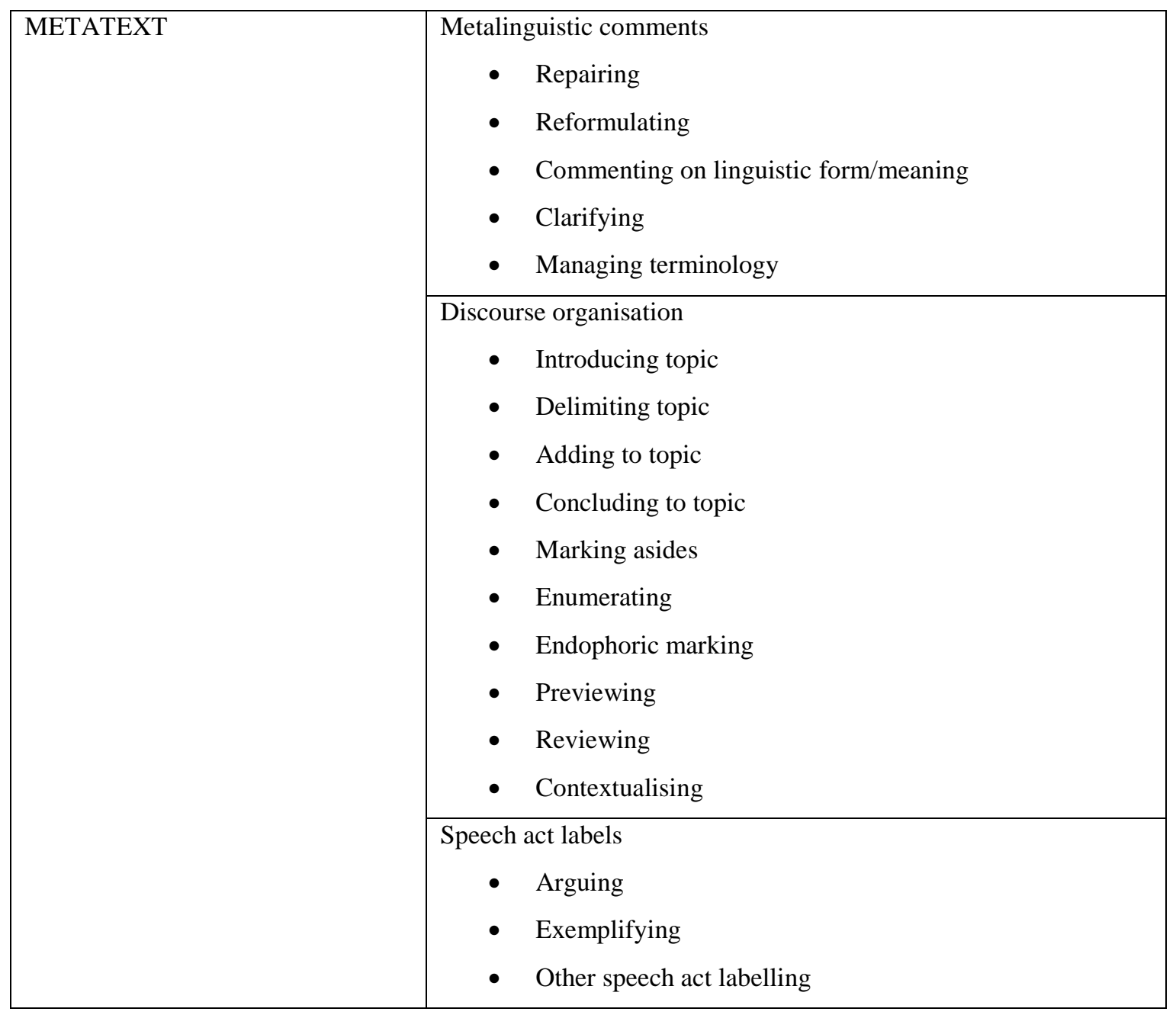




\begin{tabular}{|l|l|}
\hline AUDIENCE INTERACTION & References to the audience \\
- & Managing comprehension channel \\
- & Managing audience discipline \\
- Anticipating the audience's response & Managing the message \\
- Imagining scenarios
\end{tabular}

Other elements that are key to analyse classroom-based discourse in CLIL contexts have to do with lexico-grammatical and phonological patterns (Bellés-Calvera \& BellésFortuño, 2018b, in press; Eggins, 2004; Lahuerta, 2020; Pérez-Vidal \& Roquet, 2015; Rallo Fabra \& Jacob, 2015). The lexico-grammatical dimension provides an account of the lexical and grammatical items that occur in communication, whereas the analysis of phonological patterns involves the sound system. Failure to produce appropriate patterns may hinder communication. All of these issues have been of interest in corpusbased research, where the compilation of spoken corpora is taking a prominent role in the foreign language learning realm (Campoy et al., 2007). These spoken corpora provide access to authentic classroom discourse originated in lectures and seminars. Learner corpora, for example, may contribute to the design and adjustment of teaching practices and didactic materials in approaches such as EAP (Lee \& Subtirelu, 2015), ESP (Hyland, 2009), CLIL (Dafouz et al., 2007) or EMI (Molino, 2018). These studies can therefore contribute to overcoming the research and teaching gap mentioned by Swales (2002).

\subsection{CHAPTER SUMMARY}

Lectures and seminars, the most frequent spoken genres at tertiary education, have been the focus of the third chapter. Previous research in lecture and seminar discourse and sequence has been revisited. Given that teacher-student interaction is relevant in CLIL learning environments, this chapter has been concerned with the role of metadiscoursal markers. These studies may point to didactic implications for the CLIL classroom and for teacher training in multilingual settings, where the interpersonal metafunction happens to be the main focus of the present research. The next step is to observe these elements in the CLIL university teacher-student discourse. This analysis will serve to 
Chapter 4: Academic discourse

detect and diagnose the metadiscoursal elements occurring in CLIL learning environments in order to design pedagogical guides that improve the acquisition and dissemination of knowledge through the target language. Chapter 4 that follows describes the research questions and the methodology used for this observation. 


\section{Chapter 5: Methodology}

\subsection{INTRODUCTION}

As previously mentioned, the multilingual turn (May, 2014) taken by the EHEA has been supported through the implementation of language learning approaches, namely CLIL and EMI (Wächter \& Maiworm, 2014). As internationalisation remains a central objective, efforts have been made to review the curricula offered to the university community and encourage them to extend their linguistic repertoire. Language proficiency issues may raise some concerns when it comes to communication in the classroom setting. At this point, translanguaging practices are said to be valuable in the sense that the interaction of languages may help devise effective pedagogies (Bieri, 2018).

On this account, this chapter outlines the research framework and the methodological approach adopted for the collection, selection and detailed examination of classroom interaction in CLIL settings. First of all, the objectives of this study and the research questions are defined. Then, a description of the participants, the materials, and the research tools employed to analyse the corpus is provided. This section includes the students and lecturers enrolled in the six different degrees that took part in the study, the instruments used to explore their attitudes towards the target language and the opinions about the implementation of CLIL practices in higher education. Finally, the procedure followed to compile the texts in the resulting corpus is described. 


\subsection{RESEARCH QUESTIONS}

The aim of this dissertation is to examine the implementation of CLIL programmes at a multilingual Spanish university, and concretely at Universitat Jaume I, as it brings together a number of disciplinary areas, sociolinguistic requirements and attitudinal concerns. In this way, awareness towards classroom communication can be raised among CLIL lecturers and students. CLIL research has mainly addressed areas such as grammar, vocabulary, writing and oral production (Bellés-Calvera \& Bellés-Fortuño, 2021, 2018b; Nikula et al., 2013). Classroom interaction should also be approached as part of the learning process itself (Escobar Urmeneta, \& Walsh, 2017; Nikula et al., 2013; Papaja, 2011), but classroom interaction processes need to be further explored. Not only are features such as topicalisers and retrospective markers relevant in the CLIL classroom, but also interactional patterns (Llinares et al., 2012). Drawing on these traits, the linguistic repertoire of each individual should be taken into account since the use of all their skills can have a positive impact in bi-/multilingual learning (Hornberger, 2005). In this sense, the objectives of this research project are as follows:

1. To explore participants' attitudes towards CLIL learning programmes.

2. To analyse classroom discourse in CLIL multilingual learning environments at a tertiary level.

3. To compare and contrast the implementation of the CLIL approach in modules belonging to the fields of Humanities, Social Sciences and Health Sciences.

Through the exploration of classroom interaction in CLIL settings where English is the language of instruction, this project seeks to find an answer to these research questions:

1. $\mathrm{RQ}(1)$. What are participants' attitudes and concerns towards the implementation of CLIL practices in higher education?

2. $\mathrm{RQ}(2)$. What interpersonal traits, such as engagement, attitudinal and evaluative markers, can be observed in CLIL programmes offered at higher education?

3. $\mathrm{RQ}(3)$. Are there any significant differences among the CLIL practices in the fields of Humanities, Social Sciences and Health Sciences?

The issues underlying these questions will be covered in the next chapters. By discussing these questions, this thesis will contribute with useful information to enhance 
the accomplishment of teaching and learning outcomes. More specifically, hints can clearly serve to tailor accurate CLIL programmes with a bi-/multilingual design that meet the educational needs of new generations.

\subsection{THE CORPUS}

The corpus compiled for this study is made up of a variety of speech events, including a lecture, nine seminars and ten interview transcripts. This research project focused on CLIL modules that belonged to the disciplines of Humanities, Social Sciences and Health Sciences, with nine lecturers working at Universitat Jaume I. A variety of speech events that took place in six degrees were audio-recorded for the purpose of this study, namely History and Heritage, Humanities: Intercultural Studies, Tourism, Medicine, Nursing, and Psychology. Half of the corpus consists of five audio-recorded CLIL seminars taught in the Medicine, Nursing and Psychology degrees. The other half belongs to the instructional practices that were delivered in the degrees of History and Heritage, Humanities: Intercultural Studies, and Tourism. Table 12 that follows describes the degrees, modules and academic year where these CLIL initiatives were implemented.

Table 12. Degrees and its corresponding modules included for the analysis of the study.

\begin{tabular}{|l|l|c|}
\hline \multicolumn{1}{|c|}{ Degrees } & \multicolumn{1}{|c|}{ Module } & Year \\
\hline \multirow{2}{*}{ Medicine } & English for Medicine: Skin cancer & 1 st \\
\cline { 2 - 3 } & Anthropology and Evolution & $2 \mathrm{nd}$ \\
\cline { 2 - 3 } & Epidemiology and Public Heatlh & 3 rd \\
\hline Nursing & Women's care & 3 rd \\
\hline Psychology & Affective and Social Neuroscience & 1 st \\
\hline History and Heritage & History of the Classical World & 4 th \\
\cline { 2 - 3 } & Fundamentals and Theory of Artistic Heritage & $1 \mathrm{st}$ \\
\hline Humanities: Intercultural studies & History of the Classical World & 4 th \\
\hline Tourism & Valencian Art and Tourist Resources & \\
\hline
\end{tabular}

The selection of these disciplines was not made arbitrarily. Humanities, Social Sciences, represented by Tourism here, and Health Sciences are three academic fields of study of intrinsic relevance in our society. Scholars have claimed that the interdisciplinary nature of these fields (Callard \& Fitzgerald, 2015; Choi \& Pak, 2008) enhances the acquisition 
of the professional and social skills that are required in the labour market. It is believed that language proficiency may be a predictor of academic achievement (Kalidayan et al., 2015; Sadeghi et al., 2013) on the grounds that English is extensively used as an academic language by students pursuing health-related careers in contrast to those enrolled in Humanities and Social Sciences degrees (Kuteeva \& Airey, 2013).

Hence, in the early stages of the research eight interviews were conducted with educators teaching in a CLIL scenario along the first and second semesters of the academic year 2018/2019. Firstly, CLIL lecturers were contacted by email and interviews were arranged in order to engage them as collaborators in this project because getting their permission to attend to and record their lectures and seminars to be later transcribed was decisive to carry out this study (see Appendix I (a)). The digital sound of all these communicative events, with over seventeen hours recorded, was transcribed to gather representative corpus samples (Biber, 1993). In this sense, the compilation of this corpus, which consists of approximately 62,273 words (see Appendix I (b)), began by transferring all the lecture and seminar recordings to the computer. The second procedural step of this study comprised the transcription of the audio files, which was an arduous and time-consuming task.

At times, transcribing speech entailed some difficulties. Teachers and students moving around the classroom, interactions not related to the subject or the quality of the recordings were challenges that were encountered when transcribing the corpus. That is the reason why some of these irrelevant data were not considered in the transcription process of both interviews and classroom practices. In so doing, a set of norms had to be established to get transcript versions ready for their corresponding analyses (see Table 13). 
Table 13. Transcription codes.

\begin{tabular}{|c|c|}
\hline \multicolumn{2}{|r|}{ TRANSCRIPTION CODES } \\
\hline , & Short pause \\
\hline . & Pause \\
\hline$:$ & Long pause \\
\hline- & Repetition, reformulation \\
\hline$\ldots$ & Unfinished utterances \\
\hline$[\ldots]$ & The speech of the speaker has been omitted. \\
\hline SX & Unknown student. \\
\hline Ss & More than one student. \\
\hline [unintelligible] & Speech can be heard but cannot be understood because of phonetic features. \\
\hline [inaudible] & $\begin{array}{l}\text { Indecipherable Passages. Speech cannot be heard due to sound quality issues } \\
\text { or noises. }\end{array}$ \\
\hline <TLANG_Eng> & Participants' speech occurs in English. \\
\hline <TLANG_Sp> & Participants' speech occurs in Spanish. \\
\hline <TLANG_Cat> & Participants' speech occurs in Catalan. \\
\hline [laughs] [applause] & Non-verbals in italics. \\
\hline "..." & The speaker reproduces the speech of someone else. \\
\hline$\left[{ }^{*} \ldots{ }^{*}\right]$ & The speaker referred to something different. \\
\hline <video > & Used when a video or part of a video is played. \\
\hline$\langle$ READING $>$ & Used when short excerpts are read verbatim. \\
\hline$\langle\mathrm{PRON}\rangle$ & $\begin{array}{l}\text { Used when a speaker makes a pronunciation mistake that appears to affect the } \\
\text { comprehension and transcription of academic discourse. }\end{array}$ \\
\hline $\mathrm{H} 1$ & CLIL teacher in the History of the Classical module. \\
\hline $\mathrm{H} 2$ & CLIL teacher in the Fundamentals and Theory of Artistic Heritage module. \\
\hline $\mathrm{T}$ & CLIL teacher in the Valencian Art and Tourist Resources module. \\
\hline M1 & CLIL teacher in the English for Medicine: Skin cancer. \\
\hline M2 & CLIL teacher in the Anthropology and Evolution module. \\
\hline M3 & CLIL teacher in the Epidemiology and Public Health module. \\
\hline N1 & CLIL teacher in the Women's care module. \\
\hline N2 & $\begin{array}{l}\text { CLIL teacher in the Human Physiology module and coordinator of the } \\
\text { Nursing degree. }\end{array}$ \\
\hline N3 & CLIL teacher in the Critical care module. \\
\hline $\mathrm{P} 1$ & CLIL teacher in the Affective and Social Neuroscience module. \\
\hline $\mathrm{P} 2$ & $\begin{array}{l}\text { PhD student and CLIL teacher in the Affective and Social Neuroscience } \\
\text { module. }\end{array}$ \\
\hline
\end{tabular}


Transcription codes such as $\mathrm{H} 1$ and TLANG facilitate the identification of the participants as well as the use of multilingual patterns in the learning environment. In the case of the TLANG coding, which is referred to as the translanguaging practices occurring in the speech event, participants' contributions in English, Spanish and Catalan can be recognised under the labels <TLANG_Eng>, 〈TLANG_Sp> and $\langle$ TLANG_Cat $>$.

Not only were participants' spoken and written performance variables under study, but their proficiency level in the target language and the nature of academic event were also significant. On this account, CLIL pedagogies adopted a translanguaging approach where a wide range of multilingual strategies could be identified. To complement these data, certain materials were collected during the classroom research. These included questionnaires, placement tests, students' written assignments, students' multimedia PowerPoint presentations, and copies of teacher hand-outs. In fact, participants enrolled in the History of the Classical World and Epidemiology and Public Health modules gave their permission to use their CLIL module assignments.

\subsubsection{Corpus description}

As with any corpus, the description of its main attributes is vital to facilitate the organisation and analysis of spoken texts. In this case, the criteria followed in both parts of the corpus have been mainly adapted from the Michigan Corpus of Academic Spoken English (MICASE) (Simpson et al., 2002a). Thus, details about the academic events are specified by including categories such as field, module, discourse function, genre, number of words and duration (see Table 14 and Table 15). All of the CLIL practices have been implemented in undergraduate modules that belong to the fields of Humanities, Social Sciences and Health Sciences. Under this label, it was possible to conduct a contrastive analysis between these academic disciplines. 
Table 14. Corpus description of CLIL practices in the field of Humanities and Social Sciences.

\begin{tabular}{|c|c|c|c|c|c|}
\hline Field & Module & $\begin{array}{l}\text { Discourse } \\
\text { function }\end{array}$ & Genre & $\begin{array}{c}\text { Number of } \\
\text { words }\end{array}$ & Duration \\
\hline \multirow{2}{*}{$\begin{array}{l}\text { History and } \\
\text { Heritage } \\
+ \text { Humanities: } \\
\text { Intercultural } \\
\text { Studies }\end{array}$} & $\begin{array}{l}\text { History of the } \\
\text { Classical World }\end{array}$ & Dialogic & $\begin{array}{c}\text { SEML1: } \\
\text { Group } \\
\text { discussion } \\
\text { seminar }\end{array}$ & 3,604 & $60 \mathrm{~min}$. \\
\hline & $\begin{array}{l}\text { History of the } \\
\text { Classical World }\end{array}$ & Monologic & $\begin{array}{c}\text { SEML2: } \\
\text { Slide talk } \\
\text { seminar }\end{array}$ & 5,136 & $110 \mathrm{~min}$. \\
\hline $\begin{array}{l}\text { History and } \\
\text { Heritage }\end{array}$ & $\begin{array}{l}\text { Fundamentals and } \\
\text { Theory of Artistic } \\
\text { Heritage }\end{array}$ & Dialogic & $\begin{array}{l}\text { SEMS: } \\
\text { Video- } \\
\text { debate } \\
\text { seminar }\end{array}$ & 1,311 & 113 min. \\
\hline \multicolumn{4}{|l|}{ Total } & 10,051 & 283 min. \\
\hline \multicolumn{4}{|c|}{ Average words and time per academic event } & $3,350.3$ & 94 min. 30s \\
\hline \multirow[t]{2}{*}{ Tourism } & $\begin{array}{l}\text { Valencian Art and } \\
\text { Tourist Resources }\end{array}$ & Dialogic & $\begin{array}{l}\text { LES: } \\
\text { Lecture }\end{array}$ & 6,540 & 87 min. \\
\hline & $\begin{array}{l}\text { Valencian Art and } \\
\text { Tourist Resources }\end{array}$ & Monologic & $\begin{array}{c}\text { SEMS: } \\
\text { Slide-talk } \\
\text { seminar }\end{array}$ & 5,806 & $90 \mathrm{~min}$. \\
\hline \multicolumn{4}{|l|}{ Total } & 12,346 & 177 min. \\
\hline \multicolumn{4}{|c|}{ Average words and time per academic event } & 6,173 & 88 min. $30 s$ \\
\hline
\end{tabular}


Table 15. Corpus description of CLIL practices in the field of Health Sciences.

\begin{tabular}{|c|c|c|c|c|c|}
\hline Field & Module & $\begin{array}{l}\text { Discourse } \\
\text { function }\end{array}$ & Genre & $\begin{array}{c}\text { Number of } \\
\text { words }\end{array}$ & Duration \\
\hline \multirow[t]{3}{*}{ Medicine } & $\begin{array}{lr}\text { English } & \text { for } \\
\text { Medicine: } & \text { Skin } \\
\text { cancer } & \end{array}$ & Monologic & $\begin{array}{l}\text { SEMS: } \\
\text { Lecture } \\
\text { seminar }\end{array}$ & 11,997 & 104 min. \\
\hline & $\begin{array}{l}\text { Anthropology and } \\
\text { Evolution }\end{array}$ & Dialogic & $\begin{array}{l}\text { SEMS: } \\
\text { Reading } \\
\text { seminar }\end{array}$ & 3,399 & $80 \mathrm{~min}$. \\
\hline & $\begin{array}{l}\text { Epidemiology and } \\
\text { Public Heatlh }\end{array}$ & Monologic & $\begin{array}{c}\text { SEMS: } \\
\text { Slide-talk } \\
\text { seminar }\end{array}$ & 12,390 & 119 min. \\
\hline Nursing & Women's care & Monologic & $\begin{array}{c}\text { SEMS: } \\
\text { Slide-talk } \\
\text { seminar }\end{array}$ & 4,501 & 53 min. \\
\hline Psychology & $\begin{array}{l}\text { Affective and } \\
\text { Social } \\
\text { Neuroscience }\end{array}$ & Dialogic & $\begin{array}{l}\text { SEMS: } \\
\text { Video- } \\
\text { debate } \\
\text { seminar }\end{array}$ & 7,589 & 115 min. \\
\hline \multicolumn{4}{|c|}{ Total } & 39,876 & 471 min. \\
\hline \multicolumn{4}{|c|}{ Average words and time per academic event } & $7,975.2$ & 94.2 min. \\
\hline
\end{tabular}

As to genre typology, two general classroom events can be distinguished, namely lectures and seminars. Based on the framework designed in earlier chapters of this dissertation, seminars have been sub-classified as group discussions, projects and research talks. The feature labelled as discourse function addresses the predominant language mode that can be noticed in a speech event (i.e. monologic, panel, interactive and mixed) (Simpson et al., 2002). Bearing this in mind, group discussions tend to be primarily interactive, since students are encouraged to ask questions and share their opinions on a given topic (Shirkhani \& Jamalinesari, 2015). In contrast, project-based seminars tend to be mostly monologic, particularly because students' voices are the ones that stand out. Some of them might even be considered of mixed nature. This case can be observed in the Women's care module; students' speech is mostly monologic when presenting their projects, whilst the teacher's discourse can be perceived as interactive. Overall, the corpus includes four group discussions, four project-based seminars, a research talk and a lecture, which are rather small in terms of size. 
According to the MICASE corpus, academic discourse occurs in a wide variety of classroom events, namely lectures, seminars, undergraduate lab sessions, student presentations, and discussion sections, among others (Simpson et al., 2002). Lectures, for example, can be classified as large or small on the grounds of the number of participants. Large lectures (LEL) can be regarded as academic events with "more than 40 students" in contrast to small lectures (LES) which consist of "40 or fewer students" (Simpson et al., 2002, p.5). Even though in the MICASE corpus this distinction is not applied to seminars, the corpus presented here includes lectures and seminars based on class size variables. In general, the number of students attending most lectures and seminars is quite homogeneous, whose class size happens to be small except for the History of the Classical World module. In this case, the audience might be slightly higher considering that learners from two degrees are given instruction at the same time. The fact that some of these modules are elective and the availability of identical seminars along the week would explain why the vast majority of CLIL teaching practices are implemented in small groups.

Regarding values such as number of words and recording duration, CLIL practices in the field of Health Sciences seem to be slightly longer than the ones offered in the field of Humanities. As shown in Tables 14 and 15 above, considerable differences can be observed in terms of average words. Academic events in degrees belonging to the discipline of Humanities have 3,343 average words and a recording duration of 94 minutes and 20 seconds. In Social Sciences, the average number of words per seminar amounts to 6,173 words with a duration of 88 minutes and 30 seconds. There is a trend for the production of more words per seminar in Health Sciences, where the average number of words, registered in a 94.2 minutes recording, rises to 7,975.2. CLIL practices in Humanities seem to be shorter than the ones in Health Sciences, probably due to the use of YouTube videos and other audiovisual materials.

\subsubsection{Participants}

Participants in this study are not meant to represent the whole university community enrolled in CLIL modules, but the sample design employed to conduct the qualitative and quantitative analyses of this research is purposeful according to Patton (1990). The set of strategies described by Patton (1990) comprised selective sampling, also known 
as criterion sampling. The underlying principle in this strategy has to do with the selection of particular cases at an initial stage of the study based on a number of criteria that illustrate the preconceived ideas of the researcher (Denzin \& Lincoln, 1994).

Broadly speaking, the selection criteria were related to the CLIL approach, as stated in the theoretical framework. The selection process of CLIL modules was determined by the implication of lecturers specialised in the fields of Humanities, Social Sciences and Health Sciences at a multilingual Spanish university such as Universitat Jaume I. More specifically, six degrees were considered, these being History and Heritage, Humanities: Intercultural Studies, Tourism, Medicine, Nursing, and Psychology. Undergraduate students undertaking the aforementioned degrees and their CLIL educators were the main participants. Table 16 below summarises the total number of subjects that took part in this study.

Table 16. Participants.

\begin{tabular}{|l|l|c|c|c|c|c|}
\hline \multirow{2}{*}{ University } & \multicolumn{1}{|c|}{ Degrees } & \multirow{2}{*}{ Teachers } & \multicolumn{4}{c|}{ Number of students } \\
\cline { 4 - 7 } & & & $\mathbf{1}^{\text {st }} \mathbf{y e a r}$ & $\mathbf{2}^{\text {nd }}$ year & $\mathbf{3}^{\text {rd }}$ year & $\mathbf{4}^{\text {th }}$ year \\
\hline Universitat Jaume I & History and Heritage & 2 & 40 & - & - & 28 \\
\cline { 2 - 7 } & $\begin{array}{l}\text { Humanities: } \\
\text { Intercultural studies }\end{array}$ & 1 & 19 & - & - & - \\
\cline { 2 - 7 } & Tourism & 1 & - & - & - & 28 \\
\cline { 2 - 7 } & Medicine & 3 & 23 & 26 & 22 & - \\
\cline { 2 - 7 } & Nursing & 1 & - & - & 27 & - \\
\cline { 2 - 7 } & Psychology & 2 & - & - & - & 39 \\
\hline
\end{tabular}

The context in all of the case studies examined at Universitat Jaume I is that of a multilingual classroom where CLIL teachers and students, although not generally bilingual in Spanish and Catalan.

\subsubsection{History and Heritage}

The analysis includes 2 CLIL teachers and 87 undergraduate students coursing the modules of History of the Classical World and Fundamentals and Theory of Artistic Heritage, taught in the first and fourth years of the degree respectively (see Table 16 and Table 17). On the one hand, 40 learners enrolled in the History of the Classical World module were meant to join the study, but only 30 of them attended the CLIL seminars and completed all the tasks, placement tests and questionnaires that were 
assigned (see Table 16). The group comprised 27 males and 13 females with ages ranging from 18 to 60 years old. Most of them were local students from the Valencian Community, so they were bilingual in Spanish and Catalan. A small number of cases had an extended linguistic background, including Romanian, Arabic, French, English, and Portuguese.

This module, which is common to both the degrees in History and Heritage as well as Humanities: Intercultural Studies, was shared by two teachers during the second semester. As stated in the course syllabus, the theoretical component of the module was delivered in Spanish by one of the lecturers. As seen in Table 17, the coding given to the CLIL teacher in the History of the Classical module was H1. This educator, a 25 year-old female fluent in Spanish, Catalan and English, was the responsible for the practical component of the programme. To do so, two seminar sessions were allocated to review theoretical contents in the target language that had been previously discussed at earlier learning stages of the module. The successful completion of the tasks entailed the combination of the theoretical and practical components of the module. Students were given a list of prompts. As to the written assignment, the focal point was on the portrayal of the historical events that took place throughout the episodes and what actually happened. As regards the oral assignment, a list of prompts was designed to help students organise their group presentations where they were expected to: a) sell an interesting part of ancient Rome (e.g. architecture, sculpture, religion, education, leisure time and entertainment, food, etc.) or b) do some research about the lives of a group in the Roman society (e.g. a day in the life of a Patrician, Plebeian, soldier, gladiator, vestal virgin, etc.) (see Appendix VII).

Table 17. First-year participants in the History and Heritage degree.

\begin{tabular}{|l|c|c|c|c|c|}
\hline \multirow{2}{*}{ Participants } & \multirow{2}{*}{ Year } & \multicolumn{4}{|c|}{ History of the Classical World } \\
\cline { 3 - 6 } & & Male & Female & Total & Age \\
\cline { 4 - 6 } Teachers & \multirow{2}{*}{$1^{\text {st }}$} & - & 1 & 1 & 25 \\
\cline { 4 - 6 } & & 27 & 13 & 40 & $18-60$ \\
\hline
\end{tabular}

Progression to the fourth year of the degree implies students having the opportunity to choose from a pool of available modules that suit their interests. This is the case of Fundamentals and Theory of Artistic Heritage, an optional subject offered during the first semester (see Table 18). The group consisted of 15 males and 13 females in their 
early 20s. All of them were local students proficient in Spanish and Catalan but their command of the English language was for the most part at a beginner level. According to the programme structure, a 30 year-old female $(\mathrm{H} 2)$ with an intermediate level of English was responsible for the CLIL instruction.

Table 18. Fourth-year participants in the History and Heritage degree.

\begin{tabular}{|c|c|c|c|c|c|}
\hline \multirow{2}{*}{ Participants } & \multirow{2}{*}{ Year } & \multicolumn{3}{|c|}{ Fundamentals and Theory of Artistic Heritage } \\
\cline { 3 - 6 } & & Male & Female & Total & Age \\
\cline { 4 - 6 } Teachers & \multirow{2}{*}{$4^{\text {th }}$} & - & 1 & 1 & 30 \\
\cline { 3 - 6 } Students & 15 & 13 & 28 & $21-25$ \\
\hline
\end{tabular}

One session was arranged to implement the CLIL approach, the classroom discourse being characterised by the official languages recognised by the university (i.e. English, Spanish and Catalan). Students were required to answer a set of questions after discussing a certain number of YouTube videos based on art collection, museums and exhibitions. Some of these questions would include: a) When did the British Museum opened to the public?, b) What kind of collections can you find at the British Museum? or c) What is the objective of the Department of the Scientific Research at the Metropolitan Museum of Art? (see Appendix VII).

\subsubsection{Humanities: Intercultural Studies}

As to the Bachelor's degree in Humanities: Intercultural Studies, the subjects taking the History of the Classical World module add up to 19 students, even though only 12 participated in this study (see Table 19). The traits of this group are similar to the ones described in the History and Heritage section since instruction brought together learners from both degrees. This implies that not only the methodological approach was the same, but also the teacher $(\mathrm{H} 1)$.

Table 19. Participants in the Humanities degree.

\begin{tabular}{|c|c|c|c|c|c|}
\hline \multirow{2}{*}{ Participants } & \multirow{2}{*}{ Year } & \multicolumn{4}{|c|}{ History of the Classical World } \\
\cline { 3 - 6 } & & Male & Female & Total & Age \\
\hline \multirow{2}{*}{ Teachers } & \multirow{2}{*}{$1^{\text {st }}$} & - & 1 & 1 & 25 \\
\cline { 3 - 6 } & & 15 & 4 & 19 & $18-60$ \\
\hline
\end{tabular}


Home students, aged between 18-60 years old, were bilingual in Spanish and Catalan. In contrast, those students with different geographical backgrounds were competent in Romanian, Arabic, French, English and Portuguese.

\subsubsection{Tourism}

Participants in the Valencian Art and Tourist Resources module enjoy learning opportunities on this accredited tourism degree that equip them with the skills and knowledge they need in this dynamic and changing sector. 24 out of 28 future tourism professionals, aged from 21 to 25 years old, agreed to participate in this research (see Table 20). The international outlook of this degree has attracted subjects from a variety of cultural, linguistic and geographical backgrounds. Nearly 13 of the fourth-year students coursing this subject were Spanish, while the remaining 15 were from other European and Asian countries, including France, Germany, The Netherlands, Turkey and Korea.

Table 20. Participants in the Tourism degree.

\begin{tabular}{|c|c|c|c|c|c|}
\hline \multirow{2}{*}{ Participants } & \multirow{2}{*}{ Year } & \multicolumn{4}{|c|}{ Valencian Art and Tourist Resources } \\
\cline { 3 - 6 } & & Male & Female & Total & Age \\
\hline \multirow{2}{*}{ Teachers } & \multirow{2}{*}{$4^{\text {th }}$} & 1 & - & 1 & 42 \\
\cline { 3 - 6 } & & 5 & 23 & 28 & $21-25$ \\
\hline
\end{tabular}

Following a content-driven approach to CLIL, this module was fully conducted in English by a male lecturer (T) with an advanced level of the target language. Nonetheless, Spanish was employed to a lesser extent to negotiate meaning with local students and thus ensure better comprehension. That being said, attendance to a lecture and a seminar session were arranged. The lecture covered the features of Renaissance and Baroque art, whereas students' projects on the organisation of art exhibitions were presented in the seminar session.

\subsubsection{Medicine}

During the academic year in which the data were gathered, 138 Medicine students were registered in first-year, second-year and third-year modules, these being English for Medicine, Anthropology and Evolution, and Epidemiology and Public Health. Admissions to Medicine degrees all over Spain are known to be ferociously competitive. This is the reason why undergraduate students coursing these modules come from different regions of Spain, either monolingual or bilingual communities. 
Therefore, the presence of languages in the classroom setting may be limited to English and Spanish when dealing with the CLIL approach.

The curricula design includes English for Medicine as a basic training module offered to first-year undergraduate students (see Table 21). Even though this course is devoted to the development of their language skills in English, three seminars dealing with medical-related content are programmed along the academic year. These academic events, which are delivered by content teachers and mandatory for all the students, follow a CLIL approach. Therefore, these sessions go in line with the purpose of this research. Given that these speech events were conceived as instructional practices with smaller groups, four equivalent seminars were allocated along a given week. The CLIL seminar recorded that has been used as part of this thesis was attended by 23 students, but the completion of questionnaires and placement tests dropped to 11 and 13 respectively. Instruction revolved around skin cancer and was conducted by a 32-yearold female (M1) (see Appendix VII).

Table 21. First-year participants in the Medicine degree: English for Medicine seminars.

\begin{tabular}{|c|c|c|c|c|c|}
\hline \multirow{2}{*}{ Participants } & \multirow{2}{*}{ Year } & \multicolumn{4}{|c|}{ English for Medicine: Seminar on Skin Cancer } \\
\cline { 3 - 6 } & & Male & Female & Total & Age \\
\cline { 3 - 6 } Teachers & \multirow{2}{*}{$1^{\mathrm{st}}$} & - & 1 & 1 & 32 \\
\cline { 3 - 6 } Students & & 12 & 11 & 23 & $18-44$ \\
\hline
\end{tabular}

Another module included for analysis is Anthropology and Evolution, which was entirely taught in Spanish during the second year of the Medicine degree and where the construction of knowledge with regard to the history of medicine was granted. However, due to the internationalisation of the higher education landscape, students had to complete the practical component of the subject in English. The seminar, held in two different days to allow students attend to their regular lectures, aimed at reviewing and discussing fake news articles shared by online and printed press (see Appendix VII). As shown in Table 22, 26 Medicine students with ages ranging from 19 to 21 completed all the tasks. Despite English being the language of instruction for these seminars, both the use of English and Spanish was promoted by the CLIL lecturer (M2) so that students could express themselves easily. 
Table 22. Second-year participants in the Medicine degree: Anthropology and Evolution.

\begin{tabular}{|c|c|c|c|c|c|}
\hline \multirow{2}{*}{ Participants } & \multirow{2}{*}{ Year } & \multicolumn{4}{|c|}{ Anthropology and Evolution } \\
\cline { 3 - 6 } & & Male & Female & Total & Age \\
\hline \multirow{2}{*}{ Teachers } & \multirow{2}{*}{$2^{\text {nd }}$} & 1 & - & 1 & 48 \\
\cline { 3 - 6 } Students & & 5 & 21 & 26 & $19-29$ \\
\hline
\end{tabular}

With regard to Epidemiology and Public Health, it is a compulsory module offered to third-year students. Instruction of theoretical contents is carried out in Spanish, whereas English is relegated to a workshop. Within these scientific meetings, students were asked to work in groups and present a research protocol on a topic of their choice using visual aids. Communication in the target language entailed participants' performance and discussions with the moderator (M3). In this case, the academic performance of 22 students was examined (see Table 23).

Table 23. Participants in the Medicine degree: Epidemiology and Public Health.

\begin{tabular}{|c|c|c|c|c|c|}
\hline \multirow{2}{*}{ Participants } & \multirow{2}{*}{ Year } & \multicolumn{4}{|c|}{ Epidemiology and Public Health } \\
\cline { 3 - 6 } & & Male & Female & Total & Age \\
\hline Teachers & \multirow{2}{*}{$3^{\text {rd }}$} & - & 1 & 1 & 50 \\
\cline { 4 - 6 } Students & & 11 & 11 & 22 & $20-26$ \\
\hline
\end{tabular}

\subsubsection{Nursing}

Attendance to CLIL Nursing practices was limited to a seminar session delivered in the Women's care module. 27 Nursing degree students coursing this compulsory subject did not have any objection to being recorded and filling in the questionnaires needed for the purpose of this study (see Table 24). Within this classroom practice, two individual and group tasks were assigned: (a) after having read two research articles dealing with epidural anaesthesia, students' individual performance called for writing short pieces of text where they summarised the main the benefits and risks of using epidural anaesthesia during labour, and reading them aloud; (b) on the other hand, group performance was related to oral presentations focusing on pregnancy and birth traditions around the world. 
Table 24. Participants in the Nursing degree.

\begin{tabular}{|c|c|c|c|c|c|}
\hline \multirow{2}{*}{ Participants } & \multirow{2}{*}{ Year } & \multicolumn{4}{|c|}{ Women's care } \\
\cline { 3 - 6 } & & Male & Female & Total & Age \\
\cline { 4 - 6 } Teachers & \multirow{2}{*}{$3^{\text {rd }}$} & - & 1 & 1 & 50 \\
\cline { 3 - 6 } Students & 7 & 20 & 27 & $19-22$ \\
\hline
\end{tabular}

As to the languages of communication in this multilingual classroom setting, English, Spanish and Catalan are allowed in the teaching process since all of them are fostered in the educational system of this bilingual region. Those students with a different linguistic or cultural background may also have Romanian and Arabic as their first languages, even though these are not employed for communication purposes in formal education.

It is worth mentioning that collaboration also extended to two CLIL lecturers in the Nursing degree giving instruction in first-year (N2) and fourth-year (N3) modules. Their participation will be further explained in the research instruments and results sections.

\subsubsection{Psychology}

Drawing on the Psychology degree, an elective subject is offered in the curriculum to those undergraduate students who want to learn deeply about Affective and Social Neuroscience, a module shared by two instructors: a senior lecturer (P1) and a predoc fellow (P2). The subjects in this module are 28 girls and 11 boys belonging to the 21-28 age groups (see Table 25).

Table 25. Participants in the Psychology degree.

\begin{tabular}{|c|c|c|c|c|c|}
\hline \multirow{2}{*}{ Participants } & \multirow{2}{*}{ Year } & \multicolumn{4}{|c|}{ Affective and Social Neuroscience } \\
\cline { 3 - 6 } & & Male & Female & Total & Age \\
\hline \multirow{2}{*}{ Teachers } & \multirow{2}{*}{$4^{\text {th }}$} & - & 2 & 2 & $24-50$ \\
\cline { 3 - 6 } Students & 11 & 28 & 39 & $21-28$ \\
\hline
\end{tabular}

Spanish and Catalan remain as the language of instruction in the theoretical and practical components of the subject, but it is worth mentioning that Spanish is the one that stands out given the availability of different resources and materials in this language. On the other hand, the presence of the English language can be observed in laboratory learning environments as well as in their virtual platform. In fact, this target 
language is included in the classroom repertoire through practical sessions and a wide range of research articles and other online resources that are available on the net.

\subsection{MODEL AND METHOD OF ANALYSIS}

As has been argued in previous chapters, the focus of this dissertation is on the modules following a CLIL approach at a Spanish university. In the case of Universitat Jaume I, academic modules available in a number of degrees (i.e. History and Heritage, Humanities: Intercultural Studies, Tourism, Medicine, Nursing and Psychology) were selected. The curricula design of these CLIL programmes is meant to train learners and thus help them become highly-skilled and competent professionals over a four-year period of time. Academic discourse is pivotal when learning content in a language other than participants' mother tongue. Written or spoken discourse is the main source of information to examine the effectiveness of CLIL programmes. The integration of content and language in multilingual settings calls for the use of multimodal strategies that help scaffold students' comprehension, particularly when the credits to be taught in English correspond to $5 \%$ of the credits in each degree. Thus, speech events may involve kinesics and translanguaging processes that can be used as tools to negotiate meaning (García Mayo \& Lázaro Ibarrola, 2015; Nikula et al., 2013). Nonetheless, a great part of university discourse may be affected by differing instructional techniques, such as lectures, seminars and tutorials.

For this research project, quantitave and qualitative variables were employed to describe the data. Quantitative categories can be observed in those research instruments that included Likert scales: the researcher's observation rubric (see Appendix IV (a)), and participants' questionnaires (see Appendix V). These materials would allow respondents to show their agreement or disagreement towards the statements. The calculation of cases related to placement tests, language functions and multilingual strategies in classroom practice recordings also falls in this quantitative variable. Qualitative methods would involve the collection of field notes and students' impressions through observation rubrics and questionnaires. Qualitative data were also obtained from the analysis of participants' language production, including interpersonal patterns and metafunctions of language in CLIL learning environments. Therefore, 
classroom discourse will be examined through the use of English, Spanish and Catalan in different phases of these academic events.

\subsubsection{Classification model}

When it comes to the classification model used in this research, it is important to look at the features that can be found in the seminar sessions under study. Drawing on Cañedo Iglesias' (2008) categorisation of seminars described in Chapter 3, the typology that has been devised for the analysis of the seminars recorded in the present study is as follows:

- Reading seminars

- Video-debate seminars

- Lecture seminars

- Slide-talk seminars

Reading seminars is the term that stands for discussions being performed collaboratively with a reduced number of learners. It consists of students reading some passages or research articles on their own and then commenting on what they have understood. This type of seminars may be implemented by grouping students in small teams. It is in these practices where students share their ideas in small groups, which are usually made up of four or five members, in order to reach a decision on the main topics they will discuss (Cañedo Iglesias, 2008). In this way, all the participants involved in the same academic event are able to complement and expand what has been explained. The role of the teacher is worth mentioning as it involves guiding students through the reading process and providing them with feedback, which enable learners to analyse and construct knowledge.

Video-debate seminars are conceived as instructional practices where a film or short excerpts of videos or other audiovisual materials are observed for the construction of disciplinary knowledge (Cañedo Iglesias, 2008). For the implementation of these seminars, an outline with the main learning outcomes and aspects to be covered in the session is paramount. As a facilitator, the teacher should design or make use of materials containing precise instructions, namely guidelines or questionnaires. These actions will be valuable for the active participation of the students in the classroom setting. At this point, evaluative features of the language can be identified in students' contributions. 
Similar patterns can be drawn on lecture seminars. Contrary to Cañedo Iglesias' notion (2008), which stands for the presentation of students' individual or group work, throughout my dissertation, lecture seminars are regarded as research talks given by an expert, either a visiting researcher or a faculty member. The main reason for the use of this category relies on the description of the course syllabus. Despite the fact that the practical component of the module is labelled as a seminar in this academic document, the procedure is similar to a lecture except for the number of students. Thus, whereas lectures are usually held with more than forty students, lecture seminars are delivered with a small audience consisting of roughly thirty students.

Slide talk seminars are understood as students' academic presentations, which are performed individually or collectively. As with lecture seminars, similarities can be found in the sequence pattern of this type of instruction. Through the use of slide presentations, students take the floor and present the main aspects of their projects, including literature review and research findings. In a way, they can be regarded as mini-lectures. Nonetheless, differences may arise in terms of time management, formality and number of students. Indeed, ten minutes may be allocated for students' performances, which are likely to be more informal than other research genres.

This typology of seminars follows a sequence pattern that may be transferable to lectures as they occur in any speech event. Such patterns correspond to introduction, development and conclusion (Cañedo Iglesias, 2008; Diamond et al., 1983). Taking into account that this study consists of both lectures and seminars that need to be examined, it is necessary to create a model that can be valid for the analysis of the linguistic devices that are uttered in CLIL initiatives, where language should not only be considered as a product but also as a process. On that account, the taxonomy presented in Table 26 has been designed in an attempt to overcome the shortcomings arising from previous models. The framework below is an extended and revised version of that of Martín del Pozo (2014), stemming from the one devised by Dafouz and Núñez in 2010, as described in the previous chapter. 
Table 26. Classification model for the analysis of interpersonal traits in CLIL discourse. Adapted from Martín del Pozo (2014).

\begin{tabular}{|c|c|c|}
\hline Phases & Metadiscourse category & Subcategory \\
\hline \multirow{11}{*}{ 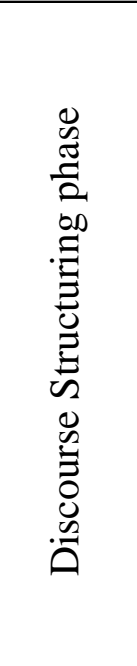 } & Openers & \\
\hline & Additive transitions & \\
\hline & Contrastive transitions & \\
\hline & Consecutive transitions & \\
\hline & Sequencers & \\
\hline & Verbal topicalisers & \\
\hline & Non-verbal topicalisers & \\
\hline & Visual topicalisers & \\
\hline & Prospective markers & \\
\hline & Retrospective markers & \\
\hline & Reformulations & \\
\hline \multirow{11}{*}{ 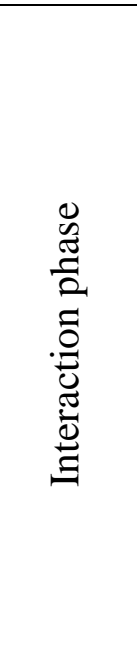 } & \multirow[t]{8}{*}{ Engagement markers } & Questions (referential, rhetorical, display, indirect) \\
\hline & & Imperatives \\
\hline & & Directives \\
\hline & & Comprehension comments \\
\hline & & Apologetic comments \\
\hline & & Contextual comments \\
\hline & & Behavioural comments \\
\hline & & Inclusive comments \\
\hline & Attitudinal markers & \\
\hline & Boosters & \\
\hline & Hedges & \\
\hline & Closing markers & \\
\hline & Recapitulation markers & \\
\hline 들 & Prospective markers & \\
\hline$\mho$ & Retrospective markers & \\
\hline
\end{tabular}

Within the Discourse structuring phase, the items included by Martín del Pozo correspond to openers, sequencers, verbal, non-verbal and visual topicalisers, prospective and retrospective markers. In this phase, Hyland's (2005) transitions (i.e. additive, contrastive and consecutive), and Ädel's (2010) reformulations, which were explained in previous sections, have been introduced. These metadiscoursal elements are primarily oriented towards the organisation and reformulation of ideas and therefore relevant for the articulation and comprehension of academic discourse in a foreign 
language. As for the Conclusion phase, closing, recapitulation, retrospective and prospective markers have remained the same.

This model is intended to analyse the interpersonal traits identified in CLIL discourse. Thus, it is the Interaction phase the one that has received most attention, with the integration of new metadiscoursal categories. Martín del Pozo's (2014) questions and comments have been incorporated as engagement markers together with other items outlined in Ädel's (2010), and Llinares et al.'s (2012) models. Referential, content, rhetoric and indirect questions serve as pedagogical tools that allow for the development of critical thinking, the evaluation of disciplinary knowledge as well as for teacherstudent and student-student interaction in the CLIL learning environment (Martin del Pozo, 2014). Apologetic and contextual comments have also been maintained as metadiscoursal devices that are commonplace in educational settings. As for new categories, imperatives and directives should be noted. These elements are frequent in CLIL discourse (Llinares et al., 2012), either in seminars or lectures, and aim at guiding students in the speech event (e.g. tasks, content or visual aids). Apart from that, in Ädel's taxonomy (2010), reprimands and compliments are of utmost importance to handle participants' behaviour. These linguistic features fell under the expression known as managing audience discipline. However, the term behavioural comments has been preferred for the current dissertation. Ädel's (2010) management of both the comprehension channel and the message has been referred to as comprehension comments. These speech acts come to light after common interaction patterns that take place in the CLIL classroom, such as the IRF sequence (Llinares et al., 2012; Nikula, 2007; Nikula et al., 2013). Within this technique the teacher starts a discussion by asking a question to the students who are expected to give an answer. Once they have exchanged information with other participants, it is the teacher the one who provides them with feedback. Therefore, some types of feedback provided by the teacher can result in comprehension comments made by students who find it challenging to understand a given concept or process. Inclusive comments are addressed to the audience when providing hypothetical scenarios. This category is what Ädel (2010) refers to as imagining scenarios. Other elements relevant to CLIL discourse involve Hyland's (2005) attitudinal markers, boosters and hedges, which have also been added as interpersonal traits. These devices signal participants' commitment, certainty and stance towards the text that is being delivered in the classroom setting. 
Despite the fact that CLIL discourse can be explored as a product by examining the ideational, interpersonal and textual metafunctions, we should not forget that language learning is a process. Therefore, translanguaging practices should be regarded as scaffolding and interaction patterns employed for negotiation and clarification purposes. An account of all the research instruments needed for the accomplishment of the objectives of this study will be given in the next section.

\subsection{RESEARCH INSTRUMENTS}

To accomplish the objectives of the present study, six research instruments were employed for the data collection and analysis processes. Based on a mixed methods design, both quantitative and qualitative variables were measured by means of interviews, audio-recordings, observation rubrics, questionnaires and placement tests. This methodological design allowed for the integration of several data sources to have a detailed report of CLIL programmes in tertiary education.

\subsubsection{Interviews}

At a starting point, interviews were allocated by email with CLIL lecturers. This initial contact allowed for the arrangement of an appointment with all the potential informants. These interviews were scheduled to provide them with a general overview of this research project and explore the dynamics of CLIL instruction in two areas of expertise at tertiary education. Ten face-to-face interviews were conducted with 11 specialists in Humanities, Social Sciences and Health Sciences using English as one of the languages of instruction (see Appendix I (a)). As for the field of Humanities, three faculty members answered all the items: a) a female teacher giving instruction in History of the Classical World, a common module in the degrees in History and Heritage, and Humanities: Intercultural Studies; b) a second female educator teaching Fundamentals and Theory of Artistic Heritage as part of the History and Heritage curriculum design; and a male lecturer explaining the contents of the Valencian Art and Tourist Resources module. On the other hand, eight instructors replied to the researcher's questions, including three Medicine instructors in Anthropology and Evolution, Epidemiology and Public Health and Skin cancer; a female Nursing educator in Women's care, and two female Psychology instructors in Affective and Social Neuroscience. In addition to these informants, two other Nursing teachers were interviewed. Even though these 
respondents also followed a CLIL approach in the modules known as Human Physiology and Critical care, instruction did not take place in the second semester. All the interviews were audio-recorded and transcribed shortly after these sessions to make sure relevant information was not missing (see Appendix I (b, c, d, e, f, g, h, i, j)).

Semi-structured interviews (Galleta, 2013) were conducted separately for each lecturer during their office hours in their mother tongue (see Appendix I (a)). A bunk of questions was asked to all the interviewees participating in the present study, who could also add any topics that were of interest. Responses to the following questions were given:

a) How many credits are taught in English? (i.e. ¿Cuántos créditos corresponden a la enseñanza en inglés?)

b) What difficulties do students have related to the use of the target language in the CLIL classroom? (i.e. ¿Qué dificultades presenta el alumnado?)

c) What difficulties do teachers have in teaching content in English? (i.e. ¿Qué dificultades tiene el profesorado?)

d) Materials and resources used, shared or delivered in the teaching process (i.e. Materiales y recursos que se suelen utilizar, compartir o entregar durante el proceso de enseñanza)

e) Tasks or assignments that students are asked to produce in English (i.e. Tareas que se suele pedir al alumnado).

In the end, 9 lecturers have taken part in this study (see Table 27). Once involved as collaborators, and on the grounds that a large number of students attended lectures regularly, seminar sessions have been the preferred genre to give CLIL instruction, particularly in the field of Health Sciences. The researcher's intention to record the sessions was made known to the informants, ideally opting for videotaping. Lecturers addressed their concerns about video-recording their teaching practices but agreed on being audio-recorded. 
Table 27. Summary of CLIL interviews and interviewees.

\begin{tabular}{|c|c|c|c|}
\hline \multirow{2}{*}{ Degrees } & \multirow{2}{*}{ Modules } & \multicolumn{2}{|r|}{ Teachers } \\
\hline & & $\mathbf{M}$ & $\mathbf{F}$ \\
\hline \multirow[b]{2}{*}{ History and Heritage } & History of the Classical World & - & 1 \\
\hline & $\begin{array}{l}\text { Fundamentals and Theory of Artistic } \\
\text { Heritage }\end{array}$ & - & 1 \\
\hline $\begin{array}{l}\text { Humanities: } \\
\text { Intercultural studies }\end{array}$ & History of the Classical World & - & $\begin{array}{c}1 \\
\text { (same as in History } \\
\text { and Heritage) }\end{array}$ \\
\hline Tourism & Valencian Art and Tourist Resources & 1 & - \\
\hline \multirow{3}{*}{ Medicine } & $\begin{array}{l}\text { English for Medicine: Seminar on Skin } \\
\text { Cancer }\end{array}$ & - & 1 \\
\hline & Anthropology and Evolution & 1 & - \\
\hline & Epidemiology and Public Health & - & 1 \\
\hline \multirow{3}{*}{ Nursing } & Human Physiology & - & 1 \\
\hline & Women's care & - & 1 \\
\hline & Critical care & - & 1 \\
\hline Psychology & Affective and Social Neuroscience & - & 2 \\
\hline
\end{tabular}

The interviews with CLIL lecturers were audio-recorded and then transcribed for the analysis of the study. These interviews relied on teaching expectations and previous experiences with CLIL modules. The emphasis was on students' weaknesses and attitudes towards the use of the target language in the classroom. In this vein, these instruments are key to understanding the perceptions of CLIL teachers in the disciplines of Humanities, Social Sciences and Health Sciences. These qualitative data offer us the opportunity to better comprehend the perspectives, opinions and beliefs of the interviewees (Berg, 2007) with regard to CLIL instruction.

\subsubsection{Lectures and seminars}

As discussed in academic interviews, informants expressed their concerns about being video-recorded. Audio-recording lecture and seminar sessions were then considered to be as a portable solution to record classroom interaction. Such an alternative would help lecturers and students feel more comfortable during this short but intrusive data collection process. The presence of the researcher in the classroom was therefore made known to all the potential participants in order to encourage them to collaborate in the current research study. A consent form was devised and distributed in each module to keep a record of their authorisation to transcribe their written and spoken performance 
and use them for the purposes of this study only (see Appendix II). The identity of all the participants remained confidential to protect their privacy.

Ten academic events were audio-recorded with the recorder being placed on teachers' desks, as these were considered to be the best spot to catch informants' language use. The recordings were made on a small $\mathrm{mp} 3$ device, named Olympus digital voice recorder WS-831, which allowed for easy transfer to computer files. Most files were approximately 120-minute long; others were cut during breaks in order to avoid the taping and subsequent transcription of irrelevant data (see Appendix III (a, b, c, d, e, f, $g, h, i, j, k))$.

The only lecture analysed in this study followed a combination of traditional and interactive strategies. The vast majority of seminar sessions were project-based workshops that would imply five-minute or ten-minute oral presentations. So far, students were required to produce written or spoken tasks on topics that were related to the contents of the module, either individually or collectively. Prior to the attendance of the researcher, all the subjects were informed about the aims of the current research so that they could decide whether they wanted to be part of the observation, audiorecording and test phases. In other words, acceptance to undertake would depend upon agreement from CLIL lecturers and undergraduate students. Once engaged in the study, CLIL learners were introduced to the instruments that they would need to fill in. First, they were shown a questionnaire about their present and past experiences with CLIL programmes and the extent to which they were familiar with the university multilingual programme. Then, every item was explained in detail as it also included Likert scales. Secondly, they were requested to complete a placement test in order to compare the results with their participation in the classroom setting. These phases would take around 30 or 40 minutes, so they were given the opportunity to fill in these instruments at home by providing them with online links that were available in their virtual platforms.

When it comes to the quantitative analysis of metadiscourse in lectures and seminars, the detection of interpersonal markers was conducted by means of Lextutor (Cobb, n.d.) a tool that provides the total number of instances occurrying in pieces of text. Even though the results given were also cheked manually, this resource was pivotal in saving time within the research process. 


\subsubsection{Observation rubrics}

Non-participant observation, which involves observing the event that is taking place from a distance, has been conducted to ensure the reliability of the interview and recording processes (Wisker, 2008). This kind of observation, less intrusive than participant observation, is thus more appropriate to minimise the impact of the researcher's participation in the classroom dynamics.

As noted in Appendix IV, an observation rubric was developed to record noticeable contextual features of the academic event, such as the room layout, furniture mobility and language use among others (Sotirin, 1999). Within this observation rubric, checklists were used in a variety of sections, namely speech acts, data of the instructor, data of the academic space used, data of the students, resources, and data of the discussion.

The incorporation of Likert scales has been helpful to rate the accuracy of predetermined criteria in the data of the recording section. Evidence may be found in the data of the recording section, which included six items that were examined based on a ranging scale from 1 to 5, that is from totally inaccurate to totally accurate (Appendix III). These criteria were as follows: a) Students are engaged in the learning process, b) Students do all the tasks, c) Students appear confident to communicate in the target language, d) Students ask questions to the teachers, e) Classroom dynamics are positive and f) The use of technology is appropriate.

Research intervention in the classroom setting may lead to the production of unnatural speech in a foreign language. This dilemma, where data collection is adversely affected by the presence of a researcher, is what Lavob (1972) referred to as 'observer's paradox'. For ethical reasons, all the participants were informed about their performance being audio-recorded with a small digital voice recorder. From my point of view, an audio-recorder can serve as a resource for participants to forget about attention being paid to their verbal and nonverbal communication. In minimising the influence of the observer in the classroom dynamics, the vast majority of the observations took place from the back of the classroom. Notes were taken by hand to register anything relevant happening during the classroom observations, thereby revolving around activities, language choice and linguistic behaviour. Such methodological procedures were meant to help students' and lecturers overcome pressure. 


\subsubsection{Questionnaires}

The students participating in this study answered an anonymous survey administered at the end of the allocated CLIL sessions (see Appendix V). The questionnaire contained fourteen questions concerning participants' previous learning experiences with CLIL programmes, their concerns towards CLIL instruction and the use of the target language. These questions were all the same for the participants enrolled in the modules under study. Some of these items were based on closed and open questions in order to get detailed responses (Oppenheim, 1992): Seminars in English have been useful, Do you think the activities and exposure to the English language meet the requirements of the module?, Would you prefer a lesson delivered in your mother tongue?, Is English relevant for your professional career?, and Have you had other content subjects in which English is the language of instruction in the degree?

This survey contained up to sections with a Likert scale and open questions which sought to gather students' opinions and suggestions to improve the quality of these CLIL programmes. Within these instruments, multiple-choice responses were thus incorporated, requiring the selection of an a, b, c option or ticking a numerical box indicating their agreement or disagreement with the statements. All of these sections were preceded by a set of questions dealing with participants' linguistic and learning personal data (e.g. mother tongue, age, gender, monolingual or bilingual speakers, and the number of years learning English).

Once all the seminar sessions came to a close, students were given access to an online questionnaire in order to gather their learning impressions towards CLIL programmes and language use. Respondent anonymity was guaranteed to protect their privacy and thus improve response rates. Depending on the timing, these surveys were completed either in class or at home where students had to reply all the items individually. As a result, not all of them filled in their responses. In an attempt to increase rate responses, reminder emails were sent to the respondents of each discipline with direct links to their surveys and placement tests.

\subsubsection{Placement Tests}

Language testing has been conducted to provide information about students' performance in the CLIL classroom. It is the linguistic component of the module which may be challenging for those unprepared or overprepared students receiving instruction 
in theoretical or practical sessions (Belfield \& Crosta, 2012; Scott-Clayton, 2012). Therefore, placements tests can be perceived as valuable sources for the establishment of correlations between academic performance (i.e. translanguaging practices) and language proficiency. These results can also bring to light disciplinary differences in the use of English in tertiary education.

When dealing with the selection of language tests, proficiency tests, achievement tests, diagnostic tests, and placement tests (Alderson et al., 1995; Brown, 2005; Brown \& Abeywickrama, 2010; Hughes, 2003) are the most common categories. Achievement tests are intended to measure the achievement of learning outcomes in language courses or students' progress (Kress, 2008; Nunan, 2015). Diagnostic tests, usually distributed before instruction, are meant to determine students' strengths and weaknesses in a given area of the target language (Kim, 2015). By and large, proficiency tests aim at measuring language learners' command of the foreign language -either in listening comprehension, vocabulary, grammar and pronunciation- and grouping them into several proficiency levels (Brown, 2005). Well-known examples of proficiency tests include the Test of English as a Foreign Language (TOEFL) and the International English Language Testing System (IELTS). In the field of foreign language learning, placement tests are designed to identify students' command of the language in order to plan courses and programmes adapted to their academic preparation.

Overall, the Outcomes Placement Test by National Geographic Learning (n.d.) was administered to match students' proficiency level in the English language and their interaction in the CLIL classroom (see Appendix VI). Access to this research instrument was possible by means of a link generated with Google docs and shared in each module's virtual platforms when CLIL educators signalled the end of the sessions. The Outplacement Test Package consists of grammar, vocabulary, oral and writing placement tests. Rather than asking students to fill in the whole package, which also included oral and written tests, a digitalised and shortened version of the test focusing on grammar and vocabulary was preferred in view of time constraints. This was the easiest and fastest way to distribute the survey and collect responses because students could take the tests in class or at home if there was no time left to do so.

As can be seen in Appendix VI, the grammar and vocabulary section consisted of 50 items with multiple-choice options and thirty minutes are allotted for completion. By 
carefully reading and understanding the utterances, test-takers were asked to choose one of the three options given that best completed the blank. The questions covered a wide range of grammatical structures, including prepositions, auxiliary verbs, modal verbs, and passive voice, among others. On the other hand, the vocabulary section addressed common English collocations, lexical items or set phrases.

Scoring below 18 points implied being a basic user with an elementary language level. When attaining between 19 and 39 points learners were said to have a pre-intermediate level, those having up to 32 correct items were at an intermediate level. Accordingly, respondents getting 33 to 39 points were considered as upper-intermediate speakers. Scoring above this cut-off stood for an advanced (i.e. 40-46 points) or a native-like command of the target language (i.e. 47-50). As with online questionnaires, reminder emails were submitted to ensure that respondents did not forget to consider the items included in the placement test, which were meant to be answered individually and anonymously.

\subsection{CHAPTER SUMMARY}

This chapter has intended to describe the objectives of this study and the contextual factors that have been crucial for the collection of data. Attendance to CLIL modules offered in Humanities, Social Sciences and Health Sciences allowed for the compilation of the corpus, which has been explained in detail. This methodology brings together elements of quantitative and qualitative research, case studies and CLIL instruction in seminars and lectures. To this end, a classification model for the analysis of the metadiscoursal elements produced in multilingual learning environments has been devised. This taxonomy complements other previous models, whose categories prevented scholars from a deep understanding of CLIL discourse. The main findings will be analysed and discussed in the next chapter. 


\section{Chapter 6: Results and Discussions}

\subsection{INTRODUCTION}

This chapter seeks to present the findings obtained in relation to the research questions posed in Chapter 5, which can be read as follows:

1. RQ(1). What are participants' attitudes and concerns towards the implementation of CLIL practices in higher education?

2. $\mathrm{RQ}(2)$. What interpersonal traits, such as engagement, attitudinal and evaluative markers, can be observed in CLIL programmes offered at higher education?

3. $\mathrm{RQ}(3)$. Are there any significant differences among the CLIL practices in the fields of Humanities, Social Sciences and Health Sciences?

In addressing these questions, the results in this chapter draw on several research instruments: teachers' comments on the interviews, students' answers on the questionnaires and placement tests, observation rubrics, and, most importantly, transcripts of oral outcomes in CLIL learning environments. For the examination of this corpus, a classification model of metadiscoursal elements was elaborated and explained in the previous chapter (see Table 26 in Chapter 5). This taxonomy is based on that of Martín del Pozo (2014), and includes categories derived from the frameworks by Dafouz and Núñez (2010), Llinares et al. (2012), Ädel (2010), and Hyland (2005). First, teachers' concerns have been examined throughout the interviews in order to discuss the results appropriately. Their teaching needs and attitudes towards the CLIL approach have been inspected to determine the issues that should be tackled in the fields of Humanities, Social Sciences and Health Sciences. 
The next two sections correspond to students' questionnaires and placement tests, which serve to interpret results qualitatively and quantitatively. Their perceptions about the pedagogical proposals as well as their proficiency level in the target language are crucial for a meaningful interpretation of classroom interaction in CLIL settings. The analysis of these results can lead to the identification of, if any, similarities and differences between the three disciplines under study, namely Humanities, Social Sciences and Health Sciences.

As regards metadiscourse, the tool known as Lextutor (Cobb, n.d.) has been employed to detect interpersonal markers and, thus, to establish the similarities and differences found between the areas of Soft and Hard Sciences. The most recurrent categories of interpersonal markers have been illustrated with excerpts taken from the corpus. Participants' language behaviour has also been subject to interpretation thanks to the presence of translanguaging practices in English, Spanish and Catalan. At this point, it is worth mentioning that CLIL discourse has not been looked into as a whole, but as teachers' discourse and students' discourse. Finally, the conclusions stemming from CLIL discourse at tertiary education are provided at the end of this chapter.

\subsection{INTERVIEWS}

As can be seen from the transcripts in Appendix I (b, c, d, e, f, g, h, i, j, k), teachers' experiences and perceptions of CLIL pedagogies were approached through semistructured interviews so that they could bring and reflect upon those issues that were worthy of attention for them. The variables that have been taken into account for the organisation of this section correspond to (a) lecturers' views on learners' concerns about CLIL as well as (b) lecturers' concerns about CLIL. According to these interviewees, issues such as language mastery, participation in the classroom setting and background knowledge stand out as some of the main difficulties for undergraduate students, as argued below. I will explain now the main issues that arouse from the interviews and deserve attention which revolve around lecturers' command of the English language, the use of supportive materials as well as the need for teacher training initiatives. 


\subsubsection{Lecturers' views on learners' concerns in the CLIL classroom}

According to interviewees, students' heterogeneous command of the English language and their lack of background disciplinary knowledge emerged repeatedly as the most common impediments for the implementation of effective practices. As shown in the excerpts 1 and 2 below, teachers stressed that the English language is not mastered homogeneously within the fields of Humanities and Health Sciences.

(1) H1: It has to do mainly with their level of English, which is rather heterogeneous. Some students have a good command of the language, but others, we could say that most of them, have a basic user or intermediate level, and since they are aware of that they struggle to produce oral outcomes in the classroom setting [...] In addition, when it comes to oral presentations, those who have a lower command of the language, read, and it's like that, even though that is not the objective $[\ldots]^{1}$. [H1: Principalment el nivell d'anglés que és molt heterogeni. Hi ha alguns que tenen molt bon nivell d'anglès, però altres, podriem dir que la gran majoria, té un nivell principiant o intermig baix, i com que són conscients d'això els costa molt participar de manera oral en classe [...] A més, a l'hora de fer presentacions en grup els que menys nivell tenen, lligen i és aixi, encara que eixe no és l'objectiu [...]]. (See Appendix I (b)).

(2) N1: Well, one of the students' difficulties would be the fear of speaking in public, another difficulty [would be] that they don't have a good command of the language. Only a few have any level at all. And yeah, being ashamed of speaking in public and not having a good communicative competence. [N1: Bueno, una dificultad sería la vergüenza que tienen de hablar en público, otra dificultad que muchos no tienen nivel. Solo muy pocos tienen algo de nivel. Y eso, vergüenza y que no tienen nivel]. (See Appendix I (h)).

Krashen's (1982) affective filter hypothesis should also be acknowledged. Those learners who are conscious of their basic linguistic competence may find it challenging to speak in public and thus do not perform actively in the CLIL classroom. They are likely to be embarrassed of committing errors, as shown in other studies (Juhana, 2012). Therefore, it is advanced speakers who end up taking the floor, as read in excerpt 3.

(3) M2: [...] And they are supposed to, when the seminar is over, participate and ask me a question. Uff, it's impossible, it's impossible. So, yes, there are three or four students who monopolise the discussion. Probably they have attended an English school, a British school, an American school because they have a very good level of English and there are others who-who do not break the ice. In other words, it is impossible for them to leap at the chance

\footnotetext{
${ }^{1}$ My own translation. When original interview transcripts are provided in Catalan or Spanish, according to interviewees' mother tongues, these have been provided a translation in English.
} 
to produce speech. So of course, forcing people to, you know, speak English is a bit violent in class and they get - they are very shy, they are in their first year of the Medicine degree. [M2: [...] Y se supone que ellos tienen que, cuando acaba, tienen que participar y hacerme una pregunta. Uff, es imposible, es imposible. Entonces, sí, hay pues tres o cuatro que acaparan la conversación. O porque han ido a un colegio inglés, británico, americano porque tienen muy buen nivel de inglés y hay otros que...que no rompen el hielo. O sea es imposible que, que se lancen. Entonces claro, obligar a la gente a, me tienes, tienes que hablar en inglés es un poco violento en clase y se ponen, son muy tímidos, están en primero]]. (See Appendix I (f)).

Such language anxiety, which happens to be debilitative in that it entails fears and insecurities when performing in a foreign language (Marcos-Llinás \& Juan-Garau, 2009; MacIntyre \& Gardner, 1991), is extended to learners who are prone to translate the materials they are provided with by using online platforms. For instance, in the Psychology degree students make use of translation tools when it comes to the reading of research articles written in English. Students complain about these tasks by stating that it is a demanding module; however, from teachers' perspective, such tasks are not required as extra homework, as noted in excerpt 4.

(4) P2: For example, most students do that. Most - most students do it that way. In other words, when it comes to studying for the exam, they do. They translate paragraphs word for word. [P2: Por ejemplo, casi todo el mundo lo hace, casi, casi todo el mundo lo hace así. O sea, a la hora de estudiar para el examen, sí. Traducen párrafo por párrafo].

P1: Of course, what I tell them, that is a lot of work. They complain about the module being demanding. But I don't ask them to do that, I don't have that in mind. I don't even think they have to translate those materials. [P1: Claro, lo que jo els dic, això és un faenon. Se queixen de que l'assignatura els done molta feina. Però claro, jo no done eixe feina, no la tinc en el cap. No se m'ocurreix que tenen que fer-ho]. (See Appendix I (k)).

The same is true for students above the average age enrolled full-time in undergraduate programmes. Because educational laws on foreign language learning disregarded teaching strategies prioritising written over oral skills when these subjects were young, they find it hard to produce speech in English. For that reason, they keep on asking teachers to facilitate contents in Spanish. This is clearly illustrated in the following excerpt, where the teacher refuses to provide them with the translation of research articles considering that they should improve their skills for the elaboration of their final degree dissertations. 
(5) N2: [...] then there's that percentage of people, who come from professional training, eh: that $25 \%$ of older people, and it is impossible, for them to read an article in fourth grade in English. The other day they were already telling me, can you send it to us in Spanish? And I told them, "no, it's in English. You're going to write a final degree dissertation in a few days' time". [N2: [...] y luego hay ese otro tanto por cien de personas, que vienen de formación profesional, eh: ese $25 \%$ de gente más mayor, que es imposible, para ellos leer un artículo en cuarto curso en inglés. El otro día ya me decían, ¿me lo puedes pasar en castellano? Y yo, “no, es que está en inglés. Es que vas a hacer un TFG en dos días”]. (See Appendix I (i)).

Despite teachers' attitudes with regard to the translation of materials, students are allowed to make use of their multilingual repertoire in the CLIL classroom. That is, questions can be asked in Spanish and Catalan if they do not feel confident enough to do that in English, as shown in excerpt 6. Nonetheless, CLIL teachers prompt and reward students who communicate in the target language with extra marks.

(6) H2: OK. Ah, well. At first they're a bit rushed, but then they go, they loose up in public. And it's also true that it gives them a lot of peace of mind to know that they can ask in Spanish. But it's true that when I told them, as regards the practical sessions which involved oral presentations, "well, you can perform in English or in Spanish, but the effort you make speaking in English will be rewarded positively", everyone spoke in English. [H2: $Y a$. Ah, bueno. Al principio les da un poco de apuro, pero luego ya, se van, se van soltando. $Y$ también es verdad que les da mucha tranquilidad saber que pueden preguntar en castellano. Pero sí que es verdad que cuando les, en el tema de las prácticas que eran exposiciones orales les dije, bueno podéis hacer en inglés o en español pero se valorará muy positivamente el esfuerzo que hagáis por hacerlo en inglés", todo el mundo lo hizo en inglés]. (See Appendix I (c)).

The role of international students involved in the field of Humanities has also been mentioned. Language mastery happens to be a relevant issue in the CLIL classroom, where differences arise among international students. Within this group of exchange students, those students coming from European countries outperform those coming from Asian countries. A similar trend may be identified when comparing international students with home students. In excerpt 7 that follows, and as explained in previous chapters, the interviewee highlights that Spanish students are expected to take some credits in English even though their communicative competence is that of a basic user. As to international students, those coming from Western countries are usually known for their good communicative skills in English, in contrast to Asian students, who barely know how to communicate not only in this international language but also in the local 
languages of the country where they are coursing this module. The following Spanish example reproducing the response given by the Tourism interviewee illustrates this:

(7) $\mathrm{T}:[\ldots]$ Em: but anyway the level is very heterogeneous. Eh: you can't demand much more either because it is compulsory for students, at least in the Tourism degree, they are obliged to take a series of credits in English which are not based on their foreign language level, that is, they have to course them and that's it, whatever their level is. Em:: then, they have a heterogeneous level and in addition, in the case of this module, language level differences can be perceived between native students and international students. Eh: I always have mmm maybe nearly $40 \%$ of students come from countries other than Spain where the level is heterogeneous. A Korean student is not the same as a Dutch student. So students in general from Central and Northern Europe have a very good, very good level of English. [...] However, students, Taiwanese students have a lower command of the language. As far as the language is concerned, that one is the biggest difficulty I have perceived. [T: [...] Em: pero de todas formas el nivel es muy heterogéneo. Eh: tampoco se puede exigir mucho más porque ellos tienen la obligación, al menos en el grado de Turismo, tienen la obligación de cursar una serie de créditos en inglés con lo cual no puede depender de su nivel, o sea, punto, los tienen que hacer y se acabó, tengan el nivel que tengan. Em:: entonces, ellos tienen un nivel muy variable y además, en el caso de esta asignatura, sobre todo las diferencias de nivel son entre los alumnos autóctonos y los alumnos extranjeros. Ehh yo tengo siempre mmm pues a lo mejor un 40\% de alumnos de fuera de España en los cuales el nivel es variable. No es lo mismo un alumno coreano que una alumna holandesa. Entonces los alumnos en general de centro y norte de Europa tienen un nivel de inglés buenísimo, buenisimo [...] Y sin embargo, pues los alumnos, los de Taiwán lo tienen bastante peor. Entonces con respecto a la lengua, esa]. (See Appendix I (d)).

Cultural issues are also important when it comes to the lack of background knowledge about European culture and history that stands out among Asian students. As a result, it is more complex for them to understand the necessary notions that should be assimilated in order to pass the module satisfactorily. In the next excerpts, such a disciplinary challenge is noticed by History and Tourism teachers.

(8) H2: [...] There were European students who were very good at English, then there were Korean students who didn't speak Spanish and who didn't speak English either, and they also didn't have any - no, they didn't have any knowledge of Western culture. So, for example, they have no idea about Christianity. If a large number of Gothic or Renaissance artworks, for example, are of religious nature, try to explain that - explain that to them all that, right? Then it is another difficulty. [H2: Ehh pues bueno ahí tienes un poco de todo. Eh los alumnos que vienen de Erasmus, muy bien. Eh bueno, luego también hay de todo, ¿no? Habian alumnos europeos que muy bien, luego habían alumnos coreanos que no sabían 
español y que no sabían inglés tampoco, y además tampoco no tienen nada de - no, no tienen nada de conocimientos de cultura occidental. Entonces por ejemplo, no tienen ni idea del cristianismo. Si una gran parte de obras de arte góticas, por ejemplo, o renacentistas, son de contenido religioso, pues a ver como tú encima le explicas - explícale además todo eso, ¿no? Entonces es una dificultad extra añadida]. (See Appendix I (c)).

(9) T: And then, there's the extra challenging part which involves international students lacking, not in the case of a Dutch student, but in the case of a Taiwanese or Korean student lacking background knowledge which is necessary for the completion of the module, therefore students' low proficiency level is mixed with their lack of sufficient knowledge, and that is an important handicap. [T: Y luego, el problema añadido es que el alumnado extranjero muchas veces carece de, no en el caso de un alumno o alumna holandés, pero sí en el caso de un alumno o una alumna de Taiwán o de Corea, carece de los conocimientos previos necesarios para la realización de la asignatura, con lo cual se me mezcla la carencia lingüística con la carencia de contenidos, y eso es un hándicap importantito]. (See Appendix I (d)).

\subsubsection{Lecturers' concerns in the CLIL classroom}

When dealing with the difficulties teachers face in CLIL instruction, their proficiency level and how to assess content and language stand out. As regards their communicative competence in English, some teachers do not need to make a great effort to deliver their lectures or seminars in English. Some of the reasons have to do with a large number of materials being available in English and teachers mastering the target language at an advanced level. In fact, two of them have studied abroad and are familiar with specific terminology in that language. In the excerpts 10 and 11 below it can be observed that teachers' academic experiences have played a significant role in their professional careers where English has been regarded as the "global language of science" (Lillis \& Curry, 2010, p.1).

(10) N1: Yes, let's see. I studied in England, so for me - I have a better knowledge of the contents in English, let's say [...]. [N1: Sí, a ver. Yo es que estudié en Inglaterra, entonces para mí, yo me lo sé mejor en inglés, digamos [...]]. (See Appendix I (h)).

(11) M3: None. I studied my Medicine degree in Scotland, so it is easier for me to teach in English as I am more familiar with the terminology and all the materials available on the net regarding the latest studies in Medicine are in English. [M3: Ninguna. Yo estudié la carrera de Medicina en Escocia, por lo que a mí me resulta más fácil dar las clases en inglés ya que estoy más familiarizada con la terminología y todo el material disponible en la web con respecto a los últimos estudios en medicina está en inglés]. (See Appendix I (g)). 
Another critical issue in CLIL instruction revolves around language level. As observed in excerpt 12 , the teacher is not worried about giving instruction in a foreign language but about students' comprehension, especially for those who need to improve their fluency in English.

(12) M2: No, I don't have any difficulties as a teacher. I am concerned about them, not about me. That is, I feel bad because they cannot understand my speech [...] In other words, if - if it is an English language module, of course, it should be taught in English. But if it is a module in which I am teaching, I don't know, the evolution of the hominid lineage, of the - of the homo sapiens ancestry, if I teach that in English there will be people who won't understand anything at all, who won't pay attention to the explanations [...] And I feel bad about it. That's the only difficulty I have]. [M2: Nada. Yo el problema que tengo es por ellos, no por mí. O sea, a mí me sabe mal [...] Es decir, si, si es una asignatura de inglés, pues claro, tiene que ser en inglés. Pero si es una asignatura en la que estoy dando, yo que sé, la evolución de la rama de los homínidos, del, del linaje de homo sapiens, si lo doy en inglés habrá gente que no se entera, que desconecta totalmente [...] Y me sabe mal. Ese es el único reparo que yo tengo]. (See Appendix I (f)).

Nonetheless, instructors in the three fields of study are aware of their linguistic competence. The quality of their speech may be affected negatively when using a language other than their mother tongue. Within the Tourism degree, the teacher refers to the role affective factors play in foreign language learning as well as in the production of classroom discourse (see excerpt 13).

(13) T: Let's see, what inconvenient I find. Em: I have no problems, I give all my lectures exclusively in English em: I have no problem but I am very aware that the - the discourse always loses quality, that is to say it is not the same to give a lecture in your mother tongue as in an acquired language. And within the range of acquired languages there are different levels, that is to say, because I - for me, Valencian is also an acquired language, it is not my mother tongue, but nevertheless I have a different background. Italian is also an acquired language, not my first language, but I have a different life experience. English is a language acquired in a mm: way - for functional purposes exclusively, where eh: the learning process has been different and the richness of the discourse is also poorer than in any of the three languages that I have just mentioned [...]. [T: Vamos a ver, yo qué inconveniente le encuentro. Em: yo no tengo problema, yo todas mis teóricas las doy exclusivamente en inglés em: no tengo problema pero soy muy consciente de que la - el discurso siempre pierde calidad, o sea no es lo mismo impartir docencia de tipo magistral en tu lengua materna que en una lengua adquirida. Y dentro de las lenguas adquiridas hay niveles, o sea porque yo - para mí el valenciano también es una lengua adquirida, no es materna, pero sin embargo tengo un rodaje diferente. El italiano también es una lengua adquirida, no 
materna, pero tengo un rodaje vital diferente. El inglés es una lengua adquirida de manera mm con objetivos exclusivamente funcionales, con el cual eh: el rodaje ha sido distinto y la riqueza del discurso es también inferior que en cualquiera de las otras tres lenguas que he nombrado [...]]. (See Appendix I (d)).

Other issues that aroused have to do with the effort and time lecturers invest in preparing CLIL lessons, as observed in excerpt 14. In the case of Medicine, one of the educators claims that CLIL instruction is more time-consuming since lectures and seminars need to be carefully prepared. For this reason, teaching strategies are meant to enhance the assimilation and comprehension of disciplinary knowledge through the use of pictures and the provision of clear examples.

(14) M1: Eh well, it is true that you have to plan your lessons in advance because it's not the same having a vague lesson planning when you speak in Spanish eh because it is easier for you to overcome this challenge as opposed to lessons delivered in English where, whether you want it or not, you need to invest more time in the design of your lesson planning [...]. [M1: [...] Eh bueno, también es verdad que te tienes que preparar más la clase porque no es lo mismo llevar la clase medio preparada cuando hablas en castellano eh porque puedes salir más del paso que cuando es en inglés porque quieras o no hay que dedicarle un poco más de tiemp]. (See Appendix I (e)).

Apart from devoting time and effort to the preparation of CLIL practices, lecturers' selfperception of their foreign language abilities is worth mentioning. Therefore, their linguistic behavior may be affected by affective factors such as anxiety and motivation (MacIntyre et al., 2002). As can be read in excerpt 15 that follows, Psychology and History teachers are aware of their skills in the English language.

(15) P1: Of course, and I feel really embarrassed. I think I've lost my shame and you lose it when-when, how do you say that? When facing challenges, which is true. Therefore, in that sense, I feel really embarrassed, eh? I feel embarrassed even when taking pictures of myself and that kind of things. But you say, "it's a matter of overcoming this challenge" and giving lectures in a master's module has been helpful for me, for example, to start speaking in English in front of the students. [P1: Claro $\left\langle T L A N G \_S p\right\rangle$, i a mi me fa molta vergonya. Crec que la he perduda i la perds per, per, com se diu? Per afrontament 〈TLANG_Cat>. Exposición en vivo $\left\langle T L A N G \_S p\right\rangle$, que açò és veritat $\left\langle T L A N G \_C a t\right\rangle$. Entonces, en eixe sentit, a mi me fa molta vergonya, eh? A mi me fa vergonya hasta fer-me fotos i eixes coses. Però dius “bueno, es una qüestió de que tinc que supéralo” i a mi m'ha vingut molt bé per ejemple el màster per a ficar-me a parlar en anglés davant dels alumnes]. (See Appendix I (k)). 
Even though the Psychology and History specialists in this study recognize that their fluency in English has benefited from exposure to these programmes, the expert in History argues that having a B2 level in English does not guarantee instruction of the highest standard. As mentioned in chapter 3, lecturers holding a B2 level certificate may find themselves giving instruction in CLIL modules as long as it takes five years for them to get a C1 level in this foreign language (Universitat Jaume I, 2020b). Not only rehearsals are necessary when educators have attained an intermediate level in English, but they should be offered more resources in order to improve their communicative abilities in this foreign language, as suggested in excerpt 16 . This is the reason why the new actions have been introduced within the institutional programme promoting the Incorporation of the English language in the classroom setting (Universitat Jaume I, 2021).

(16) H2: [... I want and need to improve my proficiency level in English, ok? Eh I have a B2 level, but honestly I think it is not enough. Thus I think that the resources we are offered as teachers should be refined a little bit so that we can improve our level of English because I don't think that we are given opportunities to do so. [H2: [...] quiero y necesito mejorar mi nivel de inglés, ¿vale? Eh tengo el B2, pero sinceramente a día de hoy yo no creo que sea suficiente. [...] Entonces yo creo que ahí sí que se tendría que mejorar un poco a lo mejor los recursos que se le puedan dar al profesorado para mejorar el nivel de inglés porque tampoco creo que se nos dé demasiadas facilidades [...]]. (See Appendix I (c)).

Students' complaints have also been considered as one of the main teachers' concerns in the disciplines of Humanities, Social Sciences and Health Sciences. According to teachers' views, learners are generally reluctant to have English as the language of instruction and complain about this fact. In excerpts 17 and 18, it can be observed that time, linguistic and affective factors may prevent students from choosing modules taught through a CLIL approach. It is precisely the fact that they find CLIL pedagogies more time-consuming than other programmes delivered in their mother tongue which may have an impact on instructional practices.

(17) P2: Ah well teachers' difficulties stand for what she [referring to P1] has just said. First, they may not course the module because of that [the amount of work invested when translating course materials] and then they may assess us badly because of the use of English. [P2: [...] Ah bueno, les dificultats del professorat és lo que ella diu. Primera que pot ser que l'assignatura no l'agafen per això [la quantitat de feina que implica tradü̈r els materials] i después que l'avaluen pitjor pel tema de l'anglès]. (See Appendix I (k)). 
(18) N1: Well, they complain, they complain about that [instruction in English] a lot. Especially those who master the language at a lower level, they feel more embarrassed, but - but well, they complain about that, they do. [N1: Hombre, se quejan, se quejan muchísimo. Sobre todo los que tienen menos nivel, que tienen más vergüenza, pero - pero bueno, se quejan, sí]. (See Appendix I (h)).

As noted in the excerpts above, such dissatisfaction towards the use of a foreign language seems to affect teachers' assessment negatively. In excerpt 19 , it is clearly illustrated that the performance of a teacher who used to be rewarded for his excellent teaching evaluations was downgraded. In the end, these results discouraged him from taking part in further CLIL initiatives.

(19) M2: [...] And so when they assessed him, they crucified him, that is, he was a... a person who got a grade of seven or eight every year and that year he got a two. Then the following year he told me X, "I'm not going to teach in English anymore". [M2: [...] Y luego en la evaluación lo crucificaron, o sea era un-una persona que sacaba entre siete y ocho cada año y ese año sacó un dos. Entonces al año siguiente me dijo " $X$, ya no voy a dar las clases en inglés, nunca más”]. (See Appendix I (f)).

Last but not least, the availability of materials in English was perceived as a teaching difficulty by History and Tourism teachers, especially those related to regional history. The scarcity of materials in English is linked to topics covered such as Valencian art, as in excerpt 20. Otherwise, access to a larger number of materials would be possible as occurs with the areas belonging to the field of Health Sciences, where research is mainly conducted in this international language.

(20) T: The balance between the materials published in English and those published in our local languages eh: depends on the availability of such materials, that is, the module I teach is a module called Valencian art and pretending to find bibliographical references about Valencian art in English is to expect to a lot. For some generic tasks, em: and if I can find some papers in English I upload them in English. But let's be realistic, neither urban planning studies about the city of Valencia nor studies about the Renaissance architecture in the province of Castellón are available in English and I am not going to translate other people's academic texts. [T: [...] La eh la proporción entre materiales en inglés y materiales en lenguas vernáculas eh: depende mucho de la existencia de dichos materiales, es decir, mi asignatura es una asignatura que se llama Arte Valenciano, y pretender que la bibliografía producida sobre arte valenciano se encuentre en lengua inglesa es mucho pretender. En algunas actividades que son de tipo genérico, em: y que puedo encontrar documentación en lengua inglesa se incluye en lengua inglesa. Pero hay que ser realista, ningún estudio de urbanismo sobre la ciudad de Valencia, así como ningún estudio sobre 
arquitectura renacentista en la provincia de Castellón está en inglés y yo no voy a ponerme a traducir textos académicos de otras personas]. (See Appendix I (d)).

\subsubsection{Supportive materials and resources for the CLIL classroom}

It should be noted that the materials and tools used, shared or delivered in the teaching process have approached the development of productive (i.e. writing and speaking) and receptive (i.e. reading and listening) skills in the CLIL classroom. In other words, supportive resources seek to the progression of participants' communicative competence.

In general, writing and reading skills are trained through the use of glossaries, newspaper articles, questionnaires or visual aids such as PowerPoint presentations. On the one hand, glossaries allow students to familiarise with specific terminology related to their field of study. Thus, these materials serve for vocabulary gathering, which in turn are in line with the learning outcomes established in the course syllabi of the modules studied. Questionnaires, on the other hand, are meant to retrieve information about students' perceptions of CLIL instruction, which in turn may boost interaction in the target language, thereby helping lecturers meet students' needs.

(21) H1: Well, when I started teaching this module, when preparing it, I created a glossary with the English terminology, its Spanish equivalents and the phonetic transcription of the terms so that students know how these words should be pronounced. I uploaded it on our virtual classroom at the beginning of the semester and every year I've taught this module I've updated it with new terms that I've learnt and that I think will be useful along their academic life. We should keep in mind that they are first-year students and they will be asked to read articles or book chapters in order to complete their assignments. [...] I also share my PowerPoint presentations as well as links of videos, articles or websites where they can find additional information on given topics, such as architecture or social classes in ancient Rome. [H1: Bé, quan vaig començar a impartir esta assignatura, al moment de preparar-la vaig crear un glossari amb la terminologia en anglès, els equivalents en castellà $i$ la transcripció fonètica de les paraules per saber com es pronuncien. Ho vaig penjar a l'aula virtual des del primer moment, $i$ cada any que l'he impartida he anat actualitzant-lo amb nous termes que he anat aprenent i que crec que els poden resultar útils, si no ara, al llarg de la seua vida acadèmica. No oblidem que estan en primer i hauran de llegir articles o capítols de llibre per tal de poder realitzar treballs [...]. També els facilite enllaços de vídeos, articles $i$ pàgines web on poden trobar informació addicional sobre temes específics, com ara l'arquitectura o les classes socials de l'època romana. I els demane que contesten uns qüestionaris de satisfacció per a poder valorar si la docència en anglès els ha agradato si hi ha algun aspecte que creuen que s'hauria de millorar]. (See Appendix I (b)). 
In line with the example above, other educational tools employed for the teaching of specific terminology may aid retention. Indeed, having access to specialised glossaries may be useful for text comprehension as well as for the production of written and spoken outcomes. The potential uses of these pedagogical tools in CLIL settings also allow for the development of the intercultural competence, which is of utmost importance in our current society. As shown in the following example, the Nursing lecturer makes use of them in the CLIL classroom.

(22) N1: [...] Then, another session - well I also give them some pages with vocabulary, which is very specific because I have worked there and I know what terms should be used in comparison with what is included in English for Nursing books. [N1: [...] Luego, otra clase, bueno otra cosa que hago es que les doy unos folios de vocabulario específico, que es muy específico porque yo he trabajado allí y sé cómo se dicen las cosas mejor que lo que ponen en los libros de inglés $\left\langle T L A N G \_S p>\right.$, English for Nursing $\left\langle T L A N G \_E n g>\right]$. (See Appendix $\mathrm{I}(\mathrm{h})$ ).

As regards oral skills, audiovisual materials such as PowerPoint presentations, pictures with English descriptors are common in the fields of Humanities, Social Sciences and Health Sciences. Generally speaking, YouTube videos are watched in the classroom setting to promote the exchange of ideas in group discussions. Because teachers belonging to the psychological domain referred to listening as one of the areas students struggle the most, the links to these resources are available for all the participants on the virtual platform. In so doing, CLIL learners can access the materials as many times as needed for comprehension purposes, as read in excerpt 23 below.

(23) P1: [...] there are people who have serious listening problems, for example, it's hard for them. Now, as these materials uploaded to our virtual classroom, I tell them "you can watchthe videos 28 times if necessary". This is great, because the more you listen to these videos and as - as... And what I also tell them is "well, now we watch the video, we make comments on the topic, we engage in a discussion, colloquium, we talk and participate. You can watch it again at home knowing what it is about and with all this information it is easier to understand what is being said. [P1: [...] pues n'hi ha gent que té problemes seriosos pa els listenings per ejemple, que li costa. Ara, com que és un material que està penjat a l'aula virtual, jo els dic el pots vore 28 vegaes si és precís. Que va bé, perquè quant més els sents $i$ com ja -ja...I també lo que els dic és "bueno, ara el mirem, fem comentaris, fem un debat, col-loqui, se parla $i$ se participa. Te'l tornes a mirar sabent ja de què va $i$ en tota esta informació és molt més fácil’']. (See Appendix I (k)). 
When it comes to spoken outcomes, students are required to perform oral presentations and group discussions in the classroom setting. For example, Tourism and Nursing seminars tend to be thematic so that students can expand their knowledge on a given topic. In this case, the preparation of art exhibitions and tourist routes was part of the teaching practice, as in excerpt 24.

(24) T: We have activities ranging from group works on a series of materials, the preparation of a discussion which aims at having two groups facing each other in the classroom, eh: group works on eh: historical records and reconstruction drawings of - of artistic elements or eh: the organisation of a tourist route. Okay, by the - by the students. So $\mathrm{mm}$ in most activities, apart from submitting a written report and participating in the classroom, at the end of the development of the session or sessions in which the activity is carried out, what is done is some kind of - of performance in which the students have to present their work in front of everyone, either through a discussion, or through a presentation before their classmates, or thorough different ways. [T: Nosotros tenemos actividades que van desde la, el trabajo sobre una serie de materiales, la preparación de un debate que es el de enfrentar dos grupos dentro del aula a eh: trabajos sobre eh: documentación histórica y reconstrucción a través del dibujo de - de elementos artísticos o eh: la organización de una ruta turística. Vale, por parte de - de los chavales. Entonces mm en la mayoría de las actividades, además de después tener que entregar una memoria escrita y del trabajo en el aula, al final del desarrollo de la sesión o las sesiones en las que se realiza dicha actividad lo que se hace es algún tipo de - de 〈TLANG_Sp> performance $\left\langle T L A N G \_E n g\right\rangle$ en la que los alumnos tienen que exponer públicamente su trabajo, bien sea a través de un debate público, bien sea a través de una presentación al resto de la clase, o de diferentes maneras]. (See Appendix I (d)).

The seminar in the Nursing domain was devoted to the use of epidural shots in pregnant women. In excerpt 25 , it is pointed out that oral communication is boosted through teacher-student and student-student interaction. Such discussion is generated through the comments on the positive and negative effects the administration of this medical treatment entail.

(25) N1: So, for example, what I'm going to do this year is a) a seminar I've taught about the use of the epidural, as in the Women Care module, my module. Eh: so I tell them that they need to search for articles, an article where the epidural benefits are acknowledged and an article where the disadvantages are discussed. The articles should be written in English, they should be taken from a valid source, evidently, and published within the last five years. Then each of them should tell me what it is about in the seminar session, I want them to tell me where they got the articles, the year in which they were published and em I want them to summarise them and tell me the benefits and drawbacks [of administering epidural shots to 
pregnant women]. And then, more or less when there is something like the - the first person who tells me, in this one it is stated that the maternal satisfaction incr... -increases, isn't it? So I tell them "has anyone find the same?" Overall, we start some kind of discussion. "What I've found is....Well, but who has found anything contrary to this view?" Some kind of discussion takes place. [N1: Entonces, por ejemplo, este año lo que voy a hacer es a) uno [seminario] sobre la epidural hemos hecho, como es la asignatura de materno, mi asignatura. Eh: pues les digo que busquen artículos, un artículo que encuentre beneficios sobre la epidural y un artículo que encuentren inconvenientes en la epidural. Los artículos tienen que ser en inglés, tiene que ser de, de una fuente válida, evidentemente y de los últimos cinco años. Entonces uno a uno me tienen que buscar artículos y me lo tienen que contar en clase, quiero que me digan de dónde vienen, los años y em que me lo resuman y que me digan beneficios e inconvenientes. Y luego, más o menos todos cuando hay como algo... - el primero me dice, pues ese, la $\left\langle T L A N G \_S p\right\rangle$ maternal satisfaction $<T L A N G \_E n g>$ incre... - aumenta, ¿no? Entonces les digo “ ¿alguien más ha encontrado esto?" Total, hacemos un poco asi de debate. "Es que yo he encontrado... Bueno, pero ¿quién ha encontrado lo contrario?" Hacemos un poco de debate de los artículos]. (See Appendix I (h)).

Technology-enhanced practices take place through the use of software that foster the practice of both disciplinary knowledge and speaking skills. Evidence may be found in the Nursing degree, where a programme of arrhythmias is introduced in the practical sessions of a module so that students get engaged in the learning process.

(26) N3: [...] This is the only thing that students encounter, once the glossary and I'll tell you a little about evolution because this is me. I'm based on what I did last year, okay? Super easy, super, nothing. Okay? Images. Why do I do it like this? Look, the first year I only give them, let's say I only give them part work, part. If it's about the fast or slow arrhythmias, they only get the fast part, I don't give them all the work done. Why? Because the one who gets something is the one who produces. [N3: [...] Esto es lo único con lo que se encuentran los alumnos, una vez el glosario y te voy a contar un poco la evolución porque esto está yo. Me baso en lo que el año pasado hice, ¿vale? Súperfácil, súper, nada. ¿Vale? Imágenes. ¿Por qué lo hago así? Mira, el primer año solo les doy, digamos que solo les doy una parte trabajo, una parte. Si es sobre las arritmias rápidas o lentas, solo tienen la parte rápida, no les doy todo el trabajo hecho. ¿Por qué? Porque el que consigue algo es el que produce]. (See Appendix I (j)).

All in all, the supportive materials for CLIL modules presented here tend to use glossaries, newspaper articles and digital resources, including online surveys, YouTube videos or PowerPoint presentations that aim at training students' productive and 
receptive skills. By developing their communicative competence in the English language, they will learn to assimilate and transmit knowledge in specialised domains.

\subsection{QUESTIONNAIRES}

At the end of the CLIL seminar sessions, a final survey was administered to the participants (Appendix V). Three variables have been considered, namely language learning experiences, attitudes towards a foreign language and knowledge of institutional information on language policies. The items focusing on foreign language instruction with an emphasis on methodology, materials, ICTs and comprehension difficulties involve Q1-Q6 (see Table 28).

Table 28. Questionnaire: First variable (Q1-Q6).

\begin{tabular}{|c|c|}
\hline \multicolumn{2}{|r|}{ QUESTIONNAIRE: FIRST VARIABLE (Q1-Q6) } \\
\hline Q1 & The lessons and methodology used here in class have been interactive and suitable. \\
\hline Q2 & The activities have been appealing. \\
\hline Q3 & Seminars in English have been useful. \\
\hline Q4 & ICTs are used as a tool to practice the contents we've seen in the module. \\
\hline Q5 & The materials provided by the teacher have been appropriate to expand my knowledge. \\
\hline Q6 & $\begin{array}{l}\text { These practical sessions were more difficult compared to other teaching practices due to the } \\
\text { English language. }\end{array}$ \\
\hline
\end{tabular}

The second variable, which seeks to explore learners' feelings towards their previous CLIL learning experience, deals with Q7-Q12. These items can be seen in Table 29.

Table 29. Questionnaire: Second variable (Q7-Q12).

\begin{tabular}{|l|l|}
\hline \multicolumn{2}{|c|}{ QUESTIONNAIRE: SECOND VARIABLE (Q7-Q12) } \\
\hline Q7 & $\begin{array}{l}\text { Do you think the activities and exposure to the English language meet the requirements of the } \\
\text { module? }\end{array}$ \\
\hline Q8 & Would you prefer a lesson delivered in your mother tongue? \\
\hline Q9 & Do you have any international certification according to the CEFR (in English)? Which level? \\
\hline Q10 & Is English relevant for your professional career? \\
\hline Q11 & $\begin{array}{l}\text { Have you had other content subjects in which English is the language of instruction? What did } \\
\text { they consist of? }\end{array}$ \\
\hline Q12 & \begin{tabular}{l} 
Have you had a positive experience learning in a foreign language? \\
\hline
\end{tabular}
\end{tabular}


Finally, Q13: Do you know the number of subjects in which English is the language of instruction in your degree? and Q14a: Were you given information before or when enrolling your degree about the requirements of the institutional ECOPOL Plan?, Q14b: Do you know anything about these linguistic requirements? Q14c: Which of these premises about the English language do you think are included in the ECOPOL Plan? Tick the correct ones are meant to determine students' familiarity with the multilingual policies devised by the university.

A total of 152 responses were received from two general branches of knowledge, including Soft Sciences and Hard Sciences. Thus, the response data have been discussed drawing on the disciplines and sub-disciplines taking part in this study. Within the Soft Sciences domain, the degrees involved have to do with History and Heritage, Humanities: Intercultural Studies, and Tourism. As for Hard Sciences, the focus is on the areas of Medicine, Nursing and Psychology, all of them belonging to the area of Health Sciences. I will now present the results of the survey according to the disciplines studied.

\subsubsection{Humanities and Social Sciences}

This section presents the results obtained from the surveys filled in by undergraduate students coursing CLIL modules in the fields of Humanities and Social Sciences. The findings related to Humanities will be discussed taking into account learners enrolled in the degrees of History and Heritage and Humanities as well as their academic year. Afterwards, the attitudes and concerns of Tourism students, who belong to the domain of Social Sciences, will be described in detail.

\subsubsection{Humanities: The cases of History and Heritage and Humanities}

Regarding undergraduate students in the field of Humanities, there are certain aspects that deserve especial attention. As to Q1, 86.04\% of first-year History of the Classical World students, which is part of the course syllabus taught within the degrees in Humanities as well as History and Heritage, answered positively to this statement (see Figure 2). These results are linked to Q2, which proves that students enjoyed the supplementary use of audiovisual materials, more specifically, the visualisation of episodes from the well-known TV series Rome. As for Q3, the vast majority agreed with this statement. These findings reveal that CLIL practices have been meaningful for these students. Some participants' responses to Q4 were unexpected. Even though most 
of them were affirmative, it seems that seven subjects disagreed with this item. They might have not conceived Kahoot surveys, which were incorporated in CLIL seminars so as to check their comprehension, as ICTs. Nonetheless, it has become clear that the teacher facilitated suitable materials for the learning of disciplinary knowledge in the target language, as in Q5. Focusing on Q6, evidence shows that nearly half of the students seemed to struggle to follow CLIL initiatives where English is the main language of instruction.

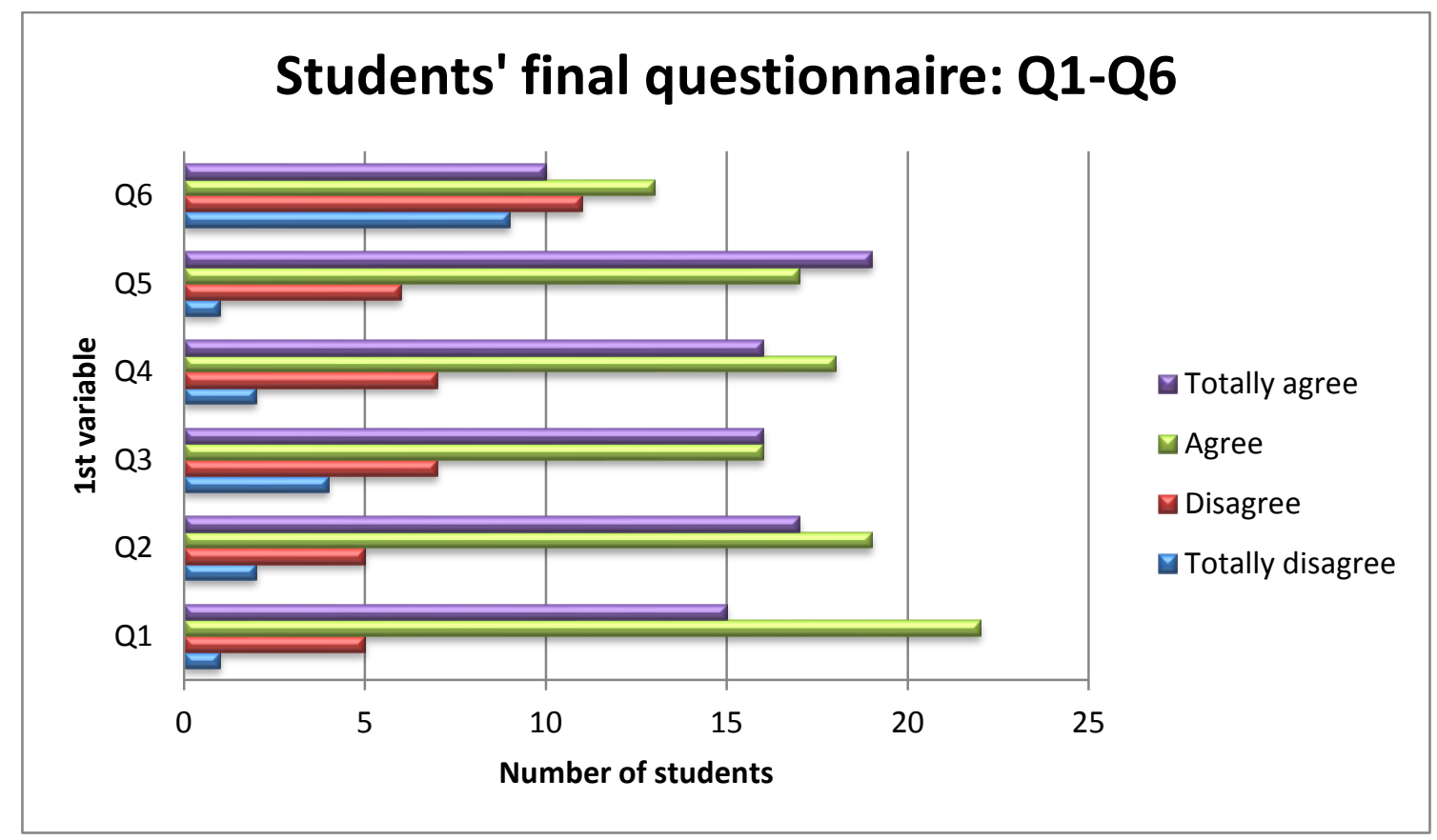

Figure 2. Results from students' final questionnaire (Q1-Q6): First-year History and Humanities students.

As regards Q7, 83.7\% of the respondents claim that they agree with this statement as opposed to the remaining $16.3 \%$, who stressed that a closer look should be given to the instruction of historical terminology, which is key in order to produce and understand speakers' speech (see Figure 3). Despite these findings being mostly positive, $48.8 \%$ of the participants prefer instruction being conducted in their L1, as reported in Q8. Such trends indicate that action should be undertaken with regard to the benefits that entail foreign language instruction. As to the command of the target language in Q9, only 16 out 43 respondents $(37.2 \%)$ have a certificate. Those who can prove their communicative abilities master the English language at an A2 (19.04\%), B1 (14.29\%), B2 $(2.38 \%)$ and even at a C1 level $(4.76 \%)$, in contrast to $59.52 \%$ of the subjects who have no official certificates. The answers for Q10 emphasise the role of English in the labour market. Actually, $95.3 \%$ of first-year undergraduate students in the degrees of 
History and Humanities are not only aware of the linguistic requirements in their future jobs but also of its usefulness in the establishment of international relationships. Contrary to this view, $4.7 \%$ of the participants do not seem to find the mastery of the English language purposeful for their professional performance. Turning to Q11, roughly $67.4 \%$ of the participants made it clear that they were familiar with CLIL programmes, which were mainly taught throughout the academic year. According to these students, didactic units and oral presentations were common in those modules following a CLIL approach, either at secondary or tertiary education. When it comes to Q12, 79.1\% of the subjects confirmed that their involvement in CLIL practices has been gratifying. As can be read in excerpt 27 , one of the students wrote:

(27) SX1: Learning through English has been hard for me, so being able to give an oral presentation in English in front of my classmates has been a real challenge that I have overcome. [SX1: Me cuesta mucho el inglés, así que el poder haber hecho una exposición en inglés delante de mis compañeros ha sido un verdadero reto que he superado].

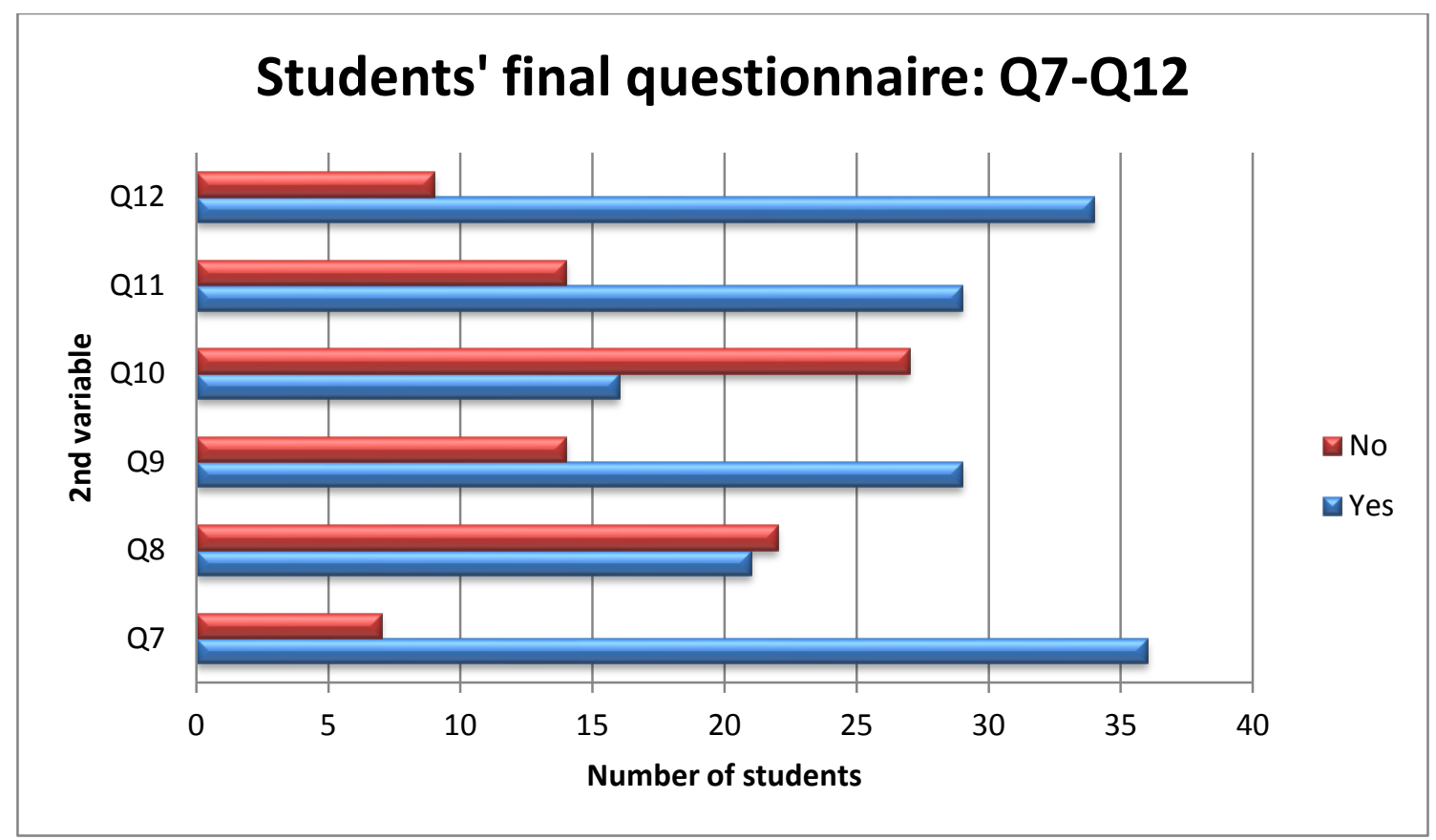

Figure 3. Results from students' final questionnaire (Q7-Q12): First-year History and Humanities students.

As regards Q13, the rate of students who are not familiar with the CLIL modules offered within their degrees is quite high (76.7\%). When dealing with the results in Q14a, it can be suggested that except for $9.3 \%$ of the subjects, students had not been previously informed about the multilingual strategy developed by Universitat Jaume I. Indeed, they answered negatively to Q14b. In their attempt to guess some of the 
premises, the attainment of a B2 level before presenting their Bachelor's thesis and the attainment of the same level before requesting the issue of their degree certificates were the most repeated options. Similarly, 10 out 43 participants reckoned that $5 \%$ of the degree's credits should be taught in English in Q14c. Conversely, those who were told about its premises knew that the attainment of such intermediate level certificate was not mandatory but highly advisable. In this case, these students were informed by the Voluntariat Lingüistic (Language Volunteering) service. It is worth mentioning that this programme, run by the Language and Terminology Service in collaboration with the Cooperation for Development and Solidarity Office, seeks to raise students' awareness and commitment towards the use of languages, more specifically, with the use of the regional language. Participation in this type of initiatives is elective. Therefore, only those students interested in receiving training and getting involved in these activities were told about the institutional multilingual language policy, the ECOPOL Plan mentioned in Chapter 3 (p. 48).

As far as fourth-year History undergraduate students are concerned, the responses in Q1 let us know that the number of students who find the methodology adequate correspond to $64.29 \%$ (see Figure 4). These results go in line with those in Q2, where it can be perceived that $39.29 \%$ of the respondents might prefer activities other than watching videos related to art exhibitions and answering a questionnaire. In this respect, it can be perceived that those students who agreed or totally agreed with seminars in English being useful equal 57.14\%, as in Q3. Therefore, it goes without saying that this lesson planning might need to be restructured in order for CLIL instruction to be successful. Focusing on Q4, it is evident that most students acknowledge the usefulness of PowerPoint presentations and YouTube videos in reviewing the contents covered in previous sessions. As shown in Q5, the findings concerning the provision of materials are not conclusive, which leads us think that additional materials should have been administered to students. Unlike first-year History and Humanities students, the vast majority of fourth-year undergraduate students enrolled in Fundamentals and Theory of Artistic Heritage did not find the CLIL seminar as a challenging initiative, as can be seen in Q6. 


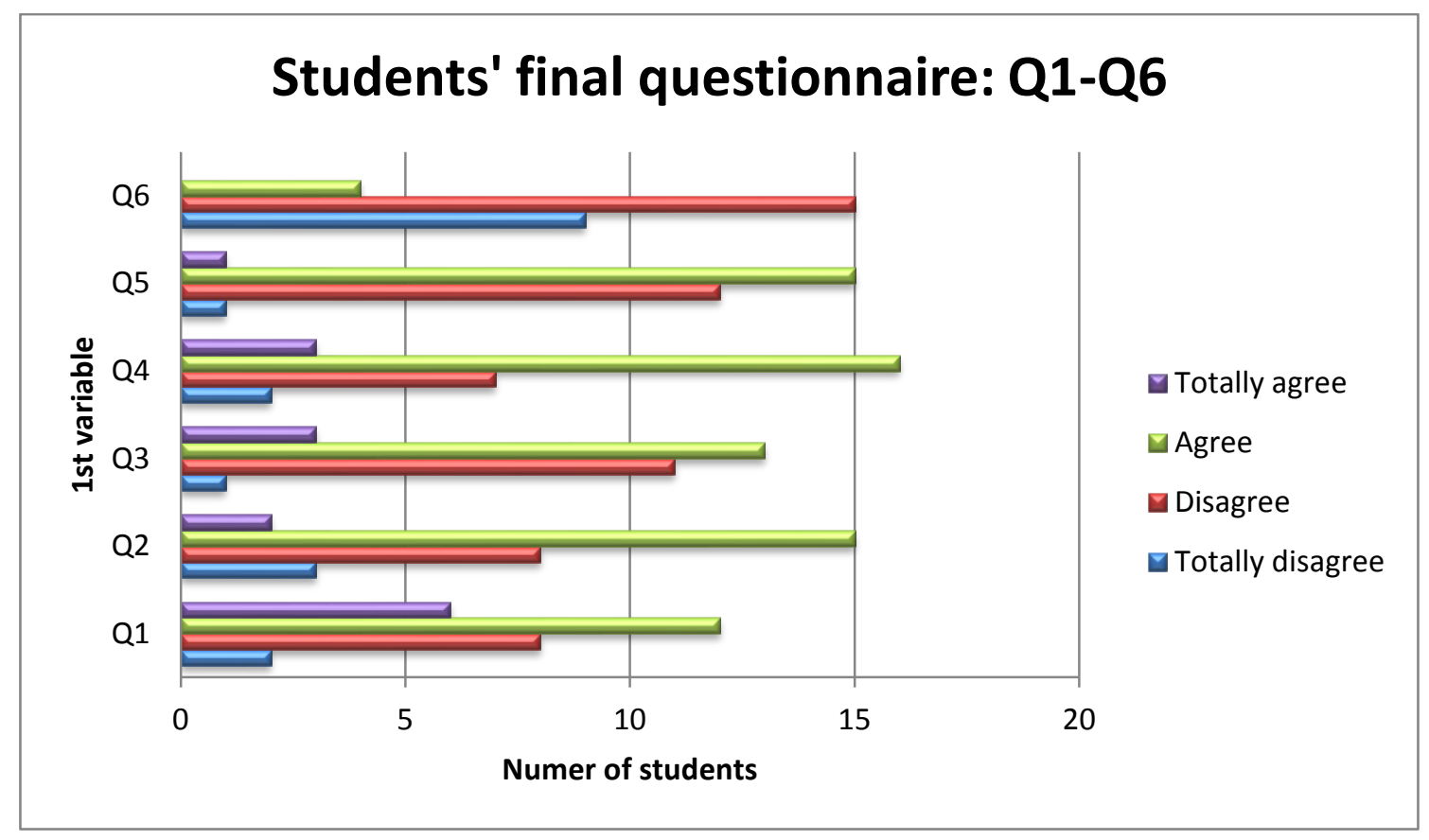

Figure 4. Results from students' final questionnaire (Q1-Q6): Fourth-year History students.

As to Q7, a high number of CLIL learners coursing Artistic Heritage of the respondents believe that the activities meet the linguistic requirements of the module (see Figure 5). In line with first-year students' answers in Q8, it seems that over half of the participants still prefer learning in their L1. Even though only 5 students claimed they owned a B1 $(10.71 \%)$ or a B2 $(7.14 \%)$ certificate in Q9, $92.86 \%$ of the subjects understood that the mastery of this target language is vital in their professional career, as specified in Q10. Concerning Q11, all these students had previous CLIL experiences through the presentation of group projects. This is clearly illustrated in Q13, where all of them affirm having coursed modules following this approach within the History and Heritage degree, especially due to linguistic policy of the university. Bearing these results in mind, $78.57 \%$ of the respondents pointed out that they have had a positive experience using English as the vehicular language in the classroom setting in Q12. 


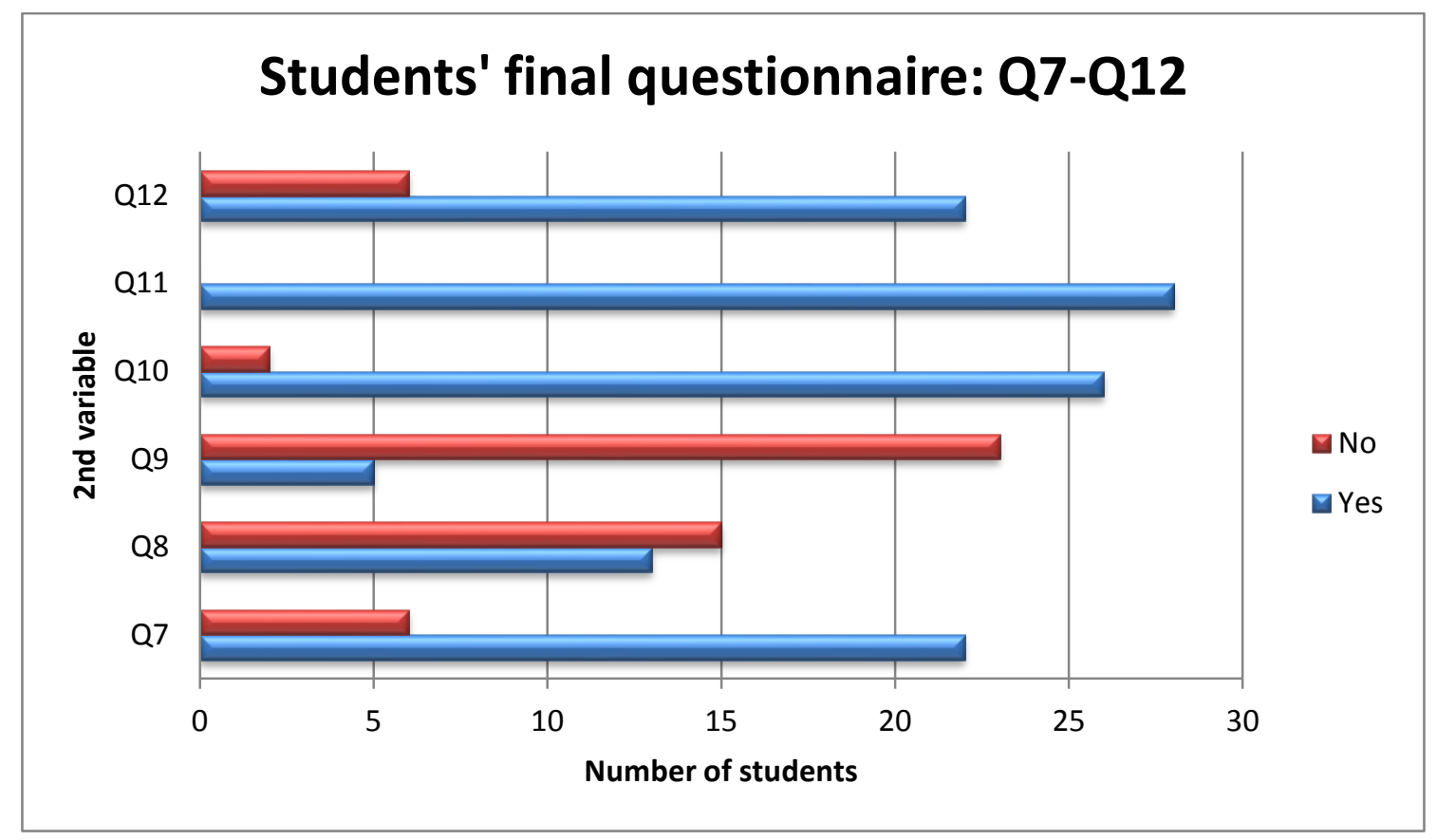

Figure 5. Results from students' final questionnaire (Q7- Q13): Fourth-year History students.

Unlike some first-year History students, who noted that they had been given some pieces of information about the linguistic policy devised by Universitat Jaume I, fourthyear undergraduate students had never heard of it, as evidenced in Q14a and Q14b. This is the reason why the subjects ticked the statement that established the need for having a B1 level in English before having access to the Master's degree in Secondary Education, Vocational Training and Language Teaching in Q14c. Similarly, other responses involved the possibility of applying for exemption if a B2 level is proved in a European language other than English.

\subsubsection{Social Sciences: Tourism}

Moving on to the domain of Tourism, the results in Q1 reveal that 4 out of 24 learners who answered the questionnaire seem to think that the methodology should be modified (see Figure 6). Such findings may be related to the fact that scarce information about Valencian art is available in English and thus uploaded to the module's virtual platform. Nonetheless, it is worth mentioning that the activities implemented in the classroom have been of interest to most of the participants, as can be seen in Q2. When it comes to Q3, 83.3\% of Tourism students agreed or totally agreed with CLIL seminars being profitable on the grounds that projects or assignments were significant for their future job prospects. As regards Q4, evidence shows that a wide variety of CLIL learners seem to consider that ICTs are integrated within instructional practices as a means to revise the assimilation of disciplinary knowledge. As for Q5, the number of subjects who 
believe that the materials provided and shared by the teacher are suitable corresponds to 62.5\%. As with fourth-year History students, the proportion of learners undertaking Valencian Art and Tourist Resources who find CLIL instruction arduous and demanding is reduced to $25 \%$.

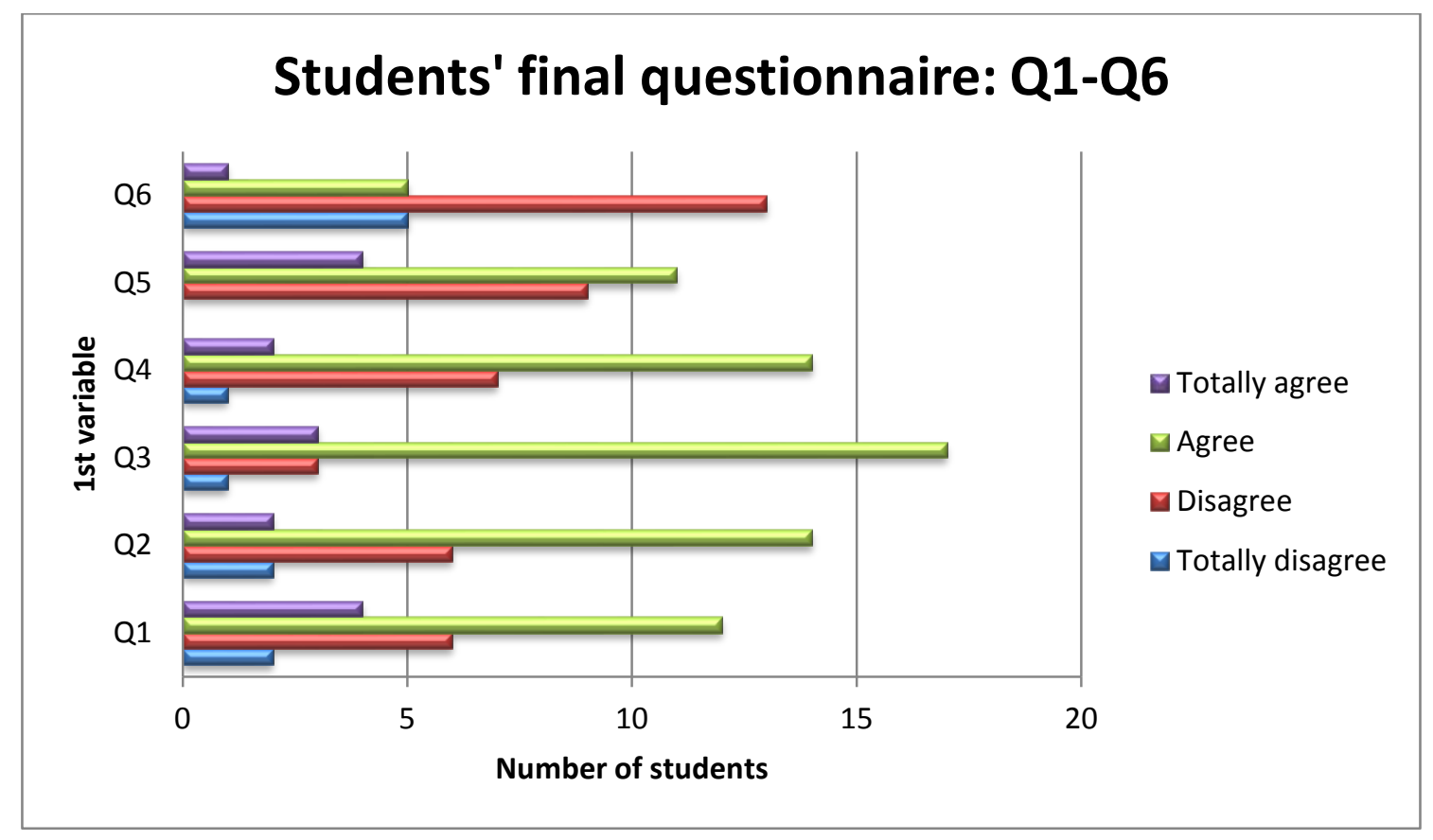

Figure 6. Results from students' final questionnaire (Q1-Q6): Fourth-year Tourism students.

As to Q7, all of the participants agree that the CLIL classroom meets the linguistic requirements of both the theoretical and practical components of the module (see Figure 7). From the answers obtained in Q8, it can be noticed that $79.17 \%$ of the respondents are eager to learn in the target language. This is especially relevant given the role foreign language communication plays in our contemporary tourism sector, particularly at an international scale. However, striking differences arise between home and exchange students in Q9. Generally speaking, Spanish students did not hold a language certificate in English as opposed to some international students. In fact, the communicative competence also differed between European and Asian students. Erasmus students were mostly independent speakers, with B1 and B2 level certificates, but some others were able to interact at advanced levels. Asian students, on the contrary, did not have a certificate indicating their foreign language skills as it was not a requirement when applying for their academic exchange. These findings seem to be contradictory taking into account that all of them admit the use of English as a lingua franca in the field of Tourism, as noted in Q10. Concerning Q11, students' learning background following a CLIL approach consisted of group projects and art exhibition 
proposals. In replying to Q12, 91.67\% of the subjects stated that their CLIL experiences had been worthwhile as it is a good way to learn about other cultures.

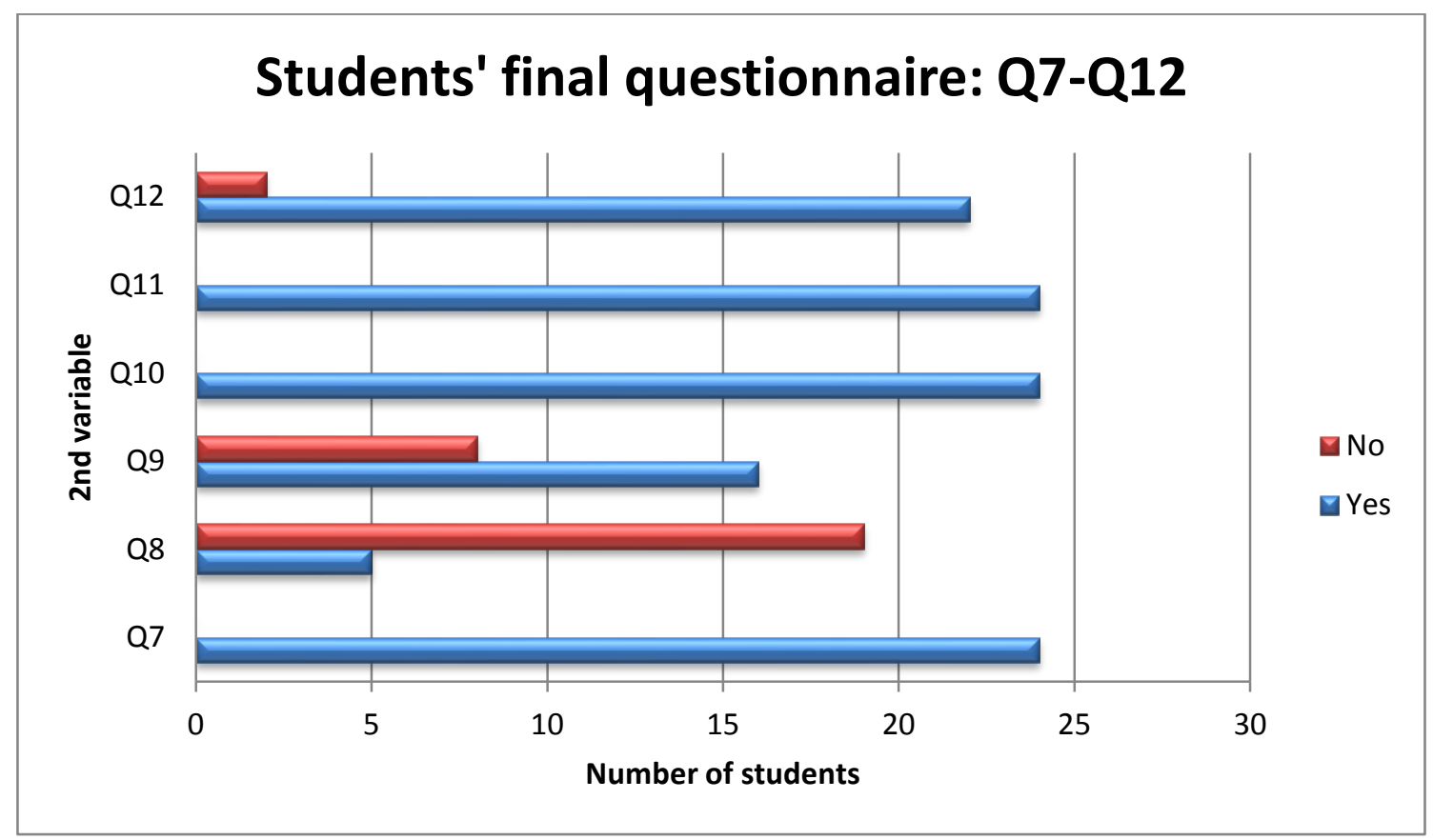

Figure 7. Results from students' final questionnaire (Q7- Q12): Fourth-year Tourism students.

However, not all of them were acquainted with the number of modules in which English was the means of instruction. Indeed, international students were not familiar with the curriculum of the Tourism degree. In keeping with Q14a, neither home nor exchange students in the Tourism degree were abreast about the policies enforced by the university in terms of language use in Q14b. As first-year History students, Tourism undergraduate students assumed that one of the requirements before receiving their degree certificate entailed having a B2 level in English, as shown in Q14c. Another assumption was tied in with the number of credits that should be taught in a foreign language during their academic life in higher education.

\subsubsection{Health Sciences: The cases of Medicine, Nursing and Psychology}

By contrast, the responses obtained within the field of Health Sciences also deserve to be examined in depth. Medicine students' answers will be discussed followed by those in the disciplines of Nursing and Psychology.

\subsubsection{Medicine}

Within the Bachelor's degree in Medicine, three different groups of CLIL learners have taken part in this research. First-year undergraduate students undertaking a seminar on The Genetics of Skin Cancer widely acknowledged the adequacy of the methodology 
with affirmative answers for the item in Q1 (84.62\%). With respect to Q2, 23.08\% of the participants are not captivated by the activities that are meant to be completed in the CLIL classroom. These findings do not mean that seminars are not valuable for the construction of knowledge. In fact, the rate of students who disagree with the statement in Q3 decreases to $15.39 \%$. The revision of contents by means of technological tools is illustrated by $84.62 \%$ of the students in Q4. The same is true for Q5 where materials are considered appropriate for a vast majority. Apart from that, the fact that English is the means of instruction did not result in this teaching practice being more complex than usual, at least for nearly $61.54 \%$ of Medicine students.

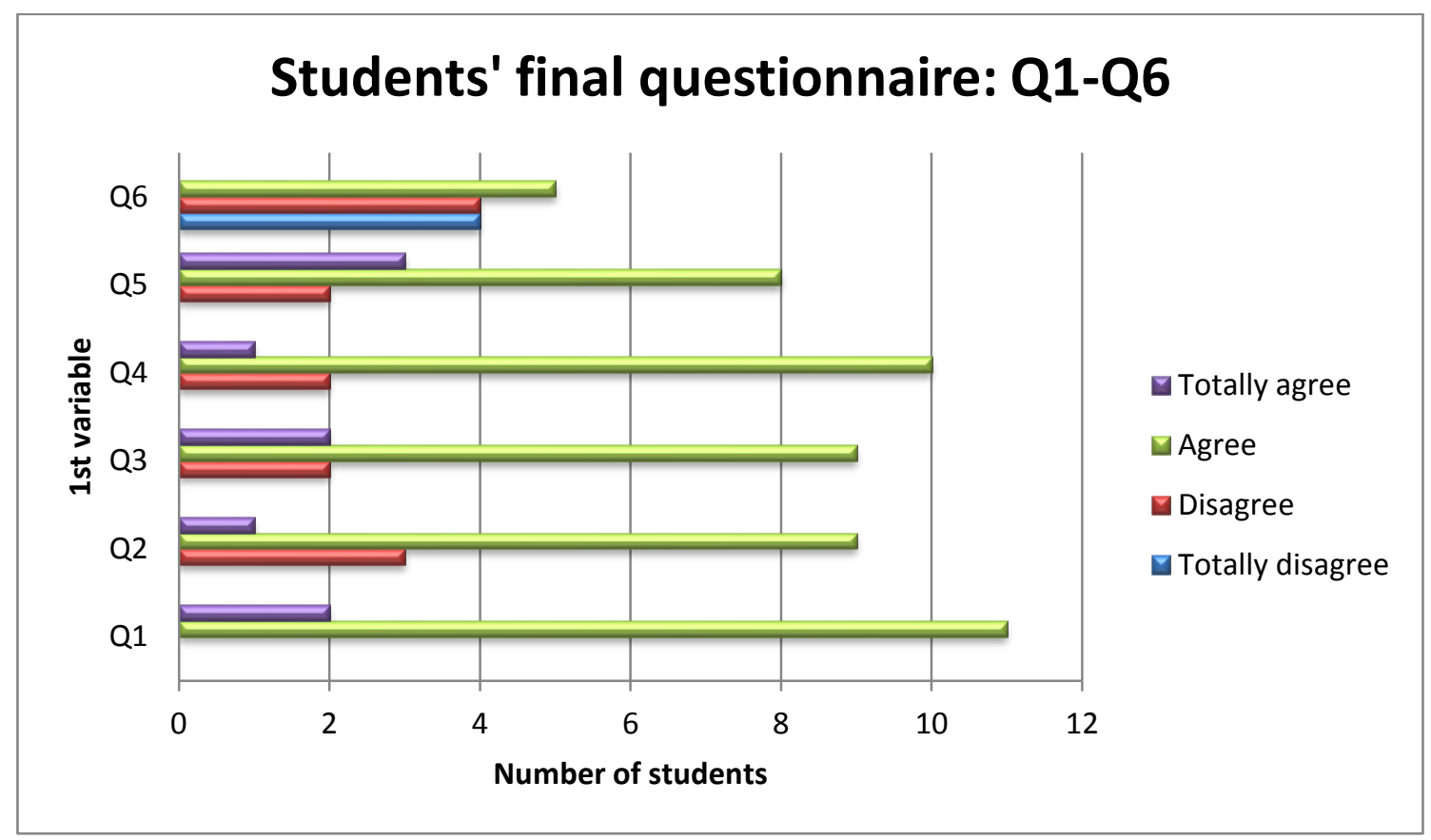

Figure 8. Results from students' final questionnaire (Q1-Q6): First-year Medicine students.

In relation to Q7, all the participants account for the adjustment of the English language exposure to the requirements of the module (see Figure 9). However, 76.9\% of them still prefer learning disciplinary knowledge in their mother tongue, as seen in Q8. As to Q9, only 10 out of the 13 respondents held an official certificate that specified they mastered the target language at B1 (23.08\%), B2 (46.18\%) and C1 (15.38\%) levels. The 3 remaining participants had no official certificates $(15.38 \%)$. None of the students neglected the practical uses of English in this field in Q10. Clear examples include coping with patients and working abroad, as shown in the comments below, which have been reproduced with errors. 
(28) SX1: To talk with the pacients ${ }^{2}$.

(29) SX2: Because in the future I probably want to be a doctor abroad.

Evidence may also be found in excerpt 30. In this case, it is emphasised that there are more opportunities to earn a-higher-than-average salary when having a good command of the English language.

(30) Because if you can speak English fluently and using a wide range of vocabulary, you will always have more chances of getting better jobs and earning more money.

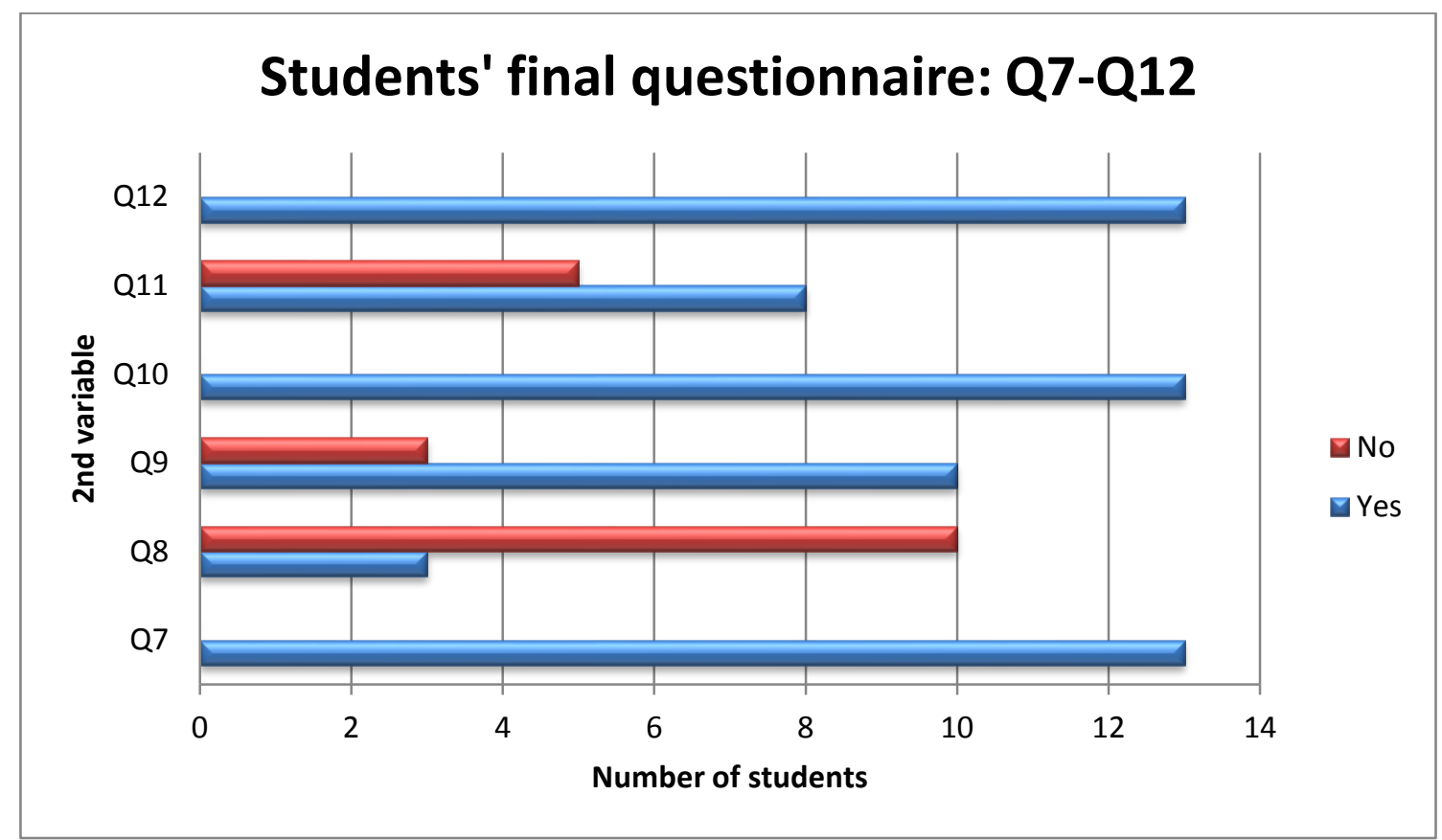

Figure 9. Results from students' final questionnaire (Q7- Q13): First-year Medicine students.

In keeping with their previous learning experiences with CLIL programmes, only $61.5 \%$ of the students had coursed these modules during their Baccalaureate studies. As specified in Q11, these initiatives were mainly taught throughout the academic year, but they could also involve oral performances or didactic units. No negative experiences through the CLIL approach were recorded. Rather, a positive correlation between their attitudes towards the English language and the beneficial effects on their learning has been found in Q12. This is the case of the following excerpt written by a medical student:

(31) Because it pushes me out from my comfort zone but at the same time I am learning things in another language, so it is double gain.

\footnotetext{
${ }^{2}$ Students responses have been reproduced without altering them or correcting any grammatical mistakes.
} 
As for Q13, the number of CLIL modules offered within the Medicine degree is not known by $84.6 \%$ of the participants. This rate happens to be higher when it comes to the information given about the institutional ECOPOL Plan before enrolment (100\%), as evidenced in Q14a and Q14b. This is the reason why they thought that a B1 level in English was necessary before admission to university in Q14c.

Following with the responses of second-year undergraduate students in the Medicine degree, around $75 \%$ of them showed their agreement with Q1 (see Figure 10). In other words, the methodological procedure was thought to be appropriate in the CLIL learning environment. Even though the number of subjects finding activities unappealing is slightly higher in Q2 (25\%), all of them admit the usefulness of CLIL seminars in Q3. With reference to Q4, the suitability of online resources aiming at upgrading and practising disciplinary contents corresponds to $75 \%$. Notwithstanding, all of them acknowledge the provision of useful materials so as to achieve the learning outcomes of the seminar. Noticeably, this teaching practice has not posed any challenges to the students, as indicated in Q6.

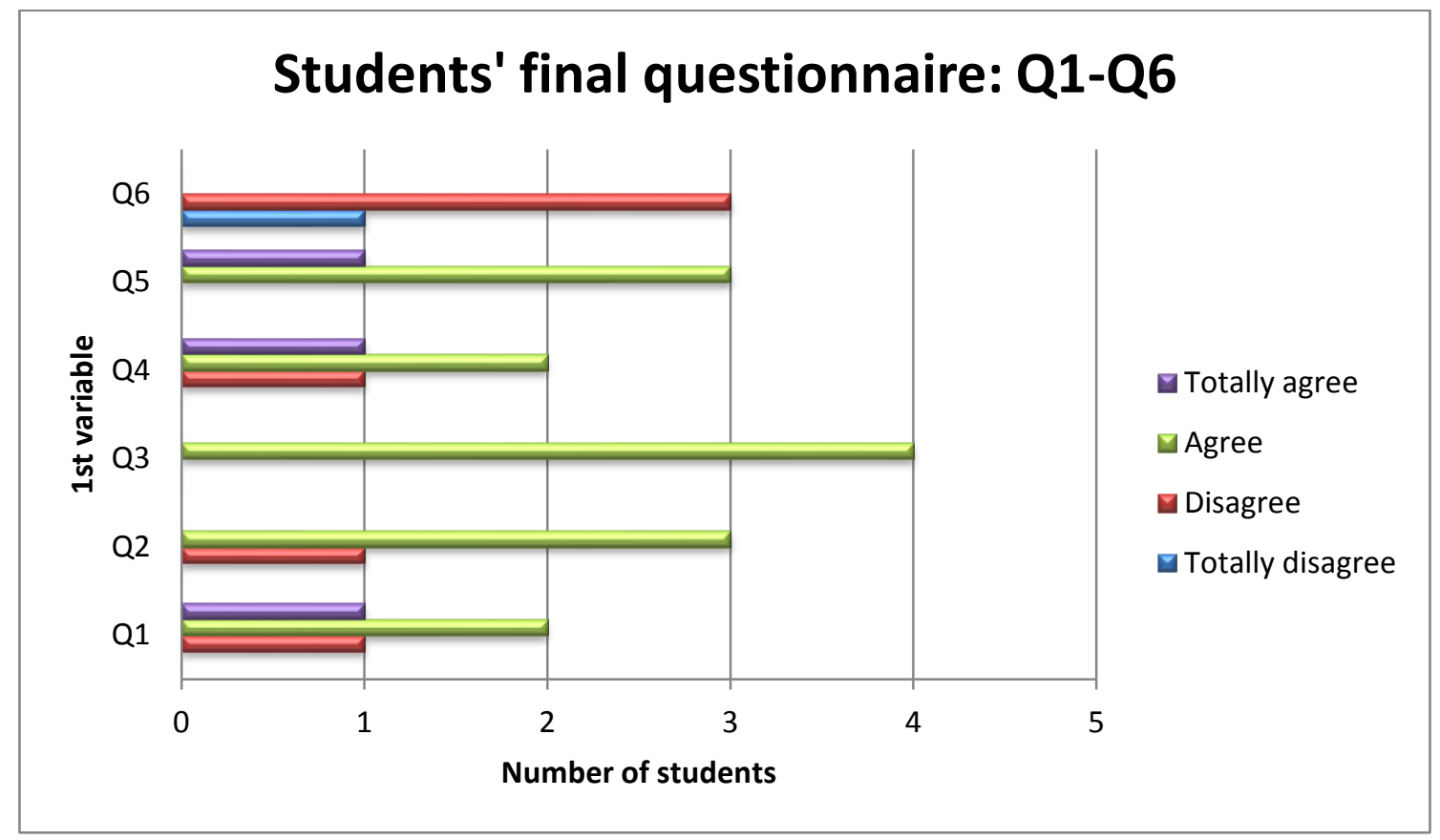

Figure 10. Results from students' final questionnaire (Q1-Q6): Second-year Medicine students.

Concerning Q7, 25\% of the students believe the activities and exposure to the English language do not meet the requirements of the module since they would like to be involved in more participative and interactive lessons (see Figure 11). Likewise, 25\% of the participants did not agree with the item in Q8 and would prefer learning through 
their L1. These findings may be related to those in Q9, where the respondents owned A2 $(25 \%), B 1(50 \%)$ and B2 $(25 \%)$ certificates in the English language. Bearing this in mind, there is no doubt that English plays a significant role in Healthcare settings, as ratified by all the surveyed students in Q10. As with first-year Medicine students in this field, second-year learners pointed to doctor-patient communication and better employment opportunities as key factors in the medical profession. This is clearly illustrated in the comments made by some medical students.

(32) SX1: Medicine is a globalised profession, and new treatments, materials, machines, etc. are constantly being studied and discovered, and these studies are usually carried out in English. $\mathrm{t}$ is also important for people to communicate with each other, even if you work or study in an area where English is not the official language. [SX1: La medicina es una profesión muy globalizada, continuamente se están estudiando y descubriendo nuevos tratamientos, materiales y máquinas entre otros y se suelen hacer estos estudios en inglés generalmente. Además, para la comunicación con la gente también es importante, aún que se trabaje o se estudie en una zona en la que en inglés no sea la lengua oficial].

(33) SX2: On the one hand, because the medical profession involves you personally with many people who may speak a different language and you need to communicate with them. Because it is a language that may offer opportunities in the labour market. [SX2: Por un lado porque la profesión de médico te expone al trato personal con muchas personas que pueden que hablen otro idioma distinto y tengas la necesidad de comunicarte. Porque es una herramienta para abrir futuras puertas laborales].

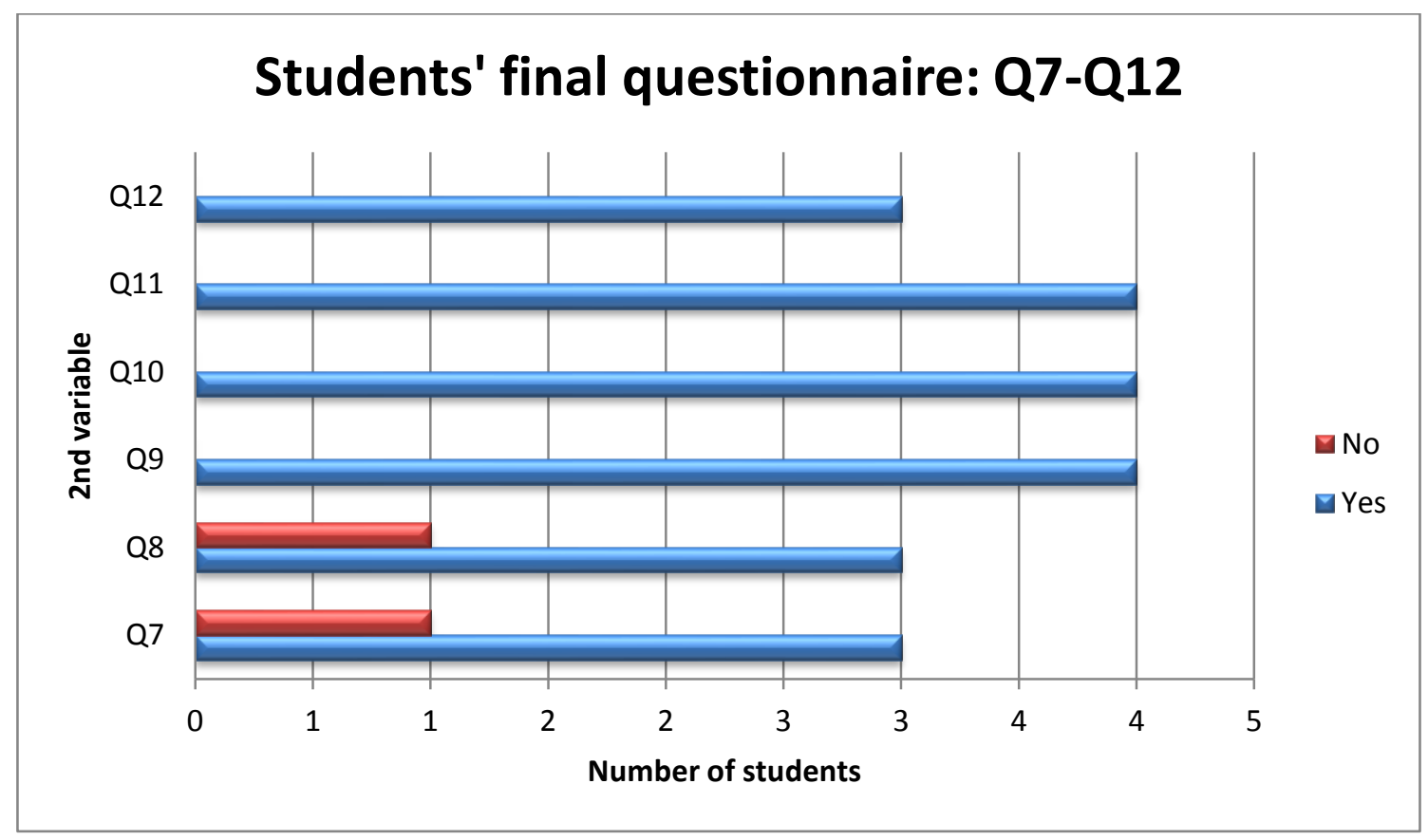

Figure 11. Results from students' final questionnaire (Q7- Q13): Second-year Medicine students. 
As to Q11, a wide range of students admitted having coursed CLIL programmes in previous years. The most common practices were delivered throughout the academic year or as part of didactic units. In this regard, interaction took place by means of group work, either discussions about research articles or oral assignments. The findings in Q12 reveal that $75 \%$ of the subjects had positive feelings about their foreign language learning. Evidence may be found in excerpt 34, where one of the respondents agreed he had improved their communicative competence in the target language.

(34) SX3: It encourages you to surpass yourself, and although at the beginning you think you might not be able to give a presentation in English before your classmates, you manage to do so by making some effort and your level improves a lot. [Te hace superarte a ti mismo, y aunque al principio crees que no puedes ser capaz de hacer una presentación en inglés a tu grupo, con esfuerzo lo consigues y tu nivel mejora mucho].

These participants also stressed that none of them were aware of the modules in which English is one of the languages of instruction, as seen in Q13. These results lead us to think that second-year Medicine students had not checked the Academic Information System available on the web in advance, as it is in this platform where information with regard to the languages of instruction is available. The results are exactly the same for Q4, where it was noticed that these university members had not been informed about the institutional ECOPOL Plan throughout their academic life.

Turning to the third-year in the Medicine degree, the responses in Q1 suggest that the methodology is appropriate for almost $66.67 \%$ of the students (see Figure 12), although $33.33 \%$ disagree with activities being attractive. The same is true for Q3, which seem to deny the usefulness of these CLIL seminars. When it comes to Q4, the implementation of ICTs in the classroom setting does not meet students' standards on the grounds that these resources are not employed for the revision of contents. According to $66.67 \%$ of these participants, the materials have promoted the achievement of the learning outcomes set in the curriculum of this module, as reported in Q5. With reference to Q6, over $66.67 \%$ of the learners did not have a hard time using English as the means of instruction. 


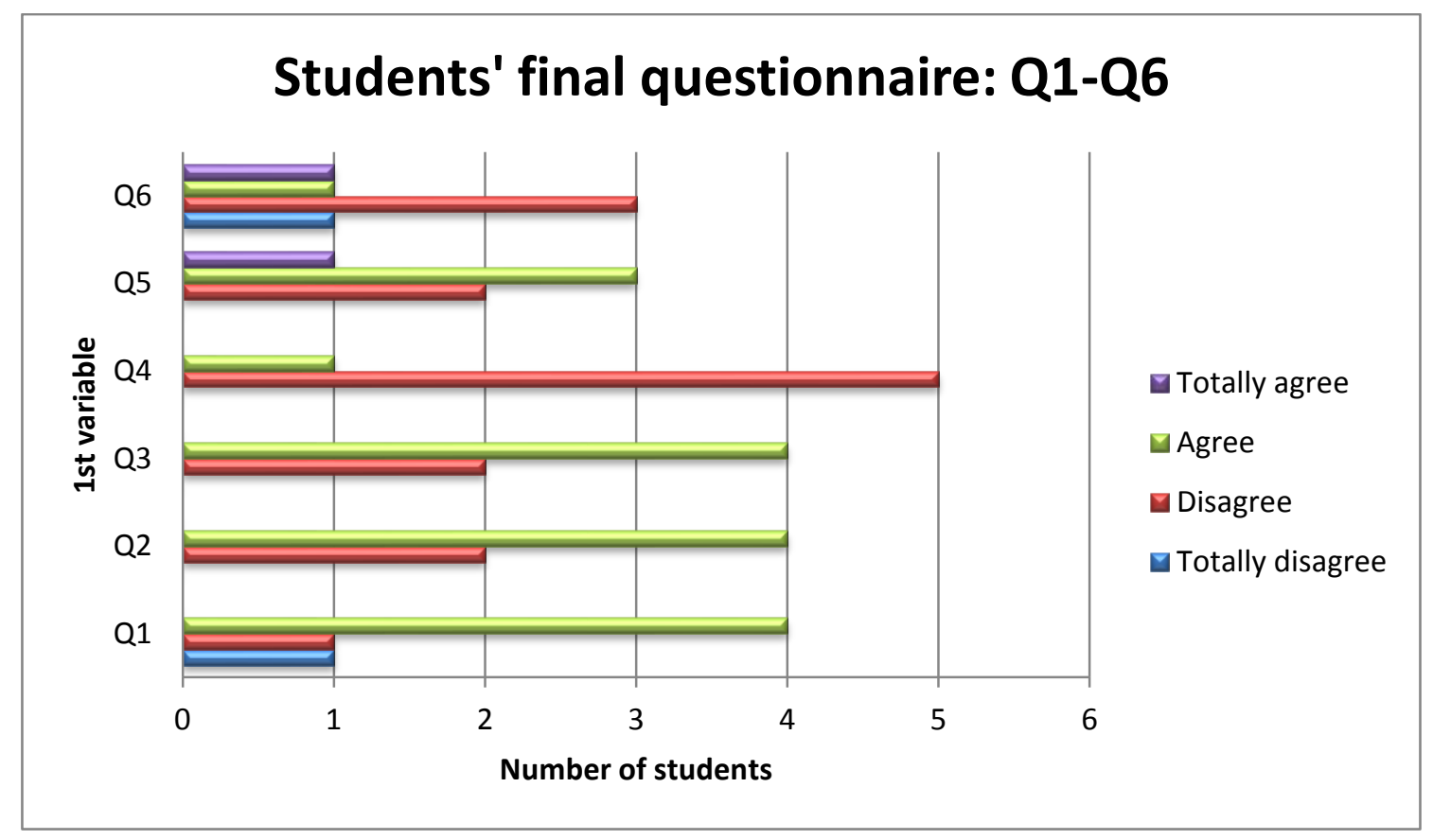

Figure 12. Results from students' final questionnaire (Q1-Q6): Third-year Medicine students.

In relation to Q7, the linguistic and interactions demands of the module were accomplished, as stated by over $66.67 \%$ of the respondents (see Figure 13). In this regard, one of them claims that their proficiency level in the target language when enrolling the module is not the problem, but their basic training during their Secondary and Baccalaureate studies. The same number of students showed their agreement with the item in Q8 and would get involved in modules where a language other than Spanish and Catalan is employed as a vehicular language. Such results go in line with those students having an official certificate in English, which according to Q9 included learners with B1 and B2 language certificates. 


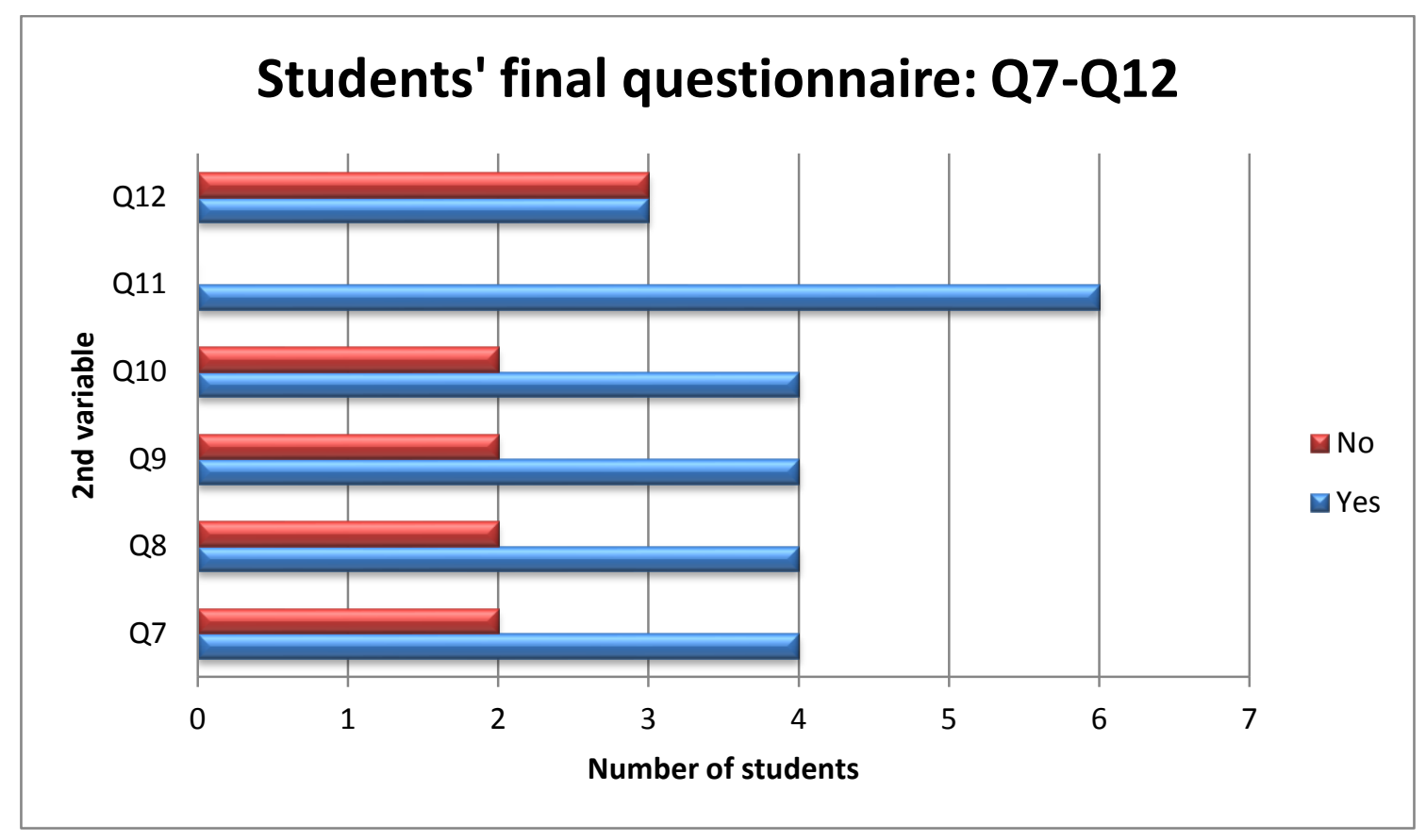

Figure 13. Results from students' final questionnaire (Q7- Q13): Third-year Medicine students.

With respect to Q10, it is evident that the role of English is not underestimated by the whole group of participants since they know that the scientific research is mostly published in this international language. As for Q11, all of them had undertaken CLIL programmes in early years on the grounds that they are not fresher students. However, negative aspects have also been noted by $50 \%$ of the subjects, who stress these initiatives have been useless. As with other Humanities, Social Sciences and Health Science students who replied Q13 and Q14, the number of students who gets to know the total amount of CLIL modules as well as the multilingual premises devised by the university are almost non-existent.

\subsubsection{Nursing}

Focusing on the Nursing area, it seems that interactional patterns should be reinforced within the methodology implemented in the CLIL classroom given that $55.56 \%$ of the students disagree with the statement in Q1 (see Figure 14). The findings in Q2 resemble those obtained in the previous item. In this case, the activities carried out in the seminar session have been unappealing for $44.44 \%$ of the learners. CLIL seminars have been regarded as effective for the construction of knowledge in Q3, where the rate involves $55.56 \%$ of positive answers. A closer look at $\mathrm{Q} 4$ denotes that the implementation of ICTs seems to be deficient, as signalled by $77.78 \%$ of the respondents. Despite these unexpected results, the preparation and transfer of resources and materials have served learning purposes in the specialised domain of Nursing, as identified in Q5. In 
recognising attitudinal factors in Q6, 33.33\% of the participants admitted that CLIL initiatives were troublesome due to the use of a foreign language.

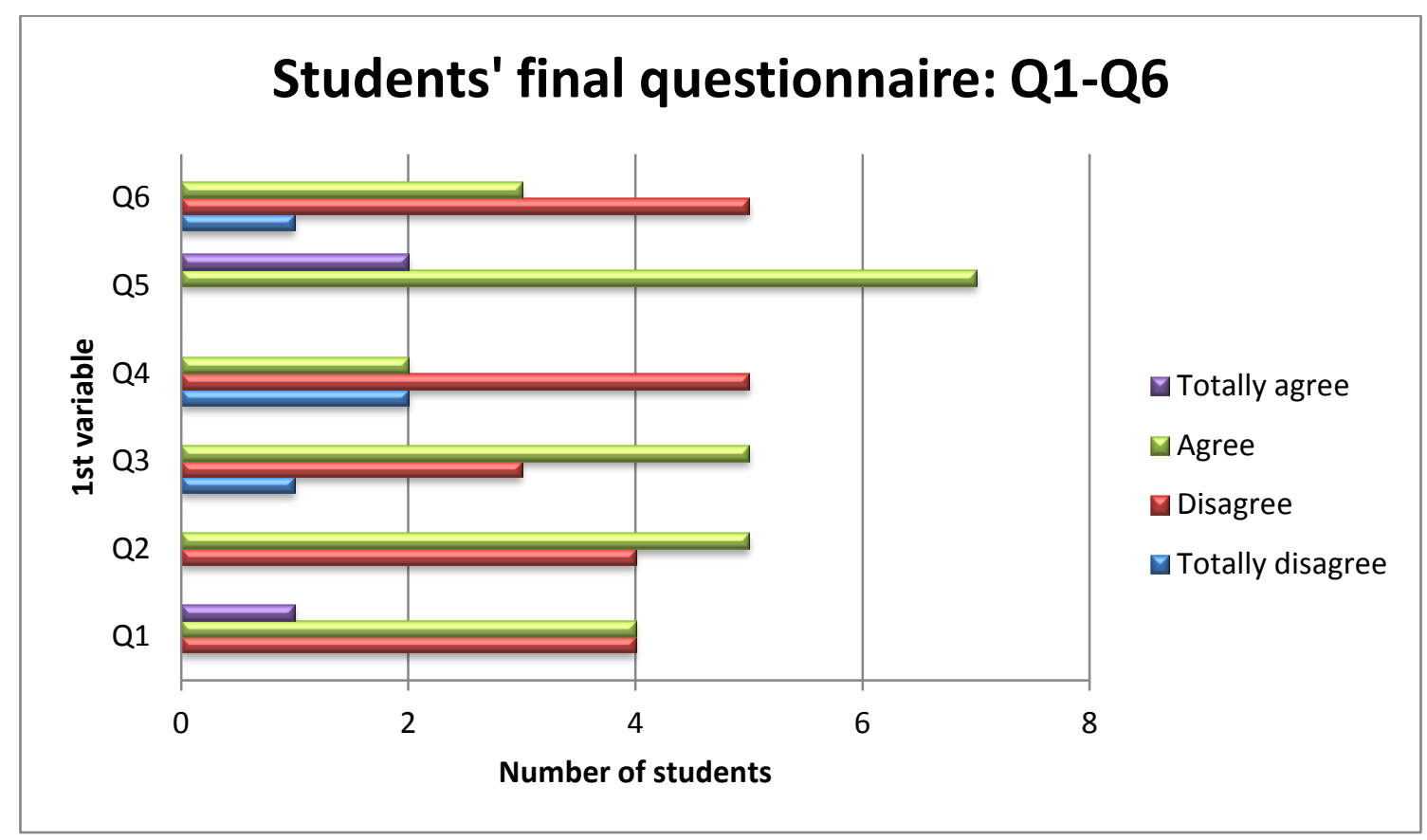

Figure 14. Results from students' final questionnaire (Q1-Q6): Third-year Nursing students.

Moving on to Q7, 77.78\% of the participants feel the objectives of the module are achieved in terms of language use and assignments (see Figure 15). Notwithstanding, there are explicit indications that $55.56 \%$ of the subjects are likely to go for modules taught in English, as shown in Q8. The communicative skills in this foreign language is described in Q9, where 7 out 9 Nursing students were basic and intermediate users with A2 (57.14\%) and B1 (42.86\%) language level certificates respectively. In the case of Q10, the relevance of English is remarkable for $88.89 \%$ of the learners due to the use of specialised terminology in this area of expertise. Job prospects were also a significant factor taken into account, as can be observed in the excerpt below:

(35)SX1: If you work in Spain it is not that relevant, but if you want to work abroad it is. [SX1: Si trabajas en España no mucho, pero si quieres trabajar en otros sitios, sí]. 


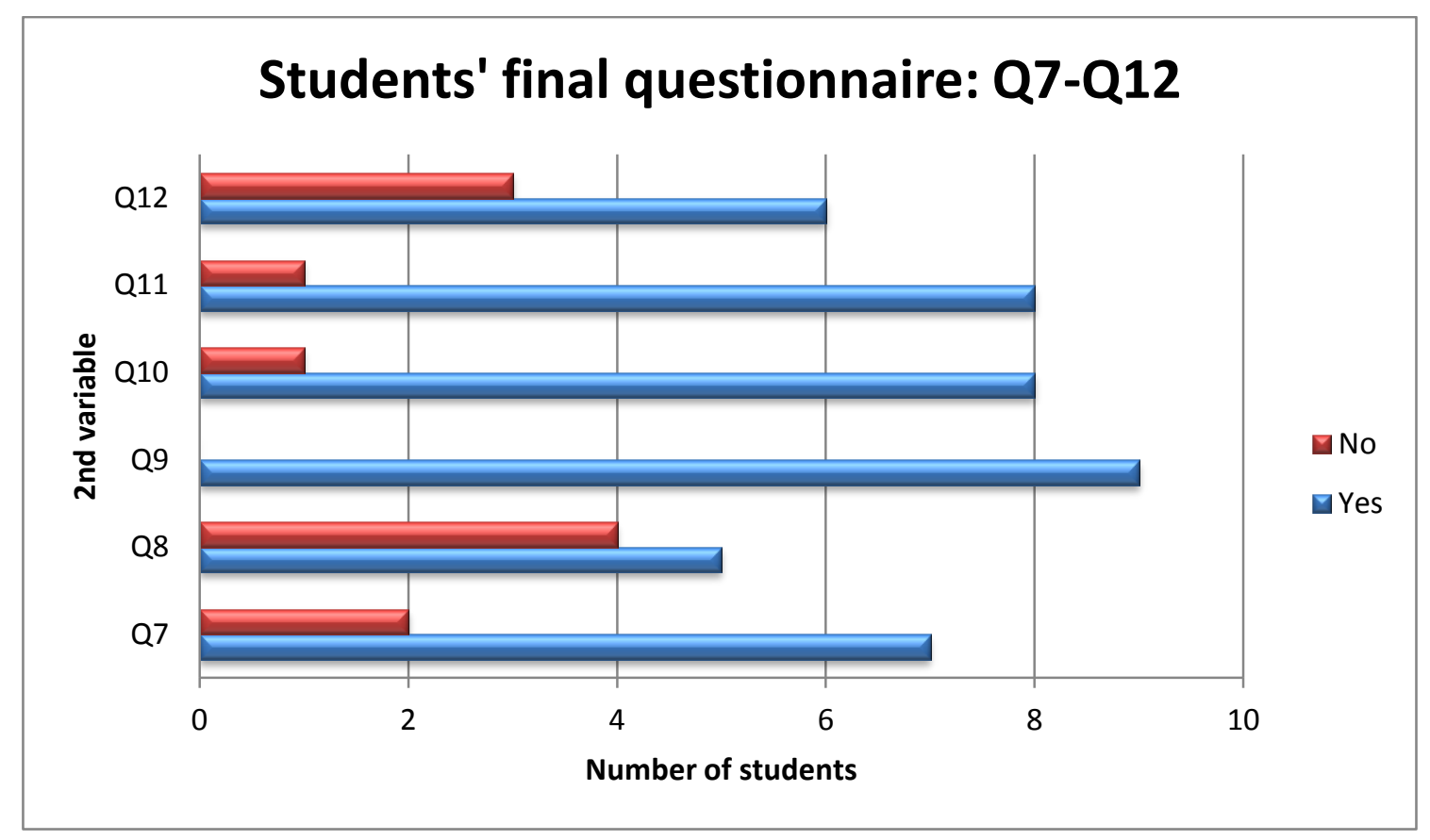

Figure 15. Results from students' final questionnaire (Q7- Q13): Third-year Nursing students.

Being third-year undergraduate students, some background on the CLIL approach was expected in Q11. Nevertheless, $11.11 \%$ of the students said they had never taken this type of modules. Most of them had received CLIL instruction throughout semesters or academic years. Other programmes consisted of oral presentations and didactic units. In addition, $66.67 \%$ of the participants reflected on their learning by subscribing its positive outcomes in Q12. As in other degrees, Q13 reveals that $77.78 \%$ of learners failed to check their degree's curriculum and thus discriminate CLIL modules. Besides, from the reports on Q13 and Q14a, it can be assumed that the premises included in the ECOPOL Plan were not presented to students when accessing the university for the first time.

\subsubsection{Psychology}

Last but not least, approximately $84.62 \%$ of the subjects involved in the Psychology degree support the methodological procedure followed in the learning environment, as shown in Q1 (see Figure 16). As reported in Q2, that rate is moderately lower when it comes to doing stimulating activities $(80.77 \%)$. Such results help students perceive the quality and value of CLIL seminars in Q3, which rises to $88.46 \%$. New technologies are integrated in the CLIL classroom for revision purposes, as indicated by $96.15 \%$ of the respondents when tackling Q4. Similar results have been obtained in Q5, where the resources they have been supplied with seem to be but ideal for the attainment of psychological concepts. As far as attitudes towards the target language are concerned, a 
considerable number of CLIL learners made a great effort to keep up with the seminar, as evidenced in Q6. Whereas this proportion stands at $46.25 \%$, the remaining percentage of students assured they had no difficulties in taking part in these instructional practices.

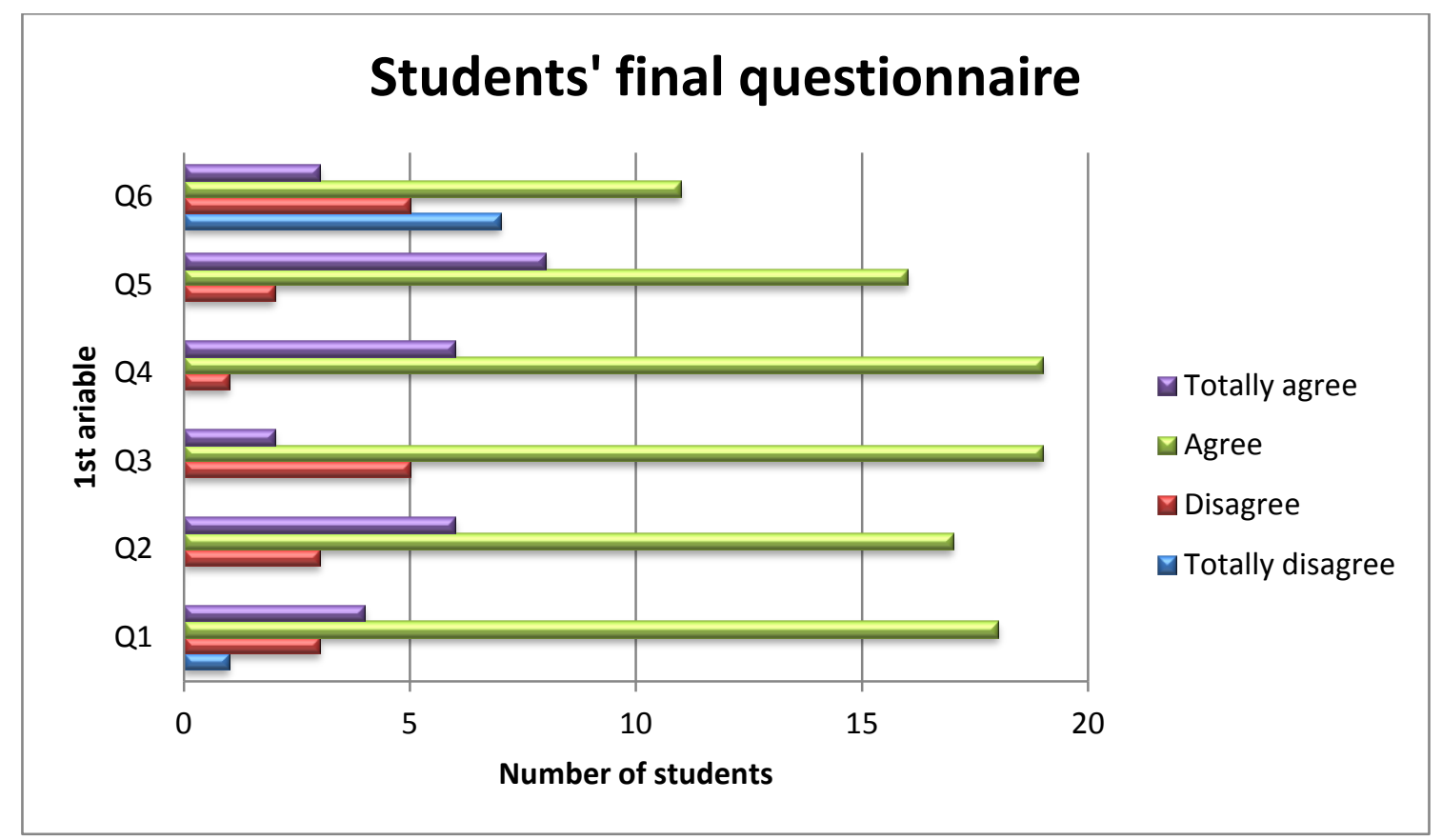

Figure 16. Results from students' final questionnaire (Q1-Q6): Fourth-year Psychology students.

According to Q7, the number of participants who are convinced of the compliance with the linguistic requirements of the module is that of $96.2 \%$ (see Figure 17). A reduced $3.8 \%$ of the subjects did not agree with that statement and considered that the level should be lower since the command of the target language happens to be heterogeneous. In spite of these results, the replies for Q8 ratify that $65.4 \%$ of the learners showed a preference for their mother tongue as the language of instruction in comparison with the rest of CLIL students who were keen on learning through English. Therefore, it can be suggested that there is not a decisive trend for the use of this international language among near-to-be psychologists. 


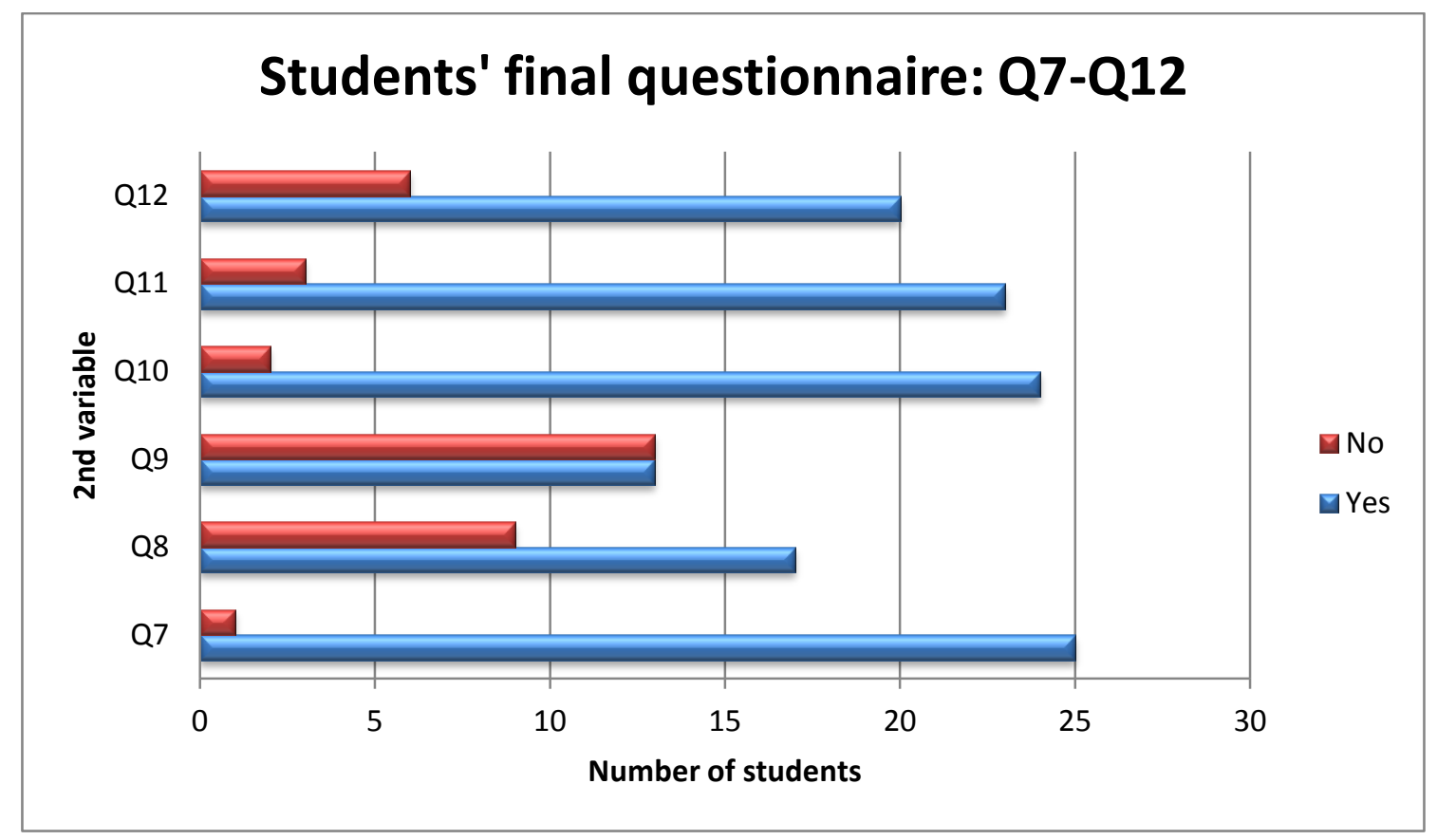

Figure 17. Results from students' final questionnaire (Q7- Q13): Fourth-year Psychology students.

As regards their English language mastery in Q9, only 16 out of the 26 undergraduate students who answered the questionnaire got an official A1 (7.69\%), A2 (23.08\%), B1 (11.54\%) and B2 (19.23\%). Professionally speaking, English is relevant in this field of study. On that account, $92.3 \%$ of the students found it relevant in Q10, which goes in line with the findings discussed in the field of Humanities. References to the availability of psychological research in this language as well as communication are two of the most repeated reasons given by students. Other examples include the mastery of this language for academic or vocational purposes and even refer to Catalan as can be read in the following comments:

(36) SX1: In order to get grants or take competitive public examinations. [SX1: Para conseguir becas u opositar].

(37) SX2: Scientific literature, and by extension psychological literature, is published in English on a daily basis. If you want to keep up to date in any field of work you are interested in, articles are meant to be read in English. Otherwise, you should wait for them to be translated and compiled in handbooks that will probably be out of date by then. The availability of literature in Valencian is even scarcer. On the other hand, I do not think I will be writing or speaking in English in my working life. [SX2: Toda la literatura científica y, por ende, la psicológica que se publica diariamente está en inglés. Para estar actualizado de en el ámbito de trabajo en el que se esté, se debe leer los artículos en inglés o esperar a que se traduzca y se compile en manuales que probablemente para entonces estén desfasados. En valenciano la oferta aún es menor. Por otra parte, dudo que vaya a escribir o hablar en inglés en mi día a día profesional]. 
As fourth-year undergraduate students undertaking an elective module, $88.5 \%$ had previous CLIL experiences, either in high school or at university. Their learning background implied reading research articles and performing oral presentations for the most part, as seen in Q11. Such learning impact has been positively valued by $76.9 \%$ of the subjects since they find communication in English enriching in terms of comprehension and expansion of vocabulary. Those who find these practices tedious point to internal factors. Clear examples include the nervousness generated by the command of the target language and the perception of these initiatives as compulsory, as can be read in excerpts 38 and 39 that follow:

(38) SX3: The truth is I haven't had a positive experience learning through English because I do not have a good command of the language and I get more nervous. [SX3: La verdad que no, ya que no lo domino bien, y me pongo más nerviosa].

(39) SX4: Learning English is boring, I see it as an obligation and not as a learning process for my own improvement. [SX4: Me aburre aprender inglés, lo veo como una obligación y no como un aprendizaje de mejora].

Despite all these results, it is surprising that only $23.1 \%$ of the respondents state they get to know the number of modules delivered through this approach. From these findings in Q13, it can be suggested that Psychology students are not familiar with their degree's curriculum, which they can all access through the university Academic Information System. In line with this, the number of students who were informed about the ECOPOL Plan prior enrolment is even lower (7.7\%), as shown in Q14a. What these participants knew had to do with instruction being conducted in Spanish or Catalan and the obligation to course some credits in English. Nonetheless, all the respondents ignored the linguistic requirements they had to comply with as university members. Having a B1 level in English to grant access to the Master's degree in Secondary Education, Vocational Training and Language Teaching and receiving CLIL instruction in a maximum of $5 \%$ of the degree's credits were some of their assumptions.

\subsubsection{Humanities and Social Sciences vs. Health Sciences}

Overall, the findings obtained from students' final survey in the areas of Humanities, Social Sciences and Health Sciences disciplines deserve consideration. Linked to the first variable referring to foreign language learning experiences, the results indicate that there is a general trend for showing agreement in the first five items (Q1-Q5) related to the instructional methodologies. Accordingly, students seem to be pleased with the 
methodology implemented in these learning environments. Notwithstanding, different points of view can be observed in Q6: These practical sessions were more difficult compared to other teaching practices due to the English language. It is evident that fourth-year undergraduate students in the History and Tourism degrees are likely to find CLIL programmes less complicated than students who are coursing first-year modules in the History domain. The fact that students enrolled in advanced years might have had the opportunity to become familiar with this this type of initiatives may be one of the possible interpretations for these results. As for Health Sciences disciplines, the option totally disagree has not been selected by Medicine, Nursing and Psychology participants in Q2-Q5. The absence of extremes is especially remarkable in the responses obtained from third-year Medicine students. This leads us to think that CLIL programmes could still be refined in order to improve the quality of the learning process. Nonetheless, it should be pointed out that the materials provided by the teacher appear to be useful in the CLIL classroom, as reported by second-year Medicine students and third-year Nursing students. Actually, no disagreement or total disagreement has been identified in Q5 referring to the adequacy of the materials provided by the teacher. In line with the responses obtained in Humanities and Social Sciences, Medicine and Nursing participants can generally follow instruction without much effort in the last year of their degrees. This is not the case in the field of Psychology, where a large number of students struggle when being taught through this approach.

As regards the second variable, which focuses on learners' attitudes towards CLIL pedagogies, first-year and fourth-year History students' answers in Q7 and Q8 are rather similar. Most of them consider that exposure to the foreign language meets the requirements of the module, but over half of the students would still prefer L1 instruction. Such findings may be linked to the number of participants who, according to their official language certificates, mastered the language at A2, B1 or B2 levels in most cases. In the case of Tourism, it should be pointed out that no disagreement was found in Q7: Do you think the activities and exposure to the English language meet the requirements of the module? Contrary to the responses given by History students in Q8, the inclination towards the use of English as a means of communication in Tourism may be directly associated with the international scope of this sector. Unlike History students, the language mastery of Tourism students included a higher number of intermediate and advanced speakers thanks to the presence of international students, and 
more specifically to European students. Spanish and Asian students were mostly basic users of the target language and some of them did not have proofs of their language proficiency. Focusing on Health Sciences, most students agree on Q7 when dealing with the activities and exposure to the English language meeting the requirements of the module. However, first-year Medicine students' preference for modules where languages other than students' mother tongue are employed as the means of communication is noteworthy. Second-year, third-year and fourth-year students in the Medicine, Nursing and Psychology degrees are prone to implement their L1 as the vehicular language in the learning process. These findings hint that the new generations who access university degrees seem to value positively the exposure to foreign languages. The command of the target language varies to a great extent not only among Humanities and Tourism students, but also among Medicine, Nursing and Psychology learners. In the Medicine degree, learners are quite proficient as they master the language at B1, B2, and C1 levels. No B2 or higher levels have been observed in Nursing, whose international certifications involve A2 and B1 levels. Psychology students, on the other hand, reported that they had official certificates at A1, A2, B1 and B2 levels. Although not all of the participants in the Humanities, Social Sciences and Health Sciences domains could formally prove their communicative skills in the target language, the vast majority acknowledged the role of English in our society and were pleased with their CLIL experiences.

When it comes to the variable dealing with institutional information on language policies, there is a common tendency in the fields of Humanities, Social Sciences and Health Sciences. It can be clearly observed that most students fail to check their programme of studies, all of them available on the university Academic Information System. Aside from that, striking results in Q14 made it clear that efforts should be made to inform undergraduate students about the premises included in the institutional language policy with regard to the use of English as a language of instruction in higher education. 


\subsection{Placement Tests}

The assessment of students' communicative abilities is an essential support tool to both language and content specialists. The purpose of these language testing practices is to get to know students' needs in the target language so that lecturers can adapt their speech in the CLIL classroom. Thus, effective classroom discourse may not be hindered by poor written or oral skills (Fulcher, 1997). Despite the fact that the English placement tests administered to students focused on grammatical and lexical items, the results are linked to Q9 in the survey which refers to the possession of international certificates.

\subsubsection{Humanities and Social Sciences}

As stated by first-year undergraduate students who had an official English language certificate in historical and humanistic domains, their foreign language skills stood at A2, B1, B2 and C1 levels (see Table 30). The findings obtained once the placement test was conducted for all the participants highlighted the heterogeneity of the CLIL group. Their command of the target language was placed at A1 (4.76\%), A2 (20.93\%), B1 $(32.56 \%), \mathrm{B} 2(21.42 \%), \mathrm{C} 1(16.67 \%)$ and even $\mathrm{C} 2(2.38 \%)$ levels, at least from a lexico-grammatical point of view. Therefore, it could be noted that basic and lowintermediate users may face some kind of comprehension and production problems in the content classroom. On the other hand, when it comes to History students coursing a fourth-year module, their command of the English language involved the use of grammar and vocabulary at A2 (17.85\%), B1 (42.86\%), B2 (32.14\%), C1 (3.57\%) levels. These findings do not seem to be consistent with their interaction in the History classroom, where Spanish and Catalan were the preferred vehicular languages.

Table 30. Results from the placement tests administered in the fields of Humanities and Social Sciences.

\begin{tabular}{|l|c|c|c|c|c|c|}
\hline \multirow{2}{*}{ MODULES } & \multicolumn{6}{c|}{ Language levels \% } \\
\cline { 2 - 7 } & A1 & A2 & B1 & B2 & C1 & C2 \\
\hline History of the Classical World & $4.76 \%$ & $20.93 \%$ & $32.56 \%$ & $21.42 \%$ & $16.67 \%$ & $2.38 \%$ \\
\hline $\begin{array}{l}\text { Fundamentals and Theory of Artistic } \\
\text { Heritage }\end{array}$ & - & $17.86 \%$ & $42.86 \%$ & $32.14 \%$ & $3.57 \%$ & - \\
\hline Valencian art and Tourist Resources & - & $25 \%$ & $29.17 \%$ & $33.33 \%$ & $8.33 \%$ & $4.17 \%$ \\
\hline
\end{tabular}

Within the field of Tourism, the mastery of the target language was significantly heterogeneous, not only between local and international students but also between 
European and Asian students. Based on students' responses, they got A2, B1, B2 and C1 levels. In the case of Spanish learners, 23.08\% of the subjects got an A2 level, whereas the rate of students with a B1 or a B2 level rises to $46.15 \%$ and $30.77 \%$ respectively. On the other hand, the number of participants with a higher proficiency level is related to European rather than Asian students. In fact, it was observed that 7 out of 11 international students who came from Germany, Turkey, France and The Netherlands and participated in the study were B2 (36.37\%), C1 (18.18\%) and C2 (9.09\%) speakers of English. As to the exchange students coming from Asia, a lower command of the target language was identified since their performance resulted in A2 $(27.27 \%)$, and B1 $(9.09 \%)$ levels. Such scores seem to be in line with the production of oral outcomes in their CLIL sessions, which will be described in the next chapter.

\subsubsection{Health Sciences}

As for first-year undergraduate students in the Medicine degree, the questionnaire results unveiled that 10 of them held official B1, B2 and C1 certificates (see Table 31). From the results of the placement tests, it could be noted that such language mastery upgraded to B2 (30.77\%), C1 (38.46\%) and C2 (30.77\%) levels when dealing with grammar and vocabulary. Even though these findings would suggest that all of them can follow a module delivered in English, the CLIL practice was more difficult than usual for roughly $38.46 \%$ of the students, as discussed in the former questionnaire section. In other words, their knowledge with regard to their professional and academic needs, such as medical processes and specific terminology in English, happens to be more complex than their general knowledge of the language, which is concerned with their overall English competence.

Table 31. Results from the placement tests administered in the field of Health Sciences.

\begin{tabular}{|l|c|c|c|c|c|c|}
\hline \multirow{2}{*}{ MODULES } & \multicolumn{6}{c|}{ Language levels \% } \\
\cline { 2 - 7 } & A1 & A2 & B1 & B2 & C1 & C2 \\
\hline English for Medicine & - & - & - & $30.77 \%$ & $38.46 \%$ & $30.77 \%$ \\
\hline Anthropology and Evolution & - & - & $25 \%$ & $50 \%$ & $25 \%$ & - \\
\hline Epidemiology and Public Health & - & - & - & $40 \%$ & $60 \%$ & - \\
\hline Women's care & - & - & $11.11 \%$ & $11.11 \%$ & $77.78 \%$ & - \\
\hline Social and Affective Neuroscience & $7.69 \%$ & $7.69 \%$ & $30.77 \%$ & $23.08 \%$ & $30.77 \%$ & $7.69 \%$ \\
\hline
\end{tabular}

Regarding the Outcomes Placement Test administered to Medicine learners undertaking a second-year module, students' command of the target language was measured at B1 
(25\%), B2 (50\%) and C1 (25\%) levels. As with the responses obtained in Humanities, Social Sciences and Health Sciences, students appear to be better at grammar and vocabulary abilities in comparison with the official certificates they hold, which comprise A2 (25\%), B1 (50\%) and B2 (25\%) levels. A closer look at third-year Medicine students' answers shows similar trends. Whereas they acknowledged being intermediate users of the English language with B1 and B2 language certificates, their placement test scores raised to B2 (40\%), and C1 (60\%) levels.

Turning to the Nursing degree, the incidence of students achieving a $\mathrm{C} 1$ level $(77.78 \%)$ was substantially higher than those performing at a B1 $(11.11 \%)$ or B2 $(11.11 \%)$ level. That is the reason why most of them stated they would be included to get involved in CLIL modules. Nonetheless, these results are quite unexpected on the grounds of both reading-aloud practices and translanguaging instances observed in the learning environment.

Last but not least, Psychology students asserted that their language mastery achievements were at A1 (7.69\%), A2 (23.08\%), B1 (11.54\%), B2 (19.23\%) levels. Those who had no certificates represented $38.46 \%$. After completion of the placement test, their command of the English language turned out to be at A1 (7.69\%), A2 (7.69\%), B1 (30.77\%), B2 (23.08\%) and C1 (30.77\%) levels. Contrary to second-year and third-year Medicine and Nursing students, a wide range of Psychology students prefer L1 instruction, which is unexpected since over $84 \%$ of the subjects are able to understand the language at intermediate and advanced levels.

\subsubsection{Humanities and Social Sciences vs. Health Sciences}

The results obtained in the placement tests show that a high number of students in the three fields of study have a good command of the language from a lexico-grammatical point of view. Nonetheless, striking differences can be observed in the fields of Humanities, Social Sciences and Health Science, with medical students outperforming students enrolled in other disciplines (see Table 32). Over half of first-year History students $(53.98 \%)$ master the language at an intermediate level, whereas $25.69 \%$ and $19.05 \%$ happen to be basic and advanced speakers respectively. In contrast to the suvey's responses given by 29 undergraduates who claimed having official certificates in Q9, the findings from the placement test, filled in by 43 History students, reveal that the group is much more heterogeneous than expected. Approximately $53.49 \%$ of the 
participants are perceived as low intermediate or upper intermediate speakers of English. Thus, these findings denote that they may be more competent from a lexicogrammatical point of view.

Lower foreign language levels have been found in the placement tests answered by fourth-year History students, whose lexico-grammatical mastery corresponds to A2 (25\%), B1 (42.86\%), B2 (32.14\%) and C1 (3.57\%). Such language levels have also been identified in the Tourism degree, where subjects got A2 (25\%), B1 (29.17\%), B2 (29.17\%), C1 (8.33\%) and C2 (4.17\%) levels, with international European students surpassing Asian and Spanish students. The fact that a limited number of students held an official certificate may be correlated with the absence of basic and advanced user levels in the questionnaires examined.

As to Medicine results, the attainment of language levels appears to be subject to the degree year students are coursing. First-year Medicine learners seem to have a higher knowledge of grammar and vocabulary with B2 (30.77\%), C1 (38.46\%) and C2 (30.77\%) levels. Second-year students got B1 (25\%), C1 (50\%) and C2 (25\%) levels, whereas third-Medicine students obtained B2 (40\%) and C1 (60\%) levels. From these results it could be interpreted that trends for higher levels are likely to occur in the earlier degree years of this disciplinary area. However, a large number of responses would be necessary to confirm this hypothesis. As for Nursing, B1 (11.11\%) or B2 (11.11\%), C1 level $(77.78 \%)$ levels were obtained from nine students who filled in the placement tests. These findings suggest that Nursing students might have a higher English proficiency level than the one they have accredited. As with first-year History students and fourth-year Tourism students, a wide range of language levels were obtained in the Psychology classroom, including A1 (7.69\%), A2 (7.69\%), B1 (30.77\%), B2 (23.08\%) and C1 (30.77\%) levels. These results pointed out that learners could communicate as intermediate and advanced users of English.

All in all, it could be stated that CLIL learners who happen to have a better command of the target language are those involved in Health Sciences, particularly medical students. The communicative abilities of Nursing students is also at an advanced level, whereas a broad range of language levels can be observed in the responses of future Psychologist, History and Tourist specialists. These findings may be due to the higher number of subjects undertaking the placement test. 
Table 32. Results obtained from the placement tests administered in the fields of Humanities, Social Sciences and Health Sciences.

\begin{tabular}{|r|c|c|c|c|}
\hline \multirow{2}{*}{ Language levels } & \multicolumn{2}{|c|}{ Humanities and Social Sciences } & \multicolumn{2}{c|}{ Health Sciences } \\
\cline { 2 - 5 } & Questionnaire (level) & Placement test & Questionnaire (level) & Placement test \\
\hline A1 & - & $2.13 \%$ & $3.57 \%$ & $3.57 \%$ \\
\hline A2 & $12.77 \%$ & $22.34 \%$ & $19.64 \%$ & $3.57 \%$ \\
\hline B1 & $\mathbf{1 5 . 9 6 \%}$ & $\mathbf{3 6 . 1 7 \%}$ & $21.43 \%$ & $17.86 \%$ \\
\hline B2 & $11.70 \%$ & $27.66 \%$ & $\mathbf{3 0 . 3 6 \%}$ & $26.79 \%$ \\
\hline C1 & $2.13 \%$ & $10.64 \%$ & $3.57 \%$ & $\mathbf{4 2 . 8 6 \%}$ \\
\hline C2 & - & $2.13 \%$ & - & $7.14 \%$ \\
\hline No recognised level & $\mathbf{3 9 . 3 6 \%}$ & - & $\mathbf{1 9 . 6 4 \%}$ & - \\
\hline
\end{tabular}




\subsection{Classroom Practices}

This section presents the results obtained through the analysis of interpersonal markers in CLIL discourse transcripts, which were counted by means of Lextutor (Cobb, n.d.). These included engagement markers, attitudinal markers, hedges, boosters, collocations, fixed expressions or multi-word units operating as interpersonal devices, as illustrated in Table 33.

Table 33. Metadiscoursal markers analysed in the fields of Humanities, Social Sciences and Health Sciences.

\begin{tabular}{|c|c|c|}
\hline \multirow{11}{*}{ 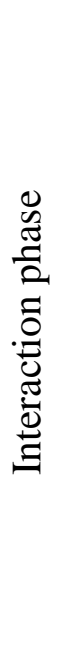 } & \multirow[t]{8}{*}{ Engagement markers } & Questions \\
\hline & & Imperatives \\
\hline & & Directives \\
\hline & & Comprehension comments \\
\hline & & Apologetic comments \\
\hline & & Contextual comments \\
\hline & & Behavioural comments \\
\hline & & Inclusive comments \\
\hline & Attitudinal markers & \\
\hline & Boosters & \\
\hline & Hedges & \\
\hline
\end{tabular}

First of all, the findings observed in the fields of Humanities and Social Sciences are discussed and followed by an overview of those identified in Health Sciences. Afterwards, the data taken from the three disciplinary areas are compared to answer the research questions posed in this study. Samples of interpersonal markers produced by both teachers and students will be provided, these being classified in the subcategories included in the taxonomy presented in Chapter 5 (p.92). Some of these linguistic items may fall into different interactional categories depending on contextual factors, thereby operating as multifunctional resources (Fung \& Carter, 2007; Bazzanella \& Morra, 2000). Metadiscoursal markers in English, Spanish and Catalan have been taken from the CLIL programmes investigated at Universitat Jaume I. Instances in Spanish and Catalan may be minimal or irrelevant in the final count of words processed in the corpus, but they have included as their incidence may differ to a certain extent in some domains. 


\subsubsection{Humanities and Social Sciences}

The results examined in the fields of Humanities and Social Sciences indicate that the occurrence and variety of interpersonal markers are subject to disciplinary conditions as well as to teachers' and students' communicative competence. The overall quantitative frequency of engagement markers, attitudinal markers, hedges and boosters found in the corpus are shown in the tables and figures below. Accordingly, no marker differences are presented here (see Table 34).

Table 34. Total number of metadiscoursal markers found in teacher discourse in Humanities and Social Sciences.

\begin{tabular}{|c|c|c|c|c|}
\hline \multicolumn{5}{|c|}{ TEACHER DISCOURSE IN CLIL LECTURES AND SEMINARS } \\
\hline \multirow[b]{2}{*}{ Modules } & \multicolumn{2}{|c|}{ Lectures } & \multicolumn{2}{|c|}{ Seminars } \\
\hline & $\begin{array}{l}\text { Number of } \\
\text { instances }\end{array}$ & $\%$ & $\begin{array}{l}\text { Number of } \\
\text { instances }\end{array}$ & $\%$ \\
\hline History of the Classical World & 573 & 57.01 & 73 & 7.26 \\
\hline Fundamentals and Theory of Artistic Heritage & - & - & 186 & 18.51 \\
\hline $\begin{array}{r}\text { Total Humanities } \\
10,051 w\end{array}$ & 573 & 57.01 & 260 & 25.87 \\
\hline Valencian art and Tourist resources & 608 & 49.25 & 93 & 7.53 \\
\hline $\begin{array}{r}\text { Total Social Sciences } \\
12,346 \mathrm{w}\end{array}$ & 608 & 49.25 & 93 & 7.53 \\
\hline $\begin{array}{r}\text { Total Soft Sciences } \\
22,397 w\end{array}$ & 1,181 & 52.73 & 353 & 15.39 \\
\hline
\end{tabular}

In Figure 18 it can be seen that a considerable number of linguistic resources are employed in the CLIL lecture seminar implemented in the Tourism degree. Such occurrence is slightly lower in the History of the Classical World module, and absent in the speech of the Fundamentals and Theory of Artistic Heritage lecturer since no similar practice had been conducted in the classroom setting. Notwithstanding, the frequency of metadiscoursal markers appears to be higher in the first-year History module, as observed in the table above. These findings seem to be altered in CLIL seminars, where a wider range of interpersonal markers can be recognised in the fourth year of the History and Heritage degree, probably due to the introduction and discussion of videos. 


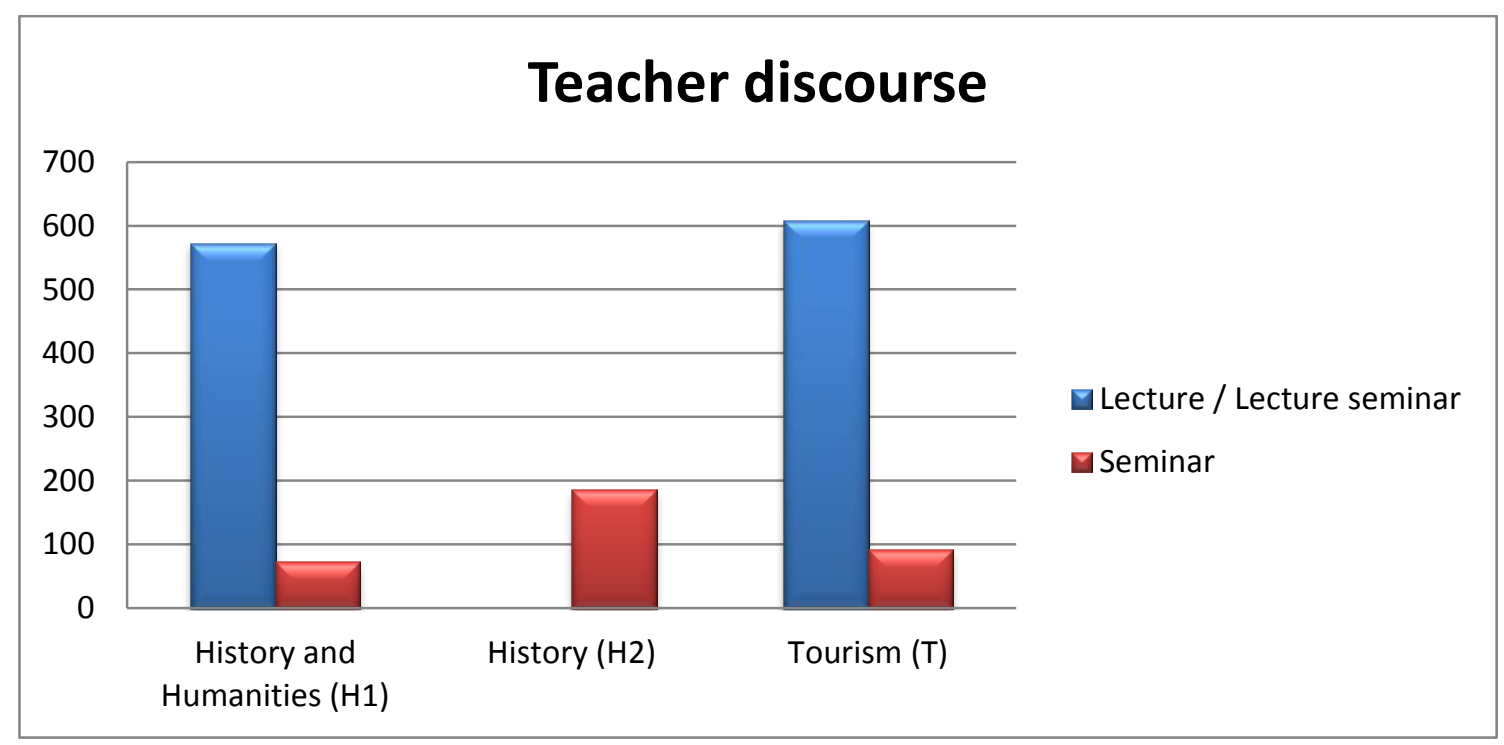

Figure 18. Total number of metadiscoursal markers in teacher discourse: CLIL lectures and seminars in Humanities and Social Sciences.

The proportion of students' spoken outcomes in the teaching practices compiled in the corpus is illustrated in Table 35. The type of academic genres implemented in the classroom setting may affect the extent to which engagement markers, attitudinal markers, hedges and boosters occur in student discourse.

Table 35. Total number of metadiscoursal markers found in teacher discourse in Humanities and Social Sciences.

\begin{tabular}{|c|c|c|c|c|}
\hline \multicolumn{5}{|c|}{ STUDENT DISCOURSE IN CLIL LECTURES AND SEMINARS } \\
\hline \multirow[b]{2}{*}{ Module } & \multicolumn{2}{|c|}{ Lectures } & \multicolumn{2}{|c|}{ Seminars } \\
\hline & $\begin{array}{l}\text { Number of } \\
\text { instances }\end{array}$ & $\%$ & $\begin{array}{l}\text { Number of } \\
\text { instances }\end{array}$ & $\%$ \\
\hline History of the Classical World & 59 & 5.87 & 529 & 52.53 \\
\hline Fundamentals and Theory of Artistic Heritage & - & - & 61 & 6.87 \\
\hline $\begin{array}{r}\text { Total Humanities } \\
10,051 w\end{array}$ & 59 & 5.87 & 590 & 59.40 \\
\hline Valencian art and Tourist resources & 14 & 1.13 & 592 & 47.55 \\
\hline $\begin{array}{r}\text { Total Social Sciences } \\
12,346\end{array}$ & 14 & 1.13 & 592 & 47.55 \\
\hline $\begin{array}{r}\text { Total Soft Sciences } \\
22,397\end{array}$ & 73 & 3.18 & 1,192 & 53.22 \\
\hline
\end{tabular}


As can be noticed in Figure 19, students' participation in CLIL lectures or lecture seminars seem to be scarce, even though History undergraduates are prone to include a higher number of metadiscoursal elements in their discourse than their Tourism counterparts. This tendency varies in CLIL seminars since the fourth-year History module has also been considered. In this vein, the wider variety of interpersonal instances is uttered by first-year History and Humanities undergraduates, closely followed by Tourism students. The fact that these linguistic resources considerably decrease in fourth-year History learners' speech denotes that exposure to comprehensible input and opportunities for outcome production should be promoted in multilingual university settings.

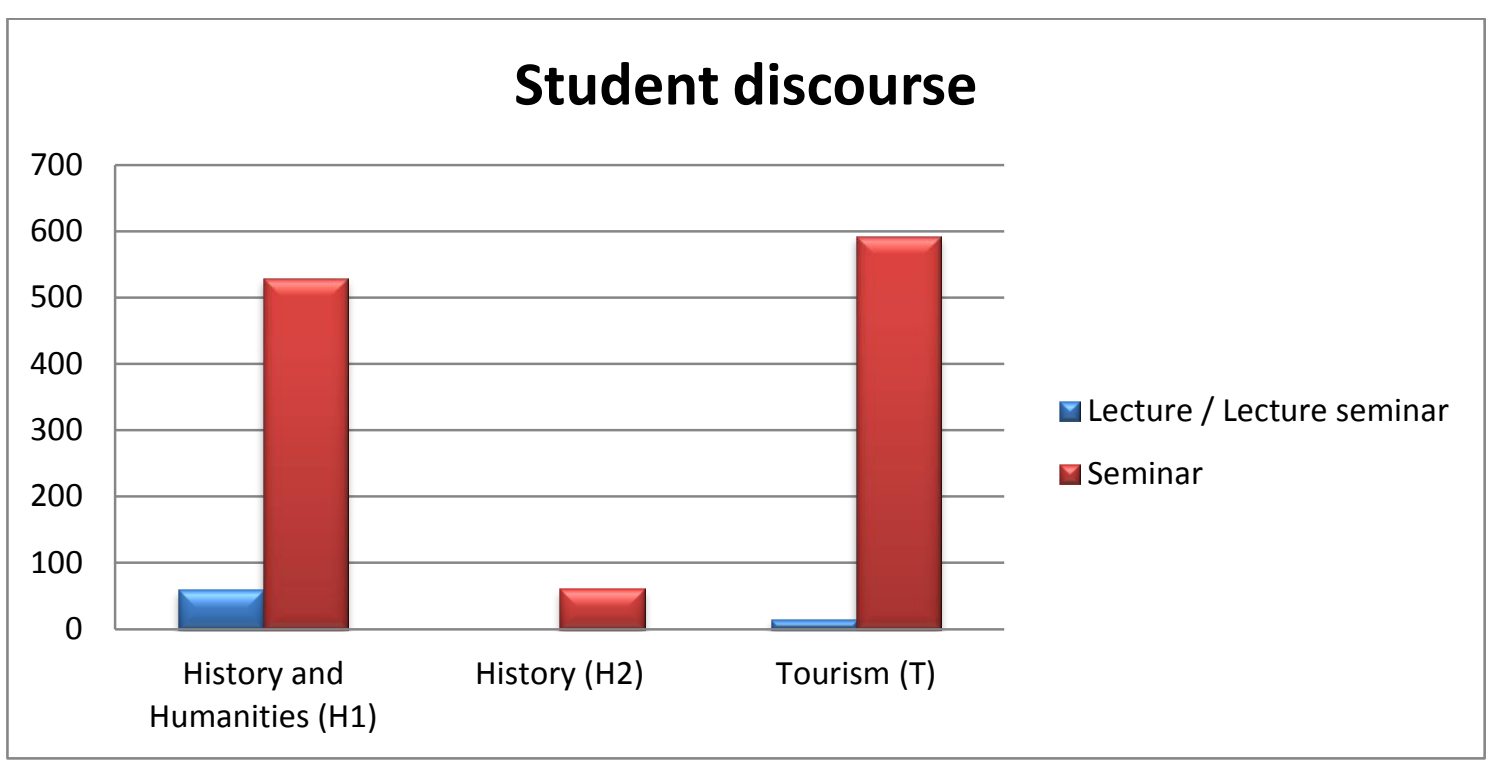

Figure 19. Total number of metadiscoursal markers in student discourse: CLIL lectures and seminars in Humanities and Social Sciences.

A closer look at the following tables can give us a broader spectrum of the similarities and differences between lecturers' and students' discourse. Given that two different classroom practices were recorded in the History of the Classical World and Valencian art and Tourist resources modules, the results have been distributed based on the academic genre registered, that is, lectures or seminars.

Table 36 displays the number of metadiscoursal devices encountered in the CLIL lectures or lecture seminars belonging to the History and Heritage, Humanities and Tourism degrees where marker differences are presented. Engagement devices seem to be more recurrent in teacher discourse, with a lower occurrence of hedges, attitudinal markers and boosters in both lecture and seminar sessions. When it comes to lectures, it 
appears that there are no significant differences in the areas under study (i.e. History and Humanities, and Tourism). The findings indicate that engagement markers and hedges seem to be more frequent in the History lecturer speech, even though there are no significant differences with the lecture delivered in the field of Tourism. The opposite applies for attitudinal markers and boosters since a higher number of these linguistic features was spotted in Tourism. The provision of comprehensible input took place in English for the most part, but Spanish was also used at some point to increase students' participation in classroom discourse.

Even though the total number of metadiscoursal features is considerably lower in CLIL seminars, engagement markers and hedges remained the most recurrent categories in teacher discourse (see Table 37). Unlike lecture discourse, the presence of more than one vehicular language is remarkable. The data reveal that the amount of engagement markers identified in English is akin in the three disciplines, whereas the use of Spanish markers is especially notable in the fourth-year History module. The rate of hedging and attitudinal devices is slightly similar in the History and Humanities when uttered in English. In contrast, it is in the fourth-year module taught in the History degree where the use of the Spanish language stands out. Interaction in this language may be linked to the lecturer's confidence in her command of the target language, as reported in the interviews' section. Therefore, the frequency of metadiscoursal elements in Spanish should come as no surprise. The extent to which the Catalan language was used almost indiscernible as only six engagement markers and one hedging case were observed.

As to student discourse, Tables 38 illustrates students' contributions, where engagement markers were detected as the most frequent devices in CLIL lectures. Hedges, attitudinal markers and boosters came as the second, third and fourth most typical categories in the fields of Humanities and Social Sciences. These interpersonal patterns were performed in English, except for attitudinal markers, which were also articulated in Spanish and Catalan. What is evident is that a larger number of interpersonal instances were distinguished in CLIL seminars, with engagement markers and hedges holding the first and second positions (see Table 39). The remaining devices, which correspond to attitudinal markers and boosters, were the least frequent in classroom discourse. This preference for hedges over boosters is consistent with the findings revealed by Livingstone (2019) and Takimoto (2015) on the use of metadiscoursal markers in academic articles. 
Table 36. Use of different markers in teacher discourse in Humanities and Social Sciences: Lecture / Lecture seminars.

\begin{tabular}{|c|c|c|c|c|c|c|c|c|c|c|c|c|c|c|c|c|c|c|c|c|c|c|c|c|}
\hline \multicolumn{25}{|c|}{ TEACHER DISCOURSE IN CLIL LECTURES / LECTURE SEMINARS } \\
\hline \multirow{2}{*}{ Modules } & \multicolumn{6}{|c|}{ Engagement markers } & \multicolumn{6}{|c|}{ Attitudinal markers } & \multicolumn{6}{|c|}{ Hedges } & \multicolumn{6}{|c|}{ Boosters } \\
\hline & Eng & $\%$ & $\mathrm{Sp}$ & $\%$ & Cat & $\%$ & Eng & $\%$ & $\mathrm{Sp}$ & $\%$ & Cat & $\%$ & Eng & $\%$ & $\mathrm{Sp}$ & $\%$ & Cat & $\%$ & Eng & $\%$ & Sp & $\%$ & Cat & $\%$ \\
\hline $\begin{array}{l}\text { History of the Classical } \\
\text { World }\end{array}$ & 434 & 43.18 & 3 & 0.30 & - & - & 27 & 2.69 & - & - & - & - & 103 & 10.25 & - & - & - & - & 6 & 0.60 & - & - & - & - \\
\hline $\begin{array}{l}\text { Fundamentals and } \\
\text { Theory of Artistic } \\
\text { Heritage }\end{array}$ & - & - & - & - & - & - & - & - & - & - & - & - & - & - & - & - & - & - & - & - & - & - & - & - \\
\hline $\begin{array}{r}\text { Total Humanities } \\
10,051 w\end{array}$ & 434 & 43.18 & 3 & 0.30 & - & - & 27 & 2.69 & - & - & - & - & 103 & 10.25 & - & - & - & - & 6 & 0.60 & - & - & - & - \\
\hline $\begin{array}{l}\text { Valencian art and } \\
\text { Tourist resources }\end{array}$ & 337 & 27.30 & 1 & 0.08 & - & - & 131 & 10.61 & 3 & 2.41 & - & - & 92 & 7.46 & - & - & - & - & 44 & 3.26 & - & - & - & - \\
\hline $\begin{array}{r}\text { Total Social Sciences } \\
12,346 w\end{array}$ & 337 & 27.30 & 1 & 0.08 & - & - & 131 & 10.61 & 3 & 2.41 & - & - & 92 & 7.46 & - & - & - & - & 44 & 3.26 & - & - & - & - \\
\hline $\begin{array}{r}\text { Total Soft Sciences } \\
22,397 w\end{array}$ & 771 & 34.42 & 4 & 0.18 & - & - & 158 & 7.06 & 3 & 0.13 & - & - & 195 & 8.71 & - & - & - & - & 50 & 2.32 & - & - & - & - \\
\hline
\end{tabular}


Table 37. Use of different markers in teacher discourse in Humanities and Social Sciences: Seminars.

\begin{tabular}{|c|c|c|c|c|c|c|c|c|c|c|c|c|c|c|c|c|c|c|c|c|c|c|c|c|}
\hline \multicolumn{25}{|c|}{ TEACHER DISCOURSE IN CLIL SEMINARS } \\
\hline \multirow{2}{*}{ Module } & \multicolumn{6}{|c|}{ Engagement markers } & \multicolumn{6}{|c|}{ Attitudinal markers } & \multicolumn{6}{|c|}{ Hedges } & \multicolumn{6}{|c|}{ Boosters } \\
\hline & Eng & $\%$ & $\mathrm{Sp}$ & $\%$ & Cat & $\%$ & Eng & $\%$ & $\mathrm{Sp}$ & $\%$ & Cat & $\%$ & Eng & $\%$ & $\mathrm{Sp}$ & $\%$ & Cat & $\%$ & Eng & $\% 0$ & $\mathrm{Sp}$ & $\%$ & Cat & $\%$ \\
\hline $\begin{array}{l}\text { History of the } \\
\text { Classical World }\end{array}$ & 47 & 5.57 & - & & 2 & 0.20 & 4 & 0.40 & - & - & - & - & 10 & 0.99 & - & - & - & - & 1 & 0.10 & - & - & - & - \\
\hline $\begin{array}{l}\text { Fundamentals and } \\
\text { Theory of Artistic } \\
\text { Heritage }\end{array}$ & 57 & 5.67 & 90 & 8.95 & 4 & 0.40 & 5 & 0.50 & 10 & 0.99 & - & - & 1 & 0.10 & 11 & 1.09 & 1 & 0.10 & - & - & 7 & 0.70 & - & - \\
\hline $\begin{array}{r}\text { Total } \\
\text { Humanities } \\
\mathbf{1 0 , 0 5 1 w}\end{array}$ & 113 & 11.24 & 91 & 8.95 & 6 & 0.60 & 9 & 0.90 & 10 & 0.99 & & & 11 & 1.09 & 11 & 1.09 & 1 & 0.10 & 1 & 0.10 & 7 & 0.70 & - & - \\
\hline $\begin{array}{l}\text { Valencian art and } \\
\text { Tourist resources }\end{array}$ & 44 & 3.56 & 31 & 2.51 & - & - & 6 & 0.49 & - & - & - & - & 8 & 0.65 & 2 & 0.16 & - & - & - & - & 2 & 0.16 & - & - \\
\hline $\begin{array}{r}\text { Total Social } \\
\text { Sciences } \\
12,346 w\end{array}$ & 44 & 3.56 & 31 & 2.51 & - & - & 6 & 0.49 & - & - & - & - & 8 & 0.65 & 2 & 0.16 & - & - & - & - & 2 & 0.16 & - & - \\
\hline $\begin{array}{r}\text { Total Soft } \\
\text { Sciences } \\
22,397 w\end{array}$ & 148 & 6.61 & 122 & 5.45 & 6 & 0.27 & 15 & 0.67 & 10 & 0.45 & - & - & 19 & 0.85 & 13 & 0.58 & 1 & 0.04 & 1 & 0.04 & 9 & 0.40 & - & - \\
\hline
\end{tabular}


Table 38. Use of different markers in student discourse in Humanities and Social Sciences: Lecture / Lecture seminars.

\begin{tabular}{|c|c|c|c|c|c|c|c|c|c|c|c|c|c|c|c|c|c|c|c|c|c|c|c|c|}
\hline \multicolumn{25}{|c|}{ STUDENT DISCOURSE IN CLIL LECTURES / LECTURE SEMINARS } \\
\hline \multirow{2}{*}{ Modules } & \multicolumn{6}{|c|}{ Engagement markers } & \multicolumn{6}{|c|}{ Attitudinal markers } & \multicolumn{6}{|c|}{ Hedges } & \multicolumn{6}{|c|}{ Boosters } \\
\hline & Eng & $\%$ & $\mathrm{Sp}$ & $\%$ & Cat & $\%$ & Eng & $\%$ & $\mathrm{Sp}$ & $\%$ & Cat & $\%$ & Eng & $\%$ & $\mathrm{Sp}$ & $\%$ & Cat & $\%$ & Eng & $\%$ & $\mathrm{Sp}$ & $\%$ & Cat & $\%$ \\
\hline $\begin{array}{l}\text { History of the Classical } \\
\text { World }\end{array}$ & 20 & 1.99 & 18 & 1.79 & 4 & 0.40 & 3 & 0.30 & 2 & 0.20 & 1 & 0.10 & 11 & 1.09 & - & - & - & - & - & - & - & - & - & - \\
\hline $\begin{array}{l}\text { Fundamentals and Theory } \\
\text { of Artistic Heritage }\end{array}$ & - & - & - & - & - & - & - & - & - & - & - & - & - & - & - & - & - & - & - & - & - & - & - & - \\
\hline $\begin{array}{r}\text { Total Humanities } \\
10,051 w\end{array}$ & 20 & 1.99 & 18 & 1.79 & 4 & 0.40 & 3 & 0.30 & 2 & 0.20 & 1 & 0.10 & 11 & 1.09 & - & - & - & - & - & - & - & - & - & - \\
\hline $\begin{array}{l}\text { Valencian art and Tourist } \\
\text { resources }\end{array}$ & 3 & 0.24 & 4 & 0.32 & - & - & 1 & 0.08 & 1 & 0.08 & - & - & 5 & 0.41 & - & - & - & - & - & - & - & - & - & - \\
\hline $\begin{array}{r}\text { Total Social Sciences } \\
12,346 \mathrm{w}\end{array}$ & 3 & 0.24 & 4 & 0.32 & - & - & 1 & 0.08 & 1 & 0.08 & - & - & 5 & 0.41 & - & - & - & - & - & - & - & - & - & - \\
\hline $\begin{array}{r}\text { Total Soft Sciences } \\
22,397 \mathrm{w}\end{array}$ & 23 & 1.34 & 22 & 0.98 & 4 & 0.18 & 4 & 0.18 & 3 & 0.14 & 1 & 0.04 & 16 & 0.71 & - & - & - & - & - & - & - & - & - & - \\
\hline
\end{tabular}


Table 39. Use of different markers in student discourse in Humanities and Social Sciences: Seminars.

\begin{tabular}{|c|c|c|c|c|c|c|c|c|c|c|c|c|c|c|c|c|c|c|c|c|c|c|c|c|}
\hline \multicolumn{25}{|c|}{ STUDENT DISCOURSE IN CLIL SEMINARS } \\
\hline \multirow{2}{*}{ Modules } & \multicolumn{6}{|c|}{ Engagement markers } & \multicolumn{6}{|c|}{ Attitudinal markers } & \multicolumn{6}{|c|}{ Hedges } & \multicolumn{6}{|c|}{ Boosters } \\
\hline & Eng & $\%$ & $\mathrm{Sp}$ & $\%$ & Cat & $\%$ & Eng & $\%$ & $\mathrm{Sp}$ & $\%$ & Cat & $\%$ & Eng & $\%$ & $\mathrm{Sp}$ & $\%$ & Cat & $\%$ & Eng & $\%$ & $\mathrm{Sp}$ & $\%$ & Cat & $\%$ \\
\hline $\begin{array}{l}\text { History of the } \\
\text { Classical World }\end{array}$ & 334 & 33.23 & 2 & 0.20 & - & - & 87 & 8.66 & 2 & 0.20 & - & - & 91 & 9.05 & - & - & - & - & 13 & 1.29 & - & - & - & - \\
\hline $\begin{array}{l}\text { Fundamentals } \\
\text { and Theory of } \\
\text { Artistic Heritage }\end{array}$ & 1 & 0.10 & 26 & 2.59 & 12 & 1.19 & 7 & 0.70 & 8 & 0.80 & 4 & 0.40 & - & - & 2 & 0.20 & - & - & - & - & 1 & 0.10 & - & - \\
\hline $\begin{array}{r}\text { Total } \\
\text { Humanities } \\
10,051 w\end{array}$ & 335 & 33.33 & 28 & 2.79 & 12 & 1.19 & 94 & 9.36 & 10 & 0.99 & 4 & 0.40 & 91 & 9.05 & 2 & 0.20 & - & - & 13 & 1.29 & 1 & 0.10 & - & - \\
\hline $\begin{array}{l}\text { Valencian art } \\
\text { and Tourist } \\
\text { resources }\end{array}$ & 122 & 9.88 & 168 & 13.61 & - & - & 35 & 2.83 & 29 & 2.35 & - & - & 59 & 4.78 & 71 & 5.75 & - & - & 21 & 1.70 & 80 & 6.48 & - & - \\
\hline $\begin{array}{r}\text { Total Social } \\
\text { Sciences } \\
12,346 w\end{array}$ & 122 & 9.88 & 175 & 13.61 & - & - & 35 & 2.84 & 29 & 2.35 & - & - & 59 & 4.78 & 71 & 5.75 & - & - & 21 & 1.70 & 80 & 6.48 & - & - \\
\hline $\begin{array}{r}\text { Total Soft } \\
\text { Sciences } \\
22,397 w\end{array}$ & 467 & 20.85 & 203 & 9.06 & 12 & 0.54 & 129 & 5.76 & 39 & 1.74 & 4 & 0.18 & 150 & 6.70 & 73 & 3.26 & - & - & 34 & 1.52 & 81 & 3.62 & - & - \\
\hline
\end{tabular}


That being said, it is worth mentioning that the number of interpersonal features produced by learners in CLIL seminars outnumbers those spotted in teacher discourse. From these results, disciplinary differences can be observed in terms of production and seminar typology. Evidence may be found in slide-talk seminars, where students have more opportunities to produce richer spoken outcomes, as opposed to the video-debate seminar implemented in the fourth-year module related to the area of History and Heritage.

Despite the fact that the lecturer in the fourth-year module offered in the History and Heritage degree is only involved in one teaching practice (i.e. video-debate seminar), quantitative and qualitative interpretations of these data suggest that there is a broader stylistic richness of teacher discourse in the remaining CLIL practices. As previously displayed in Figure 18, the responsible for the History of the Classical World module (i.e. H1) makes use of a more varied range of engagement and attitudinal markers in contrast to the Tourism lecturer. Even though the number of hedges is somewhat smaller in the field of Social Sciences, it seems that there is a wider use of metadiscoursal forms. As for boosters, the identification of a substantial number of cases in Tourism has also resulted in plenty of linguistic features when compared to the area of History and Humanities.

In CLIL slide-talk seminars, which have to do with practices in the modules known as History of the Classical World and Valencian art and Tourist resources, lecturers' use and variety of markers declined considerably. These practices were meant for students to perform academic presentations in the target language, finding more spoken outcomes in the first-year History lecturer. A prominent number of cases were spotted when dealing with the Fundamentals and Theory of Artistic Heritage module. Despite the fact that interpersonal devices in this field of study were meagre in English, this video-debate seminar is characterised by a more varied range of attitudinal, hedging and boosting devices in Spanish.

Focusing on students, their interaction in the CLIL classroom seems to be constrained, as evidenced in Figure 19. A lower number of attitudinal markers, hedges and boosters encountered in the corpus is likely to occur in the field of History and Humanities. Apart from that, attention should be drawn to learners' speech in seminar sessions. As happened with teachers in CLIL lectures, students are the ones taking the floor and 
controlling the topic in CLIL seminars. Although metadiscoursal markers are generally less frequent in students' discourse, the variety of their outcomes cannot be ignored.

A more detailed interpretation of the results is described in the next sections, where examples are given and discussed.

\subsubsection{Engagement markers}

The use of engagement markers acknowledges the presence of an audience on the grounds that questions, imperatives, directives or comprehension comments may be spotted (Hyland \& Jiang, 2016). Listeners are thus encouraged to participate and get involved in the communicative event.

Tables 40, 41, 42 and 43 show the occurrence of the categories under study in the CLIL lectures or lecture seminars delivered in the areas of History and Tourism. As can be observed, the extent to which engagement markers are employed in teacher discourse is greater in CLIL lectures or lecture seminars rather than in CLIL seminars, the latter involving students taking the floor in group presentations. It is worth mentioning that the number of engagement markers found in lectures is slightly higher in the History of the Classical World module, especially in terms of directives, questions, inclusive, behavioural and contextual comments. The use of apologetic comments barely differs between the lectures held in each of the fields examined but comprehension comments, on the other hand, are more common in the Tourism lecture. 
Table 40. Use of engagement markers in teacher discourse in Humanities and Social Sciences: Lectures or lecture seminars.

\begin{tabular}{|c|c|c|c|c|c|c|c|c|c|c|c|c|}
\hline \multicolumn{13}{|c|}{ TEACHER DISCOURSE: ENGAGEMENT MARKERS IN CLIL SEMINARS } \\
\hline \multirow{2}{*}{ Modules } & \multicolumn{6}{|c|}{ History of the Classical World } & \multicolumn{6}{|c|}{ Valencian Art and Tourist Resources } \\
\hline & Eng & $\%$ & $\mathrm{Sp}$ & $\%$ & Cat & $\%$ & Eng & $\%$ & $\mathrm{Sp}$ & $\%$ & Cat & $\%$ \\
\hline Questions & 77 & 7.66 & - & - & - & - & 79 & 6.40 & 1 & 0.10 & - & - \\
\hline Imperatives & 15 & 1.49 & - & - & - & - & 5 & 0.40 & - & - & - & - \\
\hline Directives & 58 & 5.77 & - & - & - & - & 11 & 0.89 & - & - & - & - \\
\hline Comprehension comments & 2 & 0.20 & - & - & - & - & 7 & 0.57 & - & - & - & - \\
\hline Apologetic comments & 2 & 0.20 & - & - & - & - & 2 & 0.16 & - & - & - & - \\
\hline Contextual comments & 12 & 1.19 & - & - & - & - & 4 & 0.32 & - & - & - & - \\
\hline Behavioural comments & 13 & 1.29 & - & - & - & - & 1 & 0.08 & - & - & - & - \\
\hline Inclusive comments & 255 & 25.37 & 3 & - & - & - & 228 & 18.47 & - & - & - & - \\
\hline Total & 434 & 43.18 & 3 & 0.13 & - & - & 337 & 27.30 & 1 & 0.10 & - & - \\
\hline
\end{tabular}

Table 41. Global use of engagement markers in teacher discourse in Humanities and Social Sciences: Lectures or lecture seminars.

\section{TEACHER DISCOURSE: ENGAGEMENT MARKERS IN CLIL SEMINARS}

\begin{tabular}{|c|c|c|c|c|c|c|}
\hline \multirow{2}{*}{ Modules } & \multicolumn{6}{|c|}{ Engagement markers } \\
\hline & Eng & $\%$ & $\mathrm{Sp}$ & $\%$ & Cat & $\%$ \\
\hline $\begin{array}{r}\text { Total Soft Sciences } \\
22,397 \mathrm{w}\end{array}$ & 771 & 34.42 & 4 & 0.18 & - & - \\
\hline
\end{tabular}


Table 42. Use of engagement markers in teacher discourse in Humanities and Social Sciences: Seminars.

\begin{tabular}{|c|c|c|c|c|c|c|c|c|c|c|c|c|c|c|c|c|c|c|}
\hline \multicolumn{19}{|c|}{ TEACHER DISCOURSE: ENGAGEMENT MARKERS IN CLIL SEMINARS } \\
\hline \multirow{2}{*}{ Modules } & \multicolumn{6}{|c|}{ History of the Classical World } & \multicolumn{6}{|c|}{ Fundamentals and Theory of Artistic Heritage } & \multicolumn{6}{|c|}{ Valencian Art and Tourist Resources } \\
\hline & Eng & $\%$ & $\mathrm{Sp}$ & $\%$ & Cat & $\%$ & Eng & $\%$ & $\mathrm{Sp}$ & $\%$ & Cat & $\%$ & Eng & $\%$ & $\mathrm{Sp}$ & $\%$ & Cat & $\%$ \\
\hline Questions & 11 & 1.09 & - & - & - & - & 16 & 1.59 & 14 & 1.39 & 1 & 0.10 & 3 & 0.25 & 2 & 0.16 & - & - \\
\hline Imperatives & 1 & 0.10 & - & - & - & - & 3 & 0.30 & - & - & - & - & 9 & 0.73 & 5 & 0.41 & - & - \\
\hline Directives & - & - & - & - & 1 & 0.10 & 3 & 0.30 & 13 & 1.29 & - & - & 5 & 0.41 & 8 & 0.65 & - & - \\
\hline Comprehension comments & - & - & - & - & - & - & 5 & 0.50 & - & - & - & - & - & - & - & - & - & - \\
\hline Apologetic comments & - & - & - & - & - & - & 2 & 0.20 & - & - & - & - & - & - & - & - & - & - \\
\hline Contextual comments & - & - & - & - & 1 & 0.10 & - & - & 1 & 0.10 & - & - & 2 & 0.16 & 1 & 0.08 & - & - \\
\hline Behavioural comments & 2 & 0.20 & - & - & - & - & - & - & - & - & - & - & 1 & 0.08 & - & - & - & - \\
\hline Inclusive comments & 33 & 3.28 & - & - & - & - & 28 & 2.79 & 63 & 6.27 & 3 & 0.30 & 24 & 1.94 & 15 & 1.22 & - & - \\
\hline Total & 47 & 4.67 & - & - & 2 & 0.20 & 57 & 5.67 & 91 & 9.05 & 4 & 0.40 & 44 & 3.56 & 31 & 2.51 & - & - \\
\hline
\end{tabular}

Table 43. Global use of engagement markers in teacher discourse in Humanities and Social Sciences: Seminars.

\begin{tabular}{|c|c|c|c|c|c|c|}
\hline \multirow[t]{2}{*}{ 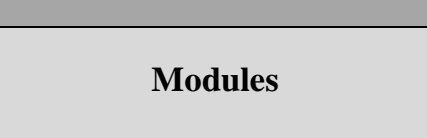 } & \multicolumn{6}{|c|}{ Engagement markers } \\
\hline & Eng & $\%$ & $\mathrm{Sp}$ & $\%$ & Cat & $\%$ \\
\hline $\begin{array}{r}\text { Total Soft Sciences } \\
22,397 w\end{array}$ & 148 & 6.61 & 122 & 5.45 & 6 & 0.27 \\
\hline
\end{tabular}


On the other hand, the speech produced by lecturers in the CLIL seminars allocated for Humanities and Social Sciences is adjusted to boost students' participation in the classroom setting. The trend observed in lectures with regard to the use of inclusive comments, which remain as the most common category, is kept in seminars. Even though these inclusive comments are the most recurrent features in the three disciplines understudy, the incidence in each of them is not at the same rate. Thus, whereas the second most common element in Humanities has to do with questions, imperatives prevail in Social Sciences. From these results, it can also be observed that the use of items in Spanish stands out in the Fundamentals and Theory of Artistic Heritage module. As seen in the table above, a decrease can be recognised in the modules of Valencian art and Tourist resources and History of the Classical World, the latter using English as the main vehicular language. The presence of Catalan, which has been identified in Humanities, is almost unnoticeable.

Within lectures, the high frequency of personal asides denotes the interactive style of the instructional practice. The use of personal pronouns allows for the inclusion or exclusion of discourse participants. Thus, pronouns like you and we serve to manage solidarity with the audience (Hyland \& Jiang, 2016), as seen in the examples below. In the extract produced in the History of the Classical World module, both students and the lecturer are conceived as a whole group. In contrast, in the Tourism lecture students are referred to as you, thereby excluding the teacher.

(40) H1: Well, we could see the conflict between Caesar and Pompey and, and how the Republic was in turmoil. (See Appendix III (a)).

(41) T: [...] As you already know, 1700 is the moment in which the dynasty that rules Spain and the Spanish monarchy changes because the last of the Spanish Habsburgs, Charles the second dies without an heir OK? (See Appendix III (d)).

In CLIL seminars, a lower presence of such linguistic devices can be noticed. In these cases, the incidence of you entails giving feedback on students' presentations or checking comprehension, as in 42 and 43 . However, we reinforces the idea that students and the teacher are part of an audience, as in 44 and 45.

(42) T: [...] Take it easy, make it, try to make it natural. And if you can, please not read, it's going to be great. OK? So eh thank you very much. And next. (See Appendix III (e)).

(43) H2: Do you understand this video? (See Appendix III (c)).

(44) H1: [...] Shh. Now we're going to listen to the second group (See Appendix III (b)). 
(45) H2: It's not necessary, OK. So now here we're going to watch how to prepare an exhibition. (See Appendix III (c)).

Pronouns such as $I$, he, she or they or their Spanish and Catalan equivalents may exclude some listeners. For example, in 46 neither the teacher nor the students are referred to as he, but Charles II. Excerpt 47 has to do with teachers' permission to one of the members of a group, allowing her to play a video during the presentation. Finally, even though in 48 the lecturer is talking about her lesson planning, students may be included through the use of $o s$, a personal reference in Spanish signaling all the participants.

(46) T: In his last will, he designates Philippe of Borbon, a French monarch, as his heir, and so the dynasty changes. (See Appendix III (d)).

(47) T: You can play it [T: Puedes ponerlo]. (See Appendix III (e)).

(48) H2: [...]So uh: I've been going through all the videos, making a selection of videos and I've given you a questionnaire, one like this where you have a series of questions, okay? [H2: [[...] Entonces eh: he estado revisando todos los vídeos, haciendo una selección de vídeos y os he os he planteado un cuestionario, uno como este donde tenéis una serie de preguntas, ¿vale?]] (See Appendix III (c)).

The presence of personal assides cannot be neglected in interactive learning practices. Thus, a variety of questions are posed by teachers in CLIL lectures and seminars to encourage students' participation in the communicative event, either by displaying knowledge or prompting speech production. These questions are more frequent in Valencian art and Tourist resources lectures as well as in Fundamentals and Theory of Artistic Heritage seminars. We may find rhetorical questions where lecturers aks and respond themselves. Evidence may be found in the Valenciant art and Tourist resources module in which it is clear that the Renaissance and the Neoclassicism are two artistic movements that differed to a certain extent. The communicative potential of the question is very limited, but this teaching strategy may be implemented to lower the anxiety levels of international students who have not been raised in Western countries and thus are not familiar with their history.

(49) T: We called it Renaissance. So is there a difference between the 16th century Renaissance and the 18th century Neoclassicism? Yes, there must be, OK? So, and indeed there is a big difference. (See Appendix III (d)). 
It is also posible to identify indirect questions with the aim of prompting CLIL learners. In the next sequence, the History lecturer in the Fundamentals and Theory of Artistic Heritage module keeps asking questions to the students to check whether they retained the contents provided in previous sessions.

(50) $\mathrm{H} 2$ : OK, we were talking about collectionism. How that eh: leads to the accumulation of different artworks and then to exhibit them in museums, didn't we? What were the functions of museums? [H2: Vale, estuvimos hablando del coleccionismo. De cómo a partir de ahí eh: surge ¿no? El acumular distintas obras y luego exponerlo en el museo. ¿Qué funciones tenían los museos?]

S3: To preserve, didn't they? [S3: Conservar, ¿no?]

H2: To preserve. What else? [H2: Conservar. ¿Qué más?]

S4: To educate [S4: Educar] (See Appendix III (c)).

Display questions may be found in slide-talk seminars where teachers may ask questions related to students' presentations, as occurs in the History of the Classical World module. The lecturer poses some questions to challenge students and encourage them to show their knowledge. As shown in 51, students are expected to explain the reasons why Roman gladiators were said to be vegetarian.

(51)H1: OK. And how did you find out about that? How did you know that they were vegetarians? (See Appendix III (b)).

The answer to other questions, labeled as referential (Morell, 2004) may not be known by the lecturer. In this vein, students' contributions are necessary as in 52, where the lecturer was curious about the topics presented in one of the group projects dealing with funerals, education and theatres in ancient Rome.

(52) H1: [...] Why did you decide to connect funerals with education and theatres? Is there any connection you found or it's just because you wanted to cover am: those issues? (See Appendix III (b)).

Leaving questions aside, directives stand for interpersonal markers that may occur when giving instructions in the classroom setting. Explaining how students are meant to proceed in classroom activities and projects entail can be recognised through the use of verbs like be going to and need to or remember that structures, as in 53, 54 and 55.

(53) H1: [...] Before watching the second episode, you need to pay attention 'cause you're going to answer an online questionnaire. (See Appendix III (a)). 
(54) H2: So now we are going to - to watch a video about eh how to use the artworks to, to teach Art History, OK? (See Appendix III (c)).

(55) T: [...] If you remember that, when we studied Renaissance, we saw that some architects took classical elements and interpreted them, creating something new [...]. (See Appendix III (d)).

Directives may be expressed through imperatives, that is, orders students should follow. Second person pronouns as well as let's structures can be found in English, whereas in the modal verb tener que (i.e. have to) is also common in teacher discourse produced in Spanish.

(56) T: I mean, why does Renaissance substitute Gothic? Think as a 16th century painter. (See Appendix III (d)).

(57)H1: Now let's get ready to listen to the third group. (See Appendix III (a)).

(58) T: Try to talk, I don't want you to read. And avoid describing the picture. I mean, I don't mind. I - I have two eyes and see the painting. (See Appendix III (e)).

(59) $\mathrm{H} 2$ : And when you have finished watching the videos, you will have to write a comment in English [H2: Y cuando acabéis de ver los vídeos, tendréis que redactar un comentario en ingles]. (See Appendix III (c)).

Other categories indicating engagement are those of comprehension, apologetic and contextual comments. These elements are not as usual as the previous categories, but may happen anytime throughout the learning process. Comprehension comments serve to check understanding and negotiate meaning with students. To do so, lecturers may ask questions, with the verb understand and the adjective clear being the most recurrent in comprehension comments.

(60) H1: Have you understood that? Yes? OK. (See Appendix III (a)).

(61) H2: Do you understand this video?

Ss: Yes

S15: Very easy, American

S6: Awesome (See Appendix III (c)).

(62) T: [...] So, Neoclassicism must be also understood as a reaction against Baroque. Okay. Is it clear? [...] (See Appendix III (d)).

Bringing technology in the classroom may be challenging at some point. Lecturers may need to face some issues deriving from technological failures, which can be identified as contextual comments. In the History of the Classical World module, students were required to access Kahoot, a game-based platform based on the completion of online 
questionnaires. On the other hand, the Tourism lecturer complains about how colours are abnormally displayed on the computer monitor.

(63) S26: We can't access Kahoot. We've tried but it isn't working. [S26: No podem accedir. Hem provat, però no ens funciona].

H1: OK. So join the group you have in front of you. (See Appendix III (a)).

(64) T: I don't know why everything is going to be blue today in this screen. I don't know why. My presentation was in white, but today everything is in blue. (See Appendix III (d)).

Contextual comments may be related to timing factors. Clear examples are shown in 65 and 66 where lecturers signal short breaks or the end of the seminar.

(65) T: [...] Ten minutes and back. (See Appendix III (d)).

(66) H2: Okay, when you're done, give me the photocopies and we're done. [H2: Vale, cuando terminéis me dais las fotocopias y hemos terminado]. (See Appendix III (c)).

Apologetic and behavioural comments are almost non-existent. Apologetic comments can be perceived to emphasise that there was some confusion, as in 67 where the lecturer mixed the notions of Renaissance and Neoclassicism. The impossibility to play subtitles for students is also illustrated in 68.

(67) T: Ah: this is not very scientific, but Renaissance is incredibly amazing and Neoclassicism is incredibly cold - cold. I mean there is no, well, there are no emotions in Renaissance, okay? This is Neoclassicism, sorry. (See Appendix III (d)).

(68) H1: [...] I'm sorry there are no subtitles, but I couldn't find them online. (See Appendix III (a)).

Listening is key for the comprehension of lectures and participants' productions. That is the reason why behavioural comments only occur in teacher discourse when asking undergraduates to respect their classmates' presentations, as in 69 and 70 . The interjection shh serves similar purposes as it is to catch students' attention and ask them to be in silence to follow the lecturer's guidelines.

(69) H1: We are going to start. Be quiet, please. (See Appendix III (b)).

(70) T: Keep quiet. (See Appendix III (e)).

(71)H1: Yes? Okay. No? So with your mobile phones. Shhh. With your mobile phones, enter Kahoot dot it (See Appendix III (b)).

According to Tables 44 and 45, the incidence of engagement markers is at low levels in student discourse registered in lectures and lecture seminars as opposed to slide-talk seminars. As can be noticed, History undergraduates make use of engagement markers 
at a higher frequency, not only in English but also in Spanish and Catalan, with inclusive comments and questions as the most prevalent metadiscoursal devices. This also applies to Tourism students, even though their proportion is not as relevant as in History.

A considerable increase can be seen in the use of engagement markers in History and Tourism seminars. For example, the number of questions is higher in the field of Humanities, more specifically in the Fundamentals and Theory of Artistic Heritage module. On the contrary, imperatives and comprehension comments appear to be more pervasive in Tourism (see Tables 46 and 47). The latter shows similar results to the ones obtained in lectures or lecture seminars since interaction is more limited due to the visualisation of videos. Despite the fact that inclusive comments and questions can be observed in both teaching practices, it is worth mentioning that behavioural comments are missing in the speech produced in lectures and seminars. 
Table 44. Use of engagement markers in student discourse in Humanities and Social Sciences: Lectures / lecture seminars.

\begin{tabular}{|c|c|c|c|c|c|c|c|c|c|c|c|c|}
\hline \multicolumn{13}{|c|}{ STUDENT DISCOURSE: ENGAGEMENT MARKERS IN LECTURES / LECTURE SEMINARS } \\
\hline \multirow{2}{*}{ Modules } & \multicolumn{6}{|c|}{ History of the Classical World } & \multicolumn{6}{|c|}{ Valencian Art and Tourist Resources } \\
\hline & Eng & $\%$ & $\mathrm{Sp}$ & $\%$ & Cat & $\%$ & Eng & $\%$ & $\mathrm{Sp}$ & $\%$ & Cat & $\%$ \\
\hline Questions & 5 & 0.50 & 7 & 0.69 & - & - & 1 & 0.08 & 2 & 0.16 & - & - \\
\hline Imperatives & - & - & - & - & - & - & - & - & - & - & - & - \\
\hline Directives & - & - & - & - & & - & - & - & - & - & - & - \\
\hline Comprehension comments & 1 & 0.10 & 3 & 0.30 & - & - & - & - & 1 & 0.08 & - & - \\
\hline Apologetic comments & - & - & - & - & - & - & - & - & - & - & - & - \\
\hline Contextual comments & 2 & 0.20 & 1 & 0.10 & 1 & 0.10 & - & - & - & - & - & - \\
\hline Behavioural comments & - & - & - & - & - & - & - & - & - & - & - & - \\
\hline Inclusive comments & 12 & 1.19 & 7 & 0.70 & 3 & 0.30 & 2 & 0.16 & 1 & 0.08 & - & - \\
\hline Total & 20 & 1.99 & 18 & 1.79 & 4 & 0.40 & 3 & 0.24 & 4 & 0.32 & - & - \\
\hline
\end{tabular}

Table 45. Global use of engagement markers in student discourse in Humanities and Social Sciences: Lectures / lecture seminars.

\begin{tabular}{|r|c|c|c|c|c|c|}
\hline STUDENT DISCOURSE: ENGAGEMENT MARKERS IN CLIL SEMINARS \\
\hline \multirow{2}{*}{ Modules } & \multicolumn{6}{|c|}{ Engagement markers } \\
\cline { 2 - 7 } & Eng & $\% 0$ & Sp & $\% 0$ & Cat & $\% 0$ \\
\hline $\begin{array}{r}\text { Total Soft Sciences } \\
22,397 w\end{array}$ & 23 & 1.34 & 22 & 0.98 & 4 & 0.18 \\
\hline
\end{tabular}


Table 46. Use of engagement markers in student discourse in Humanities and Social Sciences: Seminars.

\begin{tabular}{|c|c|c|c|c|c|c|c|c|c|c|c|c|c|c|c|c|c|c|}
\hline \multicolumn{19}{|c|}{ STUDENT DISCOURSE: ENGAGEMENT MARKERS IN SEMINARS } \\
\hline \multirow{2}{*}{ Modules } & \multicolumn{6}{|c|}{ History of the Classical World } & \multicolumn{6}{|c|}{ Fundamentals and Theory of Artistic Heritage } & \multicolumn{6}{|c|}{ Valencian Art and Tourist Resources } \\
\hline & Eng & $\%$ & $\mathrm{Sp}$ & $\%$ & Cat & $\%$ & Eng & $\%$ & $\mathrm{Sp}$ & $\%$ & Cat & $\%$ & Eng & $\%$ & $\mathrm{Sp}$ & $\%$ & Cat & $\%$ \\
\hline Questions & 7 & 0.70 & - & - & - & - & - & - & 15 & 1.49 & 4 & 0.40 & - & - & 10 & 0.81 & - & - \\
\hline Imperatives & - & - & - & - & - & - & - & - & 2 & 0.20 & - & - & 8 & 0.65 & 13 & 1.05 & - & - \\
\hline Directives & 12 & 1.19 & - & - & - & - & - & - & - & - & - & - & 2 & 0.16 & 36 & 2.92 & - & - \\
\hline Comprehension comments & 1 & 0.10 & - & - & - & - & 1 & 0.10 & 2 & 0.20 & - & - & 7 & 0.57 & - & - & - & - \\
\hline Apologetic comments & 3 & 0.30 & 1 & 0.10 & - & - & - & - & - & - & - & - & - & - & - & - & - & - \\
\hline Contextual comments & - & - & - & - & - & - & - & - & - & - & - & - & 2 & 0.16 & 27 & 2.19 & - & - \\
\hline Behavioural comments & - & - & - & - & - & - & - & - & - & - & - & - & - & - & - & - & - & - \\
\hline Inclusive comments & 311 & 30.94 & 1 & 0.10 & - & - & - & - & 7 & 0.70 & 8 & 0.80 & 113 & 9.15 & 89 & 7.21 & - & $=$ \\
\hline Total & 334 & 33.23 & 2 & 0.20 & - & - & 1 & 0.10 & 26 & 2.59 & 12 & 1.19 & 132 & 10.69 & 175 & 14.17 & - & - \\
\hline
\end{tabular}

Table 47. Global use of engagement markers in student discourse in Humanities and Social Sciences: Seminars.

\begin{tabular}{|c|c|c|c|c|c|c|}
\hline \multicolumn{7}{|c|}{ STUDENT DISCOURSE: ENGAGEMENT MARKERS IN CLIL SEMINARS } \\
\hline \multirow{2}{*}{ Modules } & \multicolumn{6}{|c|}{ Engagement markers } \\
\hline & Eng & $\%$ & $\mathrm{Sp}$ & $\%$ & Cat & $\%$ \\
\hline $\begin{array}{r}\text { Total Soft Sciences } \\
22,397 w\end{array}$ & 467 & 20.85 & 203 & 9.06 & 12 & 0.54 \\
\hline
\end{tabular}


Student discourse is characterised by a decline in the use of engagement markers, especially in the Tourism lecture. As with teacher discourse, solidarity with listeners is expressed through the use of personal references in students' productions (Hyland \& Jiang, 2016). The pronoun you fulfills two main functions. It may serve to include all the members in the classroom setting. In 72 presenters try to approach their audience by emphasising the fact that divorce was legal in ancient Rome, whereas in 73 students are introducing the topic of their exhibition.

(72) S16: [...] getting divorced is something that maybe you don't know and it's strange because you may think that it's something from nowadays. (See Appendix III (b)).

(73) S12: First, I want to introduce you our exhibition, which is about love. (See Appendix III (e)).

On the other hand, the teacher or a given student may be regarded as you. As a result, part of the audience taking part in the communicative event is excluded. In 74 a student is requesting the lecturer to play an episode of the HBO Rome with subtitles on behalf of another classmate. This also applies to other pronouns which can be identified in the three official languages promoted at university. Through personal asides like $I$, he, she, we, my or our students may express their opinion, as in 75. Another example is that of 76, where the use of our implies that the members of the group presenting their exhibition proposal are the ones who have designed it.

(74) S7: No. He asked if you could repeat the answers. (See Appendix III (a)).

(75) S1: I would say painting (See Appendix III (d)).

(76) S7: Well, our exhibition is about the male body. (See Appendix III (e)).

In line with the different uses of personal references observed in teacher discourse, these engagement markers may occur in students' questions to address specific recipients. Indirect questions are produced in order to prompt the response of the lecturer. Thus, in it can be seen how the interjection hmm and the adverb yes represent lecturers' affirmative answers in 77 and 78. Students' questions may take place in response to teachers' questions to check that they are right. Excerpt 79 shows that when using the negative particle no, the student is asking for confirmation.

(77) S14: What is this? The Metropolitan museum? [S14: ¿Esto que es? ¿El Metropolitan?]

H2: Hmm (See Appendix III (c)).

(78) S2: Do I read the question? [S2: ¿Leo la pregunta?]

H1: Yes. (See Appendix III (a)). 
(79) T: [...] How did students in Madrid learn how to produce Greek and Roman architecture? S5: Through projects, didn't they? [S5: Con proyectos, ¿no?] (See Appendix III (d)).

By asking and answering their own questions, students may be able to structure their discourse. Evidence may be found in the speech produced by a Tourism undergraduate who shares the reason why one the sections of his group's exhibition is called Looking ahead.

(80) S3: Eh: the last section has been called Looking ahead. Eh why? Eh because we thought that, as matter of fact, fashion is no longer represented in the paintings, but the paintings are represented in fashion. [S3: Eh: la última sección la hemos nombrado 'Mirando al futuro'. Eh ¿por qué? Eh porque hemos pensado que la realidad ya no es la moda la que está representada en los cuadros, sino los cuadros los que están representados en la moda].

Referential questions are produced when students do not know the teacher's answer. As can be noted in the sequence below, the student would like to know how many members should be in a group to answer the Kahoot survey in the classroom setting.

(81) S24: How many members should our group consist of? As many as we want? [S24: ¿De cuántos puede ser el grupo para el Kahoot? ¿Del que queramos?]

H1: As many as you want. [H1: Del que queráis]

S24: Or only two people? [S24: ¿O solo dos?]

H1: No, no. Whatever you want. [H1: No, no. Lo que queráis]. (See Appendix III (b)).

As to directives, they cannot be found in video-debates seminars held in the Fundamentals and Theory of Artistic Heritage module. Their occurrence is limited to slide-talk seminars delivered in first-year History and fourth-year Tourism modules. In these cases, presenters give guidelines to other members of their groups to pass on to the next slides, as in 82. Modal verbs such as can, should and must indicate that the speaker tries to get the audience to do what is correct.

(82) After that the opponent, your opponent can rise and the editor choose if your opponent lives or dies. Next one? (See Appendix III (b)).

(83) S14: OK. So this is about love and treason. There are no rules when it comes to love, right? Love should always be considered about something between two sides. (See Appendix III (e)).

(84) S13: So you can see this photo where a warrior is fighting with his body against this man. (See Appendix III (b)). 
Lack of comprehension is signalled through questions or statements. In order to provide students with comprehensible input, teachers are requested to clarify, repeat or rephrase their speech. In other words, teacher discourse is adapted to meet the needs of their students.

(85) S4: Can you repeat, please? (See Appendix III (d)).

(86) S15: Soothsayer, what does it mean? [S15: Soothsayer, ¿qué es?]

H1: It means adivino. (See Appendix III (a)).

(87) SX: ¿Qué significa MOMA?

H2: The Moma is the museum of modern art. Modern Art of New York (See Appendix III (c)).

(88) S5: The thing is that I don't know what you mean. [S5: A ver es que no sé qué quieres decir]. (See Appendix III (d)).

Apologetic comments are meagre. First-year undergraduate students enrolled in the History of the Classical World module are the participants who produce them. Being nervous and mixing or forgetting concepts and explanations lead learners to apologise in front of their audience, as in the following excerpts.

(89) S6: Gladiators fight to distingate him by the weapons and his house. Initially, it's believed that gladiator was a slave. but now ehh, ehh, sorry. (See Appendix III (b)).

(90) S1: And eh: it starts with Ludus literarius to the zero at seven years and then Grammaticus and rhetoric to the seven no, to seven to twelve years. I'm nervous. (See Appendix III (b)).

The implementation of echnological tools in CLIL lectures and seminars may boost students' motivation. Next sequence illustrates positive outcomes produced by students following the use of Flippity, a platform that provides users with different resources for the design of their lesson plannings. More specifically, it is helpful for the creation random name pickers and thus for the promotion of interaction.

(91) [use of Flippity]

Ss: [laughs]. Surprise

S5: Ah, that's cool! [S5: Ah, ¡qué guay!] (See Appendix III (b)).

Overall, engagement markers are the most common interpersonal features in teacher and student discourse. Their frequency may vary according to the type of seminar, with the Fundamentals and Theory of Artistic Heritage seminar being the teaching practice with less production. Other resources, described in the following sections, may contribute to prompting interaction in CLIL learning environments. 


\subsubsection{Attitudinal markers}

The attitudinal markers addressed in this study are metadiscoursal features attributed to spoken language. These resources, which involve the evaluation of content, behaviour and the expression of emotions, reflect the stance of the speaker. The lexicogrammatical devices that tend to be used in teacher discourse are mostly found in the field of Social Sciences rather than in Humanities, even though items such as good, main or easy may be present in the CLIL lectures of both disciplinary areas (see Table 48). The table below summarises the frequency of attitudinal devices in CLIL lectures given by History and Tourism specialists.

Table 48. Use of attitudinal markers in teacher discourse in Humanities and Social Sciences: Lecture / Lecture seminars.

\begin{tabular}{|c|c|c|c|c|c|c|}
\hline \multicolumn{7}{|c|}{ TEACHER DISCOURSE: ATTITUDINAL MARKERS IN CLIL LECTURES } \\
\hline \multirow{2}{*}{ Modules } & \multicolumn{6}{|c|}{ Attitudinal markers } \\
\hline & Eng & $\%$ & $\mathrm{Sp}$ & $\%$ & Cat & $\%$ \\
\hline History of the Classical World & 27 & 2.69 & - & - & - & - \\
\hline Fundamentals and Theory of Artistic Heritage & - & - & - & - & - & - \\
\hline $\begin{array}{r}\text { Total Humanities } \\
10,051 w\end{array}$ & 27 & 2.69 & - & - & - & - \\
\hline Valencian art and Tourist resources & 131 & 10.61 & 3 & 2.41 & - & \\
\hline $\begin{array}{r}\text { Total Social Sciences } \\
12,346 \mathrm{w}\end{array}$ & 131 & 10.61 & 3 & 2.41 & - & - \\
\hline $\begin{array}{r}\text { Total Soft Sciences } \\
22,397 \mathrm{w}\end{array}$ & 158 & 7.05 & 3 & 0.13 & - & - \\
\hline
\end{tabular}

These results suggest that the first-year lecturer in the History module did not use as many devices as the Tourist lecturer. Such occurrences were probably influenced by the information and resources displayed in the lecture session. On the one hand, the History lecturer combined short explanations with the visualisation of an episode of the HBO series Rome, activities and online surveys; on the other hand, the Tourist lecturer focused on the explanation of architects and buildings that played a vital Rome at the times of Renaissance and Neoclassicism.

Within these sessions, it could be seen that lecturers made use of appraisal devices (e.g. great, well done and perfect) and other attitudinal devices to express assessment, 
significance and emotion (Mur Dueñas, 2010). Attitudinal elements such as only, new, perfect, difficult, right or wrong would fall into the assessment category, whereas important and main would denote significance. Other elements including powerful, sorry or don't mind would manifest emotion. Some items may also fit into different typologies, as occurs with the adverb incredibly when accompanied by an adjective. In extract 93, the Tourism lecturer addresses the audience and encourages home and international students to give a definition of the concept Neoclassicism in the lecture session by integrating translanguaging practices. Having obtained the response of an international student, the teacher makes of use of incredibly as a feedback response. On the other hand, in extract 94 it can be observed that this syntactical element operates at the subjectivity level.

(92)T: Hello? Also in Spanish, I will translate into English 〈TLANG_Eng>. ¿Qué es Neoclasicismo? Come on, be brave [T: Venga, con un par].

S2: Probably a revival of the classic (See Appendix III (d)).

T: That's incredibly clever. OK. It's a revival of antiquity [...]. (See Appendix III (d)).

(93) T: [...] This is not very scientific, but Renaissance is incredibly amazing and Neoclassicism is incredibly cold, cold. I mean there is no, well, there are no emotions in Renaissance, okay? This is Neoclassicism, sorry [...]. (See Appendix III (d)).

Other issues that may draw our attention are related to anxiety and game-based learning. In the next sequence, the lecturer in the first-year History module announces an activity that is meant to be completed through an online survey platform called Kahoot. In this regard, she provides undergraduates with the necessary instructions so that they get familiar with this tool.

(94) H1: [...] You will have twenty seconds to answer the questions. Twenty seconds per question. So, don’t worry. (See Appendix III (a)).

Results in Table 49 reveal that a low representation of attitudinal markers was incorporated in lecturers' discourse registered in CLIL seminars belonging to the field of Humanities and Social Sciences. In fact, no significant differences were found as they rised up to $0.40 \%, 0.50 \%$ and $0.49 \%$ in each of the degrees studied. Some of the items encountered in English involve interesting, curiosity, necessary or best, whereas vale (OK), preferiblemente (i.e. preferably) or problema (i.e. problem) were uttered in Spanish. 
Table 49. Use of attitudinal markers in teacher discourse in Humanities and Social Sciences: Seminars.

\begin{tabular}{|c|c|c|c|c|c|}
\hline \multicolumn{6}{|c|}{ TEACHER DISCOURSE: ATTITUDINAL MARKERS IN CLIL SEMINARS } \\
\hline \multirow{2}{*}{ Modules } & \multicolumn{5}{|c|}{ Attitudinal markers } \\
\hline & Eng & $\%$ & $\mathrm{Sp}$ & Cat & $\%$ \\
\hline History of the Classical World & 4 & 0.40 & 3 & 1 & - \\
\hline Fundamentals and Theory of Artistic Heritage & 5 & 0.50 & 10 & - & - \\
\hline $\begin{array}{r}\text { Total Humanities } \\
10,051 w\end{array}$ & 9 & 0.90 & 10 & - & \\
\hline Valencian art and Tourist resources & 6 & 0.49 & - & - & - \\
\hline Total Social Sciences & & & & & \\
\hline $12,346 w$ & 6 & 0.49 & - & - & - \\
\hline $\begin{array}{r}\text { Total Soft Sciences } \\
22,397 \mathrm{w}\end{array}$ & 15 & 0.67 & 10 & - & - \\
\hline
\end{tabular}

In extract 95, the teacher' makes some recommendations following the first group performance. His purpose is to reduce students' pressure and boost their confidence when sharing their projects in the CLIL classroom. This comment is mainly addressed to non-native speakers who are prone to interact in the target language. It is through this type of feedback that conversational exchanges may become successful (Crystal, 1988).

(95) T: [...] Take it easy, make it, try to make it natural. And if you can, please not read, it's going to be great. OK? [...]. (See Appendix III (d))

In the transcript that follows, Spanish was employed as a means of communication in the CLIL seminar, with vale -okay in English- as the most frequent marker. The latter, which stands for okay in English, aims at including the audience in the speech event and enhancing interaction in the learning environment.

(96) H2: There are some, there are some [videos] that do have English subtitles and there are some others that don't. You'll see that the videos are short, okay? Eh If - if - if, if you feel that you don't understand anything, I'll switch the subtitles on, okay? [...]. [Hay algunos, hay algunos que tienen subtítulos en inglés y otros que no tienen subtítulos. Los vídeos veréis que son cortitos, ¿vale? Eh Si, si, si veis que no pilláis nada, os pongo los subtítulos, ¿vale? [...]]. (See Appendix III (c)). 
A look at student discourse in CLIL lectures indicates that the distribution of attitudinal markers in Humanities and Social Sciences is scarce in the three languages that may coexist in the classroom setting. Indeed, the count of items in English stands for $0.08 \%$ in the Tourism classroom; this result is even tripled in the History classroom with $0.30 \%$ (see Table 50). As to Spansih, the frequency of the elements decreases $(0.20 \%$ ) when articulated in Humanities and remains the same in Social Sciences $(0.08 \%)$. Instances identified in English include main and please, whereas in Spanish expressions such as vamos (i.e. yay) or sí hombre (i.e. no way) -which operate as metadiscoursal markerscan be found.

Table 50. Use of attitudinal markers in student discourse in Humanities and Social Sciences: Lecture / Lecture seminars.

\begin{tabular}{|c|c|c|c|c|c|c|}
\hline \multicolumn{7}{|c|}{ STUDENT DISCOURSE: ATTITUDINAL MARKERS IN CLIL LECTURES } \\
\hline \multirow{2}{*}{ Modules } & \multicolumn{6}{|c|}{ Attitudinal markers } \\
\hline & Eng & $\%$ & $\mathrm{Sp}$ & $\% 0$ & Cat & $\%$ \\
\hline History of the Classical World & 3 & 0.30 & 2 & 0.20 & 1 & 0.10 \\
\hline Fundamentals and Theory of Artistic Heritage & - & - & - & - & - & - \\
\hline $\begin{array}{r}\text { Total Humanities } \\
10,051 \mathrm{w}\end{array}$ & 3 & $\mathbf{0 . 3 0}$ & 2 & 0.20 & 1 & 0.10 \\
\hline Valencian art and Tourist resources & 1 & 0.08 & 1 & 0.08 & - & - \\
\hline $\begin{array}{r}\text { Total Social Sciences } \\
12,346 \mathrm{w}\end{array}$ & 1 & 0.08 & 1 & 0.08 & - & - \\
\hline $\begin{array}{r}\text { Total Soft Sciences } \\
22,397 w\end{array}$ & 4 & 0.18 & 3 & 0.13 & 1 & $\mathbf{0 . 0 4}$ \\
\hline
\end{tabular}

In the samples of the corpus, please is used by students who need more support in the target language. The examples below illustrate students' requests for clarifications or for the incorporation of subtitles within visual aids.

(97) S10: Can you put subtitles, please? (See Appendix III (a)).

(98) T: Good. How did Vicente Gascó or father Francisco Cabezas knew Roman architecture so well? Direct question.

S4: Can you repeat, please? (See Appendix III (d)).

Requests for clarifications can also be observed in Spanish, where the use of a ver emerges in interactional contexts to hesitate about a statement made by the lecturer. In 
the example below, it can be interpreted that the student uses this attitudinal marker to ask the teacher for reformulations.

(99) T: [...] And so this affection for declaration, for Baroque decoration, stucco plaster, gold, mixture of sculpture and painting and architecture, and astonishing interiors was still very alive during the 18th century and this was a kind of arts and architecture Valencian academic architects were fighting against. Clear? S5?

Ss: [laughs]

T: SX1? SX2?

S5: Honestly, I don't know what you mean [S5: A ver es que no sé qué quieres decir]. (See Appendix III (d)).

The remaining metadiscoursal features in Spanish are tied to enthusiasm and Open Educational Resources (OERs). The terms vamos proves the beneficial effects of Kahoot questionnaires in terms of motivation in the CLIL classroom (MontanerVillalba, 2018). On the other hand, the expression Sí, hombre suggests that the student, who was selected randomly by a name picker tool, needs to be pushed to participate actively in the learning process and answer the activity.

(100) H1: What did Caesar do in the last 8 years at the beginning of the episode? This has to do with the first episode. Fifteen got it right. Shhh. What legion do the soldiers belong to? $A$ random name picker called Flippity is used]

Ss: Come on! [iVamos!]. (See Appendix III (a)).

(101) S16: Sí, hombre <TLANG_Sp>. Ehh: The entire project was due to his instigation. If he had not urged us forward, the project would not have been begun. (See Appendix III (a)).

The integration of these digital gadgets may entail some drawbacks which have to do with internet connection (Lin et al., 2018). Students' concern about access failure is salient in the next extract.

(102) S26: We can't access Kahoot. We've tried but it isn't working. [S26: No podem accedir. Hem provat, però no ens funciona]. (See Appendix III (a)).

Leaving aside the lecture, the representation of attitudinal markers is much higher in CLIL seminars (see Table 51). This is particularly relevant in the slide-talk seminar implemented in the History of the Classical World module, since students are able to produce a large number of attitudinal devices in English (8.66\%). The Valencian art and Tourist resources seminar comes in the second position, with $2.84 \%$ of the items in English and 2.35\% in Spanish. A lower representation of these resources can be found 
in the Fundamentals and Theory of Artistic Heritage practice. At the same time, a limited number of linguistic resources or no occurrence at all can be distinguished in Catalan, at least in the History of the Classical World and Valencian art and Tourist resources modules.

Table 51. Use of attitudinal markers in student discourse in Humanities and Social Sciences: Seminars.

\begin{tabular}{|c|c|c|c|c|c|c|}
\hline \multicolumn{7}{|c|}{ STUDENT DISCOURSE: ATTITUDINAL MARKERS IN CLIL SEMINARS } \\
\hline \multirow{2}{*}{ Modules } & \multicolumn{6}{|c|}{ Attitudinal markers } \\
\hline & Eng & $\%$ & $\mathrm{Sp}$ & $\%$ & Cat & $\% 0$ \\
\hline History of the Classical World & 87 & 8.66 & 2 & 0.20 & - & - \\
\hline Fundamentals and Theory of Artistic Heritage & 7 & 0.70 & 8 & 0.80 & 4 & 0.40 \\
\hline $\begin{array}{r}\text { Total Humanities } \\
10,051 \mathrm{w}\end{array}$ & 94 & 9.36 & 10 & 0.99 & 4 & $\mathbf{0 . 4 0}$ \\
\hline Valencian art and Tourist resources & 35 & 2.84 & 29 & 2.35 & - & - \\
\hline $\begin{array}{r}\text { Total Social Sciences } \\
12,346 \mathrm{w}\end{array}$ & 35 & 2.84 & 29 & 2.35 & - & - \\
\hline $\begin{array}{r}\text { Total Soft Sciences } \\
22,397 \mathrm{w}\end{array}$ & 129 & 5.76 & 39 & 1.74 & 4 & 0.18 \\
\hline
\end{tabular}

Learners' discourse in the fields of Humanities and Social Sciences is characterised by their impressions and judgements about disciplinary knowledge and their own projects. The word cutre (i.e. shabby) is employed by Tourism students addressing the weaknesses in their own projects, as in extract 103. Another example is that of fun in 104 when an undergraduate student enrolled in the History and Heritage degree attemps to demonstrate expertise in the area.

(103) S4: Y luego, este bueno un poquito así cutre nuestro proyecto. No tenemos creatividad para más. (See Appendix III (d)).

(104) S2: I think the connection is the ancient Rome. In the ancient Rome education is a part important to form the future person and work in the future. The theatre Rome is I don't how to say it. Fun? to the spectacles to fun to the persons who, <TLANG_Eng> bueno $<$ TLANG_Sp> to rich people and death I think that religion is a part important and funerals is a font to say that he had. (See Appendix III (b)).

Emotion is represented through the use of adjectives and expressions. For instance, students' nervousness when performing oral presentations in the target language can be 
noticed below. The speaker, whose topic presentation dealt with Roman education, got children's age wrong due to her anxiety levels.

(105) S1: $[\ldots]$ and less familiar. OK. And eh: it starts with Ludus literarius to the zero at seven years and then Grammaticus and rhetoric to the seven no, to seven to twelve years. I'm nervous. (See Appendix (b)).

Other issues towards the implementation of CLIL practices can be observed in the next sequence. In this case, motivational deficits would have had negative effects on course attendance. This might be the reason why the History lecturer decided not to inform learners in advance of the day allocated for the CLIL seminar.

(106) S13: I didn't expect this. I didn't expect this [No m'ho esperava. Jo açò no m'ho esperava]. H2: What? This English practice? [El què? La pràctica en anglès?].

S13: Yes, I didn't expect this. [Sí, jo açò no m'ho esperaba].

H2: Well, I informed you about it last week, eh? [Pues vos vaig avisar la setmana passada, eh?]

Ss: What:? [¿Qué:?]

H2: He said that he didn't expect to come and have this English practice. But I told you about it last week [Que dice que no se esperaba venir y hacer una práctica en inglés. Que ya lo dije la semana pasada].

S14: I don't think you said it was in English. [Yo creo que no dijiste que era en inglés].

S13: If I had known it, I wouldn't have come to class. [Si ho sé, no vinc].

$\mathrm{H} 2$ : So I probably forgot to tell you that this practice was meant to be taught in English. [Pues se me olvidó decir que era en inglés]. (See Appendix (c)).

Not only were assessment or affection factors considered, but also the significance of the sections included in students' projects. This is notorious through adjectives such as vital and important, which may also be accompanied by collocates like point or work.

(107) S13: [...] Emm the second thing to gladiators is to have a vision of the combat based on the opponent is the other vital point. (See Appendix (b))

(108) S7: The most important work of this section is a painting named La caja de Pandora that it's a fusion of mythological and religious theme because it's a fusion of human Pandora that is woman eh that is a responsible of the race and Eva that is a responsible of the sins of the humanity (See Appendix (d)).

Both in lecturers' and students' speech, evaluative language can be observed in markers like problem, importance and question. Such incidence may be based on individuals' stylistic differences and their idiolect, although it should be stressed that it is in the field 
of Tourism where a higher occurrence of these metadiscoursal elements has been detected. According to some scholars (Lorés Sanz, 2006; Martín del Pozo, 2014), a greater presence of these resources in CLIL lectures and seminars would contribute to enhance comprehension and thus scaffold learning.

\subsubsection{Boosters}

The distribution of boosters shows variation among the degrees involved in Humanities and Social Sciences (see Table 52). As with attitudinal markers, these features seem to prevail in Tourism lectures. In fact, the amount of cases outnumbers those perceived in the degrees of History and Humanities, where only a few cases were listed in teacher discourse. With regard to languages, English seems to be the preferred means of communication by university teachers in the modules referred to as Valencian art and Tourist Resources (3.26\%) and History of the Classical World (0.60\%o). Spanish, on the other hand, is the language chosen by the lecturer in the Fundamentals and Theory of Artistic Heritage module (0.70\%).

Table 52. Use of boosters in teacher discourse in Humanities and Social Sciences: Lectures and Seminars.

\begin{tabular}{|c|c|c|c|c|c|c|c|c|c|c|c|c|}
\hline \multicolumn{13}{|c|}{ TEACHER DISCOURSE: BOOSTERS IN CLIL LECTURES AND SEMINARS } \\
\hline \multirow{3}{*}{ Modules } & \multicolumn{12}{|c|}{ Boosters } \\
\hline & \multicolumn{6}{|c|}{ Lectures / Lecture seminars } & \multicolumn{6}{|c|}{ Seminars } \\
\hline & Eng & $\%$ & $\mathrm{Sp}$ & $\%$ & Cat & $\%$ & Eng & $\%$ & $\mathrm{Sp}$ & $\%$ & Cat & $\%$ \\
\hline History of the Classical World & 6 & 0.60 & - & - & - & - & 1 & 0.10 & - & - & - & - \\
\hline $\begin{array}{l}\text { Fundamentals and Theory of } \\
\text { Artistic Heritage }\end{array}$ & - & - & - & - & - & - & - & - & 7 & 0.70 & - & - \\
\hline $\begin{array}{r}\text { Total Humanities } \\
10,051 w\end{array}$ & 6 & 0.60 & - & - & - & - & 1 & 0.10 & 7 & 0.70 & & \\
\hline $\begin{array}{l}\text { Valencian art and Tourist } \\
\text { resources }\end{array}$ & 44 & 3.26 & - & - & - & - & - & - & 2 & 0.16 & - & - \\
\hline $\begin{array}{r}\text { Total Social Sciences } \\
12,346 \mathrm{w}\end{array}$ & 44 & 3.26 & - & - & - & - & - & - & 2 & 0.16 & - & - \\
\hline $\begin{array}{r}\text { Total Soft Sciences } \\
22,397 \mathrm{w}\end{array}$ & 50 & 2.32 & - & - & - & - & 1 & 0.04 & 9 & 0.40 & - & - \\
\hline
\end{tabular}


The commitment of the speaker to the statement can be mostly recongised by means of grammatical elements. Adverbs such as clearly, generally and always highlight the lecturer's confidence about the contents that are being transmitted to students in the CLIL learning environment. For instance, of course is an adverbial phrase that serves to introduce an obvious idea that alludes to shared knowledge. On the other hand, adjectives may function as intensifiers by modifying some lexico-grammatical devices, as with extraordinary.

(109) H1: [...] Freedman, were slaves who had been freed by their owners, by their masters, also known as manumissio or who had bought their freedom. And slaves, of course, were non-citizens. They had no rights and they were considered property of their master. And uh, you could become a slave for several reasons [...]. (See Appendix (a)).

(110) $\mathrm{T}$ : [...] Do you remember when we started the 17th century in Valencia? We saw that there have been an extraordinary development of the stucco plaster in Valencia. (See Appendix (d)).

Booster-verbs such as know and show are frequent in the disciplines of History and Heritage, Humanities and Tourism, as evidenced in the outcomes produced by CLIL lecturers. The same is true for their Spanish equivalents saber and mostrar, which may be spotted either in CLIL lectures as well.

Graduation is primarily represented in communicative events that are conducted in English and Spanish. By adding the Spanish diminutive suffix -ito to a gradable adjective as poquito (i.e. to a small extent), shown in excerpt 111, the speaker attenuates the statement given so that the audience gets the general idea of ome of the videos that will be played in the classroom setting.

(111) H2: [...] There is also a video that shows to a small extent how temporal art exhibitions are organized [...]. [También hay algún vídeo que muestra un poquito cómo se va organizando y elaborando una exposición ehh temporal [...]]. (See Appendix (c)).

Another example of graduation produced by CLIL lecturers has to do with mucho. This adverb, which operates as an intensifier, is translated into English as a great deal or $a$ lot as seen below.

(112) H2: Look, this year we've designed an English practice to, I mean, for you to get familiar with specific terminology and all that...eh: it's related to the last units we've covered. There's a lot about art collection. What were we talking about last week? Do you remember? [...]. [A ver, este año la actividad en inglés que hemos planteado para que, ya os digo, para que os vayáis familiarizando con el vocabulario específico y demás...ehh va 
en relación al último de los temas que hemos visto. Sobre el coleccionismo hay mucho. ¿Qué estuvimos hablando la semana pasada? ¿Os acordáis? [...]]. (See Appendix (c)).

(113) S11: But it will take us a lot of time [to write this], won't it? [Pero esto nos costará mucho escribir todo esto, ¿no?] (See Appendix (c)).

In examining students' discourse, seminars were the teaching practices in which their contributions were registered (see Table 53). The occurrence of these boosters appears to be higher in Tourism, with the prevalence of Spanish devices $(6.48 \%$ ), followed by those in English (1.70\%o). The number of boosting devices in English decreases in the History of the Classical World module (1.29\%), with an even lower representation in the fourth year of the History and Heritage degree $(0.10 \%$ ) whose items were only recognised in Spanish.

Table 53. Use of boosters in student discourse in Humanities and Social Sciences: Seminars.

\begin{tabular}{|c|c|c|c|c|c|c|}
\hline \multicolumn{7}{|c|}{ STUDENT DISCOURSE: BOOSTERS IN CLIL SEMINARS } \\
\hline \multirow{2}{*}{ Modules } & \multicolumn{6}{|c|}{ Boosters } \\
\hline & Eng & $\%$ & $\mathrm{Sp}$ & $\%$ & Cat & $\%$ \\
\hline History of the Classical World & 13 & 1.29 & - & - & - & - \\
\hline Fundamentals and Theory of Artistic Heritage & - & - & 1 & 0.10 & - & - \\
\hline $\begin{array}{r}\text { Total Humanities } \\
10,051 w\end{array}$ & 13 & 1.29 & 1 & 0.10 & - & - \\
\hline Valencian art and Tourist resources & 21 & 1.70 & 80 & 6.48 & - & - \\
\hline $\begin{array}{r}\text { Total Social Sciences } \\
12,346 \mathrm{w}\end{array}$ & 21 & 1.70 & 80 & 6.48 & - & - \\
\hline $\begin{array}{r}\text { Total Soft Sciences } \\
22,397 \mathrm{w}\end{array}$ & 34 & 1.52 & 81 & 3.62 & - & - \\
\hline
\end{tabular}

Approximators and gradable grammatical features were employed both in English and Spanish. Examples include mostly, mayoría and casi (i.e. almost) as approximators, whereas the most, super or tanto (i.e. so) conveyed indefinite degree. These can be read as follows.

(114) S10: Eh and finally, Frida Kahlo was considered one of the one of Mexico greatest artist who began writing mostly since 14. (See Appendix (d)).

(115) S4: Okay. And then we have The Recovery of Saint Kitts Island which was - was requested by the king as a decoration element for the kingdom hall and eh the picture is ah was painted because it was one of the fastest victories that the Spanish army had and on top 
of that they had almost no casualties or [...]. [Vale. Y luego tenemos la Recuperación de [la isla] San Cristóbal que se - fue pedida por el rey para decorar el salón del reino y eh la representación es ah la hacen porque fue una de las victorias más rápidas que tuvo el ejército español y encima no tuvieron casi bajas ni [...]]. (See Appendix (d)).

(116) S12: Ah so it's about antique of love, typical and superomantic love. (See Appendix (d)).

Solidarity with readers was expressed through the booster obviamente (obviously), which denoted mutual background knowledge related to art.

(117) S2: Otro cuadro posiblemente más conocido de Diego Velázquez es Las Meninas, que también representa a la infanta Margarita con sus sirvientes y pues obviamente con vestidos típicos de la época.

\subsubsection{Hedges}

In analysing hedging devices in teacher discourse, the findings reveal that a great prominence of hedges occurs in the lectures held in the discipline of Humanities (10.25\%) in contrast to the field of Social Sciences (7.46\%) (see Table 54). When compared to CLIL seminars, a short number of markers is found in English, where the distribution is reduced to $0.99 \%$ in History of the Classical World, $0.10 \%$ in Fundamentals and Theory of Artistic Heritage and $0.65 \%$ in Valencian art and Tourist Resources. Not only do hedging devices occur in English the degrees examined but also in Spanish, being more prominent in the fourth-year History module (1.09\%). Even though Spanish examples are also taken from the Social Sciences corpus, the representation of Catalan markers is missing in both Valencian art and Tourist resources and History of the Classical World modules. 
Table 54. Use of hedges in teacher discourse in Humanities and Social Sciences: Lectures and Seminars.

\begin{tabular}{|c|c|c|c|c|c|c|c|c|c|c|c|c|}
\hline \multicolumn{13}{|c|}{ TEACHER DISCOURSE: HEDGES IN CLIL LECTURES AND SEMINARS } \\
\hline \multirow{3}{*}{ Modules } & \multicolumn{12}{|c|}{ Hedges } \\
\hline & \multicolumn{6}{|c|}{ Lectures } & \multicolumn{6}{|c|}{ Seminars } \\
\hline & Eng & $\%$ & $\mathrm{Sp}$ & $\%$ & Cat & $\%$ & Eng & $\%$ & $\mathrm{Sp}$ & $\%$ & Cat & $\%$ \\
\hline $\begin{array}{l}\text { History of the Classical } \\
\text { World }\end{array}$ & 103 & 10.25 & - & - & - & - & 10 & 0.99 & - & - & - & - \\
\hline $\begin{array}{l}\text { Fundamentals and Theory of } \\
\text { Artistic Heritage }\end{array}$ & - & - & - & - & - & - & 1 & 0.10 & 11 & 1.09 & 1 & 0.10 \\
\hline $\begin{array}{r}\text { Total Humanities } \\
10,051 w\end{array}$ & 103 & 10.25 & - & - & - & - & 11 & 1.09 & 11 & 1.09 & 1 & 0.10 \\
\hline $\begin{array}{l}\text { Valencian art and Tourist } \\
\text { resources }\end{array}$ & 92 & 7.46 & - & - & - & - & 8 & 0.65 & 2 & 0.16 & - & - \\
\hline $\begin{array}{r}\text { Total Social Sciences } \\
12,346 \mathrm{w}\end{array}$ & 92 & 7.46 & - & - & - & - & 8 & 0.65 & 2 & 0.16 & - & - \\
\hline $\begin{array}{r}\text { Total Soft Sciences } \\
22,397 \mathrm{w}\end{array}$ & 195 & 8.71 & - & - & - & - & 19 & 0.85 & 13 & 0.58 & 1 & 0.04 \\
\hline
\end{tabular}

The mitigation of propositions is perceived in nouns, adjectives, verbs, modal verbs, and adverbs, thereby expressing the speaker's vagueness, doubts, beliefs or speculations. Modals such as will, would, can and could are common in both CLIL modules, as shown in the next extracts. Will is used to transmit the speaker's uncertainty, whereas can, which may be substituted by may, indicates possibility.

(118) H1: Pompey will think that Caesar is weak, so he can attack him because Caesar could not defend himself. (See Appendix (a)).

(119) T: OK. Today we are going to talk about the development of arts in the Kingdom of Valencia and Whoa, this can also be applied to the rest of Spain during the $18^{\text {th }}$ century. (See Appendix (d)).

So far, the lack of lecturers' confidence is reflected in elements other than modals, such as the adverbs quite and anymore. The History lecturer (H1) makes use of quite to refer to the fairly significant extent to which an item in the Kahoot survey can be understood. On the other hand, anymore is employed by the Tourism lecturer when referring to the fact the Iberian Peninsula was no longer fragmented in different realms. 
(120) H1: [...]. Once again they elected two consuls, so it's quite easy to understand this question. [...]. (See Appendix (a)).

(121) $\mathrm{T}$ : [...] These palaces were thought to preserve the real presence of the king in the different territories of the Iberian Peninsula $\mathrm{mm}$ that were not anymore more independent kingdoms but a unified kingdom ruled from Madrid [...]. (See Appendix (d)).

Adjective-hedges can be identified in lecturers' articulated speech in CLIL seminars addressed to future professionals in the domains of History and Heritage, Humanities and Tourism. The occurrence of some, any and their Spanish equivalents reveals the use of reliability hedging strategies. In the transcript below, lack of specificity can be recognised in lecturers' discourse through items like algún, algunos, otro, otros, which are employed to give students a general idea of the topics covered in the videos played in the classroom setting.

(122) H2: [...] Well, some of them, - some of them deal with how a given museum is created, how the museum is built. Remember that some of them are located in historical buildings, others are located in new buildings. There's also another video showing how a temporary exhibition is organised and developed. Another [video] deals - deals with the field of museums, doesn't it? How they can serve as a teaching resource for students' learning through artwork [...]. [[...] Pues algunos de ellos, pues por ejemplo cómo se crea ese museo, cómo se construye por ejemplo el edificio del museo. Acordaros que hay algunos de ellos que se crean en edificios históricos, otros que se ubican en edificios de nueva planta. También hay algún vídeo que muestra un poquito cómo se va organizando y elaborando una exposición ehh temporal. Otro [vídeo] que - que habla de la vertiente relativa de los museos, ¿no? De cómo pueden enseñar a los alumnos a través de obras de arte [...]]. (See Appendix (c)).

As observed in the table above, the variety of hedges is more limited in Catalan. A clear example has to do with the verb haver de (i.e. have to) that follows, employed by the History lecturer in the second-year module when giving students the guidelines to complete the task.

(123) H2: [...] Eh a ver, açò és com una pràctica més que després com totes les pràctiques vos - vos ajuda a pujar nota. Però ho heu de fer en angles [...]]. (See Appendix (c)).

Turning to students' speech, the incidence of hedges in English appears to be slightly higher in the lecture seminar delivered in the first-year History module (1.09\%o) (see Table 55). No Spanish and no Catalan instances have been recognised in History $(1.09 \%)$ and Tourism $(0.76 \%$ ) lectures, which denote that lecturers stick to the use of English as the means of instruction. A considerable increase can be observed in first- 
year History and fourth-year Tourism seminars, with a total of 9.05\% and $4.78 \%$ of hedges in English respectively. The proportion of these interpersonal markers declines in the fourth-year History module, where it represents $0.20 \%$.

Table 55. Use of different markers in student discourse in Humanities and Social Sciences: Lectures and Seminars.

\begin{tabular}{|c|c|c|c|c|c|c|c|c|c|c|c|c|}
\hline \multicolumn{13}{|c|}{ STUDENT DISCOURSE: HEDGES IN CLIL LECTURES AND SEMINARS } \\
\hline \multirow{2}{*}{ Modules } & \multicolumn{6}{|c|}{ Lectures / Lecture seminars } & \multicolumn{6}{|c|}{ Seminars } \\
\hline & Eng & $\%$ & $\mathrm{Sp}$ & $\%$ & Cat & $\%$ & Eng & $\%$ & $\mathrm{Sp}$ & $\%$ & Cat & $\%$ \\
\hline History of the Classical World & 11 & 1.09 & - & - & - & - & 91 & 9.05 & - & - & - & - \\
\hline $\begin{array}{l}\text { Fundamentals and Theory of } \\
\text { Artistic Heritage }\end{array}$ & - & - & - & - & - & - & - & - & 2 & 0.20 & - & - \\
\hline $\begin{array}{r}\text { Total } \\
10,051 w\end{array}$ & 11 & 1.09 & - & - & - & - & 91 & 9.05 & 2 & 0.20 & - & - \\
\hline $\begin{array}{l}\text { Valencian art and Tourist } \\
\text { resources }\end{array}$ & 5 & 0.76 & - & - & - & - & 59 & 4.78 & 71 & 5.75 & - & - \\
\hline $\begin{array}{r}\text { Total } \\
12,346 w\end{array}$ & 5 & 0.76 & - & - & - & - & 59 & 4.78 & 71 & 5.75 & - & - \\
\hline $\begin{array}{r}\text { Total Soft Sciences } \\
22,397 \mathrm{w}\end{array}$ & 16 & 0.71 & - & - & - & - & 150 & 6.70 & 73 & 3.26 & - & - \\
\hline
\end{tabular}

Student discourse in both History and Tourism lectures is characterised by the use of modals such as can, could and would, as well as by other adjective and adverb devices like something, some or probably. The example below illustrates the production of spontaneous interactive patterns of CLIL discourse with the use of can and could. Students try to construct knowledge by negotiating meaning with the lecturer.

\section{(124) S13: Can you [unintelligible], please?}

H1: Subtitles?

S7: No. He asked if you could repeat the answers. (See Appendix III (a)).

Lack of certainty can be perceived in the adverb probably. As shown in the following excerpt, the Tourism undergraduate student is not sure about the answer given to the CLIL lecturer. 
These findings suggest that hedges seem to occur more frequently in lecturers' and learners' discourse involved in the History of the Classical World module. A large number of devices are also present in the domain of Social Sciences, but it is in the Fundamentals and Theory of Artistic Heritage module where differences are remarkable. Not only is the incidence of hedging features lower in this fourth-year module, but the language employed in this communicative event is limited to Spanish, as opposed to the other modules under study.

\subsubsection{Health Sciences}

The findings in the fields of Health Sciences reveal that participants' use of interpersonal devices employed by participants may differ not only among the degrees under study but also among the types of CLIL seminars implemented. Evidence may be found in the table below.

Table 56. Total number of metadiscoursal markers found in teacher discourse in Health Sciences.

\begin{tabular}{|l|c|c|}
\hline \multicolumn{2}{|c|}{ TEACHER DISCOURSE IN CLIL SEMINARS } \\
\hline \multicolumn{1}{|c|}{ Modules } & \multicolumn{2}{c|}{ Seminars } \\
\cline { 2 - 3 } & Number of instances & 34.60 \\
\hline English for Medicine & 1,380 & 14.34 \\
\hline Anthropology and Evolution & 572 & 11.99 \\
\hline Epidemiology and Public Health & 478 & 6.22 \\
\hline Women's care & 248 & 20.99 \\
\hline Social and Affective Neuroscience & 837 & $\mathbf{8 8 . 1 4}$ \\
\hline Total Hard Sciences & $\mathbf{3 9 , 8 7 6 w}$ & $\mathbf{3 , 5 1 5}$ \\
\hline
\end{tabular}

Figure 20 illustrates that teacher discourse is characterised by a large number of metadiscoursal markers, especially in lecture seminars as is the case of English for Medicine, the first-year module addressed to future doctors. A considerable decrease can be observed in video-debate and discussion seminars, with Affective and Social Neuroscience and Anthropology coming in the second and third place. The occurrence of interpersonal devices seems to be less common in oral presentations, especially in the Women's care module. 


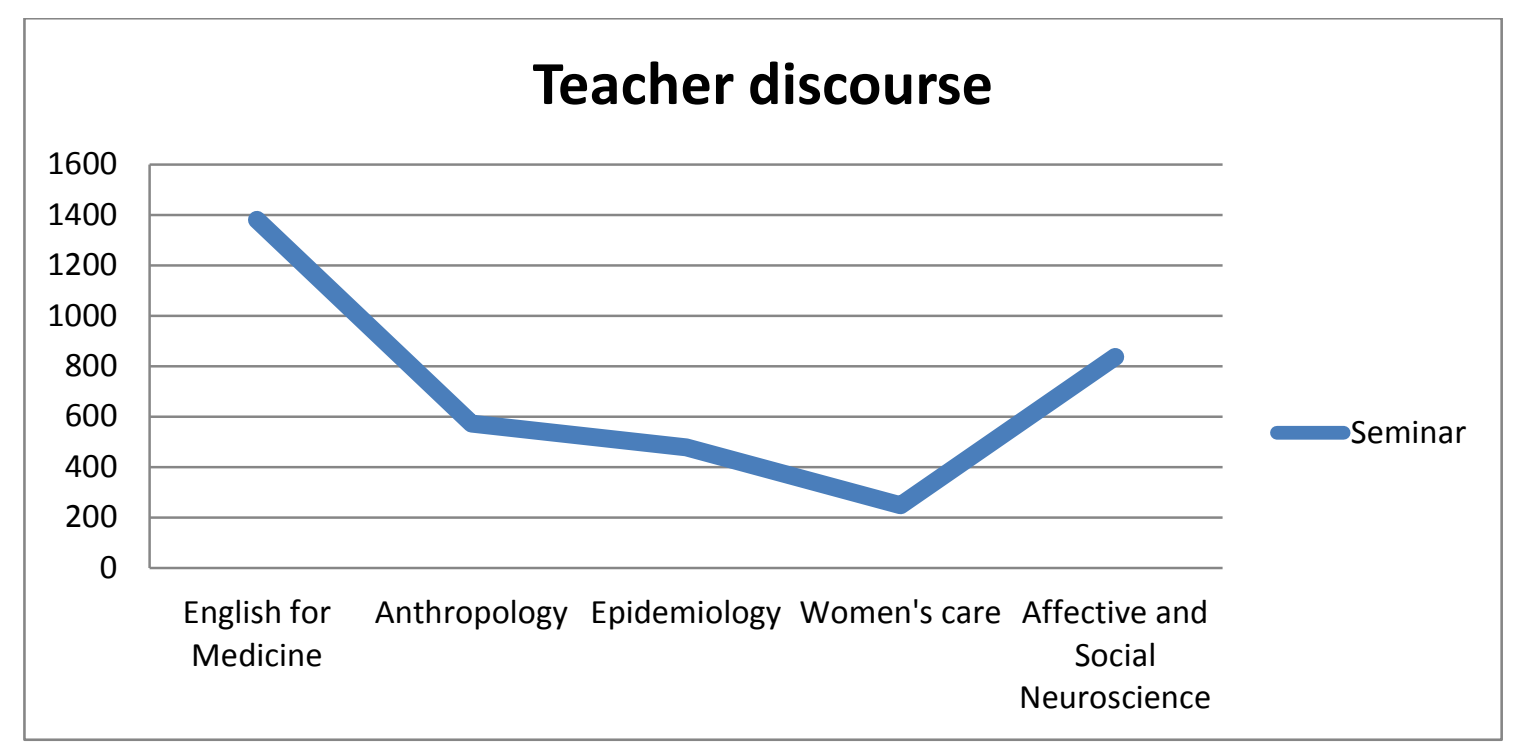

Figure 20. Teacher discourse in CLIL seminars: Health Sciences.

On the other hand, a general outlook of the interpersonal elements identified in students' speech is shown in Figure 21. It should be noted that different trends from the ones occurring in teacher discourse can be observed (see Table 57). In this sense, the distribution of these resources in student-talk seminars devoted to oral presentations (i.e. Epidemiology, Women' care and Psychology modules) stands out. The fact that learners are given the opportunity to take the floor and communicate may explain these results. Conversely, those categories encountered in discussion and lecture seminars are meagre. Evidence may be found in first-year and second-year Medicine modules which are likely to be more teacher-centred practices. The data also indicate that video-debate seminars boost participation on the grounds that Psychology undergraduates' speech remains steady when compared to lecturers in this field.

Table 57. Total number of metadiscoursal markers found in student discourse in Health Sciences.

\begin{tabular}{|c|c|c|}
\hline \multicolumn{3}{|c|}{ STUDENT DISCOURSE IN CLIL SEMINARS } \\
\hline \multirow{2}{*}{ Modules } & \multicolumn{2}{|c|}{ Seminars } \\
\hline & Number of instances & $\%$ \\
\hline English for Medicine & 121 & 3.03 \\
\hline Anthropology and Evolution & 25 & 0.63 \\
\hline Epidemiology and Public Health & 866 & 21.71 \\
\hline Women's care & 381 & 9.55 \\
\hline Social and Affective Neuroscience & 308 & 7.72 \\
\hline $\begin{array}{r}\text { Total Hard Sciences } \\
39,876 \mathrm{w}\end{array}$ & 1,701 & 42.66 \\
\hline
\end{tabular}




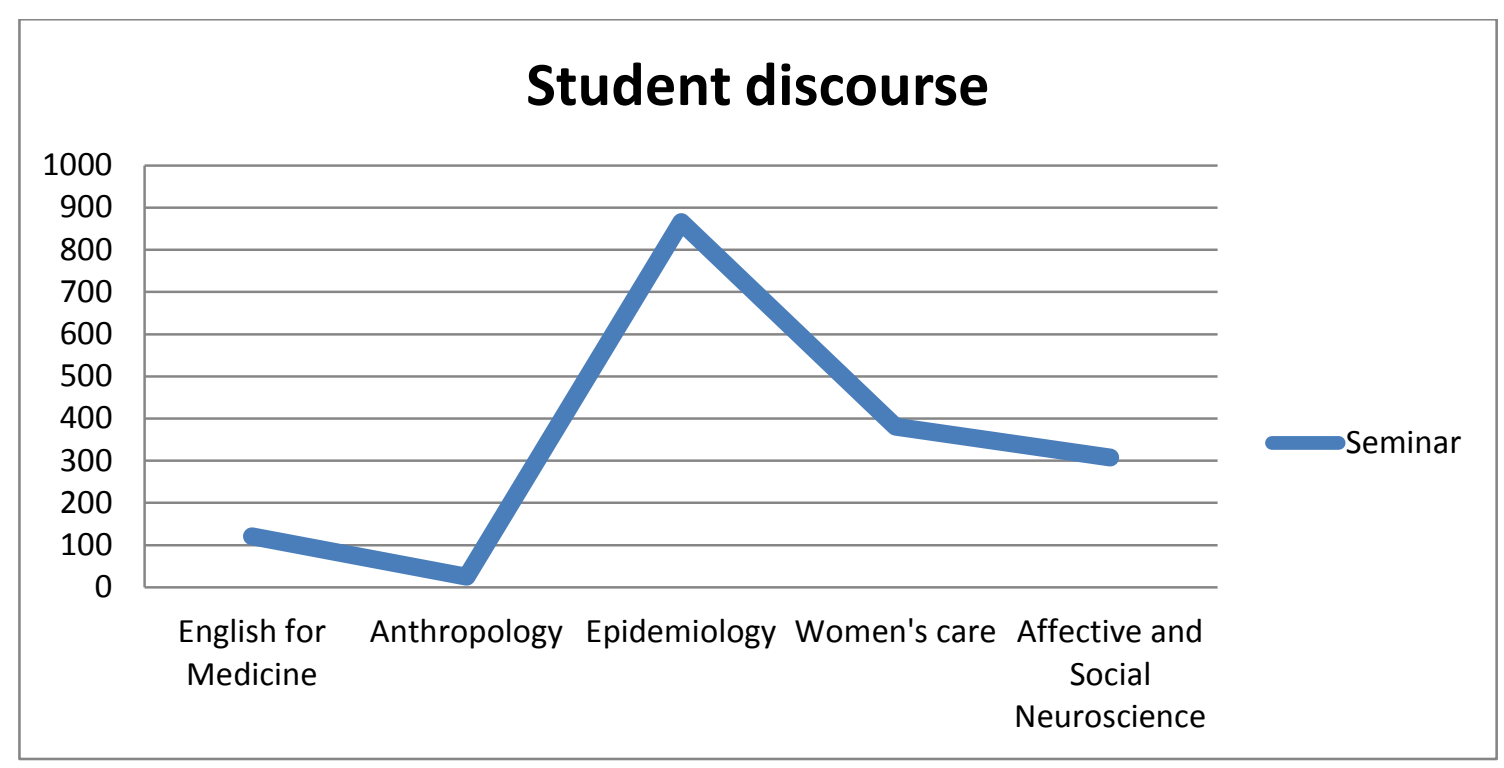

Figure 21. Student discourse in CLIL lectures and seminars: Health Sciences.

The frequency of metadiscoursal markers in CLIL seminars implemented in the field of Health Sciences differs to a certain extent, as seen in the tables below. In line with the results obtained in the domains of Humanities and Social Sciences, Table 58 shows that the most recurrent category in teacher discourse has to do with engagement markers, followed by hedges, attitudinal markers and boosters. Hedging devices mostly occur in English, with the first-year Medicine module reaching the highest peak. Neuroscience and Social Affective Factors can be identified as the second module with a higher quantity of hedges. A decrease in heding resources can be observed in the remaining modules, with the Nursing seminar being noted as the teaching practice with a lower presence of hedges. The same applies for attitudinal markers, where the main difference is found in the field of Medicine since the features in the Epidemiology module outnumber those recognised in Anthropology. Slight variation also exists in the use of boosters, where Anthropology, Neuroscience and Social Affective Factors, and Epidemiology come in the second, third and fourth positions respectively. As for the languages in which these resources occurred, oral outcomes were mainly produced in English, with non-systematic examples in Spanish and Catalan. 
Table 58. Use of different markers in teacher discourse in Health Sciences: Seminars.

\begin{tabular}{|c|c|c|c|c|c|c|c|c|c|c|c|c|c|c|c|c|c|c|c|c|c|c|c|c|}
\hline \multicolumn{25}{|c|}{ TEACHER DISCOURSE IN CLIL SEMINARS } \\
\hline \multirow{2}{*}{ Modules } & \multicolumn{6}{|c|}{ Engagement markers } & \multicolumn{6}{|c|}{ Attitudinal markers } & \multicolumn{6}{|c|}{ Hedges } & \multicolumn{6}{|c|}{ Boosters } \\
\hline & Eng & $\%$ & $\mathrm{Sp}$ & $\%$ & Cat & $\%$ & Eng & $\%$ & $\mathrm{Sp}$ & $\%$ & Cat & $\%$ & Eng & $\%$ & $\mathrm{Sp}$ & $\%$ & Cat & $\%$ & Eng & $\%$ & $\mathrm{Sp}$ & $\%$ & Cat & $\%$ \\
\hline English for Medicine & 933 & 20.79 & 18 & 0.45 & - & - & 92 & 2.31 & 2 & 0.05 & - & - & 293 & 5.99 & 7 & 0.18 & - & - & 35 & 0.88 & - & - & - & - \\
\hline $\begin{array}{l}\text { Anthropology and } \\
\text { Evolution }\end{array}$ & 378 & 9.48 & 7 & 0.18 & - & - & 79 & 1.98 & - & - & - & - & 79 & 1.98 & - & - & - & - & 29 & 0.73 & - & - & - & - \\
\hline $\begin{array}{l}\text { Epidemiology and } \\
\text { Public Health }\end{array}$ & 308 & 7.72 & 11 & 0.28 & - & - & 49 & 1.23 & 4 & 0.10 & - & - & 88 & 2.21 & 4 & 0.10 & - & - & 14 & 0.35 & - & - & - & - \\
\hline Women's care & 179 & 4.49 & 12 & 0.30 & - & - & 7 & 0.18 & 2 & 0.05 & - & - & 31 & 0.78 & 2 & 0.05 & - & & 15 & 0.38 & - & - & - & - \\
\hline $\begin{array}{l}\text { Affective and Social } \\
\text { Neuroscience }\end{array}$ & 443 & 11.11 & 139 & 3.49 & 10 & 0.25 & 87 & 2.18 & - & - & 4 & 0.10 & 96 & 2.41 & 8 & 0.20 & 2 & 0.05 & 24 & 0.60 & 22 & 0.55 & 2 & 0.05 \\
\hline $\begin{array}{r}\text { Total Hard Sciences } \\
39,876 w\end{array}$ & 2,241 & 56.20 & 187 & 4.69 & 10 & 0.25 & 314 & 7.87 & 8 & 0.20 & 4 & 0.10 & 587 & 14.72 & 21 & 0.53 & 2 & 0.05 & 117 & 2.93 & 22 & 0.55 & 2 & 0.05 \\
\hline
\end{tabular}


Table 59 below shows student discourse in the seminar sessions belonging to the area of Health Sciences. The prevalence of engagement markers as the first category employed in CLIL seminars should be noted. Similar trends can be observed with regard to the occurrence of other interpersonal markers, more specifically, hedges which seem to be recurrent in Health Sciences students' speech. Unlike teacher discourse in CLIL seminars, the use of interpersonal markers in the third-year Medicine and Nursing modules (i.e. Epidemiology and Women's care) should be highlighted. In this vein, it is worth mentioning that the fact that students were able to present their group projects allowed for a higher production of devices. The video-debate seminar in the Psychology degree was also pivotal to foster the incorporation of these linguistic features. As to English for Medicine, hedges and boosters are more regular in student discourse in comparison with Anthropology, where only attitudinal markers seem to be more prominent.

On this account, the frequency of metadiscoursal markers uttered by learners in CLIL seminars is reduced in contrast to the ones recognised in teacher discourse. As happens with Humanities and Social Sciences, the occurrence of interpersonal devices seems to be notable in slide-talk seminars, given that students are able to participate actively in classroom discourse. 
Table 59. Use of different markers in student discourse in Health Sciences: Seminars.

\begin{tabular}{|c|c|c|c|c|c|c|c|c|c|c|c|c|c|c|c|c|c|c|c|c|c|c|c|c|}
\hline \multicolumn{25}{|c|}{ STUDENT DISCOURSE IN CLIL SEMINARS } \\
\hline \multirow{2}{*}{ Modules } & \multicolumn{6}{|c|}{ Engagement markers } & \multicolumn{6}{|c|}{ Attitudinal markers } & \multicolumn{6}{|c|}{ Hedges } & \multicolumn{6}{|c|}{ Boosters } \\
\hline & Eng & $\%$ & $\mathrm{Sp}$ & $\%$ & Cat & $\%$ & $\overline{\text { Eng }}$ & $\%$ & $\mathrm{Sp}$ & $\%$ & Cat & $\%$ & Eng & $\%$ & $\mathrm{Sp}$ & $\%$ & Cat & $\%$ & Eng & $\%$ & $\mathrm{Sp}$ & $\%$ & Cat & $\%$ \\
\hline $\begin{array}{ll}\text { English for } \\
\text { Medicine }\end{array}$ & 56 & 1.28 & 41 & 1.02 & - & - & 2 & 0.05 & - & - & - & - & 9 & 0.23 & 6 & 0.15 & - & - & 7 & 0.18 & - & - & - & - \\
\hline $\begin{array}{l}\text { Anthropology } \\
\text { and Evolution }\end{array}$ & 8 & 0.20 & 7 & 0.18 & - & - & 3 & 0.08 & 1 & 0.02 & - & - & 2 & 0.05 & 2 & 0.05 & - & - & - & - & 2 & 0.05 & - & - \\
\hline $\begin{array}{l}\text { Epidemiology } \\
\text { and Public } \\
\text { Health }\end{array}$ & 491 & 12.44 & 3 & 0.08 & - & - & 130 & 3.26 & 3 & 0.08 & - & - & 186 & 4.66 & 3 & 0.08 & - & - & 48 & 1.20 & 2 & 0.05 & - & - \\
\hline Women's care & 101 & 2.53 & 76 & 1.91 & 14 & 0.35 & 44 & 1.10 & 8 & 0.20 & 2 & 0.05 & 96 & 2.41 & 15 & 0.38 & - & - & 25 & 0.63 & - & - & - & - \\
\hline $\begin{array}{l}\text { Affective and } \\
\text { Social } \\
\text { Neuroscience }\end{array}$ & 52 & 1.30 & 81 & 2.03 & 36 & 0.90 & 18 & 0.45 & 4 & 0.10 & 3 & 0.08 & 20 & 0.50 & 42 & 1.05 & 10 & 0.25 & 6 & 0.15 & 34 & 0.85 & 2 & 0.05 \\
\hline $\begin{array}{r}\text { Total Hard } \\
\text { Sciences } \\
\mathbf{3 9 , 8 7 6 w}\end{array}$ & 708 & 17.76 & 208 & 5.22 & 50 & 1.25 & 197 & 4.94 & 16 & 0.40 & 5 & 0.13 & 313 & 7.85 & 68 & 1.71 & 10 & 0.25 & 86 & 2.16 & 38 & 0.95 & 2 & 0.05 \\
\hline
\end{tabular}




\subsubsection{Engagement markers}

Participants' engagement is identified through the use of questions, personal references, imperatives, directives, comprehension, and contextual, behavioural and apologetic comments. Tables 60, 61, 62 and 63 display the incidence of engagement markers in Medicine, Nursing and Psychology seminars following a CLIL approach. As can be seen, the number of engagement markers found in the output produced by the medical expert delivering the Englih for Medicine seminar stands out (23.40\%o). A decline can be noticed in the Social and Affective Neuroscience module (11.11\%), which is even more considerable in Anthropology (9.48\%o), Epidemiology (7.72\%o) and Women's care practices $(4.49 \%$ ). These speakers may rely on their multilingual repertoire when interacting in the communicative event to convey and negotiate meaning. Such dynamics usually take place during the opening of the session to let students know that English, particularly in the Medicine classroom. The variety of languages is more remarkable in the Psychology module in order to lower students' anxiety levels and boost their participation in the target language. 
Table 60. Use of engagement markers in teacher discourse in Health Sciences: Medicine seminars.

\begin{tabular}{|c|c|c|c|c|c|c|c|c|c|c|c|c|c|c|c|c|c|c|}
\hline \multicolumn{19}{|c|}{ TEACHER DISCOURSE: ENGAGEMENT MARKERS IN CLIL SEMINARS } \\
\hline \multirow{2}{*}{ Engagement markers } & \multicolumn{6}{|c|}{ English for Medicine } & \multicolumn{6}{|c|}{ Anthropology and Evolution } & \multicolumn{6}{|c|}{ Epidemiology } \\
\hline & Eng & $\%$ & $\mathrm{Sp}$ & $\%$ & Cat & $\%$ & Eng & $\%$ & $\mathrm{Sp}$ & $\%$ & Cat & $\%$ & Eng & $\%$ & $\mathrm{Sp}$ & $\%$ & Cat & $\%$ \\
\hline Questions & 90 & 2.26 & 1 & 0.03 & - & - & 52 & 1.30 & 1 & 0.03 & - & - & 34 & 0.85 & 1 & 0.03 & - & - \\
\hline Imperatives & 5 & 0.13 & - & - & - & - & 17 & 0.43 & - & - & - & - & 8 & 0.20 & - & - & - & - \\
\hline Directives & 86 & 2.16 & - & - & - & - & 46 & 1.15 & - & - & - & - & 35 & 0.88 & - & - & - & - \\
\hline Comprehension comments & 8 & 0.20 & - & - & - & - & 13 & 0.33 & - & - & - & - & - & - & - & - & - & - \\
\hline Apologetic comments & - & - & - & - & - & - & - & - & - & - & - & - & 3 & 0.08 & - & - & - & - \\
\hline Contextual comments & 2 & 0.05 & 1 & 0.03 & - & - & 5 & 0.13 & - & - & - & - & 12 & 0.30 & - & - & - & - \\
\hline Behavioural comments & 1 & 0.03 & - & - & - & - & - & - & - & - & - & - & 1 & 0.03 & - & - & - & - \\
\hline Inclusive comments & 734 & 18.41 & 16 & 0.40 & - & - & 245 & 6.14 & 6 & 0.15 & - & - & 215 & 5.39 & 10 & 0.25 & - & - \\
\hline $\begin{array}{r}\text { Total Hard Sciences } \\
39,876 \mathrm{w}\end{array}$ & 933 & 23.40 & 18 & 0.45 & - & - & 378 & 9.48 & 7 & 0.18 & - & - & 308 & 7.72 & 11 & 0.28 & - & - \\
\hline
\end{tabular}


Table 61. Use of engagement markers in teacher discourse in Health Sciences: Nursing seminar.

\begin{tabular}{|c|c|c|c|c|c|c|}
\hline \multicolumn{7}{|c|}{ TEACHER DISCOURSE: ENGAGEMENT MARKERS IN CLIL SEMINARS } \\
\hline \multirow{2}{*}{ Engagement markers } & \multicolumn{6}{|c|}{ Women's care } \\
\hline & Eng & $\%$ & $\mathrm{Sp}$ & $\%$ & Cat & $\%$ \\
\hline Questions & 59 & 1.48 & - & - & - & - \\
\hline Imperatives & 5 & 0.13 & 1 & 0.03 & - & - \\
\hline Directives & 12 & 0.30 & 1 & 0.03 & - & - \\
\hline Comprehension comments & 4 & 0.10 & 1 & 0.03 & - & - \\
\hline Apologetic comments & - & - & - & - & - & - \\
\hline Contextual comments & - & - & 2 & 0.05 & - & - \\
\hline Behavioural comments & - & - & - & - & - & - \\
\hline Inclusive comments & 99 & 2.48 & 7 & 0.18 & - & - \\
\hline $\begin{array}{r}\text { Total Hard Sciences } \\
39,876 \mathrm{w}\end{array}$ & 179 & 4.49 & 12 & $\mathbf{0 . 3 0}$ & - & - \\
\hline
\end{tabular}


Table 62. Use of engagement markers in teacher discourse in Health Sciences: Psychology seminar.

\begin{tabular}{|c|c|c|c|c|c|c|}
\hline \multicolumn{7}{|c|}{ TEACHER DISCOURSE: ENGAGEMENT MARKERS IN CLIL SEMINARS } \\
\hline \multirow{2}{*}{ Engagement markers } & \multicolumn{6}{|c|}{ Social and Affective Neuroscience } \\
\hline & Eng & $\%$ & $\mathrm{Sp}$ & $\%$ & Cat & $\%$ \\
\hline Questions & 122 & 3.06 & 40 & 1.00 & 3 & 0.08 \\
\hline Imperatives & 5 & 0.13 & 2 & 0.05 & - & - \\
\hline Directives & 36 & 0.90 & 17 & 0.43 & - & - \\
\hline Comprehension comments & 1 & 0.03 & - & - & - & - \\
\hline Apologetic comments & - & - & - & - & - & - \\
\hline Contextual comments & 2 & 0.05 & 1 & 0.03 & - & - \\
\hline Behavioural comments & 4 & 0.10 & - & - & - & - \\
\hline Inclusive comments & 273 & 6.85 & 79 & 19.87 & 7 & 0.18 \\
\hline $\begin{array}{r}\text { Total Hard Sciences } \\
39,876 \mathrm{w}\end{array}$ & 443 & 11.11 & 139 & 3.49 & 10 & 0.25 \\
\hline
\end{tabular}


Table 63. Global use of engagement markers in teacher discourse in Health Sciences: Seminars.

\begin{tabular}{|l|c|c|c|c|c|c|}
\hline TEACHER DISCOURSE: ENGAGEMENT MARKERS IN CLIL SEMINARS \\
\hline \multirow{2}{*}{ Modules } & \multicolumn{7}{|c|}{ Engagement markers } \\
\cline { 2 - 8 } & Eng & $\% 0$ & Sp & $\% 0$ & Cat & $\%$ \\
\hline English for Medicine & 933 & 23.40 & 18 & 0.45 & - & - \\
\hline Anthropology and Evolution & 378 & 9.48 & 7 & 0.18 & - & - \\
\hline Epidemiology and Public Health & 308 & 7.72 & 11 & 0.28 & - & - \\
\hline Women's care & 179 & 4.49 & 12 & 0.30 & - & - \\
\hline Affective and Social Neuroscience & 443 & 11.11 & 139 & 3.49 & 10 & 0.25 \\
\hline Total Hard Sciences & $\mathbf{2 , 2 4 1}$ & $\mathbf{5 6 . 2 0}$ & $\mathbf{1 8 7}$ & $\mathbf{4 . 6 9}$ & $\mathbf{1 0}$ & $\mathbf{0 . 2 5}$ \\
$\mathbf{3 9 , 8 7 6 w}$ & & & & & & \\
\hline
\end{tabular}


The presence of personal asides in Health Sciences seminars signals the interactive nature of teacher discourse. In line with the results obtained in Humanities and Social Sciences, pronouns are meant to include or exclude the audience and thus prompt a response. The most common pronoun to involve the classroom community is we, as in 127, 128 and 129.

(127) P1: Yeah! Because we are psychologists, we want to be or we pretend that, OK? (See Appendix III (j)).

(128) M3: Well, thank you very much for your presentation. You have already fit to the available time ahh and well now it's the time for questions. Eh please, we have time for two questions. (See Appendix III (h)).

(129) N1: Could be? OK. We found twenty-two articles saying that [laughs] and zero saying that accelerates: So what do you think? (See Appendix III (i)).

Such pronoun is not limited to the participants in the study, but may extend to other communities. When discussing fake news about the extinction of blonde females in the Anthropology module, we refers to the percepction of anthropologists with regard to the fact that women dye their hair blond to look younger, as illustrated in 130. The audience may be included through personal asides like you, which helps learners visualise an imaginary scenario to understand how proteins and DNA mutations work, as shown in 131.

(130) M2: [...] We're used to, to equate blond to young because when we get older we get eh darker hair [...]. (See Appendix III (g)).

(131) M1: There are a premature termination of the protein and you have a certain part of the protein, you don't have all the protein and maybe it's not functional or maybe eh it presents abnormal function because you losed a part of the protein... (See Appendix III (f)).

On the other hand, exclusion may take place through personal references, including you, I or he. In 132, the Nursing lecturer addresses a given learner by means of you in order for him to display his knowledge about the benefits and drawbacks of epidural anesthesia during labour. Other lecturers make use of $I$ to provide students with corrective feedback so that they can improve their projects when submitting their final version, as in 133. Apart from these purposes, the recapitulation of the contents covered in class as well as teachers' uncertainty can be identified in 134 and 135 respectively.

(132) N1: Are there any of these ones? You already said some. (See Appendix III (i)). 
(133) M3: [...] And the objectives I recommend, you explained them really well. But I recommend to write down, it's like the conclusions, you have to read it. (See Appendix III (h)).

(134) P1: [...] We can read, yeah, it's not only about how is or how much useful is it now, because maybe it's about the devices, they are good as I said already. (See Appendix III (j)).

(135) M1: [...] It's curious because a few years ago eh the the NHS NHS that is the National Healthy I don’t know the sigles [negative transfer from Spanish]. (See Appendix III (f)).

In addition, teacher discourse is characterised by a wide range of questions. These seem to be particularly frequent in the English for Medicine module, with rhetorical questions being raised to prevent monotonous speech. A clear example is that of the first-year Medicine module in 136, in which the topic of the seminar is presented. Another case is concerned with the discussion of fake new about haplogroups and Darwin's descendants, as in 137.

(136) M1: [...] What is the major cause of skin cancer? The UVA light, the UVA radiation. (See Appendix III (f)).

(137) M2: It's ridiculous. It's... What did they do? They found that it was U5. What did they do next? They collected ten or twelve people from the same village until they found someone that was U5 as well. (See Appendix III (g)).

Questions may be posed to foster CLIL learners' contributions. To this end, the Psychology lecturer in the Social and Affective Neuroscience module wants to ensure that the groups formed in this session are ready to share their thoughts about the videos -and more specifically the devices- that have caught their attention.

(138) P1: That would be necessary. Thank you. The last two groups? Are you ready? No? (See Appendix III (j)).

The identification of display questions occurs in the Women's care and English for Medicine modules. These questions allude to students' disciplinary expertise. For instance, Nursing learners are meant to discern cultural differences on pregnancy in 139, in contrast to 140 where first-year Medicine students should reflect on the issues covered in the Skin cancer seminar.

(139) N1: OK, very good. So: which differences you found: both of you: - which differences you found in Japan and in Spain? (See Appendix III (i)).

(140) M1: [...] Skin cancer is one of the most common neoplasm in the world, especially in European populations. Why in European populations?

S16: You have just explained it like 10 minutes ago. 


\section{SX: What?}

S16: You have explained the reason 10 minutes ago.

M1: Why? S16: Because we're going to the beach, taking a lot of sunbathing, a lot of exposure to the sun. (See Appendix III (f)).

Referential questions, whose answer is unknown to the lecturers, result in students' oral productions. The following item seeks to get students' responses to know more about the particularities of their project dealing with the effect of moderate red wine intake in the development of hypertension.

(141) M3: Have you already worked out or decided the - what type of statistical analysis are you going to carry out? (h)).

The use of directives denotes that instructions are required to assist students in the completion or improvement of the activities and projects designed for these CLIL seminars. Evidence may be found in the production of the modal verb should by the Epidemiology expert as well as in the use of puedes (i.e. can) by the Women's care specialist.

(142) M3: [...] Eh you should be, especially in the objectives and hypothesis as most precise as possible. (See Appendix III (h)).

(143) N1: Que puedes decir lo del principio. (See Appendix III (i)).

Apart from directives, guidelines can be provided as imperatives. For example, the Medicine lecturer in the Anthropology module tries to encourage students' participation by addressing them directly and giving them the option to express themselves in the language they prefer. At the same time, the imperative mood may be useful for the internationalisation of new notions presented in the seminar.

(144) M2: Come on, someone. In English or in Spanish. Go ahead, break the ice. (See Appendix III (g)).

(145) M1: Imagine that this aminoacid is exactly in a place where the proteins do the function like for example it links to another protein or whatever. (See Appendix III (f)).

(146) M1: [...] Aand just to finish take a message, please. Just take care of your skin. Protect yourselves. OK? Protect your cells and don't burn. (See Appendix III (f)).

Questions may be raised as comprehension comments to prove that students have understood what has been said. Typical terms that may be detected in these comments have to do with nouns such as questions, doubts, and verbs such as understand. 
(147) M1: Emm so, before we start, does anyone have any existential questions about tomorrow's and Wednesday's Biochemistry lessons? [M1: Emm so, antes de empezar. ¿Alguien tiene alguna duda existencial con lo de bioquímica de mañana y del miércoles?] (See Appendix III (f)).

(148) M2: OK: Who has not understood absolutely anything of what I said? Raise your hand. Of course, if you don't understand what I say, you don't know you have to raise your hand (See Appendix III (g)).

Misunderstandings generated by a low command of the target language make it necessary to convey meaning in different ways. As a result, exposure to comprehensible input takes place when the Nursing lecturer translates her speech, followed by a question to foster interaction.

(149) S11: ¿Qué has dicho?

N1: ¿Qué - Qué has dicho? Tú: tú no lo tienes claro

S10: No, what's... slows labor in Spanish.

N1: In Spanish?, Eh: La epidural hace que sea más lento el parto. What do you think? (See Appendix III (i)).

Likewise, teachers may reformulate their speech to meet their students' needs and enhance learning in the English language. As seen in the next sequence, the Psychology lecturer attemps to adapt their discourse due to students' bewilderness about the discussion of a video concerned with neural devices that may help blind or hard-ofhearing people.

(150) P1: [...] So it means that our brain has a lot to do, like the boss, but we can teach the brain even when it was not set up at the beginning. Yeah?

S13: More or less [S13: Més o menos].

P1: More or less. OK, that is, you cannot have those senses when you were born, OK? But you can teach your brain because... [P1: Més o menos. Val, és a dir, tu pots no tindre eixos sentits quan vas nàixer, OK? Però al teu cervell se li pot ensenyar 〈TLANG_Cat> per el tema de...]

P2: Because the brain eh have eh has plasticity.

P1: Exacte [P1: Exactly]. Like the position of learning. (See Appendix III (j)).

When focusing on the context, timing and language issues should be considered. The Anthropology teacher emphasises the time students have to finish the test within the seminar session. As for the Epidemiology lecturer, she tries to boost the confidence of a student with a low self-perception of his abilities in the English language. 
(151) M2: Now we're going to do the exam. There are only ten questions. We usually give twenty minutes for this exam because it's quite long. There are only ten questions, but you have twenty minutes to take the, the test.

(152) S15: My English... [S15: Es que mi inglés...].

M3: No, your English is very good

Behavioural comments are represented through the interjection shh employed by lecturers in their speech to call students' attention. Learners are expected to keep silence mainly because lecturers are giving an explanation, as in 153. Nonetheless, the use of this interjection may be helpful to avoid learners' distractions and have them focused on the videos.

(153) P1: The audio está bien? Yeah you can listen it? Shhh (See Appendix III (b)).

Tables 64, 65, 66 and 67 report the occurrence of engagement markers in the field of Health Sciences. A closer look at these results reveals that the number of resources produced in student discourse occurs at a lower rate in all the modules except for the Epidemiology seminar (12.31\%o). In fact, the number of these metadiscoursal markers is limited in English for Medicine (1.40\%), Anthropology (0.20\%) Women's care (2.53\%) and Social and Affective Neuroscience (1.30\%). Imperatives, directives, apologetic, contextual and behavioural comments are some of the categories that may not be prominent in these seminars. 
Table 64. Use of engagement markers in student discourse in Health Sciences: Seminars.

\begin{tabular}{|c|c|c|c|c|c|c|c|c|c|c|c|c|c|c|c|c|c|c|}
\hline \multicolumn{19}{|c|}{ STUDENT DISCOURSE: ENGAGEMENT MARKERS IN CLIL SEMINARS } \\
\hline \multirow{2}{*}{ Modules } & \multicolumn{6}{|c|}{ English for Medicine } & \multicolumn{6}{|c|}{ Anthropology and Evolution } & \multicolumn{6}{|c|}{ Epidemiology } \\
\hline & Eng & $\%$ & $\mathrm{Sp}$ & $\%$ & Cat & $\%$ & Eng & $\%$ & $\mathrm{Sp}$ & $\%$ & Cat & $\%$ & Eng & $\%$ & $\mathrm{Sp}$ & $\%$ & Cat & $\%$ \\
\hline Questions & 12 & 0.3 & 28 & 0.70 & - & - & 1 & 0.03 & 1 & 0.03 & - & - & 17 & 0.43 & 1 & 0.03 & - & - \\
\hline Imperatives & - & - & - & - & - & - & - & - & - & - & - & - & 9 & 0.23 & - & - & - & - \\
\hline Directives & 5 & 0.13 & - & - & - & - & - & - & - & - & - & - & - & - & - & - & - & - \\
\hline Comprehension comments & - & - & - & - & - & - & 1 & 0.03 & - & - & - & - & 3 & 0.08 & - & - & - & - \\
\hline Apologetic comments & - & - & - & - & - & - & - & - & - & - & - & - & 4 & 0.10 & - & - & - & - \\
\hline Contextual comments & - & - & 1 & 0.03 & - & - & - & - & - & - & - & - & 1 & 0.03 & - & - & - & - \\
\hline Behavioural comments & - & - & - & - & - & - & - & - & - & - & - & - & 1 & 0.03 & - & - & - & - \\
\hline Inclusive comments & 39 & 0.98 & 12 & 0.30 & - & - & 6 & 0.15 & 6 & 0.15 & - & - & 456 & 11.44 & 2 & 0.05 & - & - \\
\hline $\begin{array}{r}\text { Total Hard Sciences } \\
39,876 \mathrm{w}\end{array}$ & 56 & 1.40 & 41 & 1.03 & - & - & 8 & 0.20 & 7 & 0.18 & - & - & 491 & 12.31 & 3 & 0.08 & - & - \\
\hline
\end{tabular}


Table 65. Use of engagement markers in student discourse in Health Sciences: Nursing seminar.

\begin{tabular}{|c|c|c|c|c|c|c|}
\hline \multicolumn{7}{|c|}{ STUDENT DISCOURSE: ENGAGEMENT MARKERS IN CLIL SEMINARS } \\
\hline \multirow{2}{*}{ Modules } & \multicolumn{6}{|c|}{ Women's care } \\
\hline & Eng & $\%$ & $\mathrm{Sp}$ & $\%$ & Cat & $\%$ \\
\hline Questions & 8 & 0.20 & 19 & 0.48 & 8 & 0.20 \\
\hline Imperatives & - & - & - & - & - & - \\
\hline Directives & 3 & 0.08 & 7 & 0.18 & - & - \\
\hline Comprehension comments & 1 & 0.03 & 1 & 0.03 & - & - \\
\hline Apologetic comments & - & - & - & - & & - \\
\hline Contextual comments & - & - & - & - & & - \\
\hline Behavioural comments & - & - & - & - & - & - \\
\hline Inclusive comments & 89 & 2.23 & 49 & 1.23 & 6 & 0.15 \\
\hline $\begin{array}{r}\text { Total Hard Sciences } \\
39,876 w\end{array}$ & 101 & 2.53 & 76 & 1.91 & 14 & 0.35 \\
\hline
\end{tabular}


Table 66. Use of engagement markers in student discourse in Health Sciences: Psychology seminar.

\begin{tabular}{|c|c|c|c|c|c|c|}
\hline \multicolumn{7}{|c|}{ STUDENT DISCOURSE: ENGAGEMENT MARKERS IN CLIL SEMINARS } \\
\hline \multirow{2}{*}{ Modules } & \multicolumn{6}{|c|}{ Social and Affective Neuroscience } \\
\hline & Eng & $\%$ & $\mathrm{Sp}$ & $\%$ & Cat & $\%$ \\
\hline Questions & 13 & 0.33 & 12 & 0.30 & 7 & 0.18 \\
\hline Imperatives & - & - & - & - & - & - \\
\hline Directives & - & - & - & - & - & - \\
\hline Comprehension comments & 1 & 0.03 & 1 & 0.03 & 2 & 0.05 \\
\hline Apologetic comments & - & - & - & - & - & - \\
\hline Contextual comments & - & - & - & - & - & - \\
\hline Behavioural comments & - & - & - & - & - & - \\
\hline Inclusive comments & 38 & 0.95 & 68 & 1.72 & 27 & 0.68 \\
\hline $\begin{array}{r}\text { Total Hard Sciences } \\
39,876 \mathrm{w}\end{array}$ & 52 & 1.30 & 81 & 2.05 & 36 & 0.90 \\
\hline
\end{tabular}


Table 67. Global use of engagement markers in teacher discourse in Health Sciences: Seminars.

\begin{tabular}{|c|c|c|c|c|c|c|}
\hline STUDENT DISCOURSE: ENGAG & $\overline{\text { IENT }}$ & $\overline{I A R}$ & RS I & $\overline{C L}$ & SEM & $\overline{\mathrm{ARS}}$ \\
\hline & & Eng & geme & $t \operatorname{mar}$ & & \\
\hline & Eng & $\%$ & $\mathrm{Sp}$ & $\%$ & Cat & $\%$ \\
\hline English for Medicine & 56 & 1.28 & 41 & 1.02 & - & - \\
\hline Anthropology and Evolution & 8 & 0.20 & 7 & 0.18 & - & - \\
\hline Epidemiology and Public Health & 491 & 12.44 & 3 & 0.08 & - & - \\
\hline Women's care & 101 & 2.53 & 76 & 1.91 & 14 & 0.35 \\
\hline Affective and Social Neuroscience & 52 & 1.30 & 81 & 2.03 & 36 & 0.90 \\
\hline $\begin{array}{r}\text { Total Hard Sciences } \\
39,876 \mathrm{w}\end{array}$ & 708 & 17.76 & 208 & 5.22 & 50 & 1.25 \\
\hline
\end{tabular}


Student discourse includes a variety of personal asides even though their frequency does not equate the interpersonal markers found in teacher discourse. As seen below, a firstyear Medicine student makes use of the pronoun you to envision an imaginary human being when showing disciplinary knowledge, as in 154 .

(154) Can someone explain why a genetic disease is not necessary to be a hereditary disease? S11: Because you can get a mutation in your DNA sequence eh: out of nowhere, so it's not necessary in your DNA but it can get to a - a mutation on it (See Appendix III (f)).

Inclusion may be achieved through devices other than you, such as we and our. In the Nursing module, we serves to resort to listeners' background knowledge about the gypsy culture. However, a second-year Medicine student commenting on the lack of scientific evidence about the extinction of blonde females in the Anthropology seminar makes use of we, which stands for the members of her group.

(155) S21: OK. Furthermore, we all know that hair is an important identity symbol for the gypsy ethnic rope. (See Appendix III (i)).

(156) S1: We believe that, well, as it says in the second news article, that it will not disappear because it is not a disadvantage and that even though the genotype - if a blond individual and a brunette have a child and then the child is a brunette, even if the blond hair is not visible, it is in the genes. Then, it can come out in the next generation. [S1: Nosotras creemos que, bueno, como dice en la segunda noticia, que desaparecer no va a desaparecer porque no es ninguna desventaja y que aunque el genotipo si una persona rubia y una morena tienen un hijo y luego el hijo les sale moreno, aunque no se vea el rubio, lo lleva en los genes. Entonces puede salir en la siguiente generación]. (See Appendix III (h)).

Some members of the audience may be excluded from the speech produced by students. A clear example is that of the pronoun he, employed to address one of Darwin's descedants, according to a fake news article discussed in the Anthropology classroom. Other pronouns have to do with they and $I$, which can be recognised in Nursing and Psychology teaching practices. They stands for Japanese women in contrast to the first person pronoun $I$, employed by a Psychology undergraduate student when giving her opinion about one of the videos played in the classroom setting.

(157) S4: But then it says that he has the group R1B that is from Europe (See Appendix III (h)).

(158) Furthermore, they don't use epidural normally. They believe that medication can make their child weak:: (See Appendix III (i)). 
(159) S15: Maybe it's not important but I - I just thought in either way when I saw the video and: because how can incredible can be in the future videogames like I can control my character with just my brain or...??? No? Because now we have, I mean I don't have because I don't have money, how a little technology that is like a vision that they can live in the world that the character in the videogame and I can't imagine in the near future what I would come through (See Appendix III (j)).

Personal references may be incorporated in learners' speech through questions to interaction. When the answer is unknown to students, questions are regarded as referential (Morell, 2004). In excerpts 160 and 161, learners' questions are formulated as requests so that the teacher can explain and clarify their doubts. On the contrary, in 162 and 163 student-student interaction takes place since questions are expected to be addressed to other groups presenting their research protocol.

(160) S13: Is it true that skin cancer is caused sporadically? In concrete, skin cancer. (See Appendix III (f)).

(161) S2: Una pregunta ¿Y el color de pelo no está determinado por más de un gen? ¿Son todos recesivos? (See Appendix III (g)).

(162) SX3: Why is sex a covariant instead of a main variable? (See Appendix III (h)).

(163) SX5: Why have you chosen melanoma and not other type of cancer? (See Appendix III (h)).

The sequence below shows students' curiosity about recent technological devices created for individuals with mobility problems. More specifically, a Psychology student would like to know these items work when combined with the neural system.

(164) P1: Hmm, well it's something we can explore more, no? It's just like there is another field, area, maybe, I don't know. Discovering for you new areas that may be interesting. Anyone else here?

S11: Jo tinc una pregunta. Això pots d'alguna manera, quan li fiques una pròtesi a algú, connectar o algo pa' que puga menejar-lo o...? Saps lo que vull dir? Que si va connectat al cervell d'alguna manera pa que se puga menejar la extremitat que has perdut o que no tens? [S11: I have a question. Can you somehow, when you put a prosthesis on someone, connect it or something so they can handle it or...? Do you know what I mean? What if it was connected to the brain in some way so that you can move the limb you have lost or don't have anymore?]. (See Appendix III (j)).

Rhetorical questions can be identified in slide-talk seminars as they contribute to organising students' ideas. The fact that the oral outcomes produced by third-year Medicine include this type of questions indicates that they can resort to more linguistic 
resources due to their mastery of the target language, as shown in the results obtained in their placement tests.

(165) S1: We can see in the pyramid that the, the Mediterranean diet include a moderate a moderation consumption of wine. But what is the amount, the moderate amount of alcohol? It is calculated with the standard drink units. The UBE. (See Appendix III (h)).

Regarding directives, they cannot be found in reading and video-debate seminars offered in the Anthropology, Epidemiology and Social and Affective Neuroscience initiatives. Instead, these resources tend to persist in lecture and slide-talk seminars delivered in English for Medicine and Women's care practices. The expression this image allows presenters to guide their listeners and draw their attention not only to the information being provided but to the screen, as in 166. The modal verb have to suggests that the directive is employed to determine what students should do.

(166) S14: However, this image comes from a time when exposure to the elements before and after a bath were a real risk to a new mother. (See Appendix III (i)).

(167) S15: Do we have to write down the question? (See Appendix III (f)).

Students indicate comprehension problems by means of questions or statements including verbs like mean and understand. For example, in 168 an Anthropology student asks for clarification purposes. The same applies for the sequence originated in the Epidemiology seminar, where a group is requested to explain the limitations of their project.

(168) S7: So the thing is that it was a kind of promotion or for the village? Do you mean that? (See Appendix III (g)).

(169) SX10: I don't understand why Erasmus students are a limitation in your study.

S21: Because the study, our study consists on six years, so Erasmus students ehh probably will leave our country so we could not follow them during our project. And this could be maybe lead to errors (See Appendix III (h)).

Additional comprehension issues may arise in the Women's care seminar. In an attempt to check that a student understands the information she is presenting, the Nursing lecturer asks her about terminology in English. Despite the fact that her co-presenter translates the item for her into Spanish, her unsuccessful answer reveals that she has learnt her section by heart.

(170) N1: Do you know what is bald or bold?

S21: Bald, I don’t know. B-A-L-D [spelling] [S21: Bald, no sé. B-A-L-D [spelling]] 
N1: But do you know what does it mean?

S21: Eh: I don't know. [S21: Eh: no sé]

S22: Bald [S22: Calvo $]$

S21: Sure, yes. That your hair is broken. I don't know [S21: Claro, sí, que se rompe el pelo. Es que no sé] (See Appendix III (i)).

Contextual comments have to do with issues that are not related to the contents delivered in the seminars. As can be noticed in the next excerpt, a Psychology learner asks for the publication year of one of the videos discussed in the classroom.

(171) S6: Is it specified when the video was uploaded? [S6: El video te fique de quin any és?] P1: No

S6: It's just to know...because since some of the things about this video that have b...like been already done. [S6: És per saber...perquè com d'este n'hi ha coses que s'han f...o sea que ja s'han fet [...]]. (See Appendix III(j)).

As for the Nursing module, contextual comments are linked to students' decisions about the use of PowerPoint presentations. Hence, their lack of familiarity with this visual support as well as with the classroom equipment can be noted below.

(172) S21: If you want, I'll pass the slides for you when needed. Ai what happens now? [S21:

Si vols te les passé quan siga. Ai que li passe ara?]

[unintelligible]

S21: Well, it doesn't matter, like this, don't you think? No. [S21: Bueno, és igual, aixina $i$ avant, no? Tampoc]

S22: How can slides be passed? [S22: Com se passa?]

S21: I can't view our PowerPoint presentation full screen. Ah because I've saved it as a PDF file as it was easier. [S21: És que no puc ficar-lo sencer. Ah perquè ho he ficat en pdf perquè m'era més cómodo].

S22: You move in between slides from there, right? [S22: Se passe d'ahi i avant, no?]

S21: Yes [S21: Sí]

The presence of apologetic comments in Epidemiology learners' speech suggests that reformulations and higher anxiety levels may take place. That is the reason why some students apologise and correct themselves while speaking.

(173) S18: Another difficulty, another limitation, sorry, is that there are difficulties to measure some covariates. (See Appendix III (h)).

(174) S15: Eh maternal eh mm maternal age and multiple pregnancy is a high risk because the mother have eh more complications like eh births, also preeclampsia. And for example, eh eh - eh, ay <TLANG_Sp>, sorry. Eh congenital anomalies. (See Appendix III (h)). 
Bearing all this in mind, the incidence of engagement markers is extremely relevant in the Epidemiology seminar. The production of other interpersonal markers will be considered in the following sections.

\subsubsection{Attitudinal markers}

Attitudinal markers, which are concerned with content evaluation and emotions, are present in the degrees under study in Health Sciences. A broad range of markers such as important, good, true or key are recurrent in the medical, nursing and psychological seminars delivered through a CLIL approach.

As to teacher discourse, the distribution of these metadiscoursal markers is larger in English for Medicine (2.31\%) and Social and Affective Neuroscience (2.18\%o), which indicates that the devices used by these specialists serve several functions (see Table 67). According to Mur Dueñas (2010), these linguistic resources are meant to indicate appraisal (e.g. advantages or disadvantages) significance (e.g. key, important or relevant) and emotion (e.g. silly or joke). The markers found in Anthropology (1.98\%) and Epidemiology (1.23\%o) are also frequent, but it is in the Women's care module where they seem to be irrelevant $(0.18 \%$ ). Spanish and Catalan occur at a lesser extent in the disciplines analysed. Spanish is only missing in the second-year Medicine and in the fourth-year Psychology modules. The coexistence with interpersonal elements in Catalan is reduced to a few examples $(0.10 \%)$, being only employed by the lecturer in the Neuroscience and Social Affective Factors module.

Table 68. Use of attitudinal markers in teacher discourse in Health Sciences: Seminars.

\begin{tabular}{|c|c|c|c|c|c|c|}
\hline \multicolumn{7}{|c|}{ TEACHER DISCOURSE: ATTITUDINAL MARKERS IN CLIL SEMINARS } \\
\hline \multirow{2}{*}{ Modules } & \multicolumn{6}{|c|}{ Attitudinal markers } \\
\hline & Eng & $\%$ & $\mathrm{Sp}$ & $\%$ & Cat & $\%$ \\
\hline English for Medicine & 92 & 2.31 & 2 & 0.05 & - & - \\
\hline Anthropology and Evolution & 79 & 1.98 & - & - & - & - \\
\hline Epidemiology and Public Health & 49 & 1.23 & 4 & 0.10 & - & - \\
\hline Women's care & 7 & 0.18 & 2 & 0.05 & - & - \\
\hline Social and Affective Neuroscience & 87 & 2.18 & - & - & 4 & 0.10 \\
\hline $\begin{array}{r}\text { Total Hard Sciences } \\
39,876 \mathrm{w}\end{array}$ & 314 & 7.87 & 8 & 0.20 & 4 & 0.10 \\
\hline
\end{tabular}

In the excerpts that follow, the Medicine (M3), Nursing and Psychology lecturers show appraisal through items such as controversial, bonito (i.e. beautiful) and molt bons (i.e. 
very good). The Medicine teacher gives feedback on a students' group presentation dealing with the impact of twin pregnancies in women of advanced reproductive age, making use of the term controversial.

(175) M3: That's what I thought. As you presented it was that you are not going to study dose because there was a controversial result in the literature and it was...No, because all women they are recommended to have the preventive dose. (See Appendix III (h)).

In this vein, the expressions bonito and molt bons serve to assess the information given or received. In fact, the Nursing lecturer shares her impressions about students' PowerPoint presentation through the statement Está bonito; on the other hand, the Psychology lecturer is evaluating the usefulness of new technological inventions that were incorporated in one of the videos used to foster group discussions.

(176) N1: But you can't say eveything. You can summarise the introduction. S16: Eh?

N1: You can say what you had prepared for the introductory part of the presentation [N1: Que puedes decir lo del principio].

S16: Everything is...They've already said that. [S16: Es que es todo en plan...Lo han dicho ya ellos].

N1: It's cute [N1: Está bonito]. (See Appendix III (i)).

(177) P1: Té a vore que tots estos <TLANG_Cat> devices <TLANG_Eng>, estos invents $<$ TLANG_Cat>, a lo millor poden tindre ara a curt termini perquè s'estan encara desarrollant molts dels que voreu, hm? Entonces pareixen un poc <TLANG_Cat> fancy <TLANG_Eng>, molt bons...Però realment açò quina utilitat té? Però en breu o en uns anys alguna tindran. Jo lo que vull és que <TLANG_Cat> you dream, you have to be able to fill the gap <TLANG_Eng $>$, d'omplir l'espai <TLANG_Cat $>$, the gap between now and who knows? Because maybe things are not useful at all and they won't be never $<$ TLANG_Eng>. (See Appendix III (j)).

Assessment is occasionally combined with emotion, as evidenced below. When preceded by the adverb extremely, items like silly or stupid intensifies the contribution given by the Medicine lecturer in the Anthropology seminar. In this case, the teacher was explaining the reasons why the news published about Cheddar Man in a renowned newspaper was fake.

(178) M2: Exactly. Do you think that the reporter understands what's recessiveness? Do you understand that it's extremely silly, it's stupid. (See Appendix III (g)). 
As to significance, the term key reinforces the element that comes next. Thus, emphasis is placed on specific genes that lead to the development of melanoma, as illustrated in the discourse reproduced by the Medicine lecturer in the English for Medicine module.

(179) M1: [...] So of course a positive family history is associated with an increased risk of developing a melanoma, you can inherit a mutation in key genes that control the cell cycle and of course you have a higher risk because only one sporadic mutation in the other copy of this gene can produce a fail in the cell control progression. Yeah? [...] (See Appendix III (f)).

Focusing on student discourse in the field of Health Sciences, the representation of metadiscoursal devices is displayed in Table 69. A wide range of features can be spotted in the Epidemiology classroom, where students are given the opportunity to present their research projects and the procedure to be followed. Hence, it is not surprising that attitudinal markers rise up to 3.26\% . Similar results are found in the Women's care seminar $(1.10 \%)$ on the grounds that learners also present their projects on cultural differences with regard to labour. The attitudinal markers produced by undergraduates in the Psychology module represent $0.45 \%$, but notable decreases take place in Anthropology $(0.08 \%$ ) and English for Medicine $(0.05 \%$ ). Hence, it goes without saying that the more opportunities students have to contribute in the classroom dynamics, the higher number of metadiscoursal markers.

Table 69. Use of attitudinal markers in student discourse in Health Sciences: Seminars.

\begin{tabular}{|c|c|c|c|c|c|c|}
\hline \multicolumn{7}{|c|}{ STUDENT DISCOURSE: ATTITUDINAL MARKERS IN CLIL SEMINARS } \\
\hline \multirow{2}{*}{ Modules } & \multicolumn{6}{|c|}{ Attitudinal markers } \\
\hline & Eng & $\%$ & $\mathrm{Sp}$ & $\%$ & Cat & $\%$ \\
\hline English for Medicine & 2 & 0.05 & - & - & - & - \\
\hline Anthropology and Evolution & 3 & 0.08 & 1 & 0.02 & - & - \\
\hline Epidemiology and Public Health & 130 & 3.26 & 3 & 0.08 & - & - \\
\hline Women's care & 44 & 1.10 & 8 & 0.20 & 2 & 0.05 \\
\hline Social and Affective Neuroscience & 18 & 0.45 & 4 & 0.10 & 3 & 0.08 \\
\hline $\begin{array}{r}\text { Total Hard Sciences } \\
39,876 \mathrm{w}\end{array}$ & 197 & 4.94 & 16 & 0.40 & 5 & 0.13 \\
\hline
\end{tabular}

Within the Medicine degree, appraisal can be found in third-year students's oral communication. Through the use of evaluative language like powerful negative, the student presenting his project on the effects of physical activity in cardiovascular health evaluates the data included in previous research, as evidenced in the following extract: 
(180) S8: [...] Eh the increasing functional capacity is a powerful negative predictor for cardiovascular diseases, as studies have eh have shown in in the last few years. (See Appendix III (h)).

Apart from the field of Medicine, content evaluation takes place in the Psychology module. Attitudinal markers like utilitat (i.e. usefulness) or impacte (i.e. impact) reflect participants' critical thinking skills towards disciplinary knowledge accessed by means of visual aids.

(181) S6: $[\ldots]$ Of course, but in order for a person to have this, that thing I don't really see its usefulness, a clinical impact. So, I don't know, unless it's... [...] [S6: [...] Claro $\left\langle T L A N G \_S p>\right.$, però pa una persona que tinga un d'esto, un d'açò jo realment no li veig una utilitat, un impacte clínic. O sea, no sé com no siga [...] 〈TLANG_Cat>] (See Appendix III (j)).

The relevance of the information provided in CLIL seminars is conveyed through several resources. Examples include value and irrelevant, which can be spotted in the degrees under study in Health Sciences. The term value serves to acknowledge the benefits of the Mediterranean diet, especially when accompanied by best, an adjective in its superlative form. However, irrelevant qualifies the practices implemented in China during pregnancy.

(182) S2: The hypertension is a product of a lifestyle that includes a poor diet, a sedentary life in the drugs consumption such as alcohol and tabaco 〈TLANG_Sp>. The, today the Mediterranean diet is the best valued. (See Appendix III (h)).

(183) S19: The effects of the traditional practices on health and how health staff should view these practices as beneficial, irrelevant or harmful, to help guide how they might modify women's behaviour at this time <TLANG_Eng>. (See Appendix III (i)).

Affective factors related to students' confidence or lack of it are notable in the Nursing module. On the one hand, students' motivation and positive attitude can be perceived when interacting with her peer during their presentation. Conversely, organisational issues result in a demotivated speaker who appears to be dissatisfied with her group proposal.

(184) S21: One more slide and you [can continue]. I'm on fire. [S21: [...] Una més i tu. Estic a tope [...]]. (See Appendix III (i)).

(185) S17: [...] How poorly organised this is. [S17: [...] Qué mal oganizado que está esto [...]]. (See Appendix III (i)). 
Bearing all these aspects in mind, similar interpersonal markers can be detected in lecturers' and students' discourse. The distribution of these items mainly relies on the types of CLIL seminars implemented, but it may also be subject to participants' English language level.

\subsubsection{Boosters}

The incidence of boosting devices varies when it comes to teacher and student discourse in the modules taking part in this study. A higher number of boosters can be encountered in teacher discourse produced in lecture and reading seminars, that is, in English for Medicine and Anthropology and Evolution (see Table 69). In the case of English for Medicine, boosters represent 0.88\%, whereas in the Anthropology and Evolution module 0.73\%o. Social and Affective Neuroscience comes in the third position, with $0.60 \%$, which almost doubles the proportion of markers found in Women's care (0.38\%o) and Epidemiology and Public Health (0.35\%o). Concerning the presence of languages, it should be pointed out that English is the vehicular language employed by all the CLIL lecturers, even though Spanish (0.55\%) and Catalan (0.05\%o) also coexist in the Psychology classroom.

Table 70. Use of boosters in teacher discourse in Health Sciences: Seminars.

\begin{tabular}{|c|c|c|c|c|c|c|}
\hline \multicolumn{7}{|c|}{ TEACHER DISCOURSE: BOOSTERS IN CLIL SEMINARS } \\
\hline \multirow{2}{*}{ Modules } & \multicolumn{6}{|c|}{ Boosters } \\
\hline & Eng & $\%$ & $\mathrm{Sp}$ & $\%$ & Cat & $\%$ \\
\hline English for Medicine & 35 & 0.88 & - & - & - & - \\
\hline Anthropology and Evolution & 29 & 0.73 & - & - & - & - \\
\hline Epidemiology and Public Health & 14 & 0.35 & - & - & - & - \\
\hline Women's care & 15 & 0.38 & - & - & - & - \\
\hline Social and Affective Neuroscience & 24 & 0.60 & 22 & 0.55 & 2 & 0.05 \\
\hline $\begin{array}{r}\text { Total Hard Sciences } \\
39,876 \mathrm{w}\end{array}$ & 117 & 2.93 & 22 & 0.55 & 2 & 0.05 \\
\hline
\end{tabular}

Booster adverbs serve to draw special attention to lecturers' commitment and confidence about the disciplinary knowledge provided in CLIL contexts. The lexicogrammatical elements in fact and evidence seek to emphasise the truth of a proposition and introduce supporting information, where Medicine and Nursing lecturers present details concerned with hereditary cancers, haplogroups, and previous research on epidural anaesthesia respectively. Clear examples can be read as follows: 
(186) M1: [...] Like I told you, cancer is a genetic ehh disease, but it could be hereditary or not. In fact, the most, the majority of cancers are not hereditary [...]. (See Appendix (f)).

(187) M2: [...] In fact the oldest, we talked about this eh in class, the oldest Y chromosome found ever found in - in living populations belongs to a haplogroup that has been called A00. (See Appendix (g)).

(188) N1: [...] I want to say that this is kind of the evidence. OK? We haven't read properly all the articles and we haven't choose the best of them and we...you know. We only read some articles and many of you have the same article, but this is kind of a - a systematic review. So I just want you to think properly. OK? Not think: no, epidural is very good. No, epidural nothing happens. You put the epidural and everything is fine. You know epidural is very good for all of this, OK? But it can cause all of this. OK? [...] (See Appendix (i)).

Other boosters involve the use of adverbial phrases like especially, which can be recognised in nearly all the degrees belonging to the field of Health Sciences. This item may work as an intensifier feedback strategy in medical slide-talk seminars, as indicated below.

(189) M3: The objectives and the hypothesis are well-formulated, but the eh you should be, especially in the objectives and hypothesis as most precise as possible.

A closer look at CLIL lecturers' discourse allows for the examination of graduation techniques, more specifically in Spanish. Not only is the Spanish diminutive suffix -ito added to the adjective poco (i.e. to a small extent), but other gradable resources such as muy (i.e. very), muchos (i.e. lots of), as well as the approximator tanto (i.e. so) tend to occur in the Psychology module.

(190) P1: [...] Also in many of the videos that we have played. Well, today this seminar is going to be a little bit different, okay? [...]. [P1: [...] También en muchos de los vídeos que hemos puesto. Pues bueno, hoy va a ser una clase un poco diferente, ¿vale? [...]]. (See Appendix (j)).

(191) P1: [...] Ideally, today you should also be located as close as possible to - to your working groups, right? I see that some groups are very well located and other groups not so well located, okay? [...]. [P1: [...] lo ideal de hoy también sería que estuvieseis ubicadas y ubicados lo más cerca posible de - de vuestros grupos de trabajo, ¿vale? Que a algunos grupos los veo muy bien ubicados y otros grupos no tanto, ¿vale? [...]]. (See Appendix (j)).

Turning to students' contributions, it is worth mentioning that the quantity of boosters identified in the third-year Nursing (0.63\%) and Medicine (1.20\%o) modules outnumbers those identified in the remaining disciplinary areas (see Table 70). Certainly, a decline can be identified in English for Medicine (0.18\%) and Social and 
Affective Neuroscience (0.15\%). As regards the use of other languages, $0.85 \%$ and $0.05 \%$ could be found in Spanish in the speech produced by undergraduates enrolled in the Social and Affective Neuroscience and Anhropology and Evoution modules respectively. Thus, English appears to persist as the main language employed in the production of boosters in Medicine and Nursing. A different trend can be found in the Psychology classroom, where the incidence of Spanish terms is higher.

Table 71. Use of boosters in student discourse in Health Sciences: Seminars.

\begin{tabular}{|c|c|c|c|c|c|c|}
\hline \multicolumn{7}{|c|}{ STUDENT DISCOURSE: BOOSTERS IN CLIL SEMINARS } \\
\hline \multirow{2}{*}{ Modules } & \multicolumn{6}{|c|}{ Boosters } \\
\hline & Eng & $\%$ & $\mathrm{Sp}$ & $\%$ & Cat & $\%$ \\
\hline English for Medicine & 7 & 0.18 & - & - & - & - \\
\hline Anthropology and Evolution & - & - & 2 & 0.05 & - & - \\
\hline Epidemiology and Public Health & 48 & 1.20 & 2 & 0.05 & - & - \\
\hline Women's care & 25 & 0.63 & - & - & - & - \\
\hline Social and Affective Neuroscience & 6 & 0.15 & 34 & 0.85 & 2 & 0.05 \\
\hline $\begin{array}{r}\text { Total Hard Sciences } \\
39,876 \mathrm{w}\end{array}$ & 86 & 2.16 & 38 & 0.95 & 2 & 0.05 \\
\hline
\end{tabular}

As with teacher discourse, know, in fact, and especially occur in students' oral outcomes. In the case of know, equivalent boosting strategies are employed by students English, Spanish and Catalan to demonstrate the veracity and validity of their statements. For instance, in the Epidemiology module the English contribution refers to recent studies on physical exercise leading to a better cardiovascular health. A different case is that of Student 5, who intervenes in Spanish to justify his lack of specific terminology.

(192) S7: It is known that daily exercise is an established recommendation to prevent and treat the main modifiable, eh the main modifiable factors of cardiovascular risk, such as diabetes mellitus, hypertension or dyslipidaemia. (See Appendix (h)).

(193) M3: [...] And, well and the last part is very good I will tell $\mathrm{X}$ that you're using...in the final project apart from the Gant you should write down the different task to explain them, apart from the time, you explain very well in the presentation, but just to be written. OK. OK. Oh and some of you said tamaño muestral [sample size] [...].

S5: I don't know how to say that. [S5: Es que no sé cómo se dice [...]]. (See Appendix (h)). 
Students' lack of certainty can be observed in the Psychology seminar. The expression no sé is employed by the Psychology undergraduate to make it clear that she had some comprehension problems with regard to the video about cochlear implants.

(194) S13: It's because there is a moment when the prosthesis is being made for both legs, right now, at the moment. So I don't know if it's going to be the same or lower extremities were there before [S13: Ho dic perquè lo de la pròtesis n'hi ha un moment que sí que li fan en les dos cames i li estan fent una prótesis, ara, en este moment. Entonces no sé si serà lo mateix o és algo que ja n’hi havia] (See Appendix (j)).

Another remarkable example of learners' uncertainty is that of Nursing. The analysis of the translanguaging phenomenon below suggests that content acquisition may not be successful when comprehension problems arise. This is the reason why teaching strategies such as comprehension checks are employed in CLIL learning environments.

(195) S21: Mineral intake is prohibited because they think it affects to the baby's hair. So if a women eat, ate food with vinegar her baby will be bald. Eh: spicy food <TLANG_Eng>

N1: Do you know what is bald or bold?

S21: Bald, I don't know [S21: Bald, no sé]. B-A-L-D [spelling]

N1: But do you know what does it mean?

S21: Ehh, I don't know [S21: Eh:, no sé].

S22: Bald [S22: Calvo].

S21: Yeah, sure. That your hair is broken. I don't know. [S21: Claro, sí, que se rompe el pelo. Es que no sé]. (See Appendix (i)).

\subsubsection{Hedges}

When it comes to hedges, the data indicate that the occurrence of these resources differ to a great extent among the areas of expertise under study, with Medicine $-5.99 \%$ in English for Medicine, 1.98\% in Anthropology and Evolution and 2.21\%o in Epidemiology and Public Health- and Psychology (2.41\%o) outnumbering the devices found in Nursing $(0.78 \%$ ) (see Table 71$)$. What is also evident is that not only are the hedges produced by Nursing students scarce in English but also in Spanish (0.05\%o). Catalan, however, is only present in $0.05 \%$ of Psychology students' speech.

Table 72. Use of hedges in teacher discourse in Health Sciences: Seminars.

\begin{tabular}{|l|c|c|c|c|c|c|}
\hline \multicolumn{7}{|c|}{ TEACHER DISCOURSE: HEDGES IN CLIL SEMINARS } \\
\hline \multirow{2}{*}{ Modules } & \multicolumn{5}{c|}{ Hedges } & $\%$ \\
\cline { 2 - 8 } & Eng & $\% 0$ & Sp & $\% 0$ & Cat & $\% 0$ \\
\hline English for Medicine & 293 & 5.99 & 7 & 0.18 & - & - \\
\hline
\end{tabular}




\begin{tabular}{|l|c|c|c|c|c|c|}
\hline Anthropology and Evolution & 79 & 1.98 & - & - & - & - \\
\hline Epidemiology and Public Health & 88 & 2.21 & 4 & 0.10 & - & - \\
\hline Women's care & 31 & 0.78 & 2 & 0.05 & - & \\
\hline Social and Affective Neuroscience & 96 & 2.41 & 8 & 0.20 & 2 & 0.05 \\
\hline Total Hard Sciences & $\mathbf{5 8 7}$ & $\mathbf{1 4 . 7 2}$ & $\mathbf{2 1}$ & $\mathbf{0 . 5 3}$ & $\mathbf{2}$ & $\mathbf{0 . 0 5}$ \\
\hline
\end{tabular}

Teacher discourse is mitigated by means of nouns, adjectives, verbs, modal verbs, and adverbs. As with the fields of Humanities and Social Sciences, the modals can and could are recurrent in Health Sciences. Other modals employed to hypothesise or indicate possibility involve would and might, as shown in the examples below. In the discipline of Epidemiology, the lecturer is giving learners a piece of advice on the criteria that should be considered in their research study.

(196) M3: [...] But the problem if you don't have at least for area is that the community can differ a bit according to the radiation, for example. We think that we are very uniform but it has...I'm from the south of Alicante and is very different from the north of Castellón. So at least by area, by area you should match. (See Appendix (h)).

Within the speech produced by the lecturer in the Psychology module, the modal would is meant to have an effect on students' learning behaviour. In fact, the use of think and might is aimed at negotiating meaning with students.

(197) P1: I would like you to, because you point somehow these questions, to think about the advantages and disadvantages or pitfalls of all these sort of things, OK? I think there might be since I said at the beginning really nice, cool, surprising, fancy...But they are not useful. But they might be. Or they might be really unuseful. Yeah? (See Appendix (j)).

Heding verbs (e.g. suggest, expect or believe) and adverbs (e.g. maybe, necessarily, almost, probably, possible or possibility) also serve to express speakers' lack of certainty. In the area of Anthropology, the adverb maybe fulfils that function since the lecturer's provides students with different reasons why proteins or part of proteins do not remain the same.

(198) M1: [...] There are a premature termination of the protein and you have a certain part of the protein, you don't have all the protein and maybe it's not functional or maybe eh it presents abnormal function because you losed a part of the protein. Yeah? [...] (See Appendix (f)). 
Turning to students' discourse, it should be stressed that a greater quantity of hedging markers can be found in Epidemiology (4.66\%) and Women's care (2.41\%o) as opposed to English for Medicine (0.23\%) or Anthropology (0.05\%) (see Table 72). In other words, slide-talk seminars allow for more production of hedges than lecture or reading seminars. Video-debate seminars would be somewhere in between with a hedging prominence of $0.50 \%$. Spanish contributions reflect the coexistence of languages in Psychology (1.05\%o), which comes in the first position, followed by Nursing $(0.38 \%$ ). Such results are in line with those obtained in the placement tests denoting a wider variety of language levels in these domains. Thus, students with a limited proficiency in the target language appear to opt for their L1 when communicating with their peers and lecturers.

Table 73. Use of hedges in student discourse in Health Sciences: Seminars.

\begin{tabular}{|c|c|c|c|c|c|c|}
\hline \multicolumn{7}{|c|}{ STUDENT DISCOURSE: HEDGES IN CLIL SEMINARS } \\
\hline \multirow{2}{*}{ Modules } & \multicolumn{6}{|c|}{ Hedges } \\
\hline & Eng & $\%$ & $\mathrm{Sp}$ & $\%$ & Cat & $\%$ \\
\hline English for Medicine & 9 & 0.23 & 6 & 0.15 & - & - \\
\hline Anthropology and Evolution & 2 & 0.05 & 2 & 0.05 & - & - \\
\hline Epidemiology and Public Health & 186 & 4.66 & 3 & 0.08 & - & - \\
\hline Women's care & 96 & 2.41 & 15 & 0.38 & - & \\
\hline Social and Affective Neuroscience & 20 & 0.50 & 42 & 1.05 & 10 & 0.25 \\
\hline $\begin{array}{r}\text { Total Hard Sciences } \\
39,876 w\end{array}$ & 313 & 7.85 & 68 & 1.71 & 10 & 0.25 \\
\hline
\end{tabular}

The discourse produced by students includes a range of hedging devices, as illustrated through modals (e.g. can, could, might, would or should), verbs (e.g. think, expect, suggest, seem to or appear to). The reliability of the propositions shared in CLIL seminars can be seen in the following sequences, where students answer the questions posed by their teachers.

(199) S3: I think that's because normal eh is eh having hair brown. So then people wanna be mm like more exceptional more beautiful so they like to be blond because eh it's eh mm less percentage of people that are blond. So people want strange I think. (See Appendix (f)).

(200) S17: Well, we think...well, the same as they do. The video that we found most interesting from a clinical point of view, of course, is the one about the glasses, because of what they've just mentioned. They offer, on the one hand, improvements. The medical component of them not being able to see, and on the other hand, the self-esteem they will 
gain. Being able to control their own lives, because they gain a lot at a psychological level. [S17: Pues nosotros pensamos...pues, igual que ellas. El vídeo que más interesante nos ha parecido desde el punto de vista, claro, clínico son las gafas, por eso. Tienen, por una parte, mejoras. El componente médico de decir no pueden ver, y por otro la autoestima que ellos van a sentir. Capacidad de poder controlar ellos su vida, pues ahí ganan mucho a nivel psicológico [...]. (See Appendix (j)).

Such reliability may be identified in students' group presentations. For example, a Nursing student makes use of the verb expect to refer to the recommendations pregnant women should follow in China.

(201) S17: [...] For thirty days after childbirth, the woman is expected to stay in bed and not do any heavy work, including housework [...]. (See Appendix (i)).

Comprehension difficulties are evident in the presence of Spanish and Catalan hedges. Not only are they evident in teacher discourse but in student discourse. In the Nursing module, the expression no tener claro is employed by the lecturer for negotiation purposes so that the student can understand what is being said in the discussion about the benefits and drawbacks of epidural slowing labour.

(202) N1: What - What have you just said? You, you don't understand it. [N1:¿Qué - Qué has dicho? Tú: tú no lo tienes claro]

S10: No, what's... slows labor in Spanish?

N1: In Spanish? <TLANG_Eng>. Eh:: La epidural hace que sea más lento el parto $\langle$ TLANG_Sp $\rangle$. What do you think? $\langle$ TLANG_Eng $>$. [...]]. $\langle$ TLANG_Sp $>$. (See Appendix (i)).

The verb entendre operates the same learning goal in the field of Psychology. An undergraduate student shares her thoughts about the content offered in the video played in the classroom setting.

(203) P1: Freedom, we already heard that word before. So, anything about this video? What do you think? It may also be in Spanish o Valenciano. S9.

S9: Actually, I didn't understand it: Yes, there are people who struggle with issues we don't have to, but I didn't understand the mechanism of how they do it. [S9: Que no ho he entès realment: sí, que n'hi ha persones que les coses que a mosatros no mos costa res a ells lis costa, però no he entès el mecanismo del, de lo de com ho fan]].

P1: But why they cannot do it? Because they don't have...

S9: Touch and mobility, but: I don't know. [S9: Tacte i mobilitat, però...no sé]]. (See Appendix (i)).

Contrary to what could have been expected, the occurrence of hedges was similar in the speech produced by lecturers and students in the field of Health Sciences. The domain 
where teacher discourse is prominently characterised by a higher number of hedging resources corresponds to English for Medicine, whereas CLIL seminars focusing on Epidemiology and Women's care are the modules where learners have greater opportunities for the production of these markers.

\subsubsection{Humanities and Social Sciences vs. Health Sciences}

The interviews conducted prior to the implementation of CLIL lectures and seminars were pivotal to establish a first contact with potential lecturers participating in this study. Their views on learners' concerns as well as their own thoughts about the CLIL approach were considered. On the one hand, Humanities and Health Sciences lecturers agreed that they were in charge of groups with heterogeneous levels of English. The anxiety of students who have a lower command of the target language or who are selfaware of their limited oral performance are factors that may prevent them from interacting in the classroom setting, thus hindering effective CLIL practices. The same applies for the translation of materials in areas like Tourism and Psychology. Nonetheless, in order to foster learners' participation, students may be allowed to communicate in Spanish and Catalan. As for cultural issues, they have only been stressed by lecturers in Soft Sciences, probably due to the enrolment of a higher number of international students participating in exchange programmes.

On the other hand, interviewees revealed the most challenging aspects of CLIL instruction. Self-confidence in English appears to be higher among lecturers in Hard Sciences, whereas their counterparts in Soft Sciences seem to struggle when explaining disciplinary knowledge in this language as not all of them master the language at an advanced level. In line with this, even though lecturers in both fields acknowledge that their level of English has improved, they feel that they should be given more institutional support. Another issue CLIL educators have to deal with corresponds to the availability of materials. Given that English is the language of science, Health Sciences educators do not find it challenging to retrieve materials. However, materials on specific topics may not be easy to find in English in the domain of Soft Sciences, as evidenced in the Tourism module focusing on regional art. Nonehteless, lecturers in both fields tend to create glossaries, questionnaires, look for newspaper articles and make use of 
visual aids such as PowerPoint presentations.Apart from that, timing and students' complaints may also affect negatively lecturers' perception of CLIL modules.

Drawing our attention to students' questionnaires, similar results were identified in o the variable concerning methodological aspects of instruction, more specifically in Q1-Q5. These findings prove that undergraduates undertaking disciplines in Soft and Hard Scieces are satisfied with their educational practices. As to their difficulty, the use of English as a vehicular language appears to be a handicap for younger students who may be less familiar with these programmes except for Psychology underdraduates. It should also be mentioned that in the area of Hard Sciences participants tend to avoid the choice of extremes in Q2-Q5, particularly notable in older Medicine learners. Despite the fact that CLIL modules can be improved, the materials provided meet the learning needs of CLIL students.

The second variable, which refers to attitudinal issues towards CLIL initiatives, the vast majority claims that the requirements of the module are achieved in terms of language use, although they show their preference for L1 instruction in Soft Sciences and Hard Sciences with the exception of first-year Medicine students. As reported in their questionnaire, the number of participants with an official certificate is lower in Soft Sciences who indicate having a command of the English language at A2 (12.77\%), B1 (15.96\%), B2 (11.70\%) and C1 (2.13\%) levels (see Table 73). In contrast, the subjects in Hard Sciences held A1 (3.57\%), A2 (19.64\%), B1 (21.43\%), B2 (30.36\%) and C1 (3.57\%) certificates. Another difference lies in the number of students who did not go through an official certification process, which stands for $39.36 \%$ in Soft Sciences and $19.64 \%$ in Hard Sciences. Notwithstanding, all of them recognised the social value of English.

With regard to the third variable in which items are related to institutional language policies, participants in the modules under study do not to tend to inspect the Academic Information System offered by Universitat Jaume I to grant online access to relevant information about their programmes of studies. Hence, institutional actions should be devoted to the provision of information on the implementation of CLIL instruction to freshers in the higher education context.

The results found in students' questionnaires may be influenced by the proficiency level they were assigned after the completion of placement tests (see Table 73). Generally 
speaking, and even though all the language levels have been found, students seem to have a better command of the target language in comparison with the responses given in their final survey. Students enrolled in modules delivered in Hard Sciences are likely to outperform their Soft Sciences counterparts, emphasising the results obtained by Medicine learners. Thus, whereas $69.65 \%$ of Medicine, Nursing and Psychology undergraduates master the language at B2 or C1 levels from a lexico-grammatical point of view, the scores obtained by $63.83 \%$ of students in Humanities correspond to B1 or B2 levels.

Table 74. Results obtained from the placement tests administered in the fields of Humanities, Social Sciences and Health Sciences.

\begin{tabular}{|r|c|c|c|c|}
\hline \multirow{2}{*}{ Language levels } & \multicolumn{2}{|c|}{ Humanities and Social Sciences } & \multicolumn{2}{c|}{ Health Sciences } \\
\cline { 2 - 5 } & $\begin{array}{c}\text { Questionnaire } \\
\text { (level) }\end{array}$ & Placement test & $\begin{array}{c}\text { Questionnaire } \\
\text { (level) }\end{array}$ & Placement test \\
\hline $\mathrm{A} 1$ & - & $2.13 \%$ & $3.57 \%$ & $3.57 \%$ \\
\hline $\mathrm{A} 2$ & $12.77 \%$ & $22.34 \%$ & $19.64 \%$ & $3.57 \%$ \\
\hline $\mathrm{B} 1$ & $\mathbf{1 5 . 9 6 \%}$ & $\mathbf{3 6 . 1 7 \%}$ & $21.43 \%$ & $17.86 \%$ \\
\hline $\mathrm{B} 2$ & $11.70 \%$ & $27.66 \%$ & $\mathbf{3 0 . 3 6 \%}$ & $26.79 \%$ \\
\hline $\mathrm{C} 1$ & $2.13 \%$ & $10.64 \%$ & $3.57 \%$ & $\mathbf{4 2 . 8 6 \%}$ \\
\hline $\mathrm{C} 2$ & - & $2.13 \%$ & - & $7.14 \%$ \\
\hline No recognised & $\mathbf{3 9 . 3 6 \%}$ & - & $\mathbf{1 9 . 6 4 \%}$ & - \\
\hline level & & & & \\
\hline
\end{tabular}

The findings obtained from the classroom practices reveal that lecturers' and students' contributions in the fields of Humanities, Social Sciences and Health Sciences differ to a great extent. Therefore, the main features of teacher and student discourse will be reviewed.

As for teacher discourse in the field of Humanities and Social Sciences, the Tourism specialist is the one using more attitudinal markers and boosters in CLIL lectures or lecture seminars, in contrast to the speech produced by the History lecturer in the History of the Classical World module, with a higher number of engagement markers. However, the opposite trend can be found when dealing with CLIL seminars. Actually, a higher frequency of interpersonal elements can be identified in the teacher discourse registered in the Fundamentals and Theory of Artistic Heritage module. 
The incidence of interpersonal devices in teacher discourse is even higher in the field of Health Sciences. These findings suggest that Medicine, Nursing and Psychology experts are familiar with a wider variety of metadiscoursal features. These are more common in the lecture, video-debate and reading seminars, which correspond to the English for Medicine, Social and Affective Neuroscience and Anthropology modules. The fact that slide-talk seminars have been allocated in the Epidemiology and Women's care practices is related to the decline in the use of interpersonal markers, especially in the Nursing domain.

As regards discourse markers in students' oral outcomes, their occurrence appears to go in line with the results obtained in the placement tests filled in by Humanities, Social Sciences and Health Sciences participants, with medical undergraduates outperforming students enrolled in other disciplines. Within the disciplinary areas of Humanities and Tourism, the speech produced by first-year History undergraduates coursing occurs at a higher rate than their Tourism counterparts. It should be noted that subcategories like attitudinal markers and boosters are scarce or missing in both domains. Significant differences can be observed in Health Sciences, where learners' contributions are particularly noteworthy in slide-talk and video-debate seminars. As with Humanities and Social Sciences initiatives, third-year Medicine students are aware of the learning objectives set in terms of communication. Nonetheless, a low command of the English language leads participants to communicate in Spanish and Catalan, as seen in the Psychology degree. A closer look at the results obtained in other Health Sciences programmes under study suggests that lecture and reading seminars have an impact on the lower use of metadiscoursal devices in student discourse, given that their interaction seems to be more limited.

From these findings, it can be concluded that slide-talk seminars seem to be the most appropriate option for the production of student discourse in Humanities, Social Sciences and Health Sciences. In this sense, the number of elements uttered by thirdyear Medicine students comes in the first position, followed by History, Tourism and Nursing undergraduates. Teachers, on the contrary, may take the floor and express themselves in CLIL lecture or reading seminars, where the variety of resources included in the teacher discourse of the English for Medicine module should be acknowledged. 
Table 75. Global use of metadiscoursal markers in teacher discourse: Lectures and Seminars.

\begin{tabular}{|c|c|c|c|c|c|c|c|c|c|c|c|c|c|c|c|c|c|c|c|c|c|c|c|c|}
\hline \multicolumn{25}{|c|}{ TEACHER DISCOURSE IN CLIL LECTURES AND SEMINARS } \\
\hline \multirow{2}{*}{ Field } & \multicolumn{6}{|c|}{ Engagement markers } & \multicolumn{6}{|c|}{ Attitudinal markers } & \multicolumn{6}{|c|}{ Hedges } & \multicolumn{6}{|c|}{ Boosters } \\
\hline & Eng & $\%$ & $\mathrm{Sp}$ & $\%$ & Cat & $\%$ & Eng & $\%$ & $\mathrm{Sp}$ & $\%$ & Cat & $\%$ & Eng & $\%$ & $\mathrm{Sp}$ & $\%$ & Cat & $\%$ & Eng & $\%$ & $\mathrm{Sp}$ & $\% 0$ & Cat & $\%$ \\
\hline $\begin{array}{r}\text { Total Soft } \\
\text { Sciences } \\
22,397 w\end{array}$ & 928 & 41.43 & 126 & 5.66 & 6 & 0.27 & 173 & 7.72 & 13 & 0.58 & - & - & 214 & 9.55 & 13 & 0.58 & 1 & 0.05 & 51 & 2.28 & 9 & 0.40 & - & - \\
\hline $\begin{array}{r}\text { Total } \\
\text { Hard } \\
\text { Sciences } \\
\text { 39,876w }\end{array}$ & 2,241 & 56.20 & 187 & 4.69 & 10 & 0.25 & 314 & 7.87 & 8 & 0.20 & 4 & 0.10 & 587 & 14.72 & 21 & 0.53 & 2 & 0.05 & 117 & 2.93 & 22 & 0.55 & 2 & 0.05 \\
\hline
\end{tabular}


Chapter 6: Results and Discussions

Table 76. Global use of metadiscoursal markers in student discourse: Lectures and Seminars.

\begin{tabular}{|c|c|c|c|c|c|c|c|c|c|c|c|c|c|c|c|c|c|c|c|c|c|c|c|c|}
\hline \multicolumn{25}{|c|}{ STUDENT DISCOURSE IN CLIL LECTURES AND SEMINARS } \\
\hline \multirow{2}{*}{ Field } & \multicolumn{6}{|c|}{ Engagement markers } & \multicolumn{6}{|c|}{ Attitudinal markers } & \multicolumn{6}{|c|}{ Hedges } & \multicolumn{6}{|c|}{ Boosters } \\
\hline & Eng & $\%$ & $\mathrm{Sp}$ & $\%$ & Cat & $\%$ & Eng & $\%$ & $\mathrm{Sp}$ & $\%$ & Cat & $\%$ & Eng & $\%$ & $\mathrm{Sp}$ & $\%$ & Cat & $\%$ & Eng & $\%$ & $\mathrm{Sp}$ & $\% 0$ & Cat & $\%$ \\
\hline $\begin{array}{r}\text { Total Soft } \\
\text { Sciences } \\
22,397 w\end{array}$ & 490 & 21.88 & 225 & 10.05 & 16 & 0.71 & 133 & 5.94 & 42 & 1.88 & 5 & 0.22 & 166 & 7.41 & 73 & 3.26 & - & - & 34 & 1.52 & 81 & 3.62 & - & - \\
\hline $\begin{array}{r}\text { Total Hard } \\
\text { Sciences } \\
39,876 w\end{array}$ & 708 & 17.76 & 208 & 5.22 & 50 & 1.25 & 197 & 4.94 & 16 & 0.40 & 5 & 0.13 & 313 & 7.85 & 68 & 1.71 & 10 & 0.25 & 86 & 2.16 & 38 & 0.95 & 2 & 0.05 \\
\hline
\end{tabular}




\subsection{CHAPTER SUMMARY}

This chapter has focused on lecturers' views on learners' concerns about CLIL as well as lecturers' concerns about this approach in teaching practices. The data gathered from the interviews emphasised the role of language mastery in implementing successful pedagogical practices. Likewise, individual preferences and attitudinal considerations were reported thanks to the responses collected from students' questionnaires. In this sense, interactive exchanges in the CLIL classroom may also be determined by the proficiency level scores obtained in placement tests.

The last section of this chapter has presented the findings on the main interpersonal markers employed by teachers and students involved in CLIL learning practices offered in Humanities, Social Sciences and Health Sciences. The examination of CLIL lectures and lecture seminars has revealed that a broad range of engagement markers, attitudinal markers, hedges and boosters are incorporated in teacher discourse, either in History of the Classical World, Valencian art and Tourism resources or English for Medicine modules. However, student discourse is characterised by such a variety of metadiscoursal elements in slide-talk seminars, where they are given the opportunity to take the floor and share their projects with other university members. In this case, medical students' outcomes prove that their command of the target language is at an advanced level compared to other disciplines.

As already stated in Chapter 1 and Chapter 5, this study is intended to analyse interactive patterns in CLIL programmes offered at Universitat Jaume I and discern the similarities and differences among the fields of Humanities, Social Sciences and Health Sciences. The pedagogical potential of these results may provide insights to improve CLIL practices at university by givin ideas for classroom implementation and lecturers training. The concluding remarks of this study will be provided in Chapter 7 . 


\section{Chapter 7: Conclusions}

\subsection{INTRODUCTION}

This chapter attempts to provide some concluding remarks on the study conducted, which is concerned with the implementation of CLIL programmes at Universitat Jaume I, a multilingual higher education institution located in Spain. The research process has delved into participants' concerns and contributions in the CLIL classroom. The primary motivation behind this research study has been the need to investigate and reflect upon the teaching strategies delivered in the fields of Humanities, Social Sciences and Health Sciences. Despite the variety of academic genres, with lectures having caught the most attention, there has not yet been enough research on the discourse uttered in CLIL seminars. By recapitulating the theoretical background around CLIL and academic discourse in lectures and seminars, this thesis seeks to contribute to understanding teacher and student discourse in educational contexts where a foreign language is employed as the means of communication.

In this chapter, I am going to summarise previous studies on CLIL experiences and academic discourse. I will also draw attention to the objectives and the methodological procedure, which have been key for the analysis of the results. Later, the findings obtained in each of the modules under study will be reviewed together with their pedagogical implications. Finally, the limitations of this study will be acknowledged, and ideas for further research will be suggested. 


\subsection{CONCLUDING REMARKS}

This thesis aimed to contributing to CLIL research by describing attitudinal concerns and interpersonal academic discourse that took place in content modules delivered in multilingual learning environments at Universitat Jaume I. The fact that the curriculum of these programmes belonged to different disciplinary areas, those of Humanities, Social Sciences and Health Sciences, helped to discern the similarities and differences of lecturers' and students' participation in the CLIL classroom and thus design an effective pedagogical proposal. With this in mind, three research questions were devised:

1. $\mathrm{RQ}(1)$. What are participants' attitudes and concerns towards the implementation of CLIL practices in higher education?

2. $\mathrm{RQ}(2)$. What interpersonal traits, such as engagement, attitudinal and evaluative markers, can be observed in CLIL programmes offered at higher education?

3. $\mathrm{RQ}(3)$. Are there any significant differences among the CLIL practices in the fields of Humanities, Social Sciences and Health Sciences?

Departing from the notion of language as a process, the current study investigates attitudinal and linguistic dimensions in two academic genres, namely lectures and seminars following a CLIL approach. This is the reason why contributions to multilingual education, CLIL and academic discourse have been pointed out in Chapters 2, 3 and 4.

As regards RQ(1), the interviews allowed to inspect the teaching needs and attitudes of CLIL lecturers in the fields of Humanities, Social Sciences and Health Sciences. The main issues arising from teacher interviews are related to lecturers' views on learners' concerns about CLIL as well as lecturers' feeelings towards CLIL. According to the interviewees, the mastery of the English language stands out as the main difficulty for undergraduate students. The anxiety of those with a lower command of the target language has a negative impact on classroom performance. Such attitudes can be observed with the translation of the materials available in English into the three areas of knowledge, except for international students in the Tourism degree. Apart from that, emphasis was also placed on the use of support materials and the need for teacher training initiatives. 
As for students' attitudes and concerns in CLIL contexts, these were obtained through a final survey based on three variables: 1) Experience in language learning, 2) attitudes towards the foreign language, and 3) knowledge of institutional language policies. The findings related to the first variable show the satisfaction of Humanities, Social Sciences and Health Sciences undergraduates with their previous language learning experience, particularly in the degrees of Medicine, Nursing and Psychology where no total disagreement is shown from Q2-Q5. Differences can be recognised in Q6. It is evident that fourth-year undergraduate students in the History and Tourism degrees are likely to find CLIL programmes less complicated than those coursing first-year modules in the History domain. The fact that students enrolled in advanced degree years might have had the opportunity to become familiar with this type of initiatives may be one of the possible interpretations for these results. Regarding the second variable, which focuses on learners' attitudes towards CLIL pedagogies, Tourism and Medicine students are likely to learn disciplinary knowledge through a foreign language. Some of the reasons have to do with the international nature of the Tourism domain and the high-achieving undergraduates in the field of Medicine. Finally, the results have made it clear that undergraduate students in Humanities, Social Sciences and Health Sciences are not familiar with the institutional linguistic policies implemented at university. Therefore, more dissemination actions should be taken into consideration.

When it comes to $\mathrm{RQ}(2)$, all the interpersonal elements inspected in this study have been found in teacher discourse (e.g. engagement markers, attitudinal markers, hedges and boosters). Within the lectures held in Humanities and Social Sciences, I found that the History lecturer produced a larger number of engagement markers. Nonetheless, questions are identified as the most persistent category in both History and Tourism lecture seminars. In this sense, rhetorical, referential, display or indirect questions may be formulated in order to boost students' interaction. Other features such as directives and imperatives may also be found at a lower rate in both fields of expertise (e.g. need to, write), taking into account that it is necessary to let students know what is expected from them. However, when dealing with CLIL seminars, inclusive comments are the most recurrent element in the teacher discourse registered in Fundamentals and Theory of Artistic Heritage, History of the Classical World, and Valencian art and Tourist resources modules. Therefore, personal asides seem to be used to a greater extent to involve the audience in the communicative event. The presence of attitudinal markers 
and boosters is particularly relevant to the Tourism specialist, who makes use of a wide range of adjectives, verbs and adverbs in his lecture session (e.g. great, only, don't worry, of course, clearly). In contrast, the use of hedges stands out in the History teacher discourse (e.g. will, can, could, consider). As evidenced, the occurrence of engagement markers, attitudinal markers, hedges and boosters seems to be higher in the speech produced by the lecturer in the fourth-year History module. It could be said that there is a greater need for the lecturer to communicate due to the low participation of her students, which in turn may be the result of their limited command of the target language. In analysing teacher discourse in Health Science seminars, it could be observed that engagement markers remain as the main metadiscoursal device in teacher discourse, followed by hedges, attitudinal markers and boosters. Unlike the results obtained in Humanities and Social Sciences, the most common engagement markers correspond to inclusive comments, which can be identified through the use of pronouns (e.g. you, we) and questions to catch learners' attention. However, the incidence of behavioural and apologetic comments was missing in some of the degrees, which suggests that students were behaving properly. As to attitudinal markers, hedges and boosters, verbs, adverbs, adjectives and nouns such as key, easy, true, know, show, evidence or maybe could be spotted, the lowest number of resources occurring in the Nursing domain.

As far as student discourse is concerned, the contributions of Humanities and Social Sciences undergraduates were more restricted in lectures and lecture seminars since they tend to be teacher-centred practices. Thus, it could be observed that the number of interpersonal devices dropped significantly in student discourse. When comparing the fields of Humanities and Social Sciences in lectures, there is a trend for the use of a higher number of metadiscoursal markers in History. In this line, the main engagement categories were inclusive comments (e.g. your, we, us, our) and questions in both History and Tourism areas. The absence of directives, imperatives might be related to the fact that the teacher is responsible for giving guidelines to all of them, whereas the non-existence of apologetic and behavioural comments suggests that there is no need to reformulate their speech or modify their attitudes in the classroom setting. Hedges can be detected in both fields of expertise, with History students outnumbering their Tourism counterparts (e.g. well-known, typical, offer). On the whole, History learners seem to use metadiscoursal markers more often than Tourism students, whose speech is 
characterised by a reduced number of attitudinal markers. Examples of these devices in the lectures include main and please. Boosters, however, are missing in the lectures held in both modules. As to seminars, the prevalence of engagement markers in the productions of History undergraduates is worth mentioning (e.g. let's). Inclusive comments are recognised in the History of the Classical World module (e.g. you), even though directives and imperatives may also be found in other historical and tourist areas (e.g. next one, should, ponlo). One might interpret that first-year History learners and fourth-year Tourism learners are guiding their audience or the members of their group during their oral presentations. On the other hand, the directives found in the speech of fourth-year History undergraduates may have to do with requests (e.g. tenemos que contestar a esto, ¿no?). In addition, it is possible to identify apologetic comments the first-year History module due to presenters' anxiety (e.g. sorry, perdón, nervous). In keeping with student discourse in Health Science seminars, it could be observed that engagement markers seem to be the most frequent metadiscoursal feature together with hedges. They are especially noteworthy in Epidemiology and Women's care modules, where students present their research projects. Engagement markers appear to be the preferred items by Health Sciences students, with inclusive comments (e.g. we, our) and questions at the top of the category. The same is true for the remaining linguistic features since students are given more opportunities to contribute in these seminars. Attitudinal markers such as important is common to first-year, second-year and thirdyear Medicine modules, Nursing, and Psychology modules. However, other terms such as key, controversial, necessary or scary can be detected these CLIL practices. Likewise, boosters (e.g. prove, know, show) and hedges (e.g. some, think, consider, believe, would) are just but a few of the devices employed by undergraduate students.

Focusing on RQ(3), it could be observed that the average number of words differs to a great extent among the disciplines. One might interpret that teachers' and students' contributions occur more frequently in Health Sciences, more specifically in the English for English for Medicine, Epidemiology and Affective and Social Neuroscience modules. These would be followed by Valencian art and Tourism resources, History of the Classical World, Women's care, Anthropology and Fundamentals and Theory of Artistic Heritage programmes. Moreover, the data examined in the placement tests have revealed that a high number of students have a good command of the English language from a lexico-grammatical point of view. Nonetheless, striking differences can be 
observed in the fields of Humanities, Social Sciences and Health Science, with medical students outperforming students enrolled in other disciplines. The communicative abilities of Nursing students are also at an advanced level; in contrast, a broad range of language levels can be observed in the responses of future Psychologist, History and Tourist specialists. Hence, it could be stated that CLIL learners who happen to have a better command of the target language are those involved in Health Sciences, which may have an impact on the production of oral outcomes. As reported in Chapter 6, the results examined in the fields of Humanities and Social Sciences indicate that the emergence and variety of interpersonal markers are subject to the disciplines under study as well as to the communicative competence of the subjects. In fact, in the fields of Humanities and Social Sciences, it is the discipline of Tourism the one that presents the most variety of markers in both teacher and student discourse, followed by the oral outcomes registered in the first-year module offered in History and Humanities. In contrast to other degrees, the variety of interpersonal markers that occurs in the fourthyear module of Tourism may be due to the type of academic genre, considering that teachers are expected to take the floor to present content in lecture sessions. Similarly, the seminars held in Tourism allow for a greater participation of students. The main reason may be related to a large number of international students being more fluent in English. It should also be noted that it is in the fourth-year History module where there are lower cases of metadiscoursal markers, since they tend to avoid participating actively due to their poor command of the language. In analysing these linguistic resources, engagement markers can be distinguished in all the modules through the use of questions and pronouns. Within lectures or lecture seminars, a wide range of hedges can be spotted in English in the field of Humanities, whereas Spanish appears to be the preferred language among fourth-year History students attending video-debate seminars. The latter presents a greater number of hedges in Spanish, followed by attitudinal markers and boosters. However, attitude markers and intensifiers are more common in Social Sciences. This trend varies slightly in the field of Health Sciences, where the speech of the English for Medicine teacher includes a wide variety of interpersonal resources uttered in a lecture seminar. In other words, since it is a more traditional genre than other teaching practices, teacher performance is greater than the outcomes produced by students or lecturers in other Health Science seminars. The opposite trend can be seen in video-debate seminars or slide-talk seminars, given that learners have more opportunities to show their involvement in the classroom setting. In 
this sense, it is in the third-year modules delivered in Medicine and Nursing where students can produce interpersonal markers, hedging devices being followed by attitude markers and intensifiers. Nonetheless, Nursing would be the area of health where fewer language elements are found in the CLIL classroom. All these results have allowed us to identify the needs of faculty and students.

\subsection{PEDAGOGICAL IMPLICATIONS}

Since the objectives of this study involved the identification of the linguistic traits employed in the CLIL classroom, the presence of engagement, attitudinal and evaluative markers was examined based on teacher and student discourse. Having discussed the main results obtained from teachers' interviews, students' surveys, placement tests and classroom practices, it has been witnessed that some actions should be enforced. This quantitative and qualitative research has been valuable in that interpersonal communication needs to be strengthened in some types of seminars and lectures.

Pedagogically speaking, this study may contribute to raising lecturers' awareness of a broad range of metadiscoursal markers that can be employed in the content classroom to engage the audience. At this point, they can also learn about the role of interpersonal markers in building new knowledge and triggering teacher-student interaction in English. Hence, lecturers may be able to produce a richer number of interpersonal devices that facilitate the presentation of new content and its comprehension, which in turn entails an improvement of their CALP and BICS skills. In addition, this study provides an overview of the instructional practices that seem to be more effective in attaining this goal (i.e. group presentations and video-debate seminars).

Given that confidence needs to be expressed when giving instruction in academic settings, it would be advisable to reinforce the production of boosters in teacher discourse. These happen to be the least recurrent features in all the disciplines under study, and their use could make students feel that lecturers master the notions being explained in the target language. Other metadiscoursal markers that may be reinforced in teacher discourse involve questions, imperatives, directives and comprehension 
comments, which are pivotal in giving instructions and overcoming misunderstandings in communication.

This study has also revealed to what extent metadiscoursal markers are included in student discourse. Even though a higher number of these devices can be observed in slide-talk seminars, students should be provided with materials that allow them to communicate successfully in the content classroom. In that sense, glossaries designed by CLIL lecturers would be valuable in acquiring structures that are vital in the interaction phase. In line with this, exposure to teacher discourse could have a significant impact on undergraduates coursing CLIL modules, particularly in terms of content assimilation and productive skills.

From the interviews and classroom practices, it could be noticed that lecturers need to understand the principles of the CLIL approach and be provided with some training to overcome cognitive and linguistic challenges in the CLIL classroom. Therefore, this study can help lay the foundations of a training course addressed to pre-service and inservice CLIL educators. By tackling relevant issues prompting the development of organisational, critical thinking and interpersonal skills through a foreign language, participants would be able to learn teaching strategies that can be profitable for the whole university community. This course would call for the integration of needs analysis and course design, which appear to be intertwined, as supported by previous research related to ESP and CLIL (Bocanegra-Valle, 2016; Carrió-Pastor \& Tamarit Vallès, 2015; Martín del Pozo, 2014; Flowerdew, 2013). The examination of learners' concerns is key to face a pressing yet challenging learning scenario, where several variables need to be considered, such as course details, objectives, learning outcomes or materials, to name but a few. It would be convenient for teacher training courses to delve into CLIL foundations and academic discourse in English. In so doing, notions such as the 4C's Framework, Higher Order Thinking Skills (HOTS) and Lower Order Thinking Skills (LOTS), scaffolding strategies, as well as the analysis of metadiscoursal devices registered in video-recorded lectures and seminars should be examined. Through group work and discussions, educators would not only learn the basics to structure their speech in lectures and seminars but also effective teaching strategies for the CLIL classroom that would lead to successful CLIL practices. Therefore, this research would try to provide lecturers with the necessary resources to improve existing CLIL programmes in higher education. 
The findings obtained in students' questionnaires brought the urge for institutional actions to light. Undergraduate students in Humanities, Social Sciences and Health Sciences are barely acquainted with the multilingual policies implemented at Universitat Jaume I, as far as the use of English and Catalan is concerned. Following the results of this study, some of the guidelines would involve giving more information to students about language policy at the beginning of an academic year. In this sense, several workshops could be allocated to introduce the multilingual plan at Universitat Jaume I and the rationale of the CLIL approach implemented in curricular modules offered in Soft and Hard Sciences. Within these sessions, corpora-based analyses would be conducted to raise awareness about academic discourse in these learning environments. In other words, the pedagogical implications derived from this study would contribute not only to disseminate institutional policies but also to promote the use of interactive discourse patterns in lectures and seminars.

These contributions aim at overcoming teachers' shortcomings in curricular design based on their perceptions. The same is true for undergraduates who are involved in CLIL initiatives and need to know how to proceed in educational settings. Notwithstanding, the conclusions resulting from the limitations of this study and ideas for further research will be outlined in the section below.

\subsection{LIMITATIONS OF THE STUDY}

The limitations of this research should be acknowledged. The first limitation refers to the qualitative and quantitative nature of this study, which may have had an impact on the results obtained. Although a second analysis should have been conducted to attenuate subjectivity in this analysis, this was not possible due to timing issues and the size of the corpus. The fact that the analysis of interpersonal devices was conducted through Lextutor (Cobb, n.d.) should be regarded as some sort of limitation; other more precise corpus analysis software could have been used. To make the results obtained by Lextutor (Cobb, n.d.) more precise and in order to double check validity of metadiscoursal markers (i.e. engagement, attitudinal, boosting and hedging devices), the corpus was also carefully proofread. 
The study is limited to the CLIL modules offered in a multilingual university, there are no samples from other universities in the Valencian Community, which would have contributed to generalise the results obtained in the present study. Language proficiency is another variable worth mentioning. Not did all the participants have a heterogeneous command of the English language, but lecturers' and learners' mastery differed to a certain extent in the CLIL modules under study.

Given that only six degrees have taken part in this study, the findings may not be replicable to other classroom contexts. A broader and more heterogeneous corpus including a higher number of participants and degrees would help to generalise the findings of this qualitative and quantitative study, especially when it comes to the analysis of seminars as an academic genre. In line with this, CLIL modules offered in other multilingual universities could be analysed to determine the accuracy and widening of these findings.

Last but not least, some suggestions for further research will be presented. Disciplinary areas, interpersonal communication and multimodal analysis on academic genres will be pointed out in the next section.

\subsection{FURTHER RESEARCH}

The results obtained in this study aimed to describe spoken academic discourse in the CLIL classroom and have called attention to certain issues that could be delved into in the near future. Further research could explore a higher number of seminars in the fields of Humanities, Social Sciences and Health Sciences to confirm the most effective CLIL seminar in terms of learner production. In addition, seminars other than reading, slidetalk or video-debate seminars could be inspected provided that they are implemented at the modules offered at university.

In line with this, further studies could be extended to other disciplinary areas, such as Law and Journalism in Soft Sciences, and Computer Engineering and Physics in Hard Sciences. Thus, differences could also be spotted when comparing and contrasting teacher and student discourse, taking into account that Law and Journalism are two domains where interaction is pivotal. It could be analysed if these results are 
transferable to other bi-/multilingual regions, whether in Spain or other European countries.

Teacher and student production of interpersonal markers has been the focus of the current study. The incorporation of audiovisual tools in the university classroom would also facilitate the compilation of data through video recordings. Thus, CLIL practices could be approached from a multimodal perspective, thereby examining co-speech gestures and translanguaging practices. The notion of translanguaging was introduced in Chapters 1 and 2 on the grounds that bi-/multilingual speakers may switch languages when trying to communicate. Thus, exploring translanguaging instances and the function they serve would contribute to understanding challenging CLIL learning environments.

The potential applicability of these ideas for further research would be profitable for scholars, faculty members and students willing to acquire and show disciplinary knowledge through a foreign language. 


\section{Capítulo 7: Conclusiones}

\subsection{INTRODUCCIÓN}

Este capítulo recoge algunas observaciones finales sobre este estudio, que se centra en la aplicación de los programas AICLE en la Universitat Jaume I, una universidad multilingüe situada en España. A lo largo del proceso de investigación, se ha profundizado en las preocupaciones y aportaciones de los participantes en el aula de AICLE. La motivación principal de este estudio de investigación ha sido la necesidad de investigar y reflexionar sobre las estrategias de enseñanza que se imparten en las áreas de Humanidades, Ciencias Sociales y Ciencias de la Salud. A pesar de la variedad de géneros académicos, entre los que las clases magistrales son los que más han llamado la atención, todavía no se ha investigado lo suficiente sobre el discurso empleado en los seminarios AICLE. Al recapitular los antecedentes teóricos en torno al enfoque AICLE y al discurso académico en las clases y los seminarios, esta tesis pretende contribuir a la comprensión del discurso del profesor y del alumno en contextos educativos en los que se emplea una lengua extranjera como medio de comunicación.

En este capítulo, voy a resumir los estudios anteriores sobre las experiencias de AICLE y el discurso académico. También llamaré la atención sobre los objetivos y el procedimiento metodológico, que han sido claves para el análisis de los resultados. Posteriormente, se revisarán los hallazgos obtenidos en cada uno de los módulos objeto de estudio y sus implicaciones pedagógicas. Por último, se reconocerán las limitaciones de este estudio y se sugerirán ideas para futuras investigaciones. 


\subsection{CONCLUSIONES FINALES}

Esta tesis se ha propuesto contribuir a la investigación sobre el enfoque AICLE describiendo conductas actitudinales así como el discurso académico interpersonal que se generaron en las asignaturas de contenido impartidas en entornos de aprendizaje multilingües de la Universitat Jaume I. El hecho de que el currículo de estos programas perteneciera a diferentes áreas disciplinarias, las de Humanidades, Ciencias Sociales y Ciencias de la Salud, nos ha permitido detectar las similitudes y diferencias en lo que respecta a la participación de profesores y alumnos en el aula AICLE con el fin de poder diseñar una propuesta pedagógica eficaz. Para ello, se plantearon tres preguntas de investigación:

1. $\mathrm{RQ}(1)$ ¿ ¿Cuáles son las actitudes y preocupaciones de los participantes hacia la implementación de las prácticas AICLE en la educación superior?

2. RQ(2). ¿Qué rasgos interpersonales, como los marcadores de compromiso, actitud y evaluación, pueden observarse en los programas de AICLE ofrecidos en la enseñanza superior?

3. RQ(3). ¿Existen diferencias significativas entre las prácticas de AICLE en las áreas de Humanidades, Ciencias Sociales y Ciencias de la Salud?

Partiendo de la noción de la lengua como proceso, el presente estudio investiga las dimensiones actitudinales y lingüísticas en dos géneros académicos, a saber, las conferencias y los seminarios que siguen un enfoque AICLE. Por ello, en los capítulos 2, 3 y 4 se han puntualizado las aportaciones sobre la educación multilingüe, el AICLE y el discurso académico.

Por lo que respecta a la RQ(1), las entrevistas nos permitieron descubrir las necesidades de formación y las actitudes de los profesores de AICLE en las áreas de Humanidades, Ciencias Sociales y Ciencias de la Salud. Las principales conclusiones que se desprenden de las entrevistas realizadas al profesorado participante en este estudio están relacionadas con sus propias percepciones sobre las preocupaciones de alumnos y profesores con respecto al enfoque al AICLE. Según estos docentes, el dominio de la lengua inglesa destaca como la principal dificultad para los estudiantes de grado. La ansiedad de aquellos que tienen un menor dominio de la lengua meta repercute negativamente en su rendimiento en el aula, lo cual se puede observar en la traducción de los materiales disponibles en inglés. Este comportamiento es reincidente en el 
alumnado de las áreas de conocimiento analizadas en este estudio, a excepción de los estudiantes internacionales de la titulación de Turismo. Por otra parte, los docentes hicieron hincapié en el uso de materiales de apoyo y en la necesidad de iniciativas de formación del profesorado.

En cuanto a las actitudes e inquietudes de los estudiantes en contextos AICLE, estas se obtuvieron a través de una encuesta final fundamentada en tres variables: 1) Experiencia en el aprendizaje de idiomas, 2) actitudes hacia la lengua extranjera, y 3) conocimiento de las políticas lingüísticas institucionales. Los resultados relacionados con la primera variable muestran la satisfacción de los estudiantes de grado de Humanidades, Ciencias Sociales y Ciencias de la Salud con su experiencia previa en el aprendizaje de idiomas, especialmente en las titulaciones de Medicina, Enfermería y Psicología, donde no se muestra un desacuerdo total desde la P2 a la P5. Se pueden apreciar las diferencias en la P6. Es evidente que los estudiantes de cuarto curso de las titulaciones de Historia y Turismo consideran que los programas AICLE son menos complicados que los que cursan el módulo de primer curso común a los grados de Historia y Patrimonio y Humanidades: Estudios Interculturales. El hecho de que los estudiantes matriculados en cursos superiores de la titulación hayan tenido la oportunidad de familiarizarse con este tipo de iniciativas puede ser una de las posibles interpretaciones de estos resultados. En lo que concierne a la segunda variable, que se centra en la actitud de los alumnos hacia las pedagogías AICLE, los estudiantes de Turismo y Medicina son más proclives a aprender conocimientos disciplinares a través de una lengua extranjera. En parte, podría deberse al carácter internacional del ámbito del Turismo y al alto rendimiento de los estudiantes de Medicina. Por último, los resultados han puesto de manifiesto que los estudiantes de Humanidades, Ciencias Sociales y Ciencias de la Salud no están familiarizados con las políticas lingüísticas institucionales aplicadas en la universidad. Por lo tanto, son necesarias más acciones de difusión.

En lo que respecta a la $\mathrm{RQ}(2)$, se han encontrado todos los elementos interpersonales objeto de este estudio en el discurso del profesor (p.e., marcadores de compromiso, marcadores de actitud, atenuadores e intensificadores). En las clases magistrales impartidas en Humanidades y Ciencias Sociales, hemos visto que el profesor de Historia ha utilizado un mayor número de marcadores de compromiso. No obstante, hemos identificado que las preguntas prevalecen como la categoría más persistente, tanto en los seminarios de Historia como en los de Turismo. En este sentido, se formulan preguntas 
retóricas, referenciales, expositivas o indirectas para potenciar la interacción de los alumnos. Otros rasgos como las instrucciones y los imperativos también pueden hallarse en menor proporción en ambos campos de especialización (p.e., need to, write), teniendo en cuenta que es menester hacer saber a los alumnos lo que se espera de ellos. Sin embargo, cuando se trata de seminarios AICLE, los comentarios inclusivos son el elemento más recurrente en el discurso del profesor registrado en las asignaturas de Fundamentos y Teoría del Patrimonio Artístico, Historia del Mundo Clásico y Arte Valenciano y Recursos Turísticos. Por lo tanto, parece haber un mayor uso de las referencias personales para hacer partícipe a la audiencia del evento comunicativo. La presencia de marcadores actitudinales e intensificadores es notable en el caso del experto en Turismo, quien hace uso de un amplio abanico de adjetivos, verbos y adverbios en su clase magistral (p.e., great, only, don't worry, of course, clearly). Por el contrario, en el discurso la profesora de Historia destaca el uso de atenuadores (p.e., will, can, could, consider). Como se ha podido observar, la frecuencia de marcadores de compromiso, marcadores actitudinales, atenuadores y enfatizadores parece ser mayor en el discurso producido por la profesora de cuarto año en el grado de Historia y Patrimonio. Podría decirse que hay una mayor necesidad de comunicación por parte de ella debido a la escasa participación de sus alumnos, lo que a su vez puede ser el resultado de su poco dominio de la lengua meta. Al analizar el discurso del profesor en los seminarios de Ciencias de la Salud, se ha podido observar que los marcadores de compromiso siguen siendo el principal recurso metadiscursivo en el discurso del profesor, seguido de los atenuadores, los marcadores actitudinales y los intensificadores. A diferencia de los resultados obtenidos en Humanidades y Ciencias Sociales, los marcadores de compromiso más comunes corresponden a comentarios inclusivos que pueden identificarse mediante el uso de pronombres (p.e., tú, nosotros) y preguntas para captar la atención de los alumnos. No obstante, la incidencia de los comentarios conductuales y de disculpa ha sido prácticamente inexistente en algunas de las titulaciones, lo que sugiere que los alumnos se estaban comportando debidamente. En cuanto a los marcadores de actitud, atenuadores e intensificadores, se ha podido constatar la presencia de verbos, adverbios, adjetivos y sustantivos como key, easy, true, know, show, evidence o maybe, encontrando el menor número de recursos en el área de Enfermería. 
Por otra parte, las aportaciones de los estudiantes de Humanidades y Ciencias Sociales fueron más restringidas en las clases y seminarios magistrales, ya que suelen ser prácticas centradas en el profesor. De este modo, se ha podido observar que el número de elementos interpersonales ha descendido significativamente. Al comparar las clases magistrales que tinen lugar en las disciplinas de Humanidades y Ciencias Sociales, se ha podido advertir una cierta tendencia al uso de un mayor número de marcadores metadiscursivos en Historia. En este sentido, los principales recursos de compromiso han sido los comentarios inclusivos (p.e., your, we, our) y las preguntas tanto en el área de Historia como en la de Turismo. La ausencia de directrices e imperativos podría estar relacionada con el hecho de que el profesor es el encargado de dar las pautas a todo el alumnado, mientras que la inexistencia de comentarios de disculpa y de comportamiento sugiere que no han tenido la necesidad de reformular su discurso o modificar sus actitudes en el aula. Se han identificado atenuadores en ambos campos de conocimiento, siendo los alumnos de Historia superan a sus compañeros de Turismo (p.e., well-known, typical, offer). En general, los estudiantes de Historia parecen utilizar los marcadores metadiscursivos con más frecuencia que los de Turismo, cuyo discurso se caracteriza por un número reducido de marcadores actitudinales. Algunos ejemplos de estos elementos en las clases magistrales son main y please. Sin embargo, los marcadores de actitud están ausentes en las clases magistrales de ambas asignaturas. Cabe destacar la prevalencia de los marcadores de compromiso en las producciones de los estudiantes de Historia en seminarios (p.e., let's). En la asignatura de Historia del Mundo Clásico se han podido distinguir comentarios inclusivos (p.e., tú), aunque también se han registrado directrices e imperativos en otras áreas históricas y turísticas (p.e., next one, should, ponlo). Todo ello podría deberse al hecho de que los alumnos de primero de Historia y los de cuarto de Turismo están guiando a su audiencia o a los miembros de su grupo durante sus presentaciones orales. Por otro lado, las directirices que se encuentran en el discurso de los alumnos de cuarto curso de Historia pueden estar relacionados con peticiones (p.e., tenemos que contestar a esto, ¿no?). Además, ha sido posible identificar comentarios de disculpa en el módulo de Historia de primer año, probablemente a causa de la ansiedad de los ponentes (p.e., sorry, perdón, nervous). Al enforcarnos en el discurso de los estudiantes generado en los seminarios de Ciencias de la Salud, se ha podido observar que los marcadores de compromiso parecen ser el rasgo metadiscursivo más frecuente junto con los atenuadores. Destacan especialmente en las asignaturas de Epidemiología y Cuidados la mujer, donde los alumnos presentan sus 
proyectos de investigación. Los marcadores de compromiso parecen ser los elementos preferidos por los estudiantes de Ciencias de la Salud, con los comentarios inclusivos (p.e. we, our) y las preguntas a la cabeza de la categoría. Lo mismo ocurre con el resto de rasgos lingüísticos, ya que los estudiantes tienen más oportunidades de contribuir en estos seminarios. Los marcadores actitudinales como important son comunes en las asignaturas de Medicina de primer, segundo y tercer año, al igual que en los de Enfermería y Psicología. Sin embargo, en estas prácticas AICLE se pueden detectar otros términos como key, controversial, necessary o scary. Asimismo, los intensificadores (p.e., prove, know, show) y los atenuadores (p.e., some, think, consider, believe, would) son solo algunos de los recursos empleados por los estudiantes universitarios.

Centrándonos en la RQ3, se ha podido observar que el número medio de palabras difiere en gran medida entre las disciplinas. Se podría interpretar que las aportaciones de profesores y alumnos se dan con mayor frecuencia en Ciencias de la Salud, más concretamente en las asignaturas de Inglés para Médicos, Epidemiología y Neurociencia Afectiva y Social. Les seguirían los programas de Arte Valenciano y Recursos Turísticos, Historia del Mundo Clásico, Cuidados de la Mujer, Antropología y Fundamentos y Teoría del Patrimonio Artístico. Además, los datos examinados en las pruebas de nivel han revelado que un elevado número de estudiantes tiene un buen dominio de la lengua inglesa desde el punto de vista léxico-gramatical. No obstante, se observan diferencias notables en las áreas de Humanidades, Ciencias Sociales y Ciencias de la Salud, donde los estudiantes de Medicina consiguen mejores resultados en comparación a los de otras disciplinas. Las habilidades comunicativas de los estudiantes de Enfermería también se sitúan en un nivel avanzado; en cambio, se observa un amplio abanico de niveles lingüísticos en las respuestas de los futuros especialistas en Psicología, Historia y Turismo. Por lo tanto, se podría afirmar que los alumnos de AICLE que resultan tener un mejor dominio de la lengua meta son los de Ciencias de la Salud, lo que puede repercutir en la producción de resultados orales. Como se ha recogido en el capítulo 6, los resultados obtenidos en los campos de Humanidades y las Ciencias Sociales indican que la aparición y la variedad de los marcadores interpersonales están sujetas a las disciplinas estudiadas, así como a la competencia comunicativa de los sujetos. De hecho, en los ámbitos de Humanidades y Ciencias Sociales, es la disciplina de Turismo la que presenta mayor variedad de 
marcadores en el discurso tanto del profesor como del alumno, seguida de los resultados orales registrados en el módulo de primer curso ofertado en Historia y Humanidades. A diferencia de otras titulaciones, la variedad de marcadores interpersonales que se da en el módulo de cuarto curso de Turismo puede deberse al tipo de género académico, teniendo en cuenta que se espera que los docentes tomen la palabra para presentar los contenidos en las sesiones lectivas. Al igual que las clases magistrales, los seminarios impartidos en Turismo permiten una participación más activa por parte de los alumnos. La razón principal puede estar relacionada con el hecho de que un gran número de estudiantes internacionales tienen un mejor dominio de la lengua inglesa. También hay que destacar que es en la asignatura de cuarto curso en el grado de Historia y Patrimonio donde se dan menos casos de marcadores metadiscursivos, ya que suelen evitar intervenir de manera activa debido a su escaso dominio del idioma. Al analizar estos recursos lingüísticos, se pueden distinguir marcadores de compromiso en todas las asignaturas de contenido a través del uso de preguntas y pronombres. Dentro de las clases o seminarios magistrales, se observa una amplia gama de coberturas en inglés en el ámbito de las Humanidades, mientras que el español parece ser la lengua preferida entre los alumnos de cuarto curso de Historia que asisten a seminarios de video-debate. Este último presenta un mayor número de coberturas en español, seguido de los marcadores de actitud y los intensificadores. Sin embargo, los marcadores de actitud y los intensificadores son más frecuentes en Ciencias Sociales. Esta tendencia varía ligeramente en el ámbito de las Ciencias de la Salud, donde el discurso del profesor de inglés para medicina incluye una gran variedad de recursos interpersonales emitidos en un seminario magistral. Es decir, al tratarse de un género más tradicional que otras prácticas docentes, la producción del profesor es mayor que los resultados producidos por los alumnos o los profesores en otros seminarios de Ciencias de la Salud. La tendencia contraria se observa en los seminarios de video-debate o en los seminarios de diapositivas, ya que los alumnos tienen más oportunidades de contribuir en el aula. En este sentido, es en las asignaturas de Medicina y Enfermería de tercer año donde los alumnos producen un mayor número de marcadores interpersonales, con los atenuadores seguidos por marcadores de actitud e intensificadores. No obstante, Enfermería sería el área de salud donde menos elementos lingüísticos se encuentran en el aula AICLE. Todos estos resultados nos han permitido identificar necesidades en el profesorado y alumnado. 


\subsection{IMPLICACIONES PEDAGÓGICAS}

Dado que los objetivos de este estudio implican la identificación de los elementos lingüísticos empleados en el aula AICLE, se examinó la presencia de marcadores de compromiso, actitudinales, atenuadores e intensificadores a partir del discurso de profesores y alumnos. Tras analizar los principales resultados obtenidos en las entrevistas a los profesores, las encuestas a los alumnos, las pruebas de nivel y las prácticas en el aula, se ha evidenciado que es necesario aplicar algunas medidas. Esta investigación cuantitativa y cualitativa ha sido valiosa en el sentido de que es necesario potenciar la comunicación interpersonal en algunos tipos de seminarios y clases.

Desde un punto de vista pedagógico, este estudio puede contribuir a que los profesores sean más conscientes de la amplia gama de marcadores metadiscursivos que pueden emplearse en el aula de contenidos para captar la atención de la audiencia. En este sentido, también pueden aprender sobre el papel de los marcadores interpersonales en la adquisición de nuevos conocimientos y en la interacción profesor-alumno en inglés. De este modo, los profesores pueden ser capaces de producir un número más amplio de recursos interpersonales que facilite la presentación y comprensión de nuevos contenidos, lo que a su vez conlleva una mejora de sus habilidades lingüísticas en el ámbito académico (CALP) y cotidiano (BICS). Además, este estudio proporciona una visión general de las prácticas docentes que parecen ser más eficaces para alcanzar este objetivo, en concreto, los seminarios de presentaciones y vídeo-debates.

Teniendo en cuenta que es necesario expresar seguridad a la hora de impartir docencia en entornos académicos, sería aconsejable impulsar la producción de intensificadores en el discurso de los profesores. Se trata de los marcadores menos recurrentes en todas las disciplinas analizadas en este estudio, pero un mayor uso podría hacer sentir a los alumnos que los profesores dominan las nociones que se explican en la lengua meta. Otros marcadores metadiscursivos que pueden potenciarse en el discurso del profesor son las preguntas, los imperativos, las directrices y los comentarios de comprensión, los cuales son fundamentales para dar instrucciones y evitar posibles malentendidos en el acto comunicativo. 
Este estudio también ha revelado en qué medida se utilizan los marcadores metadiscursivos en el discurso de los alumnos. Aunque se observa un mayor número de estos elementos en los seminarios de presentaciones, se debe proporcionar a los alumnos materiales que les permitan comunicarse con éxito en el aula de contenido. Por ello, la creación de glosarios por parte de profesores de asignaturas AICLE sería valiosa para facilitar la adquisición de estructuras vitales en la fase de interacción. Por otra parte, la exposición al discurso del profesor podría tener un impacto significativo en los estudiantes que cursan módulos AICLE, especialmente en lo que se refiere a la asimilación de contenidos y a sus habilidades productivas.

A partir de las entrevistas y de las prácticas en el aula, se pudo observar que los profesores necesitan comprender los principios del enfoque AICLE y recibir cierta formación para superar los desafíos cognitivos y lingüísticos en el aula AICLE. Por lo tanto, este estudio puede ayudar a sentar las bases de un curso de formación dirigido a docentes que se encuentren en formación y en servicio. Al abordar temas relevantes que propicien el desarrollo de habilidades organizativas, de pensamiento crítico así como interpersonales a través de una lengua extranjera, los participantes podrían aprender estrategias de enseñanza que pueden ser provechosas para toda la comunidad universitaria. Este curso exigiría la integración del análisis de necesidades y diseño curricular, los cuales parecen estar estrechamente relacionados, tal y como respaldan investigaciones anteriores relacionadas con inglés para fines específicos (ESP por sus siglas en inglés) y AICLE (Bocanegra-Valle, 2016; Carrió-Pastor \& Tamarit Vallès, 2015; Martín del Pozo, 2014; Flowerdew, 2013). El análisis de las inquietudes de los alumnos es primordial para abordar un entorno de aprendizaje apremiante y a la vez desafiante, en el que hay que tener en cuenta diversas variables, como los detalles del curso, los objetivos, los resultados del aprendizaje o los materiales, por nombrar algunos. Sería conveniente que dicho curso de formación de profesores profundizara en los principios del enfoque AICLE y en el discurso académico en inglés. Al respecto, deberían revisarse nociones como el marco de las 4C, las habilidades de pensamiento de orden superior (HOTS, por sus siglas en inglés) y las habilidades de pensamiento de orden inferior (LOTS, por sus siglas en inglés), las estrategias de andamiaje, así como el análisis de los marcadores metadiscursivos identificados en clases magistrales y seminarios grabados en vídeo. Mediante el trabajo en grupo y los debates, los educadores no sólo aprenderían los fundamentos para estructurar su discurso en clases 
magistrales y seminarios, sino también estrategias de enseñanza eficaces para el aula de AICLE que llevarían a prácticas de AICLE satisfactorias. Por lo tanto, esta investigación trataría de proporcionar a los profesores los recursos necesarios para mejorar los programas AICLE existentes en la enseñanza superior.

Los resultados obtenidos en los cuestionarios de los estudiantes pusieron de manifiesto la necesidad de emprender acciones institucionales. Los estudiantes de grado de Humanidades, Ciencias Sociales y Ciencias de la Salud apenas conocen las políticas multilingües implementadas en la Universitat Jaume I, en lo que respecta al uso del inglés y del catalán. Siguiendo los resultados de este estudio, algunas de las directrices pasarían por dar más información a los estudiantes sobre la política lingüística al inicio del curso académico. En este sentido, se podrían destinar varios talleres para presentar el plan multilingüe de la Universitat Jaume I y la fundamentación del enfoque AICLE implementado en las asignaturas curriculares ofertadas en ciencias blandas y duras. En estas sesiones, se realizaría un análisis basado en corpus para dar a conocer el discurso académico en estos entornos de aprendizaje. Así pues, las implicaciones pedagógicas derivadas de este estudio contribuirían no sólo a difundir las políticas institucionales, sino también a promover el uso de patrones discursivos interactivos en clases magistrales y seminarios.

Estas intervenciones pretenden subsanar las carencias de los profesores en materia de diseño curricular a partir de sus percepciones. Lo mismo ocurre con los estudiantes de grado que participan en iniciativas AICLE y necesitan saber cómo proceder en los contextos educativos. No obstante, se describirán las limitaciones de este estudio e ideas para futuras investigaciones en la siguiente sección.

\subsection{LIMITACIONES DEL ESTUDIO}

Cabe tener en cuenta las limitaciones de esta investigación. La primera limitación se encuentra en la naturaleza cualitativa y cuantitativa de este estudio, la cual puede haber tenido un impacto en los resultados obtenidos. Aunque se debería haber realizado un segundo análisis para atenuar la subjetividad en este análisis, esto no fue posible debido a cuestiones de tiempo y al tamaño del corpus. El hecho de que el análisis de elementos interpersonales fue llevado a cabo a cabo con Lextutor (Cobb, n.d.) debe considerarse 
como una limitación, ya que se podría haber empleado otro sistema de análisis de corpus más preciso. Para que los resultados obtenidos por Lextutor (Cobb, n.d.) sean más precisos y para corroborar la validez de los marcadores metadiscursivos, el corpus también fue objeto de una minuciosa revisión.

El estudio está limitado a las asignaturas AICLE que se ofertan en una universidad multilingüe; no hay muestras adicionales de otras universidades de la Comunidad Valenciana, lo cual habría contribuido a generalizar los resultados obtenidos en este estudio. La competencia linguística es otra variable que merece ser mencionada. No todos los participantes tenían un dominio heterogéneo de la lengua inglesa, sino que el dominio de los profesores y de los alumnos difería en cierta medida en los módulos AICLE examinados.

Dado que en este estudio sólo han participado seis titulaciones, los resultados pueden no ser replicables a otros contextos de aula. Un corpus más amplio y homogéneo que incluyera un mayor número de participantes y titulaciones ayudaría a generalizar los hallazgos de este trabajo cualitativo y cuantitativo, especialmente en lo que se refiere al análisis de los seminarios como género académico. En este sentido, se podrían analizar los módulos de AICLE ofrecidos en otras universidades multilingües para determinar la exactitud y la ampliación de estos hallazgos.

\subsection{SUGERENCIAS PARA FUTURAS INVESTIGACIONES}

Los resultados obtenidos en este estudio pretenden reflejar el discurso académico producido en el aula AICLE, los cuales han permitido advertir ciertas cuestiones en las que se podría profundizar en un futuro próximo. En posteriores investigaciones se podría analizar un mayor número de seminarios en las áreas de Humanidades, Ciencias Sociales y Ciencias de la Salud para confirmar cuál es el seminario AICLE más eficaz en lo que respecta a la producción de los estudiantes. Además, podrían examinarse otros seminarios que no sean de lectura, de presentaciones o de vídeo debates, siempre y cuando se implementen en las asignaturas ofertadas en la universidad.

De acuerdo con esto, se podrían ampliar los estudios a otras áreas disciplinarias, como el Derecho y el Periodismo en las Ciencias Blancas, y la Ingeniería Informática y la Física en las Ciencias Duras. Así, también podrían detectarse diferencias al comparar y 
contrastar el discurso de profesores y alumnos, teniendo en cuenta que Derecho y Periodismo son dos ámbitos en los que la interacción es primordial. Asimismo, se podría investigar si estos resultados son transferibles a otras regiones bi-/multilingües, ya sea en España o en otros países europeos.

La producción de marcadores interpersonales por parte de profesores y alumnos ha sido el objetivo del presente estudio. La incorporación de herramientas audiovisuales en el aula universitaria también facilitaría la recopilación de datos a través de grabaciones de vídeo. De este modo, las prácticas de AICLE podrían abordarse desde una perspectiva multimodal, examinando así los gestos de cohabitación y las prácticas de translenguaje. La noción de translenguaje se ha presentado en los capítulos 1 y 2 partiendo de la base de que los hablantes bi-/multilingües suelen cambiar de lengua cuando intentan comunicarse. Por lo tanto, explorar las prácticas de translenguaje y la función que desempeñan contribuiría a entender los entornos de aprendizaje AICLE que suponen un reto.

La posible aplicabilidad de estas ideas para futuras investigaciones sería provechosa para los académicos, los miembros del profesorado y los estudiantes que deseen adquirir y mostrar conocimientos disciplinarios a través de una lengua extranjera. 


\section{Chapter 8: References}

Achugar, M., Schleppegrell, M., \& Oteíza, T. (2007). Engaging teachers in language analysis: A functional linguistics approach to reflective literacy. English teaching: Practice and critique, 6(2), 8-24.

Ädel, A. (2017). Remember that your reader cannot read your mind: Problem/solutionoriented metadiscourse in teacher feedback on student writing. English for Specific Purposes, 45, 54-68. https://doi.org/10.1016/j.esp.2016.09.002

Ädel, A. (2010). Just to give you kind of a map of where we are going: A taxonomy of metadiscourse in spoken and written academic English. Nordic Journal of English Studies, 9(2), 69-97.

Ädel, A. (2006). Metadiscourse in L1 and L2 English. John Benjamins.

Aiello, J., Di Martino, E., \& Di Sabato, B. (2017). Preparing teachers in Italy for CLIL: reflections on assessment, language proficiency and willingness to communicate. International Journal of Bilingual Education and Bilingualism, 20(1), 69-83.

Airey, J. (2016). EAP, EMI or CLIL?: (English for Academic Purposes, English Medium Instruction or Content and Language Integrated Learning). In $\mathrm{K}$. Hyland \& P. Shaw (Eds.), The Routledge Handbook of English for Academic Purposes (pp. 71-83). Routledge.

Airey, J. (2011). Talking about teaching in English: Swedish university lecturers' experiences of changing teaching language. Ibérica, 22, 35-54. 
Agolli, R. (2015). Content and Language symbiosis in a maieutic, translanguaging pattern (CLSL): An exploratory practice in Italy. Latin American Journal of Content and Language Integrated Learning, 8(1), 43-54. https://doi.org/10.5294/laclil.2015.8.1.5

Agolli, R. (2013). A penetrating CLIL praxis in Italian mainstream education: Stemming novelties and visions. Research Papers in Language Teaching and Learning, 4, 138-157.

Aguilar, M. (2004). The peer seminar, a spoken research process genre. Journal of English for Academic Purposes, 3(1), 55-72. https://doi.org/10.1016/S1475$\underline{1585(03) 00043-2}$

Aguilar, M. (2008). Metadiscourse in academic speech: A relevance-theoretic approach. Peter Lang. https://doi.org/10.1080/13670050.2015.1073664

Aguilar, M. (2015). Engineering lecturers' views on CLIL and EMI. International Journal of Bilingual Education and Bilingualism, 20(6), 722-735.

Aguilar, M. (2021). Can EMI contribute to enhancing lecturers' and students' intercultural competence? In M.L. Carrió-Pastor \& B. Bellés-Fortuño (Eds.), Teaching Language and Content in Multicultural and Multilingual Classrooms: CLIL and EMI Approaches (pp.65-96). Palgrave Macmillan.

Aguilar, M. \& Muñoz, C. (2014). The effect of proficiency on CLIL benefits in Engineering students in Spain. International Journal of Applied Linguistics, 24(1), 1-18. https://doi.org/10.1111/ijal.12006

Al'Adawi, S.S.A. (2017). Exploring the Effectiveness of Implementing Seminars as a Teaching and an Assessment Method in a Children's Literature Course. English Language Teaching, 10(11), 1-14.

Alcaraz Varó, E. (2000). El inglés profesional y académico. Alianza Editorial.

Alderson, J.C., Clapham, C., \& Wall, D. (1995). Language test construction and evaluation. Cambridge University Press.

Alexander, R.J. (2008). Towards Dialogic Thinking: Rethinking Classroom Talk (4th ed.). Dialogos. 
Ali, N.L., \& Hamid, M.O. (2018). English-medium instruction and teacher agency in higher education: A case study. In C. Siew Kheng Chua, K. Taylor-Leech \& C. Williams (Eds.), Un(intended) language planning in a globalising world: Multiple levels of players at work (pp. 234-250). De Gruyter Open Poland. https://doi.org/10.1515/9783110518269-013

Arco-Tirado, J. L., Fernández-Martín, F. D., \& Hernández-Moreno, N. (2016). Skills learning through a bilingual mentors program in higher education. International Journal of Bilingual Education and Bilingualism, 21(8), 1030-1040. https://doi.org/10.1080/13670050.2016.1228601

Arnó-Macià, E., \& Mancho-Barés, G. (2015). The role of content and language in content and language integrated learning (CLIL) at university: Challenges and implications for ESP. English for Specific Purposes, 37, 63-73.

Ariza, E. (2018). Not for ESOL teachers: What every classroom teacher needs to know about the linguistically, culturally, and ethnically diverse student (3rd ed.) Kendall Hunt.

Arkorful, V., \& Abaidoo, N. (2015). The role of e-learning, advantages and disadvantages of its adoption in higher education. Instructional Journal of Instructional Technology and Distance Learning, 12(1), 29-42.

Aronin, L., \& Laoire, M.Ó. (2004). Exploring multilingualism in cultural contexts: Towards a notion of multilinguality. In C. Hoffmann \& J. Ytsma (Eds.), Trilingualism in family, school and community (pp. 1-29). Multilingual Matters Ltd.

ASEAN Secretariat (2013). Secretary General: English is indispensable to ASEAN Community. Address given at the Global Conference on Educating the Next Generation of Workforce: ASEAN Perspectives on Innovation, Integration and English, Bangkok, June. ASEAN Secretariat News, Jakarta. https://asean.org/keynote-address-by-he-le-luong-minh-secretary-general-ofasean-at-the-british-council-conference-on-educating-the-next-generation-ofworkforce-asean-perspectives-on-innovation-integration-and-english/ 
Aubrey, K., \& Riley, A. (2016). Understanding and Using Educational Theories. Sage publications.

Bahar, M. (2003). The effects of motivational styles on group work and discussionbased seminars. Scandinavian Journal of Educational Research, 47(4), 461-473. https://doi.org/10.1080/00313830308591

Baker, W., \& Hüttner, J. (2019). We are not the language police": Comparing multilingual EMI programmes in Europe and Asia. International Journal of Applied Linguistics, 29, 78-94. https://doi.org/10.1111/ijal.12246

Baker, A. (2000). Improve your communication skills. Kogan Page.

Baldwin, J. (2019). Languages other than English in Australian Higher Education Policies, Provision, and the National Interest. Springer International Publishing.

Banegas, D. L. (2019). Teacher professional development in language-driven CLIL: A case study. Latin American Journal of Content \& Language Integrated Learning, 12(2), 242-264. https://doi.org/10.5294/lacli1.2019.12.2.3

Banks, D. (2002). Systemic Functional Linguistics as a model for text analysis. ASp. la revue du GERAS, 35-36, 23-34.

Barefoot, B. O., \& Fidler, P. P. (1992). Helping students climb the ladder: 1991 national survey of freshman seminar programs. (Monograph No. 10). National Resource Center for the Freshman Year Experience, University of South Carolina.

Baron, M. (2005). The Written Turn. English Language and Linguistics, 9(2), 359-376. https://doi.org/10.1017/S136067430500170X

Barajas, M. (2003). Virtual Learning Environments in Higher Education: A European View. Edicions Universitat Barcelona.

Basturkmen, H. (1999). Discourse in MBA seminars: Towards a description for pedagogical purposes. English for Specific Purposes, 18(1), 63-80. https://doi.org/10.1016/S0889-4906(97)00049-5 
Bazzanella, C., \& Morra, L. (2000). Discourse markers and the indeterminacy of translation. In I. Korzen \& C. Marello (Eds.), On Linguistic Aspects of Translation (pp. 149-157). Edizioni dell' Orso.

Belfield, C.R., \& Crosta, P.M. (2012). Predicting success in college: The importance of placement tests and high school transcripts. CCRC Working Paper No. 42. In Community College Research Center, Columbia University. Community College Research Center.

Bellés-Calvera, L. (2018). Teaching music in English: A content-based instruction model in secondary education. Latin American Journal of Language and Integrated Learning, 11(1), 109-139. https://doi.org/10.5294/laclil.2018.11.1.6

Bellés-Calvera, L. (2019). The Linguistic Landscape of the Valencian Community: A Comparative Analysis of Bilingual and Multilingual Signs in Three Different Areas. Languages, 4(2), 38-57. https://doi.org/10.3390/languages4020038

Bellés-Calvera, L., \& Bellés-Fortuño, B. (2018a). Teaching English pronunciation with OERs: The case of Voki. Sintagma: revista de lingüística, 30, 57-80. https://doi.org/10.21001/sintagma.2018.30.04

Bellés-Calvera, L., \& Bellés-Fortuño, B. (2018b). Written corrective feedback with online tools in the Medicine classroom: Bombay TV. In C. López-García, \& J. Manso (Eds.), Transforming education for a changing world, (pp. 106-119). Adaya Press.

Bellés-Calvera, L., \& Bellés-Fortuño, B. (in press). CLIL and e-learning environments: The role of Google My Maps and students' written performance in Classical History. Verbeia.

Bellés-Calvera, L., \& Martínez-Hernández, A.I. (2021). Written discourse competence and asynchronous online learning: An analysis of lexical errors in higher education. In O. Buzón-García, C. Romero-García, \& A. Verdú-Vázquez (Eds.), Innovaciones metodológicas con TIC en educación (pp. 4009-4031). Dykinson.

Bellés-Fortuño, B. (2004). The influence of lecturing styles in the use of Discourse Markers within the spoken academic discourse of Social Sciences. In M. Labarta 
Postigo (Ed.), Approaches to Critical Discourse Analysis. Publicacions Universitat de València.

Bellés-Fortuño, B. (2007). Discourse Markers Within The University Lecture Genre: A contrastive study between Spanish and North-American lectures [Doctoral dissertation, Universitat Jaume I].

Bellés-Fortuño, B. (2008). A spoken academic discourse contrastive study: Discourse markers in North-American and Spanish lectures. Asociación Española de Lingüística Aplicada.

Bellés-Fortuño, B. (2016). Academic discourse markers: A contrastive analysis of the discourse marker then in English and Spanish lectures. Verbeia, 1, 57-78.

Bellés-Fortuño, B. (2018). Evaluative language in medical discourse: A contrastive study between English and Spanish university lectures. Languages in Contrast, 18(2), 155-174. https://doi.org/10.1075/lic.15018.bel

Bellés-Fortuño, B. (2021). CLIL assessment: Accommodating the curricular design in HE. In M.L. Carrió-Pastor, \& B. Bellés-Fortuño (Eds.), Teaching Language and Content in Multicultural and Multilingual Classrooms: CLIL and EMI Approaches (pp. 293-314). Palgrave Macmillan.

Bellés-Fortuño, B., \& Belenguer Balaguer, E. (2006). English as the instructional language in the Industrial Engineering degree: the implementation of ICTs in the EURUJI project. In U. Olster, N. Ruiz-Madrid \& M. Sanz Gil (Eds.), Towards the integration of ICT in language learning and teaching: reflection and experience (pp. 311-323). Universitat Jaume I.

Bellés-Fortuño, B., \& Ferrer-Alcantud, C. (2016). European Higher Education language requirements: English as a vehicular language in the content subject classroom. In XV International Conference AELFE: Today's and Tomorrow's Challenges in Languages for Specific Purposes and Translation (pp. 45-48). Universidad de Alcalá de Henares.

Benson, M. J. (1994). Lecture listening in an ethnographic perspective. In J. Flowerdew, (Ed.), Academic English: research perspectives (pp. 181-198). Cambridge University Press. 
Bentley, K. (2010). The TKT Course CLIL Module. Cambridge University Press.

Berg, B.L. (2007). Qualitative research methods for the social sciences. Pearson.

Bhatia, T.K., \& Ritchie, W.C. (2014). The handbook of bilingualism and multilingualism. Wiley-Blackwell.

Biber, D. (1988). Variation across speech and writing. Cambridge University Press.

Biber, D. (1993). Representativeness in corpus design. Literary and linguistic computing, 8(4), 243-257.

Biber, D. (2006). University language: a corpus-based study of spoken and written registers. John Benjamins.

Biber, D., \& Barbieri, F. (2007). Lexical bundles in university spoken and written registers. English for Specific Purposes, 26, 263-286. https://doi.org/10.1016/j.esp.2006.08.003

Bieri, A.S. (2018). Translanguaging practices in CLIL and non-CLIL biology lessons in Switzerland. EuroAmerican Journal of Applied Linguistics and Languages, 5(2), 91-109. http://dx.doi.org/10.21283/2376905X.9.142

Bilingualism matters (2019). About us. http://www.bilingualism-matters.ppls.ed.ac.uk/

Billings, L., \& Roberts, T. (2003). The Paideia seminar: Active thinking through dialogue. National Paideia Center.

Blackledge, A., \& Creese, A. (Eds.) (2014). Heteroglossia as practice and pedagogy. Springer.

Bloomfield, L. (1933). Language. Allen and Unwin.

Bocanegra-Valle, A. (2016). Needs analysis for curriculum design. In K. Hyland, \& P. Shaw (Eds.), The Routledge Handbook of English for Academic Purposes (pp. 584-600). Routledge.

BOE (2017). Real Decreto 562/2017, de 2 de junio, por el que se regulan las condiciones para la obtención de los títulos de Graduado en Educación Secundaria Obligatoria y de Bachiller, de acuerdo con lo dispuesto en el Real 
Decreto-ley 5/2016, de 9 de diciembre, de medidas urgentes para la ampliación del calendario de implantación de la Ley Orgánica 8/2013, de 9 de diciembre, para la mejora de la calidad educativa. Ministerio de Educación, Cultura y Deporte. https://www.boe.es/boe/dias/2017/06/03/pdfs/BOE-A-2017-6250.pdf

BOE (2006). Ley Orgánica 2/2006, de 3 de mayo, de Educación. Jefatura del Estado. https://www.boe.es/buscar/pdf/2006/BOE-A-2006-7899-consolidado.pdf

BOJA (2005). Acuerdo de 22 de marzo de 2005 del Consejo de Gobierno de la Junta de Andalucía por el que se aprueba el Plan de Fomento del Plurilingüismo en Andalucía. [Consejería de Educación de la Junta de Andalucía]. Consejería de Educación de la Junta de Andalucía. http://www.adideandalucia.es/normas/acuerdos/Acuerdo\%2022-32005\%20Plan\%20plurilinguismo.pdf

Bolton, K., \& Botha, W. (2017). English as a medium of instruction in Singapore higher education. In B. Fenton-Smith, P. Humphreys \& I. Walkinshaw (Eds.), English medium instruction in higher education in Asia-Pacific (pp. 133-152). Cham: Springer.

Bossaer, J. B., Panus, P., Stewart, D. W., Hagemeier, N. E., \& George, J. (2016). Student performance in a pharmacotherapy oncology module before and after flipping the classroom. American Journal of Pharmaceutical Education, 80(2), $1-6$.

Boussebaa, M., \& Brown, A.D. (2017). Englishization, Identity Regulation and Imperialism. $\quad$ Organization $\quad$ Studies, $\quad 38(1), \quad 7-29$. https://doi.org/10.1177/0170840616655494

Bredenbröker, W. (2000). Förderung der fremdsprachlichen Kompetenz durch bilingualen Unterricht: Empirische Untersuchungen [Promoting Foreign Language Competences with the Help of Content and Language Integrated Learning: Empirical Investigations]. Peter Lang.

Breuer, E., \& Archer, A. (2016). Multimodality in Higher Education. Brill. 
Brinton, D. M., \& Snow, M. A. (2017). The evolving architecture of CBI. In M.A. Snow, \& D.M. Brinton (Eds.), The content-based classroom (pp. 2-20). University of Michigan Press.

Brinton, D., Snow, M., \& Wesche, M. (2003). Content-based second language instruction. University of Michigan Press ELT.

Broughton, G., Brumfit, C., Flavell, R., Hill, P., \& Pincas, A. (1980). Teaching English as a Foreign Language. Routledge.

Brown, H. D., \& Bradford, A. (2017). EMI, CLIL, \& CBI: Differing approaches and goals. In P. Clements, A. Krause, \& H. Brown (Eds.), Transformation in language education (pp. 328-334). JALT.

Brown, H. D., \& Abeywickrama, P. (2010). Language assessment: Principles and classroom practice (2nd ed.). Pearson Education.

Brown, J. D. (2005). Research methods for applied linguistics. In A. Davies, \& C. Elder (Eds.), The Handbook of Applied Linguistics (pp. 476-500). Blackwell.

$\mathrm{Bu}$, J. (2014). Towards a pragmatic analysis of metadiscourse in academic lectures: From relevance to adaptation. Discourse Studies, 16(4), 449-472. https://doi.org/10.1177/1461445613519019

Byram, M. (2004). Routledge encyclopedia of language teaching and learning. Routledge.

Byun, K., Chu, H., Kim, M., Park, I., Kim, S., \& Jung, J. (2011). English-medium teaching in Korean higher education: Policy debates and reality. Higher Education, 62, 431-449. https://doi.org/10.1007/s10734-010-9397-4

Callard, F., \& Fitzgerald, D. (2015). Rethinking Interdisciplinarity across the Social Sciences and Neurosciences. Palgrave Macmillan.

Cambridge dictionary (n.d.). Seminar. In dictionary.cambridge.org. Retrieved 19 September 2019 from https://dictionary.cambridge.org/es/diccionario/ingles/seminar 
Cammarata, L., Tedick, D., \& T. Osborn, T. (2016). Content-based instruction and curricular reforms: issues and goals. In L. Cammarata (Ed.), Content-based Foreign Language Teaching. Routledge.

Campoy, M. C., Luzón, M. J., \& Salazar, P. (2007). Spoken corpora: New Perspectives in Oral Language Use and Teaching. In M.C. Campoy \& M.J. Luzón (Eds.), Spoken corpora in applied linguistics (pp. 3-32). Peter Lang.

Campus France (2018). Scholarships for foreign students in France. Retrieved 19 January 2019 from https://www.campusfrance.org/en/bursaries-foreign-students

Cañedo Iglesias, C. M., (2008). Fundamentos teóricos para la implementación de la didáctica en el proceso enseñanza-aprendizaje. Biblioteca virtual de Derecho, Economía y Ciencias Sociales. https://www.eumed.net/librosgratis/2008b/395/index.htm

Carrió-Pastor, M.L. (2008). Learner-Instructor collaborative design of content and language integrated writing activities. ITL - International Journal of Applied Linguistics, 156, 176-178.

Carrió-Pastor, M.L. (2009). Content and language integrated learning: Cultural diversity. Peter Lang.

Carrió-Pastor, M.L. (2011). Collaborative teaching strategies: The Internet in Content and Language Integrated Learning. In S. Maruenda, \& B. Clavel-Arroitia (Eds.), Multiple Voices in Academic and Professional Discourse: Current Issues in Specialised Language Research, Teaching and New Technologies (pp.32-45). Cambridge Scholars Publishing.

Carrió-Pastor, M.L. (2013). The Internet, collaborative writing and CLIL in second language teaching. Lenguaje y Textos, 38, 61-68.

Carrió-Pastor, M.L. (2019a). Teaching Language and Teaching Literature in Virtual Environments. Springer.

Carrió-Pastor, M.L. (2019b). The implementation of content and language integrated learning in Spain: Strengths, weaknesses, opportunities and threats. In P. 
Mickan, \& I. Wallace (Eds.), The Routledge Handbook of Language Education Curriculum Design (pp. 77-89). Routledge.

Carrió-Pastor, M.L. (Ed.) (2020a). Internationalising Learning in Higher Education: The Challenges of English as a Medium of Instruction. Palgrave MacMillan.

Carrió-Pastor, M.L. (2020b). English as a Medium of Instruction: What about pragmatic competence? In M.L. Carrió-Pastor (Ed.), Internationalising Learning in Higher Education: The Challenges of English as a Medium of Instruction (pp. 137-143). Palgrave MacMillan.

Carrió-Pastor, M.L. (2021). CLIL vs EMI: Different approaches or the same dog with a different collar? In M.L. Carrió-Pastor \& B. Bellés-Fortuño (Eds.), Teaching Language and Content in Multicultural and Multilingual Classrooms: CLIL and EMI Approaches (pp.13-30). Palgrave Macmillan.

Carrió-Pastor, M.L., \& Muñiz Calderón, R. (2012). English in China: lexical variations in cross-cultural communication. International Journal of Business and Social Sciences, 3(19), 80-87.

Carrió-Pastor, M.L., \& Tamarit Vallès, I. (2015). A Comparative Study of the Influence of the Mother Tongue in LSP and CLIL. Procedia - Social and Behavioral Sciences, $178,38-42$.

Castro-García, D. (2017). Three Forms of Bilingual Education Immersion, Dual Language and CLIL (1st ed.). Ediciones de la Escuela de Literatura y Ciencias del Lenguaje.

Cavanagh, M. (2011). Students' experiences of active engagement through cooperative learning activities in lectures. Active Learning in Higher Education, 12(1), 2333. https://doi.org/10.1177/1469787410387724

Caviglia-Harris, J. (2016). Flipping the undergraduate economics classroom: Using online videos to enhance teaching and learning. Southern Economic Journal, 83(1), 321-331. https://doi.org/10.1002/soej.12128

Cenoz, J. (2013). Discussion: Towards an educational perspective in CLIL language policy and pedagogical practice. International Journal of Bilingual Education 
Chapter 8: References

and Bilingualism, 16(3), 389-394.

https://doi.org/10.1080/13670050.2013.777392

Cenoz, J. (2015) Content-based instruction and content and language integrated learning: the same or different? Language, Culture and Curriculum, 28(1), 8-24. https://doi.org/10.1080/07908318.2014.1000922

Cenoz, J., \& Gorter, D. (2014). Focus on multilingualism as an approach in educational contexts. In A. Blackledge, \& A. Creese (Eds.), Heteroglossia as practice and pedagogy (pp. 239-254). Springer.

Cenoz, J., Genesee, F., \& Gorter, D. (2014). Critical analysis of CLIL: Taking stock and looking forward. Applied linguistics, 35(3), 243-262. https://doi.org/10.1093/applin/amt011

Centro de investigaciones sociológicas (CIS) (2016). Estudio n³162: Barómetro de diciembre 2016. Retrieved 7 November 2018 from http://www.cis.es/cis/export/sites/default/-

Archivos/Marginales/3160_3179/3162/es3162mar.pdf

Choi, B.C.K., \& Pack, A.W. (2008). Multidisciplinarity, interdisciplinarity, and transdisciplinarity in health research, services, education and policy: 3 . Discipline, inter-discipline distance, and selection of discipline. Clinical and Investigative Medicine, E41-E48. https://doi.org/10.25011/cim.v31i1.3140

Chomsky, N. (1965). Aspects of the Theory of Syntax. MIT Press.

Chostelidou, D., \& Griva, E. (2014). Measuring the effect of implementing CLIL in higher education: An experimental research project. Procedia-Social and Behavioral Sciences, 116, 2169-2174. https://doi.org/10.1016/j.sbspro.2014.01.538

Clarke, M., Hui Yang, L., \& Harmon, D. (2018). The Internationalisation of Irish Higher Higher Education. Authority. https://hea.ie/assets/uploads/2018/07/report_internationalisation_of_education_2 018.pdf

Cobb, T. (n.d.). Compleat Lexical Tutor. https://lextutor.ca/ 
Coffin, C. (2013). Using systemic functional linguistics to explore digital technologies in educational contexts. Text \& Talk, 33(4-5), 497-522. https://doi.org/10.1515/text-2013-0023

Cogo, A. (2009). Accommodating difference in ELF conversations: A study of pragmatic strategies. In A. Mauranen, \& E. Ranta (Eds.), English as a lingua franca: Studies and findings (pp.254-273). Cambridge Scholars Publishing.

Cogo, A. (2010). Strategic use and perceptions of English as a lingua franca. Pozna? Studies in Contemporary Linguistics, 46(3), 295-312. https://doi.org/10.2478/v10010-010-0013-7

Cohen, A.D. (1975). A sociolinguistic approach to bilingual education: Experiments in the American Southwest. Newbury House.

Collins dictionary (n.d.) Monolingualism. In Collinsdictionary.com. Retrieved 19 $\begin{array}{lll}\text { September } & 2018 \text { from }\end{array}$ https://www.collinsdictionary.com/es/diccionario/ingles/monolingualism

Comissió de Política Lingüística de les universitats Jaume I, de València, Politècnica de València, d'Alacant i Miguel Hernández d'Elx (2011). Marc per a les polítiques lingüístiques de les universitats públiques valencianes [Framework for the Language Policies of Valencian Public Universities]. Retrieved 19 October 2020 from https://sl.ua.es/es/dinamitzacio/documentos/marc-per-a-lespolitiques-linguistiques-de-les-universitats-publiques-valencianes.pdf

Consejería de Educación (2016). Plan estratégico de desarrollo de las lenguas en Andalucía. Horizonte 2020. Junta de Andalucía. https://www.juntadeandalucia.es/export/drupaljda/plan_estrategico.pdf

Contero, C, Zayas, F., \& Arco-Tirado, J.L. (2018). Addressing CLIL Lecturers' Needs: Reflections on Specific Methodological Training. Porta Linguarum, 3, 121-135.

Coral i Mateu, J. (2013). Physical education and English integrated learning: How school teachers can develop PE-in-CLIL programmes. Temps d'educació, 45, $41-64$. 
Corrales, K. A., Rey, L. A. P., \& Escamilla, N. S. (2016). Is EMI enough? Perceptions from university professors and students. Latin American Journal of Content \& Language Integrated Learning, 9(2), 318-344. https://doi.org/10.5294/laclil.2016.9.2.4

Costa, P., \& Albergaria-Almeida, P. (2015). The European survey on language competences: Measuring foreign language student proficiency. Procedia-Social and Behavioral Sciences, 191, 2369-2373.

Coulthard, M., \& Montgomery, M. (1981). The structure of monologue. In M. Coulthard, \& M. Montgomery (Eds.), Studies in discourse analysis (pp. 31-39). London: Routledge and Kegan Paul.

Council of Europe (2007). From linguistic diversity to plurilingual education: Guide for the development of language education policies in Europe. Executive Version. Language Policy Division. Strasbourg. Retrieved 6 May 2018 from https://rm.coe.int/16806a892c\#_Toc172301770

Coyle, D. (2009). Promoting cultural diversity through intercultural understanding: A case study of CLIL teacher professional development at in-service and preservice levels. In M.L. Carrió-Pastor (Ed.), Content and language integrated learning: Cultural diversity (pp.105-124). Peter Lang.

Coyle, D. (2013). Listening to learners: An investigation into 'successful learning' across CLIL contexts. International journal of bilingual education and bilingualism, 16(3), 244-266. https://doi.org/10.1080/13670050.2013.777384

Coyle, D., Hood, P., \& Marsh, D. (2010). CLIL: Content and language integrated learning. Cambridge University Press.

Crawford Camiciotolli, B. (2004). Interacting with the audience: modal verbs in crosscultural business lectures. In R. Facchinetti, \& F. Palmer (Eds.), English Modality in Perspective. Genre analysis and contrastive studies (pp. 27-43). Peter Lang.

Crawford Camiciotolli, B. (2005). Adjusting a business lecture for an international audience: a case study. English for Specific Purposes, 24, 183-199. https://doi.org/10.1016/j.esp.2004.05.002 
Creese, A., \& Blackledge, A. (2010). Translanguaging in the bilingual classroom: A pedagogy for learning and teaching. The Modern Language Journal, 94(1), 103115. https://doi.org/10.1111/j.1540-4781.2009.00986.x

Christie, F. (2002). Classroom discourse analysis. A functional perspective. New York: Continuum.

Cronquist, K., \& Fiszbein, A. (2017). English language learning in Latin America. Inter-American dialogue. Retrieved 24 September 2018 from: http://disde.minedu.gob.pe/bitstream/handle/MINEDU/5911/English\%20Langua ge\%20Learning\%20in\%20Latin\%20America.pdf?sequence=1\&isAllowed=y

CRUE. (2017). Documento marco de política lingüística para la internacionalización del sistema universitario español. Retrieved 23 October 2018 from https://www.crue.org/Documentos\%20compartidos/Sectoriales/Internacionalizac ión\%20y\%20Coorperación/Marco_Final_Documento\%20de\%20Politica\%20Lin guistica\%20reducido.pdf

CRUE (2018). LA UNIVERSIDAD ESPAÑOLA 3N CIFR4S 2017/2018. Retrieved 23 October 2018 from https://www.crue.org/wpcontent/uploads/2020/02/2018.12.12-Informe-La-UniversidadEspa\%C3\%B1ola-en-Cifras.pdf

Crystal, D. (1988). 'Another look at, well, you know ...,' English Today, 13, 47-49.

Crystal, D. (2003). English as a Global Language. Cambridge University Press.

Cummins, J. (1984) Bilingual Education and Special Education: Issues in Assessment and Pedagogy. Multilingual Matters.

Cummins, J. (1979). Cognitive/academic language proficiency, linguistic interdependence, the optimum age question and some other matters. Working Papers on Bilingualism, 19, 121-129.

Curry, M. J., \& Lillis, T. (2017). Global academic publishing: Policies, perspectives and pedagogies. Multilingual Matters.

Curry, M.J., \& Lillis, T. (2018). Problematizing English as the privileged language of global academic publishing. In M.J. Curry, \& T. Lillis (Eds.), Global Academic 
Publishing: Policies, Perspectives and Pedagogies (pp.1-20). Multilingual Matters.

Curry, N., \& Pérez-Paredes, P. (2021). Understanding lectures' practices and processes: an investigation of English medium education in a Spanish multilingual university. In M.L. Carrió-Pastor \& B. Bellés-Fortuño (Eds.), Teaching Language and Content in Multicultural and Multilingual Classrooms: CLIL and EMI Approaches (pp.123-156). Palgrave Macmillan.

Curry, N. (2019). 'Learners as models: the pedagogical value of near peer role models' Speak Out! Journal of the IATEFL Pronunciation Special Interest Group, 60, $34-43$.

Curzon, L. B. (1990). Teaching in Further Education: An Outline of Principles and Practice. Cassel.

Dafouz, E. (2018). English-medium instruction and teacher education programmes in higher education: ideological forces and imagined identities at work. International Journal of Bilingual Education and Bilingualism, 21(5), 540-552. https://doi.org/10.1080/13670050.2018.1487926

Dafouz, E., \& Núñez B. (2010). Metadiscursive devices in university lectures: A constrastive analysis of L1 and L2 performance. In C. Dalton-Puffer, T. Nikula \& U. Smit (Eds.), Language Use and Language Learning in CLIL Classrooms (pp. 213-231). John Benjamins.

Dafouz, E. \& Sánchez García, D. (2013). 'Does everybody understand?' Teacher questions across disciplines in English-mediated university lectures: An exploratory study. Language Value, 5(1), 129-151. http://dx.doi.org/10.6035/LanguageV.2012.5.7

Dafouz, E., \& Smit, U. (2016). Towards a dynamic conceptual framework for Englishmedium education in multilingual university settings. Applied Linguistics, 37(3), $397-415$.

Dafouz, E., Núñez, B., \& Sancho, C. (2007). Analysing stance in a CLIL university context: Non-native speaker use of personal pronouns and modal verbs. 
International Journal of Bilingual Education and Bilingualism, 10(5), 647-662. https://doi.org/10.2167/beb464.0

Dafouz , E., Núñez, B., Sancho, C. \& Foran, D. (2007). Integrating CLIL at the tertiary level: teachers' and students' reactions. In D. Wolff, \& D. Marsh (Eds.), Diverse contexts converging goals. Content and language integrated learning in Europe, (pp. 91-102). Peter Lang.

Dalton-Puffer, C. (2007). Discourse in content and language integrated learning (CLIL) classrooms. John Benjamins.

Dalton-Puffer, C. (2011). Content-and-Language Integrated Learning: From Practice to Principles? Annual Review of applied linguistics, 31, 182-204. https://doi.org/10.1017/S0267190511000092

Dalton-Puffer, C., \& Nikula, T. (2006). Pragmatics of content-based instruction: Teacher and student directives in Finnish and Austrian classrooms. Applied Linguistics, 27(2), 241-267. https://doi.org/10.1093/applin/aml007

Dalton-Puffer, C., Nikula, T., \& Smit, U. (Eds.). (2010). Language use and language learning in CLIL classrooms. John Benjamins Publishing Company.

Dalton-Puffer, C., Llinares, A., Lorenzo, F., \& Nikula, T. (2014). "You can stand under my umbrella": Immersion, CLIL and bilingual education. A response to Cenoz, Genesee \& Gorter. Applied Linguistics, 35(2), 213-218. https://doi.org/10.1093/applin/amu010

D’Angelo, L. (2018). PowerPoint presentations in the classroom: Re-evaluating the genre. $\quad$ Language $\quad$ Value, $\quad$ 29-46. http://dx.doi.org/10.6035/LanguageV.2018.10.3

Day, L.J. (2018). A gross anatomy flipped classroom effects performance, retention, and higher-level thinking in lower performing students. Anatomical Sciences Education, 11(6), 565-574. http://dx.doi.org/10.1002/ase.1772

de Klerk, V. (1995). Interaction patterns in post-graduate seminars: Tutor versus student. Language and Education, 9(4), 249-264. 
Dearden, J. (2014). English as a medium of instruction - A growing global phenomenon. British Council.

Dearden, J., \& Macaro, E. (2016). Higher education teachers' attitudes towards English medium instruction: A three-country comparison. Studies in Second Language Learning and Teaching, 6(3), 455-486.

DeCarrico, J., \& Nattinger, J.R. (1988). Lexical phrases for the comprehension of academic lectures. English for Specific Purposes, 7, 91-102.

Denzin, N.K., \& Lincoln, Y.S. (1994). Handbook of qualitative research. Sage.

Deroey, K.L.B. (2015). Marking importance in lectures: Interactive and textual orientation. $\quad$ Applied $\quad$ Linguistics, $\quad 36(1), \quad$ 51-72. https://doi.org/10.1093/applin/amt029

Deroey, K.L.B. \& Taverniers, M. (2011). A corpus-based study of lecture functions. Moderna språk, 105(2), 1-22.

DESI-Konsortium (2008) (Ed.) Unterricht und Kompetenzerwerb in Deutsch und Englisch. Ergebnisse der DESI-Studie. Beltz.

De Wit, H., Hunter, F., Howard, L., \& Egron-Polak, E. (2015). Internationalisation of higher education Study. European Parliament Committee on Culture and Education. European Union.

Diamond, N.A., Sharp, G., \& Ory, J.C. (1983). Improving your Lecturing. Office of Instructional and Management Services. University of Illinois at UrbanaChampaign.

Diari oficial de la Generalitat Valenciana Núm. 7973 (2017). DECRET 9/2017, de 27 de gener, del Consell, pel qual s'estableix el model lingüístic educatiu valencià $i$ se'n regula l'aplicació als ensenyaments no universitaris de la Comunitat Valenciana. [2017/870]. Conselleria d'Educació, Investigació, Cultura i Esport, Generalitat Valenciana. http://www.dogv.gva.es/datos/2017/04/11/pdf/2017_3090.pdf 
Doiz, A., Lasagabaster, D., \& Pavón, V. (2019). The integration of language and content in English-medium instruction courses: Lecturers' beliefs and practices. Ibérica, 38, 151-176.

Doiz, A., Lasagabaster, D., \& Sierra, J. M. (2012). English-medium instruction at universities: Global challenges. Bristol, UK: Multilingual matters.

Doiz, A., Lasagabaster, D., \& Sierra, J.M. (2013). Globalisation, Internationalisation, Multilingualism and Linguistic Strains in Higher Education. Studies in Higher Education 38(9), 1407-1421. https://doi.org/10.1080/03075079.2011.642349

Du Bois, J.W. (2007). The stance triangle. In R. Englebretson (Ed.), Stancetaking in discourse: Subjectivity, evaluation, interaction (pp. 139-182). John Benjamins.

Dudley-Evans, T. (1994). Variations in the discourse patterns favoured by different disciplines and their pedagogical implications. In J. Flowerdew (Ed.), Academic listening: Research perspectives (pp.146-158). Cambridge University Press.

Dudley-Evans, A., \& Johns, T.F. (1981). A team teaching approach to lecture comprehension for overseas students. In Milestones in ELT, The teaching of listening comprehension, (pp. 30-46). British Council.

Duszak, A. (1997). Cross-cultural academic communication: a discourse-community view. In Duszak, A. (Ed.), Culture and styles of academic discourse (pp. 11-40). Walter de Gruyter.

Edwards, J. (2004). Bilingualism: Contexts, constraints, and identities. Journal of Language and Social Psychology, 23(1), 135-141. https://doi.org/10.1177/0261927X03260811

Edwards, J. (2006). Foundations of Bilingualism. In T.K. Bhatia, \& W.C. Ritchie (Eds.), The handbook of bilingualism (pp. 7-31). Wiley-Blackwell.

Edwards, J. (2012). Bilingualism and Multilingualism: Some Central Concepts. In T.K. Bhatia, \& W.C. Ritchie (Eds.), The Handbook of Bilingualism and Multilingualism (2nd ed.) (pp. 5-25). Wiley-Blackwell.

Eggins, S. (2004). Introduction to systemic functional linguistics. New York and London: Continuum. 
Ellis, E. (2008). Defining and investigating monolingualism. Sociolinguistic Studies, 2(3), 311-330. https://doi.org/10.1558/sols.v2i3.311

Engwall, L. (2016). The internationalisation of higher Education. European Review, 24(2), 221-231. https://doi.org/10.1017/S1062798715000575

Escobar Urmeneta, C. \& Walsh, S. (2017). Classroom interactional competence in content and language integrated learning. In A. Llinares \& T. Morton (Eds.), Applied Linguistics Perspectives on CLIL. Amsterdam (pp. 189-206). John Benjamins.

Eslami, Z.R., \& Eslami-Rasekh, A. (2007). Discourse markers in academic lectures. Asian EFL Journal, 9(1), 22-38.

European Commission (1995). White Paper on Education and Training: Teaching and Learning: Towards the Learning Society. Brussels, Belgium: European Commission. https://europa.eu/documents/comm/white_papers/pdf/com95_590_en.pdf

European Commission (2002). Presidency Conclusions: Barcelona European Council, 15 and 16 March 2002. European Council. https://ec.europa.eu/invest-inresearch/pdf/download_en/barcelona_european_council.pdf

European Commission (2004). European language policy and CLIL: A selection of EUfunded projects. Brussels, Belgium. http://www.edu.xunta.gal/centros/cpicruce/system/files/clilbroch_en.pdf

European Commission (2008). A rewarding challenge. How language diversity could strengthen Europe. https://publications.europa.eu/en/publication-detail//publication/7f987cdd-dba2-42e7-8cdf-3f4f14efe783/language-en/format$\underline{\text { PDF/source33997141 }}$

European Commission (2012a). Communication from the Commission to the European Parliament, the Council, the European Economic and Social Committee and the Committee of the Regions: Rethinking Education: Investing in Skills for Better Socio-Economic Outcomes. European Commission. https://eurlex.europa.eu/legalcontent/EN/TXT/PDF/?uri=CELEX:52012DC0669\&from=EN 
European Commission (2012b). First European Survey on Language Competences. http://www.surveylang.org/media/ExecutivesummaryoftheESLC_210612.pdf

European Commission (2012c). Report from EMN Sweden 2012:1 - Immigration of International Students to Sweden. European Migration Network. https://ec.europa.eu/home-affairs/sites/homeaffairs/files/what-wedo/networks/european_migration_network/reports/docs/emnstudies/immigrationstudents/26a.sweden_national_report_immigration_of_international_students_fi nal_nov2012en_version_en.pdf

European Commission (2017). Eurydice Brief: Key Data on Teaching Languages at School in Europe. Education and Training. Publications Office of the European Union. https://op.europa.eu/en/publication-detail/-/publication/ff10cc21-aef911e7-837e-01aa75ed71a1/language-en/format-PDF

European Commission (2018a). Education and Training. MONITOR 2018. https://sciencebusiness.net/sites/default/files/inlinefiles/Report $\% 20 \% 28$ volume $\% 201 \% 20-\% 20 \mathrm{EU} \% 20$ analysis $\% 29 \% 20$ \%20Education\%20and\%20Training\%20Monitor\%202018.pdf

European Commission (2018b). Proposal for a COUNCIL RECOMMENDATION on a comprehensive approach to the teaching and learning of languages. https://eurlex.europa.eu/resource.html?uri=cellar:1cc186a3-5dc7-11e8-ab9c$\underline{01 \mathrm{aa} 75 \mathrm{ed} 71 \mathrm{a} 1.0001 .02 / \mathrm{DOC} \_1 \& \text { format=PDF }}$

European Commission (2018c). Flash Eurobarometer 466 Report: The European Education Area. http://ec.europa.eu/commfrontoffice/publicopinion/index.cfm/survey/getsurveyd etail/instruments/flash/surveyky/2186

European Commission (2020a). Communication from the Commission to the European Parliament, the Council, the European Economic and Social Committee and the Committee of the Regions on achieving the European Education Area by 2025. https://ec.europa.eu/education/sites/default/files/document-librarydocs/communication-european-education-area.pdf 
European Commission (2020b). Internal Market, Industry, Entrepreneurship and SMEs: Professional skills. https://ec.europa.eu/growth/sectors/tourism/supportbusiness/skills_en

European Council (2017). The Brussels European Council meeting (Brussels, 14 December 2017) https://www.consilium.europa.eu/media/32204/14-final-conclusions-rev1-en.pdf

Eurydice (2006). Content and Language Integrated Learning (CLIL) at School in Europe. Eurydice European Unit.

Extra, G., \& Yağmur, K. (2012). Language rich Europe: Trends in policies and practices for multilingualism in Europe. British Council/Cambridge University Press.

Ferris, D., \& Tagg, T. (1996). Academic oral communication needs of EAP learners: What subject-matter instructors actually require. TESOL Quarterly, 30(1), 3157.

Filliatreau, G. \& Vidal, P. (2011). Attractivité de la France dans le domaine de l'enseignement supérieur: points forts, points faibles. Campus France, Collection Repères, 7, 1-4.

Finn, M., \& Darmody, M. (2017). What predicts international higher education students' satisfaction with their study in Ireland? Journal of Further and Higher Education, 41(4), 545-555. https://doi.org/10.1080/0309877X.2015.1135887

Fiorella, L., Stull, A. T., Kuhlmann, S., \& Mayer, R. E. (2019). Instructor presence in video lectures: The role of dynamic drawings, eye contact, and instructor visibility. Journal of Educational Psychology, 111(7), 1162-1171. https://doi.org/10.1037/edu0000325

Firth, A. (1996). The discursive accomplishment of normality. On "lingua franca" English and conversation analysis. Journal of Pragmatics 26, 237-259.

Flowerdew, J. (1994). Academic listening: Research perspectives. Cambridge University Press. 
Flowerdew, L. (2013). Needs analysis and curriculum development. In B. Paltridge, \& S. Starfield (Eds.), The handbook of English for specific purposes (pp. 325346). Wiley-Blackwell.

Flowerdew, J., \& Miller, L. (1992). Student perceptions, problems and strategies in second language lecture comprehension. RELC journal, 23(2), 60-80.

Flowerdew, J., \& Peacock, M. (2001). Research perspectives on English for academic purposes. Cambridge University Press.

Foran, D., \& Sancho, C. (2009.) CLIL approaches in university Applied Science environments. In E. Dafouz, \& M.C. Guerrini (Eds.), CLIL across Educational Levels: Experiences from Primary, Secondary and Tertiary Contexts (pp.113124). Santillana Educación/Richmond Publishing.

Fraser, B., \& Malamud-Makowski, M. (1996). English and Spanish Contrastive Discourse Markers. Language Sciences 18(3-4), 863-881.

Frederick, P. J. (1986). The lively lecture -8 variations. College Teaching, 34(2), 4350.

Fulcher, G. An English language placement test: issues in reliability and validity. Language Testing. $\quad 1997, \quad 14(2), \quad 113-139$. https://doi.org/10.1177/026553229701400201

Fung, L., \& Carter, R. (2007). Discourse Markers and Spoken English: Native and Learner Use in Pedagogic Settings. Applied Linguistics, 28(3), 410-439. https://doi.org/10.1093/applin/amm030

Furneaux, C., Locke, C., Robinson, P., \& Tonkyn, A. (1991). Talking heads and shifting bottoms: the ethnography of academic seminars. In P. Adams, B. Heaton, \& P. Howarth (Eds.), Socio-Cultural Issues in English for Specific Purposes (pp.7588). Modern English Publications.

Gacel-Ávila, J., \& Rodríguez-Rodríguez, S. (2018). Internationalization of higher education in Latin America and the Caribbean: Leading trends and features. In J. Gacel-Ávila (Ed.), The International Dimension of Higher Education in Latin America and the Caribbean (pp.11-32). RIESAL. 
Gallardo del Puerto, F., Gómez, Lacabex, E. \& García Lecumberri, M.L. (2009). Testing the effectiveness of content and language integrated learning in foreign language contexts the assessment of English pronunciation. In Y. Ruiz de Zarobe, \& R.M. Jiménez Catalán (Eds.), Content and Language Integrated Learning: Evidence from Research in Europe (pp. 63-80). Multilingual Matters.

Galleta, A. (2013). Mastering the Semi-Structured Interview and Beyond: From Research Design to Analysis and Publication. New York University Press.

García Mayo, M.P., \& Lázaro Ibarrola, A. (2015). Do children negotiate for meaning in task-based interaction? Evidence from CLIL and EFL settings. System, 54, 4054. https://doi.org/10.1016/j.system.2014.12.001

García, O. (2011). From language garden to sustainable languaging: Bilingual education in a global word. Perspectives, 34(1), 5-9.

García, O., \& Kleyn, T. (2016). Translanguaging with multilingual students: Learning from classroom moments. Routledge.

García, O., \& Lin, A.M.Y. (2016). Translanguaging in bilingual education. In O. García, \& A.M.Y. Lin (Eds.), Bilingual and Multilingual Education (Encyclopedia of Language and Education), (pp. 117-130). Springer.

García, P. (2007). Pragmatics in Academic Contexts: A Spoken Corpus Study. In M.C. Campoy, \& M.J. Luzón (Eds.), Spoken Corpora in Applied Linguistics (pp. 97127). Peter Lang.

Garone, A., Van de Craen, P., \& Struyven, K. (2020). Multilingual nursing education: Nursing students' and teachers' interests, perceptions and expectations. Nurse Education Today, 86, 104311, 1-6. https://doi.org/10.1016/j.nedt.2019.104311

Gené-Gil, M., Juan-Garau, M., \& Salazar Noguera, J. (2012). A case study exploring oral language choice between the target language and the L1s in mainstream CLIL and EFL secondary education. Revista de Lingüística y Lenguas Aplicadas, 7(1), 133-146. https://doi.org/10.4995/rlyla.2012.1129 
Genesee, F., \& Lindholm-Leary, K. (2013). Two case studies of content-based language education. Journal of Immersion and Content-Based Language Education, 1(1), 3-33. https://doi.org/10.1075/jicb.1.1.02gen

Gnutzmann C. (2000). Lingua franca. In M. Byram (Ed.), The Routledge encyclopedia of language teaching and learning (pp.356-359). Routledge.

Goffman, E. (1981). Forms of talk. University of Pennsylvania Press.

González, J.A., \& Barbero, J. (2013). Building bridges between different levels of education: Methodological proposals for CLIL at university. Language Value, 5(1), 1-23. http://dx.doi.org/10.6035/LanguageV.2013.5.2

Graddol, D. (1999). The decline of the native speaker. AILA Review, 13, 57-68.

Graddol, D. (2007). Global English, global culture? In S. Goodman, D. Graddol, \& T. Lillis (Eds.), Redesigning English (pp. 243-279). Routledge.

Greere, A., \& Räsänen, A. (2008). Report. LANQUA subproject on Content and Language Integrated Learning: Redefining 'CLIL' - Towards Multilingual Competence. https://www.unifg.it/sites/default/files/allegatiparagrafo/20-012014/lanqua_subproject_on_clil.pdf

Grosjean, F. (1985a). The bilingual as a competent but specific speaker-hearer. Journal of Multilingual and Multicultural Development, 6, 467-577.

Guarda, M., \& Helm, F. (2017). 'I have discovered new teaching pathways': the link between language shift and teaching practice. International Journal of Bilingual Education and Bilingualism, 20(7), 897-913. https://doi.org/10.1080/13670050.2015.1125848

Halliday, M.A.K., \& Hasan, R. (1989). Language, context, and text: Aspects of language in a social-semiotic perspective (2nd ed.). Oxford University Press.

Halliday, M.A.K., \& Matthiessen, C.M.I.M. (2004). An Introduction to Functional Grammar (3rd ed.). Edward Arnold.

Hamel, R.E. (2013). El campo de las ciencias y la educación superior entre el monopolio del inglés y el plurilingüismo: Elementos para una política del 
lenguaje en América Latina. Trabalhos em Linguística Aplicada, 52(2), 321384. https://doi.org/10.1590/S0103-18132013000200008

Hamers, J.F., \& Blanc, M.H.A. (2000). Bilinguality and bilingualism (2nd ed.). Cambridge: Cambridge University Press.

Hamel, R.E., Álvarez López, E. \& Pereira Carvalhal, T. (2016). Language policy and planning: challenges for Latin American universities. Current Issues in Language Planning, 17(3-4), 278-297. https://doi.org/10.1080/14664208.2016.1201208

Hamid, M.O., \& Nguyen, H.T.M. (2016). Globalization, English Language Policy, and Teacher Agency: Focus on Asia. International Education Journal: Comparative Perspectives, 15(1), 26-43.

Hamid, M.O., Nguyen, H.T.M., \& Baldauf, R.B. (2013). Medium of instruction in Asia: Context, processes and outcomes. Current Issues in Language Planning, 14(1), 1-15. https://doi.org/10.1080/14664208.2013.792130

Hazelkorn, E. (2015). Ranking and Reshaping of Higher Education: The Battle for World-Class Excellence (2nd ed.). Palgrave Macmillan.

Heo, Y. (2006). Content-based instruction. TESL Working Paper Series, 4(2), 25-32.

Herington, R. (2019). Observation as a Tool to Facilitate the Professional Development of Teaching Faculty Involved in English as a Medium of Instruction: Trainer and Trainee Perspectives. In Carrió-Pastor, M.L. (Ed.), Internationalising Learning in Higher Education: The Challenges of English as a Medium of Instruction (pp. 65-83). Palgrave Macmillan

Hernández-Nanclares, N., \& Jiménez-Muñoz, A. (2017). English as a medium of instruction: Evidence for language and content targets in bilingual education in economics. International Journal of Bilingual Education and Bilingualism, 20(7), 883-896. https://doi.org/10.1080/13670050.2015.1125847

Hornby, P.A. (1977). Bilingualism: Psychological, social, and educational implications. Academic Press, Inc. 
Hornberger, N. H. (2005). Opening and Filling up Implementational and Ideological Spaces in Heritage Language Education. Modern Language Journal, 89(4), 605609. http://dx.doi.org/10.1111/j.1540-4781.2005.00331.x

Hughes, A. (2003). Testing for language teachers. Cambridge University Press.

Hyland, K. (2005). Metadiscourse. Continuum.

Hyland, K. (2009) Academic discourse: English in a global context. Continuum International Publishing Group.

Hyland, K. (2017). Metadiscourse: What is it and where is it going? Journal of Pragmatics, 113, 16-29.

Ibec (2014). Submission on a Foreign Languages in Education Strategy for Ireland. https://www.education.ie/en/Schools-Colleges/Information/Curriculum-andSyllabus/Foreign-Languages-Strategy/Enterprise/Foreign-Languages-TonyDonohoe-IBEC.pdf

Ikeda, M. (2013). Does CLIL Work for Japanese Secondary School Students? Potential for the 'Weak' Version of CLIL. International CLIL Research Journal, 2(1), 3143.

Ioannou-Georgiou, S., \& Pavlou, P. (2011). Guidelines for CLIL implementation in primary and pre-primary education. Cyprus Pedagogical Institute.

Jacobone, V., \& Moro, G. (2015) Evaluating the impact of the Erasmus programme: skills and European identity. Assessment \& Evaluation in Higher Education, 40(2), 309-328. https://doi.org/10.1080/02602938.2014.909005

Jakobson, R. (1960). Linguistics and poetics. In Sebeok, T.A. (Ed.), Style in Language, (pp.350-377). MIT Press.

Jenkins, J. (2000). The Phonology of English as an International Language. Oxford University Press.

Jenkins, J. (2003). World Englishes. Routledge.

Jenkins, J. (2014). English as a Lingua Franca in the international university: The politics of academic English language policy. Routledge. 
Jenkins, J., \& Mauranen, A. (2019). Linguistic Diversity on the EMI Campus: Insider accounts of the use of English and other languages in universities within Asia, Australasia and Europe. Routledge.

Jiang, L., Zhang, L.J., \& May, S. (2016). Implementing English-medium instruction (EMI) in China: teachers' practices and perceptions, and students' learning motivation and needs. International Journal of Bilingual Education and Bilingualism. http://dx.doi.org/10.1080/13670050.2016.1231166

Jordan, R.R. (1989). English for academic purposes (EAP). Language Teaching 22(3), $151-164$.

Jowi, J.O., Knight J., \& Sehoole C. (2013). Internationalisation of African Higher Education. In C. Sehoole \& J. Knight (Eds.), Internationalisation of African Higher Education. Global Perspectives on Higher Education. SensePublishers. https://doi.org/10.1007/978-94-6209-311-9_2

Juhana, J. (2012). Psychological factors that hinder students from speaking in English class (A case study in a senior high school in South Tangerang, Banten, Indonesia). Journal of Education and Practice, 3, 100-110.

Kachru, B. (1992). The Other Tongue: English across Cultures (2nd ed.). University of Illinois Press.

Kachru, B., Kachru, Y., \& Nelson, C. (2006). The Handbook of World Englishes. Blackwell Publishing.

Kaliyadan, F., Thalamkandathil, N., Parupalli, S.R., Amin, T.T., Balah, M.H., Al Bu Ali, W.H. (2015). English language proficiency and academic performance: A study of a medical preparatory year program in Saudi Arabia. Avicenna Journal of Medicine, 5, 140-144. https://doi.org/10.4103/2231-0770.165126

Källkvist, M., \& Hult, F. M. (2014). Discursive mechanisms and human agency in language policy formation: Negotiating bilingualism and parallel language use at a Swedish university. International Journal of Bilingual Education and Bilingualism, 19(1), 1-17. https://doi.org/10.1080/13670050.2014.956044 
Kaschula, R.H., \& Kretzer, M.M. (2019a). 'Hayi, they don't know Xhosa': Comparative isiXhosa teaching challenges in the Eastern Cape and Gauteng. South African Journal of African Languages, 39(3), 239-252. https://doi.org/10.1080/02572117.2019.1672318

Kaschula, R.H., \& Kretzer, M.M. (2019b). The Politics of Language Education in Africa. Oxford Research Encyclopedia of Politics. https://doi.org/10.1093/acrefore/9780190228637.013.750

Kaur, J. (2009). Pre-Empting problems of understanding in English as a lingua franca. In A. Mauranen, \& E. Ranta (Eds.), English as a lingua franca: Studies and findings (pp.107-125). Cambridge Scholars Publishing.

Kim, A. (2015). Exploring ways to provide diagnostic feedback with an ESL placement test: Cognitive diagnostic assessment of L2 reading ability. Language Testing 32(2), 227-259. http://dx.doi.org/10.1177/0265532214558457

King, L. (2018). The Impact of Multilingualism on Global Education and Language Learning. Cambridge English Language Assessment.

Kirkpatrick A. (2012). English as an International Language in Asia: Implications for language education. In A. Kirkpatrick, \& R. Sussex (Eds.), English as an International Language in Asia: Implications for Language Education. (pp. 2944). Springer. https://doi.org/10.1007/978-94-007-4578-0_3

Kirkpatrick, A. (2017). Language education policy among the Association of Southeast Asian Nations (ASEAN). European Journal of Language Policy, 9(1), 7-25. https://doi.org/10.3828/ejlp.2017.2

Kirkpatrick, A. \& Sussex, R. (Eds.) (2012). English as an International Language in Asia: Implications for Language Education. Springer.

Knight, J. (2004). Internationalization Remodeled: Definition, Approaches, and Rationales. Journal of Studies in International Education, 8(1), 5-31. https://doi.org/10.1177/1028315303260832

Kraker, M.J. (2000). Classroom discourse: Teaching, learning, and learning disabilities. Teaching and Teacher Education, 16(3), 295-313. 
Krashen, S.D. (1982). Second language acquisition and second language learning. Prentice-Hall International.

Krashen, S.D. (1985). The input hypothesis: Issues and implications. Longman.

Kress, J.E. (2008). The ESL/ELL Teacher's Book of Lists. John Wiley \& Sons.

Krulatz, A. (2021). Focus on language in CBI: How teacher trainees work with language objectives and language-focused activities in content-based lessons. In M.L. Carrió-Pastor, \& B. Bellés-Fortuño (Eds.), Teaching Language and Content in Multicultural and Multilingual Classrooms: CLIL and EMI Approaches (pp.97-121). Palgrave Macmillan.

Kuteeva, M., \& Airey, J. (2013). Disciplinary differences in the use of English in higher education: Reflections on recent language policy developments. Higher Education, 67(5), 533-549.

Kuteeva, M., \& Mauranen, A. (2018). Digital academic discourse: Texts and contexts: Introduction. Discourse, Context \& Media, 24, 1-7. https://doi.org/10.1016/j.dcm.2018.06.001

Labov, W. (1972). Some principles of linguistic methodology. Language in Society, $1(1), 97-120$.

Lahuerta, A. (2020) Analysis of accuracy in the writing of EFL students enrolled on CLIL and non-CLIL programmes: the impact of grade and gender. The Language Learning Journal, 48(2), 121-132. https://doi.org/10.1080/09571736.2017.1303745

Lanvers, U., \& Hultgren, A. K. (2018). The Englishization of European education: foreword. European Journal of Language Policy, 10(1), 1-11. DOI: https://doi.org/10.3828/ejlp.2018.1

Lapadat, J.C. (2000). Teacher Research on Classroom Discourse in Northern Canadian Communities. Networks: An Online Journal for Teacher Research, 3(2), 13137.

Lasagabaster, D. (2012). El papel del inglés en el fomento del multilingüismo en la universidad. Estudios de Lingüística Aplicada (ELIA) 12, 13-44. 
Lasagabaster, D. (2013). The use of the L1 in CLIL classes: The teachers' perspective. Latin American Journal of Content and Language Integrated Learning, 6(2), 121. https://doi.org/10.5294/lacli1.2013.6.2.1

Lasagabaster, D., Doiz, A., \& Pavón, V. (2018). Undergraduates' beliefs about the role of language and team teaching in EMI courses at university. Rassegna Italiana di Linguistica Applicata, 50(2-3), 111-127.

Lasagabaster, D., \& Doiz, A. (2015). A Longitudinal Study on the Impact of CLIL on Affective Factors. Applied Linguistics, 59, 1-26. https://doi.org/10.1093/applin/amv059

Lasagabaster, D., \& Sierra, J.M. (2011). Classroom observation: desirable conditions established by teachers. European Journal of Teacher Education, 34(4), 449463.

Lasagabaster, D., Doiz, A., \& Sierra, J.M. (2014). Motivation and foreign language learning: From theory to practice. John Benjamins Publishing Company.

Le, V.C. (2007) A historical review of English language education in Vietnam. In Y.H. Choi, \& B. Spolsky (Eds.), English Education in Asia: History and Politics (pp.168-80). Asia TEFL.

Leask, B. (2015). Internationalizing the curriculum. Routledge.

Lee, E.L. (2007). Linguistic and cultural factors in East Asian students' oral participation in US university classrooms. International Education-Knoxville, $36(2), 27-47$.

Lee, J.J. (2009). Size matters: an exploratory comparison of small-and large-class university lecture introductions. English for Specific Purposes, 28(1), 42-62.57. https://doi.org/10.1016/j.esp.2008.11.001

Lee, J.J., \& Subtirelu, N.C. (2015). Metadiscourse in the classroom: A comparative analysis of EAP lessons and university lectures. English for Specific Purposes, 37, 52-62. https://doi.org/10.1016/j.esp.2014.06.005 
Levante de Castelló (2018, September 30). La UJI se sitúa en el puesto 12 de la lista de mejores universidades de España. Levante. https://www.levanteemv.com/castello/2018/09/30/uji-situa-puesto-12-lista/1774388.html

Lexico (n.d.). Bilingualism. In Lexico.com. Retrieved 19 September 2018 from https://www.lexico.com/definition/bilingualism

Lewis, M. P. (2009). Ethnologue: Languages of the World (16th ed.). SIL International.

Liddicoat, A.J. (2016) Language planning in universities: teaching, research and administration. Current Issues in Language Planning, 17(3-4), 2316-241. https://doi.org/10.1080/14664208.2016.1216351

Lightbown, P. M. (2014). Making the minutes count in L2 teaching. Language Awareness, 23(1-2), 3-23.

Lillis T.M., \& Curry M.J. (2010). Lillis, T., Curry, M. J. (2010). Academic writing in a global context: The politics and practices of publishing in English. Routledge.

Lim, L., \& Low, E.L. (Eds.). (2009). Multilingual, globalizing Asia: Implications for policy and education. AILA Review, 22. https://doi.org/10.1075/aila.22

Lin, S. Y., \& Scherz, S. D. (2014). Challenges facing Asian international graduate students in the US: Pedagogical considerations in higher education. Journal of International Students, $\quad 4(1), \quad 16-33$. https://doi.org/10.1080/09658416.2013.863903

Lin, D. T. A., Ganapathy, M, \& Kaur, M. (2018). Kahoot! It: Gamification in Higher Education. Pertanika Journal of Social Sciences \& Humanities, 26(1), 565-582.

Liu, W. (2017). The changing role of non-English papers in scholarly communication: Evidence from Web of Science's three journal citation indexes. Learned Publishing, 30(2), 115-123. https://doi.org/10.1002/leap.1089

Livingstone, K. A. (2019). Examining the Use of Metadiscourse Markers in Academic Writing. International Journal, 5(3), 244-254.

Llinares, A., Morton, T., \& Whittaker, R. (2012). The roles of language in CLIL. Cambridge University Press. 
Llull. J. (2014). Comics and CLIL: Producing quality output in social sciences with Hergé's Adventures of Tintin. Latin American Journal of Content and Language Integrated Learning, 7(1), 40-65. https://doi.org/10.5294/laclil.2014.7.1.3

López, L. E., \& Küper, W. (1999). La educación intercultural bilingüe en América Latina: balance y perspectivas. Revista Iberoamericana de educación, 20, 1785.

Lorenzo, F., Casal, S., \& Moore, P. (2010). The effects of content and language integrated learning in European education: Key findings from the Andalusian bilingual sections evaluation project. Applied linguistics, 31(3), 418-442. https://doi.org/10.1093/applin/amp041

Lorés Sanz, R. (2006). Academic literacy vs. academic oracy: signalling nouns as devices of intratranslation. In C. Pérez-Llantada (Ed), English as a GloCalization Phenomenon. Observations from a Linguistic Microcosm (pp. 89103). Prensas Universitarias de Valencia.

Luján-García, C. (2012). The impact of English on Spanish daily life and some pedagogical implications. Nordic Journal of English Studies, 11(1), 1-21.

Lyle, S. (2008). Dialogic Teaching: Discussing Theoretical Contexts and Reviewing Evidence from Classroom Practice. Language and Education, 22(3), 222-240.

Lynch, T. (2011). Academic listening in the 21st century: Reviewing a decade of research. Journal of English for Academic Purposes, 10(2), 79-88. https://doi.org/10.1016/j.jeap.2011.03.001

Lyster, R. (2007). Learning and Teaching Languages through Content: A Counterbalanced Approach. John Benjamins Publishing Company.

Macaro, E., Curle, S., Pun, J., An, J., \& Dearden, J. (2018). A systematic review of English medium instruction in higher education. Language Teaching, 51(1), 3676. https://doi.org/10.1017/S0261444817000350

MacIntyre, P.D., \& Gardner, R. (1991). Language anxiety: Its relationship to other anxieties and to processing in native and second language. Language Learning, 41(4), 513-534. 
MacIntyre, P.D, Baker, S.C., Clément, R., \& Donovan, L.A. (2002). Sex and age effects on willingness to communicate, anxiety, perceived competence, and L2 motivation among junior high school French immersion students. Language Learning, 52(3), 537-564.

MacGregor, L. (2016). CLIL in Japan: University teachers' viewpoints. In P. Clements, A. Krause, \& H. Brown (Eds.), Focus on the learner (pp. 426-432). JALT.

Mackey, W.F. (2006). Bilingualism in North America. In T.K. Bhatia, \& W.C. Ritchie, (Eds.), The handbook of bilingualism (pp. 7-31). Blackwell Pub.

Mackiewicz, W. (2009). Translation as a strategy for multilingualism. European Journal of Language Policy, 1(1), 65-75.

Mackiewicz, W. (2012). The Context of European Language Policy. In G. Egger, \& C. Lechner (Eds.), Primary CLIL around Europe: Learning in two languages in primary education. Tectum Wissenschaftsverlag.

Madiba, M. (2013). Multilingual education in South African universities: Policies, pedagogy and practicality. Linguistics and Education, 24(4), 385-395. http://dx.doi.org/10.1016/j.linged.2013.09.002

Mahan, K.R. (2020). The comprehending teacher: scaffolding in content and language integrated learning (CLIL). The Language Learning Journal, 1-15. https://doi.org/10.1080/09571736.2019.1705879

Maíz-Arévalo, C., \& Domínguez-Romero, E. (2013). Students' response to CLIL in tertiary education: the Case of Business administration and economics at Complutense University. Revista de lingüística y lenguas aplicadas, 8, 1-12. https://doi.org/10.4995/rlyla.2013.955

Maljers, A., Marsh, D., \& Wolff, D. (2007). Foreword. In A. Maljers, D. Marsh, \& D. Wolff (Eds.), Windows on CLIL: Content and Language Integrated Learning in the European Spotlight (pp. 7-9). European Platform for Dutch Education.

Marcos-Llinás, M., \& Juan-Garau, M. (2009). Effects of language anxiety on three proficiency-level courses of Spanish as a foreign language. Foreign Language Annals, 42, 94-111. https://doi.org/10.1111/j.1944-9720.2009.01010.x 
Margic, B.D., \& Krstanovic, I.V. (2018). Language development for English-medium instruction: Teachers' perceptions, reflections and learning. Journal of English for Academic Purposes, 35, 31-41. https://doi.org/10.1016/j.jeap.2018.06.005

Marsh, D. (1994). Bilingual Education and Content and Language Integrated Learning. International Association for Cross-cultural Communication. Language Teaching in the Member States of the European Union (Lingua). University of Sorbonne.

Marsh, D. (2002). CLIL/EMILE - The European dimension: Actions, trends and foresight potential. University of Jyväskyla Press.

Marsh, D. (2009). Introduction: Culture, education \& Content and Language Integrated Learning. In M.L. Carrió-Pastor (Ed.), Content and Language Integrated Learning: Cultural Diversity (pp.11-30). Peter Lang.

Marsh, D., Mehisto, P., Wolff, D. \& Frigols Martín, M.J. (2012). European Framework for CLIL Teacher Education: A framework for the professional development of CLIL teacher. Council of Europe. https://ebuah.uah.es/dspace/bitstream/handle/10017/14881/CLILFramework_Marsh.pdf?sequence $=1 \&$ isAllowed $=y$

Martín de Lama, M.T. (2015). Making the match between content and foreign language: A case study on university students' opinions towards CLIL. Higher Learning Research Communications, $\quad$ 5(1), 29-46. http://dx.doi.org/10.18870/hlrc.v5i1.232

Martín del Pozo, M.A. (2014). Aproximación lingüístico-didáctica al discurso académico de la clase magistral en la formación del profesorado universitario en contextos bilingüe [Doctoral dissertation, Universidad Complutense de Madrid].

Martin, J.R., \& White, P.R.R. (2005). The evaluation of language: Appraisal in English. Palgrave Macmillan.

Martín-Macho Harrison, A., \& Faya Cerqueiro, F. (2020). L1 en AICLE: el caso de Castilla-La Mancha. Tejuelo, 31, 143-174. https://doi.org/10.17398/1988$\underline{8430.31 .143}$ 
Martyniuk, W. (2008). CLIL - At the Core of Plurilingual Education? In R. Wilkinson, \& V. Zegers (Eds.), Realizing Content and Language Integration in Higher Education (pp. 13-20). Maastricht u Language Centre.

Mauranen, A. (1993). Cultural Differences in Academic Rhetoric. Peter Lang.

Mauranen, A. (1994). By dint of: Student and lecturer perceptions of lecture comprehension strategies in first-term graduate study. In J. Flowerdew (Ed.), Academic listening: Research perspectives, (pp. 199-218). Cambridge University Press.

Mauranen, A. (2001). Reflexive Academic Talk: Observations from MICASE. In R.C. Simpson \& J.M. Swales (Eds.), Corpus linguistics in North America (pp. 165178). University of Michigan Press.

Mauranen, A. (2003). The corpus of English as lingua franca in academic settings. TESOL quarterly, 37(3), 513-527.

Mauranen, A. (2010). 'Discourse reflexivity - a discourse universal?' the case of ELF. Nordic Journal of English Studies, 9(2), 13-40. https://doi.org/10.35360/njes.216

Mauranen, A. (2012). Exploring ELF: Academic English shaped by non-native speakers. Cambridge University Press.

May, S. (2014). The multilingual turn: Implications for SLA, TESOL, and bilingual education. Routledge.

McDonough, J. (1978). Listening to lectures. Oxford University Press.

McDougald, J. (2019). New pedagogies for multilingual education. Latin American Journal of Content \& Language Integrated Learning, 12(1), 9-17. https://doi.org/10.5294/lacli1.2019.12.1.1

McIntyre, D. (2009). History of English: A resource book for students. Routledge.

McKay, S. L. (2002). Teaching English as an international language. Oxford University Press. 
McKeachie, W. J. (1994). Student motivation, cognition, and learning: Essays in honor of Wilbert J. McKeachie. Routledge.

McKeown, J., \& Ladegaard, H. J. (2020). Exploring dominance-linked reflexive metadiscourse in moderated group discussions. Journal of Pragmatics, 166, 1527. https://doi.org/10.1016/j.pragma.2020.05.007

MECD (Ministerio de Educación, Cultura y Deporte) (2016). Estrategia para la Internacionalización de las Universidades Españolas 2015-2020. https://sede.educacion.gob.es/publiventa/estrategia-para-la-internacionalizacionde-las-universidades-espanolas-2015-2020/universidad/21475

Mehisto, P., Marsh, D., \& Frigols, M.J. (Eds.) (2008). Uncovering CLIL. Macmillan.

Meisel, J. (2012). The acquisition of verb placement: Functional categories and V2 phenomena in language acquisition. Kluwer Academic Publishers.

Merino, J.A., \& Lasagabaster, D. (2018). CLIL as a way to multilingualism. International Journal of Bilingual Education and Bilingualism, 21(1), 79-92. https://doi.org/10.1080/13670050.2015.1128386

Mesureur, G. (2012). Content-based instruction for all levels of EFL students. Keisen University Bulletin, 24, 71-80.

Met, M. (1998). Curriculum decision-making in content-based language teaching. In J. Cenoz, \& F. Genesee (Eds.), Beyond bilingualism: Multilingualism and multilingual education (pp. 35-63). Multilingual Matters.

MEXT (2006). カリキュラム改革の実施状況 [Current state of curriculum renewal]. https://www.mext.go.jp/b_menu/houdou/20/06/08061617/001.htm

Meyer, O., Coyle, D., Halbach, A., Schuck, K., \& Ting, T. (2015). A pluriliteracies approach to content and language integrated learning - Mapping learner progressions in knowledge construction and meaning-making. Language, $\begin{array}{llll}\text { Culture, } & \text { and } \quad \text { Curriculum, }\end{array}$ https://doi.org/10.1080/07908318.2014.1000924

Ministère de l'éducation nationale, de l'enseignement supérieur et de la recherché (2014). L'état de l'Enseignement supérieur et de la Recherche en France, 7, 1- 
115.

https://cache.media.enseignementsuprecherche.gouv.fr/file/EESR_2014/60/7/EESR7 316607.pdf

Ministerio de Educación de Perú (2015). Decreto supremo $N^{o}$ 012-2015-MINEDU Decreto Supremo que aprueba la Política Nacional de Enseñanza, Aprendizaje y Uso del Idioma Inglés - “Inglés, puertas al mundo". https://cdn.www.gob.pe/uploads/document/file/105042/_012-2015-MINEDU__18-09-2015_06_08_40_-DS_N_012-2015MINEDU_\%2B_Exposici\%C3\%B3n_de_Motivos.pdf

Ministry of Education (2016). Statistics. http://moe.go.kr/

Ministry of Education and Culture (2017a). Cooperation between higher education institutions and business life. https://minedu.fi/en/cooperation-between-higher$\underline{\text { education-institutions-and-business-life }}$

Ministry of Education and Culture (2017b). International policy for Finnish higher education and research. $\quad$ https://minedu.fi/en/-/suomalaiselle$\underline{\text { korkeakoulutukselle-ja-tutkimukselle-kansainvalisyyslinjaukset }}$

Montalto, S. A., Walter, L., Theodorou, M., \& Chrysanthou, K. (2014). The CLIL Guidebook. https://www.languages.dk/archive/clil4u/book/CLIL\%20Book\%20En.pdf

Montaner-Villalba, S. (2018). The use of KAHOOT in the EFL classroom within the CLIL approach. Technological Innovation for Specialized Linguistic Domains. Languages for Digital Lives and Cultures. In Proceedings of TISLID, 18 (pp. 251-262).

Morell, T. (2015). International paper conference presentations: A multimodal analysis to determine effectiveness. English for Specific Purposes, 37, 137-150. http://dx.doi.org/10.1016/j.esp.2014.10.002

Morell, T. (2004). Interactive lecture discourse for university EFL students. English for Specific Purposes, 23(3), 325-338. 
Morell, T. (2007). What enhances EFL students' participation in lecture discourse? Student, lecturer, and discourse perspectives. Journal of English for Academic Purposes, 6(3), 222-237. https://doi.org/10.1016/j.jeap.2007.07.002

Morrison, J.W. (1974). An investigation of problems in listening comprehension encountered by overseas students in the first year of postgraduate students in science at the University of Newcastle upon Tyne [Unpublished doctoral dissertation]. University of Newcastle upon Tyne.

Mortimer, E., \& Scott, P. (2003). Meaning Making In Secondary Science Classrooms. Open University Press.

Mur Dueñas, P. (2010). Attitude markers in business management research articles: a cross-cultural corpus-driven approach. International Journal of Applied Linguistics, 20(1), 50-72. https://doi.org/10.1111/j.1473-4192.2009.00228.x

Nagao, A. (2019). The SFL genre-based approach to writing in EFL contexts. AsianPacific Journal of Second and Foreign Language Education, 4(6), 1-18. https://doi.org/10.1186/s40862-019-0069-3

Nakane, C. 1970. Japanese society. University of California Press.

National Geographic Learning (n.d.). Outcomes Placement Test. https://ngl.cengage.com/assets/downloads_b/marketing_downloads/1111031096 /Outcomes\%20Placement\%20Test.pdf

Nesari, A. J. (2015). Dialogism versus monologism: A Bakhtinian approach to teaching. Procedia-Social and Behavioral Sciences, 205, 642-647. https://doi.org/10.1016/j.sbspro.2015.09.101

Newble, D., \& Cannon, R. (1994). Teaching in a problem-based course. In D. Newble, \& R. Cannon (Eds.), A Handbook for Medical Teachers (pp. 93-106). Springer.

$\mathrm{Ng}$, C.L. (2017). English-medium instruction in Japanese universities: policy implementation and constraints. Current Issues in Language Planning, 18(1), 57-67. https://doi.org/10.1080/14664208.2016.1204053 
Nikula, T., \& Moore, P. (2016). Exploring translanguaging in CLIL. International Journal of Bilingual Education and Bilingualism, 22(2), 237-249. https://doi.org/10.1080/13670050.2016.1254151

Nikula, T., Dalton-Puffer, C., \& Llinares, A. (2013). CLIL classroom discourse: Research from Europe. Journal of Immersion and Content-Based Language Education, 1(1), 70-100. https://doi.org/10.1075/jicb.1.1.04nik

Nikula, T., Dafouz, E., Moore, P., \& Smit, U. (2016). Conceptualising integration in CLIL and multilingual education. Multilingual Matters.

Nordquist, R. (2019, July 25). What is Multilingualism? Definition and Examples. ThoughtCo. https://www.thoughtco.com/what-is-multilingualism-1691331

Northcott, J. (2001). Towards an ethnography of the MBA classroom: a consideration of the role of interactive lecturing styles within the context of one MBA programme. English for Specific Purposes, 20(1), 15-37.

Nunan, D. (2015). Teaching English to speakers of other languages: An introduction. Routledge.

O'Boyle, N. (2014). 'You'and 'I' in university seminars and spoken learner discourse. Journal of English for Academic Purposes, 16, 40-56. https://doi.org/10.1016/j.jeap.2014.08.003

OIPEP

(2014).

Convocatòries.

https://www.uji.es/serveis/oipep/base/programes/pi/convocatories/

Oppenheim, A.N. (1992). Questionnaire Design, Interviewing and Attitude Measurement. Pinter.

Pacheco, M.B. (2016). Translanguaging in the English-Centric Classroom: A Communities of Practice Perspective [Doctoral dissertation, Vanderbilt University].

Paran, A. (2013). Content and language integrated learning: Panacea or policy borrowing myth? Applied Linguistics Review, 4, 317-342. https://doi.org/10.1515/applirev-2013-0014 
Pastor Martínez, M.R. (2011). CLIL and Cooperative Learning. Encuentro 20, $109-118$.

Patton M.Q. (1990). Qualitative Evaluation and Research Methods (2nd ed). SAGE Publications.

Pérez-Cañado, M.L. (2012). CLIL research in Europe: Past, present, and future. International Journal of Bilingual Education and Bilingualism, 15, 315-341. https://doi.org/10.1080/13670050.2011.630064

Pérez Murillo, M.D., \& Steele, A. (2017). Initial Teacher Education for CLIL at Primary Education Level in Madrid: Key Issues and Challenges. In M.E. Gómez Parra, \& R. Johnstone (Eds.), Bilingual Education: Educational Trends and Key Concepts / Educación Bilingüe: Tendencias Educativas y Conceptos Clave (pp. 221-234). Spanish Ministry of Education.

Pérez-Vidal, C. (2015) Languages for All in Education: CLIL and ICLHE at the Crossroads of Multilingualism, Mobility and Internationalisation. In M. JuanGarau, \& J. Salazar-Noguera (Eds.), Content-based Language Learning in Multilingual Educational Environments (pp. 31-50). Springer.

Pérez-Vidal, C., \& Roquet, H. (2015). The linguistic impact of a CLIL Science programme: an analysis measuring relative gains. System, 54, 80-90. https://doi.org/10.1016/j.system.2015.05.004

Phillipson, R. (1992). Linguistic imperialism. Oxford University Press.

Phillipson, R. (2009). Linguistic imperialism continued. Routledge.

Piller, I., \& Cho, J. (2013). Neoliberalism as language policy. Language in society, 42(1), 23-44. https://doi.org/10.1017/S0047404512000887

Pol, P. (2017). Espacios regionales de educación superior e internacionalización: hacia nuevas solidaridades. Educación Superior y Sociedad, 21, 17-38.

Polly, D., Frazier, J., Hopper, C., Chapman, M., \& Wells, R. (2012). Examining the Influence of a Support Seminar on Pre-service Teachers' Preparedness for Student Teaching. School-University Partnerships, 5(1), 102-107. 
Querol-Julián, M., \& Arteaga-Martínez, B. (2019). Silence and engagement in the multimodal genre of synchronous videoconferencing lectures: The case of Didactics in Mathematics. In C. Sancho-Guinda (Ed.), Networking engagement in professional practices. Engagement in Professional Genres (pp. 297-320). John Benjamins Publishing Company.

Rahman, M.M., Singh, M.K.M., \& Karim, A. (2018). English medium instruction innovation in higher education: Evidence from Asian contexts. Journal of Asia TEFL, 15(4), 1156-1164. http://dx.doi.org/10.18823/asiatefl.2018.15.4.20.1156

Räisänen, C. (2009). Integrating content and language, in theory...in practice: Some reflections. In E. de Otto, \& A. López de Vergara Méndez (Eds.), Las lenguas para fines específicos ante el reto de la convergencia Europea. 8th International AELFE Conference (pp. 33-41). Servicio de Publicaciones.

Rallo Fabra, L., \& Jacob, K. (2015). Does CLIL Enhance Oral Skills? Fluency and Pronunciation Errors by Spanish-Catalan Learners of English. In M. Juan-Garau, \& J. Salazar-Noguera (Eds.), Content-based Language Learning in Multilingual Educational Environments (pp. 163-177). Springer.

Ramanantsoa, B., Delpech, Q., \& Diagne, M. (2016). French higher education beyond the borders: The urgent need for a strategy (L'enseignement supérieur français par-delà les frontiers: L'urgence d'une stratégie). France Stratégie. https://www.strategie.gouv.fr/sites/strategie.gouv.fr/files/atoms/files/rapportenseignement-superieur-26-09-2016-final-web_0.pdf

Ramos-García, A. M., \& Pavón Vázquez, V. (2018). The linguistic internationalization of higher education: A study on the presence of language policies and bilingual studies in Spanish Universities. Porta Linguarum, 3, 31-46.

Ravinet, P. (2018). On Principles, Europe and Higher Education: Reflections on European Higher Education as an Intersecting Normative Space. In C. Sin, O. Tavares, S. Cardoso, \& M.J. Rosa (Eds.), European Higher Education and the Internal Market: Tensions Between European Policy and National Sovereignty (pp.21-46). Springer. 
RGCL (n.d.). Research Group in Computational Linguistics: Research. http://rgcl.wlv.ac.uk/research/

Romova, Z., \& Neville-Barton, P. (2007). 'I Have a Lot More to Say than Actually I Am Able to': A Study of Oral Skills Development of Undergraduate EAL Learners. New Zealand Studies in Applied Linguistics, 13(2), 1.

Rose, H., McKinley, J. (2018). Japan's English-medium instruction initiatives and the globalization of higher education. Higher Education, 75, 111-129. https://doi.org/10.1007/s10734-017-0125-1

Rou-Jui, S.H. (2011). The Relationship between Demotivation and EFL Learners' English Language Proficiency. English Language Teaching 4(4), 88-96. https://doi.org/10.5539/elt.v4n4p88

Rubio-Alcalá, F. D., Arco-Tirado, J. L., Fernández-Martín, F. D., López-Lechuga, R., Barrios, E., \& Pavón-Vázquez, V. (2019). A systematic review on evidences supporting quality indicators of bilingual, plurilingual and multilingual programs in higher education. Educational Research Review, 27, 191-204. https://doi.org/10.1016/j.edurev.2019.03.003

Ruiz de Zarobe, Y. (2008). CLIL and foreign language learning: A longitudinal study in the Basque Country. International Journal of CLIL Research, 1, 60-73.

Ruiz de Zarobe, L., \& Ruiz de Zarobe, Y. (2015). New perspectives on multilingualism and L2 acquisition: an introduction. International Journal of Multilingualism, 12(4), 393-403. https://doi.org/10.1080/14790718.2015.1071021

Ruiz de Zarobe, Y., Sierra, J.M., \& Gallardo del Puerto, F. (Eds.) (2011). Content and Foreign Language Integrated learning. Peter Lang.

Saarinen, T. \& Nikula, T. (2012). Implicit policy, invisible language: policies and practices of international degree programmes in Finnish Higher Education. In A. Doiz, D. Lasagabaster, \& J.M. Sierra (Eds.), English Medium Instruction at Universities: Global Challenges (pp. 131-150). Multilingual Matters.

Sabanayagam, K., Dani, V. D., John, M., Restivo, W., Mikhaylichenko, S., \& Dalili, S. (2017). Developing and Implementing Lab Skills Seminars, a Student-Led 
Learning Approach in the Organic Chemistry Laboratory: Mentoring Current Students While Benefiting Facilitators. Journal of Chemical Education, 94(12), 1881-1888. https://doi.org/10.1021/acs.jchemed.7b00073

Salas, M.D. (2015). Reflexive metadiscourse in research articles in Spanish: Variation across three disciplines (Linguistics, Economics and Medicine). Journal of Pragmatics, 77, 20-40. https://doi.org/10.1016/j.pragma.2014.12.006

Sánchez Pérez, M.M., \& Salaberri Ramiro, S. (2017). Implementing Plurilingualism in Higher Education: Teacher Training Needs and Plan Evaluation. Porta Linguarum, 2, 139-156.

Sander, P., Stevenson, K., King, M., \& Coates, D. (2000). University Students' Expectations of Teaching. Studies in Higher Education, 25, 309-323.

Schmitz, J.R. (2012). "To ELF or not to ELF?" (English as a Lingua Franca): that's the question for Applied Linguistics in a globalized world. Revista Brasileira de Linguística Aplicada, 12(2), 249-284. http://dx.doi.org/10.1590/S1984$\underline{63982012000200003}$

Scott-Clayton, J. (2012). Do High-Stakes Placement Exams Predict College Success? (CCRC Working Paper No. 41). Community College Research Center, Columbia University.

Seikkula-Leino, J. (2007). CLIL learning: Achievement levels and affective factors. Language and Education, 21(4), 328-341.

Sehoole, M., \& Knight, J. (2013). Internationalisation of African higher education: Towards achieving the MDGs. Sense Publishers.

Seidlhofer, B. (2009). Common ground and different realities: World Englishes and English as a lingua franca. World Englishes 28(2), 236-245.

Shamsudin, S., \& Ebrahimi, S. J. (2013). Analysis of the moves of engineering lecture introductions. Procedia-Social and Behavioral Sciences, 70, 1303-1311.

Shirkhani, F., \& Jamalinesari, A. (2015). Monologism versus Dialogism: A Bakhtinian Approach to Teaching. Journal of Advances in English Language Teaching, $3(2), 27-40$. 
Shohamy, E. (2012). A Critical Perspective on the Use of English as a Medium of Instruction at Universities. In A. Doiz, D. Lasagabaster, \& J.M. Sierra (Eds.), English-medium instruction at universities: Global challenges (pp. 196-212) Multilingual matters.

Simpson, R.C. (2006). Academic speech across disciplines: lexical and phraseological distinctions. In K. Hyland \& M. Bondi (Eds.), Academic discourse across disciplines (pp. 295-316). Peter Lang.

Simpson, R. C., Briggs, S. L., Ovens, J., \& Swales, J. M. (2002). MICASE Manual: The Michigan corpus of academic spoken English. The Regents of the University of Michigan.

Sinclair, J. McH., \& Coulthard, R.M. (1975). Towards an Analysis of Discourse. The English Used by Teachers and Pupils. Oxford University Press.

Sinclair, J. McH., \& Coulthard, R.M. (1992). Towards an Analysis of Discourse. In M. Coulthard (ed.), Advances in Spoken Discourse Analysis (pp. 1-34). Routledge.

Skuttnab-Kangas, T. (2003). Linguistic diversity and biodiversity: the threat from killer languages. In. C. Mair (Ed.), The Politics of English as a World Language (pp. 31-52). Rodopi, ASNEL papers 7.

Smit, U., \& Dafouz, E. (2012). Integrating content and language in higher education: An introduction to English-medium policies, conceptual issues and research practices across Europe. Aila Review, 25(1), 1-12.

Snow, M.A., \& Brinton, D. (Eds.). (2017). The content-based classroom: New perspectives on integrating language and content. University of Michigan Press.

Soliman, N.A. (2016). Teaching English for academic purposes via the flipped learning approach. Procedia-Social and Behavioral Sciences, 232, 122-129. https://doi.org/10.1016/j.sbspro.2016.10.036

Somers, T., \& Llinares, A. (2018). Students' motivation for content and language integrated learning and the role of programme intensity. International Journal of Bilingual Education and Bilingualism, 1-16. https://doi.org/10.1080/13670050.2018.1517722 
Soria, K.M., \& Troisi, J. (2014). Internationalization at home alternatives to study abroad: Implications for students' development of global, international, and intercultural competencies. Journal of studies in international education, 18(3), 261-280.

Soter, A., Wilkinson, I., Murphy, P., Rudge, L., Reninger, K., \& Edwards, M. (2008). What the discourse tells us: Talk and indicators of high-level comprehension. International Journal of Educational Research, 47(6), 372-391. https://doi.org/10.1177/1028315313496572

Sotirin, P. (1999, November 4-7). Bringing the Outside in Ethnography in/beyond the Classroom [Conference presentation]. 85th Annual Meeting of the National Communication Association.

Spratt, M. (2017). CLIL Teachers and their Language. Research Papers in Language Teaching \& Learning, 8(1), 44-61.

Stavans, A., \& Hoffmann, C. (2015). Multilingualism: Key Topics in Sociolinguistics. Cambridge University Press.

Stapel, A. (2016). Content and Language Integrated Learning (CLIL) in Medicine Programs in Higher Education. Giessener Elektronische Bibliothek.

Steinert, Y., \& Snell, L. (1999). Interactive lecturing: Strategies for increasing participation in large group presentations. Medical Teacher, 21(1), 37-42.

Stoller, F. (2002). Promoting the acquisition of knowledge in a content based course. In J. Crandall, \& D. Kaufman (Eds.), Content-based instruction in higher education settings (pp. 109-123). TESOL.

Stoller, F.L. (2008). Content-based instruction. In N. H. Hornberger (Ed.), Encyclopedia of language and education (pp. 1163-1174). Springer US.

Straker Cook, J.R. (1975). A communicative approach to the analysis of extended monologue discourse and its relevance to the development of teaching materials for ESP [Unpublished doctoral dissertation]. University of Edinburgh.

Strong, M. (1996). The habit of thought: From Socratic seminars to Socratic practice. New View. 
Stryker, S.B., \& Leaver, B.L. (1997). Content-based instruction in foreign language education: Models and methods. Georgetown University Press.

Study in the Czech Republic (2018). Scholarships. https://www.studyin.cz/plan-yourstudies/scholarships/

Study in Denmark (2018). Tuition fees and Scholarships. $\underline{\text { https://studyindenmark.dk/study-options/tuition-fees-scholarships }}$

Study in Romania (2018). Looking for scholarships. https://www.studyinromania.gov.ro/fp/index.php?\&idA=31\&ddpN=829119993 $\underline{\text { \&we }=321 \mathrm{ebd} 54 \mathrm{~b} 1 \mathrm{~d} 24 \mathrm{a} 50 \mathrm{f} 8 \mathrm{fd} 9 \mathrm{e} 0 \mathrm{f} 7 \mathrm{~b} 92 \mathrm{e} 742 \& w f=\mathrm{dGFCall} \& w t o k=a 8 \mathrm{a} 928 \mathrm{aed} 84}$ 6a373c57d51cd9e440271b041b63a\&wtkps=FYxbCoAgEADvsv99rGXQeofuE Gn4iLJW6UV3z/4GhpmBanqYJMGRwsygHHWybSQqLgbYaSjUIIG4FsvHGi fdOjndWXtzJp9TqNCMcdC2wrzcu8A/EOVnQPXq/QA=\&wchk=50805e43402 $\underline{555260 \mathrm{~d} 7 \mathrm{e} 718 \mathrm{f} 99 \mathrm{fbc} 26 \mathrm{e} 0 \mathrm{f} 87 \mathrm{ce} 83}$

Sadeghi, B., Kashanian, N.M., Maleki, A., \& Haghdoost, A. (2013). English Language Proficiency as a Predictor of Academic Achievement among Medical Students in Iran. Theory \& Practice in Language Studies, 3(12), 2315-2321. https://doi.org/10.4304/tpls.3.12.2315-2321

Swales, J. (1990). Genre analysis: English in academic and research settings. Cambridge University Press.

Swales, J. (2002). Integrated and fragmented worlds: EAP materials and corpus linguistics. In J. Flowerdew (Ed.), Academic discourse (pp. 150-164). Cambridge University Press.

Swales, J. (2004). Research Genres: Exploration and application. Cambridge University Press.

Swedish Government Inquiries (2018). Internationalisation of Swedish Higher Education Institutions. Summary of the reports SOU 2018:3 and SOU 2018:78 by the Inquiry on increased internationalization. Stockholm: Swedish Government Official Reports. http://ecahe.eu/assets/uploads/2018/02/summaryin-english-internationalisation-of-swedish-higher-education-institutions.pdf 
Sylvén, L. S. (2017). Motivation, second language learning and CLIL. In A. Llinares, \& T. Morton (Eds.), Applied linguistics perspectives on CLIL (pp. 51-65). John Benjamins. https://doi.org/10.1075/11lt.47.04syl

Taillefer, G. (2013). CLIL in higher education: the (perfect?) crossroads of ESP and didactic reflection. Asp, 63, 31-53. https://doi.org/10.4000/asp.3290

Takimoto, M. (2015). A corpus-based analysis of hedges and boosters in English academic articles. Indonesian Journal of Applied Linguistics, 5(1), 95-105.

Tedick, D.J., Christian, D., \& Fortune, T.W. (2011). The future of immersion education: An invitation to 'dwell in possibility'. In D.J. Tedick, D. Christian, \& T.W. Fortune (Eds.), Immersion education: Practices, policies, possibilities (pp.1-12). Multilingual Matters.

The University of Edinburgh (n.d.). Networks. https://global.ed.ac.uk/partnerships/networks

The University of Edinburgh (2015). Edinburgh impact. Retrieved 12 August 2019 from https://www.ed.ac.uk/files/atoms/files/edinburgh-impact.pdf

The University of Edinburgh (2018). Internationalisation Strategy: Edinburgh Global. https://www.ed.ac.uk/files/imports/fileManager/internationalisationstrategy.pdf

The University of Edinburgh (2019). HR Excellence in Research Award September 2018: Progress Report - 8 Year Evaluation and Review. http://www.docs.hss.ed.ac.uk/iad/Researchers/University_of_Edinburgh_HR_Ex cellence_4_Page_Report_Sept2018_v2.pdf

The University of Edinburgh (2020). Factsheet of Student Figures, 2019/20: Introduction.

http://www.docs.sasg.ed.ac.uk/gasp/factsheet/Student_Factsheet_31072020.pdf

Thompson, S. (1994). Frameworks and contexts: A genre-based approach to analysing lecture introductions. English for Specific Purposes, 13(2), 171-186.

Thompson, S. (2003). Text-structuring metadiscourse, intonation and the signalling of organisation in academic lectures. Journal of English for Academic Purposes, 2, $5-20$. 
Times Higher Education (2020). The World University Rankings: University of $\begin{array}{lllll}\text { Edinburgh. } & \text { Retrieved } & 24 & \text { October } & 2020\end{array}$ https://www.timeshighereducation.com/world-university-rankings/universityedinburgh

Tollefson, J. W. (2013). Language policies in education: Critical issues (2nd ed.). Routledge/Taylor \& Francis.

Trudell, B. (2016). The impact of language policy and practice on children's learning: Evidence from Eastern and Southern Africa. UNICEF. https://www.unicef.org/esa/sites/unicef.org.esa/files/2018-09/UNICEF-2016Language-and-Learning-Executive-Summary.pdf

Tsou W., \& Kao S.M. (2017) Overview of EMI Development. In W. Tsou, \& S.M. Kao, (Eds.), English as a Medium of Instruction in Higher Education: Implementations and classroom practices in Taiwan. Springer. https://doi.org/10.1007/978-981-10-4645-2_1

Turner, M. (2013). Content-based Japanese Language Teaching in Australian Schools: Is CLIL a Good Fit? Japanese Studies, 33(3), 315-330. https://doi.org/10.1080/10371397.2013.846211

Uchihara, T., \& Harada, T. (2018). Roles of Vocabulary Knowledge for Success in English-Medium Instruction: Self-Perceptions and Academic Outcomes of Japanese Undergraduates. TESOL Quarterly, 52(3), 564-587. https://doi.org/10.1002/tesq.453

UIC Barcelona (n.d.). Institute for Multilingualism: Multimat (Grupo de Investigación 'Multilingualism Matters'). http://www.uic.es/es/ifm/investigacion/grupos$\underline{\text { lineas-investigacion }}$

United Nations (2015). Resolution adopted by the General Assembly on 25 September 2015. Transforming our world: the 2030 Agenda for Sustainable Development (A/70/L.1). United Nations. https://www.un.org/en/development/desa/population/migration/generalassembly/ docs/globalcompact/A_RES_70_1_E.pdf 
UNESCO (2003). Education in a multilingual world. UNESCO. https://unesdoc.unesco.org/ark:/48223/pf0000129728

Universitat Jaume I (2016). Model Educatiu de l'UJI. https://documents.uji.es/alfresco/d/d/workspace/SpacesStore/a92a5c90-eb2c$\underline{42 \mathrm{e} 9-\mathrm{acc} 7-7 \mathrm{c09} d 4 \mathrm{a} 7 \mathrm{~d} 657 / \text { modeduc-v.pdf?guest=true }}$

Universitat Jaume I. (2017). Guia per a la docència multilingüe de la Universitat Jaume I /Guide for Multilingual Teaching at Universitat Jaume I. https://documents.uji.es/alfresco/d/d/workspace/SpacesStore/7fcdb455-e8e7$\underline{40 \mathrm{~d} 2-9469-02 \mathrm{e} 1 \mathrm{~cd} 110 \mathrm{f} 19 / \text { manual+multilingue+vincles.pdf?guest=true }}$

Universitat Jaume I. (2019a). Estratègia de convivència $i$ promoció lingüística ECOPOL.

http://documents.uji.es/alfresco/d/d/workspace/SpacesStore/e83e1f8b-75934212-8015-abea76bf34d8/XX_SLTJM_ECOPOLfinal-oct19.pdf?guest=true

Universitat Jaume I. (2019b). Estratègia d'internacionalització de la Universitat Jaume I (2019-2022).

https://ujiapps.uji.es/ade/rest/storage/RAQIOI7E3KOJCOLHB7OK8PEYOU41 $\underline{\mathrm{AOTO}}$

Universitat Jaume I (2020a). Memoria académica y de responsabilidad social universitaria//2019-2020.

https://ujiapps.uji.es/ade/rest/storage/OTPAKE7UASX1WOPZ98WQBCPQLY TCQKMP

Universitat Jaume I. (2020b). Nivells linguistics del personal docent I investigador de la Universitat Jaume I per a impulsar la docència en valencià o en anglès. /Language level requirements for researchers and lecturers in order to enhance teaching in English. https://ujiapps.uji.es/ade/rest/storage/VSWEECXBEMRYOQGAEWDOQ720K

\section{SAWQWU5}

Universitat Jaume I (2020, May 15). The ITC has participated in the pan-European virtual hackathon to contribute ideas to the challenge of the COVID-19 disease. https://www.uji.es/com/investigacio/arxiu/noticies/2020/5/hackaton- 
itc/?urlRedirect=https://www.uji.es/com/investigacio/arxiu/noticies/2020/5/hack aton-itc/\&url=/com/investigacio/arxiu/noticies/2020/5/hackaton-itc/

Universitat Jaume I (2021). Programa d'incorporació de l'anglès a la docència per al curs $2020 / 21$. https://ujiapps.uji.es/ade/rest/storage/7GUOBQU7RYAX8JKHSZ5UZ5XVCSD $\underline{\text { YZ6HS }}$

University of Wolverhampton (n.d.). Research Group of Computational Linguistics: MA students. https://www.wlv.ac.uk/research/institutes-and-centres/riilp--$\underline{\text { research-institute-in-information-and-lan/research-group-of-computational- }}$ linguistics/ma-students/

University of Wolverhampton (2016). Strategic Plan 2016-2021. https://www.wlv.ac.uk/media/departments/office-of-the-vicechancellor/documents/Strategic-Plan.pdf

Unterberger, B., \& Wilhelmer, N. (2011). English-medium education in economics and business studies: Capturing the status quo at Austrian universities. ITLInternational Journal of Applied Linguistics, 161(1), 90-110. https://doi.org/10.1075/itl.161.06unt

Valcke, J., \& Wilkinson, R. (Eds.) (2017). Integrating Content and Language in Higher Education: Perspectives on Professional Practice. Peter Lang Publishing Group.

Valdés, G. (2001). Heritage languages students: Profilesand possibilities. In J.K. Peyton, D.A. Ranard, \& S. McGinnis (Eds.), Heritage languages in America: Preserving a national resource (pp. 37-77). Center for Applied Linguistics/DeltaSystems.

van de Craen, P., Ceuleers, E., \& Mondt, K. (2007). Cognitive development and bilingualism in primary schools: Teaching maths in a CLIL environment. In D. Marsh, \& D. Wolff (Eds.), Diverse contexts-converging goals: CLIL in Europe (pp. 185-200). Peter Lang.

van de Pol, J., Volman, M., \& Beishuizen. J. (2010). Scaffolding in teacher-student interaction: a decade of research. Educational Psychology Review 22(3), 27196. https://doi.org/10.1007/s10648-010-9127-6 
van Dijk, T. A. (2019). Macrostructures: An interdisciplinary study of global structures in discourse, interaction, and cognition. Routledge.

Veronesi, D., \& Nickenig, C. (Eds.) (2009). Bi- and multilingual universities: European perspectives and beyond. Attii Conference Proceedings. Bolzano-Bozen, 20-22 September 2007. Bozen-Bolzano University Press.

Viechnicki, G. (1997). An empirical analysis of participant intentions: Discourse in a graduate seminar. Language and Communication, 17(2), 103-131.

Villar, C.M. (2014). Las presentaciones académicas orales en E/LE de estudiantes alemanes: un análisis macrotextual, discursivo y contextual del género en nativos y no nativos. Peter Lang.

VSNU (Vereniging van universiteiten / Association of universities in The Netherlands) (2018). Internationalisation Agenda for Higher Education. https://www.vsnu.nl/files/documents/Internationalisation\%20Agenda\%20for\%2 0Higher\%20Education.pdf

Vygotsky, L.S. (1978). Mind in society: The development of higher psychological processes. In M. Cole, V. John-Steiner, S. Scribner, \& E. Souberman (Eds.), Mind in society. Mind in society the development of higher psychological processes. Harvard University Press.

Wächter, B., \& Waiworm, F. (2014). English-Taught Programmes in European Higher Education: The State of Play in 2014. Lemmens.

Walsh, S. (2006). Investigating classroom discourse. Routledge.

Wei, R. (2013). Chinese-English bilingual education in China: Model, momentum, and driving forces. Asian EFL Journal, 15(4), 184-200.

Wells, G. (1998). Some questions about direct instruction: Why? To whom? How? and When? Language Arts, 76(1), 27-35.

Wesche, M.B. (1993). Discipline-based approaches to language study: Research issues and outcomes. Language and content: Discipline-and content-based approaches to language study, 57-82. 
Wilson, K.D. (1989). Predictors of proficiency in critical thinking for college freshmen [Doctoral dissertation, Montana State University-Bozeman].

Wisker, G. (2008). The Postgraduate Research Handbook: Succeed with Your MA, MPhil, EdD and PhD (2nd ed.). Red Globe Press.

Wozniak, M. (2013). CLIL in Pharmacy: A case of collaboration between content and language lecturers. Language Value, 5, 107-128. http://dx.doi.org/10.6035/LanguageV.2013.5.6

Xarxa Vives d'Universitats (2018). Pla de Política Lingüística - Language Policy Planning. $\quad$ http://www.ub.edu/sl/ca/docs/pla-politica-linguistica-2017-2018$\underline{\text { xvu.pdf }}$

Yaakob, S. B. (2014). A genre analysis and corpus based study of university lecture introductions [Doctoral dissertation, University of Birmingham].

Young, L. (1994). University lectures: Macro-structure and micro-features. In J. Flowerdew (Ed.), Academic listening: Research perspectives (pp.159-176). Cambridge University Press.

Zappa-Hollman, S. (2018) Collaborations between language and content university instructors: factors and indicators of positive partnerships, International Journal of Bilingual Education and Bilingualism, 21(5), 591-606. https://doi.org/10.1080/13670050.2018.1491946 


\section{Appendices}

APPENDIX I (a): Interviews

\section{Module:}

Semester:

Teacher:

1. ¿Cuántos créditos corresponden a la enseñanza en inglés?

2. ¿Qué dificultades presenta el alumnado?

3. ¿Qué dificultades tiene el profesorado?

4. Materiales que se suelen entregar

5. Tareas que se suelen realizar. 


\section{APPENDIX I (b): History (H1)}

R: <TLANG_Cat> En què semestre s'imparteix l'assignatura i quants crèdits corresponen a l'ensenyament en anglès? <TLANG_Cat>

H1: <TLANG_Cat> Història del Món Clàssic és una asignatura que s'imparteix al llarg del segon semestre en primer curs. És una asignatura comú als graus d'Història i Patrimoni i Humanitats, en la qual s'han de cursar dos crèdits en anglès de manera obligatòria segons consta a la guia docent <TLANG_Cat>.

R: <TLANG_Cat> Quines són les dificultats que presenta l'alumnat en aquesta docència en anglés? <TLANG_Cat>

H1: <TLANG_Cat> Principalment el nivell d'anglés que és molt heterogeni. Hi ha alguns que tenen molt bon nivell d'anglès, però altres, podriem dir que la gran majoria, té un nivell principiant o intermig baix, i com que són conscients d'això els costa molt participar de manera oral en classe. De fet, en alguna ocasió he hagut d'agafar el llistat $\mathrm{i}$ anar dient noms per a trencar el gel i que contestaren els ejericicis o les preguntes que els feia. A més, a l'hora de fer presentacions en grup els que menys nivell tenen, lligen i és aixina, encara que eixe no és l'objectiu. Apart d'això, també és cert que estan poc familiaritzats amb la terminologia i per ejemple molts segueixen utilitzant els noms dels emperadors romans en castellà, no només a l'hora de parlar, sinó també a l'hora de produir textos escrits <TLANG_Cat>.

R: <TLANG_Cat> Quines dificultats creus que té el professorat? <TLANG_Cat>

H1: <TLANG_Cat> En el meu cas, que sóc d'una área lingüística, al principi el que més costa és familiaritzar-se amb la terminologia i contingut més específic, si ben és cert que sempre m'ha agradat molt la Història. Sempre tens eixa por de que et facen preguntes sobre un tema que no domines, ja que en el meu cas, jo no sóc professora de contingut pròpiament dit. A banda d'això, que és qüestió de pràctica i seguir aprenent, crec que la dificultat principal és tractar el temari de manera que resulte atractiu per a l'alumnat i que es mostren disposats a participar en classe <TLANG_Cat>.

R: <TLANG_Cat> Quins materials se solen utilitzar em l'assignatura? <TLANG_Cat>

H1: <TLANG_Cat> Bé, quan vaig començar a impartir esta assignatura, al moment de preparar-la vaig crear un glossari amb la terminologia en anglès, els equivalents en 
castellà i la pronunciació fonètica de les paraules. El vaig penjar a l'aula virtual des del primer moment $\mathrm{i}$ he anat actualitzant-lo amb nous termes que he anat aprenent $\mathrm{i}$ que crec que els poden resultar útils, si no ara, al llarg de la seua vida acadèmica o professional. No oblidem que estan en primer i hauran de llegir articles o capítols de llibre per tal de poder realitzar treballs. A banda del glossari, els penge totes les presentacions en PowerPoint a les quals tenen accés des del primer moment juntament amb la guia docent i les instruccions de les tasques que els demane. També els facilite enllaços de vídeos, articles i pàgines web on poden trobar informació addicional sobre temes específics, com ara l'arquitectura o les classes socials de l'època romana. I els demane que contesten uns qüestionaris de satisfacció per a poder valorar si la docència en anglès els han agradat o si hi ha algun aspecte que creuen que s'hauria de millorar $\langle$ TLANG_Cat>.

R: <TLANG_Cat> I ja per últim, quines tasques se solen demanar als alumnes? $<$ TLANG_Cat>

H2: <TLANG_Cat> Este ha sigut el meu primer any donant clase i m'he plantejat visualitzar i comentar vídeos a classe, la qual cosa els servirà per a redactar la tasca escrita que els demane. En concret han de relacionar els fets històrics que han vist amb el professor de contingut amb els capítols que veurem de la sèrie Roma. També hauran de contestar un qüestionari Kahoot per a comprovar que han estat atents al capítol i que han entés el que ha ocorregut. I <TLANG_Cat> <TLANG_Sp> bueno <TLANG_Sp>, <TLANG_Cat> crec que activitat crec que els agradarà molt. Com a tasques orals, a més de la interacció a l'aula amb preguntes i respostes, els demane que facen presentacions en grup explicant un dia en la vida d'un membre de la societat romana. I això és tot <TLANG_Cat>. 


\section{APPENDIX I (c): History (H2)}

H2: <TLANG_Sp> Sí, pues eh, lo que te comentaba. Este año lo que tengo algo de docencia en inglés es la asignatura de Fundamentos y Teoría del Patrimonio Artístico, que es una asignatura de formación obligatoria eh de cuarto curso en la carrera de Historia y Patrimonio, y - y entonces, eh lo que normalmente hemos hecho porque realmente, a lo mejor es..., - no llega a ser un crédito, es - son muy pocas horas realmente. Eh lo que hacemos es cuando ha habido oportunidad que algún compañero del área ha organizado algún congreso por, sobre noviembre y - y se impartía en inglés, lo hemos puesto como actividad eh obligatoria y que formaba parte de las prácticas: entonces todos los alumnos debían de asistir y luego hacían una reseña crítica sobre, bueno, sobre las conferencias <TLANG_Sp>.

\section{R: 〈TLANG_Sp> ¿En inglés también? $\langle$ TLANG_Sp>}

H2: <TLANG_Sp> En inglés también. Eso se evaluaba como una parte más de las prácticas. Los años que eso no se ha podido hacer, como por ejemplo, este, que no se podrá hacer porque no hay previsto ningún congreso, lo que normalmente hacemos es, pues sobre algún tema específico de - de la asignatura en las clases prácticas, pues les damos algún - algún artículo científico que se deben - que deben de leer y - y luego lo comentamos. O hacen algún comentario, analizan el artículo <TLANG_Sp>.

R: <TLANG_Sp>Y los comentarios, ¿también en inglés? <TLANG_Sp>

H2: <TLANG_Sp>Sí, eso, eso lo hacen en inglés <TLANG_Sp>.

R: $\left\langle\right.$ TLANG_Sp $>$ Vale $<T L A N G \_S p>$.

H2: <TLANG_Sp>Y - y bueno, normalmente hacemos eso. Sí que...pero porque esta asignatura tiene muy poca docencia en inglés. Sí que hay otras asignaturas dentro de Historia del Arte que son del grado de Turismo y que sí que se imparten en inglés, completamente <TLANG_Sp>.

R: <TLANG_Sp $>$ Vale $<T L A N G \_S p>$.

H2: <TLANG_Sp> Eh: se da Arte Español y Recursos Turísticos en segundo de carrera y Arte Valenciano y Recursos Turísticos en cuarto de carrera <TLANG_Sp>.

R: <TLANG_Sp > Vale $<T L A N G \_S p>$ 
H2: <TLANG_Sp> Entonces yo justamente este año eh esas no las doy, las da mi compañero X. Bueno, este primer trimestre, - este primer semestre se está dando Arte Valenciano en cuarto que la da mi compañero X y - y luego para el segundo semestre, pues bueno, estamos pendientes de, - de tener un profesor que pueda dar Arte español. Normalmente en esos grupos, porque em: en arte español concretamente que es de segundo hay un grupo que tiene la docencia en español y otro grupo que tiene la docencia en inglés. Los que tienen la docencia en inglés reciben muchísimo alumnado de Erasmus <TLANG_Sp>.

R: <TLANG_Sp > Estudiantado internacional $\langle$ TLANG_Sp $>$.

H2: <TLANG_Sp> Sí, y que viene de carreras totalmente dispares como pueda ser Periodismo, Márketing y cogen esa asignatura que está en Turismo y que además es Historia del Arte. Pero, - pero bueno, la verdad que ese es un poco el perfil que, - que tenemos. Sí que...allí, bueno los materiales, las presentaciones en PowerPoint, aunque nosotros nuestras presentaciones son imágenes, pero bueno, a veces también hay algo de texto o los pies de las imágenes, la identificación de las imágenes, todo eso está en inglés <TLANG_Sp>.

R: $\langle$ TLANG_Sp $>$ ¿Esto en Turismo o en Historia? $\langle$ TLANG_Sp $>$.

H2: <TLANG_Sp> De Turismo <TLANG_Sp>.

R: <TLANG_Sp $>$ Vale $<T L A N G \_S p>$.

H2: <TLANG_Sp> Eh porque de, - de Historia como son tan pocos créditos lo único que ponemos en inglés son las prácticas. Entonces en Turismo sí que el: - la hm: - la, los PowerPoints, las identificaciones de las imágenes, el título, el autor, el, la técnica, el lugar donde está, todo eso está en inglés. Si ponemos también diapositivas con ideas o características clave de una época o de un estilo artístico concreto, también todo eso está en inglés, y, - y en el caso de Arte español es más fácil tener bibliografía específica en inglés. Pero, por ejemplo, en Arte Valenciano: que es tan local y tan concreto es mucho más complicado, entonces no: la verdad ahí es que tenemos poco margen de maniobra. Tú lo explicas en inglés pero luego cuesta hacer prácticas teniendo algún material como un artículo de investigación que esté en inglés. Si hablan de un retablo que hay en Castellón o en Alicante, pues...pero, - pero bueno, si te pudiésemos servir de ayuda, podríamos con algún otro compañero mío $\langle$ TLANG_Sp $>$. 
R: <TLANG_Sp> Evaluaré las posibilidades de ampliar el estudio y te lo comento $\langle$ TLANG_Sp>.

H2: <TLANG_Sp> Es que claro concretamente del grado de Historia y Patrimonio, por lo menos de las asignaturas que nosotros tenemos, docencia en inglés es nada, Fundamentos y muy poquito <TLANG_Sp>.

R: <TLANG_Sp>Sí, no <TLANG_Sp>.

H2: <TLANG_Sp> Me refiero a que las de Turismo sí que te dan más juego para analizar eso <TLANG_Sp>.

R: <TLANG_Sp> Pues me lo pensaré y te lo diré porque como el proyecto sí que se basa en analizar Historia, si pudierais, bueno si me dejaras <TLANG_Sp>.

H2: <TLANG_Sp>Sí, claro <TLANG_Sp>.

R: <TLANG_Sp> Sería pasar el test de nivel y luego otro con ítems sobre sus experiencias previas y actuales con la metodología CLIL y qué es lo que saben sobre la política lingüística de la UJI. Y grabar en audio el día en el que impartas el seminario en inglés para valorar la interacción de lenguas en el aula y la participación del alumnado en inglés. Sería decirme, mira tal día vamos a hacer esto, si puedes ven <TLANG_Sp>.

H2: <TLANG_Sp> Vale, sí <TLANG_Sp>.

R: 〈TLANG_Sp> Yo sería ir como observadora <TLANG_Sp>.

H2: <TLANG_Sp>Claro, claro. Yo seguramente los temas, sería sobre noviembre o principios de diciembre cuando haríamos eso porque más o menos según voy yendo en el, en el temario sí que hay temas como por ejemplo, temas de mitología, de la importancia de la mitología en el arte o de la emblemática que ahí sí que puedo, me da más juego para introducir algo en inglés. Entonces me, me reviso el temario <TLANG_Sp>.

R: <TLANG_Sp>Sí, no hay problema. Tampoco corre prisa <TLANG_Sp>.

H2: <TLANG_Sp> No, pero me refiero a que me planifico las, - me planifico las sesiones y te digo "mira, pues tal día haremos esta práctica" y, y volvemos a hablar y entonces pues ya lo encajamos todo y ya está <TLANG_Sp $>$. 


\section{R: <TLANG_Sp > Perfecto <TLANG_Sp $>$.}

H2: <TLANG_Sp> Y no hay ningún, - no hay ningún problema. Luego también, otros años sí que hacen un, un proyecto ehh como trabajo final, que es algo así como más creativo, que a veces tamb...eh: no, - no todos los años ha sido igual, pero sí que a veces hemos, - les hemos, eh bueno, un poco conducido a que alguna parte del proyecto lo hiciesen en inglés <TLANG_Sp>.

R: $\left\langle\right.$ TLANG_Sp>Vale $<T L A N G \_S p>$.

H2: <TLANG_Sp> Y - y bueno, eso es lo que en principio trabajamos. Sobre todo también para que conozcan un poco de vocabulario específico y, - y...

R: <TLANG_Sp> Sí, porque si después hacen investigación encontrarán bastante en inglés <TLANG_Sp>.

H2: <TLANG_Sp> Sí <TLANG_Sp>.

R: <TLANG_Sp> Y luego, solo me faltan ya dos preguntitas <TLANG_Sp>.

H2: <TLANG_Sp>Sí <TLANG_Sp>.

R: <TLANG_Sp> Una era, por ejemplo. ¿Qué dificultades encuentras tú como profesora a la hora de impartir docencia en inglés? <TLANG_Sp〉.

H2: <TLANG_Sp> A ver, pues mira. Yo mm:: yo quiero, - o sea, - yo quiero y soy muy consciente de que a mí me gust..., que quiero y necesito mejorar mi nivel de inglés, ¿vale? Eh tengo el B2, pero sinceramente a día de hoy yo no creo que sea suficiente. Eh lo que pasa es que claro, mm::, claro, yo también estoy con la tesis, con esto, con lo otro, al final también no puedo centrar tampoco como me gustaría en, - en sacar más nivel de inglés. Y cuando me ha tocado dar clases en inglés completamente, pues, - pues he dicho "mira, pues, $\mathrm{X}$, te lo preparas lo mejor que sabes y puedes, $\mathrm{y}-\mathrm{y}$ te tiras al ruedo", en ese sentido. Entonces yo creo que ahí sí que se tendría que mejorar un poco a lo mejor los recursos que se le puedan dar al profesorado para mejorar el nivel de inglés porque tampoco creo que se nos dé demasiadas facilidades. Es decir, como requisito, por ejemplo, en..., cuando me presenté a la plaza de asociado, un requisito era tener el nivel B2 de inglés para poder impartir esas clases. Pero claro, luego te das cuenta de que con un nivel B2, pues...da clase de dos horas Historia del Arte 
Valenciano, pues lógicamente no tienes el mismo desparpajo para, si te preguntan una duda o alguna cuestión más concreta, poder explicarlo. Entonces, a ver, yo lo que me lo que me hacía, no sé si me estoy yendo por las ramas...<TLANG_Sp $>$.

R: <TLANG_Sp > No, - no. No te preocupes, tú tranquila $\langle$ TLANG_Sp $>$.

H2: <TLANG_Sp> Yo lo que hacía era, igual como por ejemplo, cuando me preparaba las clases pues sí que te preparas todo el PowerPoint con algunas imágenes, algunos esquemitas y yo en Word sí que me hacía un esquema o desarrollo un poco las ideas más importantes que quiero comentar. En - en inglés sí que me - como que me redactaba o me escribía todas las ideas fundamentales que quería explicar con el vocabulario específico en inglés. Yo aprendí un montón, ¿eh? Aprendí más que los alumnos preparando la asignatura. Pero, - pero, sí que claro, llevaba mucho más preparadas las clases en cuanto a estas cuestiones $\mathrm{y},-\mathrm{y}$ me las ensayaba en casa...que, que por ejemplo, si doy clase en español, que voy, - trabajo mucho más rápido, eso sí. Pero la verdad es que estoy contenta porque...A ver yo di clase en inglés, este curso pasado no, el anterior. Además, fue todo el año porque tenía la asignatura de Arte Valenciano y la de Arte Español en el segundo semestre. A, a los profesores nos ayuda mucho porque el primer día lo pasas mal, luego vas ya cogiendo también más soltura. Es verdad que también les dije, fui un poco flexible, yo daba toda la clase en inglés, pero si me preguntaban o había algo que no entendían lo podía repetir en español. Que tampoco en eso era estricta. Y los exámenes sí que los pueden hacer en español también $\langle$ TLANG_Sp>.

R: $\left\langle\right.$ TLANG_Sp $>$ Vale $<T L A N G \_S p>$.

H2: <TLANG_Sp> Em entonces pues bueno, los Erasmus sí que te lo hacían en inglés, los españoles en español y: - y ya está. Incluso algunos podían hacerlo también en valenciano si querían <TLANG_Sp>.

R: 〈TLANG_Sp> ¿Y los materiales o recursos bibliográficos? Bueno, sí que me has dicho que con Arte Español, bueno Valenciano sí que era mucho más difícil. Pero ¿en las asignaturas que has dado en Historia, por ejemplo? <TLANG_Sp>.

H2: 〈TLANG_Sp> En...em: a ver, las asignaturas que..., por ejemplo, la de Arte Español que esa sí que es más genérica, ahí sí que hay algunos catálogos que tienen la traducción al inglés. Entonces nos salen libros más genéricos como podría ser alguno de 
Velázquez, que están inglés. Entonces eso sí que lo facilitas o buscaba páginas web que estuviesen bien y que tuviesen una traducción que, - que pudieran utilizar. Les, - les subía PDFs con un vocabulario específico en inglés eh: sobre técnicas artísticas y demás. Todo eso sí, para que por lo menos con el vocabulario de la especialidad de historia del arte se fuesen realmente em familiarizando. Y luego hacíamos exposiciones orales sobre temas que habíamos hablado em: y ellos se valoraba, no estaban obligados a hacerlo en ningún momento en inglés porque la guía docente obliga al profesor a dar toda la clase en inglés pero no al alumno, y, - y lo que pasa es que yo les decía "valoraré positivamente el esfuerzo que hagáis de hablar en inglés". Y eso la verdad es que es un recurso, o sea, es una actividad que está muy bien porque cuando ellos se ponen en tu lado, no, - no es lengua y se tienen que preparar una exposición en inglés, ya como que se ponen en la piel del profesor y les cambia totalmente la percepción. Y eso es muy bueno hacerlo a principio de curso $\langle$ TLANG_Sp $>$.

R: <TLANG_Sp>Y ahora ya la última pregunta de todas $\langle$ TLANG_Sp $\rangle$. H2: <TLANG_Sp>Sí <TLANG_Sp>.

R: 〈TLANG_Sp> ¿Qué dificultad ves tú en el alumnado? <TLANG_Sp>.

H2: 〈TLANG_Sp> Eh: pues bueno ahí tienes un poco de todo. Eh los alumnos que vienen de Erasmus, muy bien. Eh bueno, luego también hay de todo, ¿no? Habían alumnos europeos que muy bien, luego habían alumnos coreanos que no sabían español y que no sabían inglés tampoco, y además tampoco no tienen nada de -, no, - no tienen nada de conocimientos de cultura occidental. Entonces por ejemplo, no tienen ni idea del cristianismo. Si una gran parte de obras de arte góticas, por ejemplo, o renacentistas, son de contenido religioso, pues a ver como tú encima le explicas, - explícale además todo eso, ¿no? Entonces es una dificultad extra añadida. Y hay alum..., ahí tenías un poquito de todo, hay alg..., - hay alg...A ver normalmente tienen un nivel quizá un poquito..., no llegan todos al B2. Estarán pues un B1 o se están preparando el B1 o un poco en ese sentido. Algunos sí que entiend...Generalmente a ver entienden más de lo que, - de lo que... $<$ TLANG_Sp $>$.

R: 〈TLANG_Sp > De lo que hablan $\langle$ TLANG_Sp $>$. 
H2: <TLANG_Sp> De lo que hablan, eso sí. Y, - y bueno, eh: el nivel es un poquito desigual. Pero bueno yo no me sentí tampoco en ningún momento, por lo menos ese curso, que todos los alumnos supiesen más inglés que yo <TLANG_Sp>.

R: <TLANG_Sp> No, también es por si los ves reticentes a utilizar el inglés o te dicen “ay, ¿ahora tenemos que hacer esto en inglés?” <TLANG_Sp>.

H2: <TLANG_Sp> Ya. Ah, bueno. Al principio les da un poco de apuro, pero luego ya, se van, - se van soltando. Y también es verdad que les da mucha tranquilidad saber que pueden preguntar en inglés [*español*]. Pero sí que es verdad que cuando les..., en el tema de las prácticas que eran exposiciones orales les dije "bueno podéis hacer en inglés o en español pero se valorará muy positivamente el esfuerzo que hagáis por hacerlo en inglés", todo el mundo lo hizo en inglés $<$ TLANG_Sp $>$.

R: <TLANG_Sp> Hombre claro, la nota es la nota <TLANG_Sp>.

[laughs]

H2: 〈TLANG_Sp> ¿Sabes? Entonces ahí sí que eso, eso sí <TLANG_Sp>.

R: <TLANG_Sp> Funciona $<T L A N G \_S p>$.

H2: <TLANG_Sp> Eso funcionó. Es verdad, - es verdad. Y, - y hacían un portfolio que una parte...El portfolio lo que era pues bueno, como un diario de reflexión de todas las sesiones en donde tenían que explicar pues el contenido que habíamos estado trabajando, las principales obras que habíamos visto porque luego eh nuestros exámenes son - proyectas imágenes y tienen que identificar la obra y analizarla. Entonces eso sí que lo hacían en español porque el..., ya lo - lo planifiqué de manera que luego fuese un instrumento que luego ellos tuvieran para estudiar. Y: eso era en español. Tenían el diario de sesiones pero luego al final tenían también como una memoria de las prácticas que eso obligatoriamente tenía que estar en inglés <TLANG_Sp〉.

R: <TLANG_Sp $>$ Vale $<T L A N G \_S p>$.

H2: <TLANG_Sp> Y así, bueno pues lo combinaba. Y nada, en fin, esa es mi experiencia con el inglés que...pues bueno, espero que a la próxima que me toque dar clase en inglés, pues vaya mejorando yo también $\langle$ TLANG_Sp $>$. 
R: <TLANG_Sp> Claro que sí. Una vez has aprendido algo, luego ya es más fácil aplicarlo <TLANG_Sp>.

H2: <TLANG_Sp> Sí, - sí eso sí. Sí que es verdad que yo también me di cuenta de que claro, la primera asignatura que tuve fue Arte Valenciano, entonces ahí me redactaba más las clases. En Arte Español ya me cogía palabras clave, me hacía un esquemita y ya pega más fácil porque al fin y al cabo, cuando ya coges unas cuantas estructuras o recursos, pues luego ya de ahí no te mueves, ¿no? Entonces pues bueno, así voy $\langle$ TLANG_Sp>.

R: 〈TLANG_Sp> Muy bien <TLANG_Sp $>$.

H2: <TLANG_Sp > Batallando y pues... $<$ TLANG_Sp $>[$ laughs $]$

R: <TLANG_Sp> No, sí, pero eso poco a poco, luego ya: te dominarás todas las asignaturas en inglés $\langle$ TLANG_Sp>.

H2: <TLANG_Sp> Pero después..., sí que al final del año sí que me quedé contenta porque generalmente, a ver, los Erasmus me entendían, que esa era también sobre todo mi mayor preocupación. Los, - los españoles había cosas que las repetía en español y, y hasta los Erasmus sí, - sí que me entendían bien y, - y dije "bueno, pues esto es la prueba de fuego". Así que bueno, bien, al final quedé contenta $<$ TLANG_Sp $>$.

R: <TLANG_Sp> Pues muchísimas gracias por darme un poquito de tu tiempo para contestar estas preguntas y por permitirme asistir al seminario que impartirás más adelante. Estoy muy agradecida, de verdad $\left\langle T L A N G \_S p>\right.$. 


\section{APPENDIX I (d): Tourism}

R: <TLANG_Sp> Te explico un poco en lo que consiste y luego las preguntitas, son cortitas. Em: mira, lo que es la tesis se basa en analizar lo que es..., no el nivel de los alumnos, sino el discurso que hay en clase de cómo ellos producen, el input que ellos reciben y luego ellos en base a lo que tu les pides cómo son ellos capaces de producir. Entonces para ello lo que necesito es asistir a clase y grabar solo el oral para ver las lenguas de interacción que hay en el aula, el castellano, el valenciano y el inglés. Y para eso, analizo lo que son asignaturas de historia, en este caso Turismo pero en Historia, luego en el grado de Historia, Enfermería y Medicina, así también haré un análisis contrastivo entre los que son ciencias y humanas. Básicamente es eso, entonces yo lo que les tengo que pasar, que lo pueden hacer online porque lo tengo hecho online también para no quitar tiempo en clase ni nada: es un cuestionario sobre qué es lo que saben ellos sobre el pla de multilingüisme de la uji [*ECOPOL*], porque a partir de ahora creo que tendrán que sacarse un B2 <TLANG_Sp $>$.

$\mathrm{T}:\left\langle\mathrm{TLANG} \_\mathrm{Sp}>\mathrm{Hm}:\left\langle\mathrm{TLANG} \_\mathrm{Sp}>\right.\right.$.

R: <TLANG_Sp> Entonces a ver qué saben ellos porque a lo mejor hay algunos que no lo saben, para que también se espabilen un poco en lo que es sacarse el título. Y luego es otro tipo...es un placement test para ver qué nivel se supone que tienen, que, - o sea, no es analizar su nivel, sino en base al nivel que se supone que saquen, luego ellos cómo reaccionan a las tareas que tu les pides en el aula. Porque a lo mejor dicen: "no, yo tengo un $\mathrm{C} 1$ o tengo un B2" y luego en el aula no quieren interactuar nada en inglés, o al contrario <TLANG_Sp>.

T1: <TLANG_Sp> Hm <TLANG_Sp >.

R: <TLANG_Sp> Eso <TLANG_Sp>.

T: <TLANG_Sp> Vale. Pues a ver, en principio a mí lo de que me grabes dando una clase teórica no me gusta, ya te lo digo. Eh no tengo inconveniente en una práctica en la que efectivamente sí que hay interacción, pero que me grabes a mí durante dos horas subido a la tarima hablando en inglés, no me gusta <TLANG_Sp>.

R: $\left\langle\right.$ TLANG_Sp $>$ No, vale $<T L A N G \_S p>$. 
T: <TLANG_Sp> ¿Vale? Entonces porque las, mis teóricas consisten básicamente en que yo hablo y ellos toman apuntes, o sea, interacción hay poca. Entonces ehm:: no me convence. Esa parte no me convence. No tengo inconveniente en que una práctica en la que hablamos todos y que es un diálogo, sí, pero lo otro me hace sentir un poco examinado de mi nivel de inglés <TLANG_Sp>.

R: <TLANG_Sp> No, ya, ya, pero es que no consiste en eso <TLANG_Sp >

T: <TLANG_Sp> Lo sé, pero sigue sin gustarme. Te quiero decir. Aparte de que no veo exactamente en qué te puede ayudar grabarme a mí durante dos horas hablando en inglés. Porque ellos no participan <TLANG_Sp>.

R: <TLANG_Sp> No, claro, yo es por si había algo más de interacción. Claro, yo tampoco...<TLANG_Sp>.

T: <TLANG_Sp> No, nosotros tenemos una distinción muy clara entre teóricas y prácticas. Entonces hay una serie de teóricas que son las mínimas eh pero claro yo por eso te dije si quieres ver una teórica hoy es la última oportunidad. Eh: pero las teóricas son de explicación de contenido. Ellos, como la mayoría de estudiantes universitarios, tienen bastante, poca tendencia a, ehh...<TLANG_Sp $>$.

R: <TLANG_Sp> Participar <TLANG_Sp>.

T: <TLANG_Sp> Participar en una clase teórica. En las prácticas no les queda más remedio. Em:: Bueno, ahora me lo pienso <TLANG_Sp $>$..

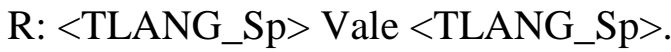

T: <TLANG_Sp> Vale. Más cosas. Preguntame cosas <TLANG_Sp>.

R: <TLANG_Sp> Luego, em a ver, ¿qué dificultades crees que presenta el alumnado a la hora de tu dar la clase en inglés? <TLANG_Sp>.

T: <TLANG_Sp> Eh: vamos a ver. Yo tengo una dicción suuuper clara, pero súper clara, entonces yo creo que eso facilita. Em: pero de todas formas el nivel es muy heterogéneo. Eh: tampoco se puede exigir mucho más porque ellos tienen la obligación, al menos en el grado de Turismo, - tienen la obligación de cursar una serie de créditos en inglés con lo cual no puede depender de su nivel, o sea, punto, los tienen que hacer y se acabó, tengan el nivel que tengan. Em:: entonces, ellos tienen un nivel muy variable y 
además, en el caso de esta asignatura, sobre todo las diferencias de nivel son entre los alumnos autóctonos y los alumnos extranjeros. Eh: yo tengo siempre mm: pues a lo mejor un $40 \%$ de alumnos de fuera de España en los cuales el nivel es variable. No es lo mismo un alumno coreano que una alumna holandesa. Entonces los alumnos en general de centro y norte de Europa tienen un nivel de inglés buenísimo, - buenísimo $<$ TLANG_Sp>

\section{R: <TLANG_Sp>Sí <TLANG_Sp>.}

T: <TLANG_Sp> Y sin embargo, pues los alumnos, - los de Taiwán lo tienen bastante peor. Entonces con respecto a la lengua, esa. Y luego, el problema añadido es que el alumnado extranjero muchas veces carece de, no en el caso de un alumno o alumna holandés, pero sí en el caso de un alumno o una alumna de Taiwán o de Corea, carece de los conocimientos previos necesarios para la realización de la asignatura, con lo cual se me mezcla la carencia lingüística con la carencia de contenidos, y eso es un hándicap importatito <TLANG_Sp>

R: <TLANG_Sp> Vale. Luego, otra. Tú como profesor, ¿qué dificultades encuentras? Porque depende del profesor dice que no se ve capacitado para dar toda la clase en inglés o tal, depende del profesor <TLANG_Sp>.

T: <TLANG_Sp> Vamos a ver, yo qué inconveniente le encuentro. Em:: yo no tengo problema, yo todas mis teóricas las doy exclusivamente en inglés em:: no tengo problema pero soy muy consciente de que la, - el discurso siempre pierde calidad, - o sea no es lo mismo impartir docencia de tipo magistral en tu lengua materna que en una lengua adquirida. Y dentro de las lenguas adquiridas hay niveles, o sea porque yo, para mí el valenciano también es una lengua adquirida, no es materna, pero sin embargo tengo un rodaje diferente. El italiano también es una lengua adquirida, no materna, pero tengo un rodaje vital diferente. El inglés es una lengua adquirida de manera $\mathrm{mm}$ con objetivos exclusivamente funcionales, con el cual eh: el rodaje ha sido distinto y la riqueza del discurso es también inferior que en cualquiera de las otras tres lenguas que he nombrado, bien sean mi lengua materna o bien sean lenguas adquiridas pero que no han sido adquiridas por motivaciones exclusivamente funcionales $\langle$ TLANG_Sp $>$.

R: 〈TLANG_Sp>Vale [laughs]. Entonces tú por ejemplo ¿qué materiales sueles entregar en el aula en inglés o para practicar? <TLANG_Sp>. 
T: <TLANG_Sp> Vamos a ver, yo en el aula virtual cuelgo absolutamente todo, cuelgo el programa de la asignatura, cuelgo mis presentaciones en PowerPoint y cuelgo todos los materiales de cada una de las actividades. Hay ademas un cronograma estricto en el que se establece lo que se va a impartir cada uno de los días eh: del semestre. La eh la proporción entre materiales en inglés y materiales en lenguas vernáculas eh: depende mucho de la existencia de dichos materiales, es decir, mi asignatura es una asignatura que se llama Arte Valenciano, y pretender que la bibliografía producida sobre arte valenciano se encuentre en lengua inglesa es mucho pretender. En algunas actividades que son de tipo genérico, em: y que puedo encontrar documentación en lengua inglesa se incluye en lengua inglesa. Pero hay que ser realista, ningún estudio de urbanismo sobre la ciudad de Valencia, así como ningún estudio sobre arquitectura renacentista en la provincia de Castellón está en inglés y yo no voy a ponerme a traducir textos académicos de otras personas. Eh: esto genera, como te decía, el - el, uno de los, - de las condiciones de esta asignatura es que tiene un porcentaje muy alto de alumnado extranjero, eh: que no domina ninguna de las lenguas vernáculas, y yo diría, no es que no las domine, es que no las conoce. Cuando empieza el semestre no las conoce, y cuando acaba el semestre tiene un nivel muy rudimentario. Entonces em: lo que genera facilidades para el alumnado autóctono, genera dificultades para el alumnado extranjero y viceversa. O sea, que es bastante, bastante entretenido encontrar el punto medio $\langle$ TLANG_Sp>.

R: <TLANG_Sp> Vale. Y luego ya..., las tareas que suelen realizar, o sea ¿tú qué les sueles pedir para que hagan? ¿Una presentación o un póster o un...? <TLANG_Sp>.

T: <TLANG_Sp> Ellos tienen eh: dentro de las actividades prácticas son muy variadas. Em: en común entre todas ellas tiene que ellos han de entregar al final de semestre una memoria escrita que incluya todas las actividades prácticas que se han realizado, la ejecución en aula, no tiene por qué ser teórica, - o sea quiero decir, el hecho de que tenga reflejo en una memoria escrita no implica que la actividad sea teórica. Y me explico. Eh: nosotros tenemos actividades que van desde la, - el trabajo sobre una serie de materiales, la preparación de un debate que es el de enfrentar dos grupos dentro del aula a eh: trabajos sobre eh: documentación histórica y reconstrucción a través del dibujo de - de elementos artísticos o eh: la organización de una ruta turística. Vale, por parte de, - de los chavales. Entonces mm en la mayoría de las actividades, además de después tener que entregar una memoria escrita y del trabajo en el aula, al final del 
desarrollo de la sesión o las sesiones en las que se realiza dicha actividad lo que se hace es algún tipo de, - de performance en la que los alumnos tienen que exponer públicamente su trabajo, bien sea a través de un debate público, bien sea a través de una presentación al resto de la clase, o de diferentes maneras <TLANG_Sp>.

R: <TLANG_Sp> Vale <TLANG_Sp>.

$\mathrm{T}:\langle\mathrm{TLANG}$ _Sp $>$ Como siempre $\langle$ TLANG_Sp $>$.

R: <TLANG_Sp> Y ya lo último es eh ¿cuántos créditos corresponden a la enseñanza en inglés? porque tú lo das, las tod... $<$ TLANG_Sp $>$.

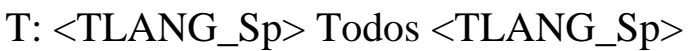

R: <TLANG_Sp> La das toda en inglés tú, ¿no? <TLANG_Sp>.

T: <TLANG_Sp > Todos <TLANG_Sp>.

R: <TLANG_Sp> Vale. Es que hay profesores que a lo mejor es solo una unidad, un seminario o un laboratorio <TLANG_Sp>.

T: <TLANG_Sp> Son todos. Los créditos de la asignatura están definidos como, como lengua inglesa. Eh: todo se imparte en inglés y sus intervenciones varían, o sea, te quiero decir, como eh uno tiene que ser consciente, pues em ante que no intervengan prefiero que intervengan en lengua vernácula a que no lo hagan. Así que su participación oral en clase eh es más o menos libre. Ellos están advertidos de que yo, evidentemente valoraré positivamente el, - el uso de la lengua inglesa, aunque les cueste más, pero pueden intervenir en la lengua que quieran <TLANG_Sp>.

R: <TLANG_Sp> Vale. Y básicamente es eso. Eran esas preguntitas para tener un background sobre el contexto en el que se desarrollan las dinámicas en la clase de contenido <TLANG_Sp>.

T: <TLANG_Sp> Venga, te dejo grabar una parte, hasta el descanso <TLANG_Sp>.

R: <TLANG_Sp> Vale <TLANG_Sp>.

T: <TLANG_Sp> Dos horas allí con el micrófono delante, paso <TLANG_Sp $>$. 
APPENDIX I (d): Tourism

R: <TLANG_Sp> Ya, si yo sé que te sientes examinado aunque no es ese el propósito $<$ TLANG_Sp>.

T: <TLANG_Sp> Ya vas a ver el nivel de participación [laughs] Y eso que son de cuarto, pero bueno...Vamos a clase $\langle$ TLANG_Sp $\rangle$.

R: <TLANG_Sp> Sí, vamos. Y muchísimas gracias por reunirte conmigo y permitirme asistir y grabar la clase <TLANG_Sp>. 


\section{APPENDIX I (e): Medicine (M1)}

R: <TLANG_Sp> Bueno, lo que te he explicado básicamente es que la investigación se basa en analizar las asignaturas de contenido que se imparten en inglés. He contactado ya con $\mathrm{X}$, con $\mathrm{X}$, también con dos profesoras de la especialidad de enfermería, y luego también he contactado con gente de humanidades ya que el objetivo principal sería hacer un análisis contrastivo entre lo que es la rama de ciencias de la salud y la rama de humanas : <TLANG_Sp>.

M1: 〈TLANG_Sp > Hm : <TLANG_Sp $>$.

R: <TLANG_Sp> Y nada, para llevar a cabo este estudio necesito ir a las clases a observar cuando tu imparte en inglés la charla o en cualquier otra asignatura, cuando los alumnos tienen que hablar en inglés, a lo mejor les pides que hagan alguna presentación o alguna cosa así. Entonces en base a eso, te hago ahora una serie de preguntas $<$ TLANG_Sp>.

M1: <TLANG_Sp>Vale <TLANG_Sp>.

R: 〈TLANG_Sp> ¿Más o menos te has hecho a la idea? <TLANG_Sp>.

M1: <TLANG_Sp>Sí,-sí, - sí, perfecto <TLANG_Sp>.

R: <TLANG_Sp> Vale. Pues, eh bueno aquí lo de cuantos créditos corresponden a la enseñanza no porque básicamente es la de inglés para fines específicos <TLANG_Sp>.

M1: 〈TLANG_Sp>Sí, la de inglés $\langle$ TLANG_Sp>.

R: <TLANG_Sp> Nada. ¿Qué dificultades crees que presenta el alumnado? $\langle$ TLANG_Sp $>$.

M1: <TLANG_Sp> Eh: pues la verdad que todavía no lo sé porque no les he dado ninguna clase a los de primero. Bueno, la primera clase la he tenido hoy. Eh supongo que el problema o la dificultad principal, una es que son alumnos de primero y el contenido que les damos es de un nivel científico mediano/alto, aunque lo intentas hacer siempre con un lenguaje o con muchas imágenes que sea fácil de digerir, pero el contenido ya es, - ya de por sí es, es duro y si además le sumas que la charla es en inglés y que, - y que claro, no les puedes hacer una explicación en español que a lo mejor entenderían muchísimo más fácil. Cuando te hagan alguna pregunta la 
contestación tiene que ser intentando eh:: que sea lo más clara posible, pero quieras o no que es en un idioma que ellos, muchos no controlan. Hay otros que sí, hay gente que viene, además es medicina que entran con una nota muy buena y entonces hay estudiantes muy buenos pero, como en todo, hay alumnos que son muy buenos en inglés, y hay otros que, - pues que les cuesta más <TLANG_Sp>.

R: <TLANG_Sp> Y en la clase esta que has tenido solo, ¿has visto si ellos te preguntan en inglés o te preguntan en castellano? <TLANG_Sp>.

M1: <TLANG_Sp> Bueno, la clase como la hemos tenido en castellano, pues te preguntan en castellano. Sí que es verdad que, que cada vez hay más extranjeros, o sea, extranjeros, que a lo mejor ya han nacido en España o que llevan muchos años en España pero que, - pero que son de padres extranjeros. Entonces eso seguramente facilita que haya más gente que controle el inglés. Eh porque claro, la enseñanza en España..., o si vienes, - normalmente si vienes de un país extranjero, depende también del país, eh: pues tienes unas nociones más que nada para, para intentar comunicarte, ¿no? <TLANG_Sp>.

R: <TLANG_Sp> Claro. Vale, la segunda es ¿Qué dificultades tienes tú como profesora? ¿A la hora de buscar materiales o...? <TLANG_Sp>.

M1: <TLANG_Sp> A la hora de buscar materiales, ninguno, porque la ciencia está toda en inglés, y todo lo que trabajamos, yo leo todos los días en inglés. A la hora de explicarte, pues quieras o no, no es tu idioma, - no es tu idioma materno. Que aunque tengas un nivel mediano/alto de inglés eh siempre que te hagan pensar con alguna duda que quieras explicar un ejemplo claro..., - o sea, yo siempre utilizo ejemplos a lo mejor muy gráficos o muy tontos que, - que les faciliten el entenderlo o verlo visualmente, pero claro en inglés siempre tienes menos recursos eh: para poderte hacer entender un poco o, - o abanico de posibilidades $\mathrm{mm}$ pero dentro de lo que cabe. Eh: bueno, también es verdad que te tienes que preparar más la clase porque no es lo mismo llevar la clase medio preparada cuando hablas en castellano eh porque puedes salir más del paso que cuando es en inglés porque quieras o no hay que dedicarle un poco más de tiempo $<$ TLANG_Sp>.

R: <TLANG_Sp> Más organizado. Y luego ¿los materiales que sueles utilizar en clase: artículos o...? <TLANG_Sp>. 
M1: <TLANG_Sp> Claro, si es científico está todo en inglés. Por ejemplo, la clase de hoy todas las bases de datos que les hemos presentado están en inglés, porque es eso, la ciencia es eso, es en inglés $\mathrm{y},-\mathrm{y}$ todo se publica en ese idioma. Entonces claro, los recursos... - sí que es verdad que intentamos a lo mejor eh hacerles llegar alguna alternativa. Por ejemplo, en la clase de hoy que era bases de datos, que - que esté en castellano o que parte de ella esté traducida, pero traducida bien, o sea en plan...Por ejemplo, hay bases de datos de la Unión Europea que tienen su versión tanto en inglés como en francés como en español porque son idiomas oficiales. Pues intentar dar alguna alternativa, pero sí que es verdad que les intentamos transmitir que, - que la cienc... o sea, toda la parte científica va a estar en inglés siempre <TLANG_Sp>.

R: <TLANG_Sp>Y con respecto al seminario que vas a dar, ¿les vas a pedir alguna tarea a los alumnos como una reseña...? <TLANG_Sp>.

M1: Sí, les paso...bueno les he preparado un...una especie de cuestionario, quizz, y...para que vayan siguiendo la charla y que lo vayan rellenando a la vez. Entonces hay unas cuatro cinco preguntas que son tipo verdadero falso, pero luego hay dos que es para que ellos escriban. Aunque sean cuatro líneas, pero que escriban, que piensen en estructuras de una frase en inglés y...<TLANG_Sp $>$

R: <TLANG_Sp> Como que han atendido también <TLANG_Sp> .

M1: <TLANG_Sp>Sí, pero un poquito para que no sea todo tipo test <TLANG_Sp>.

R: <TLANG_Sp> Vale, y he estado mirando los horarios. Bueno, ahora ya las preguntas ya están todas. Los horarios que he visto cuando impartes el seminario, es de creo que de ocho y media a diez y media y de diez y media a doce y media. Es en las cuatro horas ies el mismo seminario que se repite dos veces? <TLANG_Sp>.

M1: <TLANG_Sp> Sí <TLANG_Sp>.

R: <TLANG_Sp> Porque por asistir solo a uno ese día y luego a otro día, porque es el diez y el docecreo que era, ¿no? <TLANG_Sp>

M1: 〈TLANG_Sp>Sí, lunes y miércoles <TLANG_Sp>

R: <TLANG_Sp > Claro, por eso, por elegir hora $\langle$ TLANG_Sp $>$. 
M1: <TLANG_Sp> Sí, - sí, es lo mismo, - es lo mismo. Lo que pasa que los desglobamos en cuatro grupos. $\mathrm{Y}-\mathrm{y}$ eso, pero, es, es el mismo seminario los cuatro que impartimos es el mismo seminario <TLANG_Sp>.

R: <TLANG_Sp> Y básicamente es pedirte si puedo asistir a la, - a la clase para observarla $<$ TLANG_Sp $>$.

M1: <TLANG_Sp > Claro <TLANG_Sp $>$.

R: <TLANG_Sp> Y lo que necesitaría es grabarla en audio, pero no es para analizar el inglés ni nada, es para ver el input que ellos reciben en inglés y luego ver cómo ellos responden <TLANG_Sp>.

M1: <TLANG_Sp> Vale, sí <TLANG_Sp>.

R: <TLANG_Sp> Entonces si ellos participan hablando, ver las lenguas de interacción que utilizan entre ellos $\langle$ TLANG_Sp $>$.

M1: <TLANG_Sp> Entre ellos. Sí ningún problema <TLANG_Sp>.

R: <TLANG_Sp> Y luego ya te daré una <TLANG_Sp> <TLANG_Eng > consent form <TLANG_Eng> <TLANG_Sp> para que la firmes como que me permites asistir y grabar el seminario en audio y eso es todo $\langle$ TLANG_Sp $>$.

M1: <TLANG_Sp>Vale, perfecto $\langle$ TLANG_Sp $>$.

R: <TLANG_Sp> Muchísimas gracias por reunirte conmigo y por aceptar participar en el estudio, de verdad <TLANG_Sp〉. 


\section{APPENDIX I (f): Medicine (M2)}

M2: <TLANG_Sp> Vale, te explico un poco como está cosa. En, en la asignatura de cuarto, que es Toxicología y Medicina Legal no se dan clases en inglés <TLANG_Sp>.

R: <TLANG_Sp> Vale $<T L A N G \_S p>$.

M2: <TLANG_Sp> Porque el Plan de Estudios nuevo, que es el del 2017 eh: no llegará a cuarto hasta dentro de dos años. Es decir, el Plan de Estudios ahora mismo nuevo en el que están descritas cuáles son las asignaturas que tienen que ser en inglés o parte de las asignaturas en inglés es, - es el Plan nuevo, no...El Plan antiguo en esa asignatura no era, no había inglés. Entonces hasta dentro de dos años, esa asignatura no llegará al Plan nuevo. Por lo tanto no se hace nada en inglés $\langle$ TLANG_Sp>.

R: $\langle$ TLANG_Sp $>$ Vale $\langle$ TLANG_Sp $>$.

M2: <TLANG_Sp> La otra asignatura es una de segundo, que es Antropología y Evolución <TLANG_Sp>.

R: <TLANG_Sp>Sí <TLANG_Sp>.

M2: <TLANG_Sp> Y este será el primer año, porque el Plan nuevo acaba de llegar a segundo. Este es el primer año en el que, en teoría, deber haber clases en inglés. Entonces yo el año pasado hablé con los estudiantes y son bastante reacios a que se les, - se les impartan clases en inglés. Entonces no sé qué hacer. Realmente no sé qué hacer. Eh: no me lo he preparado todavía porque es el primer año que lo voy a hacer y entonces...A lo mejor había pensado que podría hacer un seminario, uno de los seminarios en inglés o, aparte de las clases teóricas. Pero no estoy seguro, - no estoy seguro de qué hacer realmente. Te quería preguntar de hecho, qué es lo que hace la gente $<$ TLANG_Sp>.

R: 〈TLANG_Sp> ¿En qué? ¿En clase? <TLANG_Sp>

M2: <TLANG_Sp> En este tipo de casos. O sea, ¿la gente de verdad da las clases en inglés? <TLANG_Sp>.

R: <TLANG_Sp> Por lo que yo he podido hablar con profesores ya porque he ido teniendo entrevistas, eh, o no se dan o dan uno o dos talleres, un día o dos días y ya. No hay más inglés. Porque por ejemplo, hablé con una profesora de Historia, y en Historia 
no dan inglés, los envían a una conferencia o si no los pueden enviar a una conferencia que sería en inglés, les pasan un artículo en inglés y tienen que hacer unas actividades. Eso es el inglés que se da en Historia, por ejemplo. Luego hablé también con profesores de Enfermería y una chica da un taller un día, que ya lo ha dado y ya está, y luego otra chica sí que da una o dos clases más en inglés. Pero en cuarto hay una profesora que no lo da porque también da un artículo, pero los alumnos no quieren tampoco, como no quieren pues no se da $\langle$ TLANG_Sp $>$.

M2: <TLANG_Sp> Es que ese es el problema. Entonces yo supongo que sí que lo haré, que sí que... uno de los dos seminarios que tengo con ellos en, - en el segundo semestre de esta asignatura de segundo sí que lo daré en inglés <TLANG_Sp>.

R: $\left\langle\right.$ TLANG_Sp $>$ Vale $<T L A N G \_S p>$.

M2: 〈TLANG_Sp> Entonces puedes venir sin problema <TLANG_Sp>.

R: Sí, cuando te lo planifiques sería decirme "Mira, Lucía, será este día a tal hora". Entonces yo me planifico y voy.

M2: <TLANG_Sp> Sí, y además como son cuatro grupos, cuatro veces. Vienes al grupo que mejor te venga y ya está o vienes a los cuatro grupos, o a dos o a tres <TLANG_Sp>.

R: <TLANG_Sp>Claro, tú me dices los seminarios son tal día y a tal hora y yo miro disponibilidad $<$ TLANG_Sp $>$.

M2: <TLANG_Sp> Son todos iguales, entonces con que vengas a uno, al que mejor te venga vienes, lo que quieras. Pero ese es el problema, luego veo que es muy difícil de evaluar. Si es un seminario, ¿cómo evalúas el seminario? Porque hacer un examen y tal, pero: se quejan, - se quejan <TLANG_Sp>.

R: <TLANG_Sp>Ya: <TLANG_Sp>.

M2: <TLANG_Sp>Y yo se lo noto porque una de las cosas importantes también es que ellos participen. Entonces en la asignatura de, de X, de inglés de primero yo doy, yo doy un, un seminario lo doy yo. Eh y lo doy en inglés para, para su grupo, cuatro veces. Y se supone que ellos tienen que, cuando acaba, tienen que participar y hacerme una pregunta. Uff, es imposible, - es imposible. Entonces, sí, hay pues tres o cuatro que 
acaparan la conversación. $\mathrm{O}$ porque han ido a un colegio inglés, británico, americano porque tienen muy buen nivel de inglés y hay otros que - que no rompen el hielo. O sea es imposible que, que se lancen. Entonces claro, obligar a la gente a, me tienes, - tienes que hablar en inglés es un poco violento en clase y se ponen..., son muy tímidos, están en primero $<$ TLANG_Sp>.

R: <TLANG_Sp>Claro, sí <TLANG_Sp>.

M2: <TLANG_Sp>Si a lo mejor fuera en quinto de medicina, dices "bueno, ya" $\langle$ TLANG_Sp $>$.

R: $\langle$ TLANG_Sp $>$ Se lo plantean $\langle$ TLANG_Sp $\rangle$.

M2: <TLANG_Sp> Pero el primer semestre y además de primero: Tienen todavía...No conocen bien a los demás y en público, les cuesta mucho, - mucho <TLANG_Sp $>$.

R: <TLANG_Sp> Yo es que a mí en este caso lo que se me ocurre son utilizar las apps estas para...Por ejemplo una de cuestionarios que es Kahoot, ponerlos en grupo a ver si se animan más a contestar <TLANG_Sp>.

M2: <TLANG_Sp> Pero claro yo no quiero eso, yo lo que quiero es que se suelten, - se suelten en clase y que hagan aunque sea una frase, una pregunta. $\mathrm{Y}$ es dificilísimo. Y en lugar de tener a todos haciendo una pregunta, al final lo que pasa es que tres hacen un montón de preguntas $\langle$ TLANG_Sp $>$.

R: <TLANG_Sp> Ya <TLANG_Sp>.

M2: <TLANG_Sp> Y tampoco es eso lo que quiero. ¿Sabes lo que te quiero decir? Entonces es muy difícil <TLANG_Sp>.

R: <TLANG_Sp>O puedes decirles que el nivel no se lo vas a evaluar, que solo vas a tener en cuenta la participación $\langle$ TLANG_Sp $>$.

M2: <TLANG_Sp> Si se lo digo. Pero este año lo intentaré otra vez. Pues eso, eso es lo que... $<$ TLANG_Sp $>$.

R: <TLANG_Sp> Entonces solo sería el segundo semestre <TLANG_Sp>.

M2: <TLANG_Sp> Es el segundo semestre, en la asignatura de segundo $<$ TLANG_Sp>. 
R: <TLANG_Sp> ¿No das ninguna más? <TLANG_Sp>.

M2: <TLANG_Sp> No. Y entonces a lo mejor puedes hablar con M3 <TLANG_Sp>.

R: <TLANG_Sp> Sí, hablé con M3. También iré el segundo semestre a una de sus clases $<$ TLANG_Sp>.

M2: 〈TLANG_Sp> ¿Ella lo hace también en el segundo semestre? <TLANG_Sp>.

R: <TLANG_Sp> Sí, porque ya hablé con ella el año pasado para ver si este año a ver qué tal, y claro me puse en contacto con ella y me dijo "No, la asignatura es en el segundo semestre". Porque claro, yo como vi las asignaturas que impartía ella con el Plan nuevo, habían cambiado asignaturas con enseñanza en inglés. Entonces ya, digo "voy a ponerme en contacto con ellos porque dan varias asignaturas" <TLANG_Sp>.

M2: <TLANG_Sp> Yo eh claro, el primer plan de estudios no había ningún profesor contratado. Entonces los cinco créditos anuales o no, - los, - sí creo que son cinco créditos anuales los que se tienen que dar en inglés quitando primero, se pusieron asignaturas a voleo antes de que se supiera qué profesores había contratados. Entonces nadie dio las clases en inglés. O sea, estaba hecho al revés, tú tienes que poner las clases en inglés cuando tienes profesorado adecuado. Pero claro, como no había profesorado y había que hacer el plan de estudios se pusieron estas asignaturas y luego se vio que no. Excepto una que un año, una asignatura de cuarto que es de enfermedades infecciosas, ese profesor sí que dio las clases en inglés, el, - un, - uno de los años, y: un desastre, un desastre <TLANG_Sp>.

R: <TLANG_Sp> Hombre, es que de no dar nada a de repente... <TLANG_Sp>

M2: <TLANG_Sp> Además dio veinte horas de teoría y tenían que ser dos créditos y justamente él los dos créditos que tenía en esa asignatura eran de clases de teoría y fue un fracaso total. Muchos de los estudiantes, alguno de los estudiantes dijo "bueno, ya era hora de que alguno diera las clases en inglés de verdad. Hemos tenido que llegar a cuarto para que deis las clases en inglés". Pero claro, el nivel, la gente siempre cree que tien... ¿sabes? Porque ha estado un año en Estados Unidos, se cree que tiene nivel y no $\langle$ TLANG_Sp>

R: <TLANG_Sp> Se creen que tienen nivel, pero claro, el problema es que el inglés médico es muy específico <TLANG_Sp>. 
M2: <TLANG_Sp>Ya, da igual. Pero tú tienes que tener una... <TLANG_Sp>.

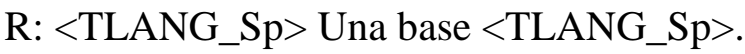

M2: <TLANG_Sp> Una base y tienes que improvisar y tienes que responder preguntas. Y es... - hizo el ridículo. Por lo que me dije... - dijeron muchos estudiantes, el profesor hizo el ridículo. Porque claro, hay muchos estudiantes que saben mucho más que él. ¿Sabes lo que te quiero decir? Entonces hizo el ridículo. Y luego en la evaluación lo crucificaron, o sea era un - una persona que sacaba entre siete y ocho cada año y ese año sacó un dos. Entonces al año siguiente me dijo "X, ya no voy a dar las clases en inglés, nunca más" <TLANG_Sp>.

R: $\left\langle\right.$ TLANG_Sp $>$ Se rindió $<T L A N G \_S p>$.

M2: <TLANG_Sp> Claro. Entonces veremos. Yo sí que voy a hacer algo en inglés este año. Entonces te lo diré <TLANG_Sp>.

R: <TLANG_Sp > Vale <TLANG_Sp $>$.

M2: <TLANG_Sp> Pero claro, en teoría tengo que dar dos créditos en inglés en esa asignatura.

R: <TLANG_Sp> Vale

M2: <TLANG_Sp> O yo o quien sea, el profesor que imparta esa asignatura. Yo lo veo inviable. Es que no, - no. No lo sé, tú lo que piensas, pero yo lo veo... $\langle$ TLANG_Sp $>$.

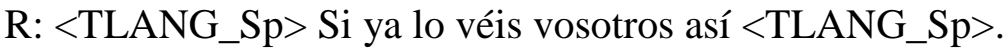

M2: <TLANG_Sp> Yo veo que se me van a quejar, se me van a quejar. Al final la gente, pues recurre a darle las diapositivas en inglés <TLANG_Sp>.

R: <TLANG_Sp>Sí, eso también me lo han comentado <TLANG_Sp>.

M2: <TLANG_Sp> Y eso no es, - eso no es <TLANG_Sp>.

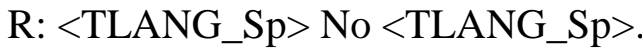

M1: 〈TLANG_Sp> Leer inglés ya saben $\langle$ TLANG_Sp $>$.

R: <TLANG_Sp>Sí, leer sí <TLANG_Sp>. 
M2: 〈TLANG_Sp> Leer se defienden todos $\langle$ TLANG_Sp $>$.

R: <TLANG_Sp> Lo que es participar no: porque como en el instituto ya no, - no se habla, porque no se practica $\langle$ TLANG_Sp>.

M2: <TLANG_Sp>Claro, el problema es que incluso escuchar el noventa por ciento de la clase yo sé que cuando hablo en inglés me sigue. El problema ya es que ellos: hablen. Les cuesta muchísimo <TLANG_Sp>.

R: <TLANG_Sp>Ya $<$ TLANG_Sp $>$.

M2: <TLANG_Sp> Muchísimo <TLANG_Sp>.

R: <TLANG_Sp> Y luego, unas preguntas que te quería hacer <TLANG_Sp>.

M2: <TLANG_Sp>Sí <TLANG_Sp>.

R: <TLANG_Sp > A ver $<$ TLANG_Sp $>$.

M1: <TLANG_Sp> Dime <TLANG_Sp $>$.

R: <TLANG_Sp> Cuántos créditos corresponden a la enseñanza en inglés en esta asignatura ya me lo has dicho, las dificultades que presenta el alumnado también, porque es eso, que no $\langle$ TLANG_Sp $>$.

M2: <TLANG_Sp> Yo uno de los problemas que veo es que del, - de lo que, de las asignaturas que - que tenemos en primero, por ejemplo, eh más o menos todos los estudiantes que entran en Biología tienen un nivel parecido de Biología. Unos a lo mejor en el instituto lo han hecho mejor, otros peor, pero...O de Bioquímica o de Fisiología, incluso de Anatomía, pero de ¿inglés? La diferencia es abismal. O sea, la gente entra en primero, hay gente que sabe muchísimo, más que el profesor y hay otros que no saben ni decir nada. Ese es uno de los problemas que veo yo con el inglés, que el nivel de los estudiantes es muy - muy - muy diferente. Entonces, claro ¿cómo...? $\langle$ TLANG_Sp>.

R: <TLANG_Sp> Claro, no es homogéneo el grupo <TLANG_Sp>.

M2: <TLANG_Sp> No es homogéneo, nada homógeneo el grupo <TLANG_Sp>. 
R: <TLANG_Sp> Vale, y luego otra pregunta era ¿qué dificultades encuentras tú como profesor a la hora de impartir las clases en inglés? <TLANG_Sp>.

M2: <TLANG_Sp> Nada, yo no tengo ningún problema. Yo el problema que tengo es por ellos, no por mí. O sea, a mí me sabe mal. Es como si...yo por ejemplo. Yo tengo un veinticinco por ciento de la clase que son de fuera de la Comunidad Valenciana. Entonces: y: incluso: de Cataluña no hay nadie y de Baleares tampoco. Claro, yo podría

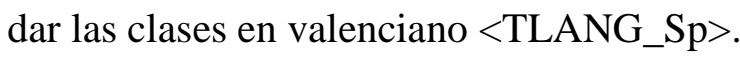

R: <TLANG_Sp> En valenciano, sí <TLANG_Sp>.

M2: 〈TLANG_Sp> ¿Tendría algún problema en dar las clases en valenciano? No, pero me sabe mal por el veinticinco por ciento de gente que dice "oye" <TLANG_Sp>.

R: <TLANG_Sp> No se enteran $\langle$ TLANG_Sp $>$.

M2: 〈TLANG_Sp> ¿Entiendes lo que quiero decir? <TLANG_Sp>.

R: <TLANG_Sp>Sí, - sí, - sí <TLANG_Sp>.

M2: <TLANG_Sp> Pues lo mismo con el inglés. Es decir, si, - si es una asignatura de inglés, pues claro, tiene que ser en inglés. Pero si es una asignatura en la que estoy dando, yo que sé, la evolución de la rama de los homínidos, del, - del linaje de homo sapiens, si lo doy en inglés habrá gente que no se entera, que desconecta totalmente $<$ TLANG_Sp $>$.

$\mathrm{R}:\langle$ TLANG_Sp $\rangle$ Claro $\langle$ TLANG_Sp $\rangle$.

M2: <TLANG_Sp> Y me sabe mal. Ese es el único reparo que yo tengo $\langle$ TLANG_Sp $>$.

R: <TLANG_Sp> Que no se enteran y que les va a costar el doble luego $\langle$ TLANG_Sp>.

M2: <TLANG_Sp > Claro <TLANG_Sp >

$\mathrm{R}:\left\langle\mathrm{TLANG} \_\mathrm{Sp}\right\rangle$ Sacarse la asignatura $\langle\mathrm{TLANG}$ _Sp $\rangle$.

M2: <TLANG_Sp> Y luego hay quien dice "pues ya no vengo más a clase porque..." $<$ TLANG_Sp>. 
R: $\langle$ TLANG_Sp $>$ Se deprimen $\langle$ TLANG_Sp $>$.

M2: <TLANG_Sp>Claro, se, - no: Ya es difícil que vengan a clase, sobre todo a partir de tercero, cuarto que empiezan a, a estudiar más y se quedan en casa como para encima dar las clases en inglés. Les desmotivas más $\langle$ TLANG_Sp $>$.

R: <TLANG_Sp>Claro, es que si se dan los primeros cursos que es cuando la asistencia sería más...<TLANG_Sp>.

M2: <TLANG_Sp> Claro, cuando la asistencia es más alta pero también les estás desmotivando. En segundo cada vez viene menos gente a clase. Si encima lo das en inglés se van a borrar definitivamente, nos quedamos allí cuatro gatos:: O sea, ese es el reparo que yo tengo $\langle$ TLANG_Sp $>$.

R: <TLANG_Sp> Hmm pero bueno, también tienen que saber que la investigación luego está en inglés <TLANG_Sp>.

M2: <TLANG_Sp> No, totalmente. Por eso yo prefiero eh: darles, - dar las sesiones que doy en inglés, darlas en seminarios, prácticas que son obligatorias, son de asistencia obligatoria $<$ TLANG_Sp $>$.

R: <TLANG_Sp>Vale <TLANG_Sp $>$.

M2: <TLANG_Sp> Pero yo sé que ahí va a haber gente que va a desconectar. Clack. Un porcentaje pequeño de la clase $\langle$ TLANG_Sp $\rangle$.

R: <TLANG_Sp> Va para firmar <TLANG_Sp>.

M2: <TLANG_Sp> Y ya está <TLANG_Sp>.

R: <TLANG_Sp>Vale. Y luego, por ejemplo, es que claro, se supone... Materiales que se suelen entregar, pero me has dicho que harás un seminario, entonces...<TLANG_Sp>.

M2: <TLANG_Sp>Sí, me prepararé un seminario y ya está <TLANG_Sp>.

R: <TLANG_Sp> Y bueno, luego tareas que suelen realizar. ¿Hay algún tipo de tarea que les vayas a pedir en inglés? O sea, ¿hacer alguna reseña o algo del taller? $<$ TLANG_Sp>. 
M2: <TLANG_Sp> Pues a lo mejor les hago el, los, o sea, después del seminario, a veces paso un cuestionario cortito de diez preguntas tipo test como máximo. Pues a lo mejor eso lo hago en inglés. Ellos lo tienen que hacer allí y me lo devuelven en el mismo, en el momento <TLANG_Sp>.

R: <TLANG_Sp> Vale, para ver que se han enterado de algo $\langle$ TLANG_Sp $>$.

M2: <TLANG_Sp > Claro <TLANG_Sp $>$.

R: <TLANG_Sp>Vale. Pues muchísimas gracias por tu tiempo, por tu disposición a participar y por permitirme asistir a tu seminario $<\mathrm{TLANG \_ Sp}>$. 


\section{APPENDIX I (g): Medicine (M3)}

R: <TLANG_Sp> Buenos días, X. Como te comenté por correo, el objetivo de mi tesis es observar cómo se implementa la política lingüística de la universidad en el aula. En concreto me centro en analizar las asignaturas de contenido de diferentes disciplinas, ya sea Ciencias de la Salud o Humanidades, que se imparten total o parcialmente en inglés. Para ello, necesitaría asistir un día a clase y observar cómo se utiliza el inglés y cómo responden los alumnos al input que reciben y su actitud hacia el uso de esta lengua en el aula. Por lo tanto, utilizaría una grabadora para tener en audio muestras sobre la producción oral de todos aquellos que se encuentren en el aula. Con la transcripción de estos audios crearía un corpus lingüístico que será el instrumento con el que trabajaría para llevar a cabo mi estudio <TLANG_Sp>.

M3: <TLANG_Sp> Perfecto, por mí no habría ningún problema. Pero déjame comentarlo primero con mis alumnos por si acaso no estuvieran de acuerdo en que los graben $<$ TLANG_Sp>.

R: <TLANG_Sp> Por supuesto. Por eso mismo, también quería mencionarte que he diseñado unas <TLANG_Eng> consent forms <TLANG_Eng> en las que el profesorado firmaría su aceptación para participar en el proyecto. Y en caso de que hubiera alumnos que no quisiesen participar, sus intervenciones no se transcribirían $\langle$ TLANG_Sp>.

M3: <TLANG_Sp> Muy bien, pues se lo comentaré y te comunicaré su decisión. Pero no creo que haya ningún problema $\langle$ TLANG_Sp $>$.

R: <TLANG_Sp> Vale. Pues continuando con las preguntas de la entrevista: ¿en qué semestre se da la asignatura? <TLANG_Sp>

M3: <TLANG_Sp> Pues verás, la asignatura que yo imparto es una asignatura anual. Este es el primer año en el que se supone que hay cierto número de créditos en inglés en esta asignatura, así que todavía no tengo muy claro que es lo que haré porque tengo que pensarlo bien. No obstante, en años anteriores se ha trabajado por proyectos en asignaturas de segundo y cuarto, así que seguramente trabajarán en inglés en algunos seminarios. Si quieres a principios del año que viene, me escribes un correo y te confirmo cuándo serán los seminarios en inglés, aunque seguramente serán en el segundo semestre $<$ TLANG_Sp>. 
R: <TLANG_Sp> Muchísimas gracias, pues sobre septiembre octubre te enviaré un recordatorio y ya me confirmas las fechas en las que se harán. Y en cuanto a los créditos, ¿sabes cuántos corresponden a la enseñanza en inglés? <TLANG_Sp>

M3: <TLANG_Sp> Pues ahora mismo no sabría decirte, posiblemente no llegue a un crédito, puede que cero con ocho. Pero supongo que podás comprobarlo en el SIA $\langle$ TLANG_Sp>.

R: <TLANG_Sp>Vale, intenté comprobarlo en el SIA y no lo encontré, pero volveré a mirarlo por si acaso. Otra pregunta sería: ¿qué dificultades crees que presenta el alumnado? <TLANG_Sp>.

M3: <TLANG_Sp> Principalmente la participación. Hay alumnos que llegan con muy buen nivel de inglés y otros no tanto, y eso puede observarse perfectamente en el aula ya que los alumnos con más nivel son los que más participan o intentan interactuar, mientras que el resto habla o pregunta en castellano <TLANG_Sp>.

R: 〈TLANG_Sp> ¿Qué dificultades tiene el profesorado o qué dificultades has tenido tú como profesora? Ya sea encontrar material o preparar las clases <TLANG_Sp>.

M3: <TLANG_Sp> Ninguna. Yo estudié la carrera de Medicina en Escocia, por lo que a mí me resulta más fácil dar las clases en inglés ya que estoy más familiarizada con la terminología y todo el material disponible en la web con respecto a los últimos estudios en medicina está en inglés $<T L A N G \_S p>$.

R: <TLANG_Sp> Entonces, ¿los materiales que se suelen entregar o facilitar a los alumnos son artículos? <TLANG_Sp>

M3: <TLANG_Sp> Artículos en inglés principalmente ya que toda la documentación del área de ciencias de la salud la podrás encontrar en inglés. Y también se les comaprten enlaces a páginas web de interés a través del aula virtual <TLANG_Sp $>$.

R: <TLANG_Sp> Muy bien. Y ya por último, ¿qué tareas se suelen entregar? ¿Qué tareas en inglés les soléis pedir a los alumnos? <TLANG_Sp>.

M3: <TLANG_Sp> La asignatura en sí se imparte íntegramente en castellano, pero para cumplir con los créditos establecidos en lengua extranjera se llevan a cabo seminarios. En este caso todavía tengo que pensar el enfoque que quiero darle, en asignaturas de 
APPENDIX I (g): Medicine (M3)

años anteriores se les ha pedido hacer la realización de pósters o presentaciones en inglés sobre un tema de investigación médica de su elección <TLANG_Sp>. 


\section{APPENDIX I (h): Nursing (N1)}

R: <TLANG_Sp> Te explico primero lo que...<TLANG_Sp>

N1: <TLANG_Sp> Vale <TLANG_Sp>

R: <TLANG_Sp> Vale. Pues mira, eh con mi tesis doctoral lo que yo trato de hacer es analizar las asignaturas de contenido que se imparten en inglés en diferentes grados del área de humanidades y ciencias de la salud, en concreto en historia y patrimonio, medicina y enfermería. Para ello, bueno, necesito grabar en audio la sesión que se les da en inglés y así analizar cómo responden ellos ante el <TLANG_Sp> <TLANG_Eng> input <TLANG_Eng> <TLANG_Sp> que reciben, es decir, qué lenguas de interacción utilizan para comunicarse con el profesor y con sus compañeros. Además, también necesitaría que contestasen dos cuestionarios, uno que se divide en dos partes y que trataría sobre su experiencia y satisfacción con asignaturas impartidas con el enfoque AICLE, y otro sería un <TLANG_Sp> <TLANG_Eng> placement test <TLANG_Eng> <TLANG_Sp> para observar cómo en base al nivel que tienen participan en clase en inglés o si en cambio, interactúan en castellano o en valenciano. En eso consiste el proyecto $<$ TLANG_Sp>.

N1: <TLANG_Sp> Vale <TLANG_Sp>.

R: <TLANG_Sp > Pues pasamos a las preguntas si te parece $<$ TLANG_Sp $>$.

N1: <TLANG_Sp>Vale <TLANG_Sp>

R: <TLANG_Sp> Eh a ver. ¿Cuántos créditos corresponden a la enseñanza en inglés de, - de esta asignatura? <TLANG_Sp>

N1: 〈TLANG_Sp> ¿Cuántas horas te diría? Porque créditos son seis horas $\langle$ TLANG_Sp>.

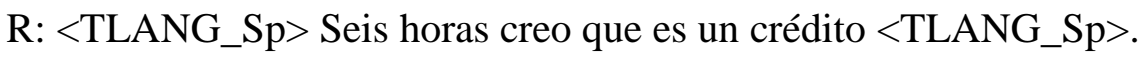

N1: 〈TLANG_Sp> ¿Un crédito? $\langle$ TLANG_Sp>

R: <TLANG_Sp> O no llega a crédito. No estoy segura $<$ TLANG_Sp $>$.

N1: $<$ TLANG_Sp $>$ Seis horas de laboratorios, o sea... $<$ TLANG_Sp $>$.

R: <TLANG_Sp> Vale <TLANG_Sp>. 
N1: <TLANG_Sp> Menos de un crédito porque la asignatura tiene nueve créditos $\langle$ TLANG_Sp>.

R: 〈TLANG_Sp> Vale, pues a lo mejor es casi un crédito, cero con cinco o algo así $\langle$ TLANG_Sp $>$.

N1: <TLANG_Sp> Sí, eso es <TLANG_Sp>.

R: 〈TLANG_Sp> ¿Qué dificultades crees tú que presenta el alumnado? <TLANG_Sp>.

N1: <TLANG_Sp> Bueno, una dificultad sería la vergüenza que tienen de hablar en público, otra dificultad que muchos no tienen nivel. Solo muy pocos tienen algo de nivel. Y eso, vergüenza y que no tienen nivel <TLANG_Sp>.

R: <TLANG_Sp> Entonces ellos no se ven capacitados como para afrontar en una clase en inglés $<$ TLANG_Sp>.

N1: <TLANG_Sp> Claro <TLANG_Sp>.

R: <TLANG_Sp>Y las actividades que tú les propones, ¿son receptivos a la hora de hacerlas o están un poco así como que no...? <TLANG_Sp>

N1: <TLANG_Sp> Hombre, se quejan, - se quejan muchísimo. Sobre todo los que tienen menos nivel, que tienen más vergüenza, pero, - pero bueno, se quejan, sí $\langle$ TLANG_Sp>.

R: <TLANG_Sp>Y ¿qué dificultades ves tú como profesora? <TLANG_Sp>.

N1: <TLANG_Sp> Pues eso, el nivel. No tienen un buen nivel de inglés y: entonces no tienen buen nivel y están desmotivados porque no tienen nivel y parece que no entiendan que se..., - o sea, yo lo único que les digo es que en mi asignatura hay seis horas de inglés y se lo repito, miradlo en la guía docente. O sea, para que lo entiendan, que no me lo estoy inventando. Pero, y, entonces bien, pero para ellos es desmotivación, vergüenza y que no tienen nivel y... $<$ TLANG_Sp $>$.

R: <TLANG_Sp> Y tú como profesora, ¿tienes fácil acceso a los materiales? $\langle$ TLANG_Sp>. 
N1: <TLANG_Sp>Sí, a ver. Yo es que estudié en Inglaterra, entonces para mí, yo me lo sé mejor en inglés, digamos. Yo no tengo ningún problema en encontrar material $\langle$ TLANG_Sp>.

$\mathrm{R}:<T L A N G \_S p>$ Es que hay veces que depende del profesor puede que sea más difícil encontrar materiales que se adapten a la asignatura o la especialidad <TLANG_Sp>.

N1: <TLANG_Sp> No, pero yo lo mío ya lo tengo en inglés <TLANG_Sp>.

R: <TLANG_Sp>Y luego los materiales o lo que que tú sueles trabajar en clase, si quieres cuéntame un poco qué es lo que haces <TLANG_Sp>.

N1: 〈TLANG_Sp> ¿Qué es lo que hago? Pues a ver, tengo cada año, pues según lo que me apetece hago diferentes talleres, porque son laboratorios <TLANG_Sp>.

R: <TLANG_Sp > Hm <TLANG_Sp>.

N1: <TLANG_Sp> Entonces, por ejemplo, este año los que voy a hacer es a) uno sobre la epidural hemos hecho, como es la asignatura de materno, mi asignatura. Eh: pues les digo que busquen artículos, un artículo que encuentre beneficios sobre la epidural y un artículo que encuentren inconvenientes en la epidural. Los artículos tienen que ser en inglés, tiene que ser de, - de una fuente válida, evidentemente y de los últimos cinco años. Entonces uno a uno me tienen que buscar artículos y me lo tienen que contar en clase, quiero que me digan de dónde vienen, los años y em que me lo resuman y que me digan beneficios e inconvenientes. Y luego, más o menos todos cuando hay como algo..., el primero me dice, pues ese, la <TLANG_Sp> <TLANG_Eng> maternal satisfaction <TLANG_Eng> incre... <TLANG_Eng> <TLANG_Sp> aumenta, ¿no? Entonces les digo: “¿alguien más ha encontrado esto?” Total, hacemos un poco así de debate. "Es que yo he encontrado... bueno, pero ¿quién ha encontrado lo contrario?" Hacemos un poco de debate de los artículos $\langle$ TLANG_Sp $>$.

R: <TLANG_Sp > Hmm <TLANG_Sp $>$.

N1: <TLANG_Sp>Y nada, luego eso sale en el examen. Ponemos junto todo lo que ha salido, ¿no? Beneficios e inconvenientes y sale en el examen. Porque el examen son ochenta preguntas, pero diez son en inglés y cuentan, o sea, no es que esas son optativas ni nada, cuentan. El primer año lo hice optativo, eran preguntas optativas, pero claro entonces venían a clase y peor aún. Y ahora como sí que entran, pues toman un poquito 
de atención, un poquito más. Luego, otra clase, bueno otra cosa que hago es que les doy unos folios de vocabulario específico, que es muy específico porque yo he trabajado allí y sé cómo se dicen las cosas mejor que lo que ponen en los libros de inglés, <TLANG_Sp> <TLANG_Eng > English for nursing <TLANG_Eng>

\section{R: $\langle$ TLANG_Sp $>$ Claro $<$ TLANG_Sp $>$.}

N1: <TLANG_Sp> Entonces para mí, - para mí, yo que he vivido la otra parte, yo que me quería ir y no lo tenía, para mí es súper valioso eso, ¿vale? Y para ellos es como "vale, bueno, sí, el folio". Es que me acuerdo, hay años..., me acuerdo no, sé que hay años que me voy a casa y no han cogido los folios [laughs] Y sale en el examen, pero ya como algunos no...les da igual $\langle$ TLANG_Sp $>$.

R: <TLANG_Sp>Sí <TLANG_Sp>.

N1: <TLANG_Sp> Y es que claro yo, me vuelvo loca. Aparte es, esas impresiones las hago yo, o sea, como para que no tengan que... $\langle$ TLANG_Sp>.

R: <TLANG_Sp> Es que encima que buscas tú el material $\left\langle T L A N G \_S p\right\rangle$.

N1: <TLANG_Sp>Sí, es que eso me cabrea y luego, bueno, eso también lo hacemos en alguna clase. Y otra cosa que hacen es que les digo que busquen en una cultura diferente a la occidental, a la nuestra, este laboratorio se llama cultura y mujer. Entonces tienen que buscar en una cultura diferente, un proceso vital de la mujer, eh cómo ocurre de manera diferente, ¿no? Digamos la men..., - cuando te baja la regla, el embarazo, el preparto, el postparto, eh la menopausia, qué ocurre en otra cultura. Entonces les digo que me lo cuenten. Y normalmente me hacen un PowerPoint. Y me lo pueden hacer entre una o dos personas y me lo cuentan en inglés, ¿no? Es en inglés. Y claro, todo el laboratorio pasa en inglés. Lo que pasa, que me encuentro muchas veces "no entiendo lo que me dices" Y luego todos se ríen. Porque yo habla alguien y no la entiendo. Y claro, la pobre está mal, pero claro es que si no la entiendo...Pero al final, como se conocen, que están en tercero, no están en primero, no es tan grave. Y: interactúamos un poco, pero claro, los que no saben hablar, hablan poco <TLANG_Sp>.

R: <TLANG_Sp > Sí <TLANG_Sp>.

N1: <TLANG_Sp> Pero luego si yo pregunto cosas es la vergüenza que tienen, ¿no? Y eso es en el de cultura y mujer, sí. Y ¿qué más hacemos ahí? Nada, eso. Y luego, el otro 
labo... Y bueno ahí también ahora este año como el PowerPoint se tiene que hacer entre una o dos personas <TLANG_Sp>

R: <TLANG_Sp>Sí <TLANG_Sp>.

N1: <TLANG_Sp> Les he dicho que si no quieren hacer presentación, que hagan otras cosas que no sean PowerPoint $\left\langle\mathrm{TLANG} \_\right.$Sp $>$.

$\mathrm{R}:\left\langle\mathrm{TLANG} \_\mathrm{Sp}>\right.$ Claro $\langle$ TLANG_Sp $>$

N1: <TLANG_Sp> Entonces hay algunos que van a hacer teatro, ¿vale? Porque así son más, son cinco máximo y hablan todos pero hablan menos. Entonces este me han dicho unos cuantos que van a hacer teatro, así que mejor, otro tipo de presentación que no es PowerPoint <TLANG_Sp>.

R: <TLANG_Sp>Claro, es que siempre lo mismo al final <TLANG_Sp>.

N1: <TLANG_Sp>Claro, entonces eso me parece bastante interesante. Y vale, y luego ¿qué más he hecho otros años? Porque eso es lo que he hecho este año. Bueno, luego hice como simulacros en inglés de la hemorragia postparto y de una cesárea de emergencia. Entonces les hice una explicación en inglés, con toda la medicación y con todas las cosas en inglés, y luego les tenía que examinar en inglés. Pero claro, me dieron tanta faena el día de la explicación y me dieron tanto tal, que luego la examinación fue en castellano. Eso fue el año pasado porque no..., digo "esto es que...". Para ellos ya, me daban demasiado problema y que no había satisfacción digamos, que me sentía yo mal porque veía que no había nada, ni motivación ni nada. Y entonces este año esa parte la vamos a hacer en castellano, o sea, directamente <TLANG_Sp>.

R: <TLANG_Sp> Hm. Bueno, esto era por tener una idea de lo que se hace en clase y para poder desarrollar la tesis necesitaría acompañarte a clase un día, al laboratorio en inglés, si te viene bien <TLANG_Sp>.

N1: 〈TLANG_Sp>Sí, eh: ¿quieres venir al de cultura y mujer? <TLANG_Sp>

R: <TLANG_Sp > Sí <TLANG_Sp>.

N1: <TLANG_Sp> A ver voy a mirar las fechas <TLANG_Sp $\rangle$. 
R: <TLANG_Sp> Y también necesitaría grabar la sesión en audio y pasarles dos cuestionarios si no te importa. La transcripción del audio será lo que me permitirá analizar las lenguas de interacción en el aula y cómo responden los alumnos a la clase de contenido impartida en una lengua extranjera, luego un cuestionario consiste en preguntas para ver si los alumnos han cursado asignaturas CLIL en otros años, si están contentos con la experiencia actual y qué es lo que saben de la política lingüística de la UJI. El otro cuestionario es un <TLANG_Sp> <TLANG_Eng> placement test <TLANG_Eng> <TLANG_Sp> para ver qué nivel se supone que tienen y si eso luego se corresponde con su participación en clase $\langle$ TLANG_Sp $>$.

N1: 〈TLANG_Sp> Vale, ningún problema $\langle$ TLANG_Sp>.

R: <TLANG_Sp>Y serían online, así si no hay tiempo suficiente para responder en clase, podrían hacerlo desde casa sin problema. Te enviaré los enlaces por correo y los puedes compartir en el aula virtual si quieres <TLANG_Sp>.

N1: $\langle$ TLANG_Sp $>$ Perfecto $\langle$ TLANG_Sp $>$.

R: <TLANG_Sp> Pues eso es todo, muchísimas gracias por querer colaborar. Me será de muchísima ayuda $<$ TLANG_Sp $>$. 


\section{APPENDIX I (i): Nursing (N2)}

N2: <TLANG_Sp> Vale, pues en la asignatura de fisiología, todo lo que son imágenes están en inglés, de tal manera que ehh como se les dice que poco a poco, es el primer curso $<$ TLANG_Sp>.

R: <TLANG_Sp>Claro <TLANG_Sp>.

N2: <TLANG_Sp>Se les dice que poco a poco van a tener que meterse en el campo de la investigación, que en fisiología hay muy poco de evidencia en castellano $\langle$ TLANG_Sp>.

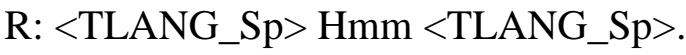

N2: <TLANG_Sp> Excepto los manuales traducidos. Si quieren tener evidencia e información eh novedosa, actualizada al respecto de fisiología van a tener que irse a publicaciones en inglés <TLANG_Sp>.

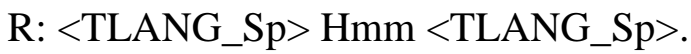

N2: <TLANG_Sp> Entonces empezar en primero metiéndoles clases en inglés de fisiología cuando ya les cuesta entender una hormona que se genera en el hipotálamo y actúa en el otro lado del cuerpo. Si eso ademas lo explicas en inglés <TLANG_Sp>.

R: <TLANG_Sp> No se enteran <TLANG_Sp>.

N2: <TLANG_Sp> No se enteran. Entonces, ¿cuál es la combinación que yo pensé? No sé si adecuadamente o no. Ponerles eh todas las imágenes en inglés de tal manera que eh tengan que eh los descriptores para poder hacer las búsquedas <TLANG_Sp>.

R: <TLANG_Sp > Hmm <TLANG_Sp $>$.

N2: <TLANG_Sp> Ir pronunciando inglês castellano, ¿vale? <TLANG_Sp>.

R: <TLANG_Sp > Hmm <TLANG_Sp>.

N2: <TLANG_Sp> Para que se queden con palabras, con términos que en castellano son nuevos para ellos y en inglés también $\langle$ TLANG_Sp $>$.

R: Las dos cosas a la vez, claro 
N2: <TLANG_Sp>Sí, entonces voy haciendo una especie de: posiblemente ya te digo que no sea lo mejor, combinación entre términos castellano inglés. En castellano, tal. En inglés, si buscáis, tendréis que utilizar el término <TLANG_Sp> <TLANG_Eng> length of stay, <TLANG_Eng > <TLANG_Sp > tiempo de estancia <TLANG_Sp $>$.

R: $\langle$ TLANG_Sp $>$ Hmm $<$ TLANG_Sp $>$.

N2: <TLANG_Sp> Pues tiempo de estancia es <TLANG_Sp> <TLANG_Eng> length of stay $<$ TLANG_Eng $>$. $<$ TLANG_Sp $>$ No podéis utilizar eh... $<$ TLANG_Sp $>$.

R: <TLANG_Eng > time of... $<$ TLANG_Eng $>$.

N2: <TLANG_Eng> Time of <TLANG_Eng> <TLANG_Sp> no sé qué $\langle$ TLANG_Sp>.

R: <TLANG_Sp>Claro, que sería traducción literal <TLANG_Sp>.

N2: <TLANG_Sp> Entonces de esa manera les voy introduciendo y luego en cuarto yo no tengo créditos en inglés, los tiene $\mathrm{X}$. Eh: pero los artículos que se leen obligatoriamente y que trabajan van en, - el mío va en inglés <TLANG_Sp>.

R: <TLANG_Sp $>$ Vale $<T L A N G \_S p>$.

N2: <TLANG_Sp>Y sistemáticamente todos los años <TLANG_Sp $\rangle$.

R: <TLANG_Sp>Y ella sí que imparte las clases en inglés, ¿no? <TLANG_Sp>.

N2: 〈TLANG_Sp> Ella imparte un laboratorio en inglés $\langle$ TLANG_Sp $>$.

R: 〈TLANG_Sp> Es que sería por intentar ponerme en contacto con ella $\langle$ TLANG_Sp $>$.

N2: <TLANG_Sp> Vale <TLANG_Sp>.

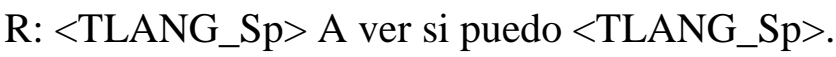

N2: <TLANG_Sp> Quien también imparte un laboratorio en inglés es X, en tercer curso que a lo mejor ahora la pillamos $\langle$ TLANG_Sp $\rangle$.

R: <TLANG_Sp > Vale <TLANG_Sp $>$.

N2: $\langle$ TLANG_Sp>iVale? $\langle$ TLANG_Sp $>$. 
R: <TLANG_Sp> Es que sería más que nada para yo asistir, sería grabar lo que - el oral que habla el profesor, la interacción con los alumnos y a partir de ahí yo ya ir elaborando mi tesis porque claro es de... - se basa tanto en comparar lo que es la facultad de ciencias, Medicina y luego Enfermería, y luego también con la carrera de Hstoria. Entonces hacer comparativa de humanas y ciencias, ver también el nivel de los alumnos y sería también pasarles pues seguramente un test de nivel para ver qué nivel es el que tienen los alumnos y luego un cuestionario para ver la satisfacción del estudiantado con la impartición de clases en inglés, solo es eso <TLANG_Sp>.

N2: <TLANG_Sp> Vale <TLANG_Sp>.

R: <TLANG_Sp> Entonces si se puede: me sería de gran utilidad si no pues... $\langle$ TLANG_Sp $>$.

N2: <TLANG_Sp> Vale, yo creo que sí, ellos están acostumbrados a colaborar cuando se les solicita: hombre si hacen un examen, si lo que vais a hacerles es un examen $\langle$ TLANG_Sp>.

R: <TLANG_Sp> No, no es examen tal cual, es un test para yo, para yo saber... <TLANG_Sp>

N2: <TLANG_Sp > El nivel <TLANG_Sp>.

R: <TLANG_Sp> Claro, se supone que es por ejemplo si hay de diez a veinte respuestas ehh bien, pues se supone que tienen un A2, de veinte a cuarenta tal, y a partir de ahí, sería contrastar el nivel que tienen los alumnos con luego las clases que ellos reciben en inglés, si tienen el nivel adecuado para luego...<TLANG_Sp>.

N2: $\langle$ TLANG_Sp $>$ Es que... $<$ TLANG_Sp $>$.

R: <TLANG_Sp > Ellos aprobar o no $\langle$ TLANG_Sp $>$.

N2: <TLANG_Sp> El problema es que eh eso es importante porque yo cuando empiezo fisiología, claro, eh, hay un grupo de estudiantes mayoritario, que sí que vienen de instituto $<$ TLANG_Sp>.

$\mathrm{R}:\left\langle\mathrm{TLANG} \_\mathrm{Sp}\right\rangle \mathrm{Hmm}\left\langle\mathrm{TLANG} \_\mathrm{Sp}\right\rangle$. 
N2: <TLANG_Sp> Y que presupones, presupones, que su nivel es elevado $\langle$ TLANG_Sp>

\section{R: $\langle$ TLANG_Sp $>$ Hm $<$ TLANG_Sp $>$}

N2: <TLANG_Sp> O por lo menos para poder entender una clase en inglés. Otros que incluso el inglés puede ser, la minoría, más elevado que el del profesor, que han estado estudiando en el... <TLANG_Sp>.

R: <TLANG_Eng > British School <TLANG_Eng>.

N2: <TLANG_Eng> British School <TLANG_Eng> <TLANG_Sp> o en donde sea, y dices "buah fenomenal". A este grupo se les podría impartir una fisiología, una anatomía en inglés <TLANG_Sp>.

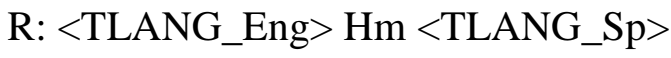

N2: <TLANG_Sp> Pero claro, tendrían que ser grupos específicos, vale, grupos de alto rendimiento. Eh: al resto no puedes. Y luego hay ese otro tanto por cien de pers..., que vienen de formación profesional, ehh ese veinticinco por ciento de gente más mayor, que es imposible, para ellos leer un artículo en cuarto curso en inglés. El otro día ya me decían: “¿me lo puedes pasar en castellano? Y yo: no, es que esta en inglés. Es que vas a hacer un TFG en dos días" <TLANG_Sp>.

R: $\langle$ TLANG_Sp $>$ Claro $<$ TLANG_Sp $>$.

N2: <TLANG_Sp> Es que lo necesitas, lo necesitamos como vosotros que sois de eh: inglés, no. A vuestro nivel no, hombre ojalá, ¿no? <TLANG_Sp>.

$\mathrm{R}:[$ laughs]

N2: <TLANG_Sp> A vuestro nivel, no <TLANG_Sp $>$.

R: $<$ TLANG_Sp $>$ Pero capaz de entender para elaborar... $<$ TLANG_Sp $>$.

N2: $\langle$ TLANG_Sp $>$ Exactamente $\langle$ TLANG_Sp $\rangle$.

R: <TLANG_Sp> Porque si solo la informacion así más actual está en inglés, tienen que saber entender, claro $\langle$ TLANG_Sp $>$. 
N2: <TLANG_Sp>Yo lo que puedo hacer es...si ahora X o X no están es ponerte en contacto con ellas mediante un correo $\langle$ TLANG_Sp>.

R: <TLANG_Sp>Vale <TLANG_Sp>.

N2: 〈TLANG_Sp> ¿Vale? Por si pudieras asistir a...porque yo no sé exactamente que día dan la docencia $<T L A N G \_S p>$.

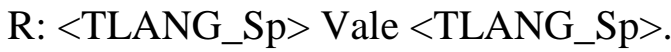

N2: 〈TLANG_Sp> En inglés <TLANG_Sp>.

R: <TLANG_Sp > Perfecto $<$ TLANG_Sp $>$.

N2: <TLANG_Sp> La docencia la dan aquí eh: delante $\langle$ TLANG_Sp $>$.

R: <TLANG_Sp>Vale <TLANG_Sp>.

N2: <TLANG_Sp> ¿Vale? <TLANG_Sp>.

R: <TLANG_Sp > Creo que ya he estado aquí en este edificio <TLANG_Sp $>$.

N2: <TLANG_Sp> Y ambas dos, creo que la dan en los laboratorios, tal cual $<$ TLANG_Sp>.

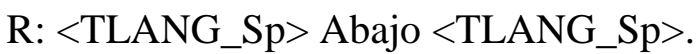

N2: <TLANG_Sp> En el sótano, ¿vale? No se me ocurre, ojala pudiéramos hacer esto en inglé pero esto supondría además que tuviéramos que traernos, mi nivel de inglés no es malo para leer, para poder mantener una conversación normal... <TLANG_Sp>.

R: <TLANG_Sp > Hm <TLANG_Sp $>$.

N2: <TLANG_Sp> Pero, ¿tengo el mismo nivel de inglés para poder impartir una clase de fisiología al nivel de castellano? La respuesta sincera es no <TLANG_Sp>.

R: $\langle$ TLANG_Sp $>$ Hm $\langle$ TLANG_Sp $>$

N2: <TLANG_Sp> Entonces tendríamos que traernos profesorado externo que pudiera impartir esas clases al nivel que exige el grado de enfermería <TLANG_Sp>.

R: Sí, - sí, son las carencias que hay <TLANG_Sp>. 
N2: <TLANG_Sp> Son las carencias que: hay porque tendrías que pillar a alguien que supiera de anatomía o de fisiología o de lo que fuera <TLANG_Sp>

$\mathrm{R}:\left\langle\mathrm{TLANG} \_\mathrm{Sp}>\mathrm{Hm}\left\langle\mathrm{TLANG} \_\mathrm{Sp}>\right.\right.$

N2: <TLANG_Sp> Que fuera enfermero, y que además viniera de una universidad eh: de habla inglesa <TLANG_Sp>

R: <TLANG_Sp> Hm. Vale. Yo, total sería asistir a las clases, sería grabar yo, ahí no participaría nada, solo es ya te digo, asistir y luego pasarles el test de satisfacción y luego el de nivel y ya está <TLANG_Sp>

N2: <TLANG_Sp> Vale <TLANG_Sp>.

R: <TLANG_Sp > Solo es eso <TLANG_Sp $>$.

N2: 〈TLANG_Sp> ¿Lo harías en los tres cursos? ¿En los cuatro cursos? $\langle$ TLANG_Sp>.

R: 〈TLANG_Sp> Yo si puedo asistir a las clases sí, si no, con dos cursos me sirve $\langle$ TLANG_Sp>.

N2: <TLANG_Sp> Vale <TLANG_Sp>.

$\mathrm{R}:$ TLANG_Sp> Con asistir a dos cursos tengo suficiente porque sería [comparar] dos cursos de enfermería, dos cursos de historia y dos cursos de medicina <TLANG_Sp>.

N2: Vale. Pues entonces podrías asistir a tercero y a cuarto

$\mathrm{R}:\langle$ TLANG_Sp $>$ Vale $<$ TLANG_Sp $>$.

N2: <TLANG_Sp> ¿Vale? Porque no me importa que vengas a fisiología, pero la clase se imparte en castellano y eso, las imágenes en inglés. A medida eso, les voy poniendo eh conceptos, palabras, eh um en inglés. Por ejemplo, en un ventilador no van a ver complianza van a ver <TLANG_Sp> <TLANG_Eng> compliance <TLANG_Eng>. <TLANG_Sp> Y en clínica no hablamos de complianza, hablamos de <TLANG_Sp> $<$ TLANG_Eng > compliance <TLANG_Eng>. <TLANG_Sp $>$ No hablamos de volumen inspiratorio, hablamos de volumen $\langle$ TLANG_Sp $\rangle$ 〈TLANG_Eng $\rangle$ tidal $<$ TLANG_Eng>. <TLANG_Sp> Y claro, dices ¿tengo palabras en castellano para eso? 
APPENDIX I (i): Nursing (N2)

Sí, pero es que cuando vayas a buscarlo, no lo encontrarás. Y así más o menos funcionamos $<$ TLANG_Sp $>$.

R: $\langle$ TLANG_Sp $>$ Vale $<$ TLANG_Sp $>$.

N2: <TLANG_Sp> Pues yo lo que puedo poner es en contacto con X y X y ya habláis sobre las fechas en las que se imparten los laboratorios <TLANG_Sp>.

N2: <TLANG_Sp> Perfecto, muchísimas gracias <TLANG_Sp>. 


\section{APPENDIX I (j): Nursing (N3)}

N3: <TLANG_Sp> Yo lo que veo es que desconocemos, todos. Ehh como colectivo universitario, no como profesorado, alumnado, gestores. Yo creo que todos tenemos una, una falta de información sobre el nivel del que partimos. Entonces, ¿qué ocurre? Que a mí me encanta el inglés. Bueno, yo creo que lo más bonito de todo esto es no tener barreras, ¿no? Y, y yo me considero una alumna de inglés. Pero sí que veo que en mi, en mi formación académica yo no tuve ningún tipo de input. Sí tuve una asignatura en primero de la carrera. No me preguntes lo que di. Vale, y yo soy muy reivindicativa a la hora de aprender lenguas a nivel peninsular. Porque yo tengo amigos fuera de España que hablan varios idiomas con fluidez. Y yo me cuesta comunicarme en valencià por ejemplo. Bueno, bueno, en mis lenguas las lenguas, las lenguas con las que yo vivo. Me cuesta comunicarme. Incluso en castellano me cuesta comunicarme. Digo, tengo un handicap ahí. Por qué la lengua es algo vivo claro, ¿no? Entonces yo parto de la base que cuando aparece la oportunidad de yo pertenecer a la universidad y estar de docente, veo que yo quería integrar el inglés en mis seminarios porque porque yo en la práctica asistencial utilizo el inglés todos los días. Nosotros el acceso de información más novedosa están en bases de datos que son anglófonas. Entonces si tú juntas, entonces si tú juntas juntas globalidad, juntas innovación y mi profesión es imposible excluir el inglés <TLANG_Sp>.

\section{R: <TLANG_Sp > Claro <TLANG_Sp $>$.}

N3: <TLANG_Sp> Vale. ¿Qué ocurre? yo soy una profesora que va a cuarto, y cuando los alumnos llegan a cuarto el cada alumno tiene un nivel <TLANG_Sp $>$.

R: <TLANG_Sp> Y empiezan así con primero y siguen así en cuarto <TLANG_Sp>.

N3: <TLANG_Sp> Entonces, yo también te quería preguntar a ti, ¿tú qué...? o sea, ¿tú qué piensas? Si tú piensas que algo está evolucinando desde que empezaste la carrera a hoy porque yo estoy perdiendo esa parte esa parte alumnado <TLANG_Sp>.

R: <TLANG_Sp> Claro, yo es que estudié como tal Filología Inglesa, entonces se ve todo en inglés bueno, excepto primero que tenemos algunas asignaturas en valenciano o en castellano. Es todo en inglés entonces ahí el input lo recibes constantemente. El tema es cuando ya he asistido a clases de historia, a clases de enfermería o de medicina, que en primero hay alumnos que tienen muy buen nivel y alumnos que no. No quieren 
hablar en inglés, les cuesta mucho participar. Hay algunos que los profesores les hacen solo actividades para que lean aunque solo sea leer para motivarlos de alguna manera. Yo también he aconsejado que a veces utilicen pues <TLANG_Sp> <TLANG_Eng> apps <TLANG_Eng> <TLANG_Sp> como Kahoot, que eso les gusta mucho $\langle$ TLANG_Sp>.

N3: <TLANG_Sp> A mí me encanta el Kahoot <TLANG_Sp>.

R: <TLANG_Sp> A mí también me gusta mucho porque lo utilizaban secundaria cuando hice mis prácticas, y luego en medicina lo he utilizado también. Y les encanta y dicen otro, - otro. Yo digo "hombre, no, ahora os centráis un poquito" y tal. Sobre todo lo utilizo para que desconecten y también repasen los contenidos que se han dado y tal $\langle$ TLANG_Sp>.

N3: <TLANG_Sp> Pero que depende mucho del contraste. Yo creo también. Vale, el seminario son el desfibrilador semiautomático y arritmias. Ahora te contaré como como la adecúo. Porque no lo hago, llevo cuatro años haciéndolo y he tenido que por el problema que tenemos el nivel de los alumnos. Esto es lo único con lo que se encuentran los alumnos, una vez el glosario y te voy a contar un poco la evolución porque esto está yo: me baso en lo que el año pasado hice, ¿vale? Súperfácil, súper, nada. ¿Vale? Imágenes. ¿Por qué lo hago así? Mira, el primer año solo les doy, digamos que solo les doy una parte trabajo, una parte. Si es sobre las arritmias rápidas o lentas, solo tienen la parte rápida, no les doy todo el trabajo hecho. ¿Por qué? Porque el que consigue algo es el que produce. Pero yo todavía no he llegado a que produzcan. Entonces, ¿cómo se gesta esto después de hacer yo el curso de de inglés para la enseñanza de la USE? ¿Lo conoces? <TLANG_Sp>.

R: $\left\langle\right.$ TLANG_Sp> No, - no lo conozco $<T L A N G \_S p>$.

N3: <TLANG_Sp> Es un inglés que es un curso que yo creo que de veinte horas que viniera que es para, - que es para, pues eso poner en contacto al profesorado que da o que tiene intención de dar clases en inglés, hablar de fortalezas y debilidades. Un poco, aparte de un foro, es un curso muy interesante sobre <TLANG_Sp> <TLANG_Eng> CLIL, <TLANG_Eng> <TLANG_Sp> el <TLANG_Sp> <TLANG_Eng> portfolio, $<$ TLANG_Eng> <TLANG_Sp> cierto tipo de herramientas, unas pinceladas. Entonces a partir de este foro hablando yo en el primer curso con ese grupo de gente nos, nos 
proponen en todos los cursos. Porque este curso es anual, entonces yo veo que a mi favor una cosa y es que yo utilizo para estudiar un simulador de arritmias [muestra el simulador de arritmias en el ordenador]. No lo encuentro. Es que este monitor es una herramienta libre, es una herramienta que está traducido al castellano y que a mí no me gusta esa traducción y que seguro que no la he hecho traductor <TLANG_Sp>.

R: <TLANG_Sp> Será automática, seguramente <TLANG_Sp>.

N3: <TLANG_Sp> ¿Vale? Y es un tipo de aprendizaje en el que el alumno puede en casa a jugar. Pero yo lo utilizo como aprendizaje. Entonces nosotros hablamos y tapamos, tenemos dos pantallas y nos dividimos en dos grupos. Antes lo hacía de otra manera porque porque a medida que pasan los cursos el alumno, no sé por qué no sé por qué motivo, a lo mejor es mi percepción, y es como si estuviera más disperso. Pero me da la sensación de que el grupo, si hago pequeños grupos, se me dispersa más. Entonces este año yo lo lo inicié como un trabajo de pequeño, grupo de tres. Ponemos una, ponemos una arritmia, ¿vale? Tapamos esto. Lo intentamos, pues eso, minimizar la pantalla. Claro, es muy rudimentario, pero bueno. Y ellos discuten en grupo ese tipo de ondas, ese tipo de segmentos y nos dan la solución. Primero describen y luego si saben el apellido <TLANG_Sp>.

R: <TLANG_Sp> Todo en inglés, ¿no? $\langle$ TLANG_Sp>.

N3: <TLANG_Sp> A ver el primer curso, todo en inglés. En segundo curso, mixto. Yo siempre he sido...Mira, yo siempre he creído en la lingüística, pero ahora tengo sobre el aprendizaje, como alumna, tengo algunas dudas porque veo que contextualmente mis grupos no acaban de captar la...No sé si es por falta de información, no sé si es por falta de base o porque tiene muchos estímulos y se distraen. Yo eso lo desconozco. Entonces yo no quería ir al mixto. No, nunca quiero ir al mixto. Es como ver una película y estar viendo los subtítulos. Pierdes ahí contenido, pero me ha tocado ir porque desconozco el nivel del grupo y veo que el grupo se desconecta si no entiende. También he hablado con otros compañeros que me dicen que también va por hornada. Que hay cursos que están más comprometidos, que tienen más nivel o por el motivo que sea tienen más destrezas, ¿vale? Entonces yo quiero pensar que esto que parece una tontería, pero que al alumno le cuesta años aprender, también tiene que ver algo. Entonces el - la clase originariamente se planteó como "hablamos de las dudas del PowerPoint que os habéis revisado en casa”. Yo hablé con X la responsable de inglés del CAL porque yo quería 
medir el nivel previo del alumnado para saber de qué grado partía para adaptar el material. Al principio me ofreció, - me ofreció la posibilidad de hacer algún tipo de evaluación pero ella me dijo "es que no existe ninguna que esté validada". Porque yo quería algo validado. Entonces claro, no tenemos una herramienta validada, pues utilicé un año de <TLANG_Sp > <TLANG_Eng > Cambridge, <TLANG_Eng > <TLANG_Sp> otro año de <TLANG_Sp> <TLANG_Eng > ESOL <TLANG_Eng>.

R: <TLANG_Sp > Un <TLANG_Sp > <TLANG_Eng > placement test <TLANG_Eng $>$.

N3: 〈TLANG_Sp> Exacto. El <TLANG_Sp> <TLANG_Eng> placement test <TLANG_Eng> <TLANG_Sp> no me dio, - es que no me aportó nada. - No me aprotó nada. Entonces, eso fue el primer y el segundo año. Yo hacía el <TLANG_Sp> <TLANG_Eng> placement, <TLANG_Eng> <TLANG_Sp> pero realmente yo no

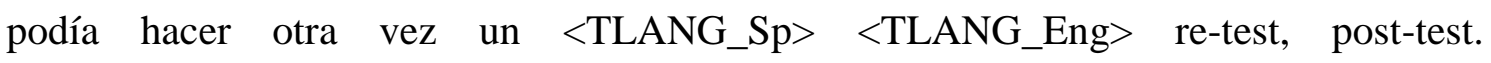
<TLANG_Eng> <TLANG_Sp> Porque realmente ¿para qué? Sí que siempre presento material antes para que los revisen y los diez primeros minutos de un taller de dos horas los utilizo para dudas. Nunca tienen dudas, - ellos nunca tienen dudas. Eso es lo primero que me inquieta, repasamos el - lo que es el documento que como ves es sencillo, si tienes un conocimiento en castellano es imposible perderete. Y luego hablamos de - del simulador. Solemos tener ahí un foro durante unos minutos que emerge, ¿no? Porque claro, ellos tienen la la reivindicación de que no llegan a más, de que les gustaría una continuidad. Pero claro las horas son las horas. Entonces tú cuando tienes que dar una serie de conocimientos, una serie de horas, yo esto se lo quito de otra cosa. Hablamos de ello, nos dividimos en grupo: el trabajo lo que es la actividad está hecha para un máximo de cuatro, yo creo que para mí tres es el número ideal en el grupo. ¿Vale? No permite que nadie se quede relegado, que todo el mundo hable. Este año he tenido que hacer dos grupos porque tenemos los laboratorios de veinte alumnos y se me dispersaban. Eh: les damos, - les damos un minuto, ellos revisan, intercambian impresiones y luego dan su veredicto. El otro grupo está de controlador. Entonces ellos revisan si hay algo que se podría añadir, si se han equivocado o no. Es difícil que se equivoquen porque nosotros hacemos un taller previo en castellano que no tiene que ver con esto pero que habla de arritmias, ellos...Pero como la cardio es muy atractiva para el alumno y esto es muy visual, pues ¿qué ocurre? Que empiezan las dudas. Pero ¿qué ocurre? Que las dudas empiezan relacionadas con la materia no con el inglés. Y normalmente pierdo treinta minuntos del taller en resolver dudas en castellano. Solo de 
estos cuatro años, yo me siento satisfecha del primer curso. Y el primer curso no tenía diferencias significativas con este, ni de notas porque lo he revisado <TLANG_Sp>.

R: <TLANG_Sp> Porque eran más trabajadores. ¿Puede ser? <TLANG_Sp>.

N3: <TLANG_Sp> Yo creo que porque les pilló previamente a la aparición. En Twitter ahora hay muchas personas que se dedican a la gamificación. Yo lo sigo bastante y yo creo que fue una temporada en la que había un hueco en la que el Kahoot todavía no se llevaba. Y el Quizzes, a mí me gusta mucho el Quizzes y yo intento todos los años hacer una valoración sobre las cosas que tengo que mejorar. Y hubo un año que estuve planteándome no hacer este tipo de - de talleres, - de taller. Pero me he dado cuenta de que no es - que no lo aprovechen. O es que yo soy muy exigente con eso y es que a lo mejor sí que no cae en saco roto. Entonces he decidido este año que voy a continuar con él y que voy a incluir el Quizzes. Entonces el problema, que tengo yo con el Quizzes. Entonces el problema es que que yo no puedo hacer dos horas de, - de test. Y no puedo hacer dos horas de test, ni media. Entonces lo que he pensado es hacer el Quizzes en la primera parte de la clase para ver hasta qué punto se han consolidado cierto tipo de aprendizaje o cierto tipo de retención. No sé cómo lo llamáis vosotros del contenido, que yo les he dado en el PowerPoint y en algún texto o en algún tipo de material que sea de lectura para ver hasta qué punto han tenido, eso, un asentamiento de la materia. Es para lo único para lo que me puede valer el Quizzes. No me puede valer para otra cosa. Y luego había pensado eso, lo que sea introducción, no hacer no hacer algo que esté abierto, sino algo que esté cerrado para captar su atención y para ver realmente, realmente dónde estoy en la práctica del electrocardiograma. Y yo quiero añadir algo más, pero es que el flujo de lo que es - lo que es la - la dinámica la dinámica del grupo no me lo permite. Y eso es lo que estoy haciendo. Y en críticos empecé haciendo una, una... $<$ TLANG_Sp $>$.

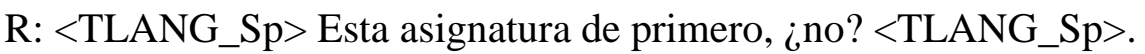

N3: <TLANG_Sp> No, - no de cuarto. Yo las asignaturas que doy son de cuarto $<$ TLANG_Sp>.

R: <TLANG_Sp> Ah vale, - vale $\langle$ TLANG_Sp $>$.

N3: <TLANG_Sp> Entonces es el taller que mejor me funciona, he estado intentando decir. Bueno vamos a ver, ¿podría en otro tipo de temática de la urgencia hacer una 
práctica así? Pues mira, en habilidades sociales que es una una optativa que doy yo sí que podría hacer algo relacionado con la búsqueda de información. ¿Por qué? Porque la herramienta está en inglés. Entonces eso a mí no me lo facilita, pero a ellos les crea un atractivo. Voy a aprender o voy a hacer esto porque a la larga me va a valer. O porque esto es el mundo, el mundo de las ciencias en inglés <TLANG_Sp〉.

R: <TLANG_Sp> Claro, también si piensan en base al tefegé [TFG], que tendrán que buscar información en inglés <TLANG_Sp>.

N3: <TLANG_Sp> Y a mí me gusta mucho el aprendizaje basado en problemas, pero para ello tengo que tener un grupo pequeño. Entonces yo estoy esperando las inscripciones del segundo cuatrisemestre para ver si podría hacer algo así. El problema es que tengo que tengo que tenerlo metido en el LLEU, sería algo exploratorio para ver. A mí me interesa hacer esto. Me interesa porque mira, sin inglés no, es que sin inglés no, no vamos adelante. Es la lengua de la ciencia. Yo sé que hay personas que no opinan como yo, pero es que yo lo tengo tan claro. Pero para mí es una barrera muy importante no saber en qué condiciones, con qué nivel llegamos todos, ellos y yo. Yo sé que creo que no sé a partir de qué año, se tiene que salir de la enseñanza universitaria con un nivel que acredite un B2 <TLANG_Sp>.

$\mathrm{R}:$ TLANG_Sp> Creo que es a partir de este año los que empiezan primero ahora, creo que tendrán que salir de la universidad con un B2 <TLANG_Sp>.

N3: <TLANG_Sp> Pero, - pero, mi, - mi reflexión es ¿de qué vale tener un título si no lo podemos incluir en lo que es la enseñanza universitaria? ¿Hasta qué punto leer mi PowerPoint o leer una información escrita les aporta algo? Yo creo que hablar, intercambiar opiniones, aunque sea articular la lengua de otra manera, yo creo que es más, les ayuda a retener más <TLANG_Sp>.

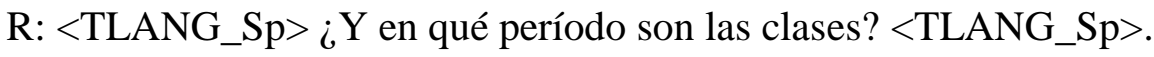

N3: <TLANG_Sp> Nosotros solemos tener clase del diez de septiembre al veintitatnos de octubre, porque el vientitantos de octubre tenemos los exámenes. Pero eso sería hablarlo de cara, de cara a junio, hablarlo y preguntárselo $\mathrm{X}$. Yo quiero, yo quiero pedirme un Erasmus plus porque la zona de Lovaina toda la zona de Países Bajos se potencia mucho el aprendizaje en inglés. Entonces yo este año no he llegado a tiempo porque estoy opositando, porque yo soy enfermera asistencial yo trabajo en urgencias: 
Y me quiero sacar mi plaza de enfermera. Y el año que viene sí que me quiero ir. Me quiero ir porque realmente es la única manera de intercambiar opiniones con con personas que están haciendo realmente un aprendizaje, una enseñanza en inglés a ese nivel $<$ TLANG_Sp $>$.

R: <TLANG_Sp> Más allí donde el inglés es la segunda, casi como si fuera la primera y más en el ámbito universitario <TLANG_Sp>.

N3: <TLANG_Sp> Que sé que a lo mejor no lo voy a utilizar en este año, pero sé que me va a aportar. Porque yo lo que necesito es que, - yo lo que veo es que necesito tener herramientas. Pero claro, es que es una barrera muy grande lo de, lo del alumnado. Yo es que no sé qué de qué manera se puede solucionar. Yo estoy viendo que la tendencia del aprendizaje está cambiando, del aprendizaje por parte del alumno. El alumno recurre a las fuentes de información, el alumno tiene en internet una...Pero yo no quiero, - no quiero quedarme desfasada. ¿Sabes lo que te quiero decir? Y me da la sensación de que de esta manera el alumno no encuentra atractiva la materia. Incluso con un simulador. Entonces yo tengo que plantearme a medio plazo, a lo mejor en dos o tres años, ir haciendo una evolución. No sé si hacer como un estudio de mercado. Entrar en twitter, ver que la gente que hace CLIL qué hace, buscar en, hablar con los de, - con los chicos del CENT, ¿vale? Que ellos son gente que están muy, - muy, - muy actualizados. Luego sí que en críticos, en la otra asignatura que doy sí que les pongo mucho material para para leer en inglés, pero porque el contexto del paciente crítico en los laboratorios que tenemos no dan tanto pie como los de urgencia. ¿Vale? Pero también hacemos cosas y les damos textos en inglés: y ya te digo, básicamente intento que produzcan algo oralmente. Es difícil. ¿Por qué no lo hago como una producción escrita? Porque quiero que actúen en el momento. Me refiero que yo cuando llego un examen de inglés en la escuela de idioma, a mí me dan un texto salgo fuera y cuando vuelvo tengo que ser productiva, ¿no? Pues mi intencionalidad es esa, pero claro, el grupo es heterogéneo. Sí que me gustaría no será una manera saber en qué punto estoy y que no fuera con el

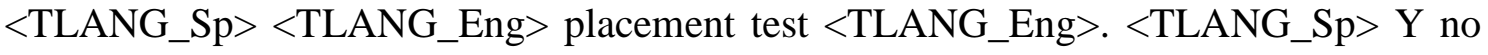
quiero hacer tanto ajuste a la baja <TLANG_Sp>.

R: $\langle$ TLANG_Sp> Ya $<$ TLANG_Sp $>$.

N3: <TLANG_Sp> Pero es que es eso a ver. Estoy contenta, estoy contenta porque mezclo dos cosas que me gustan, que son mi trabajo y el inglés. ¿Con los resultados? 
No estoy contenta. No estoy contenta, se me queda un poco mal sabor de boca porque veo que podríamos hacer mucho, pero hay algo en el camino. Hay un par de barreras en el camino y no es por la falta de interés. Es por falta de nivel. Pero vamos, que si exploro algo o quieres venir a alguna de mis clases el año que viene, en junio me vuelves a contactar y lo hablamos $\langle$ TLANG_Sp>.

R: <TLANG_Sp> Vale, perfecto. Muchísimas gracias por tu tiempo <TLANG_Sp>. 


\section{APPENDIX I (k): Psychology (P1 and P2)}

R: <TLANG_Cat> Jo la meua tesi doctoral se basa en analitzar les assignatures de contingut que se donen en anglès, o bé totalment que depèn de l'assignatura, $o$ parcialment, que a lo millor pot ser un seminari, un laboratori, eh una lecture. Lo que siga. Entonces ahí seria analitzar lo que... a vore el nivell d'anglés, jo els passaria lo que és un qüestionari de, de nivell, però no es pa dir "ui, que poquet nivell tenen els de psicologia o els de medicina, no". Es pa vore com ells responen a les activitats que vosatros els proposeu. Perquè a lo millor eh, per ejemple, ahir vaig estar en un seminari d'història, i pues als alumnes els van ficar vídeos en anglès, però ells parlaven en castellà o en valencià. $\mathrm{Pa}$ vore si ells tenen una actitud positiva en lo que és a utilitzar l'anglés o no. I: seria fer un anàlisi contrastiu entre lo que són les Ciències de la Salut, Medicina, Infermeria, Psicologia, i fer un contrast també en lo que són les Humanes, que est..., - que estic investigant lo que és Història i Turisme. I bàsicament és això, passar-los primer lo que és el placement test, que és el test de nivell, i después també preguntar-los pel Pla Pluriennal de Plurilingüisme de 1'UJI [*ECOPOL*], per a vore si saben que s'han de traure un B1 o un B2 d'anglés o de valencià pa poder tindre el títol. I en base a tot eixe anàlisi, después seria proposar un pla de millora referent a les assignatures. Per ejemple, a lo millor n'hi ha una assignatura que a lo millor no convé donar-la en anglés perquè...N'hi una professra en història que me comentava "És que es arte valenciano" i això és difícil trobar lo que són materials en anglés. Entonces a lo millor convindria, pues passar lo que és la docència en anglès a una altra assignatura en la que els alumnes puguen traure més profit i que el professorat també ho tinga més fàcil a l'hora d'accedir als materials. Això seria tot referent a la temàtica de l'estudi i ja només faltaria contestar a una sèrie de preguntetes que te faré ara. Quants crèdits corresponen a l'assignatura? $<$ TLANG_Cat $>$.

P1: <TLANG_Cat> Pues no m'arrecorde. A vore, - a vore, és una docència prou xicoteta, vale, mínima en el sentit de que, si no, els alumnes, encara que siga una optativa, si injustament li fico per ejemple la mitat. Després és que no recorde. Com açò encara estàvem en el antic sistema era com un màxim i un mínim, i en eixe sentit vull dir que el han ficat és possiblement lo que calia ficar en una optativa, com a màxim de docència que se podia ficar. Perquè al principi no ho fe...Jo porte molt de temps fent la mateixa metodologia, però ni tan siquiera ho ficava en el POD i me vaig donar conter, que no, que era al revés, vam escomençar ja com en l'anterior Vicerrectorat no, en el pla 
de multilingüisme, i a partir d'ahí vaig dir "ui, açò hi ha que reflectir-ho" perquè passa lo mateix en el valencià versus el castellà o el que siga. Entonces lo que sí que te podíem explicar és un poc com l'assignatura en sí se dona tota en castellà, vale en el sentit de que l'anglés és només una llengua vehicular i passaria un poc com en el seminari que tu comentaves fins ara. És a dir, els vídeos están...hi ha prou vídeos en anglès, subtitulats, en una subtitulació que diria $X$, prou roïna moltes vegades eh: tant en la versió original en anglés com el castellà i te trobes ahí un poc de tot. És un poc lo que jo sempre mire i m'agradaria poder-lo corregir en un sistema o en alguna ajuda o en algun servei, però açò estem ja parlant de futur. De forma més immediata eh jo sí que utilitze prou la llengua anglesa i sobretot en el màster. En el màster sí que hi ha una assignatura que tot el material esta en anglés, les diapositives estan en anglés, el, - els vídeos estan tots en anglés subtitulats en anglés i ademés portem a gent de fora que òbviament se fa tota una classe en anglés i parla en anglés, jo parlo en anglés i tots - eh tota la docència. I els estimulem a ells a que participen, a que pregunten i tal. En la optativa de quart, com és <TLANG_Cat> <TLANG_Sp $>$ "un poco la antesala" $<$ TLANG_Sp $>$, no sóc tant...Fins ara, $<$ TLANG_Cat $><$ TLANG_Sp $>$ claro $\langle$ TLANG_Sp>. $\langle$ TLANG_Cat> Però fins ara fee el que jo una miqueta entre cometes, volie. Vull dir perquè si de cara a participar d'una manera més xula i també que tinga més sentit per a tu, si vullgueres ho podríem fer, que jo donara tot un seminari, per ejemple a lo millor no les classes, la teoria, les lectures, però sí el, - podria fer el seminari a lo millor en anglés i que ells intentaren participar en la mesura de lo possible. Un poc, com no obliga-los, sinó fomentar o convidar-los, convidar-los a que ells...<TLANG_Cat>.

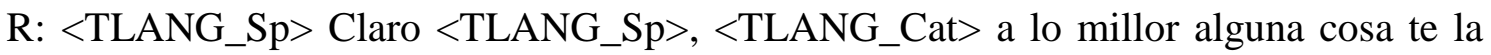
pregunten en castellà o en valencià perquè no s'aclarixen a dir-t'ho d'una altra manera. Però que si <TLANG_Cat> <TLANG_Sp> después <TLANG_Sp> <TLANG_Cat> algú te parla en anglés, pues se valora positivament $\langle$ TLANG_Cat>.

P1: <TLANG_Cat> Ara bé, els materials que utilitzem, pues també estan casi tots en anglès <TLANG_Cat>.

P2: 〈TLANG_Sp>Sí, casi todos, sí <TLANG_Sp>. 
P1: <TLANG_Cat> Casi tots els articles. Però com te dia el màster és tot en anglés. L'únic que fan és parlar. De fet, hui han tingut unes presentacions i ahir també i els vaig dir "ai, se me va olvidar". Claro, jo ho donava per defecte, pues claro, però les diapositives totes en castellà i ells ho han presentat en castellà però perquè a mi se me

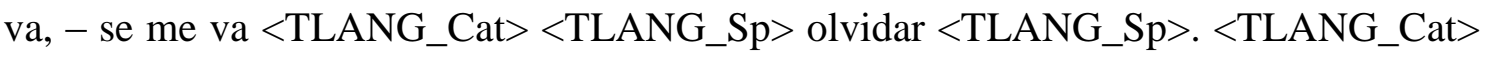
Però sí que per ejemple també els convide quan tenen que fer un <TLANG_Eng> report <TLANG_Eng>, uns informes, jo els convido per ejemple a que ho facen en anglés. Normalment la gent ho fan tot en castellà, però vaig tindre un cas d'una persona que era prou bilingüe i va utilitzar l'anglés. Tot el temps. Enguany podríem fer algo semblant <TLANG_Cat>.

\section{R: <TLANG_Cat> Sí <TLANG_Cat>.}

P1: <TLANG_Cat> A banda de que siga escoltar, sinó que el report corresponent que han de fer, que procuraren fer-lo també en anglès, que total són dos fulles <TLANG_Cat>.

R: <TLANG_Cat>Claro, alguna coseta $<T L A N G \_C a t>$.

P1: <TLANG_Cat> Se m'ocurrixen varies coses que jo podria introduir com a nou enguany acord a...bueno, d'acord a lo que tu me digueres <TLANG_Cat>.

R: Sí, també això, que jo el dia que a lo millor tu digues. Mira, tal dia vaig a donar el seminari en anglès o un taller o lo que siga en els dies també que a tu te convinga. Jo això me faria falta lo que és gravar-ho en audio pa transcriure-ho i después vore les llengües d'interacció en el aula

P1: <TLANG_Cat> Molt bé, però gravació tu a banda...? <TLANG_Cat> .

R: <TLANG_Cat> No, gravadora <TLANG_Cat>.

P1: <TLANG_Cat> Ah, gravadora de àudio <TLANG_Cat>.

R: <TLANG_Cat>Sí, perquè si és en vídeo la gent normalment no... <TLANG_Cat>.

P1: <TLANG_Cat> No vol <TLANG_Cat>. 
R: <TLANG_Cat> No vol. En la gravadora també és veritat que se senten menos intimidats tant els alumnes com el professorat, perquè als professors tampoc els fa molta gràcia. Entonces clar, jo els deixe la gravadora pues damunt la taula del professor pa captar lo que ell parla i después jo o bé en el mòbil o en una altra gravadora, més a lo que són els alumnes també. Perquè ells a vegaes estan parlant i diuen coses però a lo millor amollen alguna cosa "no, esto són les <TLANG_Cat> <TLANG_Eng> references <TLANG_Eng>”.

P1: I tu al final, realment, què és lo que valores? Valores el número d'intervencions, valores...? <TLANG_Cat>

R: <TLANG_Cat> Sí, el número d'intervencions en anglés, perquè se suposa que l'assignatura té docència en anglès, en el cas de que eh en esta assignatura, l'actitud de l'alumnat cap a la utilització de la llengua anglesa <TLANG_Cat>.

P1: <TLANG_Sp> Vale, pues <TLANG_Sp> <TLANG_Cat> saps què farem? Venia un moment de reflexió en el sentit de que també me tenia que sentar d'alguna manera i ella és el primer any que dona docència. Entonces per repartir-nos estos seminaris. Eh ella ho pot fer estupendament bé, però a lo millor el primer any que està donant classe, si damunt li dic ho tens que fer en anglés. Ara, podrie donar-se que un dia ho fage jo tot en anglés i a lo millor ella utilitze els materials en anglès i pots entrar igualment <TLANG_Cat>

R: <TLANG_Cat> És tindre accés a això, o siga...<TLANG_Cat>.

P1: <TLANG_Cat> Lo que mirarem és això. Quantes coses, perquè aixina jo estic fent repàs. De materials en anglés n'hi ha prou per a llegir i de vídeos també <TLANG_Cat>.

R: <TLANG_Cat> Inclús també vosatros si a l'hora d'explicar, expliqueu, esteu parlant en anglés i a lo millor alguna cosa l'expliqueu en castellà perquè sino no s'enteren. Això també, no és que siga tot exclusivament en anglés, sino que també podeu fer servir una altra llengua $<$ TLANG_Cat $>$.

P1: <TLANG_Cat> Sí, jo faig prou de...com se diu, <TLANG_Cat> <TLANG_Eng> Spanglish <TLANG_Eng>. <TLANG_Cat> Sobretot quan estic parlant de coses en molta terminologia directament utilitze les paraules angleses, però no per res. Perquè ho 
he après aixina i segona perquè com ho lliges més habitualment, pues me costa a lo millor dir ressonància magnètica i dic <TLANG_Cat> <TLANG_Eng > em ar ai (MRI) <TLANG_Eng>. Entonces els alumnes, és veritat, no? o <TLANG_Cat> <TLANG_Eng> TBCS <TLANG_Eng> que són tècniques de registre i és perquè són coses que jo no utilitze en el meu dia a dia i en l'entorn, no? i això és interessant també i entonces vore si els contagies a ells també o no. Més que res per saber quin és el teu objectiu i vore en quina mesura te podem ajudar. No voler-lo fer <TLANG_Cat> <TLANG_Eng> fake <TLANG_Eng> <TLANG_Cat> ara perquè tu vages a fer. Però enguany igual podem modificar un poquet o fer més específic <TLANG_Cat>.

R: <TLANG_Cat> Jo és les llengües d'interacció en l'aula, vore també com els alumnes responen a les activitats que els proposeu per a fer en anglès i després en base a això i als qüestionaris que els passaré proposar o no el canvi de docència d'anglés d'assignatura o proposar lo que seria uma <TLANG_Eng> pedagogical proposal <TLANG_Eng> per a fer a l'aula, que això també havia esat pensant-ho $<$ TLANG_Cat>.

P1: <TLANG_Cat> Hmm <TLANG_Cat>.

R: <TLANG_Cat> Perquè a lo millor podria ser una manera d'ajudar-vos $<$ TLANG_Cat>.

P1: <TLANG_Sp > Claro <TLANG_Sp $>$.

R: <TLANG_Cat> Una <TLANG_Eng> pedagogical proposal <TLANG_Eng > en les diferents àrees, Medicina, Infemeria, Psciologia i Turisme <TLANG_Cat> .

P1: <TLANG_Cat> Però com a recurs? <TLANG_Cat>.

R: <TLANG_Cat>Sí, - sí <TLANG_Cat>.

P1: <TLANG_Cat> No, no, jo pense que aprendré molt d'açò < TLANG_Cat $>$.

R: <TLANG_Cat> A lo millor hi ha una cosa que fan un àrea i que se pot implementar en un altra <TLANG_Cat>.

P1: <TLANG_Cat> A mi quan me vas contactar me va parèixer molt atractiu, perquè clar és el moment de l'anglès i això passa a tothom. I quan més prompte comences, més 
fàcil és. Jo me va costar molt l'anglès, que un dels meus màxims objectius com a mare era que el meu fill parlara anglès i ho fa des dels dos anys. I això és una qüestió que te dones conter de dir "ostras". Pues quan més fàcil i més ràpid tens l'accés a l'informació, és molt millor". I ara estem en el procés este de llevar-li la por a X. De fet, en el TFM tenia que escriure un paper i el va escriure en castellà i i vaig dir "no te pense corregir l'article en castellà hasta que me'l presentes en anglés" <TLANG_Cat>.

P2: <TLANG_Sp $>$ Es verdad $<$ TLANG_Sp $>$.

P1: <TLANG_Cat> I ella s'enfadava i eixe <TLANG_Sp> enfado <TLANG_Sp> <TLANG_Cat> és lo que parlàvem per ejemple en X el dia que mos va reunir, saps? Pel tema de multilingüisme, de com ho van a intentar implementar en el aula. I ho tenim que treballar <TLANG_Cat>.

P2: <TLANG_Sp> Sí, claro <TLANG_Sp>.

P1: <TLANG_Cat> I eixe <TLANG_Cat> <TLANG_Sp> enfado <TLANG_Sp> <TLANG_Cat> jo l'he viscut <TLANG_Cat>.

R: <TLANG_Cat $>$ És que és la por <TLANG_Cat>.

P1: 〈TLANG_Sp>. Pero es que ni hablo ni hablaré en la vida <TLANG_Sp> [reproducing's P2 words]

R: <TLANG_Sp> Porque crees que no tienes el nivel sufieciente <TLANG_Sp $>$.

P2: <TLANG_Sp> Correcto <TLANG_Sp>.

P1: <TLANG_Sp>Claro, <TLANG_Sp> <TLANG_Cat> i a mi me fa molta vergonya. Crec que la he perduda i la perds per, - per, com se diu? Per afrontament. <TLANG_Cat> <TLANG_Sp> Exposición en vivo, <TLANG_Sp> <TLANG_Cat> que açò és veritat. Entonces, en eixe sentit, a mi me fa molta vergonya, eh? A mi me fa vergonya hasta fer-me fotos i eixes coses. Però dius bueno, és una qüestió de que tinc que superalo i a mi m'ha vingut molt bé per ejemple el màster per a ficar-me a parlar en anglés davant dels alumnes i dir-los...Jo tinc molt d'accent valencià, entonces en anglès també el tinc <TLANG_Cat>.

P2: 〈TLANG_Sp> No es que... <TLANG_Sp> 
R: <TLANG_Cat> Pero això no importa <TLANG_Cat> .

P1: <TLANG_Cat> Ella sempre me dona molt de <TLANG_Cat> <TLANG_Eng>

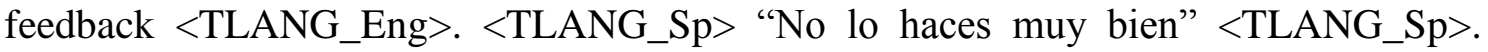
<TLANG_Cat> I jo dic "calla, si jo me sent com si fóra de l'horta, de dir què mal $<$ TLANG_Cat>

R: <TLANG_Cat> Però lo que és l'accent això no importa perquè és d'on tu vens, o siga tampoc pots fer altra cosa. A mi també m'han dit que tinc <TLANG_Cat> <TLANG_Sp> Spanish accent <TLANG_Sp> <TLANG_Cat> parlant anglès. Me fan <TLANG_Cat> <TLANG_Sp> you have a lovely Spanish accent <TLANG_Sp>. <TLANG_Cat> I per lo menos penses <TLANG_Cat> " $\langle$ TLANG_Sp> bueno,

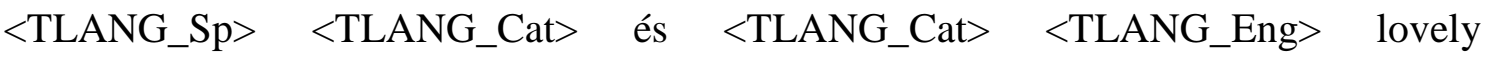
$<$ TLANG_Eng>".

R: <TLANG_Cat> I seguint en les qüestions, quines dificultats creieu que presenta l'alumant al, quan has donat docència en anglès? <TLANG_Cat>.

P1: <TLANG_Cat> Açò vols que t'ho passem per escrit? <TLANG_Cat>.

R: <TLANG_Cat> No fa falta, ho esteu contestant ara <TLANG_Cat>.

P1: <TLANG_Cat> Quant als crèdits de antes, cinquenta per cent en anglés per a la part de teoria, cent per cent en dos seminaris però com hi ha varios, seminari i pràctiques però tampoc ho dintinguim. És una assignatura de quart <TLANG_Cat>.

R: <TLANG_Cat> A mi lo únic que heu de dir-me és "donarem classe en anglès tal dia, a tal hora" <TLANG_Cat>.

P1: <TLANG_Sp>Vale <TLANG_Sp>, <TLANG_Cat> és lo únic que tenim que dirte. Les dificultats que presenta l'alumnat, pues n'hi ha gent que té problemes seriosos pa els listenings per ejemple, que li costa. Ara, com que és un material que està penjat a l'aula virtual, jo els dic el pots vore vint-i-huit vegaes si és precís. Que va bé, perquè quant més els sents i com ja, ja...I també lo que els dic és "bueno, ara el mirem, fem comentaris, fem un debat, col-loqui, se parla i se participa. Te'l tornes a mirar sabent ja de què va i en tota esta informació és molt més fácil <TLANG_Cat>. 
P2: <TLANG_Sp> De hecho, yo me acuerdo que en mi promoción cuando nos teníamos que coger las asignaturas, yo tengo amigas que no se la cogieron por eso $<$ TLANG_Sp>.

P1: <TLANG_Sp> Por el inglés <TLANG_Sp>.

P2: <TLANG_Sp> Por el inglés, por decir tengo materiales en inglés, aunque sean materiales que tú puedes trabajar en tu casa $\langle$ TLANG_Sp $\rangle$.

R: <TLANG_Sp> De ahí viene también que yo en el cuestionario de multilingüismo pregunte qué saben ellos sobre el plan de la UJI. Porque a lo mejor en este año todavía no, pero en los siguientes ya tendrán que tener un B1 de inglés. Entonces...tendrán que ponerse un poco las pilas <TLANG_Cat>.

P1: <TLANG_Cat> Sí, - sí. La veritat és que sí. I dificultats del professorat? <TLANG_Cat>.

R: <TLANG_Cat> Material o algo? O això no...? <TLANG_Cat>.

P2: <TLANG_Sp> Yo creo que es más dificultad encontrarlo en castellano $\langle$ TLANG_Sp>.

P1: <TLANG_Cat> Sí, això anava a dir-te que tenim molt de material en anglés perquè també treballe fonamentalment en <TLANG_Cat> <TLANG_Eng> papers <TLANG_Eng> <TLANG_Cat> més que en llibres, és de recerca i és tot molt puntero i molt nou. Entonces és que és casi tot en anglés. És al revés, buscar material en castellà per a que se lligen <TLANG_Cat>.

R: <TLANG_Cat> I no adapteu res al nivell dels estudiants, no? Tal com ho trobeu els ho passeu <TLANG_Cat>.

P1: <TLANG_Cat> Jo busque el material més bàsic i complementari, i el bàsic intente que hi hague: $\mathrm{O}$ a lo millor intente trobar un article en anglés $\mathrm{i}$ un article en castellà per als bàsics, per ejemple. El complementari tot en anglés i intente buscar algun manual també en castellà, per a alguna part particular com la de metodologia. Però en això ella té raó, és que pràcticament està tot... Però fixa’t que hui he tingut una presentació del màster en una alumna que va fer l'assignatura l'any passat i m'ha dit <TLANG_Cat> 
<TLANG_Sp> "no me riñas però yo el artículo me lo he traducido" <TLANG_Sp> <TLANG_Cat> pa poder-lo entendre bé <TLANG_Cat>.

P2: <TLANG_Sp> Sí, eso lo hacen muchos $\langle$ TLANG_Sp $>$.

P1: 〈TLANG_Cat> Copiar i pegar-lo en <TLANG_Cat> <TLANG_Eng> Google <TLANG_Eng> i dius "bueno, per lo menos no serà $100 \%$ fiable, però..." <TLANG_Cat>.

R: <TLANG_Cat> Se fan una idea de lo que diu <TLANG_Cat>.

P1: <TLANG_Sp> Eso es. <TLANG_Sp> <TLANG_Cat> I después ja se'n van a la font anglesa $<$ TLANG_Cat>.

P2: Por ejemplo, casi todo el mundo lo hace, casi, casi todo el mundo lo hace así. O sea, a la hora de estudiar para el examen, sí. Traducen párrafo por párrafo

P1: <TLANG_Sp>Claro <TLANG_Sp>, <TLANG_Cat> lo que jo els dic "Això és un faenon". Se queixen de que l'assignatura els done molta feina. Però claro, jo no done eixe feina, no la tinc en el cap. No se m'ocurreix que tenen que fer-ho. Però $\langle$ TLANG_Sp> bueno $\langle$ TLANG_Sp>, és veritat a mosatros a vegaes se mos desdibuixa, no? Però la perspectiva òbviament se difumina en el temps, però a tu com alumne te assusta. El tema de treballar en anglés, parlar en anglès, escoltar i escriure en anglés. Vull dir que...Ah bueno, les dificultats del professorat és lo que ella diu. Primera que pot ser que l'assignatura no l'agafen per això i después que l'avaluen pitjor pel tema de l'anglès <TLANG_Cat>

R: <TLANG_Cat> D'això també m'han comentat coses altres professors $<$ TLANG_Cat>.

P1: <TLANG_Sp> Materiales que suelen entregar <TLANG_Sp>. <TLANG_Cat> No entenc la pregunta $<$ TLANG_Cat>.

R: <TLANG_Cat> No, això. Els papers i les coses que pugeu a l'aula virtual $<$ TLANG_Cat>.

P2: <TLANG_Sp> Vídeos, sí <TLANG_Sp>. 
R: <TLANG_Cat> Clar, això. Però ja ho hem parlat. I <TLANG_Cat> <TLANG_Sp> después, bueno, tareas que se suelen realizar:: <TLANG_Sp> <TLANG_Cat> Fan alguna presentació en anglès? <TLANG_Cat>.

P1: <TLANG_Cat> No, fins ara, no. Però lo que sí que a lo millor els podríem demanar és que fiquen les diapositives en anglés, almenys si te pareix. O siga, més que demanarlos que la facen en anglés <TLANG_Cat>.

R: <TLANG_Cat>Si ho fan valorar positivament <TLANG_Cat>.

P1: <TLANG_Cat> Clar, exacte. Jo quan presente l'assignatura els diré que forme part d'un grup d'investigació educatiu i que anem intentar potenciar un poquet més algo que ja venim fent. Aixina si diuen “¿Y por qué este año?" "I per què natros?” Saps? Perquè sí, es veritat, jo ademes és que faig un trilingüe total perquè me passe del valencià al castellà, que és molt habitual en mi, i en el anglés sí que és un poc a vegades...<TLANG_Cat $>$.

R: <TLANG_Cat> I si no, si els demaneu el report en anglès, pues també $<$ TLANG_Cat>.

P1: <TLANG_Cat> Exacte, exacte <TLANG_Cat>.

P2: <TLANG_Sp>Si lo pueden hacer de manera optativa, mejor <TLANG_Sp>.

P1: <TLANG_Cat> Claro, què te pareix? En vega de que siga una imposició <TLANG_Cat>

R: <TLANG_Cat> Jo conforme doneu l'assignatura en que intenteu implementar un poquet l'anglés i jo vore lo que se fa, en això <TLANG_Cat>.

P1: <TLANG_Cat> Sí que podríem dir-los que a lo millor no tots els <TLANG_Eng> reports <TLANG_Eng>, però podríem triar el seminari que ja vingues. Perquè dels seminaris ells sempre entreguen un informe, no és un informe individual, sinó que el fan en grup. L'horari és dimecres, de quatre a huit, de quatre a sis teoria i de sis a huit pràctiques, però se podria canviar l'ordre perquè te ve millor a tu o lo que siga, pues ho podríem fer. Però a priori pues és això, començarem la primera setmana, crec que és la última de gener i fins a maig <TLANG_Cat>. 
APPENDIX I (k): Psychology (P1 and P2)

R: <TLANG_Cat> Val <TLANG_Cat>.

P1: <TLANG_Cat> Val, o siga seguir el període lectiu i t'avisem. No sé si t'hem contestat a tot <TLANG_Cat>.

R: <TLANG_Cat> Sí, moltíssimes gràcies <TLANG_Cat>. 
APPENDIX II: Consent form

\section{Consent Form for Participation in a Research Study at Universitat Jaume I}

\section{Multilingual Education: A Contrastive Analysis in Humanities and Health Sciences}

\section{Description of the research and your participation}

You are invited to participate in a research study conducted by Lucía Bellés Calvera. The purpose of this research is to analyse the implementation of CLIL/EMI programmes in the fields of Medicine, Nursery, History and Tourism, taking into account students' and teachers' interactions. To do so, the main researcher should attend teachers' lectures.

Your participation will involve being video- or audio-recorded when giving instruction, and allowing us to hand in surveys and placement tests.

\section{Risks and discomforts}

There are no known risks associated with this research. Participants will be audiorecorded in case they do not feel comfortable with video-recordings.

\section{Potential benefits}

This research may help us to understand the extent to which CLIL programmes are implemented properly at Universitat Jaume I.

\section{Protection of confidentiality}

We will do everything we can to protect your privacy. Your identity will not be revealed in any publication resulting from this study.

\section{Voluntary participation}

Your participation in this research study is voluntary. You may choose not to participate, and you may withdraw your consent to participate at any time. You will not be penalized in any way should you decide not to participate or to withdraw from this study. 


\section{Contact information}

If you have any questions or concerns about this study or if any problems arise, please contact Lucía Bellés Calvera at lucia.belles@uji.es.

\section{Consent}

I have read this consent form and have been given the opportunity to ask questions. I give my consent to participate in this study.

Participant's

signature

Date:

Researchers's

signature

Date:

A copy of this consent form should be given to you. 


\section{APPENDIX III: Classroom practices}

\section{APPENDIX III (a): History of the Classical World}

H1: Good morning, everybody! Today we are going to review some of the contents that we dealt with during the first session. We watched the first episode of the HBO series Rome which is set in the last years of the Republic. More specifically, it focused on the initial conflict between Caesar and Pompey. At the very beginning, Caesar was in Gaul with his legion, whereas Pompey was in Rome. Apart from these two powerful men, we could also observe other characters, such as Lucius Vorenus and Tittus Pullo, who were two Roman centurions; Atia and her daughter, who belonged to the Julii family; Brutus, Caesar's adopted son, and Octavian who would become the first Roman emperor. That being said, a character is missing. Can any of you think of a character that appeared in the first episode? He was a member of the Second triumvirate. There was a member of the second triumvirate who appeared in the first episode of the series. Can you guess? <TLANG_Eng>

S1: Marco Antonio <TLANG_Sp>

H1: Yes, so Marco Antonio <TLANG_Sp> in English is Mark Antony <TLANG_Eng>. So here we have Mark Anthony, you can think about him and then here we have Mark Antony. It is pronounced differently. Remember that. After that, I asked you to do a reading activity, and we are going to correct it right now. So: is there any volunteer who wants to start with the first question? If not, I will select a person randomly $\langle$ TLANG_Eng $>$.

[S1 raising his hand]

H1: Do you want to start? OK <TLANG_Eng>.

S2: ¿Leo la pregunta? <TLANG_Sp>

S3: Nosotras no tenemos la hoja <TLANG_Sp>.

H1: But, where you here last day? <TLANG_Eng>

S3: No - no <TLANG_Sp>

H1: We are going to start. Be quiet, please. <TLANG_Eng> 
S2: ¿Leo la pregunta? <TLANG_Eng>

H1: Yes <TLANG_Eng>.

S2: One. How long did the Etruscans rule Rome before the Roman Republic? B. One hundred years <TLANG_Eng>

H1: Yes, that's true because if read the second paragraph it says that the Etruscans ruled for nearly a century. You can find it in the second and third lines of the second paragraph. Then, next question. Any other volunteer? <TLANG_Eng>

S3: When did the Roman Republic end? B. 27 BC. <TLANG_Eng>

H1: Yes. 27 before Christ. Let's see if I can find the answer: Yes, it's here. The answer to this question is in the last line of the tenth paragraph, just at the end of the text. Thus, 27 before Christ became both the end of the Roman Republic and the beginning of the Roman Empire: Third question? <TLANG_Eng>

S4: How often was the election of the consuls? Once a year <TLANG_Eng>

H1: Once a year. And it is said again. Once again they elected two consuls. It's quite easy to understand this question. The following one? Following question? <TLANG_Eng>

[use of Flippity]

Ss: [laughs]. Surprise <TLANG_Eng>

S5: Ah, iqué guay! <TLANG_Sp>

H1: Here we have S6 <TLANG_Eng>.

H1: Which of the following statements about the consuls in the Roman Republic is true? Eh: C. The commoners in the Roman Republic did not gain the right of being a consul until 367 B.C. <TLANG_Eng>

H1: Yeah, that's the correct one. If you selected... <TLANG_Eng > Uy: <TLANG_Sp> If you selected $\mathrm{A}$ as the correct option you're wrong because they followed the advice given by the Senate. $\mathrm{B}$ is false because they attempted to reach unanimous decisions; if 
not, uhh, they had to appoint a dictator. And finally D is also false because all citizens had right to vote. OK, so number 5? <TLANG_Eng>

S7: Under the Roman laws, how long could a dictator hold the power? D. Six months <TLANG_Eng>

H1: Yes, perfect. Next question? S8? <TLANG_Eng>.

S8: Eh: the purpose of the Twelve Tables was D. To make all the citizens aware of the Roman laws and constitution <TLANG_Eng>.

H1: Yes. D. To make all the citizens aware of the Roman laws and constitution. And the answer is in the one, two, three, four, in the fifth paragraph because it says that the Law of the Twelve Tables codified the Roman laws and constitution. Now, question number 7? SX1? <TLANG_Eng>

Ss: [laughs]. No - no - no está <TLANG_Sp>.

H1: I don't know <TLANG_Eng>.

[laughs]

H1: S9 <TLANG_Cat>.

S9: Why did the plebeians establish their own assembly in 494 before Christ? C. Because they wanted to get more land <TLANG_Eng>

H1: No, this is incorrect. It's B. Because they wanted to have the same rights as the patricians. So, it's B. Number 8. S10? <TLANG_Eng>.

S10: I wasn't here so no... <TLANG_Eng>

H1: You weren't here. OK. SX2? <TLANG_Eng>

S11: What? <TLANG_Eng> ¿Quién es ese? <TLANG_Sp>

H1: Well, he's in the list. S12? <TLANG_Eng>

S12: Why would the Roman senate want a dictator? To settle a dispute: Romans never wanted a dictator in charge of their government <TLANG_Eng> 
H1: No, it's C $-\mathrm{C}$. To settle a dispute between the two consuls that dragged on too long. You were saying it correctly, but then you just confused. So everybody, the correct answer for the eighth question is C. Question number 9? <TLANG_Eng>

S13: What is the main idea of the seventh paragraph? A. Caesar's power continued to increase until his murder <TLANG_Eng $>$.

H1: Yes, that's correct. What is the main idea of the 7th paragraph? A. Caesar's power continued to increase until his murder. And final question? Mmm S14? <TLANG_Eng>.

S14: What event marked the end of the Roman Republic? D. A group of senators assassinating Julius Caesar <TLANG_Eng>.

H1: It's not that. It was Augustus having complete control of Rome. When he controlled Rome, it was considered the end of the Republic and the beginning of the Roman Empire. Before watching the second episode, you need to pay attention 'cause you're going to answer an online questionnaire. I'm sorry, there are no subtitles, but I couldn't find them online. Now, first of all, we are going to do an activity based on vocabulary and once we correct it, we'll watch the episode I talked to you about. It's a fill in the gap activity. Thus, it's quite quick <TLANG_Eng>.

S15: Soothsayer <TLANG_Eng>, ¿qué es? <TLANG_Sp>

H1: It means <TLANG_Eng > adivino <TLANG_Sp>.

[students are given time to complete the following task]

H1: Have you finished the first exercise? <TLANG_Eng>

Ss: Yes <TLANG_Eng>

H1: Yes? We are going to correct the activity. The first sentence is for SX3. He isn't here. SX4, no? [rejecting participation] S16 <TLANG_Eng>.

S16: Sí, hombre <TLANG_Sp>. Eh: The entire project was due to his instigation. If he had not urged us forward, the project would not have been begun <TLANG_Eng>.

H1: Correct. The entire project was due to his instigation. The second sentence is for SX5. He has already appeared. Is he here? Uy <TLANG_Sp>.S17 <TLANG_Eng> 
S17: There were rumours of mutiny among the troops <TLANG_Eng> .

H1: Correct. There were rumours of mutiny among the troops. Mutiny. S18? <TLANG_Eng>

S18: The soothsayer warned Caesar to Beware the Ides of March twice $<$ TLANG_Eng $>$.

H1: It is the soothsayer warned Caesar to Beware the Ides of March twice. The soothsayer would be the adivino <TLANG_Sp>. Soothsayer. S19 <TLANG_Eng>.

S19: The legacies of the Roman civilization involve law, language, architecture, culture and philosophy <TLANG_Eng>.

H1: It is the legacies of the Roman civilization involve law, language, architecture, culture and philosophy. Legacies. [laughs]. Has he appeared or not? If not, I will take the list and I will say a name <TLANG_Eng>.

S20: A tribune was a magistrate who protected the rights of the lower classes $<$ TLANG_Eng>.

H1: A tribune was a magistrate who protected the rights of the lower classes. Tribune. I will take the list...uhh. S21 <TLANG_Eng>.

S21: A tribune was a magistrate who protected the rights of the lower classes $<$ TLANG_Eng $>$.

H1: That was the previous sentence. Tribune <TLANG_Eng>.

S21: A Roman judge or magistrate, next to consul in rank, was regarded as praetor $<$ TLANG_Eng>.

H1: Yeah. Sentence number 6 is praetor. Then, mmm: S22 <TLANG_Eng>.

S22: A centurion was a Roman soldier in charge of a group of about eighty to one hundred men called a century <TLANG_Eng>.

H1: A centurion was a Roman soldier in charge of a group of about eighty to one hundred men called a century. Century. And number eight was done accidentally. Now we are going to watch the second episode. Pay attention <TLANG_Eng>. 
S13: Can you [unintelligible], please? <TLANG_Eng>

H1: Subtitles? <TLANG_Eng>

S7: No. He asked if you could repeat the answers <TLANG_Eng>.

H1: Yes, of course. Sentence number one instigation. Sentence number two mutiny. Number three soothsayer. Number four legacies. Number five tribune. Number six praetor. Number seven centurion. And number eight coffers. OK. Now pay attention. After the episode you are going to answer an online questionnaire <TLANG_Eng>.

S10: Can you put subtitles, please? <TLANG_Eng>

H1: I couldn't find a website with subtitles, I'm sorry for that <TLANG_Eng>.

[an apisode of the HBO series Rome is played]

H1: Well, we could see the conflict between Caesar and Pompey and, and how the Republic was being in turmoil. So now we're just going to answer an online questionnaire and I need you to put in pairs or in groups. You need to decide a group name and take your mobile phones 'cause we are going to answer it online. So, we will only need one mobile phone per group. Decide your group name and once you have it, uh, enter Kahoot on Google and click Kahoot dot it. This one. And you click play Kahoot, this one <TLANG_Eng>

[students make some comments trying to enter Kahoot: inaudible]

SX6: Van a ser las mismas personas que nuestro grupo <TLANG_Sp>.

H1: Vale <TLANG_Sp>

S24: ¿De cuántos puede ser el grupo para el Kahoot? ¿Del que queramos? $<$ TLANG_Sp>

H1: Del que queráis <TLANG_Sp>

S24: ¿O solo dos? <TLANG_Sp>

H1: No - no. Lo que queráis <TLANG_Sp>.

S24: Vale <TLANG_Eng>. 
H1: OK. Have you, have you got your group names? Have you decided your group names? <TLANG_Eng>

Ss: Yes <TLANG_Eng>.

H1: Yes? OK. No? So with your mobile phones. Shh. With your mobile phones, enter Kahoot dot it <TLANG_Eng>.

Ss: Eh? <TLANG_Sp>

H1: Kahoot dot it, in your mobile phones. And, enter the first option. Play Kahoot, like this. And in game pin, you need to enter this pin. Have you understood that? Yes? OK <TLANG_Eng>.

[unintelligible]

H1: Are you all here? Are all the groups here now? We have sixteen groups. Is there any other group missing? <TLANG_Eng>

Ss: No <TLANG_Sp>

H1: So now, shh, be quiet. No? You will have twenty seconds to answer the questions. Twenty seconds per question. So, don't worry <TLANG_Eng>. ¿Ya? <TLANG_Sp> So we have eighteen groups. Then I will need to know the members of the groups because not everybody has entered their names. Just some of them. Will. Is that yours? <TLANG_Eng>

S25: No me deja <TLANG_Sp $>$.

H1: ¿No? <TLANG_Sp> And any other member of your group? Or you can join - you can join another group. Let's see <TLANG_Eng>

[inaudible]

S26: No podem accedir. Hem provat, però no ens funciona <TLANG_Cat>.

H1: OK. So join the group you have in front of you. Well, we are going to start now. So, let's get ready. Do you have the colours on your mobile phone or on your tablets? The First Triumvirate was formed by three powerful men. Who is missing in the series? <TLANG_Eng> 
[students are given time to answer the question]

H1: You need to be quick. So eleven groups. Shhhh. Eleven groups got it right. And now we're going to see the fastest group. So Brillosas were the fastest ones. Then we have Vi...Violetas, C\&L, Hispania team and Isi güin. Next question. What did Caesar do in the last eight years at the beginning of the episode? This has to do with the first episode. Fifteen got it right. Shh. What legion do the soldiers belong to? $<$ TLANG_Eng>

Ss: ¡Vamos! <TLANG_Sp>

H1: 12 groups. Let's see who was the fastest one. And next question, why is the Roman legionary known as Tittus Pullo punished? Tittus Pullo was punished at the beginning of the first episode. Do you remember why? <TLANG_Eng>

[inaudible]

H1: Because he was drunk <TLANG_Eng>.

Ss: Uhhh

H1: Here we are. Who surrendered to Caesar? Who was this man? The king of the Gauls, the prince of the Gauls, an ordinary man or a semi god?: He was the king of the Gauls <TLANG_Eng>

[inaudible]

H1: Shh. After killing the king of the Gauls, what uh - what are soldiers allowed to do? They can go home, they can leave the legion, they can sack the town or they can be centurions <TLANG_Eng>.

Ss: [inaudible]

H1: They can sack the town. And they are allowed to take slaves. Atia asked Octavian to: Take a horse and live in Gaul, take a horse and kill the Gauls. Take a horse and go to Iliria or take a horse and give it as a gift to Caesar. Take a horse and give it as a gift to Caesar, but then shh: When he was in his way to the Gaul to give it ah, as I gift to Caesar, he was captured by some goals in there. So next question: Cato wants Caesar 
to...It was this one. He was against Caesar's policies. So he wanted him to answer charges of illegal warfare, bribery and treason. How does Atia want to accomplish Caesar's task? That is...Ah: Caesar asked Atia to select Pompey's wife. How does Atia accomplish this task?: By forcing her daughter to get divorced. And next question. Octavian says that the loss of the Eagle is useful because: he wants to be weak. He wants to attack Pompey first. Pompey won't attack him or Pompey will attack him: [unintelligible] Pompey will attack him. If Pompey knows about the loss of the eagle, Pompey will think that Caesar is weak, that is, he can attack him because Caesar could not defend himself. Caesar nominated Mark Antony for people's tribune, senator, praetor or consul?: People's tribune. Shh. If you remember in the - in this second episode, Mark Antony had the option to veto the motion because he was the people's tribune and all the Senate was acting against Caesar. Once they saved Octavian, how are Lucius Vorenus and Tittus Pullo rewarded? They take money, they eat food and drink with Octavian's family. They 1 - they lie with other women. Or they are given new titles: They eat food and drink with Octavian's family. Shh. If you remember, they were taking wine and there were taking some food talking to Atia. OK. Mark Antony has been delegated to negotiate with, to negotiate something with Pompey and other members of the Senate. What did they negotiate? Caesar's prosecution, Caesar's legal immunity, Caesar's exile or Caesar's resignation: OK. It was Caesar's legal immunity. Shh. They were talking about the possibility of giving Caesar a province so that they could not attack him. OK. At the Senate, a proposal ultimatum is delivered against Caesar, but Cicero supports the motion. Pompey does not support the motion. Mark Antony is able to veto the motion or Mark Antony is not able to veto the motion: Mark Antony is not able to veto the motion, shhh, because there was a fight against senators. So that was not possible. Why is Lucius Vorenus's wife worried when he returns after seven years? Because she's, she doesn't love him anymore, because she has committed adultery, because she thought he was dead, because she wants to get divorced: Because she has committed adultery <TLANG_Eng>.Shhh.

H1: If you...As we watched in the episode, the baby was hers. But, uh: when Vorenus returned home, she - she told him that the baby was her daughter's baby. And last question, why does Vorenus feel unhappy when the legion is crossing the river? Because crossing the river the - the Rubicon River implies they are traitors. Because crossing the Rubicon River implies they are fighters. Because crossing the Rubicon 
River implies killing children. Or because crossing the Rubicon River implies they have won: The first one. He said that he was not a traitor and crossing the river implies that they are traitors to Rome because uh: Mark Antony could not veto the motion at first. So Caesar was considered a traitor in Rome: And after that, we have the winners. Brillosas, who are they? Who are Brillosas, you? [laughs]. Then, we have C\&L. Who are C\&L? Well done. And, and then, Team name. OK. So we have three winners

\section{[applause]}

H1: Now I'm going to save the results: Direct download. Okay. So, all the members of the groups are included within the, within this group names' document? Or is there anyone who is not included here? <TLANG_Eng>

\section{Ss: ¿Qué? <TLANG_Sp> What? <TLANG_Eng>}

H1: I mean, you have - you have Brillosas and then you had the option of including your names there. Have you all included your names or is there any group who has not included their names and want to tell me? OK. And now, shh, we're just going to do the last activity of today's session. And it has to do with where these people citizens or noncitizens? You have five minutes more or less and then I will explain why they are citizens or non-citizens. So now you have some time <TLANG_Eng>.

[students are given some minutes to complete the task]

H1: OK. I'm coming. <TLANG_Eng>

S7: Can gladiators be citizens? <TLANG_Eng>

H1: Gladiators were mainly slaves <TLANG_Eng>

S7: But not all gladiators were slaves. Some free men decided to fight as gladiators, so they had rights as Roman citizens <TLANG_Eng>

H1: Yes, of course. If they were freeborn men, they were citizens and they could vote as Plebeians did. Hence, they can be classified in both columns as long as you point out that difference <TLANG_Eng>. 
H1: Have you finished? Yes? Okay. So now is there any volunteer who wants to tell me who are citizens or non-citizens? Or do I say...? You? <TLANG_Eng>

S7: Eh: citizens: patricians, plebeians and freedmen <TLANG_Eng $>$.

H1: And non-citizens? Then, I will explain what social groups were considered citizens and non-citizens <TLANG_Eng>.

S7: Non-citizens: women, slaves, gladiators and foreigners <TLANG_Eng>.

H1: OK. So there are some correct and incorrect answers. Citizens are Patricians plebeians and free-born women. And then, non-citizens are gladiators, foreigners, freedman and slaves. And I'm going to explain that in detail: Here we have the answers if you want to take some notes. So, first of all, if you remember, we have two kinds of citizens. We have Patricians and Plebeians and here, uh, Patricians belonged to the wealthiest group of the society. And the highest political positions were held by two consuls who were elected by a Senate formed by Patricians. In this case, social division between Patricians and Plebeians at the beginning of the republic was based on political rights because Plebeians had no say in the government. They were free, but they could not vote in the Senate. Then, uh, after the law of the Twelve tables was passed, as you, uh, read in your readings, Plebeians, uh, attained the same rights, the equal rights as Patricians, so they could vote. After...so: Then, once the law of the Twelve tables was passed, social division was based on wealth, the wealthy group and the poor group. So, apart from being divided into Patricians and Plebeians, then citizens were sub-divided into two types. We have honestiores, who belonged to the wealthiest part of the society. Honestiores were Patricians. And then, we have humiliores who were Plebeians belonging - belonging to lower classes, and they have a much lower status both in the city and in the country. And then, uh: female citizens were citizens if they work freeborn in a Roman family, but they could not vote. They were expected to raise their children and - and to take care of the home. Then, as for non-citizens, we have conquered populations or foreigners. And, uh, at first they were not citizens, but after the Edict of Carcalla was passed, they all became citizens. So, you were citizens if you were born in Rome. If you were born in Spain or in France, you were not considered a citizen until the Edict of Carcalla was passed and was applied. Then, we have Freedman. Freedman, were slaves who had been freed by their owners, by their masters, 
also known as manumissio or who had bought their freedom. And slaves, of course, were non-citizens. They had no rights and they were considered property of their master. And uh, you could become a slave for several reasons. Here I have three of them. And you can see, you could become a slave if you were conquered in war. As you saw, Romans ehh: took slaves when - when they won against the Gauls. Then, you can... you could also become a slave as a punishment for paying debts. And also, in this case, um: the pater familias could sell members of their family if they could - if they could not afford giving food to them. And then, you could also become a slave if your parent was a slave. If your mom was a slave, you were born a slave. OK?: And that's old for today. We have five minutes left, you can ask some doubts if you want: Remember that during next session we will see the last two activities you have in your workseets. Bring them on Monday the fifteenth 'cause I will take them home. And if you have any questions or any doubts, contact me for your oral presentations. I will also send you an email with the - with the timing of your presentations. Okay? <TLANG_Eng>

\section{APPENDIX III (b): History of the Classical World (Oral Presentations)}

H1: OK. Be quiet. Now we're going to start with your oral presentations and the first group here is S1, S2 and S3 <TLANG_Eng>.

S1: Hello. I am S1 and these are my companions S2 and S3. We - we, eh: want to talk about education, theatre and funerals in Rome. Eh: I will start with: - with education in ancient Rome. A::nd the first, the first I want to do is eh:: eh: is to make a partition of three periods. The first period was the ancient Rome and eh: it was eh: the biggest period of education in Rome. Eh: the second place is for the Greek period and it was eh: it was eh: growing the - the ancient system of Rome with eh: a lot of preceptors, philosophs and rhetorics from Greek. And the - the third period of the education in the under empire was the - the time for the Christian religion. It makes that the Greek concepts of the education eh: ah: grow down and the Christian concepts of the education, religion grow up. OK? Then we start with the ancient Rome. At first the education of the Roman people starts with the mother. The: the mother starts education, domestic education and a little bit of public education eh: to the zero, until year, until seven years. Ehh then we start with father education. Ehh it starts at seven years and finish until seventeen years. This education is centrate to be a good Roman in a public life and for the world of the pater. In third place, we have to the preceptor education. It 
was more public education. It was for education make for the State: and starts at seventeen years and finish more less at 19 years. OK? Eh:: then we can pass to the Greek period. Eh: the Greek period changed something like something very important in the Roman culture. Roman culture was a familiar culture where appears the Greek preceptors, philosophs and rhetoric. And this education is more public and menos fami... $<$ TLANG_Sp $>$ and $<$ TLANG_Eng $>$ menos $<$ TLANG_Sp $>$

[laughs]

S1: A:nd <TLANG_Eng>

H1: less <TLANG_Eng>

S1: and less familiar. OK. And eh: it starts with Ludus literarius to the zero at seven years and then Grammaticus and rhetoric to the seven no, to seven to twelve years. I'm nervous <TLANG_Eng>.

[laughs]

S1: Ay: <TLANG_Sp> OK. And then we finish with the under empire. Eh: is the last classical education in Rome and it makes the start of medieval age because Christian religion starts to make, starts to grow up ehh in the culture of Roman people. And now I finish and I pass to my companion <TLANG_Eng>.

S2: Hi, my name is S2 and I'm going to talk about the Roman theatre. First I will explain the... - its origin and its parts <TLANG_Eng>. Vale <TLANG_Sp>. The Roman theatre is a copy of the Greek theater. What surprise, right. But everything wasn't a Greek copy. The theatres also had parts that were Roman. One difference eh: is that Romans has a semicircular plant and the Greek hasn't have $<$ TLANG_Eng $>$. Pasa, S2. <TLANG_Sp> [making reference to the slideshow presentation]. Now I will briefly explain to the parts of the theatre. The theatre had many different parts. Some of them are. The number one is the Scenic front. The number two is eh: the space with columns behind the scene. Number three and number four is the same and haa and are the same <TLANG_Eng> ay perdón <TLANG_Sp> is where actors act. Eh number five S2, Bueno <TLANG_Sp>, is where the choir act <TLANG_Eng>. The number six is where people sat. Eh:: the number seven is the side entrance with corridors to the orchestra. And number eight it's where people come in. In second place I'm going to talk about 
the importance of the theatre for the Romans. The Roman theatre was important because it had different objectives: dynastic advertising, interpretation of Greek and Latin works, religious proposes bound to the cult of Dionysus, distract the population from problems. In third place I will say some the works that were represented. In the theatre two types of works were represented like comedies and tragedies. Just say a few examples of two. In comedy we have works como ah: eh: Cupuncula esta [laughs] ehhh Anfitrión and Las comedias de los asnos $\langle$ TLANG_Sp $\rangle$. And in the tragedies we have Edipo rey, Electra <TLANG_Sp> and works. S3? <TLANG_Eng>.

S3: I am S3 and I will talk about funerals in the ancient Rome. In the ancient Rome, funeral was a transaction eh: between the pass of life to the death. It was very important to did it correctly the rite because they avoid the bad spirits [laughs] And - and, generally the funerals divide in five parts: ehh percession, cremation and burial, eulogy, feast, and commemoration. In the first part, procession, eh: consist in the move of the bodies. When more wealthy and well-known the deceased was in life, more ostentatious was the procession em:: with musicians and mimes (mains). The poor people, maybe only a few flute players. Also in the rich people, eh: professional mourners formed part of the procession. These womens weren't part of the family members [pronounced as menbars] em:: of the defunct and they would wail loudly. As well freedmen or clients formed in this part of the funeral to show respect to their patron. In the second part, ehh cremation, the body was taken to the necropolis to burn it. Fragments of bones and teeth were keep in a funerary urn. Ehh If the defunct was an important member of the society the family would offer a eulogy in the funeral. The last part is the feast. The feast is the last point to tell the defunct to be continue his trip to on to the underworld. In this part commemorative, Rome set apart certain days to remember deceased, and individual families had a personal days to commemorative the person who pass away. And this is the funerals in Rome <TLANG_Eng $>$.

\section{[applause]}

H1: Thank you very much for being the first group in doing your oral presentation. And I just have one question and it's: why did you decide to connect funerals with education and theatres? Is there any connection you found or is it just because you wanted to cover amm those issues? <TLANG_Eng>. 
S1: It's because we think one thing for one person. And three $<$ TLANG_Eng $>$.

S2: I think the connection is the ancient Rome. In the ancient Rome education is a part important to form the future person and work in the future. The theatre Rome is I don't how to say it. Fun? to the spectacles to fun to the persons who, <TLANG_Eng > bueno $<$ TLANG_Sp> to rich people and death I think that religion is a part important and funerals is a font to say that he had. The persons who the spirits I think they are represented in the theatre <TLANG_Eng>.

H1: OK. And then some pronunciation aspects just for you to bear in mind in the near future. So Ah: Rome - Rome, OK? Then, amm we also had cult, it's cult, el culto de algo <TLANG_Sp>, cult. Am philosophs, philosophers. And then for example, you had in one of the slides, consist in, and it would be consist of. OK? And that's all, thank you very much <TLANG_Eng>.

\section{[applause]}

H1: Now the second group today consists of S4, S5, S6 and S7. Shh. Now we're going to listen to the second group <TLANG_Eng>.

S4: Good morning everyone. First of all, Well, I see some faces, so I introduce myself. We are ehh S5, S6, S7 and S4. And today we are here to talk about eh the Roman entertainment, we are going to talk how the Romans had fun. We took the example of a Roman gladiator and first - the first thing we have to know is what a Roman gladiator is. A gladiator is - was a man who was trained to fight in: - with weapons in - in public places like the Colisseum or the amphitheatre. We this point we know this because of the paintings in the walls of the ancient Rome, and most of the gladiators to fight were volunteer themselves because they wanted to became famous or earn some money. Like the - the gladiators, like I said, they trained, their lives is not easy and they trained in public places like the arena and they trained so hard to be in good form. They were trained by another gladiator that he needed by the work eh: and he trained to the gladiators and... eh: to finalise my presentation eh: we're going to talk about the families, wives, they lived in their houses but not all the gladiators have families. The father was the household of the house and he was in control of the - of all of the member of the house and eh: some values in the family was the religion. And now my partner S5 is going to talk about the family in the ancient Rome <TLANG_Eng>. 
S5: Hello, I am S5 and I am going to talk about the family gladiators and why is important. Eh: first of all, the gladiator is a solitary man eh: but many gladiators haven't got families. Eh many gladiators were undervalued because em they were criminals or slaves. Ehh when thee ehh gladiator are liberty, free man and volunteer, the gladiator are famous because eh this gladiator eh has got eh social obligation and family obligation eh and this [coughs] is important because em the gladiator are famous and not valorate and insignificant. Then, emm in the ludus the gladiator, well in the ludus lived the gladiator family and the gladiators showed affection and respect among themselves and next is S6 <TLANG_Eng>.

S6: Hi, I'm S6 and I'm going to take, talk about teps, types of gladiators today. The first thing we should the gladiators. Gladiators fight to distingate him by the weapons and his house. Initially, it's believed that gladiator was a slave. but now eh: eh: sorry. Later to define weapons and dress. Why do you know suddenly how many types of gladiators decide but from the study it take a place at now? It's calculate that there were twenty-six different types of gladiators. Now I talk about different types. The Samnite has a sword or lance, large square shield, protect armour is the most famous ones. The Thracian gladiator had a curve short sword, very small square and round shield. The Myrmillo gladiator: short sword, scutum, and armour only of padding, arm or leg. The Retiarius: no armour, padded soulder piece, weighted net, and trident. The first, there are four types of gladiators, the first group is the Elite type gladiators, Amazones, Gladiatrices, Rudiarius, Tertiarius, Sagitarius. The second group is the types of heavy arm: Catafarius (Cataphractarius), Gallus, Gallus is the people who Gallia, Hoplomachus, Provocatores, Samnites, Secutores, Scissores [pronounced as scissors] and Murmillones. The third group types are lightly armed: Dimachaeri, Thracian Eques, Essedari, Laquerarii, Paegniarius, Retiarii, Velites. The fourth group are unusual: Andabatae, Bestiarii, Bustuarii, Naumachiarii, Praegenarii, Venatores, Paegniarius. Finally, to talk about other types of gladiators: Auctorati, Veterani, Meridiani, Catervarii, Noxii, Gladiatores Fiscales, Gladiatores Postulatitii, and Taurarii gladiators. And now S7 about the exposition <TLANG_Eng>.

S7: Two mens eh two mens reading reports. In the, the gladiator is a man about participate in the combat, in the combats in the Colosseum [pronounced as colisseum]. Colosseum is a place in the centre city and in there realise a different games. It's a stadium in three levels. It's in circular, it's a circular place and is where realise the 
games in a more expensive eh eh extravagant and is most famous because is a combat the two mens on different differents things. Emm in the - in the Colosseum is a, is amm upper level is for a eh com - commoners eh ah and box seats for the wealthy and powerful [pronounced as payful]. Ese $\langle$ TLANG_Sp > in this - in this - in this box are people and who eh, people have more - more money and - and important important...<TLANG_Eng $>$.

H1: positions <TLANG_Eng>.

S7: positions. Eh:: in different, in strange occasions, combats realise men and animals but ehh in - in a different games realising to the in the Colosseum, battles navals eh, eh, eh battles navals, gladiator race, eh gladiator battles, and animals and gladiators. For example, battles in ah navals battles eh in the Colosseum eh uff. The Colosseum was also with things are flood, food and water. And the problem is this... - the - is in the infrastructure of the Colosseum are desgasted and destroyed because amm this game is celebrated. And a typical animals battle is realised in the Colosseum are, were wolves, lions, tigers, emm, elephants. Eh ah and the battles the humans and lions emm is realised after the battles the gladiators because kill human and destroyed everything and this is final <TLANG_Eng>.

[applause]

S4: ¿Te lo quito esto? <TLANG_Sp>.

S7: Sí, por favor <TLANG_Sp>.

H1: OK. Thank you very much. And amm it's just a curiosity. Why did you decide to talk about gladiators? <TLANG_Eng>

S4 Well I thought that one part that. We thought that we could eh talk about the entertainment in the daily life of a gladiator <TLANG_Eng>.

H1: Then, some things amm. You said mens and womens. And it would be just men and women because that's already plural. And then, more or less <TLANG_Eng>.

S6: Not all types of gladiator are women <TLANG_Eng>.

H1: No, I'm not saying that. I'm just saying that you said mens. It's men 
<TLANG_Eng>.

S6: Ah <TLANG_Sp>.

H1: It's already plural. It's just that, a grammatical aspect. And that's all, thank you very much <TLANG_Eng>.

[applause]

H1: Now the third group is $\mathrm{S} 9, \mathrm{~S} 10, \mathrm{~S} 11$ and $\mathrm{S} 12$. Who uploaded the project? $<$ TLANG_Eng>.

S9: Eh S10

H1: Açò si voleu menejar-ho o lo que siga, podeu menejar-ho, eh?:: <TLANG_Cat>. OK. Now let's get ready to listen to the third group. <TLANG_Eng>.

S10: Hello, good morning. We're going to talk about the gladiators like the other group. Emm gladiators live in residences like schools of gladiators eh where they live there together or together. And in that places they trained, ate, rested all together. Eh these places usually were usually were near to the Colosseum, the place where they used to fight in front of the public. Emm in that places the gladiator schools everything involves around the Arena. It's the place - it's the place they eat, train and all rooms in place have used to that arena. Eh these rooms are quite small, without luxury except the ones for the famous gladiators. They have a different place with more comfort and the other ones, average gladiators emm have to share the room. Emm the first thing that gladiators did in the morning were to the dining room and have breakfast and then they went to the arena and start the training. Eh if someone - If something happened during the session, they have a medical centre in the school itself because eh gladiators is an expensive investment, so the owners of gladiators ehh procures everything for its investment. Eh at the end of the morning they retire to the dining room and eat abundant leaf because they have, they followed a special diet based on legumes and rice and cereals to gain weight. In the afternoon more training and at the end of the day they come back to the school, bath and massage. Eh ah the day ends with a dinner with the other gladiators and the trainers altogether. When they finished they went to their rooms and rest for the other day. And... $<$ TLANG_Eng $>$. 
S11: And I'm going to talk about the train of the gladiators and they have $a-a-a$ trainer who he learns to them how to fight and where to do some expectation. Because to train a gladiator is very expensive and they want they don't die. And for that they fight with wooden weapons when they are training. The iron weapons and all of these are only for the arena. Emm this is the training academy and they have an arena and they have two, and they are fighting with animals, like horses or something like that. And there are four types of there are four specific or more famous types of gladiators. The Retiarius who have a net, and a trident and they have a loft armour because they need more agility to throw the net or for move more specifically. The Myrmillo gladiator wear a sword and a shield and they have $\mathrm{a}-\mathrm{a}-\mathrm{a}$ light armour because they don't need mobility and they need more protection <TLANG_Eng>. Después $<$ TLANG_Sp>, the Tratius has a main armour. They are more fondness, they have more strength. For this they need a lot of protection, but they eat more strongly. And the last type that needs more protection and more strength who have played armour and this is the protection for them and this eh biggest shield and the longest sword because they move very rude and they need to do all his, to do all his potential of strength. Now we are going to talk about the diet of the gladiator <TLANG_Eng>.

S12: Hello, I'm S12 and I'm going to talk about the gladiators' diet. Most studies say that gladiators had a vegetarian diet. It is because we haven't got any indication of the ingestion of meat after analysing the fossils of these, of these Roman bones. While I was saying is that:: the diet was based on cereals, such as garlic, wheat, legumes or other grains. Eh bueno <TLANG_Sp>, finally it is observed that the analysis of the Roman gladiators had much, much higher levels of calcium than other. It is cause by a great number of plants that they consumed to recover the energy <TLANG_Eng>.

S13: Hello. I'm going to talk about the combats of the gladiators. I'm gonna talk about the...before about the shoulder-shoulder combats. The combat about the weapons and the games, and its powerful weapon was - were: his body. I mean they train for a strongest body because they want to be relentless warriors on the field. So the train before the skills with a sword, they trained his body. So you can see this photo where a warrior is fighting with his body against this man. One point of the physical combat is that of the gladiators is part of the [unintelligible]. Another point of the combat is to throw the other man on the floor, so he can defend himself but also it's easy to keep him. Emm the second thing to gladiators is to have a vision of the combat based on the 
opponent is the other vital point. They were the armpit, the neck, the knee and the stomach. Only one scratch because only one catch or one scratch is one win. After that the opponent, your opponent can rise and the editor choose if your opponent lives or dies. Next one? Most of the times, they choose the death because it's more fun for the public. So, that's all <TLANG_Eng $>$.

[applause]

H1: OK. Thank you very much. I think it was a very good presentation and I found it really interesting that gladiators didn't eat meat $<$ TLANG_Eng $>$.

S11: They were vegetarians <TLANG_Eng>.

H1: OK. And how did you find out about that? How did you know that they were vegetarians? <TLANG_Eng>

S11: Because of his complexity. They have a high weight because they need so much energy because they train like hours daily and for this they eat more to get more energy to stand because if not, they die <TLANG_Eng>.

H1: OK. Thank you very much <TLANG_Eng>.

[applause]

H1: Next group? We have S13, S14, S15, S16 and S17. OK, so let's start with this presentation <TLANG_Eng>.

S13: Hi everybody, ehh we are S14, S15, S16, S17 <TLANG_Eng> y mi <TLANG_Sp> name is S13. And our group, the topic - the topic that our group has chosen is the family in the ancient Rome. We are going to talk about the structure of the family where pater familias had the main role and we are going to talk about also em emm another aspects like the wedding, the divorce and a: - a Roman wedding, that's all $<$ TLANG_Eng $>$.

S14: Hi, I'm S14 and I'm talking about Roman family. My figure is a pater familias, the father, and he was a governing body. Ehh he has an obligation to support family and represented it in ehh in politics. Eh the children they have they were ah: citizens. They were who slaves. The wives do the work at home and ehh he had an obligation to satisfy 
the pater familias. Eh the slave didn't' have a freedom and they do some tasks in the eehh in the home and labour home. Eh the freedmen were the slave more loyal to the pater familias and the - a long time if do the task well, they obtain the freedom. And finally the clients were free people who support the pater familias economically $<$ TLANG_Eng>.

S15: I'm going to talk about the marriage in the ancient Rome. For a valid marriage in the ancient Rome it was necessary with respect ehh three requirements. A minimum age of fourteen for men and twelve years for women, legal capacity and the consent of the respective pater familias. Eh there were two legal forms for marriage: cum manu and the sine manu. The marriage cum manu the woman pass for the authority of her father to the authority of her husband. It was a patrilineal and patrifocal form of marriage. Eh this form of marriage was manifested in three forms: confarreatio, coemptio and the uses. The formal marriage was fall in desuse around the end of ehh the end of the Republic with a rising in the form sine manu and the wish the woman remained under the potestas of her father or a guardian if the father died <TLANG_Eng>.

S16: Hi, everyone. My name is S16 and I'm going to talk about the ceremonies. First of all, the rituals of the wife house, sorry, the bride's house and what they do is to start the ritual in which they celebrate a little in ehh in honour of the goddess Juno in which they sacrifice an animal and if the remains are good what they do is to continue with the ritual. After this, what they start is the ceremony in which the capitulations wear it and they, the authorization for the dowry that the father of the bride received here reflected in the tabulae nuptial. What they do is to, when they finish, $\mathrm{mm}$, they provide the - to the couple and after this the godmother take their hands and they start to, what they do is symbolise the right of the family of the husband and they start to make a dinner. After this they go to the husband house and the husband goes to the room to pray and the woman also goes to pray in other room and what she wants is to have a good future and when they are finished she, she go where the guests are and they altogether pray for a good future and a good fertility. And that's all. Now, S17 is going to continue with the presentation <TLANG_Eng>.

S17: There were three types ay <TLANG_Sp> three types of divorce in Rome: Strictu sensu is the divorce with the mutual agreement and the decision is made by the - by the woman. Contrary to this, repudium is the divorce decided by the husband and this is 
made in front of seven witnesses. And the usus is an immediate divorce and it occurs when a woman em: when a woman spends three days away from home. And... $<$ TLANG_Eng $>$.

\section{[applause]}

H1: Thank you very much. I just have one question. And when did couples get divorced? In upper classes? Lower classes? <TLANG_Eng>

S17: Eh:? <TLANG_Sp>.

S14: Que en qué clases sociales se divorcian <TLANG_Sp>.

S17: Oh [laughs] I don't know <TLANG_Eng $>$.

S15: Upper classes: Upper classes because they had rights that low classes didn't have $<$ TLANG_Eng $>$.

H1: OK. So, apart from that, what is the most striking thing, the most unexpected or surprising thing that you have learnt about weddings or divorces? <TLANG_Eng>

S16: getting divorced is something that maybe you don't know and it's strange because you may think that it's something from nowadays <TLANG_Eng>.

H1: OK. Thank you very much <TLANG_Eng>.

[applause]

H1: Now we're going to have the last group and then we'll have a short break. S18, S19 and S20 <TLANG_Eng>.

S18: Hi, we are S19, S20 and S18 and we are going to play a role of different kind of women in the Roma. We are going to explain the day to day of her depending on their social status. First, we are going to start with Andrea, who is going to perform the role of a patrician woman who get married with a procrastinate. Then, we're gonna continue with the performance of S19, who is gonna be a virgin woman who has to get married with a man who she doesn't love just because the volunty of her father. And finally I'm going to do the perform of a prostitute woman who get married to the emperor Claudio and who's going to sleep wise a lot her job $<$ TLANG_Eng $>$. 
S19: Hi, I am a Roman woman and ehh I'm in love to the Patricians. My family is one of the oldest eh: in Rome. We have a older privilege, for example in eh prosecutors eh and to descent. My destiny was written in child. When I was born I was a child I had learnt to obey. I've always known that I would be the one to make it the status of my family. Eh: I married in the richest eh: And more important senator in all of Rome. With him I have had ah five children, but only one varon is the future senator in Rome. Emm my life is based on taking care of my childrens because I don't dedicate eh: housework since <TLANG_Eng> ehh a ver <TLANG_Sp> all work is done the slaves. <TLANG_Eng> Ehh a ver <TLANG_Sp> I live without obligations. I must attend with him in public always, for example in spectacles, in games, eh: but my influence is never recognited <TLANG_Eng>.

S20: Hi, I want to say that in a few weeks my life will change, but before telling what happens I put some context em: since I was little em: I have been taught to show respect and be very polite, especially to my father because a woman must show loyalty to her father and after to her husband. Em: em:: I have never questioned that my parents tried me differently from to my <TLANG_Eng> a ver <TLANG_Sp>. They tried me in a different form - form than my brother Marco. Em: I went to school, but when I was 12 years old em: I had to stop going to school and stay home. I must thank them I suppose they let me play with my brother, but if I start having a backlit my father would scold me. And speaking about scold that few months ago mm my father was talking to my brother about politics and I asked about it. They both got mad at me and I understand that that isn't commecicius [cautius] and my mum explained to me more kindly that that's not permitted. Eh: em: All this, $<$ TLANG_Eng $>$ uy $<$ TLANG_Sp $>$ all this has always been normal. Now coming back to the beginning, I know that in a few weeks I'm - I'm going to marry with a man that I almost don't know and who is ten years older than me just because my father has an agreement with him. I could only reject the marriage if I could prove that he is a man with a bad character, that's the only option to free myself, but according to my father this deal is the best for him and I suppose for me too. This makes me think that it's the right thing, but on the other hand it seems like he's selling me as an object and that is how my marriage and life works <TLANG_Eng>.

S18: I'm tired. I'm really tired 'cause I wanna be recognised socially and I wanna be treated as a roman citizen. I wanna have more privileges like them and that's why I'm 
so tired. I'm feeling tired to this profession. Emm I'm not feeling bad; I'm not feeling bad because of this because I think it's the only way to be a free woman. I have heard this works so many times to so many different kinds of prostitutes, but it's not my case, not at least in the negative way. I mean because I'm feeling a free woman being a citizen woman, Roman citizen and being a married woman and I think able because my job. I'm Valeria Messalina, I'm the woman of the emperor Claudio and I have so many influence in his political decisions, but anyone recognize my job. Eh people criticise my job just because they think that a woman with a good life like me can't do this but I enjoy a lot. Maybe again because I had, because I'm a scandalous and libidinous woman. But I think that the problem is that men in this time, they don't they don't, they never have to face a woman who doesn't be scared for have to be her amm heard that open. I must told you that em I must tell you that em there are different kinds of prostitutes. I'm in the highest rank, I'm a delicatae Emm people consider me a higher cache and I'm like the most wanted prostitute. That's why o sea, that's why they. Therefore, just powerful men can offer my service, but first of all, I'm the one who chose my clients and who decide when and with who and where I wanna offer my service. But I have to told that not all prostitutes have this privilege. A normal or an ordinary prostitute has to wait in the open air and spend time there with the clients. Ehh I think that I will never give my service in a place like that. That's why this next weekend I'm gonna organise ah - a - a festival in my palace in the absence of my man of the emperor Claudio and I'm gonna do a challenge with the rest of prostitutes for looking who can get sleep with more men <TLANG_Eng>.

[laughs]

S18 and S19: That's all <TLANG_Eng>.

[applause]

\section{APPENDIX III (c): Fundamentals and Theory of Artistic Heritage}

H2: Esta asignatura es en castellano pero hay que hacer alguna actividad en inglés para ir familiarizándoos con el vocabulario específico en historia del arte en inglés y tenemos que hacer una actividad vinculada a la asignatura. A ver, este año la actividad en inglés que hemos planteado para que, ya os digo, para que os vayáis familiarizando con el 
vocabulario específico y demás eh: va en relación al último de los temas que hemos visto. Sobre el coleccionismo hay mucho. ¿Qué estuvimos hablando la semana pasada? ¿Os acordáis? :: No ¿Nada? <TLANG_Sp>.

S1: Museos <TLANG_Sp>.

H2: ¿Y qué hablamos de los museos? <TLANG_Sp>

S2: Del coleccionismo de las monarquías y de la nobleza, los mecenas <TLANG_Sp>.

H2: Vale, estuvimos hablando del coleccionismo. De cómo a partir de ahí eh: surge ¿no? El acumular distintas obras y luego exponerlo en el museo. ¿Qué funciones tenían los museos? <TLANG_Sp>.

S3: Conservar, ¿no? <TLANG_Sp>

H2: Conservar. ¿Qué más? <TLANG_Sp>

S4: Educar <TLANG_Sp>.

H2: Educar, enseñar, restaurar. Son también centros de investigación. Pues es un poquito, en torno a todas esas ideas, vale, yo lo que he hecho para esta práctica es em: buscar en las páginas oficiales de museos, vale, em: ¿A alguien le falta el cuestionario? Bueno, lo que os decía <TLANG_Sp>.

S5: ¿Y del Museo del Prado no hablaremos? <TLANG_Sp>

H2: Sí, pero el problema del Museo del Prado es que no cuelga material en inglés, entonces no:::::: Escuchadme un segundito, empezamos ya. Entonces lo que he hecho ha sido seleccionar una serie de vídeos eh de extraídos de las páginas oficiales que cuelgan museos tipo el British, el Metropolitan, o el Getty en sus páginas oficiales de YouTube y están dedicadas a, cada uno de ellos se dedica a un aspecto. Pues algunos de ellos pues por ejemplo cómo se crea ese museo, cómo se construye por ejemplo el edificio del museo. Acordaros que hay algunos de ellos que se crean en edificios históricos, otros que se ubican en edificios de nueva planta. También hay algún vídeo que muestra un poquito cómo se va organizando y elaborando una exposición eh: temporal. Otro que, que habla de la vertiente relativa de los museos, ¿no? De cómo pueden enseñar a los alumnos a través de obras de arte. Y otro que habla un poquito de eh, de lo que es el departamento de investigación dentro de un museo. Entonces eh: he estado revisando 
todos los vídeos, haciendo una selección de vídeos y os he os he planteado un cuestionario una como este donde tenéis una serie de preguntas, ¿vale? Y cuando acabéis de ver los vídeos, tendréis que redactar un comentario en inglés <TLANG_Sp>.

S6: ¡Cómo no! <TLANG_Sp>

H2: Preferiblemente <TLANG_Sp>.

S7: En cualquier lengua extranjera <TLANG_Sp>.

H2: No, en cualquier lengua extranjera, no. En inglés, como podáis. A ver tenéis ordenadores, tenéis el linguee, el wordreference. Bueno, hay muchas herramientas hoy en día y se puede redactar en inglés $\langle$ TLANG_Sp $>$.

S8: ¿Pero lo hacemos solos o en grupo? <TLANG_Sp>

H2: Lo podéis hacer individual o en parejas <TLANG_Sp>.

S9: ¿Pero habrá subtítulos? <TLANG_Sp>

H2: Hay algunos - hay algunos que tienen subtítulos en inglés y otros que no tienen subtítulos. Los vídeos veréis que son cortitos, ¿vale? Eh Si, si, si veis que no pilláis nada, os pongo los subtítulos, ¿vale? Pero en inglés siempre. Bueno, ¿estáis preparados? Si tenéis cualquier duda o cualquier cosa, me lo decís, ¿vale? Eh ¿cómo queréis que lo estructuremos? ¿Veis primero un vídeo y os apuntáis en sucio aunque sea ideas clave y tal y luego ya lo redactáis todo? <TLANG_Sp>

Ss: Sí <TLANG_Sp>.

H2: Vale <TLANG_Sp $>$.

S10: Yes <TLANG_Eng>.

S7: Yes, of course <TLANG_Eng>.

S5: ¿Este cuál es, este? <TLANG_Sp>

H2: El British Museum <TLANG_Sp>.

[Video 1 played in English] 
H2: Did you understand the video? <TLANG_Eng> ¿Lo vuelvo a poner con subtítulos? $<$ TLANG_Sp>.

Ss: Sí <TLANG_Sp>.

H2: Sí <TLANG_Sp>.

S11: ¿Pero tenemos que contestar a todas las preguntas? <TLANG_Sp>

H2: No, a ver - a ver. Yo os he puesto aquí una serie de preguntas para que os sirvan de guía. Vosotros vais cogiendo apuntes, ¿vale? Y en vuestro comentario podéis incluir estas preguntas y además ampliar con lo que vayáis entendiendo, ¿vale? Pero más que nada os he puesto unas preguntas guía para que, no sé, "al ver los vídeos a ver yo ahora aquí que cuento"<TLANG_Sp>.

S12: Tenemos que contestar a esto, ¿no? <TLANG_Sp>.

[Video 1 played in English with subtitles]

S13: No m'ho esperava. Jo açò no m'ho esperava <TLANG_Cat>.

H2: El què? La pràctica en anglès? <TLANG_Cat>

S13: Sí, jo açò no m’ho esperava <TLANG_Cat>.

H2: Pues <TLANG_Sp> vos vaig avisar la setmana passada, eh? <TLANG_Cat>.

Ss: ¿Qué:? <TLANG_Sp>.

H2: Que dice que no se esperaba venir y hacer una práctica en inglés. Que ya lo dije la semana pasada.

S14: Yo creo que no dijiste que era en inglés <TLANG_Sp>.

S13: Si ho sé, no vinc <TLANG_Cat>.

H2: Pues se me olvidó decir que era en inglés <TLANG_Cat>.

S13: Jo vaig vore eixa diapositiva. Eixa diapositiva la vaig vore $<$ TLANG_Cat $>$.

H2: Eh a ver açò és com una pràctica més que després com totes les practiques vos vos ajuda a pujar nota. Però ho heu de fer en anglès <TLANG_Cat>. 
S14: ¿Esto que es? ¿El Metropolitan? <TLANG_Sp>.

$\mathrm{H} 2: \mathrm{Hmm}$

[Video 2 is played in English]

T: Do you understand this video? <TLANG_Eng>.

Ss: Yes <TLANG_Eng>.

S15: Very easy, American <TLANG_Eng>.

S6: Awesome <TLANG_Eng>.

H2: So now we are going to - to watch a video about eh how to use the artworks to - to teach Art History, OK? <TLANG_Eng>

S11: ¿Qué? <TLANG_Sp>.

SX1: ¿Qué significa MOMA?

H2: The Moma is the museum of modern art. Modern Art of New York <TLANG_Eng>.

S13: Pots tirar cap arrere un moment? Al prinicpi? <TLANG_Cat>

H2: Eh? <TLANG_Sp>.

S13: Pots començar? <TLANG_Cat>.

S17: In English, please <TLANG_Eng>.

[laughs]

H2: Do you want subtitles? <TLANG_Eng>

Ss: Yes <TLANG_Sp>.

H2: Yes. Are you sure? <TLANG_Eng>

Ss: Yes - yes - yes <TLANG_Sp>.

H2: ¡Qué pregunta! <TLANG_Sp>.

SX2: Pon los subtítulos en búlgaro <TLANG_Sp $>$. 
H2: ¿En búlgaro? <TLANG_Sp>.

SX3: En ruso <TLANG_Sp>.

S10: Però en castellà no n'hi ha? <TLANG_Cat>.

H2: No, no, no n'hi ha castellà <TLANG_Cat>.

[Video 2 is played with subtitles]

H2: Do you understand this video? <TLANG_Eng>

Ss: Yes <TLANG_Eng>.

H2: Do you want to see again? Do you want to watch again the video? No? <TLANG_Eng>

Ss: No <TLANG_Eng>.

H2: It's not necessary, OK. So now here we're going to watch how to prepare an exhibition <TLANG_Eng>.

[Video 3 is played in English]

S4: ¿Este vídeo no lo repites? <TLANG_Sp>

H2: ¿Este? No. ¿Para qué?:: <TLANG_Sp> Now we're going to watch a video about the - the Getty Museum <TLANG_Eng>

[Video 4 is played in English]

H2: Do you need to watch the video again with subtitles? Yes? No? <TLANG_Eng>

S: Sí, ya está <TLANG_Sp>.

Ss: Yes <TLANG_Eng>.

H2: Yes? <TLANG_Eng>

SX4: Pero hay que poner poca cosa, ¿no? No hay que poner un testamento $\langle$ TLANG_Sp>.

H2: A ver pero si lo ampliáis mejor <TLANG_Sp>. 
S6: Esto es improvisación, ya está <TLANG_Sp〉.

S11: Yo el principio necesitaría verlo otra vez <TLANG_Sp>.

S15: Sí, yo también <TLANG_Sp>.

S10: Es igual - es igual <TLANG_Sp>.

H2: No <TLANG_Sp>.

[Video 4 is played with subtitles]

SX5: Vale, ahora sí <TLANG_Sp>.

SX6: El último <TLANG_Sp>.

SX7: Pero esto nos costará mucho escribir todo esto, ¿no? <TLANG_Sp>.

H2: And now the last one <TLANG_Eng>.

SX8: Esto es una barbaridad. Con este trabajo no acabamos nunca <TLANG_Sp>.

H2: About the Gunggenheim in New York <TLANG_Eng>.

[Video 5 is played in English]

H2: So do you...? [music played by error on YouTube]. Ay Sorry, sorry. Ya. Now you have time to write your commentary, OK? <TLANG_Eng>

SX9: Ahora? <TLANG_Sp>.

H2: Any questions? Yes <TLANG_Eng>.

[students work in groups]

[inaudible]

H2: Vale, cuando terminéis me dais las fotocopias y hemos terminado <TLANG_Sp>. 


\section{APPENDIX III (d): Valencian Art and Tourist Resources (lecture)}

T: OK. Today we are going to talk about the development of arts in the Kingdom of Valencia and Whoa, this can also be applied to the rest of Spain during the 18th century. And I'm going to talk to you about a very particular phenomena that is called academicism. So the creation of Academy of Fine Arts [today we are going to focus mainly on architecture], which I'm going to say: can be applied to architecture, painting and sculpture and it's a very different situation that is always linked with the development of politics in Spain. As you already know, 1700 is the moment in which the dynasty that rules Spain and the Spanish monarchy changes because the last of the Spanish Habsburgs, Charles the second dies without an heir OK? In his last will, he designates Philippe of Borbon, a French monarch, as his heir, and so the dynasty changes. From this moment onwards, a new dynasty, till now, rules Spain and its kingdoms. The situation of Spain also changes because immediately after the death of Charles II, Eh, there is a war between the Spanish Borbons and part of Europe:: And after his oath Spain loses most of its: - of: its European possessions, including Flanders, Naples, Sicily: mmm, and emmm:: Spain remains only the Iberian Peninsula and the American Empire mmm. But the rest of possessions go to different rulers of Europe. OK? So, the Borbons, the French rulers, were incredibly different from the previous Spanish Habsburgs. The Spanish monarchy of the Habsburgs was a system of different realms, of different kingdoms with one and only king in Madrid, but different kingdoms with a relative independence mm such as Castille, Valencia, Aragon, Catalonia, Naples, Mexico, mmm. The Borbons, that had ruled in France for three centuries in this moment, are completely different. France was, during the 18th century, a very centralized State. So not a system of kingdoms, but only one kingdom with a strong ruler in Paris. When Philippe of Borbon arrives in Spain, he tries to transform the previous system, the previous political system into something similar to his homeland, to France, OK?:: Tries to...Well, he actually abolishes this independence of the different kingdoms and creates an absolute state as France was during the 17th century. Okay? So with a French mind and a French braining and a French point of view on the way the country must be ruled hmm, he establishes, different systems of the main over the Spanish curriculum hmm and they can be seen perfectly, also through architecture because he creates a system of royal palaces, surrounding the capital Paris. Most of them will be perfectly known to Spanish students, such as La Granja or Aranjuez mm. 
And also a different system of royal factories mm. All the, through the territory. These palaces were thought to preserve the real presence of the king in the different territories of the Iberian Peninsula mm that were not anymore more independent kingdoms but a unified kingdom ruled from Madrid and affected as well:: The eyes, the development of the eyes. We have been shown through the previous lessons, the situation of architecture and painting and visual arts in the kingdom of Valencia mmm. And we have been setting its incredibly rich architecture with a lot of stucco and gold and the volume and sculpture everywhere and fresco paintings and all of that. We have also seen this religious thing taking that was typical for Spain during the 17th century with a lot of emotions, a lot of blood, a lot of religious actions in the century, France, and Philippe of Borbon, was completely different, OK? That he can sustain and he takes with him that French fashion on arts, dressing and everything and tries to impose this new taste in the Iberian Peninsula. Also, the first Borbon in Spain were incredibly worried about the development of arts. Why? Because they considered that a strong ruler mm had the duty to control the development of arts. So they didn't want a great territory to produce what they want it, but to create a Spanish style, easy to be identified from Compostela to Valencia to Madrid to Seville. They created the first Royal Academy of Fine Arts and now here comes the real question, what a Fine Arts Academy is, a Fine Arts Academy, an Academy of Fine Arts:: So it's a teaching institution, OK and uh, you go there and learn what? <TLANG_Eng>

S1: Principles <TLANG_Eng>

T: Mmm? <TLANG_Eng>

S1: Principles on Fine arts <TLANG_Eng>

T: Which are the fine arts? Which ones? <TLANG_Eng>

S1: Paintings, architecture <TLANG_Eng>

T: Paintings, architecture and sculpture. These are the three main arts <TLANG_Eng>

S1: I would say painting <TLANG_Eng> 
T: Architecture, painting and sculpture. Ok. So it's a teaching institution. This is true, but it's not only a teaching institution. A Fine Arts Academy, a Fine Arts Academy and they probably brought a contemporary one is also an institution that controls the public taste. So, this Fine Arts Academy, in this case Royal Fine Arts Academy, are the ones that will decide which paint is good and which one is not that good. So if a Fine Arts Academy is royal, and it is a teaching institution, will it transmit the personal taste of the kings? Yes. So teaching is the best way to control the development of arts in a country because you teach what you want to be taught. and you avoid the different tendencies you want to eliminate. Mmm. For the first time in the whole history of Spain, there is an official arts place that is going to establish which is the proper way to paint, to produce architecture and sculpture. Okay. Do you understand the difference between the previous situation and this one? More? And what? Um, if you study, for three years for instance, in a Fine Arts academy, what do you get at the end of your three years of artistic development? <TLANG_Eng>

S2: A curriculum <TLANG_Eng>

T: Emm? <TLANG_Eng>

S2: A curriculum <TLANG_Eng>

T: A curriculum, that's it. Yeah, alright. What's a title for? <TLANG_Eng>

S1: For creating architectural pieces <TLANG_Eng>

T: Yes. Um, and keep those get in work. I mean, if you don't have a degree in law, you can't be a lawyer. Once you create an institution that delivers degrees of painter, sculptor and architect, it's going to become compulsory to obtain this title in order to work. And this is incredibly important as well, because the situation before was completely different. A painter was only a skilful person that was called and his works depended on his capability, and as an artificier, could decide perfectly among the views of the city depending on their abilities. Now it's noin not going to be tasking for, because now, the ones that are going to pay for a painting, sculpture or a building need to engage that person with the title. Otherwise this person's not an architect, is not a painter, is not a sculptor. So think of it, it's always a matter of control, OK? I control the knowledge that is transmitted from one generation to the following ones. I control 
people working, and I decide who can paint and who cannot. And so it's always a system to impose the royal taste to the Iberian Peninsula. Have you ever heard this term? Neoclassicism? <TLANG_Eng>

Ss: Yeah <TLANG_Eng>

T: Yeah. And uh, could you provide to the rest of the class with a very brief and simple explanation of the term Neoclassicism? <TLANG_Eng>

\section{Ss: No <TLANG_Eng>}

T: Hello? Also in Spanish, I will translate into English <TLANG_Eng>. ¿Qué es Neoclasicismo? Venga, con un par <TLANG_Sp>.

S2: Probably a revival of the classic <TLANG_Eng>.

T: That's incredibly clever. OK. It's a revival of antiquity. And we have already talked about a classical revival like two months ago or so, and we called it? <TLANG_Eng>

\section{S2: Reinassance <TLANG_Eng>}

\section{T: Renaissance <TLANG_Eng>}

Ss: [laughs]

T: We called it Renaissance. So is there a difference between the sixteenth-century Renaissance in the eighteenth-century Neoclassicism? Yes, there must be, OK? So, and indeed there is a big difference. The difference between Reinassance and Neoclassicism, if you remember that, when we explained the definition of Renaissance, we considered the artistic term renaissance inside a much wider concept we called Humanism. OK? It was a revival of the classical world in philosophy, history, pitching, painting, in everything. Like leaving apart, the Middle ages, the dark and Middle ages, and putting again the human kind of in the center of creation. Now listen to me, I'm going to be like that Neoclassicism is strictly an artistic movement that wants to impose the classical antiquity as the one and only model for realness, okay? Only an artistic movement:: And there is also a big difference and we will say it slowly between a formal difference between Renaissance and Neoclassicism. If you remember that, when 
we studied Renaissance, we saw that some architects took classical elements and interpreted them, creating something new. Neoclassicism is not like that. Neoclassicism is an archeological copy of Antiquity, kind of a scientific revival. It's not enough to use the classical formulas, it's not enough to have a general classical flavour. It's not enough. Now the propose is going to reproduce exactly what Romans did 2000 years ago. Hmm. And it's very easy to recognise ah this is not very scientific, but Renaissance is incredibly amazing and Neoclassicism is incredibly cold, cold. I mean there is no, well, there are no emotions in Renaissance, okay? This is Neoclassicism, sorry. This is a neclossaical building: OK? It's just white, a copy of a Greek temple over a copy of another Greek temple. This is Neoclassicism. Reinassance was much more about the classical language and adapting it to the sixteenth-century situation. OK. Our historians identify these two terms: academicism and and Neoclassicism. OK. If academicism was the creation of a model for artistic production that wants to be imposed to society, usually our historians have explained that this model is Neoclassicism, OK? This is $50 \%$ true, only $50 \%$ true. And it will be $50 \%$ true only by the end of the eh of the eighteenth century. And we are going to see it also much more slowly. It will be then that there will be inside the Royal Academy of Fine Arts a little reproduction that wants to recover as archeology does, the classical antiquity. There will be publications of Roman criticism of architecture, such as this Marco Vitruvio Polión mm. And a neoclassical model will be taught and imposed all through Europe, not only in the Iberian Peninsula:: But from the very beginning of academicism it was not - it had not been like that $\mathrm{mm}$. There are two main royal academies in Spain and the part of development of these two royal academies can easily explain the different situation of arts in the different territories of the monarchy. The first one to be created was obviously the Fine Arts Academy of Madrid called San Fernando and directly linked to the crowd, so it was proposed by Philippe V and afterwards created by Ferdinand VI, his son. OK, this is the only royal academy that was directly created by the monarchy $\mathrm{mm}$, projected and paid by the monarch. The second royal academy created in the Iberian Peninsula was San Carlos in Valencia. And it is a completely different situation because it's the result of the will of Valencian architects that sent a letter to the king and proposed the creation of a second Royal Academy in Valencia. The development is quiet simple. So first, there is a committee before the creation of the official creation of the academy, in Madrid from 1744 to 1752, in Valencia from 1762 till 1768 that somehow prepared the administrative system of the academy:: OK. At the end of this 
period, in 1752 and in 1768 , the statutes, the law that is going to rule the teaching activity of the academy, the titles and everything were published, in Madrid and in Valencia. Neoclassicism is the term applied mainly to architecture and yet the first year of the artists of all the academies were known architects. In Madrid, it was an Italian sculptor Giovanni Domenico Olivieri mmm and in Valencia, a local painter, Cristóbal Valero. Only after some years, an architect becomes the general director of the academy, but after some decades. The titles granted by all the academies are not the same ones. So in Madrid are the typical ones for an Academy of Fine Arts, so it can be painters, sculptors or architects. In Valencia, we will see why they create a new category: not only painters, scultprs and architects, but also a new fine art defined as decoration, whatever it is. OK. I told you the development and, from the very beginning of both institutions, was very, very different: San Fernando, now we're going to talk about the Royal Academy in Madrid. San Fernando was created by these two kings: Phillipe V and Ferdinand VI, and entrusted to their personal sculptor Giovanni Domenico Olivieri who was the first director. Why did they create this academy so soon? And why a sculptor became his first director? Because the propose of the Royal Academy of Fine Arts of Madrid was to provide sculptures for the Royal Palace of Madrid. The old castle of the Habsburgs had burned in 1732 and Philippe of Bourbon decided to construct a new one following the French fashion for architecture, late Baroque fashion, very similar to [unintelligible]. OK. But he needed a lot of sculptures in order to decorate façades, rooms, staircases, whatever mm, and so he wanted to create an institution with a lot of artists producing for the Royal families: The beginning is not neoclassical at all because that institution is created in order to decorate a Roman building with Baroque sculptures and the French taste of Phillippe V, in this moment, is Baroque. In fact, the first director of the Royal Academy of Fine Arts in Madrid that was an architect, Ventura Rodríguez, was El [unintelligible] architect. This is the portrait that we presence him as director of the Royal Academy of Fine Arts and this week. I don't know why everything is going to be blue today in this screen. I don't know why. My presentation was in white, but today everything is in blue. Ammm so this is the official portrait of this first architect that directed the Royal Academy of San Fernando and he decided to represent himself with the layout of one of his buildings:: This building is the chapel of El Pilar in Zaragoza. This chapel inside the huge cathedral of Zaragoza. The chapel itself is a very elaborated marble baldachin that is incredibly baroque. So even in the sixties of the eighteenth century, the ideals inside the Royal 
Academy of Fine Arts of Madrid were still Baroque and not neoclassical. OK. How does the Model of the Royal Academy become neoclassical, how does it become neoclassical from this Baroque beginnings? Mainly through the grants and fellowships paid by the monarchy to the students of the academy. They begin in 1750 and every year architects, painters and sculptors were sent to Rome, at least for two years in order to study Antiquity. The change of taste. And these students came also be decently fault. OK? They begin in this period, let's see José Hermosilla, copying the big buildings of the Roman world. It happens with San [unintelligible], which is one the first pictures that were sent by José Hermosilla from Rome to Madrid and that is the direct copy of San [unintelligible]. OK. This is a drawing that José Hermosilla sent from Rome to Madrid: The same can be said for this one, uh, no structured project for Saint Peter here that was called directly by Hermosilla and even in his ideal projects with this call. Now that that hope is constructed by the meeting in Santa María Maggiore. So, during the first moments of the Academy the ideal, the buildings' students copy are still Baroque. We have to wait to the eighties of the eighteenth century to find a real neoclassical architect, and we only have classical buildings and it doesn't happen until Juan de Villanueva comes back to Madrid after five years in Rome. One of his first designs was the chapel of El caballero de Gracia in Madrid:: This is a neoclassical building. For the first time in Madrid this is a real, a really neoclassical building. Why? Because it is copying a classical basilica in Rome and it's not copying anymore a Baroque building as previous fellows did, OK? So here you can see that there is no decoration, no gold, no anything but classical architecture, where this basilica with columns, and a direct copy of Antiquity. What did it happen to assist to this change of taste? Have you ever heard about Pompey? Pompey, the Roman city, OK? By Naples, okay. So another Spanish king, Charles III, had discovered Pompey. OK. The first archeological missions began in the central days of the eighteenth century. And it is a moment in which archeology begins. This new archeological point of view on architecture, painting and sculpture was step by step transmitted to the artistic production of Europe. And that's the reason this is the reason why the trends inside the Royal Academy of Fine Arts changed so from Baroque to Neoclassical. OK. It was the fault of archeology, developed by Charles of Bourbon, and then published and publicised:: What did it happen in the main chain in Valencia? In Valencia we can follow the development of architecture exactly as we have done with the Fine Arts Academy of Madrid. But the very beginning of this development is completely different. This is the first project designed by an academic 
architect in Valencia mm. It is a project, sent by Vicente Gascó, the first architect that directed the Valencian academ, sent in 1762 to Madrid in order to get the title of architect from the Fine Arts Academy of Madrid because the Valencian one was not created until 1762. What do we have here? More than twenty years before?: A direct copy of a Roman basilica. OK. The same way, the same thing that had been proposed in Madrid only during the eighties of the eighteenth century was being proposed in Valencia twenty years before: Did you understand it? Good. Not only and always before the official creation of the Royal Academy of Valencia in 1768, another architect constructed this amazing building in the historical center of Valencia, the Church of Las Escuelas Pías. Does this also remind you of something? <TLANG_Eng>

\section{S3: [inaudible] Basilica [inaudible]}

T: The Pantheon, that's it. OK. This is the Pantheon in Rome and this is the church of Las Escuelas Pías in Valencia. If you eliminate the first story, it's exactly the same building, let's do it again. Wait, uy, sorry. Okay, fathers of this academy, I mean, I don't mind about the architect who designed it. I want you only to understand that who knows why Valencia was much more updated than Madrid in this moment and that neoclassical taste during the sixties of the eighteenth century was still not developed in Madrid, while in Valencia, this archaeological interest in classical architecture was an important trait already. OK? In fact, it's much more this recreation of the Roman Pantheon. It is much more intellectual that it seems at first view because, I told you, it's a copy of the Pantheon. [unintelligible]. He made the first story but the first story that uses bubbles and chaples. So that's completely different from the Pantheon is a copy of another Roman building called the temple of Minerva Medica. So the Valencian architect took two Roman buildings and combined them in order to create something original but always with an eye in archeology, ok ,so being incredibly faithful to Roman architecture. Is it clear? <TLANG_Eng>

Ss: Yeah <TLANG_Eng>

T: Good. How did Vicente Gascó or father Francisco Cabezas knew Roman architecture so well? Direct question. <TLANG_Eng>

S4: Can you repeat, please? <TLANG_Eng> 
T: How could Vicente Gascó, our designer of the Roman basilica, or father Francisco Cabezas, the designer of the Valencian Pantheon...How could they know so well Roman architecture? <TLANG_Eng>

S4: Because they travelled to Rome <TLANG_Eng>

T: Yeah, but it happened in Madrid because they had a Royal Academy but the Valencian Royal Academy was created only in 1768 so when these two architects designed that these two buildings, there was not a Royal Academy to send Valencian artists to Rome. So, what they knew was only an architecture in paper. They could only knew Roman and Greek architecture through books. It's a completely different knowledge of architecture <TLANG_Eng>.

S2: Just to say it's a knowledge in black and white. So you can't see the colour of architecture if you studied through engravings. Hmm. So even this very beginning of academic Valencian architecture is incredibly updated if we consider the European trends, much more updated than Madrid. Ten minutes and back <TLANG_Eng>.

[inaudible]

T: OK. Only forty more minutes. It's time. OK. Em:: so... Two royal academies in Madrid and Valencia with an unexpected situation in Valencia, being much more updated than the official Royal Academy of Madrid that was supposed to be the one ruling the public space in Spain, OK? So... Now we are going to...well, I'm going to explain why this different stituation in these two cities. Before doing that amm, Gothic, just don't write. OK. That's it, look into my eyes [laughs]. OK, gothic. Reinassance, Baroque, Neoclassical. We more or less understand the development of arts following these four categories. OK. What do you think that links Renaissance and Gothic? <TLANG_Eng>

\section{S1: Art <TLANG_Eng>}

T: Yeah, that's, well, I know it's obligated. I'm trying to make it much more simple. OK. Why do we divide art history in periods? In concrete periods? In order to establish a law for the arts produced during a historical period. Why do we do so? Because they are supposed to be different <TLANG_Eng>, no? <TLANG_Sp> 


\section{S4: Habla en español <TLANG_Eng>}

T: So...well, it's...It's difficult [unintelligible]. OK. Which is the relationship between a medieval movement and Renaissance? I mean, why does Renaissance substitute Gothic? Think as a sixteenth-century painter. Why am I so convinced that I have to follow Renaissance patterns instead of following medieval arts, that were the most popular in the country for centuries? Why? <TLANG_Eng>

S2: Because of Rome [unintelligible] <TLANG_Eng>

T: Because? They were born <TLANG_Eng>

\section{S2: No, Rome <TLANG_Eng>}

T: Well, not that, but. Why do I choose Rome as a model? And if I decide to paint as Rafael instead of painting as Valmerick, obviously I'm establishing that model is better than the other. OK. This is all, all generally, which we understand, uh, you know, we're going to explain the change of taste only 'cause its an election. I decide to forget about architecture because we have scholars, new trends, that I decide are much better. Usually if we accept these labels of Gothic, Renaissance and Baroque and Neoclassical, we accept that the Renaissance painter has made a decision in order to forget the previous trends and adopt new ones. There is usually a relationship between movements, between periods of reaction. So I don't like Gothic because it's too religious, because it's...it hasn't an order and I want a different artistic world with less religious content, much more organized following rules and whatever. So, Neoclassicism must be also understood as a reaction against Baroque. OK. Is it clear? Yes? Good:: What do you think? So...If this is a Baroque façade, and it is a Baroque façade, and this is a Neoclassical façade, which do you think has been the main reaction against?::

T: Speak in English:: [addressing to students who were speaking in Spanish] OK. It's variation against the over decoration, okay. It's a try of establishing very rigid rules or architecture. So you have to use that because it was used in the Parthenon or in the Pantheon. mm. But you can, you do whatever you want. These classical orders, even with orders that are not classical anymore artists' art, you can mix all of this decoration and sculpture and vegetables and whatever, so it's a reaction against the Baroque 
craziness somehow. OK, trying to take arts back to the older. mmm. As always, it's a matter of control. OK. So, if neoclassicism, academic neoclassicism is a reaction against Baroque, why was the reaction in Valencia happened sooner than in Madrid?:: And why was it stronger in Valencia than in Madrid? Because the situation of arts in Madrid and in Valencia in the central decades of the eighteenth century was completely different. This different situation explains a different reaction $\mathrm{mm}$ and the different development of arts in both cities. At the beginning of the class, we told that the arrival of the Bourbons to the Spanish crown was fundamantel to establish a different taste, a Baroque one, but a French Baroque one that was not this crazy use of architecture and decoration. Indeed, the main architects working in Madrid during the first half of the century were not Spaniards, were mainly French and Italian artists and their proposals were moderate. OK. This is the case of church of Saint Michael, by the Italian architect Giacomo Bonavia that is slightly Baroque. Okay. It uses a concave façade, but there is no extra decoration. There is not a lot of sculptures. There is not a mixture of classical orders. Everything is quite formal. Let's say. The same can be applied to the biggest church constructed in Madrid during those years, the church of St Francis, that is again, concave. So, it is Baroque as the façade of the cathedral of Valencia was, mm, but it's incredibly classical. Hm. This is the reason why the development from the local Baroque to the archaeological Neoclassicism in the Royal Academy of fine arts of Madrid was kind of natural. OK. And it can be, it can perfectly follow all of them through the drawings of the students in the academy. They began copying Baroque buildings in Madrid [unintelligible] college and step by step they become more and more classical. And then, they imagine buildings that have a direct relationship with Roman or ancient architecture OK <TLANG_Eng >.

[inaudible]

T: The natural development from this classical French Baroque till Neoclassicism resulted in the production of Juan de Villanueva hmm. Again, the designer of the Prado museum, and a clear, a clearly neoclassical building hmm that copied a Greek temple and it's not only neoclassical, uh, because externally it isn't neoclassical, it's a museum. But there's nothing more illustrative and enlightened than a museum. and in Madrid it is quite a few. In Valencia, they begin with amm most innovative proposals, the Roman basilica by Vicente Gascó in 1762 and the Valencian Pantheon in 1767, much more 
neoclassical than the proposals in Madrid. But the situation of architecture was incredibly different. In fact, when Vicente Gascó sent to Madrid the project of his Roman basilica to obtain the title of architecture from the Royal Academy of Fine Arts of Madrid, there were another two architects that sent their drawings to obtain the same title. And the Royal Academy of Fine Arts of Madrid granted the title to the three of them. To one proposing an incredibly neoclassical building, to one sending the façade of a Baroque building actually constructed in Valencia:: And to one that had sent a Baroque plant for a church. In fact, the church of Sant Jaume in Vila-real. OK. So, the situation wasn't tumultaneous at all. There were innovative neoclassical architects, but living together with Baroque models. In fact, most of the projects that were constructed in Valencia during the second half of that 18th century were not constructed by. architects. hmm. This is a case of the chapel of St Vicent that was designed by an sculptor and even if it was constructed in 1772, so after the Valencian Pantheon and after the Valencian Roman basilica, it is completely Baroque. Hmm. With concave and convex walls with this mixture of - between fresco paintings, architecture and sculpture and the Academy of Fine Arts of Valencia had proposed a different model for this same chapel that was rejected. Hmm. Vicente Gascó, the author of the Roman basilica proposed a neoclassical building to be constructed, but the Dominicans decided to grant the project to an sculptor instead of choosing the project of an architect. Why? Because this project was much colder that the Baroque one: Did you understand it? hmm, sure? Good. Which was the problem? That, well, I told you that one duties of an Academy of Fine Arts was the expedition of official titles of architect, painter and sculptor. Hmm. The problem is that the only real official academy was the one in Madrid. So the only one that could grant the title of architect, sculptor and painter was San Fernando, and not the academy in Valencia. So in Valencia, many artists continued working even if they had not the title, the official title. This is the reason why the Dominicans could engage an sculptor for a little bit and could reject the proposal of the academy:: In fact, the situation in Valencia was actually weird because we told that in Madrid, the first half of the eighteenth century was characterised by a French classical world that was very similar that, to what was going to be Neoclassicism. In Valencia it was not like that and it's the reason why the Royal Academy of Fine Arts in Valencia created a new title, this was told at the very beginnning of the lesson today, that was decorator. Because decoration in Valencia was still incredibly important during the second half of the 17th century. And in fact, after the Valencian Pantheon, after the Valencian Roman basilica, 
we can stil find this kind of productions in the city. This is the first church of St Andrew that was decorated during the seventies of the century. So, after the creation of the Royal Academy of Valencia, after the establishment of an official taste for arts in the Iberian Peninsula and yet it is incredibly Baroque. You see? You can't identify this as Baroque and not neoclassical. Do you? Good. OK. Do you remember when we started the seventeenth century in Valencia? We saw that there have been an extraordinary development of the stucco plaster in Valencia. Hmm. Well, with all these roots and vegetables and flowers and whatever covering the walls of our churches? And it continued during the eighteenth century because the king, the Borbon was not in Valencia, so there was not an official taste that can be, that could be established in the city. And so this affection for declaration, for Baroque decoration, stucco plaster, gold, mixture of sculpture and painting and architecture, and astonishing interiors was still very alive during the 18th century and this was a kind of arts and architecture Valencian academic archtiects were fighting against. Clear? S5? <TLANG_Eng>

\section{Ss: [laughs]}

\section{T: SX1? SX2?}

S5: A ver es que no sé qué quieres decir $\langle$ TLANG_Sp>.

T: OK. So, Madrid, Valencia. Ok. Ah. Madrid, a natural development from classical Baroque, cordially classical Baroque to archeologic Neoclassicism. Why it was so natural and peaceful and whatever? Because there was not an opposition between classical Baroque and Neoclassicism. OK? After decades of the students going to Rome and understanding classical architecture, Neoclassicism was established. Step by step, OK? Without fighting against no one $\langle$ TLANG_Eng>. Vale. $\langle$ TLANG_Sp $\rangle$. Crazy Baroque situation in which everybody works together, I mean, a sculptor can design a building, a painter can design another piece, everybody's working together and creating these astonishing interiors, full of decoration, vegetables, fabrics, gold and whatever. And there is not cordially classical Baroque. There is this. So, once some architects decide to create a Fine arts academy in Valencia, they need to fight against the local production in order to establish a new one. And this is the reason why the first proposals of the Royal Academy in Valencia are much more neoclassical that the ones in Madrid 
because they want to reject this kind of architecture <TLANG_Eng $>$. ¿Ahora tampoco? $<$ TLANG_Sp>

S5: Sí - sí, ahora sí <TLANG_Sp>.

T: Júralo <TLANG_Sp>.

S5: T [laughs]

T: ¿Sí? Vale <TLANG_Sp>. OK. Yet - Yet. We have these two parallel situations with different developments and a very promising development of the Valencian Fine arts academy. Hmm. because neoclassicism began much earlier in Valencia than in Madrid. But the point is that at the end of the path, so at the end of the eighteenth century, Valencian neoclassical architecture will become like this. And permit me to compare this with this. Which one do you think is more archaeologically neoclassical? This one constructed in Madrid at the end of the eighteenth century or this one constructed in Valencia at the end of the eighteenth century? Which one of them do you think is more pure neoclassical, Greek. This one? Well, I'm trying to help you <TLANG_Eng>.

T: This one? Or this one? <TLANG_Eng>

S5: This one [laughs] <TLANG_Eng>

T: Here there's not extra decoration. There's no gold, there is no combination of architecture with other arts such as painting or sculpture, but pure Greek architecture. And here, in Valencia, there is a little bit of everything. Okay. It's not exactly this, not at all, OK? This is Baroque, pure Baroque. But this is a little bit too decorated Neoclassicism. Okay, a little bit. I - as I'm - 'cause I'm a historian, I clearly recognize this building as neoclassical but it's not that easy. Because it's a little bit too shiny to be neoclassical. So. If at the very beginning of the development of both academies, Madrid and Valencia, the one that was more neoclassical and more updated was the one in Valencia $<$ TLANG_Eng $>$.

T: Why after twenty-eight years Valencia has lost the leadership of Neoclassicism and Madrid is much more neoclassical? It is a direct question <TLANG_Eng>.

S2: English...so the fine art is more... <TLANG_Eng> 
T: This would be an interesting question [laughs]. No, I mean you are true. It could perfectly be, I mean that after this personal dogmatic neoclassicism in Valencia the situation could have softened somehow. OK. But it's not the case. We are fighting against between Baroque artists and neoclassical archtiects in the academy of Valencia continued for two years. But after some case the architecture that we studied from the Valencian Fine Arts academy was not that neoclassical, was less neoclassical than the initial one. And the reason is something we have somehow already seen. Do you remember? How did students in Madrid learn how to produce Greek and Roman architecture? <TLANG_Eng>

S5: Con proyectos, ¿no? <TLANG_Sp>

T: More, I mean they had the possibility to face Roman architecture directly, ok? Because they were awarded with grants and fellowships to travel to Rome. How did Valencian architects get this knowledge about Antiquity? Through? <TLANG_Eng>

\section{S: Books <TLANG_Eng>.}

T: Books. And which was the problem of printed architecture? <TLANG_Eng>

\section{Ss: Colour <TLANG_Eng>.}

T: It was in black and white. So, this is a project designed by Vicente Gascó for the chapel of El Carmen, the one that we have seen. Fortunately, the contract for the construction of the building is preserved. Hmm. And Vicente Gascó that was only the architect, but not the constructor of the building tried to take control of every single element of the construction through this contract. So he establishes perfectly what kind of columns, what kind of decoration, height, measures everything. OK. He establishes everything. And in order to control even more every single element of the building, he provides models taken from a book. And this book. Hey [drawing students' attention to the screen]. Is this one. The ruins of Palmyra is one of the many books that were published during the eighteenth century with an archaeological purpose in order to spread the knowledge of Greek and Roman civilization and it is a incredibly well illustrated book. OK. So, as Vicente Gascó, the architect knows that he cannot be there during the construction every single moment of the day: He says in the contract perfectly, ok, in this place, the constructor must use that decoration contained in The 
ruins of Palmyra page forty. OK, so the constructor knows perfectly what to do in every single element of the church. Which is the problem? That The Ruins of Palmyra is as it always happens a black and white book. So even if Vicente Gascó established how the covered dome should be, while the constructor decided to construct it, he also had complete freedom to imagine gold, colours, and whatever. Probably Vicente Gascó wanted a black and white architecture, but the constructor, as every Valencian artist would have done in the eighteenth century, decided that it was too cold. So it was much better to make it a little bit more alive. It happens with the covered dome, it happens with the classical orders in the walls of the church that imitate [unintelligible] also in Madrid, but that are much more decorated in the Valencian version. It happens in the garlands of the building, and it happens [unintelligible] I don't know if you can appreciate. There is a circle of decoration that surrounds the land term and that imitates this. It's called Greca. OK?: So this is the reason why the result of neoclasssical architecture in Madrid was after twenty years, a really neoclassical architecture, with an archaeological imitation of Antiquity, and so, consequently, avoiding gold and decoration. And the Valencian publication of neoclassical concepts was much less pure than the quarterly one. And this is the reason why, if you remember, when the first architects that ruled the different academies, Ventura Rodríguez in Madrid, Vicente Gascó in Valencia, they represented themselves very similar. Which is the difference between these two portraits? <TLANG_Eng>

\section{S5: Colours <TLANG_Eng>}

T: No, colours are terrible because everything's blue. No? Which is the main difference between them? What they are holding in hand. OK? Ventura Rodríguez, the main architect in Madrid, was proud enough of his own creations in a very comfortable situation with local artisans and architects, in an environment dominated by late Baroque, French architecture. Hmm. And so he felt confident enough to be represented with one of his buildings, the chapel of El Pilar that was again a Baroque building. When Vicente Gascó was represented as director of the Academy of Fine Arts of Valencia, he did it represent himself with one of his projects, but with a book, a book of Roman architecture that Marco Vitruvio Polión [unintelligible]. It doesn't matter, OK? But this is because the source of authority for an architect in Madrid and for an architect in Valencia was completely different at the end of the eighteenth century. For an 
APPENDIX III (d): Valencian Art and Tourist Resources (lecture)

architect in Madrid it was his own work. For an architect in Valencia that wanted to impose the neoclassical ideal against the Baroque situation of the city, the only possible authority was the book. Is it clear? Any question? OK. So we can leave it here $\langle$ TLANG_Eng $>$. 


\section{APPENDIX III (e): Valencian Art and Tourist Resources (Oral presentations)}

S1: Vale, eh: hola. Buenos días a todos. Nosotros somos S1, S2 y S3 <TLANG_Sp>.

\section{T: Keep quiet <TLANG_Eng>.}

S1: Y vamos a hacer una exposición sobre la moda y como bueno es en francés La Mode <TLANG_Fr>. Y bueno, vamos a hacer una exposición sobre cómo nos ha acompañado la moda en las diferentes maneras de vestir durante la historia, los diferentes... eh: durante nuestras vidas y: - y bueno, lo hemos dividido en cinco secciones, en cinco partes que podéis ver aquí, y que ya os iremos explicando cada uno. Y bueno, yo voy a empezar por el primer punto:: eh las imágenes, los orígenes de la actualidad eh bueno esta sección eh podremos apreciar eh pinturas y piezas de arte que hemos escogido porque representan no solo las diferentes maneras de vestirse, sino porque también representan los períodos e imperios de la historia. Eh: en este caso podemos ver los egipcios, no sé si - si ve también pero por los ropajes y... $\langle$ TLANG_Sp>.

\section{S2: ¿Paso? <TLANG_Sp>.}

S1: Eh: y, un poco las herramientas que están utilizando. Vale, la siguiente es eh: la Escuela de Atenas, que más que por los personajes que aparecen: Epicures, Aristóteles, Platón y - y varios. O sea, este fresco en este caso lo que vemos es, podemos ver la luz, la perspectiva y se ve la puerta del final y: también a Platón. Y bueno, podemos ver ahí los diferentes ropajes eh la mayoría de veces llevaban túnicas o incluso dos túnicas con una dentro. Y lo que solían haber era cinturones a modo de cuerda, ¿vale? Que parecerá un poco así raro pero era la manera de...que tenían de vestir allí. Esos cinturones con eh con cuerda, hecha con cuerda de pita, solía ser. Por ejemplo, también llevaban un broche de metal y: bueno, por ejemplo el calzado en el dibujo a lo mejor no sé. O sea en el fresco, a lo mejor no se ve, no se puede apreciar muy bien, pero llevaban las típicas sandalias eh alpargatas que se llamaban. Estaban hechas como con - con cuerda y sí bueno. Eh la siguiente es la de los frescos de la vida de los misterios de Pompeya. En este caso no sé si lo apreciáis pero más que por el ropaje también, podemos ver el como el paso de una niña. O sea, se puede diferenciar que están como arreglando a una niña que - que bueno se va haciendo como más, mayor y - y bueno: pues está rodeada 
de sus eh esclavos y de sus cortesanas. Y bueno, se puede ver aquí, en plan la - la evolución de - de lo que sería la vida de - de la joven o de la persona <TLANG_Sp>.

S2: Pasa <TLANG_Sp>. Vale, esta es la segunda sección eh la esclava de la moda, A woman slave of the mode <TLANG_Eng>. Eh y bueno, aquí os... - aquí sobre todo en este punto principalmente presentamos a nuestro - a nuestro... es uno de los puntos más importantes de la exposición realmente. Y le planteamos a nuestro público un poco también, si piensa que la mujer es un simple objeto que se ha utilizado en la moda para vestir o desvestir o para llevar tendencias como un - como si fuera un maniquí o si realmente es una persona y, o sea, lo que hemos visto a lo largo de la historia cómo se ha visto reflejada. En este caso tenemos eh el - el retrato de [unintelligible] primera [unintelligible]. Y bueno, no estoy seguro, es un óleo y creo que se pinta con como con - con oro así con más relieve, o sea, la técnica es un poco más eh complicada. Y está en el museo de Nueva York. Esta en realidad es otra obra que, bueno, hemos pensado que estaría bien. Es, puede que no sea tan - que no tenga tanto tiempo en la historia, pero es de Frida Kahlo, una mujer mexicana. Y en este caso está en el [unintelligible]: Y bueno, Frida Kahlo pintó muchas, no solo muchas mujeres, sino que estaba vinculada con con lo que era un poco la moda eh las formas de vestir y era una autora que también le gustaba mucho. Destacó por - porque le gustaba utilizaba mucho lo natural, le gustaba mucho utilizar el paisaje y todo: Y bueno, popularmente, esta imagen eh de modo tiene un poco de sentido así religioso. O sea, se atribuye un poco como al... - como a la cristiandad. Y podéis ver algunos así rasgos...Esta es la de...Ah sí [unintelligible] y se trata también de que veamos el arte y - y la moda a través de la historia. Y bueno, ocurre en este caso, en este algo así de la Escuela de [unintelligible]. Podemos ver las típicas túnicas y las [unintelligible] así. Bueno, esta es [unintelligible]. Y - y bueno, es otra manera también de - de que veamos la - la moda [unintelligible] <TLANG_Sp>.

S2: La siguiente sección la hemos titulado hábitos en miniatura. Y es que en muchas ocasiones, debido al estatus social que tenían, pues se les representaba, bueno se les vestía con ropa más característicos de un adulto que de un niño de su tamaño. Este es el caso de este cuadro que es la infanta Margarita Francisca, hija de - una de las hijas de Felipe III que murió a temprana edad. Y se la representa mirando un... - a Santiago Moran, y pues hace que resalte más y los accesorios que lleva que se supone que prevenían a los niños de los - de distintos males que acechaban en la época, que 
también hace que cree una conexión con la pintura popular de carácter supersticioso que había en ese entonces. Otro cuadro posiblemente más conocido de Diego Velázquez es Las Meninas, que también representa a la infanta Margarita con sus sirvientes y pues obviamente con vestidos típicos de la época. Otro cuadro que también podemos ver ahora mismo son las infantas Clara Eugenia y Catalina Micaela, que eran hijas del rey Felipe II y que fueron representadas por Alonso Sánchez Coello, uno de los pintores de la corte. Y representa a las niñas con un aspecto solemne y distanciado que refleja su condición como hijas del rey. Y haciendo que ambas sostengan con sus manos una corona de flores. Otro más es el retrato de Carlos Manuel Víctor, duque de Aosta, que parece... en el que, bueno se representaba cuando tenía diez años y llegó a ser duque de Saboya y se pretende combinar el carácter oficial de la imagen cortesana con la peculiar gracia infantil que presentaba jugando con un pajarillo. Y el último de esta sección es el retrato de una niña con un atuendo y un perrito, que es - fue pintado por Antonio Lucas Velázquez que se inspiró en un pequeño detalle que hay en el cuadro de la familia de Felipe $\mathrm{V}$, que es la - la misma distribución del cuadro, los mismos mates, lo único que cambia es el color. Otra sección, la siguiente sección la hemos nombrado Feliz siglo $\mathrm{XX}$, un estilo para cada ocasión y es que con los cambios sociales, las revoluciones y las conjeturas históricas, muchos diseñadores aprovecharon para crear nuevos estil...nuevos estilismos, y marcando las tendencias siendo el siglo $\mathrm{XX}$ una de los más influyentes. Este cuadro, por ejemplo, Mujer de rojo de Daniel Vázquez Díaz, eh representa a una mujer vestida de rojo donde la máxima expresión se - se observa gracias al uso del color y la luz. Este es de Charles Courtney Curran. Se llama En las alturas y es lo mismo. Simplemente representa a tres mujeres vestidas, que... mostrando también el ambiente natural del paisaje que observamos. Luego tenemos estos cuadros de Sorolla, que son a su mujer. Y el primero que pintó, uno de los primeros que pintó es este de 1990, de 1900 que es Clotilde con traje gris, presentada de una manera muy risueña em:: marcando su esbelta cintura yendo a la moda del momento. Luego el siguiente cuadro, bueno, uno de los siguientes de 1910 ya se puede observar la... cómo cambió el vestuario y se añadió complementos haciendo también una referencia al ascenso social que su familia. Este es Gótico americano, que ilustra a un granjero y a su esposa enfrente de una casa de estilo gótico rural y es una de las imágenes más conocidas del arte estadounidense del siglo. Y la última obra de esta sección es el retrato de Montserrat Güell López-Beltrán, que está en el Museo del Prado <TLANG_Sp>. 
S3: Eh: la última sección la hemos nombrado 'Mirando al futuro'. Eh ¿por qué? Eh porque hemos pensado que la realidad ya no es la moda la que está representada en los cuadros, sino los cuadros los que están representados en la moda. Em: em:: diferentes diseñadores intentaron hacer un homenaje a - a diferentes pintores como Goya por ejemplo. Y al final pues tenemos algunos - algunos vestidos. Eh: este por ejemplo, 'Litografía', de Georges Braquede. Se trata de un vestido de novia que cerraba el desfile de 1988 de Yves Saint Laurent, y está inspirado en uno de los eh: en uno de los elementos característicos de - en uno de los motivos más característicos de la obra del pintor: los pájaros. Em: este cuadro se trata de un Retrato de Adele Bloch-Bauer I. Este es del desfile de primavera verano de alta costura de Dior. El diseñador es Gustav Klimt, y en este lo que intentó plasmar eh son los colores y las figuras doradas de - del pintor. Em: en el siguiente, eh se trata de un autorretrato, del Autorretrato con collar de espinas de - de Frida Kahlo. En este más que, se centraba en los ropajes que llevaba Frida Kahlo. Eh este fue en el desfile de, de primavera-verano de Moschino y, y eso. Intentaban hacer un homenaje a, a Frida Kahlo. Em: Los almendros en flor, de Van Gogh. Eh se trata de la colección primavera verano Ready-to-Wear <TLANG_Eng> de Rodarte. Em: en este eh lo que intentó el diseñador, digamos que es vestir a las modelos de princesas. Con él utilizó el color característico de los almendros y lo plasmó en, en sus ropajes con tonos también azules y - y eso, con flores. Em: el siguiente de Adán y Eva. Eh este fue plasmar el cuadro, lo que sería el cuadro del autor. Intentó poner todos los detalles, em están Adán y Eva. Y lo que hizo fue hacer el vestido como si fuera el como si fuera el Edén. Em: en este vestido em: se llevó en el desfile de primavera verano de alta costura de 2014. Y por último, Flores en un jarrón azul, de van Gogh también eh: este también consistió en lo mismo que el anterior, plasmar exactamente el cuadro eh en el vestido de la modelo. Eh:: este diseño eh: fue eh: se llevó en el desfile de alta moda de Dolce \& Gabanna. Sus diseñadores eran italianos y su intención era transformar a las mujeres en obras de arte vivientes. Vale, eh después nuestro taller gráfico consistiría en un photocall de arte y moda. Em: es un poco difícil de explicar. A ver, nosotros lo que queríamos era crear diferentes photocalls <TLANG_Eng> con los cuadros, pero estos cuadros estarían incompletos. Sería el propio visitante el que completaría el cuadro. Uno completaría con diferentes ropajes. ¿Cómo lo completaría? Con diferentes ropajes que ellos se podrían poner en la tercera foto del mismo cuadro. Am:: ¿los objetivos? Sería crear una relación entre - entre la moda y el arte. Experimentar la situación de llevar los trajes y sentir a la propia persona dentro del arte. 
Y relacionar el estilo del traje con la época representada. Los trajes que ponían de una época pues relacionarlo con el cuadro. Y ya está <TLANG_Sp〉.

\section{[applause]}

T: ¿Me, me dejáis que os haga una crítica en tiempo real? Pero no lo toméis como algo personal, es para que ellos también piensen un poco $\langle$ TLANG_Sp>. Eh: OK. If I have to give a mark to their presentation, she has done it really well. Second best. And third. OK? Try to talk, I don't want you to read. And avoid describing the picture. I mean, I don't mind. I - I have two eyes and see the paintings. I - I don't want them to be described every time. What I want to transmit to me is the general idea of the exhibition, the general idea of every single section. But I don't want you to give me the dates, location, measures and materials of the paintings. I don't mind about it. OK? And try to eh, not to have me here until midnight. It would be a good idea. So if you describe every single artwork, we are going to stay here until tomorrow, OK? Take it easy, make it, try to make it natural. And if you can, please not read, it's going to be great. OK? So eh thank you very much. And next <TLANG_Eng>.

S4: Bueno, nuestra, empezamos, nuestra exposición de arte. ¿Me escucháis o no? Sí, vale. Es que ya iba a decir [laughs]. Bueno, va sobre la Guerra, el conflicto y el arte. Pasa. Eh. Y el objetivo principal es introducir a la gente eh en el mundo de la guerra y relacionado con el arte. Pasa. Bueno estas son..., da igual, las - las diferentes secciones y eso. Bueno, pues yo, vale, yo voy a explicar la primera sección que se trata de la visión que tenían los ganadores. La primera que tenemos es la mano en la que se conmemora la victoria de las tropas británicas frente a las españolas. Aquí podemos ver a tropas, a la sección española decidida a destrozar a los británicos, pero acabaron ellos destrozados, como se ve aquí. En el centro está la imagen de la reina Isabel, su cónsul de guerra y eh poniendo la mano encima de - de la tierra porque en aquella época España era el imperio donde el sol nunca se ponía. Entonces una guerra como esta era una más. Aquí tenemos lo que se conmemora la victoria de: em de: - de las tropas católicas del rey Fernando - ay Felipe IV frente a los protestantes alemanes. En el plano central eh aparece... $<$ TLANG_Sp $>$.

T: S4 no me contéis cada cuadro. Es lo que os he explicado antes. Decidme de qué va la sección y enseñadme las obras. Pero no me contéis las... - cada cuadro porque son 
APPENDIX III (e): Valencian Art and Tourist Resources (Oral presentations)

cinco secciones con cinco obras cada una, no vamos a salir de aquí nunca $\langle$ TLANG_Sp>.

S4: Vale. Pasa $<$ TLANG_Sp $>$.

S5: Esa es la que has puesto antes y esta es la siguiente <TLANG_Sp $>$.

S4: Vale. Y luego tenemos la recuperación de San Cristóbal que se, fue pedida por el rey para decorar el salón del reino y eh la representación es ah la hacen porque fue una de las victorias más rápidas que tuvo el ejército español y encima no tuvieron casi bajas ni... Pasa. Y estas son otras obras que podemos ver. Como por ejemplo aquí, la recuperación de Cádiz en $1634<$ TLANG_Sp>.

S5: Bueno, ahora vamos a pasar a... vamos a hablar sobre la visión de los de los derrotados. Em: aquí he seleccionado dos obras que seguramente habéis visto, son muy - súper conocidas en España. Y son el 2 de mayo y 3 de mayo o La lucha contra los mamelucos y la otra se llamaba también: Los fusilamientos. Entonces eh la historia es que España eh bueno en ese día, concretamente el 2 de mayo, eh los madrileños se reunieron en el Palacio real - real haciendo: un poco de una manifestación y tal porque estaba, se querían llevar a los franceses al único, a la única persona de la realeza que quedaba en España. Y entonces fueron allí y pues también estaban los franceses. Y eh unos pegaron a otros y al final hubo una rayada monumental. $\mathrm{Y}-\mathrm{y}-\mathrm{y}$ nada que, pues eso que se pegaron. Entonces em Murat se llamaba dijo que - que eso no podía ser, que él debía volver a España. Por lo tanto, eh a: a las - a las cuatro de la mañana del día siguiente:: em pues eh decidió coger a todos los que había por allí y a todos los que llevaban navajas que eran prácticamente todos porque había muchos apresados y muchas cosas, muchas personas. Pues entonces decidió llevarlos a Los recoletos, El príncipe Pío, La Puerta del Sol, La Moncloa, a varios sitios, ¿vale? donde los eh asesinaban. Y pues esta es la de - la de - la del Príncipe Pío, una de tantas que Goya ilustró después. Y ya está. Luego eh hablaremos, vamos a hablar sobre algunos guerreros y guerreras eh de la historia, ¿no? Pasa. Entonces yo...eh habíamos elegido a esta mujer que se llama Artensia I de Caria que fue una..., bueno porque su padre fue rey de Halicarnaso y luego su padre murió y así, su padre no, su marido murió, ella se quedó viuda y tenía un hijo muy pequeño y no podía gobernar, entonces tenía que gobernar ella. Y entonces esta era una ciudad eh: una ciudad ¿vale? griega que estaba 
situada en Caria y le llevó a tomar parte de la expedición que el rey persa llevó a cabo contra Grecia en el año 480 a.C. Y - y, tal. Ella aportó los navíos para la guerra. Siguiente. Y luego el otro personaje del que hablamos es Ulises que fue uno de los, bueno también es súper conocido por la Ilíada y la Odisea. Y había elegido esta imagen porque, bueno se llama Ulises en su barca luego del ataque del dios Zeus porque me recuerda mucho a La libertad guiando al pueblo de Delacroix. Y - y nada, me da curiosidad ver que arriba del todo sale todo como súper, como que tienen mucha vida, están como "por favor, que voy a llegar" y luego llegan y es que como "ay dios, mío", ¿sabes? Como una especie de pirámide. Y tal, y la vida, no sé. Es muy curioso. Y ya está <TLANG_Sp>.

S6: Vale, bueno. Pues aquí tenemos a Napoleón cruzando los Alpes, que representa pues el mando de sus tropas, y aquí se supone que van a atacar a las tropas austríacas para recuperar parte del territorio que habían perdido. Vale, este es Felipe V, y podemos ver aquí que hay elementos que representan su - su gran poder y su - su gran poder. Y, ya está. Pasa <TLANG_Sp>.

S4: Y bueno, yo ahora voy a hablar de los desastres de la guerra. Bueno, pues esta eh sec... Este cuadro se llama La invencible que lo que pretende recrear es la - la armada española eh destruida en el mar británico, como vemos - como vemos se encuentran en el barco con un navío que se acerca - acercándose a los acantilados donde ya acaba acaba de hundirse. Y las más representativa es El Guernica de Pablo Picasso. Que fue el gobierno de la República, le pidió que hiciera un cuadro y justamente sobre esta ciudad española. Y los alemanes, especialmente Hitler, manda un avión a España para mostrar su apoyo a Franco, y - y bombardearon la ciudad de Guernica y se puede ver sobre todo en la - en los rostros. Por ejemplo, manos y brazos que habían acabado en el suelo $\langle$ TLANG_Sp>.

S5: Eh la última sección es la y aquí tenemos el cuadro de las Sabinas que es que es mitología básicamente. Y lo que paso es que Roma no tenía muchas mujeres. Entonces eh hicieron como unos juegos y invitaron a muchas poblaciones. Y una de ellas fue la población de las Sabinas y entonces los romanos secuestraron a las mujeres. Y, pues eso empezaron a pelear y entonces las - las Sabinas se pusieron en medio para evitar el conflicto. Y este es [unintelligible] tiene un... - tiene unos elementos, objetos que contrarrestan a la vez están el conjunto científico, político, la literatura [unintelligible] y 
la fama:: Y ya está. Ah vale. Em nuestra propuesta didáctica como era para niños y era una situación un poco enrevesadilla, pues habíamos pensado en algo muy basiquillo, ¿vale? Em: les pondríamos a los niños en un proyector las imágenes. Entonces, ellos tend..., a partir de ahí tendrían que elegir la que más les gustara y tal. Y entonces se elegirían las tres mejores y habría un premio. Y el premio, pues: no sé. Y ya está $\langle$ TLANG_Sp>.

S4: Y luego, este bueno un poquito así cutre nuestro proyecto. No tenemos creatividad para más $<$ TLANG_Sp>.

\section{[applause]}

T: Si me volvéis a describir la historia de cada cuadro, os cortaré <TLANG_Sp>.

S7: Well, our exhibition is about the male body. The first section, in the Genesis, there's a tradition that says that Lilith was the first woman before Eve. How Adam and Lilith knew they had problems, God decided to leave another woman to Adam and Lilith decided to leave the paradise and go away. The most important work of this section is a painting named La caja de Pandora $<$ TLANG_Sp $>$ that it's a fusion of mythological and religious theme because it's a fusion of human Pandora that is woman eh that is a responsible of the race and Eva that is a responsible of the sins of the humanity. This is a fresco in the Renaixença [Renaissance] <TLANG_Cat> and <TLANG_Eng> del ángel Gabriel <TLANG_Sp〉.

S8: Ah: the second part of the work is Antiquity, mythology female anatomy. Ehh in ah classical representations of Antiquity, women were portrayed - portrayed with overweight and broad hips, which were a symbol of fertility. The first example is the, was Venus. Was a goddess who affected the feminine pardon eh: of the time. In this possible period she would have represented perfection of nature. That's a sculpture. In the - the Middle Age, religion about modern world and holiness, the Christian church had two perspectives of women. In one hand, we have Eve. And in the other hand, we have the - the Holy Virgin, Mary, that affects the - the women and the nations of modern world. There were conflicts were...OK. This. Am: Eve was saw as the woman that is not pure am: because she:: ate the fruit, the forbidden fruit. In the other hand, we have Mary that was seen as a goddess because she is the mother of the God. Am: yeah. 
And last one is the modern age [unintelligible]. Eh: in nineteenth century is usually as a century where religion begins to decline. But if we look at the global rich of the world religions, eh: the spread of secrets, texts, their levels of identity, eh: centralisation and control, and the prof - proliferation of secret buildings of the world religions help far more at the - the nineteenth century than in the start. Eh: these parts of our work, we am: we found the information in a New York Times article, in the newspaper <TLANG_Eng>.

S9: Well, in the next section, five women, Mujeres en lucha $\langle$ TLANG_Sp>, and em: I'm going to talk about the three most important painters during the different periods of the history. Eh the first is Artemisa Gentileschi. Was a Baroque painter, daughter of artist Orazio Gentileschi. Emm she was the first woman who, to get into the Academy of Fine Arts in <TLANG_Eng> Florencia $\left\langle T L A N G \_S p\right\rangle$. At the age of eighteen she was the victim of a rape by one of her father's friends, Agostino Tassi. Em: he was convicted in sixteen twelve [1612] but the releasement was very soon. Eh: in this way the young painter reflected her suffering through the painting. Eh: one of the most important is eh Susana and the Elders. Em: taken from the bible, Susana is a woman surrounded by two elders who falsely accuse her of adultery if she slept with him. It's a work in a realistic room. And the other one is Judith Slaying Holofernes eh: depicts Judith [unintelligible] <TLANG_Eng>.

S10: [unintelligible]. OK. Camille Claudel was a paint sculptor was the muse, pupil, and lover of Auguste Rodin, as well as a major artist in her own right. She is perhaps better known for her tempestuous relationship with Rodin. After her breakup with Rodin in 1898, Claudel composed some of her best sculptures. Well, some of them. Em:: The Mature Age was one of the best sculptures by Claudel, was interpret[ed] by her brother, the famous poet, Paul Claudel, as a powerful allegory of her break with Rodin. This work's reflect Claudel's abandonment by him. Eh and finally, Frida Kahlo was considered one of the one of Mexico greatest artist who began writing mostly since fourteen. She was married to Diego Rivera and now is still admired as a feminist icon. She suffe... - she suffered several serious bad accidents, including fractures in her spin and pelvis. Ehh later Frida began painting during her recovery and finished her first self-portrait the following year. Frida is remembered for her self-portrait and patience. Eh Frida is a icon of feminism. Frida smoked, contrasting to her mother and sisters. She 
refused to alter her masculine features, including her eyebrows and moustache. Emm and one of the paintings is Henry Ford Hospital and secondly [unintelligible]. This picture, this painting is a reflection of what Frida felt when she was in bed. There are six objects flying around her. And the other is Frida with a [unintelligible] <TLANG_Eng>.

S11: The next section is called women as objects. And well, as they said, the history of art can be understood as the history of human days and is historical, cultural and [unintelligible] and experiences over the years. So this painting is mainly [unintelligible] babies on the patriarchal model woand men has enjoyed for many centuries a little role in art history. So this has relieved, this has relieved women to the role of muses or goddess leaving them with an artistic point of view. Women have not been treat, eh shown as according to [unintelligible]. It has been assumed eh that they [unintelligible]. OK. So due to these facts, the women are just creators ehh starting with their position and tries to put in evidence this feature of art. So through claims against the traditional patriarchal point of view, mm starts to be construction of this system which is currently development and it starts to question traditional thoughts. So here is an example of a a traditional painting, La primavera, by Sandro Boticelli. In contrast, we have a modern portrait by Romina. Romina is a contemporary painter born in Ohio, based in Brooklyn, New York and also feminist. [unintelligible] female paintings and breaks down ideas about feminism, sexuality, and gender-roles identities [unintelligible] <TLANG_Eng>

S7: OK. The last section is the the actualitzation of the body. Normally, when we refer to deacralisa <TLANG_Eng>.

S11: The next section is called women as objects. And well, as they said, the history of art can be understood as the history of human days and is historical, cultural and [unintelligible] and experiences over the years. So this painting is mainly [unintelligible] babies on the patriarchal model wound men has enjoyed for many centuries a little role in art history. So this has relieved, this has relieved women to the role of muses or goddess leaving them with an artistic point of view. Women have not been treat..., eh: shown as according to [unintelligible]. It has been assumed eh that they [unintelligible]. OK. So due to these facts, the women are just creators eh: starting with their position and tries to put in evidence this feature of art. So through claims against the traditional patriarchal point of view, $\mathrm{mm}$ starts to be construction of this 
system which is currently development and it starts to question traditional thoughts. So here is an example of a - a traditional painting, La primavera $\langle$ TLANG_Sp $>$, by Sandro Boticelli. In contrast, we have a modern portrait by Romina. Romina is a contemporary painter born in Ohio, based in Brooklyn, New York and also feminist. [unintelligible] female paintings and breaks down ideas about feminism, sexuality, and gender-roles identities [unintelligible] <TLANG_Eng>

S7: OK. The last section is the - the actualization of the body. Normally, when we refer to deacralisa <TLANG_Eng>.

T: desacralization <TLANG_Eng $>$.

S7: desacralization of the body means to remove the sacred meaning to a place or a theme. Eh: in this case, we speak of desacralization of the woman body as a term that could imply the passage of the object woman to the passage of the woman as an individual person. eh: $\mathrm{OK}$ : eh: A symbol of a portrait of woman is the most evident is the Las Meninas, of Velázquez. In this portrait, the infant Margarita. Eh: is an example of how feelings and emotions should not be expressed due to the aristocratic class to these servants and because of her condition as a woman she's adored until it becomes an object. OK. From the Renaissance, a body or flesh personal script begins. The female nude eh within the representation of mythological character begins to ah situate its erotic and unrealistic characteristic. And later it has a vision of feminism incorporating poetry and beginning to its representation <TLANG_Eng>. Ehh vuelve a la de antes $<$ TLANG_Sp>.

S9: OK. We have two paintings, La Sagrada Familia del pajarito <TLANG_Sp>, by Murillo. And Mujer friendo huevos <TLANG_Sp>, by Velázquez. Eh: the psychological study ehh the Virgin is an independent woman while San Jose is the one who helps. Or the Velazquez painting eh: protagonist and painted by itself suppose an important change and concept in the collective imaginary [imagery] about the woman <TLANG_Eng>. Vale. Eh: pues esta es lo que yo tenía que haber dicho <TLANG_Sp>.

S10: No, esta es mía. Esta es mía <TLANG_Sp>.

S9: Vale, pues ya os he contado la historia $\langle$ TLANG_Sp $>$. 
S10: Artists joined the essence of darkness and decandence that wil be that will be placed even more to the desacralization of the femine body, although also masculine. For example, Caravaggio, this painting ehh with the Judith painting <TLANG_Eng>, Judith decapitando a Holofernes <TLANG_Sp> [laughs] ehh where the a Biblical heroine, with her maid, goes into the enemy camp <TLANG_Cat> [battlefield], seduces and than, then meets Holofernes, the fierce enemy general.

S11: OK. However, the use of these gentlemen until something later when the beauty comes that a new away from any logical connotations. Venus is no longer a goddess, is a woman who shoes, shows her body. And this happens in La maja desnuda <TLANG_Sp>, painted by - by Goya. And the last one eh it's them where the vision object of the woman's body is desacralized in order to empower and run her in a new perspective, away from the gaze of man, independent of its other components or characteristics that had behind, before. In definitive, to create for himself an image that doesn't depend on the masculinity.

\section{[laughs]}

T: Puedes ponerlo $<$ TLANG_Sp $>$.

S8: Ponlo - ponlo <TLANG_Sp>.

[a video is played on YouTube]

T: Muchas gracias <TLANG_Sp $>$. Next $<T L A N G \_E n g>$.

S12: First, I want to introduce you our exhibition, which is about love. Em: it's about how do we look at love, em: how it was years ago and how we look at it now. First we're going to talk about our different parts of the exhibition. It contains five parts and we're going through them very quickly. Em: and we're going to start with the first one. The first section is called lovers. It's about em: most ancient love and am:: how can we tell it eh, for example, paintings probably all of you know them. Ah so it's about antique of love, typical and super romantic love. And em we also include, just to be a bit funny, we also include paintings. We think that it's the most...- some ideal of love, from nowadays. Because those are mm love paintings that work together love in time, or long time in history [unintelligible]. This piece is about Brad Pitt and Angelina, but they 
broke up, so unfortunately we couldn't make that, but it's a picture of them $<$ TLANG_Eng>.

S13: Second part is central love. It's about passion and as you think of central love, you think about sex <TLANG_Eng>.

T: I know what you're talking about <TLANG_Eng>.

[laughs]

S13: Amm yeah [laughs]. Amm kissing, yeah [show a picture included in the slideshow]. I can't say anything about it [laughs] <TLANG_Eng>.

S14: OK. So this is about love and traition. There are no rules when it comes to love, right? Love should always be considered about something between two sides. Further in some countries, people stick to the traditional rules of love, as traditional love which thought of kidnap a man and woman's heart. So this is where we show you some examples of some paintings about central love, for example. This one. It is an artwork that combines six pictures painted by women entering society <TLANG_Eng>.

S15: OK. So this section is about the diversity of love and the risk of love. So, there were times where that wasn't expected - accepted. And I think that nowadays widely it is, but there are still some countries or regions where it isn't. So we have chosen this first picture, which am is a picture by [unintelligible] who was one of the ransom sculptors. And there's a lot of quotations about this sculpture but apparently, a guy interpreted it as the state as power and am: someone who just want to defeat the other person. But then there's also this interpretation that the guy on top was one of ah [unintelligible] lover's actually. The next point is action women, age and great poets living in the fourth century. [unintelligible] painted this picture. He was am: yeah, he painted this kind of things when he lived and he got arrested for homosexual offensive at this time. Am:: that would be done until the modern art and we have this picture of [unintelligible]. He created this when [unintelligible] was a little island yet in 1967. So this is therefore the most sad, the picture at the start. Am: and then we have [unintelligible] by an artistic couple who married in 2008 and they portrayed many young powerful compositions and devoted to manhood, young boys that are beautiful. And they are criticised by having too like homochromotical features. But they say that 
sex is just sex. And last, I have this which just popped into my head because I've done some research about love am:: so it's more like a formality than anything else. But I think [unintelligible] walls walking down. And it's like a sad freedom of love or whatever. Yeah <TLANG_Eng>.

S16: And the last section of our exhibition is the last kiss of love. The last kiss of love cannot be conflicted by any disruption and circumstances. And we find this kind of love in stories like Romeo and Juliet. Ah and here the window that enclose two people means the hardships and difficulties of their love that would last also after hugging each other. Closing the window just can be expressed as expressing their commitment and willingness to overcome their circumstances faced by them. And the second picture is ah the death of Romeo and Juliet. Montague and Capulets which are enemies and have bad relationship between the two families. After the death of Romeo and Juliet, the families finally were reconciled, so the scene of the two families shaking hands in front of the dead Romeo and Juliet in this painting shows that as well [unintelligible] <TLANG_Eng>.

S17: OK. The last part we're going to talk about is the workshop that we created. Am: because love is such an abstract concept, especially for kids from six to twelve years old, we created a workshop for kids from six to twelve years old. When I was a kid I didn't know what love was. I mean I loved my parents but am other people would be scared. So to get them know with the concept, we created the workshop. So the idea is to - to - to create a love story ah: based on the paintings in the exhibitions, one or more paintings. So the kids can dress up as people from - from these paintings, Cupid or whatever. And dress up and make a nice play which they play their love story and that's our work. And that's basically the workshop that we created. And it's the end of our presentation <TLANG_Eng>.

\section{[applause]}

\section{T: Next <TLANG_Eng>.}

S18: [unintelligible]

[inaudible]

S19: [unintelligible] 
APPENDIX III (e): Valencian Art and Tourist Resources (Oral presentations)

S20: [unintelligible]

S21: [unintelligible]

S22: [unintelligible] 


\section{APPENDIX III (f): English for Medicine. Seminar on Skin Cancer}

M1: Emm so <TLANG_Eng>, antes de empezar. ¿Alguien tiene alguna duda existencial con lo de bioquímica de mañana y del miércoles? Porque he recibido doscientos mil emails <TLANG_Sp>.

S1: ¿Eliges tú quién empieza? <TLANG_Sp>

M1: No, ya lo dijimos. Podéis empezar quién queráis <TLANG_Sp>

$\mathrm{S} 1:$ Ah ¿sí? <TLANG_Sp>

M1: Sí, os organizáis vosotros <TLANG_Sp>.

$\mathrm{S} 1:$ Ah vale - vale $<\mathrm{TLANG \_ Sp}>$

S2: ¿Entonces decidimos nosotros el orden de los contenidos de la presentación? $<$ TLANG_Sp>

M1: Lo que vosotros queráis <TLANG_Sp>.

[unintelligible]

M1: El aula sabéis todos que se mira en el SIA porque también he recibido emails preguntando por el aula. ¿Vale? El aula en el SIA está puesto <TLANG_Sp>.

S3: Y una pregunta. Bioquímica del miércoles es por la tarde, ¿no? <TLANG_Sp>

M1: De una a cinco creo, ¿no? Y la de mañana también <TLANG_Sp>.

S4: Mañana a las diez y media <TLANG_Sp>.

S5: Yo creo que también <TLANG_Sp>.

S6: ¿Entonces aquí presentamos el miércoles? <TLANG_Sp>

S7: No, nosotros mañana $\langle$ TLANG_Sp $>$.

S6: Pero es que mañana es tutoría. ¿Se presenta en tutoria o en prácticas? $<$ TLANG_Sp>

M1: En prácticas. En problemas que es de una a cinco, ¿no? <TLANG_Sp>

S7: ¿Y entonces el martes que se hace? <TLANG_Sp> 
M1: Ah no lo sé. Yo eso ahí no...<TLANG_Sp>

S7: En el correo, X [lecturer's name], nos ponía en el correo que unos exponían el 11 y otros el $12<$ TLANG_Sp>

M1: Shh

S7: Que nos ponía que se exponía el 11 y el 12 <TLANG_Sp>

M3: Pero yo tengo las clases de problemas que es PR1 y PR2 que es de una a cinco, martes y miércoles. ¿Sí? <TLANG_Sp>

$\mathrm{S} 4:$ ¿Y nosotros? <TLANG_Sp>

M1: Vosotros cuando lo tengáis <TLANG_Sp>.

S7: ¿Y entonces la tutoria de mañana? <TLANG_Sp>

M1: Pues no lo sé porque yo no soy la responsable de la asignatura. No lo sé $\langle$ TLANG_Sp >.

SX: ¿Pero se pueden faltar a las tutorías? <TLANG_Sp>

S8: No se pueden faltar a las tutorías $\langle$ TLANG_Sp $>$.

M1: Vale. Hecho. Ninguna duda más, ¿no? <TLANG_Sp>

S8: No <TLANG_Sp>

M1: Vale $<$ TLANG_Sp $>$. So, where we... $<$ TLANG_Eng $>$

S9: ¿Pero mañana sí que tenemos bioquímica y tutoría o es otra cosa distinta? $\langle$ TLANG_Sp>

M1: No lo sé lo que es <TLANG_Sp>

S8: Tenemos tutoría pero no es la presentación <TLANG_Sp>

M1: A mí me tocan problemas, PR1 y PR2 que es martes y miércoles de una a cinco. Cada uno donde le toque. Vale <TLANG_Sp>, so we're to start with the seminar aaand I prefer that if you want to talk with your colleague [college], do it in English, OK? So 
because we are in English class, so please ineract with your colleagues (mispronounced as college) in English. If not, don't talk. OK? <TLANG_Eng>

[laughs]

M1: I want that you like express yourselves in English. So, because I suppose that...Well, if I'm not wrong this is the last seminar of English for medicine and I know that my...that other professors ah: insist you about the importance of English in your future career, yeah? So because English is the language of science and maybe you don't think that now is important for your degree, Medicine, but when you ah: will be a doctor or a resident or whatever, you're going to go to international congress and you have to interact with other residents or other doctors that are from different countries and you need to express yourselves in English and to do the presentation of your data ah: in that language because it's the communication language $<$ TLANG_Eng $>$.

S9: It's a ligua franca $<$ TLANG_Eng $>$

M1: What? <TLANG_Eng>

S9: English is a lingua franca $<$ TLANG_Eng $>$.

M1: It's a - it's the language for com like international for communicate between the different like scientists because at the end, you will be a scientist. You are not only, you are not going to be a doctor, you're only, you're going to be also a scientist. OK? The other things that I want to express to you is that there are two other subjects that are really important for your future. One is data analysis, statistics. Just pay a lot of attention in statistics classes because it will be really useful at the end because you, when you are working in a hospital, you will have a lot of data, of patients [pronounced as /'pa.Jonts/] or epidemiology and things like that and it's these data need to be analysed to present what is happening in your region, in your hospital, in your country or wherever. OK? So ahh it's a really like...I think that nobody loves statistics, nobody, more when you are like studying a degree, but it's really important, it's essential for doing science, OK? And the other subject is Genetics. Genetics is the future of Medicine, Genetics is used to, to do a prevention, to do a screening of your genetic alterations just to know ahh which is the risk of having this disease or this risk of developing a cancer or whatever. It's also important for diagnosis, like to know as we see in Biochemistry, to know if this person have this genetical alteration because it has 
that disease or the other or whatever so it's important for diagnosis and it's also important for treatment. Now personalised medicine it's one of the fields that are more growing in a...hello [student coming in the classroom] in ah OK. So personalised medicine is growing every single day like exponentially. Like you do a screen of a tumor, for example, aand you know depending the genetic alterations, what treatment you have to use for these specific patients or not. So you have to know a little background about genetics ahh for your ah future career as a doctor. And, well, we have a subject of Genetics in the second semester and I hope that you enjoy it, but also pay a lot of attention on the on the subject because it's it's important at the end. And for example if you want to do the final project in in for example in our group, it's like ehh genetics is fundamental, statistics is fundamental and it's just ahh these subjects are the most impotant that you are going to apply at the end because maybe you specialise in dermatology or another in I don't know, in oncology or another in ahh cardiology but ahh it doesn't matter if you know about other areas. You have to be specialised in cardiology, for example, but you need to know statistics and you know to know English and Genetics to be the as good as you can in your field. OK? So, well I gave you a questionnairy [M3 meant a questionnaire]. I want that you just write down the answers during the presentation. At the end you just have to give the ah the the questionnaire is really easy. It's just about amm things that we are going to talk about during the seminar and I would like that you write down in the back, in the eh in the back part of the of the paper a question. A question of the seminar or a question about life related with more or less with Genetics and Skin cancer. But it's like questions that you have related with this with this area. OK?:: <TLANG_Eng>

S2: ¿Qué? [talking to S3] <TLANG_Sp>

S3: Que tenemos que escribir esto <TLANG_Sp>.

M1: So...First of all, I would like that you express to me or express to you colleagues or whatever what do you sugg what this title suggest to you. What you think we are going to talk about if the title of the seminar is Genetics of skin cancer. Come on! Ah...Any volunteer that wants to say "Well, I think we're going to talk about..." <TLANG_Eng> S9: About skin cancer <TLANG_Eng>.

M1: Well, that's the point. So, we're going... what? <TLANG_Eng> 
S9: inheritance <TLANG_Eng>

M1: inheritance. We're going to talk about inheritance mutations and <TLANG_Eng>

S9: DNA or I don't know <TLANG_Eng>

M1: DNA, of course. It's Genetics, it's DNA. It's like we have where are the alterations, the genetic alterations <TLANG_Eng>.

S9: The sun <TLANG_Eng>

M1: The sun. What is the major cause of skin cancer? The UVA light, the UVA radiation. So we're going to talk about what causes skin cancer, environmental, about Genetics, about gentic alterations, about DNA variants and about cancer, obviously. And our skin. OK? So [clears throat]. First of all, what is cancer? A cancer is a disease in which abnormal cells divide without control. They just invade nearby tissues and they just grow, grow, grow and they proliferate and just go to nearby tissues and expand. That is cancer. It's a...alteration of our cells that just don't control the selfcreation, the self-cycle and just progress. OK? And of course, cancer is a genetic disease because cancer is caused by genetic alterations in controls the way our cells function and especially how they grow and divide. Normally the genetic alterations in a cancer cell eh are in oncogenes or tumor suppressor genes that our genes to like that controls the cell-cycle progression. I'm sure that in biology you know what is the cell cycle prop, the cell cycle. There are different phase of the cycles and there are like policemen in all the parts of this ahh of these phases of the cycle to control. OK, everything is correct, just go to the next phase. OK, it's correct, go - go. Like all the parts are controlled. So, if you have an alteration in the protein who controls the eh different phases of the cycle. Just there are not any composement controlling that and the cell just grow grow grow and proliferate. OK? So, there are two different alterations that can cause cancer. One is mutation that are alterations in the DNA segments that that is what we are going to focus in this seminar. And there are epigenetic changes. Epigenetic changes are changes or modifications in the chromatine, in stones or in DNA that doesn't alter the sequence of the DNA but can alter the exspression of the different genes. For example, changing the structure of the chromatine am there are some genes that can express more or not or silenced or. That's the difference between epigenetic changes and mutations. OK? So, there are different types of mutations or alterations in our DNA. There are some of them 
can cause cancer or can cause alterations in our genes in ourselves but there are others that doesn't have any prob...doesn't have consequence. As for example, there are mutations that there are a change in the in the in a nucleotide of the DNA, but it doesn't translate in a protein change. So fi the protein is the same, it doesn't matter. The protein is working at the same eh level as if - as if you - if we have the normal gene. We don't have this alteration because the protein is...the function of the protein is exactly the same. But there are four types of mutations that can cause cancer [clears throat]. One of this is the missense mutation. The missense mutation ehh just if we if you can see there are changes of the $\mathrm{G}$ by a $\mathrm{T}$ and the aminoacids that are eh that is $\mathrm{mm}$ encode by this codon is changed. So you know that whenw e are reading a gene like our machinery, we like three nucleotides, three nucleotides, three nucleotides, three - three - three. And it's three nucleotides ah it encodes one aminoacid. Yeah? Every... Everybody. That is clear, no? So in that point, for example, this change of the nucleotide ah do a change in the aminoacid of this protein so they are a point mutation in the protein because there are one aminoacid that is different. That can cause that the eh the mut... - the protein doesn't work as it has to be like because... Imagine that this aminoacid is exactly in a place where the proteins do the function like for example it links to another protein or whatever. In that cases, the protein doesn't work as it has to be and ahh and the protein ahh the cell has an alteration in their normal function. OK? There are another type of protein that is the nonsense mutation that when it's inserted a stop codon. A change in the base. This alteration creates a stop codon and the protein is broke. So, it's broke. There are a premature termination of the protein and you have a certain part of the protein, you don't have all the protein and maybe it's not functional or maybe eh it presents abnormal function because you losed a part of the protein. Yeah? Imagine that the point, the, the domain where do the function is that that you losed. It's like you don't have the the function of that protein after you have a part of this protein. OK? Ahh there are another change that is the frameshift mutation. So ehh a nucleotide is inserted [pronounced as insert] or removed. So the reading frame is altered. It's like you start to read three, three, three but if you have an insertion it chang...the reading changes because you insert one and rather than be three, three, three. Itt's like three and then $\mathrm{O}$ and then another one and starts with this rather than with a T. OK? So all the reading frame is changed and the protein is altered, of course. And the protein resulted is very different from this point to the end. Normally they are non-function proteins or they have a altered function. And the last one is the chromosome rearrangements. The other 
three mutations are point mutations. They are alterations of one nucleotide or maybe two. Something like that. But in this case, a piece of chromosome is, is altered because it breaks and losts entirely. So you have a relation or maybe it changes to another position and it's a translocation or just flip the, the direction of the, of the chromosome and have an inversion or duplication or whatever. So it's a change of, that affects to all the chromosomes or to all the genes of these parts of the chromosome. So normally these problems are like worse. (8) But what is a cancer? Like I told you, cancer is a genetic ehh disease, but it could be hereditary or not. In fact, the most, the majority of cancers are not hereditary. So, hereditary diseases are, obviously, are genetics because you inherit a mutation from your parent, but a genetic disease is not necessary to be hereditary. You understand that? Why? Can someone explain why a genetic disease is not necessary to be a hereditary disease?

S11: Because you can get a mutation in your DNA sequence eh: out of nowhere, so it's not necessary in your DNA but it can get to a - a mutation on it.

M1: So, yes, but I think you don't really explain what... I - I say that what. Because it's like the mutation is always in the DNA, OK? But the point I think you wanted to tell is like the mutation is in a somatic cell. It's not in your - in the cells in the gamets that goes to your oathrew. So you can have by chance a mutation in any cell of your body but this doesn't mean that this mutation has to go to your offspring, so it's not hereditary disease. Maybe I'm going to outside and the UVA light goes to my... - this cell of my skin and cause mutation. This mutation is not going to be inherit by my offspring, it's only in my skin and I have a problem in my skin, but that's all. OK? That's the difference between genetic and herediraty disease. Hereditary disease is always genetics, but a genetic disease is not always hereditary. OK? Ahh the majority of cancers are sporadics. They just occur by chance. Maybe an environment factor cause a mutation in your genes and you have a mutation in this cell and proliferates a lot and cause the cancer. That is sporadic. But emm there are some cancers that are hereditary cancers or familiar cancers that more or less is the same that is that you inherit from a change, a alteration in one gene from your parents. This genetic alteration pass from the aprents to the child. OK? Ehh For that reason ehh if you have a family, a family member who has a cancer, you have a higher risk of having a cancer as well because this eh genetic alteration is passed through the different generations and you can inherit that mutation from your parents. So for that reason you have a higher risk of developing 
a cancer if you have relatives ahh presenting this disease. OK? Well, so here for example is like as ah: Well, hereditary disease as I told you is a disease that is inherited genetically and is transmittable from parents to offspring. And as you see in the - in the left eh family tree, all the generations have the have the disease, have the cancer, the tumor because you eh inherit a genetic mutation normally

\section{S12: Because if not the inviable the child didn't eh didn't bear}

M1: You have a general mutation in one copy of your gene, in the oncogene or in the tumor supressor gene, one copy of these genes. But you have higher risk because you only need one somatic mutation in the other copy of the gene to don't have the protein and don't have the protein to control the cell growth. For that reason you are at higher rise - risk. But if you have an sporadic cancer, you don't have. You have normal genes in the two copies of your genes of all the cells of your body, but you have to acquire two different mutations in the same gene that is quite difficult, like it's less probably and for that reason you have less risk of having a, a tumor. Yeah? <TLANG_Eng>

S13: Is it true that skin cancer is caused sporadically? In concrete, skin cancer <TLANG_Eng>.

M1: Well, skin cancer, we'll see like later, but there are some cases that are ehh that are family, family-related eh there are other cases that are sporadic and they are caused normally because UV exposure. But there are the two parts. Normally I think that the percentage is a $90 \%$ of the cancers are sporadic and a $10 \%$ of the cancers are family cancers, more or less. OK? So, ehh of course the general mutation occurs in gamets because if not, it's not eh it's not able to pass on to the offspring. You need to have thus mutation in your gamets to be able to pass to your child. And every cell in the entire organism has this mutation. Hmm. However, a somatic mutation is a genetic alteration acquired but by a single body cell and cannot be inherit [inherited], only tissues deliverd from this cell, this ehh mutated cell are affected. So, for example if I acquire a somatic mutation in one oncogene, in a cell of my lug [lung], I'm going to have only lug [lung] cancer. If not, it goes to metastasis and invade other tissues or whatever. But you, you have this mutation only in the cells of your lug [lung]. OK? And your childs do not have any prob...any risk of having this disease. Well, we see which mutations we have aand...but what causes mutation? There are two ways of causing mutation. One is a gene, a gene. When you are older, your cell machinery goes, works worse aaand just 
doesn't have ahh the same, well they produce more errors during DNA replications, or during DNA repair and of course you accumulate more mutations because you are older and your cells are not working well. Another cause is environmental factors like can be chemicals, smoking, for example, or radiation like UV radiation. UV radiation is the principal cause of skin cancer. It's like it's the most important factor in in developing an skin cancer cancer. Aand it's a real problem nowaydays because we love sun and we go lot of time to the beach and just to tan and without any protection in our skin cells. So nowaydays skin cancer is one of the most important problems in healthy eh institutions and they are eh they really aware of the high incidence of skin cancer in in European populations. OK? <TLANG_Eng>

S14: Can epigenetic changes be inherited in a cancer? <TLANG_Eng>

M1: Ah well, normally eh no because the epigenetics can changes change during the different phases of the development of the embryo and then the different cells and for this reason although you have the same genetic information in all the cells, one are one cells are skin cells, other are from others are lung cells. You know? There are different differences in the embryo development to produce different type of cells because of more the majority of these changes are epigenetic changes. So normally you don't ehh the epigenetic changetic changes, you don't inherit that and cause the cancer because of this. OK? OK. So but there are a lot of epigenetic changes in the tumors, inside the tumors. And maybe that is one thing that ahh that differs, a melanoma that you have and the melanoma that I have and the treatment should be different because we have different epigenetic changes. OK. So, UV radiation, UV sunlight is...damage our cells, cause mutations. OK? And these mutations are the principal cause of developing a skin cancer because these mutations can be ehh can affect onco...oncogenes or tumor suppressor genes. There are two things that can happen after acquiring a UV mutation. One is repair. We can repair our mutation and that don't alter the skin integ, the genoma integrity and the skin function, the skin cell function and you don't develop a, the disease because you can repair these al, genetic alterations caused by the UV light. But there are some times that you don't repair the DNA alteration. Maybe your machinery didn't detect that mutation and this mutation is accumulated in the cell and the cell can death if, for example, the immune system responds, ehh ehh detect that this cell is wrong and it just kill it. Or maybe it increases the immunodeficiency of these cells and it starts to accumulate a lot of mutations and just grow and proliferate and cause the 
cancer. OK? There are these two possibilities. Ahh the point is that if one cell accumulate mutations and strats to proliferate without any control, just start to do a lot of cells that derives from this mutated cell and of course it cause the cancer that can invade different tissues and just grow <TLANG_Eng>.

S15: What? <TLANG_Eng>

S16: OK. One second, 'cause I'm getting confused. So for example, UV radiation damages a cell, alright? <TLANG_Eng>

$\mathrm{M} 1: \mathrm{Hm}$

S16: And in order to avoid cancer, our body with oncogenes and tumor suppressor genes tries to repair or destroy the - the damaged cell <TLANG_Eng>.

M1: But not with these genes <TLANG_Eng>.

S16: But, no <TLANG_Eng>

M1: So you avoid that alteration that can affect these genes with machine... like the different machinery that we have in our cells to repair the DNA. There are different genes. Other. Other genes that encodes from proteins who correct these mutations. So eh if you are able to correct these mutations, you don't have problem because this alt... - this genetic alteration is correct and it's done. And the cell functions correctly $<$ TLANG_Eng>.

S16: But the thing is that, for example, we have the protein to repair the DNA of a damaged cell, alrgiht? But it fails. This is due to...it can happen or because there's something wrong with P53? <TLANG_Eng>

M1: Well, P53 really like it's not the gene, well it's not the protein who corrects, it's the protein who initiates the, the expression of genes that correct the DNA alteration. The point of P53 is that this gene, well this protein can amm can have an alteration. For example, you inherit an alteration from your parents of this gene. If you have a genetic alteration in this gene, maybe you can start the correction of the mutations because you, this gene is not working in your cells <TLANG_Eng>.

S16: So in order for cancer to happen there there has to be already something wrong with for example your protein cells? <TLANG_Eng> 
M1: Yeah normally for cancer arise for airisng a cancer you need to have accumulate different mutations. It's not only one. It's like, it's an accumulation in key $p$, in key genes that when you have all these eh alterations, just start the the cancer development. It is true that there are some genes that are ah like more important than others that just have the genetic environment or the genomic stability to initiate or not. For example, in

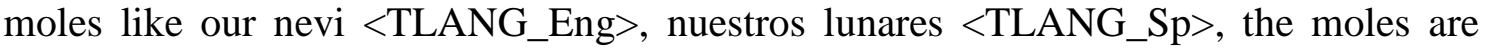
cells that start to grow a lot and they don't have a control in the proliferation but there are another genes that say "STOP”. You can't ehh you can't become a cancer, just stop and be latent. And these cells start to proliferate but there are a point that they say "I know I have to stop my growing because I have another gene that give me that information". So it's a, it's a variety of mutations, there are different genetic alterations that have to occur at the same time. OK? So how does UV light damage the DNA? Because it cause pyrimidine dimers. Ah just to remember you, there are four tones of nucleotides and two of them are pyrimidines and two of them and the others are purines and the pyrimidines are cytosine and thymine and when we have in the DNA sequence two pyrimides together they are eh they can be ehh altered by the UV radiation. OK? So, for example, in here this is strand we have a T-T in the in the sequence in the DNA sequence we have two thymine together and when the UV light ahh affects to these thymines they ah bond each other ahh creating a binding between the two thyimines. And it's called pyrimidine dimers that can be these two types. The more typical ones the more typical dimers caused created is the CPDs. CPDs are really common between two pyrimidines and when the UV light goes to these two, they just bond each other routing to be linked with the opposite ehh with the opposite nucleotide. OK? So, ahh the point is that there are sometimes that these pyrimidine dimers can be corrected and there are not an insertion of a mutation but there are sometimes that it doesn't be corrected. And normally when it can be corrected is when a cytosine is involved in the CPDs because it's not stable and is prone to be the amine to tease. Obviously, that you don't need to write down that in the in the questionnairy. It's just to know the information, ¿vale? So it's like doesn't matter about it. It just you to know what is happening in our DNA. In our DNA when we have two pyrimidines together, for example a thymine or a cytosine, the UV light cause a bond, a link between these two nucleotides and this cytosicne because it's not stable can be deaminated to a thymine. And as you see, it conv, it is converted to a thyimine, so we have two thyimines rather than a thymine and a cytosine. So, if it is not repaired, when you do a replication of this part of the DNA you insert an 
A rather than a $\mathrm{G}$ and you introduce a mutation. You understand? Sure? OK. So the most common mutation in ahh a cause by the UV light and the most common mutation in skin cancer samples are the CT substitution. OK? Ahh that is quite common because for example we are now doing a doing a research with samples of normal skin samples, so samples that doesn't have cancer, and from different eh patients, volunteers and we are seeing that there a high percentage of this CT substitution in their eh in their DNA, although they are not cancer samples. So our normal cells because we are exposed to sunlight every single day, we accumulate mutations in our eh in our genome. But the point is that if these mutations affects to a gene that is important for cell cycle or cell progression is like we can develop a cancer. But if these mutations are accumulated in other genes it don't it doesn't matter, a little bit, but the problem is that other genes that for example are involved in eh immunoresponse or involved in the correction of the errors, are affected but is not affected exactly the oncogene or gene that controls the cell cycle and for this reason we you don't have a cancer. But our skin cells have mutations accumulated, OK? So, ah well, at the beginning... Well, now we are we are going to start with skin cancer more like more concretely. But ahh I - I want before to you know what the UV cause just to understand the importance of skin cancer now in our scoety. Skin cancer is one of the most common neoplasm in the world, especially in European populations. Why in European populations? <TLANG_Eng>

S16: You have just explained it like ten minutes ago <TLANG_Eng $>$.

SX: What? <TLANG_Eng>

S16: You have explained the reason ten minutes ago <TLANG_Eng>.

\section{M1: Why? <TLANG_Eng>}

S16: Because we're going to the beach, taking a lot of sunbathing, a lot of exposure to the sun <TLANG_Eng>.

M1: Yeah. And we are not prepared for that. We are white-skinned. We don't have enough melanin to protect agsainst the UV light. Melanin absorbs UV radiation and protects our cells from the UV damage but if you are white-skinned we don't tan, we burn after a certain exposure, we are in risk because we are not prepared, we're, we don't have this this layer of melanin absorbing de UV light. For this reason it's really an important problem in European-origin populations because we're we are fair-skinned 
and we go to sun we go to beach we have summer holidays and that that attitudes increase the the incidence of skin cancer in in in these type of populations. OK? <TLANG_Eng>

S17: Can a person with that skin suffer skin cancer? <TLANG_Eng>

M1: Yeah, I - I have an example later on, but yeah of course. Anybody, anybody like can avoid the - a possible skin cancer. OK? So, eh all of us are there are in contact with the UV light. There are people who has more risk because they are fair-skinned, but there are people who doesn't have this increased risk but also have can have a melanoma a or a kin cancer, us usually a melanoma. But that's the point. Everybody although we tan ah in summer with the UV exposure eh can develop a skin cancer. OK? So there are two types of skin cancer eh depending on the the cells that arise. So there the non-melanoma cancers are arise from keratinocytes. Eh the basal cell is the - is when the keratinocytes are in the base layer of the epidermis and the skema cell skin cancer is when keratinocytes are in the upper layers of the epidermis. These two, well, these two types of skin cancer are really common are the most common cancers around the world. The point is that they use to appear in the in the statistics or in epidemiology studies because of they are not aggressive, they...the mortatility is nothing, it's like any died because a non-melanoma skin cancer. It's it's really easy to remove it, remove the area, they don't invade other tissues and there are not any problems related to metastasis and anthing like that. So, for that reason they don't use to appear in the statistics. But for example, in, we collaborate with dermatologists of the Hospital La Plana and in the General, and the told us that maybe when they have a session of quirofan [operating room] that they have ten patients, imagine, like eight of them are because they have a non-melanoma skin cancer per day. So imagine the incidence of these cancers in our society. And, well, then we have the melanoma. The melamona rise from melanocytes, the cells who eh who produce the melanin and they are located in the basal part of the epidermis. Melanoma is the opposite is like, it's there's a higher incidence of melanoma and it's increasing every and every single year but it's really aggressive and the ehh mortatiliy rates are really hight, a majority or a high percentage of people who had melanoma died because of this cancer. Eh because eh it invade the tissues or the other tissues easily, it just metastise to another tissues and maybe you don't die because of melanoma but you die because of, you have a lung cancer caused by the metastasis of this melanoma. So this is a really big big problem nowadays in our healthy, healthy life. 
And this is a image about a melanoma. This is $\mathrm{X}$ and this is the melanoma, it's really really small and it can kill you, so that's the point. It's like it's really small, it's really difficult to detect and you have to follow the prevention, the pevention attitudes and recommendations that your dermatologist gives you if you have a higher risk of course. Because if you detect the melanoma in stage 3 or 4 , normally they have like it invades other tissues and it's really late to detect it. It's better to detect it at the first phass and usally they remove the melanoma and the borders just to be sure that there are not any malignant cell that can proliferate again <TLANG_Eng>.

S8: Is it painful in first phases? <TLANG_Eng>

M1: Painful the melanoma? I don't lnow No, normally they arise from a mole and it's like "Ohh my mole is growing”. It's like just grows. You know? It's just very localised the melanoma, it's not like other cancer. But rather than to grow in a horizontal area it grows vertical so it invades the other tissues <TLANG_Eng>.

SX: And can you feel it growing or...? $<$ TLANG_Eng $>$

M1: Now for example there are applications for mobile phones that you photograph you do a photograph of you mole like the moles that you have to to screen the little ones is normally you don't have any prolem. You do a picture of your moles and the application tells you if it grows or the color is uniform or if changes the borders just to have and uniform, an screen of your moles duing the different time. Or if for example, appers like a spot that doesn't have good borders the best thing is to go to the dermatologist as soon as possible just to prevention. OK, so what factors are associated with predisposition to skin cancers? Of course, environmental factors because depending on UV radiation you have if you have higher UV raditation, solar exposure you are at higher risk and it depends also about geographical localisation [location]. If you are living near the Equator where the UV radiation is really high is really intense, you are at higher risk that if you are living in Finland where they don't see the sun during the year, for example. Or they have low levels of UV radiation. And the other things are genetic factors. You can inherit genetic variants that influence your phenotypic traits. So for example, the colour of your skin, the colour of your eyes, hair or if you are able to ehh to tan or versus burn when you expose to UV aand other traits related to response, repair, immune response. If you are, if you have a protein involved in DNA repair that is mutated, that is not working, you can't repair these errors 
introduced by the UV radiation in your DNA. So all these genetic alterations can ah influence on the risk that you have developing a melanoma or a skin cancer in general. Well, as, as I told you before, normally the majority of skin cancers are sporadic, are non-familial melanoma. And and 5 to $12 \%$ of these melanomas are familial. So the people who have this melanoma report a relative who have affected with melanoma. So of course a positive family history is associated with an increased risk of developing a melanoma, you can inherit a mutation in key genes that control the cell cycle and of course you have a higher risk because only one sporadic mutation in the other copy of this gene can produce a fail in the cell control progression. Yeah? Well, these genes are normally called hypenetrant genes and the most common gene ahh that is mutated is the CDKN2A. A $20 \%$ of the cases, more or less, $20 \%$ to $40 \%$ of the cases with melanoma, familial melanoma history have a mutation in the CDKN2A gene. This gene is a tumor suppressor gene and controls the entry to the end phase of the cycle. There are other genes as you see but the percentage of the people ah with this mutation is really low, so the most important is this one. As I told you, CDKN2A is a tumor suppressor gene and controls the cell cycle. It could emm emm produce two different proteins ah depeding on when the reading frame starts but the most important is the P16. So the P16 is an oncogene that controls the S-phase entry. And the point is that P16 links, is binded with the CDK4 aand because they are linked they can phosphorelay another proteins that that allow the entry to the S-phase of the cycle. So if these two proteins can't link, can't bind together and they are just by themselves, they are not together, the phosphorylation of these proteins are always occurrying. So there are not any control about when I want to phosphorylate this protein and when I don't want to phosphorylate these proteins and the cells are always entring to the S-phase of the cycle without any control. OK? So there's, this is the protein ahh in the right up and there are a lot of mutations in these genes but the most common mutation in European populations, well, in populations with European origin, are is the substitution of valine to asparagine in the position 126. In...in this position there's a change of this aminoacid caused by am a change in the nucleotide a point mutation, the thyimine changes to amine in the position 377 . And as you see in this graph, if the if the individual is om is have the two copies normal for this gene, this blue peak is not occurrying, you only have one peak of the $\mathrm{T}$ but if you have one copy of the gene mutated, so you inherit a genetic alteration from your parents, you see for in this graph this individual for this genetic alteration. They, this individual, this patient has one copy of the gene with the $\mathrm{T}$ that is the normal eh form of the gene and 
then it have the other copy with an A that is the altered sequence of the gene. Do you understand? Because you have one copy of it and then you have a higher risk because you can't utate the other copy of the gene and you produce the cancer if you don't have the protein to control the S-phase of the cycle. Hmm OK. This mutation affects ANK domain that these domains mediates the protein-protein binding. So as I told you P16 links to CDK4 to phosphorylate or other protein, so if you have a mutation that ehh that is reduced the binding between these two proteins that affect this binding you don't have this control because they can't bind together. OK? So this mutation predict is predicted to confirm a lot of functions to the P16 protein and therefore is a reduced bind with CDK gene. OK? Well, so Bob Marley had, passed away because of an acral melanoma. He carried a general mutation in the CDKN2A gene he inherited from his father. So his father passed to him a mutation in this gene and he has higher risk of developing a melanoma. Ahh in fact, the point is that they, eh the dermatologist detected the acral melanoma but Bob Marley didn't want to have any treatment. And for that reason he passed away because of the melanoma. And... $<$ TLANG_Eng $>$

S18: Just one question, he used to smoke weed, a lot of weed <TLANG_Eng>.

M1: Yeah. But he didn't die because of that <TLANG_Eng>.

S18: No? <TLANG_Eng>

M1: No <TLANG_Eng>

S18: Is it related to any kind of skin [cancer]? Smoking? Especially smoking weed, I mean $<$ TLANG_Eng $>$.

M1: No, I don't know. Everybody thought that it's because of that but he died of an acral melanoma. And because he inherited that mutation from his father. Because his father from, was from UK and his mother was from Jamaica. So his father was, well this mutation is really common in Europe aand he just passed away to the offspring. Aand well an acral melanoma that arise in the nails used to in the foot. It's a non-exposed area of sun but an intense radiation can ah can produce has more mutagenic action than for example a chronic exposure of low level of intensity of UV radiation. For that reason, for example, when you go, in summer holidays, when North, people from North Europe come and - and just receive an intense radiation of UV light eh it's worse it's more aggressive than - than for example having a a exposure to sun during all the days of the 
year, like daily exposure, it's worse to have an intense UV radiation. OK?:: So ah well, but it's true that the $90 \%$ of cases $<$ TLANG_Eng $>$.

SX1: Shh

M1: I hope that you're speaking in English all the time that you speak together $<$ TLANG_Eng>.

SX2: More or less <TLANG_Eng>

M1: More or less. OK. So as I told the $90 \%$ of cases of melanoma are sporadic, so they don't have any relative any family member who developed a melanoma. And it is, well epidemiology studies relveals a correlation between the pigmentation traits that are genetical determinant, obviously and the level of sun incidence damage. So people who are fair-skinned who don't tan when they are exposed to UV are more are at higher risk of developing a skin cancer than people who tan or have brown skin or dark skin because you are less protected against the UV radiation <TLANG_Eng>.

S19: And for example, if you a mixed-y you are like in the middle of getting a...? $<$ TLANG_Eng>

M1: Yeah there are graduations as you can see here. It's like there are people who never never tan and burn always like for example red-haired individuals. It's like they have to really protect themselves against the UV light, but there are people who just... There are sometimes that tan but normally burn, like there are different graduations. Of course, if you ah increase the tanning ability of the individuals, you reduce the risk of having a skin cancer. But it's always a, a graduation. OK? So individuals with a pigmentation risk phenotypes, it's like people who has fair skin, green, blue eyes, red, blonde hair, freckles. Freckles is the - the different... $<$ TLANG_Eng $>$

SX: ¿Pecas? <TLANG_Sp>

M1: Yeah. From the kids but the like the small ones that arise with the sun that when the sun increase the level of the freckles and when is winter, for example, they have less freckles. So, that is freckles. And then inability to tan. The people who don't tan and always burn they are at higher risk or greater sensibility to skin cancers than people who eh has brown skin, tend to tan easily, don't burn and have dark skin or dark hair or eye colour. And in dermatology ahh in the dermatology subject, you ahh study this 
classification. This is a typical classification that the, that the dermatologists use to classify your skin, your ability to tan or not. In Spain there are these four [types], one, two, three, four, depending on the, your pigmentation traits. But there are two more. The five and the six that is the five more or less typical of Amerindian people, like from Mexico. But the aborigin people, not not the mixed with European populations. And the six is the black people like African-origin people. Aaand but this phenotypes are not typical from Spain but the we can have a graduation between these four types of ah skin phototypes ehh in Spain. So these pigmentation traits are determined by genetic alterations in genes involved in human pigmentation pathway. This is a scheme of all the genes, all the proteins that are involved in eh pigmentation pathway, in the synthesis of melanin, in the transport of melanin from the melanocytes to the keratinocytes or whatever. So all these genes can have any gnetic alteration that affects two our pigmentation phenotype. For this reason we are very different between each other in our eyes, colour eyes, colour the hair or for example, colour of our skin. So these determine our phenotype and our visible characteristics related to pigmentation. And general mutation in this gene contributes sign significantly to predisposition to skin cancer. So depending on the genetic alteration that we have in these genes we have more or lower risk of developing a skin cancer. Of course, people who has general mutations related to a fair skin or mm don't...inability to tan or whatever if they don't go to the sun and they don't go outdoors, they are not going to develop a skin cancer because they are not affected by the UV radiation. OK? Or if they protect themselves. Well, from all these genes the most important is the MC1R is the receptor of the melanocytes and MC1R starts the route, the pathway to produce melanin or to em to act against the UV damage in the DNA. OK? This receptor when it works well when it don't have any genetic alteration that affects the eh its function just starts the route to in increase the production of eumelanin, that is the melanin that has the brown colour, and the DNA damage repair, start proliferation or whatever. And, but it can also be blocked by the another another ehh signal that is ASIP, it's another protein ah who is... These two proteins the alpha-MSH and ASIP are produced by the keratinocytes, so the keratinocytes receive sun from the from the environment, produce alpha-MSH to to say to the melanocytes to produce melanin and to protect against the UV. But if there are not UV the keratinocytes produce another protein that is the ASIP and blocks the initiation of this route, of this pathway because it's not needed to produce eh eumelanin because there are not UV radiation in the environment. <TLANG_Eng> 
S19: And it's someone with no melanin at all? I don't know the word, <TLANG_Eng> albino? <TLANG_Sp>

M1: albino, albini.

S19: They have a way higher risk of getting a skin cancer?

M1: Of course, and a - a 100\% [pronounced as cen, linguistic transfer from the Catalan] higher risk of having canc... - skin cancer. In fact, it's one of the most problems from people who are albin in Africa. They died or they have health problems because of skin cancer, developing a skin cancer. They are not protected at all from UV radiaton. They don't have any melanin. Hmm. Aand well, there are people who has variants in these receptors and there are some variants that are called RHC variants redhair colour variants so it's the typical variants found in red-haired individuals that blocks that ah the function of the receptor and the melanin is not produced. So it's increased the pheomelanin cysteine that is the melanin who has $\mathrm{mm}$ red ah red colour and for that reason is typical in the in the red-haired in the red-haired individual. For example, in freckling. People who has a lot frecklings aand they use to have this mutation in these genes, for example, that impair the function of the receptor. I have one copy of my gene, one copy of my gene have this type of mutation, for example, ah but the other works perfectly and I have - I have a function of these receptors but one of the one gene, one copy of my gene produce a receptor that doesn't have any function and the other copy produce a receptor who has who has function and can produce eumelanin. OK?:: Amm well, this is two maps, world maps about the upper one is about incidence of melanoma world time, worldwide, and the other is the annual UV radiation. You can see the highest rates of melanoma occur in countries where the inhabitants are light-skinned. And are exposed to high levels of UV radiation, but why we think that, for example, individuals from Finland has higher. Ah well in Finland there are a higher risk of skin cancer, of melanoma than for example in Spain where we have a daily high levels of UV radiation <TLANG_Eng>.

S18: Because they have fair skin colour <TLANG_Eng>.

M1: And? Where do they go to summer? <TLANG_Eng>.

S18: In here <TLANG_Eng>. 
M1: In Canarias, in Spain, in north of Morocco, in North Africa. That is the point, summer holidays are horrible for north European countries. Because they come to Spain, like they want to enjoy sun but they are not prepared for that. They are really fair-skinned individuals and they just burn their skin aand because it's like it0s just society. They want to enjoy the beach and the summer of Spain and the sun of Spain but they are not adapted for that. OK? So for that reason, countries, north eh European countries have a really high incidence of of skin cancer aand we don't have as much as they have although it is increasing a lot in the last years. For example, in America the high incidence there are a really high incidence of skin cancer in America and it's because the summer holidaus in Florida. The go to Florida to enjoy beach or to enjoy the the this area and or for example in this in the west part of of the United States there are high levels of UV radiation and the majority of people living in Texas, Arizona or California are white people. They are not ehh they don't have the same pigmentation characteristics that than the Amerindians that used to live in that area, so they are not prepared for that UV levels. OK? But for example the opposite part, the opposite example is Australia. Australia is a country where the levels of UV radiation are really high every single day and the people are white-skinned because they are of European origin they are from well they are descendants of England individuals because Australia was a colony of the UK. So they are fair-skinned, they are white people and they have a really intense UV radiation. They enjoy a lot of outdoors because they do a lot of activities outdoors and they are constantly eh affected by the UV radiation. For that reason, Australia is the country where the incidence of skin cancer is the highest in the world. Because they are not prepared for that levels of UV radiation. Hmm. Anyone knows who is this guy? <TLANG_Eng>

\section{S16: John McCain <TLANG_Eng>}

M1: John McCain died, passed away because of glioblastoma but this glioblastoma was caused by because of melanoma. OK? John McCain was the opponent of Barack Obama in the US president elections and he has a cutaneous melanoma on the face in I think that in 2010 and five years I think that he died two years ago or one year ago $<$ TLANG_Eng $>$.

S16: one year. In fact, this year <TLANG_Eng>.

M1: What? <TLANG_Eng> 
S16: He died this year <TLANG_Eng>.

M1: This year? In two...? Well, this year. Aand he died because glioblastoma but it was caused because a metastasic melanoma. As I told you melamona is really aggressive and invade a lot of the nearby nerve tissues. Aand ah and the point is that John McCain was a fair-skinned individual living in Arizona that is the state with the highest levels of UV radiation in the United States. So this guy was not prepared physicially, phenotypically for living in this country, in this part of the country where normally the people who lived there was Amerindians who has darker skin and has phenotypic traits different from European-origin populations. Hmm. It's curious because a few years ago eh the the NHS NHS that is the National Healthy I don't know the sigles [negative transfer from Spanish]. But they they present a statistics about the use of sunscreen in the United States and it's really curious because the people who most use sunscreen was who lived in the north part of the country rather than in the south where the sun the sun is higher, the intensity of sun is higher in the south of USA rather than in the north. So it's quite opposite that it should be. But it used to be because people who die, who has sun eh daily, so has a good weather, don't really mm aware about the problems of the sun because every single day they are enjoying the sun and maybe people who are living in in parts where there are not used to be exposed to be sun are more aware about the problems of UV light can produce in our cells. I don't know, I think it's a - a - a education point, prevention. OK. So:: skin colour adaptation, as I told you, people who are not prepared to live in a UV, in ah countries where the UV light is really intense ehh they are not originary from there. Natural selection ahh was ahh was ahh select skin colour depending on the intensity of UV radiation. For that people ah the originary population of countries near the Equator where the intensity of UV light is high has like ah has darker skin, they are dark-skinned people and people who lives far away from the Equator where the UV light is lower eh has eh a fair skin. You know? Because they don't have this intensity of UV radiation and they don't have to protect themselves against this damage caused by UV radiation. Because melanin, the quantiy of melanin is proportional to the UV light that eh that eh that the intensity of UV light in the area. Ahh because the melanin has to absorb this UV light and ah and it's a a biological protection against the UV damage, and the breakdown of pholeiss, pholeiss are the essential nutrients. Like UV light also brokes this essential nutrients, so it's another way to protect themselves. For this reason, for example, the the woman who are pregnant use 
to increase the pigmentation when they are in pregnancy. For example, they have melasma that is these spots that occur, like dark spots that occur in the face or in upper lips, or for example the linea nigra it's because it's an adaptation of, well I have to protect the fetus, I have to protect my child and have all the phooleds to to development of this fetus. OK? It's a natural adaptation. Aand but the other point is that people who lives far away from the Equator have to have to present lower levels of melanin to be able to absorb the UV light for vitamin D [pronounced as in Spanish], vitamin D production [self-corrects]. OK? So you need to absorb vitamin D if you have low radiation of UV light you have to have lower melanin, lower skin tone to be able to absorb the UV light for vitamin D production. Aand because if you don't absorb produce vitamin $\mathrm{D}$, you can have problems of calcium absortion, or rakitism [negative transfer from Spanish, M3 meant 'rickets'] or these type of problems. So it's a balance between I need to protect myself against the UV radiation, but I have to absorb UV for produce vitamin D. Ahh for example in UK the black childs [children] ahh need to intake vitamin D because they have a lot of melanin and they cant absorb the UV light for produce vitamin D so they have to supplement the the this nutrient taking a pill, taking vitamin D. I think the Social Security [National Health Service] is like they give to the parents who have black childs just to don't have rakitism [rickets] problems. But this distribution of skin colours has changed because the the the global migrations of the of the people during the last years. Ahh there are a lot of changes and people who are black and live in northern countries have problems of calcium absortion, for example. But people who live who are from Europe goes to live to Africa and they have problems of skin cancer. So this has changed a lot in the last years. Well, ehh one of the examples of Austrlian guy having a developing a skin cancer is Hugh Jackman. Hugh Jackman, of course, is from European origin, although he lives in Australia, his parents, his grandfather his bla bla other genrations come from UK so his fair-skinned and he has different pigmentation traits that are not eh eh adapted to live in Australia where the UV intensity is quite high. Of course, he didn't pass because of the skin cancer. And he has five times Basal Cell Carcinoma, five times. Aand it was just removed from his nose and there are not any problem about it. But he is really, he is a good example because he is really active in social networks to encourage people for using sunscreen and for protect themselves against the UV radiation. Amm in OK. In Spain, I think that in 2015 they asked to different populations about the use of sunscreen or not, of their protection against UV radiation aand only $22 \%$ of the people protect themselves from sunlight 
daily. So it's a really low percentage of people that every single day protect themselves using sunscreen from the sun. So we are not really aware about the problem of UV radiation in our, in our cells. Aand from this $22 \%, 77 \%$ of these people say that they only apply it for the protection on the face, but not in other body areas exposed to the sun. So I protect myself but I'm going with shorts and a t-shirt, short t-shirt, doesn't matter. My arms and my legs can have skin cancer, but my face no. No, if we are going to protect ourselves, we have to protect all the body parts that are exposed. Hmm. So because. For example, epidmeology studies ahh says that woman, the most common area of developing a melanoma is the legs, the upper part of the legs. Why? Because we use to use trousers, but when we go the beach, we use the bikini, so these areas are not used to be protected against UV radiation, but in summer just the first day that we that they the sun they just burn themselves in the beach. And in males the most common part of the of the melamona rise is in the back or in the shoulders because they just take away the shirt and normally these parts are not chronically exposed to the sun and they are not prepared because they don't have this layer of melanin waiting for the UV radiation to absorb it. OK? Well, in ahh, in USA they have a really big, big problem with skin cancer. They are initiating a lot of ahh prevention activities to just to for everybody to don't use, like avoid the use of tanning beds, for some tanning beds are horrible. Don't use tanning beds never and ever. For example, use sunscreen or protect themselves against the UV radiation because they really they are having a really big problem ahh in healthcare related with skin cancer. The use of tanning beds in northern countries and in in USA it's really high and it's the worst thing you can do to your skin cells. Aand another important thing that you can do, as I told you about the app, the application of, the mobile [pronounced as in Spanish] application to screen your moles because moles are, are a group of cells that start to proliferate but they just stop aand there they can be UV intense radiation and initiates the development of a melanoma arising from this mole. So, for that reason is important to screen your moles and is...Ehh you have to use the $\mathrm{ABCD}$ rule that is about the symmetry, it has to be symmetric, the border, have a regular borders, and colour, uniform colour, diametre, not be higher than 6 milimetres and then the most important thing is the moulding, that the mole don't grow with the time, don't change during time. If the mole change with time, it's like "no way". Go to the dermatologist quickly as soon as possible. OK? Aand just to finish take a message, please. Just take care of your skin. Protect yourselves. OK? Protect your cells and don't burn. Just having red your skin, a low level of red in your 
skin is because is there is a damage in your cells. So never ever ever burn yourselves and just use sunscreen. Don't worry if you are the most brown person in the world, you're a tan person, you're tanner than your friends, no. OK? So ahh now just finish the questionnary and it's time for questions. If anyone, well you have to write down a question. So write down the question that you have, if you have any of...the people who asked during the presentation, you can ask another if you want or if not, don't worry. Aand just I want that everybody do one question aand just to discuss a little bit about the the field. OK?:: So when you want to start <TLANG_Eng>.

S18: Yeah, it's about Bob Marley. You said that it's a mutation, but is a kind of melanoma too? <TLANG_Eng>

M1: What? Acral melanoma? <TLANG_Eng>

S18: Is it - is it a kind of melanoma? <TLANG_Eng>

M1: Yeah, yeah. There are different types of melanoma. There are cutaneous melanoma, that is from the cells of our skin. There are acral melanoma that use to arise in the part of the nails and in parts where there is not a chronic exposure of UV light. And then a mucous [mucosal] melanoma. The melanoma can also arise in for example in the pharynx or in the moles or in the parts of the mucosas because they are also amm there are also malign cells in these parts <TLANG_Eng $>$.

S2: You said that you had a mutation. How do you know that? <TLANG_Eng>

M1: That I have mutation? Because I sequenced my gene. So we have a I think that maybe now we have 700 samples, DNA samples of volunteers of different ehh of different studies that we have in the lab and we have the DNA of all these persons. And we just sequenced, ah do a sequencing of this gene to know he sequence of of each person. And for example, I did mine. I'm a volunteer of my prop of my research. Aand it's the same of that chromatograph I showed you with the CDK. You obtain, you obtain this. Like different points. If you have only one peak it's like you are [unintelligible] in this part. But for example in my chromatograph I have one point where I have two. So it's like in one copy I have the normal gene and in the other I have the mutation. So I know that I have this alteration in my eh genes <TLANG_Eng>.

S18: And do you have to worry if your body is full of freckles? <TLANG_Eng> 
M1: Well, people who has normally more...but freckles in the body? Like no, you have moles in your body. Normally freckles occur here [touching M3's face] or red hair or normally occurs also in other parts. But normally the freckles, the freckles is here. Like the other thing that you can have is lentigos that are sun spots that occur because of sun and they are always there or moles. The freckles appear when the sun when you have a sun incidence in your skin and then if you cover your body they just disappear. So... $<$ TLANG_Eng $>$

S18: But do I have to worry? <TLANG_Eng>

M1: Yes. Because a melanoma can arise from a mole. So you have to protect your skin $<$ TLANG_Eng>.

S20: I have a question, but it has nothing to do with skin cancer. When you see those tests that they say they can sequence your DNA and can tell you where you come from <TLANG_Eng>

M1: Hmm. The ancestry <TLANG_Eng>

S20: How does it work? <TLANG_Eng>

M1: How does it work? Well, they are...Well, that class is for fourth. You have a, you have a subject that is Toxicology and Legal Medicine and I give the part of genetics and there aims that is ancestry amm ancestry inherit markers <TLANG_Eng>

\section{S20: Yeah <TLANG_Eng>}

M1: Ancestry inherit markers that you can analyse these markers and know where the sample comes from, what is the ancestry of this sample. For example, if you come fro Africa, if you come from Europe, if you come from... and different countries because there are differences between the different populations ehh around the world. So you analyse these strains to know eh where are you from. They are point mutations, for example imagine that you have a chip. Well, they used to do it like a chip and you have like 300 or 3000 point mutation that you analyse together and you know if the sample is from wherever. Or if you have a mixture between different populations $<$ TLANG_Eng>. 
S6: And do we need to have an error in our DNA reparation in order to develop a cancer? <TLANG_Eng>

M1: Normally the mutation accumulates because there are not a repair in the error. If this alteration is repaired, don't worry because the cell is working well. But this alteration when it's not eh corrected is when accumulates and produce a a a worse function of your cells. OK? So, it have to accumulate. Another question $<$ TLANG_Eng $>$.

S11: Everyime you burn your skin, there are some errors? <TLANG_Eng>

M1: Hmm <TLANG_Eng>

S11: But normally they are corrected, no? <TLANG_Eng>

M1: Mmm yeah, they can correct or they cannot. So... $<$ TLANG_Eng $>$

S11: They are very common <TLANG_Eng>

M1: They are very common. For example, in the study that we are doing with normal cells, normal samples we have like mm samples with $\mathrm{mm}$ for example hours that are chronically exposed to the sun, face or the neck or the hand that they can have like 400 mutations per...we are analysing 50 genes, so in these 50 genes you can have 400 mutations. So imagine the common that it is to accumulate a somatic mutation. But the point is where this somatic mutation is located. So that's the difference between normal samples or cancer samples <TLANG_Eng>.

S11: OK <TLANG_Eng>

M1: And you have to protect yourself a lot. You have freckles <TLANG_Eng>.

S21: Can I have in...a melanoma in an area which is not exposed to the sun? $<$ TLANG_Eng>

M1: Hmm. Like for example the acral melanoma or the mucosal melanoma. It can arise eh in these parts. Normally the genes that are altered in these in these ehh melanomas are different from genes in cutaneous melanoma. They are researching about why but the there are different papers in this year that show that the profile, the genetic profile, 
the genetic mutations accumulate in cutaneous melanoma and in melanomas that are not exposed to sun are completely different <TLANG_Eng>.

S22: Emm in skin cancer, in the causes is more common the mutation or the epigenetic change? <TLANG_Eng>

M1: It's more common the mutations. It's more common that a mutation affect ah the function of a protein, in this case. Hmm <TLANG_Eng>

S23: Ehh if we know eh what cause a mutation, why don't we know how to cure it? $<$ TLANG_Eng>

M1: Yeah. Because it's more difficult that that we think. Like, for example, we know what a mutation is causing in a gene, but to do like a specific treatment for replacing this protein that is incorrect eh at cellular level is really difficult just to ah affect to this specific cell that is causing the the gene. At the same time, because maybers, maybe you can thought "OK, I'm going to introduce that protein that is not working to the cell and now everything is going to work". No, because it's not stable. Normally, it just disappears, it just affect one cell but if there are one other cell that is not corrected, just the melanoma starts again. So it's quite difficult to do a really, and that's that's the key point for future researchers <TLANG_Eng>.

S24: And how can you develop a melanoma in an area that is not exposed to the sun? <TLANG_Eng>

M1: That is a really good question. Because for example for mucosal or acral melanoma it's quite strange to think that it can be a melanoma in that point. But the pathway is tot, totally different. It used to be because you inherit a, a specific mutation, normally. Aand and there are other genes that are affected, that are not the same for cutaneous melanoma. And they don't really know why, exactly why these genes are affected. So, it's one of the ways where the researchers are going. It is true that the mucosal and the aaand acral melanoma is, well, the incidence there are not a lot of cases every year. The most common is the cutaneous melanoma and for this reason there are investigations related with this area, but it's a good point $<$ TLANG_Eng $>$.

S25: And M1, is it worthy to undergo a immunotherapy or justlet the patient die? <TLANG_Eng> 
M1: Well, the doctor always tries to save you, of course. It's like, they try to give you chemotherapy, immunotheraphy or just remove the melanoma or try to <TLANG_Eng> S25: But if the patient is going to die <TLANG_Eng>

M1: Well, it's depending on the stage of the diagnosis is done. Normally $<$ TLANG_Eng>

S26: Is there a high frequence of mutation in our DNA sequence? <TLANG_Eng>

M1: Is what? Is the high? <TLANG_Eng>

S26: Is there a high frequence <TLANG_Eng>

M1: A high frequence? Yes, S26: it's a high frequence of mutation. As I told you and your colleagues [pronounced as college], in the study that we are doing to the cell, like normal cell, normal samples, we have a rate of more or less like 400 mutations per sample in in in we are investigating like 50. So imagine the high rate. Like maybe you have 4 or 5 nucleotides mutated per kilobase of the the, it's quite high:: Any question else? <TLANG_Eng>

S15: Do we have to write down the question? <TLANG_Eng>

M1: Yeah, please <TLANG_Eng>

S15: All of them? <TLANG_Eng>

M1: No, one. Yours::: Done? OK. So it's done for today. Just when you finish just give me the questionnaire <TLANG_Eng>. 


\section{APPENDIX III (g): Anthropology and Evolution}

M2: OK - OK. Shall we? Shall we get started? As you know, this seminar is going to be about fake news. Different news that have appeared in different media, usually quality prestigious media. BBC news, the Independent, El País, El Mundo and so on. These are not second-rate newspapers. They're quite good newspapers. These are general media that are not specialised or scientific media, OK? These are different news that appeared in the last fifteen years that make no sense at all. These, these news are completely distorted, OK? And then what you have to do is, for example, New number 1, News Number 1. You have to fill in this ehh this box here with why you think this news doesn't make any sense at all. You have news in Spanish and in English. It's not the same. They are two different articles, two different ehh magazines, different newspapers. In this news number 1 all the information that you have available here is the news, OK? In Spanish and in English. For news number 2 there's two pages with the, with the news and then you have truthful information that I have been taken from the Internet. This news is about the Y chromosmose. In this Y chromosome I have taken an article ehh in Wikipedia and I have changed things that were not correct. So I have modified am an article from Wikipedia about this Y chromosome and I have given it to you. So this second page is not the news. The news is the first one, OK? The second one is true information that you have to eh compare and see what's wro'g with the, with the news. And finally, news number 3 you also have the, the, the piece of news in Spanish by El País and then in English. It's not a translation, OK? They are two different versions. I give you one in Englihs and another one in Spanish. And this is by The Independent. And then, the last two pages are also information that I give you in English in order for you to eh to have trutuhful information about eh, about the topic that been exposed in this, in this news, OK? This is about Cheddar Man. Cheddar is a village in the UK where they make very famous cheese and they also have a very famous skeleton, one of the oldest skeletons eh in the in Europe. So this is true information about Cheddar Man and this is true information about a Mitochondrial DNA that is called U5. You get started reading. News number 1. Write about what you think is wrong and then when you, when you are done eh we'll talk about in four or five inutes, we'll talk about what is wrong, what is right. You don't have to write it in English. You can, if you want. But you can write in Spanish. And the most important 
thing. When you are done with the three news there is an exam. A test, a test. Ten questions. Multilple eh, multiple options. The test is not easy <TLANG_Eng>.

[laughs]

M2: It's in Spanish. It's in Spanish and it's not easy. And it doesn't ask about data. It asks about concepts that you have to learn in this, in this seminar. OK? Ehh because it's not easy the eh the negative points are only -0.10 . So you, you eh have one incorrect answer, it only eh eh takes from your final mark only -0.10 points, OK? Instead of 0.25 which would be the normal eh penalty. Questions? If you have questions, we'll be here. $\mathrm{X}$ and I will be here to answer questions that you have and so on. Questions, they can be in Spanish. They don't have to be in English if you don't want, OK? Most of the information is new. I'm sure you'll be able to deal with it and cope with it without any problem. Please do eh write the, the box to fill it up. You'll be able to use that information during the exam, OK? So at the end of the seminar, you'll have to hand in the test, the exam test and what you have written in the, in the, in this eh, in this folder. But during the test you can take a look at your answers there, both at the news and what you have written about the news. And you can form like groups of three or four, three or four people and you can talk about. You read the news and then you can talk about the news in groups of three, for example. Three and four or three and four, you three, you four and then you can make two different groups. OK, so one, two, three, four, five, six. Six groups in total, OK. But you have to fill in this individually, OK? And the exam is also individual <TLANG_Eng>

[laughs]

M2: OK: Who has not understood absolutely anything of what I said? Raise your hand. Of course, if you don't understand what I say, you don't know you have to raise your hand <TLANG_Eng>.

\section{[laughs]}

M2: Are you fine? Did you follow everything I said? My Spanish accent didn't bother you? Ok so we have about an hour and a half. You have, you can read the news carefully and then discuss in your group what's wrong, what's right. Ask M1 and or me. And then we'll talk about. I'll ask you "What do think about this news? Why is it 
completely distorted? Why is it twisted?" OK? And then we go to eh to news number 2 and news number 3 .

M2: So what can you tell me about this piece of news? English or Spanish. Don't doubt, someone over there. In Spanish? Spanish is fine

S1: Nosotras creemos que, bueno, como dice en la segunda noticia, que desaparecer no va a desaparecer porque no es ninguna desventaja y que auneuqe el genotipo si una persona rubia y una morena tienen un hijo y luego el hijo les sale moreno, aunque no se vea el rubio, lo lleva en los genes. Entonces puede salir en la siguiente generación $\langle$ TLANG_Sp>.

M2: Exactly. Do you think that the reporter understands what's recessiveness? Do you understand that it's extremely silly, it's stupid. It has no scientific basis at all, OK? A recessive trait can be obscured or or masked by a dominant trait and it's impossible to get rid of it. Humans, we have recessive eh recessive traits that cause terrible diseases, genetic diseases and they haven't disappeared in many thousand years. So why is a recessive trait like blond hair going to disappear? It's impossible. It's eh it's eh. And it's also quite, I don't know if you've, if you've, if you've noticed but it's quite sexist. They never talk about blond men. They always talk about the last female, no? blond female will die. They tell you the place and the, and the year specifically when...it's all bullshit, OK?:: Any more comments? Comments? <TLANG_Eng> ¿Comentarios? $<$ TLANG_Sp>

\section{[laughs]}

M2: ¿Dudas? <TLANG_Sp>

S2: Una pregunta ¿Y el color de pelo no está determinado por más de un gen? ¿Son todos recesivos? <TLANG_Sp>

M2: In - in - in general there are a few snips a few ehh genetic variants that are responsible for blond hair. Some of them are very specific. So if you are if you are homocyclic for this specific trait, you'll be blonde. Almost for sure. Those are eh variants that are very infrequent in population and there are a bit more eh common in northern Europe. Finland especially, Sweden, the Baltic eh countries and they are. But not everyone that is blond is blond because of the same genes, OK? There are other 
genes thar eh are more complex. And there are maybe ten, twenty genes that eh depending on the allyl they have in those genes, you are more or less blonde. So there, there's more than one way for being blond and is not that easy. They're not blond- or brown-haired people, there's a gradient, there's a gradient. Why do you think that women tend to dye their hair with blond dye? What is the reason for that? There was an article I read a couple of years ago where they said they stated that $60 \%$ of the Swedish women dyed their hair blond. $60 \%$ of Swedish women dyed their hair blond. Why? <TLANG_Eng>

S3: I think that's because normal eh is eh having hair brown. So then people wanna be $\mathrm{mm}$ like more exceptional more beautiful so they like to be blond because eh it's eh $\mathrm{mm}$ less percentage of people that are blond. So people want strange I think <TLANG_Eng>.

M2: Yes, it's one of the reasons. Following that logic, Swedish women would want to be brown-haired because most of them or many of them are blond. But they want to be blonder. You know that when we are young, until we're eighteen, seventeen, nineteen, twenty many of us have lighter hair. No, maybe not extremely blond but we usually have lighter hair and when we grow older hair starts being darker. Most, what, the only, the only reason, the only argument in favour of dying their hair blond is that I - I'm actually convinved that is meaningful is that you look younger. We're used to, to equate blond to young because when we get older we get eh darker hair. So if you've got blond hair, you have a younger appearance. That's the argument or the, the reason that many anthropologists eh actually say that that's the reason why many women, not because it's the less common hair colour but because it makes you look younger. Is it true? Is it not true? No one knows. And there's, there's been different studies trying to analyse if this trait, as eh eye colour, eye colour in blue and hair colour if there's sexual selection in place and none of the studies have found any relevant or any significant results. So could it be sexual selection? It could be. But we're not sure why. Why this hair is more common in northern Europe than in southern Europe? We don't know, we don't really know. Was it sexual selection in the north? Could be. It's not clear at all. What I want you to understand - the concept I want you to - to comprehend is recessiveness is extremely difficult to get rid off. Something that is in the recessive state is hidden underneath the dominant variant, the dominant alil and it'll be very difficult for sexual selection or natural selection to eh to eliminate it or to get rid of it. OK? Any questions? 
Doubts? No? OK so you can fill that in and then move onto News Number 2. So, what's - what's wrong with this news? What's wrong with this article eh that makes no sense? It's actually quite absurd <TLANG_Eng>.

S4: First it says that Darwin is from Africa <TLANG_Eng>

M2: Yes

S4: But then it says that he has the group R1B that is from Europe <TLANG_Eng>.

M2: Exactly. So they analyse Darwin's DNA or a descendant in the paternal line of eh of Darwin. They look at the... - at his Y chromosome and they end up with the result that this person is R1B. R1B is a haplogroup that is typical from Europe, from Western Europe. If that is the the result, why do they say, no? In big letters "Darwin's African origin" <TLANG_Eng>.

S5: Because we are descendants of an African person <TLANG_Eng>.

M2: Of course. We all descend from an African ancestor. Do they really needed to look at Darwin's Y chromosome to find out that we al descend from Africans? No, but this news is... Imagine they would have said "Darwin's typical English origin". It's not very striking. It's not catchy. It's not a catchy [laughs] news to - to read. Of course, we all descend from Africa. Yes, but that is 70,000 years ago and the th... since then different $\mathrm{Y}$ chromosomes have evolved and have formed from previous ones. So if this is a typical European Y chromosome, this Y chromosome descends from another one, and this from another one and another one and this is the first or the the ancestor of all $\mathrm{W}$ chromosomes now exiting in in homosapiens. We all, we do all descend from one person, one man in this case that had one specific Y chromosome of African origin. But all the R1B chromosomes are in Europe. Most of them. So there's nothing striking about Darwin having a R1B Y chromosome. It's actually the normal, the most common haplogroup to have. About 67-70\% of the Y chromosomes in Spain, in Portugal, in the British Isles come from long to R1B so there's nothing striking. What did the writer, what did the reporter do? He or she either did not understand a single thing or does not understand a single thing about the white chromosome or tried to make the news more interesting, more readable, OK? Did you follow the eh the explanation? We all descend from African ancestors but you don't know to analyse Darwin's Y chromosome to find out. So the the eh the reporter is actually mixing two different studies that have nothing 
to do in common, they have nothing in common. One is the migrations that took place out of Africa and they went to the near east and then these populations entered Europe 40,000 years ago and so on. That has nothing to do with Darwin's Y chromosome. So this news reporter is actually mixing the two the two concepts and he doesn't understand any of them. Questions? Are you all set, ready for News Number 3? In fact the oldest, we talked about this eh in class the oldest $\mathrm{Y}$ chromosome found ever found in in living populations belongs to a haplogroup that has been called A00. This the people that have this this this eh chromosome belong to an African tribe called Khoisan. Remember that they have these click languages. When they when they speak they go cla cla [sounds produced with the tongue and mouth] they have three or four different clicks. They have very old languages and they also have very old Y chromosomes. If you build a phylogeny of all the Y chromosomes in the world, you end up with this eh Y chromosome belonging to these tribes. They now live in Namibia, Botsuana, Congo and then many of them are still ehh hunters. And eh they don't they are not farmers. So some of the oldest languages are spoken by some of the oldest or the most, not primitive, but they they they retain some eh haplogroups some DNA that when you build a phylogeny it comes out that the oldest of the remaining of the remaining eh $\mathrm{Y}$ chromosomes eh existing now on Earth. And that has nothing to do with Darwin $<$ TLANG_Eng $>$.

[students are given some time to complete the next task]

M2: Alright. Have you have you had have you had enough time? <TLANG_Eng>

Ss: Yes <TLANG_Eng>

M2: What can you tell me about this news? In my opinion this is the funniest <TLANG_Eng>

[laughs]

M2: The best of all. Why do you think is twisted? Come on, someone. In English or in Spanish. Go ahead, break the ice <TLANG_Eng>.

[S6 raises his hand]

M2: Yes <TLANG_Eng> 
APPENDIX III (g): Anthropology and Evolution

S6: Eh because eh they have $\mathrm{a}-\mathrm{a}-\mathrm{a}$ <TLANG_Eng>, en español <TLANG_Sp>

[laughs]

M2: Sí- sí <TLANG_Sp>

[laughs]

S6: Vuelvo a empezar. Que básicamente eh la familia de Andrea o como se llame $<$ TLANG_Sp>

M2: Adrian Targett

[laughs]

S6: Esa, le analizaron los restos [unintelligible] y han visto que tenía que ver con el Cheddar Man pero que en realidad el $10 \%$ de la población europea decide o sea que tiene que ver con el mismo haplotipo el 5. Entonces, por ejemplo, yo podría ser un descendiente del Cheddar Man <TLANG_Sp>.

[laughs]

M2: He's right. He's actually right. So how lucky Adrian Targett. He has found his ancestor his loved ancestor 9,000 years ago. Just because they share a piece, a piece of the -of the mitochondrial DNA. It's the silliest argument I've ever seen in a - in a. This is a prestigious mainstream eh newspaper The Independent and this - this - this man he's he's a teacher. He became very famous in the UK in ehh and several televisions interviewed him and he appeared in different eh programmes and sitcoms. It's extremely funny and this problem comes from the researcheers. The the research team they designed a project that was skewed from the beginning and it was done on purpose. So this misunderstanding is the fault of the researchers. What did they do? They analysed the the remains of this Cheddar Man. The Cheddar Man is the probably the most famous skeleton in the UK by far. Because it's very well-preserved and it's the one of the oldest found in in in the British Isles and in Europe as well. And because it's very well-preserved you can actually extract DNA and analyse it. They analysed the mitochondrial DNA. This mitochondrial DNA belonged to hapllogroup U5. Haplogroup U5 9,000 years ago was the most common in Europe and now 10\% of us are U5. That's 
here. People in this room. $10 \%$ of us have U5. Does that mean that we descend from Cheddar Man? <TLANG_Eng>

Ss: No <TLANG_Eng>

[laughs]

M2: It's ridiculous. It's... What did they do? They found that it was U5. What did they do next? They collected ten or twelve people from the same village until they found someone that was U5 as well. And they sold, they sold the news as if saying "Look, this one guy who has been, his family has been living in the same place for 9,000 years". That has no basis at all. Eh Adrian Targett his mitochondrial DNA could come from someone who was U5 that lived 9,000 years ago in Turkey or in Finland. It's impossible to know that Cheddar Man is actually an ancestor to Adrian Targett. It's the silliest argument. Maybe one of us, as I was saying, maybe one of us is truly descends, truly descends from Cheddar Man and not Adrian Targett. OK? But when we read the news is very convincing. It's like WOW, this is incredible. It's so much more interesting, so much more interesting. It's very difficult, it's very easy to sell the - this news. They will run the world. It was published in Spain, in Germany, in the, in the US, the UK. All of the word. And it's all blatant ehh not a misunderstanding it was it was done on purpose. This is not the fault of the reporter. This is the fault of the research team. OK. We'll give five more minutes to fill news number 3. Fill in. Yes? <TLANG_Eng>

S7: So the thing is that it was a kind of promotion or for the village? Do you mean that? $<$ TLANG_Eng>

M2: No - no - no. This, the - the - the village is already quite famous because it's ah Cheddar is in Devon. Devonshire which is a quite rural ehh county in the UK. And this this village is already very famous because of the cheese and because of the skeleton. These, these remains that are there. They don't need anymore. It was the team, research team that wanted to to eh to to improve the the message to arrive to reach a lot of people than just saying. OK, Cheddar Man is U5. Because you say "Cheddar Man had U5 mitochondrial DNA". Is that interesting? Yes, it's not bad. But it doesn't have eh it's not striking, it's not eh. So what they did is OK, now we're going to and that for a scientist to do that you can tell all that all he in this case he, all that he wanted to do is to is for the news to have more repercussion, more social repercussion <TLANG_Eng>. 
APPENDIX III (g): Anthropology and Evolution

[Students fill in the box in News number 3]

M2: Now we're going to do the exam. There are only ten questions. We usually give twenty minutes for this exam because it's quite long. There are only ten questions, but you have twenty minutes to take the, the test. 


\section{APPENDIX III (h): Epidemiology and Public Health}

M3: No tenéis que preocuparos porque vamos a seguir como ayer. Os digo lo último en castellano antes de empezar el role-play. Y totalmente, ayer de verdad, todo el mundo se expresó, las preguntas, los comentarios, yo creo que es lo bueno de un problema. Y luego pues, pudimos discutir realmente los contenidos que es lo importante. O sea, realmente ver en qué fase estáis, a ver qué cosas tenéis medio a decidir. Que vosotros os probéis y vosotras, cuál es vuestro nivel. Esto es un role-play, una simulación pero es algo que vamos a ver muchas veces, pero muchas veces en nuestra carrera profesional. ¿Vale? Venga, vamos allá <TLANG_Sp>. Welcome to this medical meeting. Ehh you will have the opportunity to present your research project that you are planning, in the phase that you have reached so far and the, and you know you will have, well you have the instructions in the virtual classroom. Every group, every group will have a maximum of 15 minutes to present eh: your proposal. OK? So when there's one minute left, I will warn you in order to finish. Afterwards we have some questions and I will ask you to ask at least two questions for each group. Yesterday, we started asking each group two questions and we had the time proper for the end late, so it's not possible to ask five questions or four questions to each presentation, so at least two questions in each presentation. OK? Well, feel free, really, the important thing is "Express yourselves in English". Don't worry. OK?:: So well, we start with the first group. OK? <TLANG_Eng>

[unintelligible]

S1: OK. Hi, everyone. As you know eh: my name is $\mathrm{S} 1$, and my team members are $\mathrm{S} 2$, $\mathrm{S} 3, \mathrm{~S} 4$ and S5 and we have decided to talk about the effect of - of moderate red wine intake in the development of hypertension in both men and women. Eh: for that reason we want to study the relationship between the red wine intake and hypertension and see the differences between men and women. And our objective is to be able to answer if the question, whether red wine is a risk or a protective factor. Em: for this study we have men and women belonging to the Health department of Castellón de la Plana. And for that we want to make a retrospective cohort study with unpaired data. Eh: first of all, we will explain eh: the reason why we think this is an important em: study and why we have chosen this subject and then we will explain the objectives, the methodology, hypothesis and methods of the study eh: as well as we want to make it possible. Eh: and 
now my partners are going to explain more about our investigation project and I hope you find it interesting <TLANG_Eng>.

S2: First, we have chosen the topic of the work because many people believe that drink a glass of wine prevents on cardiovascular diseases, especially hypertension. The hypertension is a chronic disease that affects a one billion people worldwide. There is hypertension when the systolic pressure is higher than [pronounced as $\theta$ an] 140 millimetres of mercury and the diastolic higher on 90 millimetres of mercury. The hypertension is not as as silent death because without treatment it increase the cardio, the risk of cardiovascular disease. The hypertension is a product of a lifestyle that includes a poor diet, a sedentary life in the drugs consumption such as alcohol and tabaco <TLANG_Sp>. The - today the Mediterranean diet is the best valued. We can see in the pyramid that the, the Mediterranean diet include a moderate a moderation consumption of wine. But what is the amount, the moderate amount of alcohol? It is calculated with the standard drink units. The UBE. Eh we can see in the following table the moderate consumption in men is less than a 17 per week, but in woman is less than 11 per week. Em: the relation between cardiovascular disease and the wine drink was studied for the first time by doctor Liam. Doctor Liam observed a group of French people that with a high fat diet but and a wine drink. This group developed fewer cardiovascular diseases. And another group of American people with a diet with less fat. And this this evidence suggested the possibility that wine could have a protective effect on cardiovascular disease, especially hypertension. And from several investigations it has been observed that moderate wine drinkers developed fewer cardiovascular disease. But nevertheless, excessive alcohol increased the risk on hypertension <TLANG_Eng>.

S3: Em: from this detail in this investigation of what is known so far about the effect of wine consumption on the human body, a series of hypothesis have emerged but we want to resolve in this research. Em: hay two hypothesis. The first hypothesis is a, the consumption of wine is a risk factor against the onset of hypertension. And the second hypothesis is this. The effect of this use on hypertension is greater in men than in women. Em: therefore, the objective of this study are to assess whether wine consumption acts as a protective factor and cause the - a risk of hypertension a population of 40 years of age. Em: our second objective is analyse whether wine consumption and the onset of hypertension varies between men and women $\langle$ TLANG_Eng $>$. 
S4: OK. Now we're going to talk about the methodology. Eh: first of all we used the programme Epidad in order to know how many patients eh will need to carry out our project. As everybody could, we need 1260 patients in order to develop the investigation. Eh: the most important information that we use in this part is obtained by a, by a lot of articles that we have read and <TLANG_Eng> La Encuesta Nacional de Salud del año 2017 <TLANG_Sp>. Then, we have located our investigation in El departament de Salut de Castelló <TLANG_Cat> because it's a department that most of us know and we have contact with all of the GP or general practitioners in order to explain our project. Our project consists in a validated test that is - is from the University of Navarra in order to measure some variables such as red wine, gender, age and lifestyle. Finally, eh: we did a few measurement of blood results in order to make an average of the blood pressure of the patient. It's important to say that our project have some limitations. The most important limitation is that our investigation is not comparable in, between countries because there is a difference eh: in countries about the moderate consumption of alcohol or wine <TLANG_Eng $>$.

S5: Well, and now we're going to talk about this graph. Em first the project approach as carried out eh this includes the proposal of the subject and the establishment of the objectives and the pertinent hypothesis and we used the first week. Em also information from other studies was also little, was verified, that there weren't others that had reached a conclusion on the topic. We used eh six months, no six months, no, two weeks. Then, <TLANG_Eng> el tamaño muestral <TLANG_Sp> was calculated in six months and then the project was presented to the Ethics committee using one month. And now the second part is the real project. To do this, we will contact the centres of Castellón during one month and we will explain to the health workers the objective of the study using another one month. We gather information from hypertensive and nonhypertensive people who drink wine eh using six months and then em this information will be gathered during two months and it will be analysed during another two months. So we will get eh some results after all during one month. And finally, the third part, the third objective of the study will be making a conclusion and all the project will be finished. A:nd that's it $<$ TLANG_Eng $>$.

M3: OK <TLANG_Eng>.

[applause] 
M3: Well, thank you very much for your presentation. You have already fit to the available time ahh and well now it's the time for questions. Eh please, we have time for two questions <TLANG_Eng >.

SX1: Why did you, why did you choose this department? <TLANG_Eng>

S1: Eh we chose the <TLANG_Eng> Department de Salut de Castelló <TLANG_Sp> because as I said because it's a department that all of us know a:nd is more, it's not difficult to contact with the GP and explain our project and it's a department that have all the requirements that we need <TLANG_Eng>.

M2: Thank you. Another question, please <TLANG_Eng>.

SX2: Why did you choose this topic? <TLANG_Eng>

S2: Eh we chose this topic because many people believe that drink a glass of wine prevents a cardiovascular disease and we want to study about the true or...the false $<$ TLANG_Eng>.

M2: Yeah. But what do you think? I mean, you not really collected the data. Of course, because this is only the planning phase, but ah based on your literature review, what do you think? That really is a... $<$ TLANG_Eng $>$

S3: At first we think that the drink wine is a risk <TLANG_Eng>

M2: You think that is a risk factor? <TLANG_Eng>

Ss: Yeah <TLANG_Eng>

S4: It's a controversial topic, but we have searched a lot and we think that is a risk factor because most of the other articles that say that it have a protective factor are paid by he wine industry. <TLANG_Eng>

M3: Topic of interest <TLANG_Eng>

S4: Yeah <TLANG_Eng>

M3: This is very important when you carry out ah the literature review, to take into account this type of things and this occurs also with the pharmaceutical industry regarding many of the pharmacy of the drugs. Well, thank you. I have one more desk 
question. More than a question it's just to - to comment to - to I mean to improve your presentation and your future protocol. Em, well the introduction was really good presented and very well supported eh the only point, if you are detectives, you say that apart from assessing the relation between wine and hypertension, that you propose there is a gender differences. So in the introduction is also, it would have been convenient or advisable just to discuss or at least to - to discuss why you think there is a difference gender-affected. You think that is affect more on men than women? <TLANG_Eng>

S4: Eh no. We think the risk factor is more on men <TLANG_Eng>

M3: That is at greater risk, no protective effect. The objectives and the hypothesis are well-formulated, but the... eh you should be, especially in the objectives and hypothesis as most precise as possible. Precise in the sense that the hypothesis is the - the wine intake or the wine consumption eh protects I don't know and then, well, as you were explaining in the introduction, it depends on the dose. So you say wine consumption is very general. You should say moderate or mild, or whatever, no? And regarding regarding methods. Methods protocol, they should be very - very well structured. I mean, with all the sections. And, for example, in the summary you presented at the beginning you said a design that this was a plan. But afterwards in the methods you should follow the same design. You started explaining the, the sample size. It's important but first of all you have to explain clearly which is your design. OK? <TLANG_Eng>

\section{S1: OK <TLANG_Eng>}

M3: And - and the variables eh - eh they were specified, but they should be classified. Classified in the sense which is your outcomes variables, that is, your results. <TLANG_Eng>

S1: We have classified the variables in the work but not in the presentation <TLANG_Eng>

M3: Yeah - yeah. I know, just in the presentation. But you know, the methods section is so important, design, population, variables, my outcome variables and which are my covariants. And well, there is a part that is the analysis. Have you already worked out or decided the what type of statistical analysis are you going to carry out? <TLANG_Eng> 
S1: Uff we have some doubts <TLANG_Eng>

[laughs]

M3: Because you haven't presented there and it's OK. If you have not already decided what you're going to do, it's good not presenting it. In the final project you will have to decide what type of data analysis are you going to use. OK? <TLANG_Eng>

\section{Ss: OK <TLANG_Eng>}

M3: And, well and the last part is very good I will tell M2 that you're using...in the final project apart from the Gant you should write down the different task to explain them, apart from the time, you explain very well in the presentation, but just to be written. OK - OK. Oh and some of you said <TLANG_Eng> "tamaño muestral" $<$ TLANG_Sp> [laughs]

S5: Es que no sé cómo se dice [laughs] <TLANG_Sp>

M3: No - no. One of the objectives is just to learn terminology, you know? Or terms. It's sample size, sample size <TLANG_Eng>

\section{S5: OK <TLANG_Eng>}

M3: Yesterday one of your friends and your colleagues the confusing variables, they are very confusing, but they are confounding. It's just to, how to...OK. Thanks a lot. Very good $<$ TLANG_Eng>.

\section{[applause]}

\section{M3: OK. Next group <TLANG_Eng>.}

S6: Hello. Good morning everyone. My name is S6, as you know and I'm here with S7, S8, S9 and S10 and we are going to present our research protocol. Eh first of all I want to say that this is a draft, so there are things that are made in a bad way. And at the end of the presentation if you want, you can make some questions about it. And then OK. Eh - Eh OK. Eh I'm going to start and this is our main topic. We are going to talk about the influence of - of exercise in improving the quality of life and compliance of the left ventricle of the heart of people with heart failure. Eh well, I'm going to do a summary first to explain a little bit the - our presentation and, a:nd. So you will understand better 
later the all the results project. OK. As you know, cardiovascular diseases are one of the, are the first cause of death in most of the developed countries. And one of these diseases is the heart failure eh which is a, which has a higher prevalence and is a disease which is chronic and degenerative of the heart. And it, it affects because it prevents the blood from being properly pumped throughout the body. And it affects also the the compliance that is measured by the LVF, LVEF. It's the Left ventricular ejection fraction and in Spanish is <TLANG_Eng> la FEVI <TLANG_Sp> and OK. On the other hand, physical exercise has always been considered ehh good to prevent cardiovascular diseases and to strengthen the organism in front of multiple diseases. And as well as to improve the quality of life of people with heart eh failure eh both physically and psychologically. OK. Our objective is to observe the improvement in the quality of life and the LVEF in adults aged 60 to 75 with heart failure when performing physical exercise. And then X will explain, will explain you the methodology. But there is a little bit a summary, the design is a prospective cohort study from May 2019 to May 2020. Eh the study population is adults aged 60-75 with heart failure belonging to the health area of Hospital General de Castellón. Eh we have main variables such as sex, tobacco, diabetes, time and type of heart failure... and we are going to do measurements that are every 3 months. We are going to do the, this, the MLWHF that is a Minnesota heart failure questionnaire about the quality of life of people with heart failure. And we are going to do an echocardiogram to measure the MLWHF. And the data analysis is an ANOVA test and lineal regression analysis $<T L A N G \_E n g>$.

S7: Well, I'm going to talk about the background and current status of the topic. The purpose of our project is to see the influence of aerobic exercise in patients aged 60 to 75 with heart failure over a year of evolution. To represent the aerobic exercise, we will use activities such as swimming, walking and cycling which are soft activities that do not cause a bad feedback on a physical level. We will assess this relationship through two parameters, the quality of life and the compliance. Well, heart failure is a syndrome of complex pathology which can result from any function, functional or structural alteration that affects the heart and consequently compromises the ventricles' ability to fill in blood satisfactorily. It is known that daily exercise is an established recommendation to prevent and treat the main modifiable, eh the main modifiable factors of cardiovascular risk, such as diabetes mellitus, hypertension or dyslipidaemia. And in the pathophysiology of patients with heart failure and a LVEF decrease there's a 
decline in the function of the, of the left ventricle with a progressive reduction in cardiac failure. On the other hand, physical exercise increases physiological adaptations that improve physical performance and only in strange cases can lead to an increased risk of complication. These - these complications, eh the incidence of these complications during the physical exercise is very low and it is concentrated in people with heart failure, with heart disease or with very pathophysiological eh cardiac adaptation to exercise. Absolute contraindications are reduced to deep aneurisms and severe obstructions of the left ventricle of track. Eh these complications must be resolved before physical exercise is initiated <TLANG_Eng>.

S8: In the last few years eh physical the use of physical exercise programmes has been demonstrate[d] in several publications about patients with heart failure. The physical training programme, depending on the result eh could have a functional capacity, a increase in the functional capacity or a increase in the mortality. Eh this increase in the functional capacity have eh, is a multifactorial - multifactorial origin. This mean that different points from variables can affect the functional capacity eh. We have sample, some size samples like increased variability of heart rate or if it's of the lipids. The function, sorry. Eh the increasing functional capacity is a powerful negative predictor for cardiovascular diseases, as studies have eh have shown in in the last few years. The improvement of quality of life eh is in mode of the patients depends on, on clinical controls, functional capacity or in self-confidence. Eh to measure the quality of life we have, as my - as my as S7 said we have the Minnesota life with heart failure. This is a questionnary [questionnaire] where we talk about eh physical symptoms and psychological symptoms. Em: this questionnary [questionnaire] has to 21 question and an example of a physical could be "Do you find difficulty when you go up or downstairs?". From a psychological question it could be "How depressed do you feel?". This is measured from 1 to 5 and then we have a, em, a score eh from a letter we see how is the quality of life. Then we have the bibliography, it's here <TLANG_Eng $>$.

S9: And I'm going to talk about hypothesis, general and specific objectives, how do we take people disease. Eh the first thing we have to do is to have a question to achieve our hypothesis. Eh our question was: Aerobic exercise, such as swimming, walking, biking, helps to improve the quality of life and compliance of people aged to 60, eh 60 to 75 who suffer from heart, heart failure? And this [is] our hypothesis. Then, we have our general objectives are two general objectives, the quality of life and the compliance, 
compliance [self-corrects his pronunciation] and these two main objectives we are going to relate with the patients we had that have heart failure. And from this relate we are going to test our two general objectives that are if, if, if aerobic exercise could improve our quality life in people that have heart failure and the other objective, objective [selfcorrects his pronunciation] is that eh we want to find out if aerobic exercise have an improvement in the compliance of people with heart failure. Then we have specific objectives that em are - are taken by coverage. Here we have the frequency and type of exercise, the time the patient have been with heart failure and the Body Mass Index. This coverage we are going to compare with the quality of life and compliance of people with heart failure <TLANG_Eng>.

S7: Now I'm going to talk about the methodology. Eh we have a Prospective cohort study in which we, the LVEF is measured and the at the same time, the Minnesota test of the quality of life is, eh, is performed from May 2019 to May 2020. The study population eh are adults aged 60 to 75 belonging to the sanitary [negative transfer from Spanish] area, well to the health area of the General Hospital of Castellón. They will be included in the cohort after they have signed and accepted the inform... - the informed consent. Eh: the sample size, the sample size expected to be achieved is 180 patients, 36 exposed and 144 unexposed and eh the study will provide a power of $80 \%$ an $80 \%$ and a ratio of unexposed and exposed of all am: all of these data. Eh I'm talking about, $<$ TLANG_Eng $>$ bueno <TLANG_Sp>, we have this with Epidad programme. I'm talking about the variables eh the main variables are eh heart failure and quality of life. In the heart eh in the heart failure patients in our study, patients in our study have a heart failure of more of one year of evolution, of evolution and we - we measure this a - a - a echocardiogram in the cardiology service. And the quality of life is measured with a Minnesota test. And explanatory variables, we have Physical exercise. Eh exercise will consist of aerobic exercise like eh swimming, biking, running and eh with a minimum exercise of 30 minutes 5 days a week and with intensity 50 and $70 \%$ of volume of his volume maximum, oxygen volume. And we have this, the co-variants, for example socio-demographic variables like eh like eh age, sex, country of origin, anthropometric variables, like BMI, cardiovascular history, lik eh the hypertension, diabetes or coronary failures and Lifestyle variables. These data will be collected within in the first interview with a personal questionnary [questionnaire] and all this information will, will be supplemented with the patients history eh history, with the 
patients' medical history that will be provide[d] by the hospital. And then, the data analysis, we have eh we have numerical and graphical description of the quality of life in patients with heart failure measured by the Minnesota test and we have a description of the exercise in patients with heart failure and a correlation between physical exercise, practice and the quality of life with an ANOVA Test. And eh and eh control the variables which are potential confusing with lineal models. OK. Regarding the study limitations difficulties, one of the main limitations in the study has been to minimise the patient follow-up losses and to continue to guarantee data collection at the time of performing echocardiograms to see the LVEF. In addition, the simultaneity and overlap of tasks like collecting data, questionnaries [negative transfer from Spanish], tests, that require effort and time of the researchers and qualified doctors. On the other hand, it is necessary that is a good coordination and collaboration between the research staff and the doctors of the General Hospital de Castellón to provide all the follow-up of the coverage and for having a good communication with the patients. Also, the fact of quantifying the quality of life is complicated because even though the Mionnesota test is complete, it cannot be assessed well. These limitations could be avoid[ed] by assuring a correct monitoring <TLANG_Eng>.

M3: Sorry, one minute left...<TLANG_Eng $>$.

S7: as well as a collection of data in a computer system <TLANG_Eng>.

S10: I would like to introduce you basically to the work plan. The work plan is done project. This project is to have an outline of the - of the different concerns of the project which are basically based on the objectives, tasks and resources. We are going to consider resources and we have defined five basic objectives which are the definition of the work plan, eh background research, meth, methodology and em: em: $<$ TLANG_Eng>

M3: OK. Don't worry. You have time <TLANG_Eng>.

S10: basic objectives of the proposal, background research, eh: meth..., methodology and collection of the data and analysis, analysis and el, elaboration of the - of the research. As you can see, the tasks that took us the longest were the design and the - the eh coll..., collection of data $<$ TLANG_Eng $>$. 
S6: And now I'm going to talk about the interest and relevance of the research project. The interest of our study was about the number of cases with of people with heart failure in the General Hospital of Castellón <TLANG_Sp> because we see an increase in recent years. We weren't so surprised by these data. Eh: then we thought that another significant change could have occurred in this period and we saw that there has been a boom in awareness about bringing a healthy lifestyle. We don't want to - to do - to do a sim... - a simple study, but we could saw that this exercise is really beneficial for those who suffer from heart failure. Eh and to make them the best quality of life possible and the disease. And we thought how to help these people and how to help the medical area. And we thought that we could eh make seminars to the doctors to explain them how to explain the patients eh the type of exercise they could do, the leaflets to patients about the disease and about the exercise. Eh make the patients have a control of the daily physical activity using the mobile phone, a bracelet.... and also encouraging patients to, to, to include this lifestyle at the end of their, their disease <TLANG_Eng>.

M3: OK. Thank you <TLANG_Eng>.

\section{[applause]}

M3: Well, thank you very much, but I have to warn you with the time because it's the... normally in a scientific meeting even when you have to present results and conclusions. Eh you have only 10 minutes and you've used 15 minutes, but well...it's - it's OK. I will tell you how to cut just to synthesise some parts. But apart from the time, thank you very much for the presentation, I'll make some questions and comments. Ah

SX3: Why is sex a covariant instead of a miain variable? <TLANG_Eng>

S6: Because, well, sex is not a main variable because it doesn't affect to our main variables eh since it is an - an observational study and which we only have patients regardless of the sex. We don't. Also, because it, it can be a - a - a confounding variable that could affect our study, so we thought that it was a covariant not a main variable $<$ TLANG_Eng $>$.

M3: Thank you. Some other questions, please <TLANG_Eng>.

[laughs] 
SX4: You said that your study population is from the health area of Hospital General. But how would you choose it? <TLANG_Eng>

S8: Yeah, we begin with patients from the healthcare area of the hospital where adults would who have who meet age requirements would be included in the study <TLANG_Eng>.

S7: And in this period of a year you would see all the patients who have failure to go to other healthcare centres and we choose them to, to, to be in the study <TLANG_Eng>.

M3: Well, thank you very much. I have enjoyed your presentation. It's a very good presentation apart from the time, but well. If I have to suggest, for example, the summary, when you have this short time, it's not necessary to - to present the summary because the summary is just a summary. It's something that...because you spent three minutes just with the summary and eh: well the introduction was very good presented. And just to present the bibliography. The only point is that sometimes when you're doing a presentation it's not easy to follow all the references. And sometimes it's better, for example, to select one of the key references you say. For example, a systematic reason, a systematic review of data, data review. And just to paste in the previous slides. For example, you say some research or some studies that, in that sense you could point out just this reference that is based your introduction. Em: the hypothesis section and objectives, two - two points. Eh: I mean in the hypothesis you cannot state it as a question. You have to state it as an...<TLANG_Eng>.

S9: As an answer to the question? <TLANG_Eng>

M3: Yes, if you say it's an hypothesis, you have to state it. It's an statement. And the objectives I recommend, you explained them really well. But I recommend to write down, it's like the conclusions, you have to read it. It's much better if you write down because if not, you have to explain them and some, someone cannot follow you properly or whatever. The methods, perfect. Very well, very well structured, very well justified, all the sections, the variables were very well classified ah: and the - and the analysis was specified. So very good. And the last part eh sorry S6 because you had to do it very quick the plan. But the plan was very well specified, all the tasks, just only time and the relevance it was fast at the end. So, I think that you have a good draft <TLANG_Eng > 
Ss: Thank you <TLANG_Eng $>$.

M3: Thank you <TLANG_Eng>.

[applause]

M3: Next one, please <TLANG_Eng>.

S11: Well, hello. I think you know who we are. But just in case, we are S11, S12, S13 and S14 and our study is about coffee being a protective factor in, in melanoma. And well, the different parts of our study are background, the hypotheses, the methodology, the workplan, the interest and relevance and finally the bib... the bibliography. And as normal presentations, we are going to start with our work <TLANG_Eng>.

S12: OK. Well, I'm going to start talking about the background and the current status of the subject of our study. Eh nowadays, coffee is consumed in almost the entire planet. And it's due to its important aromatic properties and its excellent flavour. Also, in addition, as many people don't know eh coffee has ah several eh medicinal use and healing application. Em: many - many studies in humans show that eh coffee has eh several cognitive effects such as memory, moves, general commute, and etc. Eh: another part coffee is not only a powerful stimulant. It also has a passionating effect and it also seems to have a positive effect in some diseases like diabetes type two and other types of cancer such as breast and melanoma. Eh a group of research from the American society from nutrition show in a study that when you intake high levels of coffee eh you will reduce the risk of colon cancer. In other study from the, a Swedish study shows the same results, but they say they say that you need to take five or more cups of coffee a day. And finally, it's well-known the coffee, the caffeine and other components of the coffee have a protective effect on the skin against the eh ultraviolet eh radiation. Em eh for us, and as medical students, this is the most important eh: effect of the coffee, so we want to know more about this. Also, for this study we want to focus mainly in malignant melanoma. So eh malignant melanoma is the 6th tumour in Spain in prevalence, a cancer where around 5,000 cases are diagnosed every year. Eh the incidence of melanoma in Spain is 10 per 100,000 inhabitants, but Spain is, has the the lowest rate of incidence and mortality in the eh Europe and in the rest of the world. And, but its one of the most common diseases in our country, it's one of the most booming diseases in our country. For searching the information in our project we have 
found a lot of very interesting eh articles or investigations, but this article of the eh: Spanish National Cutaneous Melanoma Registry. Tumour characteristics at diagnosis: 15 years of experience that was created by the Spanish Academic of Dermatology and Venereology was very important to us. The aims of the article was knowing the incidence of this type of tumour, its clinical-pathological and prognostic characteristics at the moment of diagnosis. Of this article we have found a lot of information that it had been it has been very useful to us <TLANG_Eng>.

S13: OK. So this information is that the, at the moment of diagnosis the patients are 57 years old and the age range from most of them is between 40 and 80 years old. The trunk cancer is observed with a $37 \%$, followed by the lower extremity with a $26 \%$. And the most clinical type is the superficial with a $62.6 \%$, and the second one is the nodular melanoma with a $16.8 \%$. The $86 \%$ of the cancers is at the moment of the diagnosis are without metastasis, but the $10 \%$ is local metastases like in this image, and the fourth restant is with distant metastasis and high levels of AVH that shows a [unintelligible]. Among the different tumours that we can have in the skin, melanoma, cutaneous melanoma is the most harmful. We just took this study from the Internet by the NIHAARP Diet and Health Study, by Loffield and his colleagues about coffee intake based on non-Hispanic white men and women during 10 years. All of them were cancer free at the beginning of the study. Data adjusted for avoid eh confusing factors, for example, ultraviolet radiation, age, sex and consumption of alcohol, smoking, etc. And the results of the study show that a highest consumption highest coffee consumption was inversely associated with the risk of this malignant eh melanoma. Eh: it showed that $20 \%$ lower when you take up to 4 cups per day or more. And only if it is caffeinated, the caffeinated coffee has got the effect <TLANG_Eng>.

S11: After we've seen the background and the current status. We're going to present the hypothesis, the general and the specific objectives. First of all, our hypothesis is that coffee is a protective factor in melanoma, and regardless of age and gender. And after this, the general, the main objective is obviously to prove that ah our hypothesis is accurate. And to prove it we're going to ask both cases and controls, if they drink coffee and how much per day <TLANG_Eng>.

S14: And well, the specific objectives are the following ones, which are: Does drinking decaffeinated coffee have the same effect as drinking it with caffeine? Just in case this 
happens, does the amount of caffeine intake have any influence? And well, also to analyse if coffee is really a protective factor or, in the other hand, a risk factor. And finally, eh: find out if there are differences between sex, age or place of residence. To prove them, we are going to take advent, advantage of all the information we've collected to accomplish our main objective. Starting with the method, we designed a case-control study. Our target population is adults between 40 and 80 years old because this range of ages is the incidence of melanoma. And we selected the Valencian community because the results obtained in Epidad was that we need 283 cases and the incidence of melanoma in the Valencian Community 552 cases per year <TLANG_Eng>. And according to the sampling we designed a consecutive sampling of the cases because we don't need randomization and we said that the incident cases of last year and to the control we designed a prob..., sorry a probabilistic em: sampling because here we need randomization and to do that we select random health centres in the Community. But who we contact with the cases? We check nominative listings in order to know mm every single person who have melanoma and to avoid any ethical problem we, we first talk with the doctor in charge of the cases and they explained the work and the study to the patient and we give the survey to those patients who accept to participate. And in the other hand how we contact with the controls? We go to the randomly, to the random health centres and we propose the study to all patients who come to the centre to any reason about melanoma and those who want to participate ehh we give the survey and they answer. And, but to do this study first of all we elaborate the survey which is composed of 16 questions, but em before give the survey to our target population, we need to verify the survey eh to know if there are any type of doubt in the survey or something else. Then we give the survey to our target population. And finally, the results obtained in the survey, we put in Excel in order to obtain frequencies, media. A::nd our survey, as I said is composed of 16 questions. Am: in this survey are the main variables like eh sex, the eh amount of coffee and the what kind of coffee, if the...there are a lot of questions related that, some confounding variables. Em: and finally, we found some limitations in our study like the confounding variables because there could be a lot of confounding variables in the appearance or not of melanoma. Another limitation is that the cases have passes a lot of $-1 \ldots$ of chemo, stress, and this make that they live in a bubble, away from the reality, and the may not remember perfectly their habits. Another limitation is our target population. There are. It's a adult elderly target population and they may suffer some problem relate with memory loss or 
something similar, which may affect the accuracy of information. And finally, we only focus on the Valencian Community, so it's difficult to know if in other Spanish location or in the rest of the world, it's true that the coffee is a protective factor <TLANG_Eng>.

S11: We continue with our workplan that is designed to last about a year if everything goes according to plan. Eh: the researchers work 5 days a week, 7 hours a day. And eh: they have a break in January due to university issues, call it issues, call it exams. And there are eleven different tasks. The first one is the constitution of the group and the election of the coordinator, which is X. After this, we have the - the, we choose the topic and the objectives. Then, we have the selection and the type of study, though, these are quite short tasks, then we have the longer ones. After this, we have the bibliographic[al] search. Then, we have the break because we have exams. After this, we have the sample size calculation using the Epidad. Eh well, the completion of the questionnaire and and these questions will have must be answered by both cases and controls. Then, we have the, the distribution of the consents and after this, the longest part of the study which is the search for cases and controls because well, there are more or 552 cases in the Valencian Community and we need 253. So eh at first eh given this, we don't need that much time to find them, but in order to avoid running out of time, we've expanded the time of this task a little bit. And <TLANG_Eng>, a ver $\langle$ TLANG_Sp>, to finish the job we have sending out the questionnaire, eh: the analysis or the data, which is carried out by the statistical analysts and then the two editors will write ah the study which described all the process carried out and the results obtained OK. The interest and relevance of the research project. Eh coffee is an important source of caffeine and is one of the most be... consumed beverage worldwide. And it's an important source of caffeine so it has a stimulating effect and detects error systems in the humans. However, we don't know much about it, so eh why, why if it has another beneficial and protective effects. So we want to study this. And also knowing the relevance of melanoma in our society, especially in Spain where we have a lot of sun radiation, eh we know a lot of risk factors such as ultraviolet radiation exposure, but know just a few attitudes that can prevent them. So we want to study eh any source of prevention and, and, so to carry out the study <TLANG_Eng>.

S12: Despite the limitations of our eh study, we think that we have arrived to a, to the conclusion <TLANG_Eng>. 
M2: One minute <TLANG_Eng>.

S12: OK <TLANG_Eng>.

M2: No, no, don’t worry. One minute, one minute <TLANG_Eng>.

S12: To the conclusion that eh our study can be very useful because we live in a country, Spain, that we have a high intake of coffee and also Spain is one of the countries with the highest exposure to ultraviolet eh: radiation. In other part, cancer is one of the biggest eh problems in the world healthcare, so any information, any evidence of reducing the risk of having one deserved to be studied and reviewed. And finally, with this study we intend to record a possible and important benefit of coffee intake and see objectively to what extent can be beneficial for the purpose that is proposed. Finally, it's worth mentioning that the progressions could be extrapolated to the public in general [unintelligible]. Thank you <TLANG_Eng>.

[applause]

M3: Well <TLANG_Eng>.

\section{S12: Any question? <TLANG_Eng>}

M3: Thank you very much, 17 minutes to, to...Amm apart from the time, it was a very clear presentation and well questions. Do you have any imaginative question? $<$ TLANG_Eng>

SX5: Why have you chosen melanoma and not other type of cancer? <TLANG_Eng>

S11: Because, well, here in the Valencian Community we have a lot of sun and this is one of the risk factors. That's why it's not eh: the most common cancer. So it's good, well it's good to find if we can do something to avoid it <TLANG_Eng>.

S14: Because we find that melanoma is a very dangerous cancer and the incidence and mortatily is increasing over the years. So we think that it's an important topic $\langle$ TLANG_Eng $>$.

SX6: Why have you chosen eh: the incident cases of the X? <TLANG_Eng> 
S13: The main reason is the patient has rare ability to remember their past habits and like melanoma is a high mortality cancer; we need to select the most incident cases in the year <TLANG_Eng>.

M3: Hmm. OK. Thank you. I have another question. Ah are you going to match your controls with the patients according to age? <TLANG_Eng>

Ss: Yes <TLANG_Eng>.

S12: Because it's very difficult find the case that one case that wants to participate, then we chose a control <TLANG_Eng>.

M3: In what area are you going to do in - in? I mean the cases are from the whole community <TLANG_Eng>.

S12: We select randomly the health centres <TLANG_Eng>.

M3: As an advice. Normally, I mean your criteria for selecting the cases and the controls are really good because you are going to - to do a consecutive sampling for the cases and their incidence and is very - very good. But the problem if you don't have at least for area is that the community can differ a bit according to the radiation, for example. We think that we are very uniform but it has...I'm from the south of Alicante and is very different from the north of Castellón. So at least by area, by area you should match. Normally, the matching is also, it is used to be made by gender and by age. But in your case, do you think that is advisable to match for this? <TLANG_Eng>

S14: You said that the Valencian community is quite variable. So by location is better $\langle$ TLANG_Eng>.

M3: By location. Yeah. By location for the reason. But by gender and age one of your objectives is to see if there is difference according to gender and age. And if you match, you can't see the differences. Because you are matching, you are controlling for that $\langle$ TLANG_Eng $>$.

S13: In the questionnaire there are questions about sex and age <TLANG_Eng>.

M3: If you don't have this type of objective, the difference by gender and by age, you should match by age and gender. You know? But if you want to see the differences, then you can't match $<$ TLANG_Eng $>$. 
S12: Also in our survey we would include what location of the com of the Valencian Community you live and also what type of, what is your residence like? The beach, the city or the mountains <TLANG_Eng>.

M3: Yeah. You can control with the questionnaire. But it would be too risky just by location. Because you, apart from the ultraviolet or the sun radiation risk, there is another type of factors. It's very different if you live ehh in the city or if you live in whatever... Well, regarding the presentation, very very good. Apart from the time, and if it's time at the end you cannot read something quick because time is over. Just finish $<$ TLANG_Eng $>$.

\section{S11: OK <TLANG_Eng>.}

M3: But don't worry, it's normal. It's - it's not easy. But you fit really, really well to the time. It was just at the end. And just very few questions. For example, what we commented in the previous presentations is that it's very well that you focus on the introduction in some key articles and this is good. You say "I have bibliography, but there is a key article that give me important information". Eh: the objectives is just the same comment that in the previous one. It's better just to write down, for example, the general objective cannot be just verify the hypothesis, to write one as a general one. The method, apart from the matching eh: well very good, very good, well-structured and explained, the workplan is OK. The only thing is you, you need also the data analysis in your in your method. Are you still thinking about deciding what type of data analysis? <TLANG_Eng>

\section{S13: We don't have it clear $<$ TLANG_Eng $>$.}

M3: And just the work plan it's really good because you have all the phases and the. But just one comment. In a project there is no problem if you include for this exercise the time that you have spent planning the project, I mean just with the research, the bibliography search and all that. Eh but in a real proposal, you start your plan, work plan just from the moment that you start the-the real data collection. You know because you say I'm presenting in my protocol the time that I already spent is the time spent, but I need to guarantee that in the next year, two years or three years, I will accomplish all these tasks. But it's not necessary to change. If you have included the part you spent 
with the planning is OK. Don't, don't change for the exercise. In a real proposal you don't have to include it. OK? <TLANG_Eng $>$

Ss: OK <TLANG_Eng>.

M3: OK. Thanks a lot. Very good <TLANG_Eng>.

[applasuse]

S15: Hello, good morning. We are S15, S16, S17 and S18 and we are going to talk about the impact of advanced age, folic acid consumption and twin history in double pregnancy. Eh during - during the last years, according to the recent data have increased the multiple pregnancy risk in Spain. This fact has been fostered by an increase in pregnancy through assisted reproduction techniques. Also, eh - eh there are other factors that will eh that have influenced this emergence such as an increase of maternal age and also folic acid consumption. Eh: though it may paradoxical, most eh studies claim that the increase of maternal age is not only associated to a decrease of fertility. Also, it's associated to a increase of multiple pregnancies. Eh there are contradictions in the study because eeh someone says that eh this increase of multiple births are eh have relation with a FHS mutation on their cells. But there are others that say that it's not a relation. In the case of folic acid [pronounced as in Spanish], most of the studies says that eh as, as we can now, says that the folic acid eh reduces the risk of neural to defects. But, also they say that supplementation with this vitamin also, yes? [addressing to her group colleagues] <TLANG_Eng > sí <TLANG_Sp>. Also increase the multiple pregnancy risk. But there are disputes because some of them says that this relation is due to confounders. Eh maternal eh mm maternal age and multiple pregnancy is a high risk because the mother have eh more complications like eh births, also preeclampsia. And for example, eh - eh - eh, ay <TLANG_Sp>, sorry. Eh congenital anomalies. A::nd this increase the cost of-of ay <TLANG_Sp> the head cost and the personal pressure. Also eh in the case of folic acid eh it required more information about this topic because there is not a conclusion of is there is a relation or not. And in the case of maternal age is required more updated information of this topic. Finally, eh the relevance of all of this lies at the time to prescribe eh the folic acid or not because you have to keep in mind ii the benefits but eh if there are risks you also have to know $\langle$ TLANG_Eng $>$. 
S16: Now I'm going to talk about objectives and hypothesis. First of all, our objective are. One. To evaluate if pregnant women at advanced ages have a higher risk of multiple pregnancy. And two. To study if there is a relationship between multiple pregnancy and folic acid supplementation. Eh secondly, our hypothesis is the percentage of multiple pregnancies is higher among women who have become pregnant at an advanced age as well as those who have taken folic acid <TLANG_Eng>.

S17: Eh now I would like to continue explaining about the methodology. Referring to the design, this is a retrospective case-control analytical study with data of the Hospital $\mathrm{La} \mathrm{Fe}$. In this case, we have done two groups. The first is about women pregnant with triplets and in the second one we have include women with simple pregnancy, it's also important studying subjects. So in this case, the study population that we are interested in are eh all pregnant women between 15 and 55 that had been gone to the Hospital La Fe between 2014 and 2018. Nevertheless, we have to consider that only those that had been pregnant with double or single pregnancy will be part of the study. OK. About the sampling and sample size, it is studied a simple random probabilistic sampling of all the pregnant women who meet the inclusion criteria. In this case, we have used the Epidad software in order to eh calculate the sample size of our study. From an OR of one point 58 [1.58] and taking into account that the proportion of cases control eh chosen has been one three [1:3], the sample size that we have reached for our study is about 1,080 pregnant women. Eh: in this 270 were cases and 810 controls <TLANG_Eng>.

S18: Our main variable is double pregnancy. Ah we prefer pregnant women of two foetuses, born alive or not, but without being eh the result of in vitro fertilization. We refer to double pregnancy to maternal age and folic acid intake. About folic acid, we only consider its consumption or not. We do not talk about specific doses because in bibliographical references there are controversies. Em: referring to maternal age, we establish 38 to 55 years old as advanced age. As covariates, we found, we find all these, socio-demographic variables like residence, educational level and job of pregnant women. Clinical variables, personal and family history of twins and pathologies. And individual variables, marital status, religious beliefs, or diet of pregnant women. All of them are variables that increase or decrease the probability of pregnancy. And all these data belong to the Obstetric Service of the Hospital $\mathrm{La} \mathrm{Fe}$ eh in Valencia $<$ TLANG_Eng>. 
S15: ¿Me toca? OK. Another important aspect is the data collection. Apart from PubMed, eh the National Institute of Statistics has been used in order to collect information about the total birth rate and the number of multiple births. Eh eh we have also used medical records in order to eh collect all the documents where all the information is. And finally, to collect all the information that is not mentioned in the medical records eh we have done a survey to figure it out where we have put questions about toxic habits, educational level, diet and physical exercise <TLANG_Eng>.

S16: eh mainly we are going to do a numerical and graphic description of periconceptional and pregnancy folic acid consumption and age in woman who submit multiple pregnancy. All of this ehh obtained by questionnaire <TLANG_Eng>.

S18: Ethics aspect. Ehh this protocol is a project of the medic medical degree of the <TLANG_Eng> Jaime primero <TLANG_Sp> University (Castellón) <TLANG_Eng>. It's approved by Ethics Committee of the Hospital la Fe in Valencia. Patients, who are totally anonymous, and the Hospital gave us access to the data. And the data will be processed according to European regulation. In the study, we have some but important ethical aspects. Eh as you know eh study participants must be protected and well informed about benefits and possible risks. For this reason we make an informed consent to cancel the participation in the study. But eh our study has some limitations. The main limitation is the sample representativeness. As it has been said before, eh, the project participants eh are patients of the Obstetric Service in the Hospital La Fe of Hospital La Fe eh and simple pregnancy is much more frequent than the double one. Ehh these facts limit even more the study population. Eh it's difficult to minimise the loss to follow-up and to guarantee the correct folic acid intake. Another difficulty, another limitation, sorry, is that there are difficulties to measure some covariates. Also, random errors may be present. And we take into account that the study requires an economic investment that could become a limitation <TLANG_Eng>.

S17: OK. About the work plan this project was carried out from 30th of November to 2nd of April. And considering the eh question-question chosen, we distribute[d] the tasks among the four components of the group, such as: choose the question to focus on our plan of work, bibliography research, development of the first work's guide, eh sample of calculation of the sample size, eh development of the protocol, eh planning the schedule and make the presentation <TLANG_Eng>. 
S16: To finish I want to talk about the relevance of the proposal and the applicability to improve health or medical practice. Eh: with our results eh: no, with results have relevance in. One. Pregnant women or couples who are considering having offspring because our results contribute[d] in their decision about age of conception or taking folic acid. Two. In medical practice because it will allow doctors to inform their patients about the relationship between getting pregnant or use folic acid at multiple pregnancy. And three. In the academic field because with our results, we can motivate the realization of future studies about this topic. Eh In applicability to improve health, we have to considerate [negative transfer from Spanish] that multiple pregnancy entails more risks and stress than a simple one. With our results, couples will be able to decrease their probabilities of multiple pregnancy avoiding its risks or complications. And to conclusion, I want to say that nowadays it is necessary to have more information on this topic because in recent years, age of first-time women and folic acid prescriptions is increasing. And that is why more information about the subject is necessary. And this is all and if you have any questions <TLANG_Eng>.

M3: Thank you very much. You have just eh fit very well to the time. Only 12 minutes, but you have explained everything and very well structured. So, please some questions $<$ TLANG_Eng $>$.

SX7: If - if a woman is pregnant with triplets, would she be part of your study or not? $<$ TLANG_Eng>

S17: Eh no because like only those that had pregnant, ay, simple or double pregnancy will be part on the study, even if that woman had been pregnant between 2014 and 2018 $<$ TLANG_Eng $>$.

SX7: Thank you <TLANG_Eng>.

SX8: Why multiple pregnancies involves more risk than eh simple pregnancies? $<$ TLANG_Eng>

S16: Mmm because multiple pregnancy entails more premature birth and fetal death than a simple one <TLANG_Eng>.

S15: And also, as I said mothers who have able to pregnancy have more risk like preeclampsia and also, you can get, for example, personal pressure is very important for 
a mother who is getting pregnant. And also, eh for example, stress, etc. <TLANG_Eng>.

[laughs]

S15: Es que mi inglés... $<$ TLANG_Sp $>$.

M3: No, your English is very good. I have also a question. It's regarding dose, folic acid dose. Because you said we are going to ask about the dose because there is a controversy between the literature. Is that? <TLANG_Eng>.

S17: In the literature it has, we have seen that some of the the studies show different levels of the doses of folic acid. So it was like a controversial conclusion, so we decide[d] write it like a limitation on our - on our study <TLANG_Eng>.

S18: But em - em all studies say that there are high levels of foleid. But no the levels. Ah: most of them don't talk about what is the high level, they say "high levels of foleid increase multiple pregnancy" but ah as I said in...when I talked, also they are controversial. They say. There are contradictions in the study. And that's why we are going to study this topic <TLANG_Eng>.

M3: Why you are going to study the dose? <TLANG_Eng>

S18: Yeah. Yes <TLANG_Eng>.

M3: That's what I thought. As you presented it was that you are not going to study dose because there was a controversial result in the literature and it was...No, because all women they are recommended to have the preventive dose <TLANG_Eng>.

Ss: Yes <TLANG_Eng>.

M3: 400 micrograms [pronounced as microgrames]. OK. And all women. And older. The point is the dose, the high dose bigger than this 400 or something, bigger than one milligram is the problem to have a high dose. It's important that you mention dose. And also timing. Because you know that it's recommended to start supplementation before $<$ TLANG_Eng >

Ss: before pregnancy, we know <TLANG_Eng>. 
M3: Well, but sometimes it has started later and - and in this situation the doctor should prescribe high doses jus to know <TLANG_Eng>.

Ss: Yes <TLANG_Eng>.

M3: So doses are really important in your study. OK? <TLANG_Eng>

Ss: OK <TLANG_Eng>.

M3: Well, regarding the presentation, very well. Was so synthetic. Ah very clear. Very well-structured. Really, very - very good. Well, in the data. Sorry, in the method section, well, you, it's missed the analysis because OK. You said something about medical prescription, but you have to explain how you are going to analyse relation $<$ TLANG_Eng >.

S17: In the protocol is - is <TLANG_Eng>.

M3: It's there $<$ TLANG_Eng $>$.

S17: Yeah <TLANG_Eng>.

M3: Regarding the workplan, probably I miss it because I was writing down, but $<$ TLANG_Eng>.

S16: We didn't realise that we confused how to do the workplan <TLANG_Eng>.

M3: I mean, you can keep what you have done, but you have to put how long it will take to collect the data, to analyse the data, the manuscripts and all that. And regarding the ethical issues, very good. Because you addressed we don't have enough knowledge. The only point is although the the the data the hospital has provided you can't be anonymous, that you have to contact women for the questionnaire. So at the end you won't be anonymous because you need the data $<$ TLANG_Eng $>$.

Ss: Yeah <TLANG_Eng>.

M3: So you are going to ask for an informed consent. OK? <TLANG_Eng>.

Ss: Yeah <TLANG_Eng>.

M3: Very good <TLANG_Eng>. 
Ss: Thank you <TLANG_Eng>.

[applause]

M3: And the last one. The winner is... $<$ TLANG_Eng $>$.

S19: Good morning eh: we are S19, S20, S21 and S22. And we are going to present our research protocol which topic is the Effects of using elect electronic devices on myopia development among medical students. Firstly, we will focus on what is currently known about the topic of our project and for this we have used the latest articles on it. There are three refractive errors: myopia, hypermetropia [farsightedness] and astigmatism and myo..., among them, myopia is considered to be the most common refractive error eh worldwide. Eh recently there has been a dramatic rise in both prevalence and evolution of myopia, eh mainly in adolescents and children. And what is more, a cohort study made in China also states that this rise also occurs among medical students. Em:: another added to this. There is another study which compares the prevalence of myopia eh: between Asia, Europe and India, and it says that in Asia the - the prevalence is about eh 70 to $90 \%$ and India about $45 \%$, but about Europe it doesn't say any figure but it says that the prevalence is higher than in India but less than in Asia. Another study, a cohort study eh: says that the prevalence in in Chinese medical students is 70 to $90 \%$ and in European medical students about 50\%. So once we can see the prevalence eh of <TLANG_Eng> miopía <TLANG_Sp>, of myopia is really high, eh we are going to analyse em:: the factors that are associated with this pathology. Em: myopia depends on both, is a multifactorial disease, and it depends on both environmental factors and genetic factors. Many authors has eh: observed that better educated and more intelligent population is more is at higher risk of developing myopia. So, eh, as, taking into account that medical students are generally a population of these features, is understandable eh that the prevalence is higher among them. Other factors such as reading, computer or microscope use are also related to medical students and have also a bad effect among them. Nevertheless, the most important factor is near work hours. Many authors argue with the fact that this factor is eh the most important one because eh well, it's the most studied and the most demonstrated. And there are other factors, such as rural ambience, mobile phone, left-handedness, weight, Maths, architecture, and sport skills, which are also, which seem to be related with myopia, but have been included in very few studies so their importance is poor. Finally, we are eh: we are 
going to analyse genetic factors. Eh: a publication in BMC ophthalmology journal announces that genetic factors play a role in the development of myopia. Another stu..., another cross-sectional study also observed that the prevalence of myopia among medical students was increased with an increased number of myopic parents. It also says than when both parents were myopic, myopia occurred in kindergarten and school. And then when parents were not myopic, myopia occurred later in university. So as we can see there are different articles about the topic of our project and, but most of them have been carried out in the Asiatic population, so the scientific evidence in Europe remains lacking yet. So with our project we pretend to explore the factors associated with developed myopia or worsen it in, among the medical students from our area $\langle$ TLANG_Eng $>$.

S20: OK. So once we've talked about the background and the current scientific knowledge about our topic, now we're going to describe our work hypothesis. Then, I will mention the objectives that we want to achieve with our study. After that, S21 will talk about the method and S22 then will explain our workplan. Finally, I will summarise the presentation talking about the relevance of the proposal and the applicability that it has in both medical practice and the visual health. So now, turning into the first part that I'm going to explain you, let's consider our hypothesis. The use of electronic devices such as computer laptops, mobile phones and, for example, tablets, eh increases the risk of suffering from myopia eh in medical students during their career. As well as we know, medical students are bigger users of technologies. We use them to study, we use them to take notes in classes, and also we use them to do our university task. So if this evidence eh leads us to the timing and use of these electronic gadgets is leading to a deterioration of sight. Secondly we are going to make clear the objective that we want to achieve with our eh - eh research protocol. In the first place, we want to determine the association between the use of electronic devices and refractive errors in particularly myopia in <TLANG_Eng> Jaume I <TLANG_Cat> University medical students, making use of a questionnaire of frequency and use of these gadgets by this study population. Moreover, we want to explore the eh possible effects of studying habits such as the light we employed and the pauses or hours of rest while they are studying on the risk of developing myopia. Also, we would like to examine the relations between the graduation of myopia and the eh year of Medicine these students are in. Another objectives are to evaluate the correlation between hours of study and medical stress 
suffering from this visual problem. And however, apart from the objectives that I just mentioned, we also want to consider the need to control myopia among young medical students and to avoid further cases of low vision in a future. Furthermore, our last objective eh that we want to to determine which study habits are appropriate in order to avoid this myopia development <TLANG_Eng>.

S21: Now I'm going to talk about the methodology of our study, first of all, we have the study design. It is a prospective cohort study from the first year to sixth year of Medicine degree in <TLANG_Eng> Jaume primer <TLANG_Cat> University among six years. Then, we have a study population. In our study, our population is Medicine students enrolled in Medicine degree in <TLANG_Eng> Jaume primer <TLANG_Cat> University. This is our only inclusion role together with informed consent, but we haven't got any exclusion role. Eh also we analyse sampling type and sample size. In our research protocol we carry out a random simple probabilistic sample, in which all the students have the same chance to be select[ed] in our study. Eh: in this case, we use the Epdat three point one programme and we have the different information based on the article "Prevalence of and factors associated with Myopia in Inner Mongolia Medical Students in China, a cross-sectional study". From this, from this article we take the following information. O ratio one dot thirty-three [1.33], Confidence level $95 \%$ Potency $80 \%, 70 \%$ exposed risk and 52.63\% non-exposed risk. With all this information we used Epidat and we calculate[d] 246 students for the study. Then, we have variables. There are a lot of variables that we are keeping in mind in our study. Of the effects of using electronic devices myopia development among medical students. The variables are. Sex. Students add on the platform if they are men or women, age, genetic. Students have to say if their mother or father have myopia. Myopia diagnostic. Eh Students in their personal information add if they are diagnosed with myopia" and if they say yes, myopia, they have to add the dioptre, glasses and contact, Study hours. They add how many hours they study during the week and they have to add if they use or not use a lamp, their use of PC hours, this is our main variable in the study, using mobile hours, using TV and others like tablets. Sleep hours. Here students add the average of hours that they sleep during the week. Stress and finally lifestyle. This variable is very important too and the students add on the platform how many hours they do their activity outdoor activities. Furthermore, we analyse data collection and analysis. First we do a measuring test of visual acuity every 6 months. And then we do a 
virtual platform - platform we eh on, they have an anonymous personal account and they add sex and age, but they don't put their names or surnames. Then the register of electronic devices, using electronic devices hours, study hours, lifestyle and other variables. Then, we analyse Pearson and Spearman correlation and Logistic and lineal regression. Eh: we have three important ethical aspects. All the students are informed about the objectives, purpose, methods, risks and benefits of the study. All the students signed the informed consent. This point is absolutely necessary. And the assurance of the confidentiality and anonymous of the information from each student. And finally, the limitations in our study are Erasmus students. Students who dropped out the medicine degree. Students who join up years later. Students who leave the study of their own free will. Subjectivity and results reliability <TLANG_Eng>.

S22: OK. Now <TLANG_Eng>. Uy <TLANG_Sp> I'm going to talk you about the work plan we are going to design for the eh development of this study. Eh this study will last 6 years, counting both preparation and preliminary design of five months. We started the study in February of this year. We ask for the email from all medical students and send an email to contact them. Eh: in April of this year every student who agrees to participate in the study must sign eh: the informed consent. After May we received the student's response and each student will then be assigned the keys to enter the virtual platform anonymously. Eh: this first survey will collect a series of student data, which may be modified later if any changes occur. Eh: July 2019 eh: From now on, every three months there will be a talk to raise awareness between students eh: to not drop the study though, due to their myopia. Eh: from September eh: 2019 to eh: July 2025 students will enter the virtual platform every week to include the data it asks for. In September of this year, collect, we will collect the data obtained during the last 6 years and classify it in order to see if the associations considered during all work exist. And finally, to October eh: from - from October to November we will analyse and interpret and interpret the results. And from December to March we will write articles and reports. Writing the conclusions about whether there is a relationship between being a medical students and being myopic <TLANG_Eng>.

S20: OK. So, finally and to conclude our research is the relevance of the proposal and the applicability that it has. Eh: we want to emphasise that nowadays Errors of refraction in students, in particularly, in particularly short-sightedness continue rising globally. Eh: as we see from the introduction about 70 to $90 \%$ of Chinese medical 
students are myopic and Spain is about $50 \%$ of them suffer from this visual problem. Secondly, although there are other similar studies eh that have postulated about a possible relationship between the hours of study and eh the risk of suffering this eh myopia. Em:: with - with this study we are trying to discover if our study population, I mean, our <TLANG_Eng> Jaume primer <TLANG_Cat> University medical students and our main variable, which is the use of electronic devices are interrelated. And then, eh finally, we talk about the applicability that has our study and if eh we ask ourselves how can we take advance of the results of this study with these results, we want to improve the consideration of myopia and medical students and making them aware of this serious problem. Also, and finally, we hope getting involved sanitary authorities eh in visual health and visual problem because although in the near future there will be a generation that will have the largest life expectancy, they will have also a very poor quality of vision. In addition, it will generate a high social cost and very big medical problems <TLANG_Eng $>$.

M3: OK. Thank you <TLANG_Eng>.

\section{[applause]}

M3: Thank you very much. Just on time. Thanks a lot. Please, one, a couple of questions <TLANG_Eng>.

SX9: Why did you decide that the study will last six years? <TLANG_Eng>.

S20: Because as we have said, our study population is <TLANG_Eng> Jaume primer <TLANG_Cat> medical students and their career lasts six years, so we can see the evolution <TLANG_Eng>.

M3: Thank you <TLANG_Eng>.

SX10: I don't understand why Erasmus students are a limitation in your study <TLANG_Eng>.

S21: Because the study, our study consists on six years, so Erasmus students ehh probably will leave our country so we could not follow them during our project. And this could be maybe lead to errors <TLANG_Eng>. 
M3: Thank you. A few comments. Very well presented, structured, explained. Very clearly. Very good. Eh: just two points. Hypothesis and objective. Very well just the structure. The only point is that in the specific one, the specific objectives, I can't remember, the last one or the last two ones, they are not research objectives. They are more applicability of the results, you know? This is very common, to get eh that. Because you have objectives that at the end of the project you, you have accomplished, no? And, and this is more applicability. You are going to use these data to improve that. But very well structured. Very well. Ah: well, the only - only thing is the variables. They were just shhh a list of all the variables and you have to classify them. And the last one, regarding to workplan how you said that students should eh: answer the questionnaire? Every week? <TLANG_Eng>.

S22: Yes <TLANG_Eng>.

[laughs]

M3: This is very unrealistic. You know that $\langle$ TLANG_Eng $\rangle$, no? $\langle$ TLANG_Sp $\rangle$.

S22: Yes <TLANG_Eng>.

M3: Well, very - very good. Thanks a lot <TLANG_Eng $\rangle$. 


\section{APPENDIX III (i): Women's care}

N1: Who wants to start? <TLANG_Eng>

S1: Los del otro día: ¿no? que no acabaron <TLANG_Sp>

N1: Sorry? <TLANG_Eng>

S2: Hostia, qué pena, ¿no? <TLANG_Sp>

[laughs]

N1: Yes, I forgot but I had it written down. I mean I was gonna say that. So who's left from the other day? You? OK:: Thank you <TLANG_Eng>.

S3: The articles that I found was... is called Retrospective study of the association between epidural during labour and complications for the new one. It is from PubMed in 2015 and the disadvantages that I found was that Apgar index values at one minute and five minutes were slightly but significantly lower in neonates whose mothers received epidural analgesia. Neonatal intensive care unit admission was significantly more frequent in the epidural group and resuscitation was significantly more frequent in the epidural group versus the non-epidural. And the last disadvantage is that early breast feeding was more frequent on the non-epidural group than the epidural one $\langle$ TLANG_Eng>.

N1: OK. And the other one? <TLANG_Eng>

S3: The other one is called Epidural versus non-epidural in labour and it's from 2012 from PubMed. The conclusion of this article is that epidural analgesia appears to be an effective... an effective in reducing pain labour in women who use this as - as a form of pain reducer. But epidural analgesia have an impact on the risk of caesarean section $<$ TLANG_Eng $>$.

N1: OK. Who's next? <TLANG_Eng>

S4: The article of benefits is from in 2018. Epidural analgesia had no impact on the risk of caesarean section or low-term backache, and did not appear to have an immediate effect on neonatal status as determined by Apgar scores or in admissions to neonatal intensive care. Further research may be helpful to evaluate rare but potentially severe 
adverse effects of epidural analgesia and non-epidural analgesia on women in labour and long-term neonatal outcomes. And against is from a journal of [unintelligible] eh::: 2014 and say that non-inferiority of routine EA could not be demonstrated in this trial. Routine EA use is likely to lead to more operative deliveries and more maternal adverse effects. The results of our study do not justify routine use of EA <TLANG_Eng>.

N1: OK. Thank you....And?:: Yeah one of you <TLANG_Eng>

S5: Vale <TLANG_Sp>. My first article is epidural Epidural versus non-epidural or no analgesia for pain management in labour from Cochrane library and it was published in ehh 2018 and...eh it says that more women in the epidural group experienced assist[ed] vaginal birth. Women with epidural experienced more hypotension, motor blockade, fever, and urinary retention. Women with epidural experienced more... Ah no. and there were no clear difference between caesarean section rates and maternal long-term backache and there were also no clear between groups for the neonatal outcomes, admission to neonatal intensive care unit and Apgar score less than seven at five minutes $<$ TLANG_Eng $>$.

N1: OK. This article is the same of one of you? Was yours that one? OK $<$ TLANG_Eng >.

S5: And the other one is The effects of epidural analgesia on labor, maternal, and neonatal outcomes: a systematic review. It's from the University of York, Centre for Reviews and Dissemination. And ehh benefits it says that existing evidence suggests that women should not avoid epidural analgesia for fear of neonatal harm, breastfeeding difficulties, Caesarean delivery, long-term back pain or long-term urinary incontinence. And disadvantages epidural analgesia may alter the dynamics of labour and maternal temperature regulation <TLANG_Eng>.

N1: OK. Thank you <TLANG_Eng>.

S6: Eh:: well eh: my first article is called Obstetric analgesia: Current situation and alternatives. Eh: It's a receipt of a revista de Colombia ah: anestesiología no, no $<$ TLANG_Sp>. Colombian journal of Anaesthesiology

[laughs] 
S6: In this article I found some disadvantages and ehh. Despite good effectiveness and safety, it done done [does entail] complications, including neurological abnormalities during the peripartum period: lateralised analgesia, eh: vessel puncture pun... puncture, eh: paresthesias, difficult technique, eh:: ineffective analgesia, and arterial hypotension. In the postpartum period, complications include lumbar pain, urinary retention, post dural puncture headache, and peripheral neuropathy:.:: Eh: in another article eh: Position in the second stage of labour for women with epidural anaesthesia. A review of Cochrane Library. I found another disadvantages that epidural analgesia for pain relief in labour prolongs the second stage of labour and results in more instrumental deliveries:::: And finally eh: in a eh: review college Epidural versus non-epidural or no analgesia for pain management in labour of Cochrane library I found... $\langle$ TLANG_Eng $>$.

N1: Is that a third article? <TLANG_Eng>.

S6: Sí <TLANG_Sp>.

N1: OK. That one is the same of everyone <TLANG_Eng>.

S6: Sí <TLANG_Eng>. Yes <TLANG_Sp>.

N1: So doesn't matter [laughs] Don't repeat it again. That's fine <TLANG_Eng>.

S6: Ah no? <TLANG_Sp>.

N1: No - no. That's fine. Thank you: And you are next? <TLANG_Eng>

S7: I have two articles. One is called Epidural versus non-epidural...<TLANG_Eng>.

N1: That is the same of everyone <TLANG_Eng>.

S7: Yes <TLANG_Eng>.

N1: Tell me the other one <TLANG_Eng>.

S7: OK. The other article is eh: Risk Assessments of Epidural Analgesia During Labor and Delivery. It's from SAGE Journal Clinical Nursing Research and the year was 2017:: Epidural analgesia eh: inflates the risk of instrumental delivery and loss of fetal labor because of the... Eh: In this article they do a retrospective cohort study ehh in 
Spain hospital and the results of the study determine that women who decide epidural analgesia have no progression of labour and craving stimulation: and: <TLANG_Eng>.

N1: That's it? OK. Thank you: And have you all read? <TLANG_Eng>

[Ss nodding]

S8: OK. My first article is called Maternal and foetal outcome after epidural labour analgesia in high-risk pregnancies. It's from NCBI. National Centre of Biotechnology Information, of Indian Journal of Anaesth...OK. Amm. They are in 2016 and it says that well-controlled and effective epidural blockade may provide improved neonatal cord blood gas parameters probably resulting from better uteroplacental perfusion along with intrapartum pain relief in parturients with intrauterine growth restriction. Eh: moreover, epidural labour analgesia improves sugar and ionised calcium levels and the analgesic efficacy and maternal satisfaction. Ehh <TLANG_Eng>.

N1: And the other one <TLANG_Eng>.

S8: And the another one is Pregnancy and birth: epidurals and painkillers for labor pain relief. It's from Informed health of Institute for Quality and Efficiency in Health Care emm and they year is 2018. OK. Ehmm. When - when women have an epidural, their baby is more likely to need to be...to be delivered with the help of instruments that use vacuum suction or forceps. Ehh and other and other effects are low blood pressure, which can lead to dizziness or nausea. Ehh fever, Ehh problems urinating: Ehh epidurals can also cause numbness or tingling in the legs <TLANG_Eng>. And...no hay más $<$ TLANG_Sp>.

N1: Are there any of these ones? [making reference to the disadvantages on the board] $<$ TLANG_Eng>

S8: What? <TLANG_Eng>

N1: Are there any of these ones? You already said some <TLANG_Eng>.

S8: Yes <TLANG_Eng>.

N1: Yes, you said that one. And fever <TLANG_Eng>.

S8: Last day I - I - I - I take my hand - I take my hand <TLANG_Eng>. 
N1: Ah OK <TLANG_Eng>.

S8: Es que ya lo dije, no sé cómo decirlo <TLANG_Sp>.

N1: So you said everything already <TLANG_Eng>.

S8: Yes <TLANG_Eng>.

N1: And I think is one person left. Who's left? <TLANG_Eng>

S9: Why are you put in so <TLANG_Eng > ehh arriba <TLANG_Sp>? In so labour nine and journal? <TLANG_Eng>

N1: Because about slow labour nine articles were talking about that and now thirteen about prolong second stage but we have to summarise thirteen and nine because slow labor means the same. Twenty-two here. OK, so this is what you have to study for the exam if you want to study. I might delete some of them. I'm gonna...maybe one or two. OK. Do you believe what we found? Do you believe epidural slows labor? What do you think? Or you are not sure? <TLANG_Eng>.

S10: I don't know if it slows labor <TLANG_Eng>.

N1: You don't know? Are you - Are you joking? Are you...<TLANG_Eng>.

S10: No, sí [laughs] <TLANG_Sp>.

N1: Sorry? <TLANG_Eng>.

[laughs]

S11: ¿Qué has dicho? <TLANG_Sp>.

N1: ¿Qué - Qué has dicho? Tú: tú no lo tienes claro <TLANG_Sp>.

S10: No, what's... slows labor in Spanish <TLANG_Eng>.

N1: In Spanish? <TLANG_Eng>. Eh:: La epidural hace que sea más lento el parto $\langle$ TLANG_Sp>. What do you think? <TLANG_Eng>.

S10: I don't know <TLANG_Eng>.

N1: You don't know? <TLANG_Eng> 
S10: Could be <TLANG_Eng>.

N1: Could be? OK: We found twenty-two articles saying that <TLANG_Eng> [laughs]

N1: and zero saying that accelerates: So what do you think? <TLANG_Eng>

Ss: Slows <TLANG_Eng>.

S11: Puede ser <TLANG_Eng>.

S12: Slows labor <TLANG_Eng>.

S10: I don't know <TLANG_Eng>.

N1: Still could be. OK: I don't know. I want to say that this is kind of the evidence. OK? We haven't read properly all the articles and we haven't choose the best of them and we...you know. We only read some articles and many of you have the same article, but this is kind of a - a systematic review. So I just want you to think properly. OK? Not think: no, epidural is very good. No, epidural nothing happens. You put the epidural and everything is fine. You know epidural is very good for all of this, OK? But it can cause all of this. OK? I just want you to understand. Because the other day in the other group: one stu...one of you said <TLANG_Eng>:

“SX1: No, I don’t believe epidural slows labor <TLANG_Eng>.

N1: OK, why not? <TLANG_Eng>

SX2: No, because I can't believe that <TLANG_Eng>.

\section{N1: I said OK <TLANG_Eng>."}

N1: She couldn't believe it because you know because of the culture that we have. Everyone says it's fine. But you're gonna be nurses o you have to know properly when you offer something or when you are talking about something. OK? Well, I will send this document to all of you, OK? <TLANG_Eng>

Ss: OK <TLANG_Eng>. 
N1: So who wants to start now with Culture and women. Do you want to start? <TLANG_Eng>

S13: Sí <TLANG_Sp>, yes <TLANG_Eng>.

S6: Estás a tope, ehh? <TLANG_Sp $>$.

N1: OK. Start, start <TLANG_Eng>.

S13: ¿Desde aquí puedo? <TLANG_Spg>

N1: Yes, if you feel more comfortable <TLANG_Eng>.

S13: Means and belief of maternity in Japan. As a concept, pregnancy is understood as a period of mental and physical discipline for women, and they are considered responsible of abortion or premature birth. Men are not responsible about the pregnancy process because it is not occurring in their bodies. And they are exempt from medical visit and even sometimes from birth. During pregnancy the doctors are very strict about the weight that pregnant women could have. By the fifth month women go to the temple with their mother and grandmother to pray. They also buy a special clothes wrapped to the women's abdomen to protect the uterus from the cold and keep the fetus stable. During the delivery Japanese doctors encourage eating and drinking during childbirth and women eat a lot to have the strength to push. It is not considered acceptable to shout or move. Furthermore, they don't use epidural normally. They believe that medication can make their child weak :: Post-partum. The next ten days after the birth the woman rests in the hospital. They think the cord is related with the health of the child. It is also considered as a symbol of destiny. For the reason apart is delivered in a box to the mother. This cord pack is showed to the child on certain occasions such as birthdays or the day he marries or leaves home to symbolize separation with the mother. It is also common to keep the cord to help the child when he is sick the first month. The baby doesn't have to leave the home during the first month to avoid getting infected because He has low defences. The father is responsible for bathing the child because it provides closeness and intimacy between the baby and his father <TLANG_Eng>.

N1: OK, very good. So:: Which differences you found:: both of you: Which differences you found in Japan and in Spain? <TLANG_Eng> 
S14: Here the father is more responsible: <TLANG_Eng> responsable: ¿no? $\langle$ TLANG_Sp>.

N1: But: when? During the birth or after the birth? <TLANG_Eng>

S14: Em:: during the birth <TLANG_Eng>.

N1: No: he only said after the birth:: not during the birth <TLANG_Eng>.

S14: No sé, es que no...No, si ya, ya <TLANG_Sp>.

N1: You don't know because you want...you weren't listening [laughs] So...who wants to read next? <TLANG_Eng>

S15: Vamos [unintelligible] <TLANG_Sp>

SX: China <TLANG_Eng>.

S16: Al final somos muchos $<$ TLANG_Sp $>$.

N1: China. How many of you are China? <TLANG_Eng>

S16: Five, no? <TLANG_Eng>

S15: Five or six [moving towards the whiteboard] <TLANG_Eng>.

N1: No, but all of you no. In two parts <TLANG_Eng>.

SX: Ah <TLANG_Eng>.

N1: Because you are five or six <TLANG_Eng>.

S15: Seven <TLANG_Eng>.

S3: ¿Cuántos son? <TLANG_Sp>

N1: Seven. So four and three <TLANG_Eng>.

S16: Vale, pues lo pongo yo <TLANG_Sp $>$.

[unintelligible]

S15: Porque tengo el de... pues ¿ponemos cada uno una, una parte o qué hacemos? $\langle$ TLANG_Sp> 
APPENDIX III (i): Women's care

S17: Bien<TLANG_Sp>.

S18: Como quieras <TLANG_Sp>.

S16: Yo si queréis hacemos eso <TLANG_Sp>.

S3: A ver vosotros [unintelligible] <TLANG_Sp>.

S15: Yo lo tengo aquí preparado. Lo digo yo primero <TLANG_Sp>.

S16: Yo si queréis pongo el mío <TLANG_Sp>.

S17: Vale <TLANG_Sp>

S16: Y luego cada uno que diga un par de frases <TLANG_Sp>

[unintelligible]

S15: Yo es que he hablado...<TLANG_Sp $>$

[unintelligible]

S18: Pero eso es al principio lo de que las mujeres... $<$ TLANG_Sp $>$

S17: Pues si puedes, como tú lo tienes todo redactado, hago yo esto <TLANG_Sp>

S16: Yo introduzco <TLANG_Sp>.

S15: Un segundo, un segundo <TLANG_Sp>.

S18: Se está cargando el ppt <TLANG_Sp>.

S16: Esto es una diapositiva. Yo lo tengo entero todo. Lo mío son todo fotos ehh $\langle$ TLANG_Sp $>$.

S17: Vale <TLANG_Sp $>$.

S18: Vale, ¿entonces esto yo no lo digo? <TLANG_Sp>

[unintelligible]

S17: Esto es de comidas [unintelligible] <TLANG_Sp>

S15: Seis puntos <TLANG_Sp> 
S16: Sí, no, no. Estar está <TLANG_Sp>.

S15: Es que somos tan trabajadores que tenemos un power cada uno $\langle$ TLANG_Sp $>$.

S17: Tres ppt $<$ TLANG_Sp $>$

SX: Ellos van tres <TLANG_Sp>

S15: Un poco así <TLANG_Sp>

S17: De las 40 semanas <TLANG_Sp>.

S16: Ohh yo también la he puesto esa foto <TLANG_Sp>

S15: We are S16, S17 and S15 and we are going to talk about pregnancy:: Motherhood in this culture is an experience by the mandarin culture. Some things that have caught our attention is that when a woman gets pregnant she usually becomes the centre of attention and care for the whole family. Any situation that may cause risk to the correct development of the pregnancy has to be avoided. Ehh some women drink medicinal plants to elimitate toxins and if there has been a cesarean section beef and sausage are avoided as they think they slow down the healing process:: Ehh about the feeding, the..they have to consume hot drinks to balance the energy and protein rich food to face correctly the childbirth Ehh and avoid cold foods and cold time with cold water. Ehh they have some prohibitions::

[laughs]

S15: they: - they can't laugh very - very loudly and [unintelligible] it. They can't get angry, and look bright colors. And they can't have sex and remodel his house during the pregnancy. And they have to sleep with a knife under the bed <TLANG_Eng>.

SX: Ole $[$ laughs] $<$ TLANG_Sp>.

N1: Espera, pero ¿y lo demás que tenías ahí? <TLANG_Sp> And the rest? $<$ TLANG_Eng>

S15: Es que coincide <TLANG_Sp>

S16: Es que ahora vamos nosotras, ¿no? <TLANG_Sp>

S15: Sí, lo demás es ehh después del parto. Había puesto <TLANG_Sp> 
S17: ¿Quién habla despues del parto? <TLANG_Sp>

S15: Vosotras <TLANG_Sp>

S17: No, nosotras hacemos... <TLANG_Sp>

SX: Sí [laughs] <TLANG_Sp>

S18: ¿Qué pasa? <TLANG_Sp>

S16: Yo lo explico desde aquí

S17: ¿Por qué no se abre? <TLANG_Sp>

[unintelligible]

S17: Qué mal oganizado que está esto <TLANG_Sp>

S15: Ahora dale al link y abres <TLANG_Sp>

[unintelligible]

S17: No, no pero no se puede - no se puede. O sea tiene que entrar desde su cuenta $<$ TLANG_Sp>

S16: Pero yo lo tengo en el correo, no lo tengo en el drive <TLANG_Sp>

[unintelligible]

S15: Me quedo aquí que tengo que pasar $\langle$ TLANG_Sp $>$

S16: OK, now: S17 and I are going to talk about Zuo Yuezi. It's a Chinese art postpartum recovery and... $<$ TLANG_Eng>

SX: Uy míralo <TLANG_Sp>

S16: Zuo Yueti was translated to sitting the month. It's an integral part for a postpartum mother. It's a transitional time known as the summer of the first trimester. The mothers body is underoging a major change from pregnancy to postpartum which lasts a minimum for 30 days. Em after a baby's birth, the mother's Yin and Yang get adjusted. The Yang forgets from pregnancy its spirit at a birth and the new mother is now cold. This is where the novalty coming in. The idea is that the mother body is susceptible to 
all things cold, including water. Experiencing a cold bath can affect the mothers' already weak state and immune system. However, this image comes from a time when exposure to the elements before and after a bath were a real risk to a new mother. And:: Bueno, esto ya lo he leído <TLANG_Sp>.

SX: Ay míralo. Ohhh $<<T L A N G \_S p>$

S16: ¿Dónde voy? <TLANG_Sp>

[initelligible]

N1: But you can’t say eveything. You can summarise the beginning <TLANG_Eng>.

S16: Eh? <TLANG_Sp>

N1: Que puedes decir lo del principio <TLANG_Sp>.

S16: Es que es todo en plan. Lo han dicho ya ellos <TLANG_Sp $>$.

N1: Está bonito <TLANG_Sp $>$.

S17: Yo iba a hablar de esto <TLANG_Sp> :OK. For thirty days after childbirth, the woman is expected to stay in bed and not do any heavy work, including housework. The woman has to stay warm, putting on many layers of clothing to make sure she doesn't catch a cold. During the sitting month, she should not comb or wash her hair so as not to get a headache. Eating protein-rich soup would increase breast milk and balance the "coldness" of the post-partum period. Avoid fruits and other "cold" foods. Sexual activity is not encouraged during this month. And some of these traditional beliefs, especially those related to the sitting month, are still practiced in parts of China, of China [correcting pronunciation] they should not be taken as medical advice $<$ TLANG_Eng $>$. Ya está <TLANG_Sp $>$.

SX2: Muy bien <TLANG_Sp>

[applause]

[unintelligible]

S17: Qué mal - qué mal - qué mal <TLANG_Sp〉.

N1: China?: Are you listening everything? Are you understanding? <TLANG_Eng> 
SX3: Yes <TLANG_Eng>

N1: Because this comes into exam as well. You don't have to take notes but the most important things can come <TLANG_Eng>.

[unintelligible]

SX4: Sí, creo que sí <TLANG_Sp>

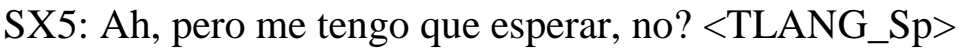

[unintelligible]

S18: Ehh Hi, we are S19 and S18 and we are going to talk about Chinese culture. Ehh pregnants [pregnant women] <TLANG_Sp> don't usually go to revision during pregnancy because in Chinese culture if you are pregnancy people think that you are sick and for the same women don't go the revision. Pregnants [pregnant women] <TLANG_Sp> usually take a special diet during the pregnancy and after the labour. According to the traditional Chinese medicine, the health is the balance between of the yin and yang and during pregnancy the woman is in a state of Yin so she is necessary to take hot food for get the balance and after the labour the woman is in a state of Yang and she need take cold food. Women don't usually because the socially could bad considerate in China. Eh: in China it is not usually spent analgesia for pregnant but it is usually used Acupuncture analgesia. It's usual for women to rest a lot during the pregnancy and after the labour. When a woman becomes pregnant she usually becomes the centre of the attention and care for the family. Women doesn't work and rests in bed for a lot of time. And woman can show the interest to watch the new-born baby. Emm This is in reality. This is due to the custom that the woman holds a position of absolute rest after the childbirth <TLANG_Eng>.

S19: In China the one-month post-partum is called Zuo Yuezi, the literal translation means doing the month. Traditionally, a woman remains at home during this period. During this time her behaviour in relation to diet, activity and hygiene is determinated <TLANG_Sp> by tradition and the theory behind traditional Chinese medicine. And there is some of these beliefs and practices. Health is seen as harmonary between Yang and Ying and illness an imbalance between two forces. Pregnancy is a yang state but during childbirth the women loses heat and becomes ill. The behaviour around diet 
activity and hygiene that eh: that comprise during the month becomes. It will restore health:: Food. Eat more food because women at this time are weak and food will help revive her state, promote recovery and improve breastfeeding. Eat hot food protein-rich: meat, eggs were regarded as hot foods. Food could also be made warmer by adding ginger and wine. Avoid cold food, fruit and vegetables. Rural families identified numerous effects of eating cold food: diarrhoea in baby and mother, body swelling, stomach discomfort, aches and pains and cough:: Higiene ehh Hygiene. No bath or washing hair. They believed that as the postpartum woman's skin is loose, water can enter the body through holes in the skin:: No brushing teeth. Many people believed that brushing teeth during this period would make teeth loose and gums bleed. Behavioural precautions. Staying inside the home. All families believed that when the mother goes outside wind will enter her body and cause illnesses, namely arthritis and rheumatism later in life but also headache, poor appetite and catching a cold:: Abstaining from sexual activity. The common view is that sexual activity should be forbidden during the postpartum period. There were several reasons for this restriction: the woman is weak; she has no energy and is concentrating on looking after the baby; she needs to rest; to scar has not healed; she is still bleeding; and it cause an infection. Health workers and traditional medicine practitioners supported this restriction. All families followed this restriction for a period ranging from one to three months. The effects of the traditional practices on health and how health staff should view these practices as beneficial, irrelevant or harmful, to help guide how they might modify women's behaviour at this time <TLANG_Eng>.

N1: Sorry, you said they can eat hot food in the post-partum? <TLANG_Eng>

S18: Yeah <TLANG_Eng>

N1: And he said they don't eat hot food. Only cold food? <TLANG_Eng>

S19: Avoid cold food. Cold food not <TLANG_Eng>

N1: Avoid cold food. But I think you said they eat hot food during pregnancy and in the post-partum period they eat cold food <TLANG_Eng>.

S19: Ah <TLANG_Eng>

N1: Maybe you find something different <TLANG_Eng>. 
APPENDIX III (i): Women's care

S19: A ver si, a ver si... [laughs] <TLANG_Sp>

S18: Un article <TLANG_Cat>

S19: A ver, a ver yo sí que es verdad que al principio... $\langle$ TLANG_Sp $>$

N1: En inglés <TLANG_Sp>

S19: No, es que no, es que no me sale <TLANG_Sp>

[laughs]

S18: És que com ho hem trobat de fonts diferents... $<$ TLANG_Cat $>$

N1: What did you find in the post-partum? They eat cold or hot food? <TLANG_Eng>

S19: They can't eat hot not, they can't eat hot food <TLANG_Eng>.

N1: During pregnancy? <TLANG_Eng>

S19: Any soup <TLANG_Eng>

[laughs]

N1: So you don't know the answer? The ones who read about Chinese culture? You don't know the answer? <TLANG_Eng>

[unintelligible]

SX: During pregnancy hot food. In the post-partum, in the post-partum cold food $\langle$ TLANG_Eng $>$.

[unintelligible]

[a new group is getting ready for their oral presentation]

S21: Si vols te les passé quan siga. Ai que li passe ara? <TLANG_CAt>

[unintelligible]

S21: Bueno <TLANG_Sp>, és igual, aixina i avant, no? Tampoc <TLANG_Cat>.

S22: Com se passa? <TLANG_Cat> 
S21: És que no puc ficar-lo sencer. Ah perquè ho he ficat en pdf perquè m'era més cómodo <TLANG_Cat>.

S22: Se passe d'ahi i avant, no? <TLANG_Cat>

S21: Sí <TLANG_Cat>

S21: Bueno <TLANG_Sp>, hello::

[laughs]

S21: Bueno <TLANG_Sp>, hello. We are $X$ and $X$ and we are going to talk about the pregnancy in gypsy woman, women. We are going to talk about their belief, eh: values and practice. Eh: when we were searching information we found an interesting article. In this article seven gypsy women from different families were interviewed about their belief in different areas like nutrition, hygiene, physical activity, toxic habits and medication. Eh: these women were between the age of 22 and 27. Vale. First of all, about nutrition. The gypsies believe that their food cravings are aliments for the so if they don't satisfy the cravings the future child have the shape of these aliments like a birth mark <TLANG_Eng>.

N1: Do you know what are cravings? <TLANG_Eng>

S21: Antojo <TLANG_Sp>

SX: Antojo <TLANG_Sp>

N1: Antojo <TLANG_Sp>

Ss: Antojo <TLANG_Sp>

S21: Because of that women always eat what they want. Baby eh: need thee this food $\langle$ TLANG_Eng $>$.

N1: That's what they believe <TLANG_Eng $>$.

S21: Eh? <TLANG_Eng>

N1: That's what they believe <TLANG_Eng $>$. 
S21: OK. Furthermore, we all know that hair is an important identity symbol for the gypsy ethnic rope. Mineral? <TLANG_Eng> No sé cómo se pronuncia <TLANG_Sp>.

N1: Mineral <TLANG_Eng>

S21: Mineral intake is prohibited because they think it affects to the baby's hair. So if a women eat, ate food with vinegar her baby will be bald. Eh: spicy food <TLANG_Eng> N1: Do you know what is bald or bold? <TLANG_Eng>

S21: Bald <TLANG_Eng>, no sé <TLANG_Sp>. B-A-L-D [spelling] <TLANG_Eng>

N1: But do you know what does it mean? <TLANG_Eng>

S21: Ehh, no sé <TLANG_Sp>

S22: Calvo <TLANG_Sp>

S21: Claro, sí, que se rompe el pelo. Es que no sé <TLANG_Sp>

S21: The spicy food is also a taboo because it could produce blindness [pronounced in the wrong way] to the child. Blindness. [laughs]. They believe also affects the way they cook their food <TLANG_Eng >, o sea $\langle$ TLANG_Sp>

SX6: O sea <TLANG_Sp>

S21: They believe also affects the way they cook their food. Usually a pregnant woman clean and cook the aliments more careful than she does habitually. OK? Perfect $<$ TLANG_Eng>.Seguisc jo? <TLANG_Cat>

S22: Seguisc jo si vols <TLANG_Cat>.

S21: Tu? <TLANG_Cat>

S22: Lo que vullgues <TLANG_Cat>

S21: Una més i tu. Estic a tope [laughs] <TLANG_Cat>. Hygiene. During the pregnancy is important to pay special attention to the personal hygiene. It's really important for gypsy woman to wash herself with warm water or hot water because they believe that cold water can produce abortions. OK? <TLANG_Eng>

[laughs] 
S22: Em:: they also think abortion can be produced by making great efforts. For this reason eh: housework is usually done by their daughters and mothers-in-law, etc. they also think that women have to rest. About the toxic habits all the women that were interviewed in this art...in this article didn't give up smoking but they reduced the intake because they knew it was harmful for the baby. And finally, about the medication gypsy woman think oral medication can produce foetal death or malformation. For this reason, medication is totally forbidden during pregnancy. A woman say a pregnant woman can only take < TLANG_Eng> Paracetamol. Ya está <TLANG_Sp>

[applause]

N1: ¿Queréis ir a almorzar y a las 10:30 volvemos? < TLANG_Sp>

Ss: Vale <TLANG_Sp> 


\section{APPENDIX III (j): Affective and Social Neuroscience}

P1: Bueno, buenas tardes. ¿Nos hemos despejado un poquito? Ehh shhh. Si sabéis de alguien que se había quedado así un poco como...Me han dicho "Ay, estoy muy cansada" y se han ido a la cafetería o lo que sea y los podemos captar porque esta práctica va a ser igual a uno. Sesión 1, sesión 2, ¿vale? Recordad. Y hoy, además, es una práctica un poquito especial. Ahora explicaremos. Mientras la gente va tomando asinto, lo ideal de hoy también sería que estuvieseis ubicadas y ubicados lo más cerca posible de, de vuestros grupos de trabajo, ¿vale? Que a algunos grupos los veo muy bien ubicados y otros grupos no tanto, ¿vale? Es lo ideal. Porque vais a tener que hacer luego algunas cuestiones en grupo o al menos que tengáis al lado a alguien de vuestro grupo. Al menos una persona, ¿vale? Hay un grupo que se me ubica siempre de manera fantástica <TLANG_Sp $>$. Dos davant $\langle$ TLANG_Cat> y dos detrás <TLANG_Sp $>$.

\section{[laughs]}

P1: Pero el resto no lo acabo yo de ver. ¿Vale? Lo más cerca posible. Lo digo porque así ahora si os toca moveros, podéis hacerlo, ¿vale? <TLANG_Sp>

[unintelligible]

P1: Vale, pues: si os parece vamos a empezar. Sí, realmente sí, ahora sí, ya, de verdad. Que esto es lo que queda de mí. Y he recuperado un poco de voz. ¿Dónde está X? ¿A que sí? Vale. Eh: chicos, pediros que tengáis un poquito más de silencio porque vamos a tener que estar trabajando hoy de manera más activa. Vale, entonces mirad. Recordáis al principio, cuando introduje la asignatura os expliqué que uno de los objetivos también era, que además si miráis la guía docente, etc. Hay una carga de inglés que la habéis visto a nivel de lectura, ¿no? También en muchos de los vídeos que hemos puesto. Pues bueno, hoy va a ser una clase un poco diferente, ¿vale? Porque vamos a intentar poner a prueba a ver cómo funcionaría, es decir, si...imaginemos, vamos a soñar que estamos en el 2021, ¿vale? O 22 o 25 y realmente ya todo el mundo se siente cómodo y flexible, eh, con - con hablar en - en esta otra lengua. Que os guste o no os guste, pues sigue siendo todavía, ¿no? la lengua científica. Vale, entonces, antes de empezar, espero que os guste la clase. La verdad es que es una práctica muy relajada. Va a consistir todo el tiempo en ver aud... - material audiovisual. Vamos a ver una serie de vídeos, luego os explicaremos más cosas. Por tanto, como de lo que depende la clase y la dinámica para 
que funcione del material que vamos a proyectar, lo primero que cabe esperar es que miréis los materiales que ponemos, ¿de acuerdo? Vale, dicho esto, os voy a presentar a R. Bueno, ahora os contará ella. Ella es una estudiante de doctorado, ¿vale? Y ha venido para, bueno, para explicarnos un poco por qué vamos a hacer esta práctica en esta ocasión y en qué la enmarcamos $\left\langle T L A N G \_S p>\right.$. So you're gonna be talking today in English or first of all in Spanish <TLANG_Eng>.

R: I don't know if all of them are going to understand the purpose of my study, so I think I'll explain that in Spanish and then we can turn into English $<$ TLANG_Eng $>$.

P1: So, as you can see, we're gonna be mixing languages $<$ TLANG_Eng $>$.

R: Hola a todos. Yo soy R, estudiante de doctorado del programa de lenguas aplicadas, literatura y traducción y hoy estoy aquí para contaros un poquito sobre qué va mi tesis y para pediros vuestra colaboración. La tesis se basa en analizar las asignaturas que siguen la metodología AICLE, es decir, aquellas asignaturas de contenido que se imparten en una lengua extranjera, en nuestro caso, el inglés. Bien, el análisis se centra en dos ramas de conocimiento diferentes, ciencias de la salud y ciencias humanas. Para ello participan seis grados, Medicina, Enfermería, Psicología, Historia, Humanidades y Turismo. Consiste básicamente en analizar cómo se desarrolla la docencia en inglés teniendo en cuenta las lenguas de interacción en el aula y los materiales utilizados. En este caso, estoy aquí para informaros de que necesitaría contar con vuestro permiso para grabar la sesión en audio, con una grabadora como esta. Así que no os preocupéis, porque sé que en si fuera en vídeo seguramente tendríais más inconvenientes. Y bueno, una vez termine la sesión, necesitaría que contestaseis dos cuestionarios. Le envié los links a P1 y creo que os los ha compartido en el aula virtual, si no me equivoco. Un cuestionario contiene ítems sobre vuestra experiencia con asignaturas CLIL, que como os he dicho son asignaturas de contenido impartidas en inglés, ya sea esta experiencia u otras que hayáis tenido a lo largo de la carrera o en el instituto. Y ya lo último sería un placement test, que es un test de nivel. Pero no quiero que penséis que voy a evaluar el nivel que tenéis y decir "Qué poco saben los de psicología". No, ese no es el propósito. Más bien es que en base a los resultados que saquéis compararlo luego con vuestra interacción o participación en el aula, con cómo utilizáis el inglés en clase. Y no os preocupéis porque también he ido a otras clases de Enfemería, Medicina y Turismo en la que hacían 
presentaciones. Y bueno, os agradecería mucho si participaseis y contestaseis los cuestionarios. Y eso es todo $\langle$ TLANG_Sp $>$.

P1: Bueno, y aparte esto forma parte de un seminario. Como muy bien ella nos ha introducido, es decir, una experiencia docente de innovación docente, ¿vale? Es un seminario permanente $\mathrm{y}$ hemos sido elegidos. O sea, que nos podemos sentir afortunadas y afortunados, ¿eh? Es decir, la coordinadora nos ha elegido, igual que ha elegido otras asignaturas de Enfermería, como muy bien ella nos ha dicho, y de, de Medicina, ¿de acuerdo? ¿vale? Dicho esto, porque mm cambiaré al inglés, es decir, yo puedo ir cambiando como normalmente hago entre castellano y valenciano, que ya a eso os tengo acostumbradas, ¿vale? Simplemente lo que quiero que sepáis es que, aunque ella graba, porque ella graba, necesita luego codificar. Nadie se sienta observado ni observada. Es una grabación de audio y...<TLANG_Sp>.

\section{R: Con esta maquinita <TLANG_Sp>.}

P1: Para que no os sintáis como “ay - ay - ay”, ¿vale? Que no importa cómo lo diga, ¿vale? Lo que importa es lo que quiero decir, ¿de acuerdo? No sé si con esto me estoy explicando. ¿Sí? ¿Sí? Sí <TLANG_Sp>. So thank you, R. So, amm, first of all, we’re gonna see a short video and the idea of the class of today is that we're just gonna start from the very - very close, I mean, starting with a group of people, of researchers from UJI, from the university and that you will see will be moving progressively far and far and far away. We will start with UJI, then we move to other researchers, close to our environment, even at, even in Castellón and so on, and then we will go further - further -further until we arrive to some international researchers, OK? And you see my pronunciation is not the best, I don't care because I try to speak in English so feel comfortable about that, right? It's the first thing I told her. She speaks really well as you will see but it doesn't matter. You have to feel comfortable, OK? So, first of all...before starting seeing the first video, which is gonna be in Spanish to warm-up a little bit. Ah it's going to be the present and future of neurotechnology and my first question. This is the title of the, of the class. What do you think is neurotechnology? And what do you expect in this class according to the title? I mean if we are talking about neurotechnology, what do you think? And you can answer in the language you feel more comfortable. You can try English or you can go ahead in Spanish. This is just like a quick brainstorming <TLANG_Eng>. No vale irse, ¿eh? <TLANG_Sp>. 
SX1: No, es que estaba picándome la pierna $\langle$ TLANG_Sp>.

P1: No, es broma. Y digo "Ui, ja la primera me fuig". Això...<TLANG_Cat>So, what do you think is neurotechonology? Any volunteer? Anyone that wants to...? Yeah? Thank you S2 <TLANG_Eng>.

S2: Maybe it's a mix between technology and neuroscience $<$ TLANG_Eng $>$.

P1: A mix...? $<$ TLANG_Eng $>$

S2: Yeah <TLANG_Eng>.

P1: A little bit loud? <TLANG_Eng>

S2: Maybe it's a mix between technology and neuroscience <TLANG_Eng>.

P1: OK. A mix between neurology and neuroscience. That would be a good definition. Anyone else wants to add anything else? <TLANG_Eng>.

S3: A lo mejor es una vía para hacer nuevas técnicas de imagen, o sea, juntar a personas que tienen otra especialidad, juntar informáticos con psicólogos para que hagan nuevas técnicas <TLANG_Sp>.

T: Hmm <TLANG_Eng>.

S3: O por ejemplo, analizar las emociones, cosas así <TLANG_Sp>.

P1: Hmm. So what about if we go and see the video and then we come back again to see what's exactly neurotechnology, OK? Thank you [to both students] <TLANG_Eng $>$.

[video played in Spanish]

P1: Bueno <TLANG_Sp>, so what would you highlight? <TLANG_Eng> ¿Qué destacaríais del vídeo? <TLANG_Sp> What thing you most it was more surprising for you or brought your attention? <TLANG_Eng> ¿Qué os ha llamado más la atención? <TLANG_Sp> What do you think? <TLANG_Eng>.

S4: A mí por ejemplo, eh: más de - de... - desde mi punto de vista, también del pasado que el vídeo era presente y futuro, pero pasado porque lo de los implantes cocleares, por ejemplo, hace poco, bueno, hace unos cuantos años era inviable y ahora se están viendo incluso en vídeos, ves como niños que ven a sus padres y los escuchan por primera vez. 
Y yo digo en un futuro, eso sí, acabas llorando, en un futuro eso será tan normal, o sea puede llegar a ser tan normal que...eso me parece muy - muy importante. Que también ha habido mucho cambio entre el pasado y el presente <TLANG_Sp $>$.

P1: Molt bé, S4. ¿Sí? <TLANG_Cat>.

S5: Yo lo sabía pero me ha impresionado al pensar el cómo, porque - porque ha dicho S4 que, que es verdad que hay niños que por las prótesis que tienen pueden mover perfectamente las piernas desde, o sea, como nosotros. Eso es algo que, cómo hemos llegado ahí y todo lo que viene <TLANG_Sp>.

S6: I think it's scary, a little bit scary the line between being human and being a robot, you know, like, are we turning into robots just because we want to live longer and heathier lives and I understand that science helps, but I also think there are some ethical consequences to think about, you know? Before, ah not before, but as science develops, you know. What are we doing? <TLANG_Eng>

P1: There's a thin line...<TLANG_Eng $>$.

S6: Yeah, there's a very thin line <TLANG_Eng>.

P1: Between the good and the bad consequences of all of this techonology, right? <TLANG_Eng>

S6: Yeah. Let's be critical <TLANG_Eng>.

P1: OK. So keeping in mind the arguments you have been writing because, thank you, the three of - of your interventions have been really - really good and of help because basically all the videos that we are gonna continue seeing, they're gonna be more deep <TLANG_Eng>, es decir, vamos a profundizar <TLANG_Sp>. So basically, what we're gonna be doing is just trying to go further and further. OK? So we are gonna be touching a subject in three things, in all, in all the videos. So how we are gonna work? This was exactly like the test opening, a warming up as I said. Amm basically this question is gonna be, it has to be in your text, in every of the videos, in each one of the videos I mean, OK? But amm what do you have to pay attention and take notes, of course, because after the videos we give you some time so that you can take some work together and then we'll discuss all the answers at the very end. Why? Because all of the videos are gonna be connected, as you will see, OK? So then, basically, what you have 
to... - you - you - you will need to pay attention, especially to all the eh inventions, OK? Like the extension for the people that don't have a hand or a leg, whatever. So you have to em: think which is the one that impact more, you, the one that it was bringing more your attention, or the one you think it's the best. And also you will have to think about the advantages and disadvantages, OK? And also you have to think in the clinical impact of the application of this, hmm? Because it might be something really cool and really fancy, but which is the use or which thing is gonna be usefully, we're gonna say that in these activities <TLANG_Eng>. Cuando veáis los videos, vais anotando, ¿vale? Aquellas cosas que os han llamado más la atención, ¿de acuerdo? Vais pensando cuál es el invento que más os impacta, ¿de acuerdo? ¿vale? Y además tenéis que pensar en ventajas y desventajas, ¿de acuerdo? Y emm em las aplicaciones clínicas. Pero todo esto no lo iremos contestando en cada uno de los vídeos, ¿eh? lo discutiremos, lo debatiremos al final, pero a medida que vais viendo los vídeos, podéis ir eligiendo. ¿De acuerdo? Vais cogiendo información <TLANG_Sp>.

S5: Ehh se me ha olvidado, iba a decírtelo en inglés <TLANG_Sp>.

\section{[laughs]}

S5: The clinical explication [explanation] the writing should be about the present or future? <TLANG_Eng>.

P1: Present and future. You can read, OK? So you can just have like a more...help in the present and in the future. Something, for example, this video is from 2012 and this one is from 2013, that is the thing, it develops more and more, OK? So am <TLANG_Eng> Ya?? <TLANG_SP> And the other thing you have to pay attention, so you will need at least paper and write some things and notes. You don't have to write a lot, some notes, is like similarities and differences between or across videos, yeah? So this is a couple of questions, so we go more and more seen more videos so you have to write and integrate information, basically. OK? So you understand basically what you have to do? Yeah?

S7: El video te fique de quin any és? <TLANG_Cat>

P1: No <TLANG_Eng>. 
S7: És per saber...perquè com d'este n'hi ha coses que s'han f...o sea que ja s'han fet <TLANG_Cat>.

P1: El següent...En alguns no ho sé. El següent vídeo que anem a vore <TLANG_Cat>, which is the eyesynth, I don't know whether you know it's now five oops $<$ TLANG_Eng>.

[The video was played by mistake]: My name is Antonio Quesada and before present...

P1: OK, so <TLANG_Eng>.

[laughs]

P1: So we know him already, I wanted to introduce him, but you already know. Ah is This invention is being now 5 years, it's 5 since 5 years ago. Yeah:: <TLANG_Eng> The audio está bien? Yeah you can listen it? Shhh <TLANG_Eng>.

[Video 2 played in English for 10 seconds]

P1: Well, one thing more. You have the Spanish version, so later on you can also find exactly the same video in Spanish, OK? So you have to do the effort, eh? $\langle$ TLANG_Eng $>$.

[Video 2 played in English]

P1: So, what do you think about this video? Anything you would like to share with the others? <TLANG_Eng>

S8: I don't know how the representation of the objects eh can represent on your brain <TLANG_Eng>. Emnmm. Bueno, emm bueno, porque ehh lo vi. En El Hormiguero $\langle$ TLANG_Sp>.

P1: Yes <TLANG_Eng>.

S8: salió una vez <TLANG_Sp>.

P1: Yeah <TLANG_Eng>.

S8: Y...y nada, era como una vibración que te ponían aquí <TLANG_Sp>.

P1: It was a psychology student? <TLANG_Sp>. 
S8: Sí, y vibraba, pero creo que te tenían que enseñar a - al hacer sonar, que, bueno siendo una vibración más profunda, el objeto era más denso, que tenía una forma y ya $<$ TLANG_Sp>.

\section{P1: Yeah <TLANG_Eng>.}

S8: No sé si era por esto o algo más avanzado <TLANG_Sp>.

P1: Exactly, basically this mechanism. And that we also have this video, which is gonna be in class, you will see it. But not today at class. But as I was telling you, this is a really interesting programme where they, because imagine this is a...Well, this guy had the idea, which is very cool, but as you pointed, there is gonna be like a multi or transversal team, because he's not only an engineer, psychologist, neurologist, and so on and so on. So this is the proof that most of the things you are gonna, most of these devices, they are gonna need the ahh the joint work, the team, really, teamwork, OK? But why is important for us like psychologists? Why are we bringing this device, this creation here today at the class? More than the wage working? X [the teachers says the name of a student] This is a good point because we are talking about sex, I mean, we don't have eye blind, we cannot see, so this is like a substitution, right, so we are replacing we cannot see, so maybe we can use, probably, as you know, the people that is blind they have more plasticity so maybe they have like the other senses more developed, especially $<$ TLANG_Eng $>$ el oído $<$ TLANG_Sp $>$, the ... $<$ TLANG_Eng $>$.

\section{R: Hearing <TLANG_Eng>.}

P1: Hearing, thank you. Yeah. So, why are we bringing these devices today? $<$ TLANG_Eng $>$.

S9: Pues a mí se me ocurren dos cosas. Una eh observar si con este dispositivo el cerebro vuelve a cambiar y si muestra más plasticidad en ese aspecto y también cómo mejoran el estado de salud psicológica $\langle$ TLANG_Sp $>$.

P1: Yeah! Because we are psychologists, we want to be or we pretend that, OK? <TLANG_Eng>

[laughs] 
P1: We want to improve the quality of their lives, no? Thank you, $\mathrm{X}$. Thank you, $\mathrm{X}$. Good job!! OK? Sí? So don't forget this important point. If you want to be psychologists or neuroscientists, you don't think, you don't have to forget that. We are working trying to improve the quality of the people, OK? The life. OK? Thank you. So, next one [video]. So this is giving the brain a, it's gonna be very short. Pay attention, please. It's gonna be supershort. Am, OK. So just pay attention, this is giving the brain a new sense of touch. So it's a little bit related to what we have been doing before. OK? X would you like to add anything else, before? <TLANG_Eng>

P2: No <TLANG_Eng>.

[Video 3 played in English]

P1: Freedom, we already heard that word before. So, anything about this video? What do you think? It may also be in Spanish o Valenciano. S9. <TLANG_Eng>.

S7: Que no ho he entès realment: sí, que n'hi ha persones que les coses que a mosatros no mos costa res a ells lis costa, però no he entès el mecanismo del, de lo de com ho fan <TLANG_Cat>.

P1: But why they cannot do it? Because they don't have $<$ TLANG_Eng $>$.

S7: Tacte i mobilitat, però...no sé $<$ TLANG_Cat $>$.

S9: Pero, ¿es por un ac... - por un accidente o de nacimiento? $\mathrm{O}$ se puede hacer. Porque recuerdo que cosas así, es que no lo tengo muy claro, cosas así se podían hacer o se podían mejorar prótesis y tal, pero se le había perdido porque el cerebro tenía ahí ya como que esas zonas preparadas, lo que pasa que lo había perdido. Pero si nacía sin brazo por alguna malformación o algo, esas zonas como que no habían trabajado lo suficiente y no se podía hacer, pero ahora no sé cómo está la cosa <TLANG_Sp〉.

P1: Hmm, well it's something we can explore more, no? It's just like there is another field, area, maybe, I don't know. Discovering for you new areas that may be interesting. Anyone else here? <TLANG_Eng>

S10: Jo tinc una pregunta. Aixó pots d'alguna manera, quan li fiques una pròtesi a algú, connectar o algo pa que puga menejar-lo o...? Saps lo que vull dir? Que si va connectat 
al cervell d'alguna manera pa que se puga menejar la extremitat que has perdut o que no tens? <TLANG_Cat>

S11: Jo d'això vaig vore un documental anit $<$ TLANG_Cat $>$

P1: Yesterday? <TLANG_Eng>.

S11: I saw a documental [documentary] about neurosc, neurotechonology that explain, explain eh, how the <TLANG_Eng $>$ los nervios $\langle$ TLANG_Sp>

P1: Yeah, the nerves <TLANG_Eng>.

S11: ¿unir cómo era? <TLANG_Sp>

S12: connect <TLANG_Eng>.

S11: connect ehh the nerves and the prótesis and the person <TLANG_Eng>.

P1: sending <TLANG_Eng>.

S11: sending <TLANG_Eng>, podía coger cosas <TLANG_Sp>

[laughs]

P1: I think we are gonna somehow see it in the next videos. X? <TLANG_Eng>.

P2: Emm I don't know, it's like ah - like em read the mind. The next video is like ah move cars or... $<$ TLANG_Eng $>$.

P1: actions with your brain <TLANG_Eng>.

P2: with your brain <TLANG_Eng>.

P1: and might be at work as I said before [unintelligible]. We can read, yeah, it's not only about how is or how much useful is it now, because maybe it's about the devices, they are good as I said already. Because they are not really useful yet. But they might be in the future. The future here is not 30 years later. It might be just two, three, five. Because in five years there are like high development about all of this technology. I don't know if you're taking the point we are going to bring you. Are you understanding me? Yes? If I'm explaining something be translated in Spanish, let me know, OK? You are understanding, right? Yes? Anyone is not truly comfortable? <TLANG_Eng> 
S13: Jo no ho he entès massa bé. <TLANG_Cat>

P1: Té a vore que tots estos <TLANG_Cat> devices <TLANG_Eng>, estos invents $<$ TLANG_Cat>, a lo millor poden tindre ara a curt termini perquè s'estan encara desarrollant molts dels que voreu, hm? Entonces pareixen un poc <TLANG_Cat> fancy <TLANG_Eng>, molt bons...Però realment açò quina utilitat té? Però en breu o en uns anys alguna tindran. Jo lo que vull és que <TLANG_Cat> you dream, you have to be able to fill the gap <TLANG_Eng>, d'omplir l'espai <TLANG_Cat>, the gap between now and who knows? Because maybe things are not useful at all and they won't be never <TLANG_Eng>.

S13: Ho dic perquè lo de la prótesis n'hi ha un moment que sí que li fan en les dos cames i li estan fent una prótesis ara <TLANG_Cat> en este momento <TLANG_Sp>. Entonces <TLANG_Sp> no sé si será lo mateix o és algo que ja n'hi havia $<$ TLANG_Cat>.

P1: Well, the idea is just emm. There is some sort of explanation, but one that teach your brain either if you have been already, I mean it's not the same if you are losing the arm or are losing the sight or you are losing any sense. So it's not the same because some day before the past you were able to see, listen, touch, OK? It's not the same if you are...But you will see, like with the cochlear implants the people that is, for example, deaf since they are...since the beginning, since birth, OK? But they are able to. So it means that our brain has a lot to do, like the boss, but we can teach the brain even when it was not set up at the beginning. Yeah? <TLANG_Eng>

\section{S13: Més o menos <TLANG_Cat>}

P1: Més o menos. Val, és a dir, tu pots no tindre eixos sentits quan vas nàixer, OK? Però al teu cervell se li pot ensenyar <TLANG_Cat> per el tema de

P2: Because the brain eh have eh has plasticity <TLANG_Eng>

P1: Exacte <TLANG_Cat> Like the position of learning. No matter whether it never works <TLANG_Eng> No importa que no estiguere mai o que, que algun dia vas perdre eixe sentit o una extremitat. D'acord? Sí? <TLANG_Cat>. OK? So and you have to start thinking which is the, the device or the invents you like more, OK? We are...the one or the several. So this is <TLANG_Eng>. 
[Video 4 is played in English]

P1: Bueno <TLANG_Sp> So that one was emotive neuroscience <TLANG_Eng>.

S6: I have a question <TLANG_Eng>.

P1: Yeah <TLANG_Eng>.

S6: Is it possible that they can move the car because it is an electrical object? Like: could they move an apple, for example? Or is it just, is it just connect: right now maybe just useful for electrical objects? Like I can turn on my TV but I cannot move a glass of water, for example <TLANG_Eng>.

P1: Well, I don't know exactly. I don't have the answer, OK. I don't know the device sensor. Emm my guess would be, I mean: the answer would be no. I mean is like you are moving the things because you are creating, which doesn't matter that you creating electrical thing, right? Because if you remember if go and revise the scanner, it's gonna be basically this. So we are all and when we have sensors in our body we are producing amm electricity all the time. But: - and you know what I'm thinking that's not true is because...I don't know if we are gonna see it today the next video $<$ TLANG_Eng $>$. Ay, la tuya ya $<$ TLANG_Sp $>$. But for example, I don't know whether you know about these kinds of patients they had like either an accident or some other neurological disorder. They are locked in $\langle$ TLANG_Eng $\rangle$, están encerrados $\langle$ TLANG_Sp $\rangle$, and they cannot talk. And they cannot communicate at all. They are not able to send any message because they basically are like in coma, OK? But I know there are experiments, there is a researcher, a German guy that is Neil Vilvaumer, later I will repeat the name and he has done really spectacular experiments with them. So they... - he was able to teach the patients to communicate using the breath like using the electrical wayforce. I told when I am falling asleep I feel something in here. I don't know whether you had this feeling, at any point. So it's like, of course, we have electricity. And this is a good question, X. But I don't think it's just the way to move only electrical devices. Ah? For example, the experiments with these patients, if you are interested I can send you more information about them, so he was. I mean they are basically with the brain moving a, a dog. They teach them to say if that works, yes or no, which is of course not like a full communication, it's not like a full dialogue $<$ TLANG_Eng $>$. 
S14: ¿Pero eso realmente lo hace la máquina, no? ¿Lo que se usa más o menos es la interfaz de una máquina? <TLANG_Sp>.

P1: Exacto. ¿Vale? Pero eso no significa que sea todo eléctrico, as I would say. But in the case specifically of the recent motive am newer interface am I don't know, I have to read more about that. But you can look. So any other question? Because another thing is like am when we discuss all the videos together before you die eh, because you are falling <TLANG_Eng>.

\section{[laughs]}

P1: Es tarde. I would like, because you point somehow these questions. Think about the advantages and disadvantages or pitfalls of all these sort of things, OK? I think I might be since I said at the beginning really nice, cool, surprising, fancy, but they are not useful. But they might be. Or they might be really unuseful. Yeah? Espero que al final hablemos un poquito, OK? Estamos viendo todos los vídeos para intentar generar un poco el debate. Yeah, S15 <TLANG_Eng>.

S15: I would like to talk in English, OK? <TLANG_Eng>.

P1: Thank you! <TLANG_Eng>.

S15: Maybe it's not important but I - I just thought in either way when I saw the video and: because how can incredible can be in the future videogames like I can control my character with just my brain or...? No? Because now we have, I mean I don't have because I don't have money, how a little technology that is like a vision that they can live in the world that the character in the videogame and I can't imagine in the near future what I would come through <TLANG_Eng>.

P1: Yeah. We can't imagine. I mean when I was small, I wanna say younger, you don't have... - no one had cellphones, or no one had control remotes, we always need a key to open the car. And things like that. And always turning into the things because you are millennials and you grow up with all the technology. And this is really normal in your life. But the technology is not being here always. When you told your grandparents, probably they say ahh or probably the plastic magic card of course or probably not saying nothing. But is not, is not something that has been always in our life. But this is just for making the, the life moto of your talk or we are not talking only about this. We 
are talking about things that can improve our lives, especially the quality of our life when we have problems <TLANG_Eng>.

S7: Claro <TLANG_Sp>, però pa una persona que tinga un d'esto, un d'açò jo realment no li veig una utilitat, un impacte clínic. O sea, no sé com no siga...<TLANG_Cat>

P1: But he also meant...in this video, for example, they mentioned like improve the attention. You know about a disorder that has specifically a problem with attention, which is ADHD <TLANG_Eng>, el TDAH <TLANG_Sp>, yeah? So it's a problem with hyperactivity and attention. So maybe <TLANG_Eng>. Ahora sí. Esto sí que no sé decirlo en inglés <TLANG_Sp> Vaig a fer de <TLANG_Cat> abogado del diablo <TLANG_Sp>. I'm not defending any, any devices but...<TLANG_Eng>

S7: Però com milloraria la funció això? <TLANG_Cat>

P2: I think that when you try to maintain the attention <TLANG_Eng>.

P1: Instead of this, open the mind, OK? That's what I'm trying < TLANG_Eng >.

P2: I think that when you try to maintain the attention in one thing eh consequently you have em you improve your attention. For example, if this em in the <TLANG_Eng>si tú pones en el vídeo y tu tienes <TLANG_Sp>, you have to move for example em I don't know so far or $<$ TLANG_Eng $>$ eh ¿más cerca? $<$ TLANG_Sp $>$

\section{R: Closer <TLANG_Eng>}

P2: Closer, for example, and you have to return this type of exercise several times, next you have the, you maintain the concentration or attention. So this is a type of...I don't know...the basis of the meditation for example. Maintain the attention in your senses or in your body. <TLANG_Eng>

\section{P1: Controlar la respiración <TLANG_Sp>}

P2: with an external object, for example. I think that this is the relation. <TLANG_Eng> P1: So, thank you, $\mathrm{X}$. We are moving out to the last video, this is the last one and after that wel'll start, we'll swtich on the light, OK? and we'll start talking, OK? So this is a little bit longer, I suggrest you take some notes. You have the computer or at least piece 
paper. I'm gonna may it a little bit slower because of the... and we'll see just a part, not full. <TLANG_Eng>

\section{[Video 5 played in English]}

P1: Bueno, lo abro un poquito. <TLANG_Sp> OK? So we are a little bit more awake. You will have all the videos so you can of course see them again at home. Emm you can finish it. It's really interesting at the very end and we've had more than enough. Amm if you remember, at the beginning you had a task. So now it's the time to work a little bit. So basically you will have around 5 minutes so then you can discuss with eh your group ah about which is the device or the, the creation, the invent, you better like or the ones because it may be a few of them, OK? A little remember, you have to think about the clinical applications or the implications it might have either they have it now in the computer, advantages and disadvantages or pitfalls of this, OK? Anyone has already? Yeah? Are you understanding me? Yes? Similarities and differences between the videos, which we will discuss later and am one more activity. P2? <TLANG_Eng>

P2: at the end <TLANG_Eng>

P1: At the end? After that? OK? Yeah? So everyone was understanding what you have to do? <TLANG_Eng> Y podéis discutir, discutir, bueno, comentar, debater eh sobre el contenido del vídeo. Ahora cuando venga SX2, si os queréis poner más hacia aquí. O que se ponga ella aquí <TLANG_Sp>

S16: Que se ponga ella ahí y yo me abro así <TLANG_Sp>

[Ininitelligible]

P1: OK, shh. Amm so basically now is like the moment of create some sort of debate, OK like... $<$ TLANG_Eng $>$, debate $<$ TLANG_Sp $>$

\section{R: Discussion <TLANG_Eng >}

P1: Discussion, thank you. And then the idea is like at least one person in each group, $\mathrm{OK}$, at least one person in each group, amm shares with us the impressions or the main ideas they have been talking about. OK? Sí? No? <TLANG_Sp>. S16 you wanna do that? <TLANG_Eng>

S16: No. But in Spanish? <TLANG_Eng> 
P1: You can choose the language you want. You can mix also. <TLANG_Eng>

SX3: Spanglish <TLANG_Eng>.

P1: OK <TLANG_Eng>

S4: Bueno, el vídeo que nos había llamado más la atención era el cuarto, el de la diadema, vale eh que les ponían porque eh nos ha sorprendido como algo tan $<$ TLANG_Sp>

P1: Shh. And the other groups, please listen. OK? Thank you. <TLANG_Eng>

S4: Bueno, una que algo tan sencillo, ¿vale? que estemos usando los TACS eh bueno máquinas enormes y con algo pequeñito como una diadema puedas ver la actividad cerebral y las posibilidades <TLANG_Sp>

P1: And this is because it's wireless, the table, you know? <TLANG_Eng> Sin cable $<$ TLANG_Sp>

S4: Ah ya <TLANG_Sp>

P1: No lleva cables que transportan la luz <TLANG_Sp>. The table <TLANG_Eng> es ammm <TLANG_Sp>

R: Inalámbrica $<T L A N G \_S p>$

P1: Inalámbrico, <TLANG_Sp > thank you <TLANG_Eng>. No me salía <TLANG_Sp>

S4: Y la capacidad que permite, bueno las posibilidades que permite trabajar porque al final es una forma de entrar al cerebro. Porque es lo que decía, no piensas, no le dices al cochecito "Vamos - vamos - vamos" <TLANG_Sp> "go - go - go" <TLANG_Eng>, sino que tienes que imaginarte al coche en movimiento. Es como el mindfulness <TLANG_Eng> pero aplicado a esto. <TLANG_Sp>

P1: Hmm. Advantages, disadvantages. Clinical applications <TLANG_Eng>

S4: Es un poco lo que estaba diciendo anteriormente, ya está <TLANG_Sp>

P1: Hm 
S4: Eh qué cómo se va a desarrollar esto en un futuro, ¿vale? Es más, las personas que sí que tienen alguna alteración o algún defícit obviamente sí que les va a facilitar la vida un montón. Pero claro, a las personas ricas que a lo mejor sí que también quieren otras posibilidades o aplicar sus conocimientos, no sé hasta qué punto se podrá llegar ahí. $<$ TLANG_Sp>

P1: This is also similar to what we discussed in the PMS <TLANG_Eng>

S4: Hmm

P1: in a previous seminar. It's always like what is the ethical problem associated with the technical development. The other group should also be paying attention because the idea is that later on in the report you write down you have to incorporate the ideas. OK? Not only your own idea, but the ideas that have been arised by the other groups. Yeah? <TLANG_Eng> Que todo el mundo tiene que estar escuchando porque en vuestros informes tendréis que integrar las ideas del debate. ¿De acuerdo? <TLANG_Sp> This is gonna be a little talk. Thank you, S4. Anything else? Thank you very much. Anyone else? It's the next one. Please, when we'll be done, you will be released, so... $<$ TLANG_Eng>

S9: Un vídeo, o sea, el último vídeo una parte en concreta del futuro me ha gustado mucho la parte de los aparatos que serían, eh que han conseguido comunicar con sonido entre dos personas, cómo se puede llegar a, solo por el hecho de relacionarse qued animales se pueden escuchar y conectan al fin y al cabo. Y pensando en una ventaja del futuro para eso sería no tener que hacer eso. Es decir, solo con tener el aparatito puedes comunicarte con otra persona sin que nadie te escuchara $\langle$ TLANG_Sp $\rangle$.

P1: Or the teaching with the students, ah? It connect directly to you and communicate

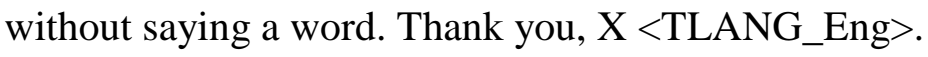

S16: Nosotras, eh, nos ha parecido interesante lo de la <TLANG_Sp>

P1: ¿Se, se oye bien? ¿Sí? <TLANG_Sp>.

S16: Las gafas que se utilizan para la gente que es ciega. Porque...hemos visto como más claramente reflejado una utilidad médica para mejorar la vida de los demás y la salud también psicológica. Y, y, este en concreto, este X no, pero con los otros sí que 
nos da un poco de miedo porque a mí personalmente me recuerda a la serie de Black Mirror $<$ TLANG_Sp $>$.

\section{$\mathrm{P} 1: \mathrm{Mmm}$}

S16: Entonces claro, que sería que toda esta tecnología puede traer cosas buenas pero siempre va a traer cosas malas y el uso que le podamos dar a esa tecnología la verdad es que me da un poquillo de miedo. <TLANG_Sp>.

P1: Have you ever seen the movie, this guy that is taking pills and is able to like develop good memory and learning a lot of languages? I think...but you know the end is a little bit terrifying because...X $\langle$ TLANG_Sp>.

S8: Que en este grupo estamos hablando de lo mismo. El, el vídeo, bueno el objeto que nos ha parecido más interesante era el de las gafas que no nos hemos enterado muy bien, tenemos que averiguar mejor cómo funciona porque es una rayada y también estábamos hablando de que, de que...Eso, que en parte lo, la, los objetos estos que nos han parecido más interesantes eran porque si de alguna manera hay algunas personas que tienen unas limitaciones $\mathrm{x}$ eh por ser ciegas o sordas o tal y creamos objetos para que estén más en la línea de la, de lo normal eh si creamos objetos que también les vienen bien a ellos y también nos vienen bien a nosotros vamos a crear así grosso modo eh un desnivel. También por el hecho de, de la gente rica que también podría cogerlo y al final hasta qué punto va a llegar a las personas que lo van a necesitar si no tienen dinero a todas esas cosas. $\langle$ TLANG_Sp>

P1: Hmm

S8: Eso <TLANG_Sp>

P1: Good point. Next one? You have to talk. Every, every group. <TLANG_Eng>

S17: Pues nosotros pensamos pues igual que ellas. El vídeo que más interesante nos ha parecido desde el punto de vista, claro, clínico son las gafas por eso. Tienen, por una parte, mejoras el componente médico de decir no pueden ver, y por otro la autoestima que ellos van a sentir. Capacidad de poder controlar ellos su vida, pues ahí ganan mucho nivel psicológico. Y entonces eso, nos parecen las ventajas sobre todo a ese nivel. Y como desventajas eh de momento parecía como que lo que podían ver era muy reducido pero que también creemos que eso a medida que vayan desarrollando pues va a ir 
mejroando. Y claro, pues hay que ir con cuidado porque realmente esas gafas, lo que decía Rebeca. ¿Van a llegar realmente a la gente que lo necesita? ¿O se van a usar para otros fines que no son nada...? <TLANG_Sp>

S8: La tecnología en general <TLANG_Sp>

P1: So it's a device that was developed originally in Onda? There was the factory. So it's really, really close to us mm? Thank you. Next one? <TLANG_Eng>

S17: Como ventajas lo mismo de las gafas. 〈TLANG_Sp>

SX4: ¿Cómo? <TLANG_Sp>

S17: Lo mismo de las gafas también nos parece una buena idea pero y que luego tenemos una desvetnaja en cuanto a lo del de mot...esto como se diga <TLANG_Sp>

P1: The motor senses? <TLANG_Eng>

S17: Eh vamos a ver. La realidad, las gafas de realidad virtual por un lado. Y luego está el casco. Si en el futuro eso se va a juntar. Porque qué van a hacer un casco de realidad virtual en el que las personas se van a meter en otro mundo, yo creo que lo que va a hacer es que si ya de por sí con móviles, ordenadores y tal estamos desconectados del entorno, con eso va aumentar muhco más el aislamiento social en el mundo y creo que va a ser la peor desventaja, o sea, el peor invento del mundo. 〈TLANG_Sp>

S8: Deshumanización. Hay una película que se llama Ready [pronounced as radi] one player [making reference to the film called Ready Player One], que sí que es tal cual lo que acabas de decir. O ready player, no sé el orden, ¿vale? Pero es tal cual, hay una guerra virtual, nadie vive en el mundo real y todo el mundo vive en... $<$ TLANG_Sp>

P1: Wall-E is the same It's science fiction but maybe in the future. <TLANG_Eng>

S18: Bueno, mosatros ens ha cridat l'atenció el vídeo de la diadema. I una cosa que veia en el vídeo es que se podia vore l'activitat del cervell a l'ordinador i...clar, jo això com ventaja que jo li veig és que podires estudiar els processos i l'activitat del cervell digam més en la vida diaria que no només en el laboratori. Que en el laboratori hi ha molts sesgos, però també han comentat lo del tema de neuromarketing i tal. Tot això se podría utilizar per a digam d'alguna forma poder controlar el nostre cervell. No sé si m'explique. Lo del neuromarketing per ejemple, que si portes això i te fan el típic 
experiment que tu estàs en la tenda $\mathrm{i}$ te fiquen tres tipos de llum,tres tipos de música $\mathrm{i}$ tal. Entonces <TLANG_Sp> aleshores això també ho poden gastar com a en contra nostra. <TLANG_Cat>

P1: Yeah. In order to sell the product <TLANG_Eng>

S18: A banda de tots els avantatges que han dit els demés <TLANG_Cat>

P1: Validez ecológica o something about that. Thank you. <TLANG_Eng>

S19: El vídeo que más nos ha llamado la atención es el Leitmotiv, la diadema $\langle$ TLANG_Sp>

P1: Wow <TLANG_Eng>

S19: porque es el más novedoso <TLANG_Sp>

P1: It's like fifty fifty [50/50] <TLANG_Eng>

S19: porque nosotros ya habíamos hablad...habíamos oído hablar de ellos pero nos parece el más novedoso y tal y porque creemos que tiene muchas aplicaciones, no solo en el neuromarketing, sino en muchos ámbitos. Las desventajas que hemos puesto, un poco lo mismo. Que el tema de la desigualdad, del dinero y todo eso y...y ya está. $<$ TLANG_Sp>

P1: Vale. There is a lot of congruence between...<TLANG_Eng>

S19: Ah y que como las tecnologías han avanzado muy rápido, la sociedad todavía no está preparada para ello. Se necesitan hacer leyes y regular más el tema legal para evitar esos problemas. <TLANG_Sp>

P1: That would be necessary. Thank you. The last two groups? Are you ready? No? X? $\mathrm{X}$ ? X? <TLANG_Eng>

S20: I need to see eh another time last video but the communication devices are so interesting and so dangerous too because eh there is a limit between brain to brain, OK? And how the eh legacy can prove that you are not replied another person, you know? <TLANG_Eng> 
P1: Yeah, but in terms replacing to the other? Or the danger when you are trying to link two people like happened in the last video? <TLANG_Eng>

\section{S20: Hmm <TLANG_Eng>}

P1: There is a lot of risky things, a lot of inconsistency that you may really <TLANG_Eng>

S20: and in other devices I think <TLANG_Eng>

P1: Yeah. But in terms of application, the clinical applications of...<TLANG_Eng >

S20: in brain to brain? Emm <TLANG_Eng>

P1: Yeah <TLANG_Eng>

S20: Maybe supplying positive thoughts <TLANG_Eng>

P1: For example. People that is really depressed, for example. Because we are not turning into a machine <TLANG_Eng>

S20: Maybe it can help anxiety <TLANG_Eng>

S8: Meditación <TLANG_Eng>

P1: Some other ideas? People that think have luck with the internet? Thank you. So there is just one missing group I think. You haven't talked yet and then, X [saying a student's name tallowing her to share her ideas]. <TLANG_Eng>

S6: No, I wanted to add something that I also found very surprising in the last video because he did say that communication skills have to be better, you know? That technology has improved communication skills but I think that affirmation is a bit too wide. And a bit too hold because we, there are psychological problems in society that derive from the use of technology that we don't know how to handle and how to solve. So keep calm, you know? And go to the mountain and fresh breathh air and talk to the people around you instead of staring at your screen all day. In that sense I think technology is interesting but communication and technology is going to change a lot and I think new types of communication are going to develop that we cannot imagine yet. So, you know, be open to be surprised but also scary. <TLANG_Eng> 
P1: Somehow you collected all the opinions, this group has talked about social isolation, so we'll touch this, this topic. I don't wanna go further. They have to discuss this topic, which is gonna be interesting. Well, this is the end of the seminar. So now please access the links shared on your virtual platform to fill int eh questionnaires $\mathrm{R}$ needs for her study. Once you finish you can home. Thank you. <TLANG_Eng>. 
APPENDIX IV (a): Observation rubric

\section{APPENDIX IV (a): Observation rubric}

CODE:

DATE:

GENRE: $\square$ Lecture $\square$ Seminar

OBSERVER: Lucía Bellés Calvera

RECORDING: $\square$ audio $\square$ video

\section{SPEECH ACT}

Subject: $\square$ basic training $\square$ compulsory $\square$ elective $\square$ course

Field: $\square$ Humanities $\square$ Social Sciences $\square$ Hard Sciences

Language: $\square$ Spanish $\square$ Valencian $\square$ English

Time: 9h Duration: 60 minutes

\section{DATA OF THE INSTRUCTOR}

Academic status: $\square$ Junior Lecturer $\square$ Senior Lecturer $\square$ Others

Nationality: Spanish

Mother tongue: $\square$ Spanish $\square$ Valencian

Gender: $\square \mathrm{M} \square \mathrm{F}$

\section{DATA OF THE ACADEMIC SPACE USED}

PLACE: Humanities Building

Type of classroom:

$\square$ ordinary classroom $\square$ aula magna $\square$ seminar $\square$ laboratory $\square$ others

Other relevant information: The furniture arrangement is not flexible. Tables and chairs are fixed. 


\section{DATA OF THE STUDENTS}

Participants:

Number of students: 40 Males: 27 Females: 13

\section{RESOURCES}

$\square$ ppt presentation

$\square$ DVD

$\square$ audio CD

blackboard

$\square$ YouTube $\square$ projector

$\square$ computer

$\square$ mobile phones

$\square$ others:

\section{DATA OF THE DISCUSSION}

Language of instruction: $\square$ Spanish $\square$ Valencian $\square$ English

Language of interaction (teacher): $\square$ Spanish $\square$ Valencian $\square$ English

Language of interaction (students): $\square$ Spanish $\square$ Valencian $\square$ English

\section{DATA OF THE RECORDING}

Time: 60 minutes

Transcription (number of words): 3,604

Item: Olympus digital voice recorder

\begin{tabular}{|l|l|l|l|l|}
\hline \multicolumn{1}{|c|}{ CRITERIA } & Weak & Adequate & Strong & Comments \\
\hline Students are engaged. & & & & \\
\hline Students do all the activities. & & & & \\
\hline $\begin{array}{l}\text { Students appear confident to } \\
\text { communicate in the language of } \\
\text { instruction. }\end{array}$ & & & & \\
\hline $\begin{array}{l}\text { Students interact with questions } \\
\text { and answers. }\end{array}$ & & & & \\
\hline Classroom dynamics are positive & & & & \\
\hline $\begin{array}{l}\text { Use of technology is appropriate. } \\
\text { Which? }\end{array}$ & & & & \\
\hline
\end{tabular}


APPENDIX IV (b): History of the Classical World

\section{APPENDIX IV (b): History of the Classical World}

CODE: HU1511 / HP1511

DATE:

GENRE: $\square$ Lecture $\square$ Seminar

OBSERVER: Lucía Bellés Calvera

RECORDING: $\square$ audio $\square$ video

\section{SPEECH ACT}

Subject: $\square$ basic training $\square$ compulsory $\square$ elective $\square$ course

Field: $\square$ Humanities $\square$ Social Sciences $\square$ Hard Sciences

Language: $\square$ Spanish $\square$ Valencian $\square$ English

Time: 9h Duration: 60 minutes

\section{DATA OF THE INSTRUCTOR}

Academic status: $\square$ Junior Lecturer $\square$ Senior Lecturer $\square$ Others

Nationality: Spanish

Mother tongue: $\square$ Spanish $\square$ Valencian

Gender: $\square \mathrm{M} \square \mathrm{F}$

\section{DATA OF THE ACADEMIC SPACE USED}

PLACE: Humanities Building

Type of classroom:

$\square$ ordinary classroom $\square$ aula magna $\square$ seminar $\square$ laboratory $\square$ others

Other relevant information: The furniture arrangement is not flexible. Tables and chairs are fixed.

\section{DATA OF THE STUDENTS}

Participants: 
Number of students: 40 Males: 27 Females: 13

\section{RESOURCES}

$\square$ ppt presentation

DVD

$\square$ audio CD

blackboard

YouTube

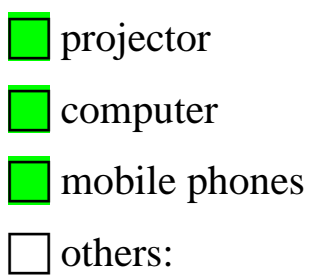

$\square$ others:

\section{DATA OF THE DISCUSSION}

Language of instruction: $\square$ Spanish $\square$ Valencian $\square$ English

Language of interaction (teacher): $\square$ Spanish $\square$ Valencian $\square$ English

Language of interaction (students): $\square$ Spanish $\square$ Valencian $\square$ English

\section{DATA OF THE RECORDING}

Time: 60 minutes $\quad$ Transcription (number of words): 3,604

Item: Olympus digital voice recorder

\begin{tabular}{|l|c|c|c|l|}
\hline \multicolumn{1}{|c|}{ CRITERIA } & Weak & Adequate & Strong & \multicolumn{1}{c|}{ Comments } \\
\hline Students are engaged. & & & $\mathrm{X}$ & $\begin{array}{l}\text { Students show } \\
\text { their engagement } \\
\text { while answering } \\
\text { the Kahoot survey. }\end{array}$ \\
\hline $\begin{array}{l}\text { Students do all the activities. } \\
\text { Students appear confident to } \\
\text { communicate in the language of } \\
\text { instruction. }\end{array}$ & & $\mathrm{X}$ & & $\begin{array}{l}\text { Students do all the } \\
\text { activities in the } \\
\text { classroom setting. }\end{array}$ \\
\hline
\end{tabular}




\begin{tabular}{|c|c|c|c|}
\hline & & & $\begin{array}{l}\text { but they do the } \\
\text { activities and read } \\
\text { their answers in } \\
\text { English. }\end{array}$ \\
\hline $\begin{array}{l}\text { Students interact with questions } \\
\text { and answers. }\end{array}$ & $\mathrm{X}$ & & $\begin{array}{l}\text { Most questions are } \\
\text { posed in Spanish } \\
\text { and Catalan, but a } \\
\text { few questions were } \\
\text { also spotted in } \\
\text { English. }\end{array}$ \\
\hline Classroom dynamics are positive & $\mathrm{X}$ & & \\
\hline $\begin{array}{l}\text { Use of technology is appropriate. } \\
\text { Which? }\end{array}$ & & $\mathrm{X}$ & $\begin{array}{l}\text { PowerPoint } \\
\text { presentations are } \\
\text { employed as visual } \\
\text { support. Other } \\
\text { resources, such as } \\
\text { episodes of the } \\
\text { HBO series Rome } \\
\text { and Kahoot } \\
\text { questionaires, are } \\
\text { employed to boost } \\
\text { students' } \\
\text { motivation. }\end{array}$ \\
\hline
\end{tabular}


APPENDIX IV (c): History of the Classical World (Oral presentations)

\section{APPENDIX IV (c): History of the Classical World (Oral presentations)}

CODE: HU1511 / HP1511

DATE:

GENRE: $\square$ Lecture $\square$ Seminar

OBSERVER: Lucía Bellés Calvera

RECORDING: $\square$ audio $\square$ video

\section{SPEECH ACT}

Subject: $\square$ basic training $\square$ compulsory $\square$ elective $\square$ course

Field: $\square$ Humanities $\square$ Social Sciences $\square$ Hard Sciences

Language: $\square$ Spanish $\square$ Valencian $\square$ English

Time: 9h Duration: 110 minutes

\section{DATA OF THE INSTRUCTOR}

Academic status: $\square$ Junior Lecturer $\square$ Senior Lecturer $\square$ Others

Nationality: Spanish

Mother tongue: $\square$ Spanish $\square$ Valencian

Gender: $\square \mathrm{M} \square \mathrm{F}$

\section{DATA OF THE ACADEMIC SPACE USED}

PLACE: Humanities Building

Type of classroom:

$\square$ ordinary classroom $\square$ aula magna $\square$ seminar $\square$ laboratory $\square$ others

Other relevant information: The furniture arrangement is not flexible. Tables and chairs are fixed. 


\section{DATA OF THE STUDENTS}

Participants:

Number of students: 40 Males: 27 Females: 13

\section{RESOURCES}

$\square$ ppt presentation

$\square$ DVD

$\square$ audio CD

$\square$ blackboard

$\square$ YouTube $\square$ projector

$\square$ computer

$\square$ mobile phones

$\square$ others:

\section{DATA OF THE DISCUSSION}

Language of instruction: $\square$ Spanish $\square$ Valencian $\square$ English

Language of interaction (teacher): $\square$ Spanish $\square$ Valencian $\square$ English

Language of interaction (students): $\square$ Spanish $\square$ Valencian $\square$ English

\section{DATA OF THE RECORDING}

Time: 110 minutes

Transcription (number of words): 5,116

Item: Olympus digital voice recorder

\begin{tabular}{|l|c|c|c|l|}
\hline \multicolumn{1}{|c|}{ CRITERIA } & Weak & Adequate & Strong & \multicolumn{1}{c|}{ Comments } \\
\hline Students are engaged. & & & $\mathrm{X}$ & $\begin{array}{l}\text { Students showed } \\
\text { their engagement } \\
\text { with original } \\
\text { presentations about } \\
\text { social groups in } \\
\text { ancient Rome. }\end{array}$ \\
\hline Students do all the activities. & & $\mathrm{X}$ & & $\begin{array}{l}\text { All the participants } \\
\text { presented their } \\
\text { projects. }\end{array}$ \\
\hline Students appear confident to & & $\mathrm{X}$ & & Some students \\
\hline
\end{tabular}




\begin{tabular}{|l|l|l|l|l|}
\hline $\begin{array}{l}\text { communicate in the language of } \\
\text { instruction. }\end{array}$ & & & $\begin{array}{l}\text { were not confident } \\
\text { enough to present } \\
\text { their projects in } \\
\text { English and ended } \\
\text { up reading their } \\
\text { notes. }\end{array}$ \\
\hline $\begin{array}{l}\text { Students interact with questions } \\
\text { and answers. }\end{array}$ & & $\mathrm{X}$ & & $\begin{array}{l}\text { Students answer to } \\
\text { the questions } \\
\text { posed by the } \\
\text { teacher. }\end{array}$ \\
\hline $\begin{array}{l}\text { Classroom dynamics are positive } \\
\text { Which? }\end{array}$ & & & $\mathrm{X}$ & \\
\hline
\end{tabular}




\section{APPENDIX IV (d): Fundamentals and Theory of Artistic Heritage}

CODE: HU1511 / HP1511

DATE:

GENRE: $\square$ Lecture $\square$ Seminar

OBSERVER: Lucía Bellés Calvera

RECORDING: $\square$ audio $\square$ video

\section{SPEECH ACT}

Subject: $\square$ basic training $\square$ compulsory $\square$ elective $\square$ course

Field: $\square$ Humanities $\square$ Social Sciences $\square$ Hard Sciences

Language: $\square$ Spanish $\square$ Valencian $\square$ English

Time: $11 \mathrm{~h} \quad$ Duration: 113 minutes

\section{DATA OF THE INSTRUCTOR}

Academic status: $\square$ Junior Lecturer $\square$ Senior Lecturer $\square$ Others

Nationality: Spanish

Mother tongue: $\square$ Spanish $\square$ Valencian

Gender: $\square \mathrm{M} \square \mathrm{F}$

\section{DATA OF THE ACADEMIC SPACE USED}

PLACE: Humanities Building

Type of classroom:

$\square$ ordinary classroom $\square$ aula magna $\square$ seminar $\square$ laboratory $\square$ others

Other relevant information: The furniture arrangement is not flexible. Tables and chairs are fixed.

4. DATA OF THE STUDENTS

Participants: 
Number of students: 28 Males: 15 Females: 13

\section{RESOURCES}

$\square$ ppt presentation

$\square$ DVD

$\square$ audio CD

blackboard

YouTube $\square$ projector

computer

$\square$ mobile phones

$\square$ others:

\section{DATA OF THE DISCUSSION}

Language of instruction: $\square$ Spanish $\square$ Valencian $\square$ English

Language of interaction (teacher): $\square$ Spanish $\square$ Valencian $\square$ English

Language of interaction (students): $\square$ Spanish $\square$ Valencian $\square$ English

\section{DATA OF THE RECORDING}

Time: 113 minutes

Transcription (number of words): 1,311

Item: Olympus digital voice recorder

\begin{tabular}{|l|c|c|c|l|}
\hline \multicolumn{1}{|c|}{ CRITERIA } & Weak & Adequate & Strong & \multicolumn{1}{c|}{ Comments } \\
\hline Students are engaged. & $\mathrm{X}$ & & & \\
\hline Students do all the activities. & & $\mathrm{X}$ & & $\begin{array}{l}\text { After having } \\
\text { watched the } \\
\text { videos, students } \\
\text { answer the } \\
\text { questions as } \\
\text { required. }\end{array}$ \\
\hline $\begin{array}{l}\text { Students appear confident to } \\
\text { communicate in the language of } \\
\text { instruction. }\end{array}$ & $\mathrm{X}$ & & $\begin{array}{l}\text { Spanish and } \\
\text { Valencian are used } \\
\text { as the means of } \\
\text { communication in }\end{array}$ \\
\hline
\end{tabular}




\begin{tabular}{|c|c|c|}
\hline & & $\begin{array}{l}\text { the classroom } \\
\text { setting. They are } \\
\text { reluctant to } \\
\text { participate in } \\
\text { English. }\end{array}$ \\
\hline $\begin{array}{l}\text { Students interact with questions } \\
\text { and answers. }\end{array}$ & $\mathrm{X}$ & $\begin{array}{l}\text { Students interact in } \\
\text { Spanish and } \\
\text { Valencian. }\end{array}$ \\
\hline Classroom dynamics are positive & $\mathrm{X}$ & \\
\hline $\begin{array}{l}\text { Use of technology is appropriate. } \\
\text { Which? }\end{array}$ & $\mathrm{X}$ & $\begin{array}{l}\text { YouTube videos } \\
\text { related to the } \\
\text { contents covered in } \\
\text { previous sessions } \\
\text { are played in the } \\
\text { classroom to } \\
\text { generate some } \\
\text { discussion. }\end{array}$ \\
\hline
\end{tabular}




\section{APPENDIX IV (e): Valencian Art and Tourist Resources}

CODE: TU0935

DATE: $20 / 11 / 2018$

GENRE: $\square$ Lecture $\square$ Seminar

OBSERVER: Lucía Bellés Calvera

RECORDING: $\square$ audio $\square$ video

\section{SPEECH ACT}

Subject: $\square$ basic training $\square$ compulsory $\square$ elective $\square$ course

Field: $\square$ Humanities $\square$ Social Sciences $\square$ Hard Sciences

Language: $\square$ Spanish $\square$ Valencian $\square$ English

Time: 13:30h Duration: 87 minutes

\section{DATA OF THE INSTRUCTOR}

Academic status: $\square$ Junior Lecturer $\square$ Senior Lecturer $\square$ Others

Nationality: Spanish

Mother tongue: $\square$ Spanish $\square$ Valencian

Gender: $\square \mathrm{M} \square \mathrm{F}$

\section{DATA OF THE ACADEMIC SPACE USED}

PLACE: Social Sciences Building

Type of classroom:

$\square$ ordinary classroom $\square$ aula magna $\square$ seminar $\square$ laboratory $\square$ others

Other relevant information: The furniture arrangement is not flexible. Tables and chairs are fixed.

4. DATA OF THE STUDENTS

Participants: 
Number of students: 28 Males: 5 Females: 23

\section{RESOURCES}

$\square$ ppt presentation

DVD

$\square$ audio CD

blackboard

YouTube

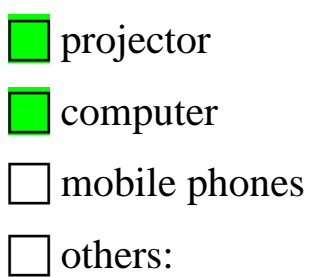

others:

\section{DATA OF THE DISCUSSION}

Language of instruction: $\square$ Spanish $\square$ Valencian $\square$ English

Language of interaction (teacher): $\square$ Spanish $\square$ Valencian $\square$ English

Language of interaction (students): $\square$ Spanish $\square$ Valencian $\square$ English

\section{DATA OF THE RECORDING}

Time: 87 minutes $\quad$ Transcription (number of words): 6,540

Item: Olympus digital voice recorder

\begin{tabular}{|l|c|c|c|l|}
\hline \multicolumn{1}{|c|}{ CRITERIA } & Weak & Adequate & Strong & \multicolumn{1}{c|}{ Comments } \\
\hline Students are engaged. & & $\mathrm{X}$ & & \\
\hline Students do all the activities. & & $\mathrm{X}$ & $\begin{array}{l}\text { There are no } \\
\text { activities as such } \\
\text { during the lecture. } \\
\text { tudents only need } \\
\text { to answer the } \\
\text { questions posed by } \\
\text { the lecturer. }\end{array}$ \\
\hline $\begin{array}{l}\text { Students appear confident to } \\
\text { communicate in the language of } \\
\text { instruction. }\end{array}$ & $\mathrm{X}$ & $\begin{array}{l}\text { Erasmus students } \\
\text { appear to be the } \\
\text { most confident }\end{array}$ \\
\hline
\end{tabular}




\begin{tabular}{|c|c|c|}
\hline & & $\begin{array}{l}\text { when interacting in } \\
\text { English, whereas } \\
\text { Spanish } \\
\text { undergraduates } \\
\text { prefer } \\
\text { communicating in } \\
\text { Spanish. Asian } \\
\text { students, however, } \\
\text { do not interact in } \\
\text { the classroom. }\end{array}$ \\
\hline $\begin{array}{l}\text { Students interact with questions } \\
\text { and answers. }\end{array}$ & $\mathrm{X}$ & $\begin{array}{l}\text { Erasmus students } \\
\text { interact with } \\
\text { questions and } \\
\text { answers in English }\end{array}$ \\
\hline Classroom dynamics are positive & $\mathrm{X}$ & \\
\hline $\begin{array}{l}\text { Use of technology is appropriate. } \\
\text { Which? }\end{array}$ & $\mathrm{X}$ & $\begin{array}{l}\text { Use of PowerPoint } \\
\text { presentations }\end{array}$ \\
\hline
\end{tabular}


APPENDIX IV (f): Valencian Art and Tourist Resources (Oral presentations)

\section{APPENDIX IV (f): Valencian Art and Tourist Resources (Oral presentations)}

CODE: TU0935

DATE: $04 / 12 / 2018$

GENRE: $\square$ Lecture $\square$ Seminar

OBSERVER: Lucía Bellés Calvera

RECORDING: $\square$ audio $\square$ video

\section{SPEECH ACT}

Subject: $\square$ basic training $\square$ compulsory $\square$ elective $\square$ course

Field: $\square$ Humanities $\square$ Social Sciences $\square$ Hard Sciences

Language: $\square$ Spanish $\square$ Valencian $\square$ English

Time: $13 \mathrm{~h}$ Duration: 90 minutes

\section{DATA OF THE INSTRUCTOR}

Academic status: $\square$ Junior Lecturer $\square$ Senior Lecturer $\square$ Others

Nationality: Spanish

Mother tongue: $\square$ Spanish $\square$ Valencian

Gender: $\square \mathrm{M} \square \mathrm{F}$

\section{DATA OF THE ACADEMIC SPACE USED}

PLACE: Social Sciences Building

Type of classroom:

$\square$ ordinary classroom $\square$ aula magna $\square$ seminar $\square$ laboratory $\square$ others

Other relevant information: The furniture arrangement is not flexible. Tables and chairs are fixed.

4. DATA OF THE STUDENTS

Participants: 
Number of students: 28 Males: 5 Females: 23

\section{RESOURCES}

$\square$ ppt presentation

DVD

$\square$ audio CD

blackboard

YouTube $\square$ projector

computer

$\square$ mobile phones

$\square$ others:

\section{DATA OF THE DISCUSSION}

Language of instruction: $\square$ Spanish $\square$ Valencian $\square$ English

Language of interaction (teacher): $\square$ Spanish $\square$ Valencian $\square$ English

Language of interaction (students): $\square$ Spanish $\square$ Valencian $\square$ English

\section{DATA OF THE RECORDING}

Time: $90 \mathrm{~min}$

Transcription (number of words): 5,806

Item: Olympus digital voice recorder

\begin{tabular}{|l|l|c|c|l|}
\hline \multicolumn{1}{|c|}{ CRITERIA } & Weak & Adequate & Strong & \multicolumn{1}{c|}{ Comments } \\
\hline Students are engaged. & & $\mathrm{X}$ & & \\
\hline Students do all the activities. & & & $\mathrm{X}$ & $\begin{array}{l}\text { All the students } \\
\text { present their } \\
\text { projects. }\end{array}$ \\
\hline $\begin{array}{l}\text { Students appear confident to } \\
\text { communicate in the language of } \\
\text { instruction. }\end{array}$ & & $\mathrm{X}$ & & $\begin{array}{l}\text { International } \\
\text { students present in } \\
\text { English. Erasmus } \\
\text { students do not } \\
\text { read their notes in } \\
\text { comparison with } \\
\text { Asian students }\end{array}$ \\
\hline
\end{tabular}




\begin{tabular}{|c|c|c|c|}
\hline & & & $\begin{array}{l}\text { who do read them. } \\
\text { On the other hand, } \\
\text { most Spanish } \\
\text { undergraduates } \\
\text { present in their } \\
\text { mother tongue. }\end{array}$ \\
\hline $\begin{array}{l}\text { Students interact with questions } \\
\text { and answers. }\end{array}$ & $\mathrm{X}$ & & $\begin{array}{l}\text { Students present } \\
\text { their projects, but } \\
\text { they do not ask } \\
\text { questions to other } \\
\text { groups. }\end{array}$ \\
\hline Classroom dynamics are positive & & $\mathrm{X}$ & \\
\hline $\begin{array}{l}\text { Use of technology is appropriate. } \\
\text { Which? }\end{array}$ & & $\mathrm{X}$ & $\begin{array}{l}\text { Students use } \\
\text { PowerPoint } \\
\text { presentations and } \\
\text { YouTube videos as } \\
\text { visual support. }\end{array}$ \\
\hline
\end{tabular}


APPENDIX IV (f): Valencian Art and Tourist Resources (Oral presentations) 
APPENDIX IV (g): English for Medicine

\section{APPENDIX IV (g): English for Medicine}

CODE: MD1706

DATE: $10 / 12 / 2018$

GENRE: $\square$ Lecture $\square$ Seminar

OBSERVER: Lucía Bellés Calvera

RECORDING: $\square$ audio $\square$ video

\section{SPEECH ACT}

Subject: $\square$ basic training $\square$ compulsory $\square$ elective $\square$ course

Field: $\square$ Humanities $\square$ Social Sciences $\square$ Hard Sciences

Language: $\square$ Spanish $\square$ Valencian $\square$ English

Time: $13 \mathrm{~h}$ Duration: $1 \mathrm{~h} 44$ minutes

\section{DATA OF THE INSTRUCTOR}

Academic status: $\square$ Junior Lecturer $\square$ Senior Lecturer $\square$ Others

Nationality: Spanish

Mother tongue: $\square$ Spanish $\square$ Valencian

Gender: $\square \mathrm{M} \square \mathrm{F}$

\section{DATA OF THE ACADEMIC SPACE USED}

PLACE: Health Sciences Building

Type of classroom:

$\square$ ordinary classroom $\square$ aula magna $\square$ seminar $\square$ laboratory $\square$ others

Other relevant information: The furniture arrangement is flexible. Tables and chairs are wheeled. 


\section{DATA OF THE STUDENTS}

Participants:

Number of students: 23 Males: 12 Females: 11

\section{RESOURCES}

$\square$ ppt presentation

$\square$ DVD

$\square$ audio CD

blackboard

$\square$ YouTube $\square$ projector

$\square$ computer

$\square$ mobile phones

$\square$ others:

\section{DATA OF THE DISCUSSION}

Language of instruction: $\square$ Spanish $\square$ Valencian $\square$ English

Language of interaction (teacher): $\square$ Spanish $\square$ Valencian $\square$ English

Language of interaction (students): $\square$ Spanish $\square$ Valencian $\square$ English

\section{DATA OF THE RECORDING}

Time: $104 \mathrm{~min}$

Transcription (number of words): 11,997

Item: Olympus digital voice recorder

\begin{tabular}{|l|l|l|l|l|}
\hline \multicolumn{1}{|c|}{ CRITERIA } & Weak & Adequate & Strong & Comments \\
\hline Students are engaged. & & & & \\
\hline Students do all the activities. & & & & \\
\hline $\begin{array}{l}\text { Students appear confident to } \\
\text { communicate in the language of } \\
\text { instruction. }\end{array}$ & & & & \\
\hline $\begin{array}{l}\text { Students interact with questions } \\
\text { and answers. }\end{array}$ & & & & \\
\hline Classroom dynamics are positive & & & & \\
\hline $\begin{array}{l}\text { Use of technology is appropriate. } \\
\text { Which? }\end{array}$ & & & & \\
\hline
\end{tabular}


APPENDIX IV (h): Anthropology and Evolution

\section{APPENDIX IV (h): Anthropology and Evolution}

CODE: MD1714

DATE: 01/04/2019

GENRE: $\square$ Lecture $\square$ Seminar

OBSERVER: Lucía Bellés Calvera

RECORDING: $\square$ audio $\square$ video

\section{SPEECH ACT}

Subject: $\square$ basic training $\square$ compulsory $\square$ elective $\square$ course

Field: $\square$ Humanities $\square$ Social Sciences $\square$ Hard Sciences

Language: $\square$ Spanish $\square$ Valencian $\square$ English

Time: 15:30h Duration: 80 minutes

\section{DATA OF THE INSTRUCTOR}

Academic status: $\square$ Junior Lecturer $\square$ Senior Lecturer $\square$ Others

Nationality: Spanish

Mother tongue: $\square$ Spanish $\square$ Valencian

Gender: $\square \mathrm{M} \square \mathrm{F}$

\section{DATA OF THE ACADEMIC SPACE USED}

PLACE: Health Sciences Building

Type of classroom:

$\square$ ordinary classroom $\square$ aula magna $\square$ seminar $\square$ laboratory $\square$ others

Other relevant information: The furniture arrangement is flexible. Tables and chairs are wheeled.

\section{DATA OF THE STUDENTS}

Participants: 
Number of students: 26 Males: 5 Females: 21

\section{RESOURCES}

$\square$ ppt presentation

$\square$ DVD

$\square$ audio CD

blackboard

YouTube $\square$ projector

$\square$ computer

$\square$ mobile phones

$\square$ others: Newspaper articles

\section{DATA OF THE DISCUSSION}

Language of instruction: $\square$ Spanish $\square$ Valencian $\square$ English

Language of interaction (teacher): $\square$ Spanish $\square$ Valencian $\square$ English

Language of interaction (students): $\square$ Spanish $\square$ Valencian $\square$ English

\section{DATA OF THE RECORDING}

Time: $80 \mathrm{~min}$

Transcription (number of words): 3,399

Item: Olympus digital voice recorder

\begin{tabular}{|l|l|c|c|l|}
\hline \multicolumn{1}{|c|}{ CRITERIA } & Weak & Adequate & Strong & \multicolumn{1}{c|}{ Comments } \\
\hline Students are engaged. & & & $\mathrm{X}$ & \\
\hline Students do all the activities. & & & $\mathrm{X}$ & $\begin{array}{l}\text { Students complete } \\
\text { the activities } \\
\text { required in the } \\
\text { classroom by } \\
\text { discussing the } \\
\text { articles in goups }\end{array}$ \\
\hline $\begin{array}{l}\text { Students appear confident to } \\
\text { communicate in the language of } \\
\text { instruction. }\end{array}$ & & $\mathrm{X}$ & $\begin{array}{l}\text { Students' discourse } \\
\text { occurs primarily in } \\
\text { Spanish rather than } \\
\text { in English }\end{array}$ \\
\hline
\end{tabular}




\begin{tabular}{|l|l|l|l|l|}
\hline $\begin{array}{l}\text { Students interact with questions } \\
\text { and answers. }\end{array}$ & & & $\mathrm{X}$ & $\begin{array}{l}\text { Most students } \\
\text { interact with } \\
\text { questions and } \\
\text { answers in } \\
\text { Spanish, even } \\
\text { though some } \\
\text { others try to } \\
\text { contribute in } \\
\text { English. }\end{array}$ \\
\hline Classroom dynamics are positive & & & $X$ & \\
\hline $\begin{array}{l}\text { Use of technology is appropriate. } \\
\text { Which? }\end{array}$ & $\mathrm{X}$ & & & $\begin{array}{l}\text { Digital tools have } \\
\text { not been used in } \\
\text { the classroom } \\
\text { practice. }\end{array}$ \\
\hline
\end{tabular}


APPENDIX IV (i): Epidemiology and Public Health

\section{APPENDIX IV (i): Epidemiology and Public Health}

CODE: MD1760

DATE: 02/04/2019

GENRE: $\square$ Lecture $\square$ Seminar

OBSERVER: Lucía Bellés Calvera

RECORDING: $\square$ audio $\square$ video

\section{SPEECH ACT}

Subject: $\square$ basic training $\square$ compulsory $\square$ elective $\square$ course

Field: $\square$ Humanities $\square$ Social Sciences $\square$ Hard Sciences

Language: $\square$ Spanish $\square$ Valencian $\square$ English

Time: 10h Duration: 119 minutes

\section{DATA OF THE INSTRUCTOR}

Academic status: $\square$ Junior Lecturer $\square$ Senior Lecturer $\square$ Others

Nationality: Spanish

Mother tongue: $\square$ Spanish $\square$ Valencian

Gender: $\square \mathrm{M} \square \mathrm{F}$

\section{DATA OF THE ACADEMIC SPACE USED}

PLACE: Faculty of Health Sciences Building

Type of classroom:

$\square$ ordinary classroom $\square$ aula magna $\square$ seminar $\square$ laboratory $\square$ others

Other relevant information: The furniture arrangement is flexible. Tables and chairs are wheeled.

\section{DATA OF THE STUDENTS}

Participants: 
Number of students: 22 Males: 11 Females: 11

\section{RESOURCES}

$\square$ ppt presentation

DVD

$\square$ audio CD

blackboard

YouTube $\square$ projector

computer

$\square$ mobile phones

$\square$ others:

\section{DATA OF THE DISCUSSION}

Language of instruction: $\square$ Spanish $\square$ Valencian $\square$ English

Language of interaction (teacher): $\square$ Spanish $\square$ Valencian $\square$ English

Language of interaction (students): $\square$ Spanish $\square$ Valencian $\square$ English

\section{DATA OF THE RECORDING}

Time: $119 \mathrm{~min} \quad$ Transcription (number of words): 12,390

Item: Olympus digital voice recorder

\begin{tabular}{|l|l|c|c|l|}
\hline \multicolumn{1}{|c|}{ CRITERIA } & Weak & Adequate & Strong & \multicolumn{1}{c|}{ Comments } \\
\hline Students are engaged. & & & $\mathrm{X}$ & \\
\hline Students do all the activities. & & & $\mathrm{X}$ & $\begin{array}{l}\text { All the groups } \\
\text { present their } \\
\text { projects and ask } \\
\text { questions to other } \\
\text { students }\end{array}$ \\
\hline $\begin{array}{l}\text { Students appear confident to } \\
\text { communicate in the language of } \\
\text { instruction. }\end{array}$ & & $\mathrm{X}$ & $\begin{array}{l}\text { They communicate } \\
\text { in English when } \\
\text { presenting, but } \\
\text { when interacting } \\
\text { with thir peers, }\end{array}$ \\
\hline
\end{tabular}


APPENDIX IV (i): Epidemiology and Public Health

\begin{tabular}{|c|c|c|c|}
\hline & & & $\begin{array}{l}\text { they speak in } \\
\text { Spanish. }\end{array}$ \\
\hline $\begin{array}{l}\text { Students interact with questions } \\
\text { and answers. }\end{array}$ & & $\mathrm{X}$ & $\begin{array}{l}\text { Students ask } \\
\text { questions to the } \\
\text { groups presenting } \\
\text { their projects }\end{array}$ \\
\hline Classroom dynamics are positive & & $\mathrm{X}$ & \\
\hline $\begin{array}{l}\text { Use of technology is appropriate. } \\
\text { Which? }\end{array}$ & $\mathrm{X}$ & & $\begin{array}{l}\text { PowerPoint } \\
\text { presentations are } \\
\text { employed as visual } \\
\text { support }\end{array}$ \\
\hline
\end{tabular}


APPENDIX IV (j): Women's care

\section{APPENDIX IV (j): Women's care}

CODE: IN1120

DATE: $30 / 10 / 2018$

GENRE: $\square$ Lecture $\square$ Seminar

OBSERVER: Lucía Bellés Calvera

RECORDING: $\square$ audio $\square$ video

\section{SPEECH ACT}

Subject: $\square$ basic training $\square$ compulsory $\square$ elective $\square$ course

Field: $\square$ Humanities $\square$ Social Sciences $\square$ Hard Sciences

Language: $\square$ Spanish $\square$ Valencian $\square$ English

Time: 9h Duration: 53 minutes

\section{DATA OF THE INSTRUCTOR}

Academic status: $\square$ Junior Lecturer $\square$ Senior Lecturer $\square$ Others

Nationality: Spanish

Mother tongue: $\square$ Spanish $\square$ Valencian

Gender: $\square \mathrm{M} \square \mathrm{F}$

\section{DATA OF THE ACADEMIC SPACE USED}

PLACE: Health Sciences Building

Type of classroom:

$\square$ ordinary classroom $\square$ aula magna $\square$ seminar $\square$ laboratory $\square$ others

Other relevant information: The furniture arrangement is flexible. Tables and chairs are wheeled.

\section{DATA OF THE STUDENTS}

Participants: 
Number of students: 27 Males: 7 Females: 20

\section{RESOURCES}

$\square$ ppt presentation

$\square$ DVD

$\square$ audio CD

blackboard

YouTube $\square$ projector

computer

$\square$ mobile phones

$\square$ others:

\section{DATA OF THE DISCUSSION}

Language of instruction: $\square$ Spanish $\square$ Valencian $\square$ English

Language of interaction (teacher): $\square$ Spanish $\square$ Valencian $\square$ English

Language of interaction (students): $\square$ Spanish $\square$ Valencian $\square$ English

\section{DATA OF THE RECORDING}

Time: $53 \mathrm{~min} \quad$ Transcription (number of words): 4,501

Item: Olympus digital voice recorder

\begin{tabular}{|l|c|c|c|l|}
\hline \multicolumn{1}{|c|}{ CRITERIA } & Weak & Adequate & Strong & \multicolumn{1}{c|}{ Comments } \\
\hline Students are engaged. & & $\mathrm{X}$ & & \\
\hline Students do all the activities. & & & $\mathrm{X}$ & $\begin{array}{l}\text { All the participants } \\
\text { read their } \\
\text { summaries and } \\
\text { present their } \\
\text { projects. }\end{array}$ \\
\hline $\begin{array}{l}\text { Students appear confident to } \\
\text { communicate in the language of } \\
\text { instruction. }\end{array}$ & & $\mathrm{X}$ & & $\begin{array}{l}\text { Students are likely } \\
\text { to read their notes, } \\
\text { especially when } \\
\text { retelling the } \\
\text { information they }\end{array}$ \\
\hline
\end{tabular}




\begin{tabular}{|c|c|c|c|}
\hline & & & $\begin{array}{l}\text { have found in } \\
\text { different research } \\
\text { articles. However, } \\
\text { in their oral } \\
\text { presentations, a } \\
\text { few } \\
\text { undergraduates } \\
\text { may read their } \\
\text { notes. }\end{array}$ \\
\hline $\begin{array}{l}\text { Students interact with questions } \\
\text { and answers. }\end{array}$ & $\mathrm{X}$ & & $\begin{array}{l}\text { Students do not ask } \\
\text { questions to their } \\
\text { classmates. }\end{array}$ \\
\hline Classroom dynamics are positive & & $\mathrm{X}$ & \\
\hline $\begin{array}{l}\text { Use of technology is appropriate. } \\
\text { Which? }\end{array}$ & & $\mathrm{X}$ & $\begin{array}{l}\text { PowerPoint } \\
\text { presentations are } \\
\text { employed as visual } \\
\text { support. }\end{array}$ \\
\hline
\end{tabular}


APPENDIX IV (k): Social and Affective Neuroscience

\section{APPENDIX IV (k): Social and Affective Neuroscience}

CODE: IN1120

DATE: 03/04/2019

GENRE: $\square$ Lecture $\square$ Seminar

OBSERVER: Lucía Bellés Calvera

RECORDING: $\square$ audio $\square$ video

\section{SPEECH ACT}

Subject: $\square$ basic training $\square$ compulsory $\square$ elective $\square$ course

Field: $\square$ Humanities $\square$ Social Sciences $\square$ Hard Sciences

Language: $\square$ Spanish $\square$ Valencian $\square$ English

Time: $17 \mathrm{~h} \quad$ Duration: 115 minutes

\section{DATA OF THE INSTRUCTOR}

Academic status: $\square$ Junior Lecturer $\square$ Senior Lecturer $\square$ Others

Nationality: Spanish

Mother tongue: $\square$ Spanish $\square$ Valencian

Gender: $\square \mathrm{M} \square \mathrm{F}$

\section{DATA OF THE ACADEMIC SPACE USED}

PLACE: Health Sciences Building

Type of classroom:

$\square$ ordinary classroom $\square$ aula magna $\square$ seminar $\square$ laboratory $\square$ others

Other relevant information: The furniture arrangement is flexible. Tables and chairs are wheeled.

\section{DATA OF THE STUDENTS}

Participants: 
APPENDIX IV (k): Social and Affective Neuroscience

Number of students: 39 Males: 11 Females: 28

\section{RESOURCES}

$\square$ ppt presentation

$\square$ projector

DVD

$\square$ computer

$\square$ audio CD

$\square$ mobile phones

blackboard

$\square$ others:

YouTube

\section{DATA OF THE DISCUSSION}

Language of instruction: $\square$ Spanish $\square$ Valencian $\square$ English

Language of interaction (teacher): $\square$ Spanish $\square$ Valencian $\square$ English

Language of interaction (students): $\square$ Spanish $\square$ Valencian $\square$ English

\section{DATA OF THE RECORDING}

Time: 115 minutes

Transcription (number of words): 7,589

Item: Olympus digital voice recorder

\begin{tabular}{|l|l|c|c|l|}
\hline \multicolumn{1}{|c|}{ CRITERIA } & Weak & Adequate & Strong & \multicolumn{1}{c|}{ Comments } \\
\hline Students are engaged. & & & $\mathrm{X}$ & \\
\hline Students do all the activities. & & & $\mathrm{X}$ & $\begin{array}{l}\text { All the students } \\
\text { work in groups as } \\
\text { required by the } \\
\text { lecturer. }\end{array}$ \\
\hline $\begin{array}{l}\text { Students appear confident to } \\
\text { communicate in the language of } \\
\text { instruction. }\end{array}$ & & $\mathrm{X}$ & & $\begin{array}{l}\text { Some students } \\
\text { participate in } \\
\text { Spanish and } \\
\text { Valencian, but a } \\
\text { few also try to } \\
\text { communicate in }\end{array}$ \\
\hline
\end{tabular}


APPENDIX IV (k): Social and Affective Neuroscience

\begin{tabular}{|c|c|c|c|}
\hline & & & English. \\
\hline $\begin{array}{l}\text { Students interact with questions } \\
\text { and answers. }\end{array}$ & & $\mathrm{X}$ & $\begin{array}{l}\text { Questions are } \\
\text { posed throughout } \\
\text { the seminar, either } \\
\text { to give their } \\
\text { opinions or to } \\
\text { negotiate meaning. }\end{array}$ \\
\hline Classroom dynamics are positive & & $\mathrm{X}$ & \\
\hline $\begin{array}{l}\text { Use of technology is appropriate. } \\
\text { Which? }\end{array}$ & $\mathrm{X}$ & & $\begin{array}{l}\text { YouTube videos } \\
\text { related to the } \\
\text { contents covered in } \\
\text { previous sessions } \\
\text { are played in the } \\
\text { classroom to } \\
\text { generate some } \\
\text { discussion. }\end{array}$ \\
\hline
\end{tabular}




\section{APPENDIX V: Questionnaire}

\section{Students'Questionnaire}

Gender: $\square$ Male $\square$ Female

Born in (YEAR):

My mother tongue is...

$\square$ Spanish $\square$ Valencian

- If your mother tongue is different to the ones above, please indicate your first language:

\begin{tabular}{|c|c|c|c|c|c|}
\hline \multirow[b]{2}{*}{ Questions } & \multicolumn{5}{|c|}{ disagree-agree } \\
\hline & 1 & 2 & 3 & 4 & 5 \\
\hline $\begin{array}{l}\text { 1. The lessons and methodology used here in class } \\
\text { have been interactive and suitable. }\end{array}$ & & & & & \\
\hline 2. The activities have been appealing. & & & & & \\
\hline 3. Seminars in English have been useful. & & & & & \\
\hline $\begin{array}{l}\text { 4. ICTs are used as a tool to practice the contents } \\
\text { we've seen in the module. }\end{array}$ & & & & & \\
\hline $\begin{array}{l}\text { 5. The materials provided by the teacher have been } \\
\text { appropriate to expand my knowledge. }\end{array}$ & & & & & \\
\hline $\begin{array}{l}\text { 6. These practical sessions were more difficult } \\
\text { compared to other teaching practices due to the } \\
\text { English language. }\end{array}$ & & & & & \\
\hline
\end{tabular}

7. Do you think the activities and exposure to the English language meet the requirements of the module?

Yes

No

- If you answered negatively, would you change anything? 
8. Would you prefer a lesson delivered in your mother tongue?

Yes, I prefer learning a content subject in my native language.

No, I don't mind.

9. Do you have any international certification according to the CEFR (in English)?

$$
\begin{aligned}
& \text { Yes } \\
& \text { No }
\end{aligned}
$$

- Which level?
$\square \mathrm{A} 1$
$\square \mathrm{A} 2$
$\square \mathrm{B} 1$
$\square$ B2
$\square \mathrm{C} 1$
$\mathrm{C} 2$

10. Is English relevant for your professional career?

Yes. Explain why:

No. Explain why:

11. Have you had other content subjects in which English is the language of instruction in the degree?
$\square$ Yes
No

\section{What did they consist of?}

Didactic unit

Project

Academic year

Presentation

Search for articles and read them in class

Semester

Others

12. Have you had a positive experience learning in a foreign language? 
Yes. Explain why:

No. Explain why:

13. Do you know the number of subjects in which English is the language of instruction in your degree?

$$
\begin{aligned}
& \text { Yes } \\
& \text { No }
\end{aligned}
$$

14. The ECOPOL Plan, developed by Universitat Jaume I, states the linguistic policies that are being implemented in every degree at the moment.

a) Were you given information before or when enrolling your degree about the requirements of the institutional ECOPOL Plan?

Yes. Explain:

No

b) Do you know anything about these linguistic requirements?
Yes

$\square$ No

- What do you know about the PPM?

c) Which of these premises about the English language do you think are included in the ECOPOL Plan? 


\begin{tabular}{|l|l|}
\hline \multicolumn{1}{|c|}{ Requirements } & $\checkmark$ \\
\hline $\begin{array}{l}\text { Students should have, at least, a B1 level in English before admission to } \\
\text { university. }\end{array}$ & \\
\hline $\begin{array}{l}\text { Students must have a B2 level in English if you want to present your final } \\
\text { degree project (TFG). }\end{array}$ & \\
\hline $\begin{array}{l}\text { Students must prove they have passed a B2 level English test before they can } \\
\text { request the issue of their degree certificates. }\end{array}$ & \\
\hline $\begin{array}{l}\text { Students must have a B1 level in English if you want access the Master's } \\
\text { degree in Secondary Education, Vocational Training and Language Teaching. }\end{array}$ & \\
\hline $\begin{array}{l}\text { Students can apply for exemption from proving a B2 level in English provided } \\
\text { they have passed, at least, 12 credits in the form of subjects taught or assessed } \\
\text { in English at UJI or another Spanish or foreign university. }\end{array}$ & \\
\hline $\begin{array}{l}\text { Students can apply for exemption from proving a B2 level in English if they } \\
\text { have a B2 level in another European language. }\end{array}$ & \\
\hline A maximum of 5\% of the degree's credits should be in English. & \\
\hline
\end{tabular}

\begin{tabular}{|l|l|}
\hline \multicolumn{1}{|c|}{ Requirements } & $\checkmark$ \\
\hline Students should have a C1 level in Valencian before admission to university. & \\
\hline $\begin{array}{l}\text { Students can apply for exemption from proving a C1 level in Valencian if they } \\
\text { have taken Bachillerato or other courses leading to university admission } \\
\text { entirely in Catalan. }\end{array}$ & \\
\hline $\begin{array}{l}\text { Students can apply for exemption from proving a C1 level in Valencian if you } \\
\text { have studied in a monolingual region where Catalan is not an official language. }\end{array}$ & \\
\hline $\begin{array}{l}\text { Students don't need a C1 level in Valencian if they want to enrol Capacitació } \\
\text { courses. }\end{array}$ & \\
\hline Students need a C1 level in Valencian if they want to enrol a master's degree. & \\
\hline $\begin{array}{l}\text { The number of subjects taught in Valencian is higher than those taught in } \\
\text { Spanish. }\end{array}$ & \\
\hline $\begin{array}{l}\text { The plurlingualism programme aims at promoting the use of Valencian in the } \\
\text { classroom. }\end{array}$ & \\
\hline
\end{tabular}


APPENDIX VI: Placement test

Name: Date:

\section{PLACEMENT TEST}

Circle the correct letter.

1 I'm 18 and my brother is 20 , so he's ....... me.

a the oldest of

b older than

c as old as

2 Carl's very ........ . He's never late, and he never forgets to do things.

a reliable

b patient

c strict

3 We stayed in a lovely villa ........ the sea. a it overlooks

b overlooked

c overlooking

4 Not until the $1980 \mathrm{~s}$......... for the average person to own a computer.
a it was possible
b was it possible
c was possible

5 Jan ........ her arm on a hot iron.

a broke

b burned

c sprained

6 Tomorrow's a holiday, so we ........ go to work.

a have to

b mustn't

c don't have to

7 I usually ........ swimming at least once a week.
a go
b do
c play

8 My friend Siena ........ to Russia last year. a went

b has gone

c has been

9 This is ........ area, with a lot of factories and warehouses.

a an agicultural

b an industrial

c a residential

10 If I ........ well in my exams, I ........ to university.

a will do; will go

b will do; go

c do; will go

11 She was so upset that she burst ........ tears.
a into
b out
c with

12 Where did you go ........ holiday last year?

a for

b on

c to

13 Ocean currents ........ play an important part in regulating global climate.

a are known to

b thought to

c are believed that they

$14 \mathrm{My}$ cousin ....... getting a job in Bahrain a would like

b is planning

c is thinking of 
15 I can't ........ your hair, because I haven't got any scissors.

a brush
b cut
c wash

16 I wish I ....... have an exam tomorrow!
a don't
b didn't
c won't

17 The government plans to ........ taxes on sales of luxury items.
a increase
b expand
c go up

18 When I first moved to Hong Kong, life in a different country was very strange, but now I'm used here.
a living
b to live
c to living

19 There ........ mill in the fiidge.
a is some
b are some
c is a

20 Criminals are people who are guilty of the law.

a breaking

b cheating

c committing

21 Why on earth isn't Josh here yet? for him for over an hour!
a $\mathrm{T}$ m waiting
b I've been waiting
c I've waited

22 "It's pouring down, and it's freezing." What are the weather conditions?

a high winds and snow

b heavy rain and cold temperatures

c thick cloud but quite wam

23 ........ feeling OK? You don't look very well.
a Do you
b You are
c Are you

24 Daniel's hair is getting far too long; he should soon.
a cut it
b have cut it
c have it cut

25 Mandy works for a computer software company. She got ........ recently, and so now she's an area manager.
a made redundant
b promoted
c a raise

26 I can't hear you - it's noisy in here.
a too
b too much
c too many

27 Jamal has just sent me to anange plans for this weekend.
a a blog
b an email
c a website

28 I promise I'll call you as soon as I

a I anive

b I anived

c I'll anive 
29 Photographers and designers need to be very
a creative
b fit
c annoying

30 The global financial crisis, ........ is forcing lots of small businesses to close, does not look set to end soon.
$a$ it
b that
c which

31 There ........ a temible accident if the pilot hadn't reacted so quickly.
a had been
b was
c would have been

32 "Are you ready to order?"

'Not yet -I'm still looking at the
a bill
b menu
c service

33 "My job is never boring."

The speaker's job is always
a interesting
b popular
c difficult

34 I've been working here ......... about the last two years.
a during
b for
c since

35 "It leaves from Platform 2 at 4.15." The speaker is talking about
a an airline flight
b a train
c a taxi

36 I went to a lovely ........ last Saturday. The bride was my best fiiend when we were at school.
a anniversary
b maniage
c wedding

37 "I've got a headache."

"Maybe you ........ to take an aspirin."
a should
b ought
c don't

38 The patient had an ........ to insert metal pins in his broken leg.
a injection
b operation
c X-ray

39 She won a seat in parliament at the last
a general election
b opinion poll
c referendum

$40 \mathrm{I} \mathrm{m}$ suprised you didn't get upset. If someone said that to me, ........ really angry.
a I'm
b I was
c I'd be 
41 This used to be ........ part of the city, but since the old buildings were renovated it's become a very fashionable area.

a an affluent

b a run-down

c a trendy

42 Cassie went to bed early because she was
a tired
b stressed
c relaxed

43 In the 1960 s, computers were expensive that ordinary people couldn't afford them.
a so
b such
c too

44 Do you want ........ the match tonight?

a watching

b watch

c to watch

45 Researchers claim the new discovery is a major ........ in the fight against malaria.

a breakthrough

b investigation

c progress
46 The Maths problem was really difficult and I just couldn't the answer.

a check in

b set off

c work out

47 When I was a child, I never about the future.
a have worried
b used to wony
c was worrying

48 A local politician has ....... charges of comuption made by the opposition party.

a accused

b blamed

c denied

49 ........ womies me about society today is how completely we have come to depend on technology.
a That
b What
c Which

50 Cats and dogs are usually kept as
a farm animals
b wild animals
c pets 
APPENDIX VII: Activities

APPENDIX VII (a): Fundamentals and Theory of Artistic Heritage

\section{Practical activity: The museums}

Watch the ideos and write a commentary including the following questions:

- When the British museum opened to the public?

- What kind of collection can you find at the British museum?

- Which museums have been built in historic buildings? Which museums have been built in new buildings?

- What is the objective of the Department of Scientific Research at the Metropolitan Museum of Art?

- In your opinion, what is the best tip for teaching with artworks?

- Write a brief report about how to prepare an art exhibition

- What wanted Jean Paul Getty when he imagined the museum?

- What you find from the Guggenheim Museum of New York? 
APPENDIX VII: Activities

\section{APPENDIX VII (b): English for Medicine}

MD1706 English for Medicine

Seminar - The Genetics of Skin Cancer

Name and Surnames:

1. Explain the impact of UV radiation on genome stability and human health. How our skin protects against UV light?

2. For each of the following exercises, write True if the statement is true or False if the statement is false.

a. A genetic disease is always inherited from your parents

b. Skin cancer is by far the most common type of cancer in populations of European origin

c. People with dark skin don't need to worry about skin cancer

d. If you have a family history of melanoma, you are at greater risk for developing the disease

e. Skin cancer is found only on areas of your body which are exposed to the sun

3. Indicate which of the following celebrities passed away from melanoma. Which type of melanoma develop? Why they were at high risk of developing melanoma?
a. Bob Marley
b. Freddie Mercury
c. John Lennon
d. John McCain 
APPENDIX VII (c): Anthropology and Evolution

\section{Seminario 2-Antropología}

\section{NOTICIA 1}

Explica en dos o tres párrafos porqué crees que esta noticia número 1 está equivocada o es engañosa.

Nombre y apellidos:

Grupo:

Otros miembros del grupo:

Otros miembros del grupo:

Otros miembros del grupo: 
LA FASCINACION POR EL PELO CLARO TIENE RAZONES HISTORICAS Y ANTROPOLOGICAS El fin de las rubias: dicen que en 200 años ya no existirá ese color de cabello natural

Para los científicos, desaparecerá por el mayor crecimiento de la población con genes morenos.

Alrededor de 2200 nacerá en Finlandia la última rubia del planeta. Esta afirmación fue Alredentes medios, desde The New Yimes hasta la Como transmitida desde 2002 por diferentes extinción del gen que caracteriza a las rubias auténticas" se citaba a la Organización Mundial de la Salud.

Aunque el organismo no lo confirmó, el pronóstico tiene fundamentos. En el planeta hay 6.500 millones de individuos. 1.000 millones se encuentran en Africa y 4.000 millones en Asia, según el Buró de Referencia Demográfica. En 2050, habrá 9.000 millones. Los 3.000 millones adicionales serán principalmente originarios de Africa, Asia y América del Sur.

La frecuencia de rubios, raros fuera de los países occidentales, disminuirá mecánicamente. Sobre todo si se tiene en cuenta que este color de pelo, al igual que los ojos azules, se debe a Sobre todo si se tiene en cuenta que este color un gen que imponga ese carácter venido de genes recesivos. "Para ser rubio, es necesario un gen que padre y otro de la madre -señala el genetista Axel Kahn-. Si el número de genes rubios se mantiene constante pero aumenta el de morenos, habrá una probabilidad decreciente de que dos personas hereden dos genes rubios. Una herfil de humano mestizado, como el brasileño".
perto

perfil de humano mestizado, como el brasileño. La empresa de belleza Lón cóna nueva forma de dedicado a la investigación capilar, donde belleza, el cabello mestizado, explica Patricia miles de cabelleras, L'Oréal ya enumeró ocho, de investigaciones. Según un estudio hecho en mile distinguía el caucásico, africano y asiático. en vez de tres, tipos de cabello: "Hasta ahora, se distinguia el caucásico, africano y asiático. Establecimos una clasificación más respetuosa de la geografia humana, basada

del cabello: desde muy lacio (Asia, Mexico) hasta muy cró En las próximas décadas, la proporción de color rubio natural irá achicándose, pero el mito podría crecer. Ya en Europa una de cada tres mujeres se tiñe de un matiz de rubio cuando, en realidad, afirma Joanna Pitman -autora del libro "Las rubias"-, sólo "un adulto de cada en EE.UU. y Europa tiene ese color auténtico". ¿Por qué tal fascinación? La historia se remonta, según la escritora, a Venus-Afrodita, diosa del amor de pálida cabellera. "Cada remonta, según la escritora, a Venus-Afrodita, diosa del amor sus preocupaciones. Vicio durante la Edad epoca le confirio al rubio valores que rística en la Inglaterra isabelina, ideología en los años Media, obsesion en el Renacimiento, mis". ¿Y hoy? Para la autora británica Marina Warner, 30 , senal de incitacion ser rubio es recordar el color de la infancia, buscar la eterna juventud".

El psicoanalista Samuel Lepastier afirma que el mito está ligado a la historia europea. El continente, invadido por pueblos rubios (dorios, francos) asoció el color al vencedor. "Es un mito fundador de la desigualdad de las razas humanas. Su versión más delirante fue el 
racismo hitlerista", señala.

Pero hay otras explicaciones, más allá del fenómeno sociologico. El antropólogo canadiense Peter Frost sostiene que está ligado a la "selección sexual que privilegia los matices intensos pero también los colores raros. La atracción sexual se orienta hacia las variantes menos frecuentes. Así se instala un equilibrio dinámico que lleva a una diversidad de la especie".

Para Lepastier, la fuerza simbólica del rubio es fruto de 200 años de supremacía de occidente. $Y$, con el vuelco del planeta hacia Asia y otras culturas dominantes, nada dice que el mito rubio no pueda ser reemplazado por otro. Los genetistas están seguros de algo: el fenotipo rubio no se apagará. "Podrá resurgir, como lo hacen actualmente las enfermedades raras", dice Axel Kahn. 
SEARCH

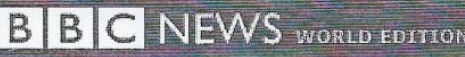

You are in: Health

News Front Page Friday, 27 September, 2002, 11:51 GMT 12:51 UK

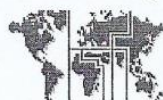
Blondes 'to die out in $\mathbf{2 0 0}$ years'

\begin{tabular}{|c|c|}
\hline $\begin{array}{r}\text { Africa } \\
\text { Americas } \\
\text { Asia-Pacific } \\
\text { Europe } \\
\text { Middle East } \\
\text { South Asia } \\
\text { UK } \\
\text { Business } \\
\text { Entertainment } \\
\text { Science/ Nature } \\
\text { Technology } \\
\text { Health } \\
\text { Medical notes } \\
\text { Talking Point } \\
\text { Country Profiles } \\
\text { In Depth } \\
\text { Programmes } \\
\text { BiBlGisporm } \\
\text { B]BG WEATHER } \\
\text { SERvrCES } \\
\text { Daily E-mail } \\
\text { News Ticker } \\
\text { Mobile/PDAs } \\
\text { Text Only } \\
\text { Feedback } \\
\text { Help } \\
\text { Changeto UK }\end{array}$ & $\begin{array}{l}\text { Scientists believe the last blor } \\
\text { The last natural blonde } \\
\text { years, scientists believ } \\
\text { A study by experts in } \\
\text { people with blonde hai } \\
\text { species and will becom } \\
\text { Researchers predict th } \\
\text { blonde will be born in } \\
\text { with the highest propo } \\
\text { But they say too few } \\
\text { people now carry the } \\
\text { gene for blondes to las } \\
\text { beyond the next two } \\
\text { centuries. } \\
\text { The problem is that } \\
\text { blonde hair is caused } \\
\text { a recessive gene. } \\
\text { In order for a child to } \\
\text { must have the gene or } \\
\text { family in the grandpar } \\
\text { Dyed rivals } \\
\text { The researchers also } \\
\text { bottle blondes may be } \\
\text { demise of their natura } \\
\text { They suggest that dye } \\
\text { attractive to men who } \\
\text { partners over true blo } \\
\text { But Jonathan Rees, } \\
\text { professor of } \\
\text { dermatology at the } \\
\text { University of } \\
\text { Edinburgh said it was }\end{array}$ \\
\hline
\end{tabular}

See also:

28 Mar 01 | Education

What is it about blondes?

09 Apr 99 | Health

Platinum blondes are

labelled as dumb

$17 \mathrm{Apr} 02$ | Health

Hair dye cancer alert

Internet links:

University of Edinburgh

The $\mathrm{BBC}$ is not responsible for the content of external internet sites

Top Health stories now:

Heart risk link to big

families

Back pain drug 'may aid

diabetics'

Congo Ebola outbreak

confirmed

Vegetables ward off

Alzheimer's

Polio campaign launched in Iraq

Gene defect explains high

blood pressure

Botox 'may cause new wrinkles'

Alien 'abductees' show real symptoms

\section{Links to more Health}

stories are at the foot of

the page. 
unlikely blondes would die out completely.

"Genes don't die out unless there is a disadvantage of

having that gene or by chance. They don't disappear," he told BBC News Online.

"The only reason blondes would disappear is if having

the gene was a disadvantage and I do not think that is the case.

"The frequency of blondes may drop but they won't disappear."

E-mail this story to a friend

Links to more Health stories

In This Section

$\nabla$ Go

(c) $\mathrm{BE}$ B $\wedge$ Back to top

News Front Page | Africa | Americas | Asia-Pacific | Europe | Middle East |

South Asia | UK | Business | Entertainment | Science/ Nature |

Technology | Health | Talking Point | Country Profiles | In Depth |

Programmes

To BBC Sport >> | To BBC Weather $>>\mid$ To BBC World Service $>>$

(c) MMIII | News Sources | Privacy 


\section{Seminario 2-Antropología}

\section{NOTICIA 2}

Explica en dos o tres párrafos porqué crees que esta noticia número 1 está equivocada o es engañosa.

Nombre y apellidos: Grupo:

Otros miembros del grupo:

Otros miembros del grupo:

Otros miembros del grupo: 


\section{EVOLUCIÓN | Estudio}

\section{El origen africano de Darwin}

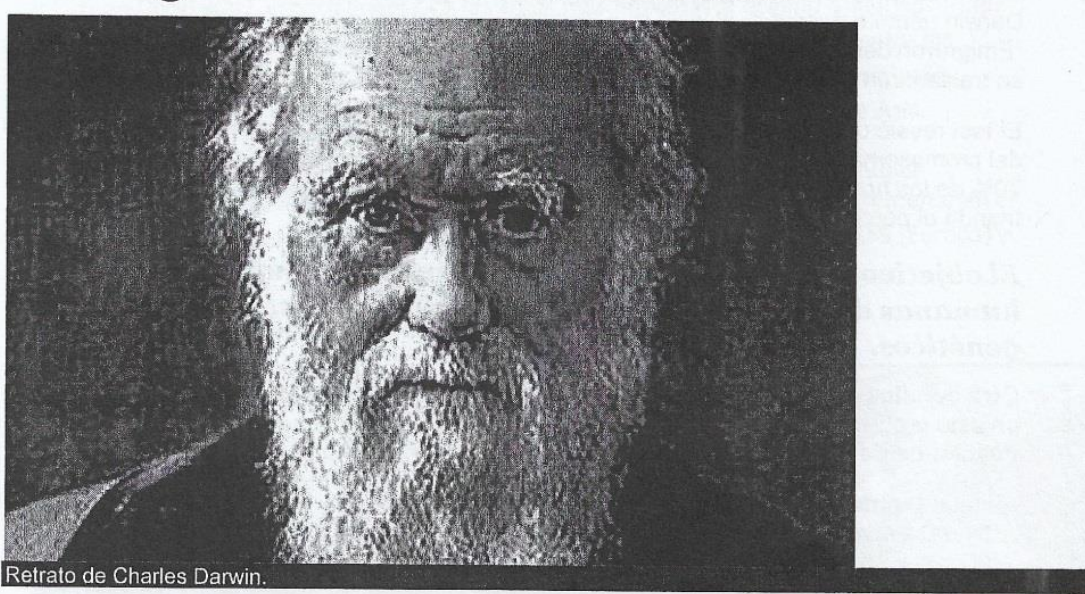

- Estudiaron el ADN de su tataranieto, Chris Darwin, que vive en Australia

- El proyecto pretende determinar las migraciones humanas hasta la actualidad

- La investigación sostiene que la humanidad desciende de un mismo antepasado

- Se trataría de un hombre africano que vivió hace 60.000 años

Efe | Sydney (Australia)

Actualizado domingo 07/02/2010 09:29 horas

- Disminuve el tamaño del texto

- Aumenta el tamaño del texto

Los antepasados de Charles Darwin (Inglaterra, 1809-1882) habitaron África hace 45.000 años, según las conclusiones del 'Provecto Genográfico' presentadas este jueves en Sydney.

El viaje hacia el pasado de los expertos fue posible gracias al estudio del ADN del tataranieto del autor de 'El origen de las especies', Chris Darwin, que reside en Australia.

'Sus antepasados emigraron del nordeste de África hacia el norte o Oriente Próximo y después se trasladaron a Europa'

"Una parte del cromosoma Y de cada hombre, llamada 'región que no se

recombina", contiene una información genética exacta a la del padre, el resto cambia en cada generación", explicó Lisa Matisson Smith, la investigadora principal para la región de Oceanía, durante la presentación.

Matisson añadió que la "región que no se recombina" sufre alteraciones por eventos de mutación aleatorios y estos cambios se convierten en marcadores genéticos.

"Al seguir el marcador genético desde la actualidad hasta su origen, se puede determinar cuál es el antecesor común de todos los hombres vivos portadores de ese marcador", detalló la científica. 


\section{Antepasado común}

El director del proyecto, Spencer Wells, manifestó que la lectura de los marcadores de Darwin permite descubrir el viaje que hicieron los antepasados del científico inglés. "Emigraron del nordeste de África hacia el norte o hacia Oriente Próximo y posteriormente se trasladaron a Europa", aseguró Wells.

El test reveló que Chris, y por tanto, también su tatarabuelo, pertenecen al haplogrupo R1b del cromosoma Y, uno de los más comunes en Europa Occidental. "Aproximadamente el $70 \%$ de los hombres del sur de Inglaterra pertenecen a él. En algunas zonas de España e Irlanda el porcentaje alcanza el $90 \% "$, según Wells.

\section{El objetivo de la investigación es determinar las migraciones humanas desde el origen hasta la actualidad, basándose en datos genéticos.}

Otra conclusión a la que han llegado los especialistas de todo el mundo que participan en este programa, liderado por 'National Geographic' e IBM, es que la humanidad desciende de un mismo antepasado, un africano que vivió hace 60.000 años.

Aunque las mujeres carecen de cromosoma $Y$, tienen $A D N$ mitocondrial que atesora el ADN de la madre y marcadores.

El científico español de la Universidad Pompeu Fabra David Comas, investigador principal para la zona de Europa Central y Occidental, explica que el objetivo de la iniciativa, que se ha dividido en tres apartados, es determinar las migraciones humanas desde el origen hasta la actualidad, basándose en datos genéticos.

'Proyecto Público' recoge muestras de ADN de personas interesadas en conocer el viaje efectuado por sus antepasados, a cambio de una suma de dinero. 'Proyecto de Investigación' busca ejemplos determinados de una parte de la población de cada país.

\section{0 muestras recogidas en España}

"En España, por ejemplo, hemos recogido muestras de 600 personas, porque en todo Europa recogeremos un total de $10.000 "$, apuntó el catalán Comas.

Señaló que hay poblaciones que viven en lugares remotos, otras no tienen un acceso tan fácil a los medios de comunicación o a Internet, y también tienen que asegurarse de que se incluye una representación de tribus indígenas.

Los datos recogidos son anónimos, aseguró por su parte Spencer Wells, y están a la disposición de la comunidad científica internacional.

El investigador español opinó que la información que recaban dará lugar a numerosas investigaciones desde otros sectores científicos. Asimismo, sugirió que la

documentación es relevante tanto para el estudio del cambio climático, la lingüística o la arqueología, es como abrir una nueva caja de Pandora. 


\section{HAPLOGRUPO R1B DEL CROMOSOMA Y}

El haplogrupo R1b es el haplogrupo del cromosoma Y más común entre los habitantes de Europa Occidental, especialmente en las áreas más próximas al océano Atlántico, donde llega a alcanzar el $90 \%$ de los pobladores. Actualmente también es frecuente entre los habitantes de América y Oceanía, debido a la emigración. Porcentajes menores pueden encontrarse en Europa del Este, Anatolia, Asia Central, Cercano Oriente, Sur de Asia.

El haplogrupo R1b se define por la presencia de un solo polimorfismo de nucleótido simple: M343, descubierto en 2004. ${ }^{2}$ Deriva de R1-M173, originándose probablemente en el Cercano Oriente hace casi 20000 años y sus principales descendientes son M269 (Europa) y M73 (Eurasia Central).

DISTRIBUCIÓN DEL HAPLOGRUPO R1B DEL CROMOSOMA Y.

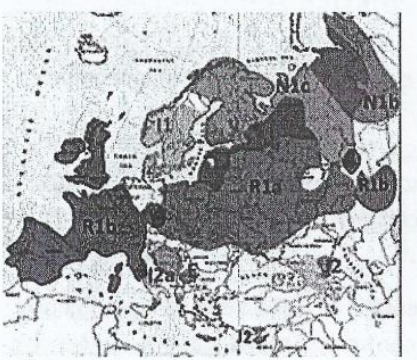

R1b en Europa Occidental.

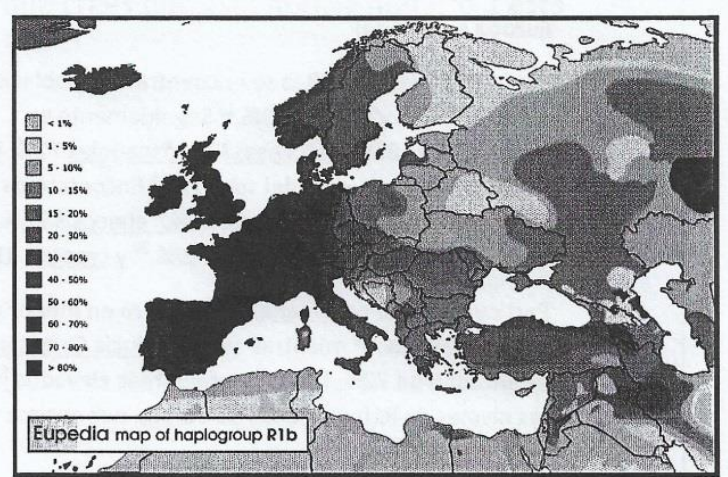

ORIGEN Y EXPANSIÓN

R1b (M343) se origina en el Paleolítico superior. Algunas variantes al este hace postular en algunos genetistas un origen en Cercano Oriente ${ }^{3} \circ$ Asia Central $^{4}$ y se le da una antigüedad de 18500 años. ${ }^{5}$ La variante R1b-M269 llega a Europa durante la Edad del Bronce procedente del Cáucaso y de las estepas del Mar Negro, entrando en Europa Occidental a partir del 2500 a.C., junto con la dispersión de las lenguas indoeuropeas. La predominancia de R1b y R1a en Europa, demostraría que la mayor parte del acervo genético patrilineal europeo proviene de migraciones post-neolíticas, mientras la mayor parte de la genética matrilineal viene del Paleolítico.

Si bien R1b tiene la mayor frecuencia en Europa Occidental, también se ha afirmado que podría haberse originado en Anatolia (actual Turquía) donde hay alta diversidad, durante la Edad de hielo; en un primer momento se le relacionó con la cultura auriñaciense ${ }^{8}$ ( 32000 $21000 \mathrm{AC}$ ). La evidencia arqueológica parece demostrar la llegada de la cultura auriñaciense a Anatolia desde Europa durante el Paleolítico superior en lugar de tener un origen en la meseta iraní. ${ }^{9}$ Esta cultura se asocia tradicionalmente con el Hombre de cromañón, quienes fueron los primeros humanos modernos en entrar a Europa; de tal manera se consideró que los europeos de las costas del Atlántico con mayor frecuencia de R1b, conservarian el linaje de los primeros pobladores de Europa,,$\frac{10}{}$ en especial aquellos de origen celta y poblaciones de la península ibérica.

No obstante, nuevas investigaciones con DNA antiguo han obligado a revisar estas teorías, puesto que se ha descubierto que la variante europea (M269) no entró a Europa antes de la 
Edad del Bronce, encontrándose con que la gran mayoría de mutaciones de esta variante datan su presencia en Europa Central y Occidental a finales de la Edad del Bronce, con la llegada de pueblos esteparios del este. El haplogrupo R1b en Europa se le vincula con la Cultura del vaso campaniforme y simultáneamente coincidiendo con la expansión de las lenguas indoeuropeas, por lo que ha sido sugerido como candidato para un origen indoeuropeo 11 . El hallazgo importante de R1b-M269 en restos masculinos de yacimientos arqueológicos proto-indoeuropeos de las estepas de Ucrania y Rusia, como los de la cultura Yamna, parece confirmar definitivamente esta teoría ${ }^{12}$.

DISTRIBUCIÓN

Se encuentra ampliamente distribuido en Eurasia Occidental, pero principalmente en Europa Occidental (ver mapa R1b).

\section{Europa occidental}

Las frecuencias más altas se encuentran en poblaciones de Europa Atlántica principalmente en vascos $87 \%$ y galeses $89 \% \cdot{ }^{13}$ Seguidamente en

los irlandeses $81 \%$, escoceses $77 \%$, españoles $72 \%$, ingleses $60 \%$, belgas:

$63.0 \%, \frac{14}{14}$ portugueses del sur $50 \% \cdot{ }^{15}$ Encontramos menos frecuencia en los italianos (Italia continental): $40 \%, \underline{16}$ alemanes: $39 \%,{ }_{1}^{17}$ checos $35.6 \%, \underline{13}$ sicilianos: $24.5 \%,{ }^{18}$ noruegos: $25.9 \%$, ${ }^{19}$ suecos: $20 \%$. ${ }^{19}$ sardos: $19 \%$, ${ }^{20}$ croatas: $15.7 \%$. ${ }^{21}$

Particularmente en España, se encontró en menor porcentaje en Galicia con $58 \%$ y Andalucía Occidental $55 \%, \underline{22}$ mientras que Andalucía Oriental y el centro de España, Castilla-La Mancha, alcanzaban un $72 \%$, los porcentajes más elevados junto con Cataluña y País Vasco, y cerca de los niveles de R1b más altos de Europa por encima del $80 \%$ obtenidos en Gales, Irlanda y la Bretaña francesa. $\frac{23}{}$

\section{Europa oriental y Cáucaso}

Encontramos en eslovacos: $35.6 \%,{ }^{13}$ polacos: $11.6 \%{ }^{24}-16.4 \%,{ }^{13}$ letones: $15 \%, \stackrel{25}{\text { húngaros: }}$ $13.3 \%,{ }^{25}$ griegos: $13.5 \%{ }^{26}-22.8 \%,{ }^{13}$ albanos: $17.6 \%,{ }^{13}$ rumanos: $13 \%,{ }^{27}$ eslovenos: $21 \%$, búlgaros: $17.0 \%$, serbios: $10.6 \%{ }^{121}$ y rusos: $2.8 \% .{ }^{28}-21.3 \%$,

En el Cáucaso se presenta $43 \%$ en osetios ${ }^{25}$ y $32.4 \%$ en armenios..$^{30}$

Asia

En Asia encontramos $37 \%$ en turcomanos, 31 $40 \%$ en la zona del mar Muerto (en Jordania) ) $^{32}$ y $8 \%$ en general en Jordania. $16.3 \%$ en Turquía, ${ }^{33} 11.3 \%$ en Irak , $^{34} 11.2 \%$ enkurdos ${ }^{35} 10 \%$ en judios askenazi,, 36 en sirios, ${ }^{37} 9.8 \%$ en uzbekos (Wells2001), $18 \%$ en uzbekos de Afganistán, $7.4 \%$ en Pakistán y menor frecuencia en otras poblaciones.

\section{América[editar]}

En nativos americanos es común especialmente en los pueblos algonquinos de Norteamérica y no se ha demostrado aún si su origen está relacionado con el mestizaje europeo ${ }^{44}$ o es debido a migraciones siberianas. ${ }^{45}$ Su presencia se identificó primero como $\underline{P}$ (M45), pero se refiere en realidad al haplogrupo R1b-P25 y el enigma de su origen se revelará luego de su estudio subcladístico. 
Seminario 2 - Antropología

NOTICIA 3

Explica en dos o tres párrafos porqué crees que esta noticia número 1 está equivocada o es engañosa.

Nombre y apellidos: Grupo:

Otros miembros del grupo:

Otros miembros del grupo:

Otros miembros del grupo: 
Un británico es el descendiente directo de un fósil de hace 9.000 años ISABEL FERRER

Leicester - 9 MAR 1997

Los alumnos de Adrian Targett, un profesor británico de historia de 42 años, no habían logrado ponerle aún un apodo. Un esqueleto humano de 9,000 años de antigüedad descubierto a principios de siglo en su propio pueblo, Cheddar, al suroeste de Inglaterra, les ha facilitado ahora la tarea. El fósil, conocido precisamente como el hombre de Cheddar, es uno de sus antepasados directos. Su información hereditaria (ADN) es tan similar que, según el Instituto de Medicina Molecular de la Universidad de Oxford, el parentesco puede establecerse por línea materna, Mientras el docente trata de ver en los huesos más famosos del Reino Unido el reflejo de un lejano tío suyo, Catherine, su esposa, ha puesto las cosas en su sitio: "Ahora entiendo por qué le gusta tanto la carne cruda", ha dicho en un alarde de flema inglesa. El hombre de Cheddar es el esqueleto más antiguo desenterrado completo en el pais. Para efectuar el estudio genético los

investigadores de Oxford utilizaron el ADN hallado en la cavidad de uno de sus molares. Una vez aislado lo compararon con el de una veintena de vecinos de la localidad. Todos eran miembros de familias que viven en la región desde hace varias generaciones. Adrian Targett se sumó al experimento cuando faltaron candidatos apropiados. Le bastó lavarse los dientes y dejar una muestra a disposición del equipo científico. Para asombro de todos, pudo concluirse que ambos varones comparten un pariente por línea matema. EI ADN mitocondrial, heredado del óvulo y presente en el molar, confirmó el hallazgo. "Es una extraña sorpresa. Había estado antes en la cueva donde le encontraron, claro, pero ya lo miro con otros ojos", ha señalado el aturdido profesor.

La caverna de Gough donde yacía su pariente es la más grande del centenar que salpica el mayor yacimiento británico del Paleolítico. Fue enterrado solo cerca de la entrada un millar de años antes de que los cazadores dieran paso a los agricultores. Hace 9.000 años, el área debía de estar poco poblada y llena de espesos bosques. Cheddar senior pudo capturar ciervos y conejos y tal vez fue también pescador. Frutas, tubérculos y nueces completaban su dieta.

* Este articulo aparecí́ en la edición impresa del Domingo. 9 de marzo de 1997

\section{ARCHIVADO EN:}

Antropologia - Reino Unido · Genoma · Europa occidental - Europa - Sociedad · Genes · ADN · Cromosomas - Células - Genética - Biología $\cdot$ Ciencias naturales $\cdot$ Ciencia

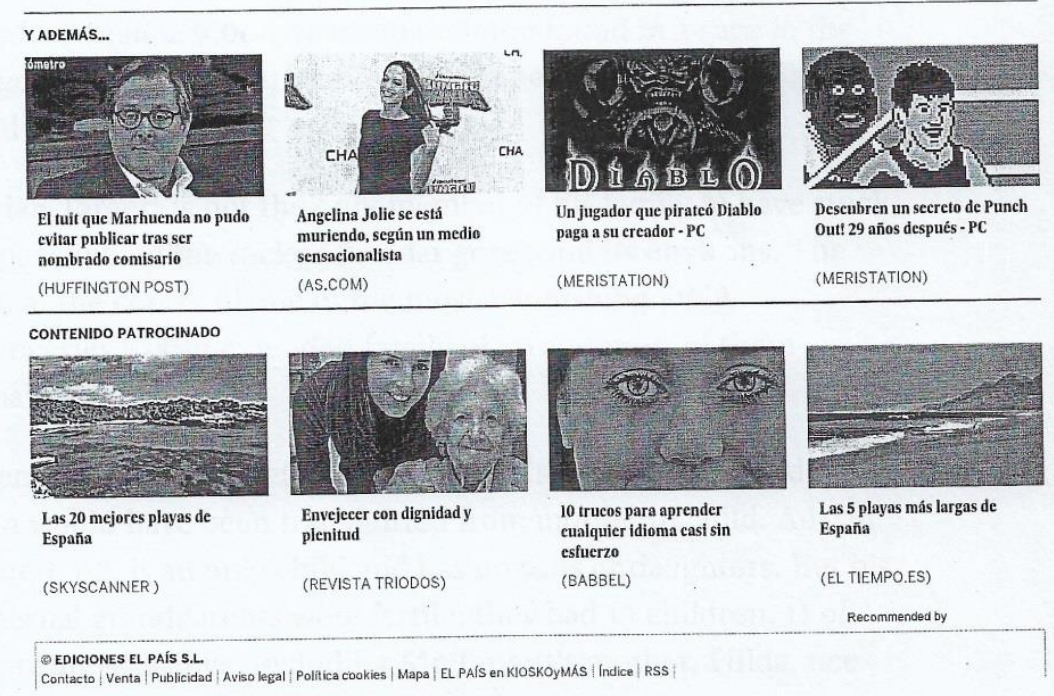




\section{There's no place like home, says 'son of Cheddar Man'}

Keith Nuthall | Sunday 9 March 1997| $\square 0$ comments

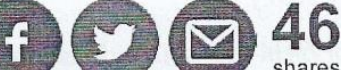

They are the family for whom the phrase "born and bred" was made: Adrian Targett and his family have lived in the same area of Britain for 9,000 years.

Until yesterday, the Somerset village of Cheddar was best known for its cheese and its gorge. Now, it is famous across the world for the Targetts, a tribe who may not be adventurous but are certainly constant.

Adrian, a history teacher, has had his DNA matched to that of Cheddar Man, a 9,000-year-old skeleton found in a cave in the gorge, proving that generation after generation of his family have lived in the same area.

Adrian Targett is not the only member of his family to have stuck, limpet- like, to the rocky Cheddar gorge and its environs. The man at the centre of one of the most astonishing DNA discoveries has an extended family of 46 and most of them remain in Somerset.

Scientists say the genetic fingerprint he shares with Cheddar Man would have been transmitted from mother to child. Adrian Targett, 42, is an only child and has no sons or daughters. But his maternal grandparents were fertile: they had 13 children, 11 of whom are still alive, including Mr Targett's mother, Hilda, nee 
17/4/2016

There's no place like home, says 'son of Cheddar Man' | News | The Independent

Gibbings.

Mr Targett himself is unsure why he and his relatives chose to remain in the Somerset and Bristol area. His father's family is also large. He had eight brothers and sisters, and they had 10 children between them. Again, few have moved away.

"We've always been a tight-knit family. If there had been any necessity to move away for work, then maybe they would have moved. But it's very pleasant living here," he said.

Mr Targett was born in Bristol and only left the West Country to go to university in Swansea. After teacher training in Bath, he returned to the family's home territory and became a history teacher at Cheddar's King of Wessex Upper School in 1981, where he has remained.

"Cheddar is not too big," he says. "It's friendly, it's close to where I work. The school is very nice, because the people near here are very nice. With Somerset, there is a sense of being proud of the county. I was glad to see the back of Avon."

Mr Targett's family is not unique: the local studies library run by Somerset County Council says there is a tradition of people staying put in rural parts of the county. Common Somerset names like Webb, Crossman and Hippsley can be read in the local military rolls from the time of the attack by the Spanish Armada, and the history teacher says at least half-a-dozen families have been in the village for more than 200 years.

The manager of the Cheddar Show Caves museum, Bob Smart, said: "We have always thought that there was a link between these early cave-dwellers and ourselves."

More about: | Cheese | Dairy Products | Somerset| Teachers

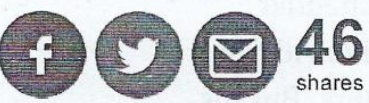

Sponsored Links by Taboola

¡Lotería para el recuerdo! Conozca una coincidencia casi paranormal

http://www.independent.co.uk/news/theres-no-place-like-home-says-son-of-cheddar-man-1271817.html 
$18 / 4 / 2016$

\section{Cheddar Man}

From Wikipedia, the free encyclopedia

Cheddar Man is the name given to the remains of a human male found in Gough's Cave in Cheddar Gorge, Somerset, England. The remains date to the Mesolithic, approximately $7150 \mathrm{BC}$, and it appears that he died a violent death. A large crater-like lesion just above the skull's right orbit suggests that the man may have also been suffering from a bone infection at the time. It is Britain's oldest complete human skeleton.

Excavated in 1903, the remains are kept by the Natural History Museum in London, currently on display in the new Human Evolution gallery. ${ }^{[1]} \mathrm{A}$ replica of the skeleton is exhibited in the "Cheddar Man and the Cannibals" museum in Cheddar village. The death of Cheddar Man remains a mystery. A hole in his skull suggests violence, and Gough's Cave was used for cannibalism, trophy display or secondary burial by pre-historic humans. ${ }^{[2]}$ Speculation based on

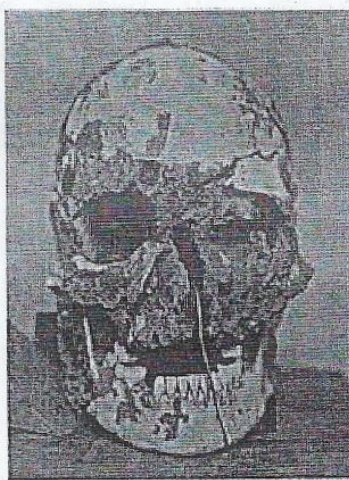

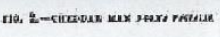
scientifically investigated known ritual or warfare practices which existed during this early period is inconclusive.

\section{Contents}

- 1 Mitochondrial DNA testing

- 2 See also

- 3 References

- 4 External links

\section{Mitochondrial DNA testing}

In 1996, Bryan Sykes of Oxford University first sequenced the mitochondrial DNA of Cheddar Man, with DNA extracted from one of Cheddar Man's molars. Cheddar Man was determined to have belonged to Haplogroup U5, a branch of mitochondrial Haplogroup U, which has also been found in other Mesolithic human remains. ${ }^{[3][4]}$ Sykes obtained DNA from the 9,000-year-old Cheddar Man's tooth and from a 12,000 -year-old tooth found from the same cave. ${ }^{[5]}$

Bryan Sykes's research into Cheddar Man was filmed as he performed it in 1997. As a means of connecting Cheddar Man to the living residents of Cheddar village, he compared mitochondrial DNA (mtDNA) taken from 20 living residents of the village to that extracted from Cheddar Man's molar. He found two people who shared the same mtDNA as Cheddar Man, because around $10 \%$ of Europeans belong to Haplogroup U5. ${ }^{[6]}$ They, like anyone else carrying haplogroup U5 today, share an ancestor with Cheddar Man of many thousands of years ago through his maternal line. ${ }^{[7][8]}$ In May 2013, Craig Dent, from Melbourne, Australia travelled to Cheddar Gorge to visit Gough's Cave following mtDNA testing which confirmed that he too belonged to haplogroup U5 and thus shared a distant ancestor with Cheddar Man. ${ }^{[9]}$ 
$18 / 4 / 2016$

Haplogroup U5 (mtDNA) - Eupedia
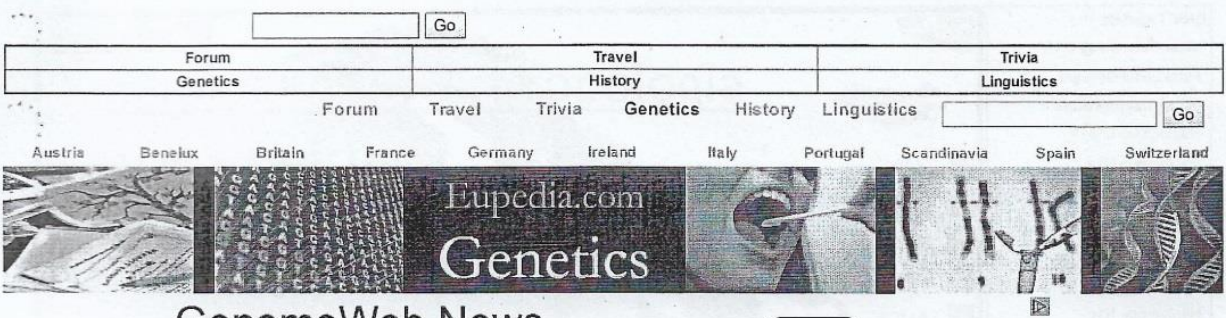

\section{GenomeWeb News}

The life science community's home page for news and information

0 o

Eupedia Home $>$ Genetics $>$ Haplogroups (homel $>$ Haplograup U5

Haplogroup U5 (mtDNA)

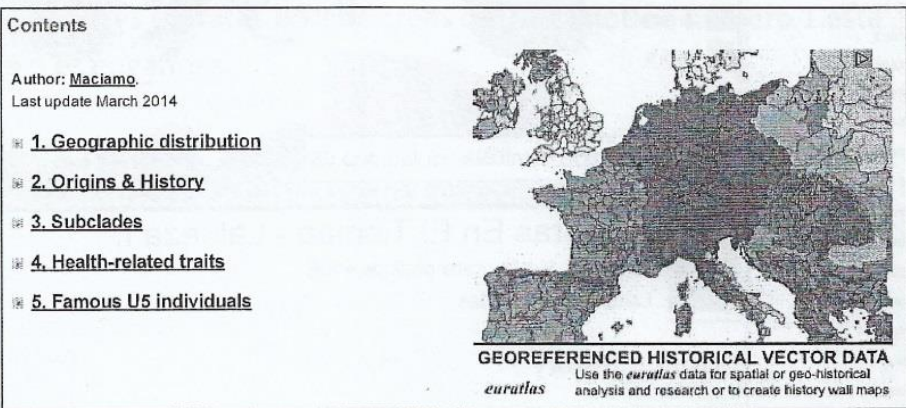

Geographic distribution

Haplogroup U5 is found throughout Europe with an average frequency ranging from $5 \%$ to $12 \%$ in most regions. U5a is most common in north-east Europe and U5b in northern Spain. Nearly half of all Sami and one fifth of Finnish maternal lineages belong to U5. Other high frequencies are observed among the Mordovians ( $16 \%$, the Chuvash $(14.5 \%)$ and the Tatars $(10.5 \%)$ in the Volga-Ural region of Russia, the Estonians $(13 \%)$, the Lithuanians $(11.5 \%)$ and the Latvians in the Baltic, the Dargins (13.5\%), Avars $(13 \%)$ and the Chechens $(10 \%)$ in the Northeast Caucasus, the Basques $(12 \%)$, the Cantabrians $(11 \%)$ and the Catalans (10\%) in norhern Spain, the Bretons ( $10.5 \%)$ in France, the Sardinans $(10 \%)$ in thaly, the Slovaks $(11 \%)$, the Croatians $(10.5 \%)$, the Poles $(10 \%)$. the Czechs $(10 \%)$, the Ukrainians (10\%) and he Slavic Russians $(10 \%)$.
lineages already clithic Europeans.

U5 is rarer in South Caucasus (3.5\%), Iran (3\%), Turkey (3\%), Syria, Lebanon, Iraq and Egypt (all around $1.5 \%$ ). It is only found at trace frequencies $(<1 \%)$ in Jordan and the Arabian peninsula. In North Africa, U5 peaks in Morocco $(4 \%)$, followed by Libya $(3.5 \%)$, Tunisia and Algeria (both $2 \%$ ).

U5 is also found in Central Asia and Siberia, where it was brought chiefly by the Indo-European migrations. U5 is mos common in Tajikistan $(7.5 \%)$, followed by Uzebekistan $(3.5 \%)$, Turkmenistan $(2.5 \%)$, Kyrgyzstan $(2.5 \%)$, Kazakhstan $(2.5 \%)$, among the Altaians $(2 \%)$ and the Buryats $(2 \%)$, and further east as far as Mongolia ( $1 \%)$.

Distribution of mtDNA haplogroup U5 in Europe, North Africa and the Middle East 
18/4/2016

DNA Tutorials Facts about Genetics Y-DNA haplogroups Haplogroup E1b1b Haplogroup G2a Haplogroup I1 Haplogroup 12 Haplogroup J1 Haplogroup J2 Haplogroup N1c Haplogroup Q Haplogroup R1a Haplogroup R1b Haplogroup T

Famous Y-DNA Y-DNA by country Y-DNA Maps MtDNA haplogroups Haplogroup $\mathrm{H}$ Haplogroup HV Haplogroup I Haplogroup J Haplogroup K Haplogroup $T$ Haplogroup U2 Haplogroup U3 Haplogroup U4 Haplogroup U5 Haplogroup U6 Haplogroup V

Haplogroup W Haplogroup X MtDNA by country MiDNA Maps Diseases linked to mtDNA Regional history Britain \& Ireland DNA France \& Benelux DNA thaly DNA Spain \& Portugal DNA Autosomal ONA Autosomal admixture maps HLA-A by country HLA-DR by country HLA-DR Maps SNPs of HLA-DR types Other DNA page Ancient DNA Haplogroups timeline Medical DNA Migration maps Origins of red hair Royal DNA Video Tutorials @ DNA

Haplogroup U5 (mtDNA) - Eupedia

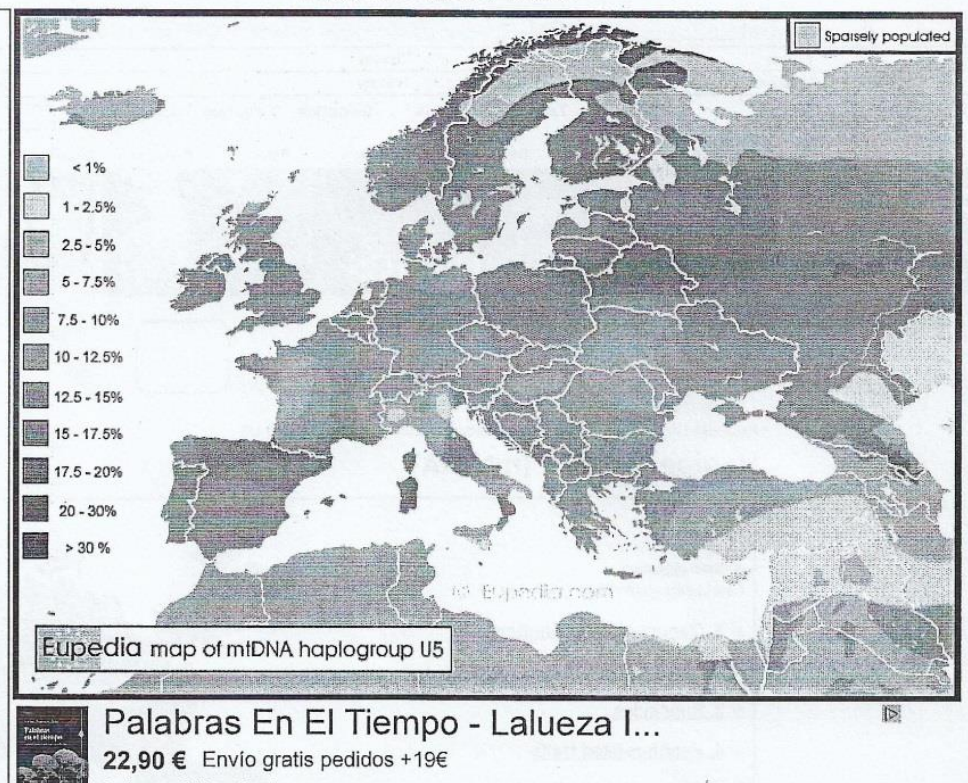

$22,90 €$ Envio gratis pedidos +19 Lalueza I Fox Carles

Origins \& History

The age of haplogroup U5 is uncertain at present. It could have arisen as recently as 25,000 years ago, or as early was 50,000 years ago. In any case, U5 appeared to be the dominant maternal lineage among Paleolithic and Mesolithic European hunter-gatherers, until the arrival of farmers and herders during the Neolithic. More than half of the Mesolithic European mtDNA tested to date belonged to Us.

\section{LGM refugia and postglacial recolonisation of Europe}

Carriers of haplogroup U5 might have entered Europe during the Aurignacian (45,000 to 35,000 years ago) or during the Gravettian period (32,000 to 22,000 years ago). It is unlikely to have arrived later. During the Last Glacial Maximum (LGM, 26,000 to 19,000 years ago), U5 people would have retreated into refugia in southern Europe, from which they would have re-expanded during the Late Glacial and postglacial periods.

It is likely that U5a and U5b lineages already existed prior to the LGM and they were geographically scattered to some extent around Europe before the growing ice sheet forced people into the refugia. Nonetheless, founder effects among the populations of each LGM refugium would have amplified the regional division between U5b and U5a. U5b would have been found at a much higher frequency in the franco-Cantabrian region. We can deduce this from the fact hat modern Wostern Eut identified belonged to U5b.

Conversely, only U5a lineages have been found so far in Mesolithic Russia (U5a1) and Sweden (U5a1 and U5a2), which points at an eastern origin of this subclade. Mesolithic samples from Poland, Germany and ltaly yielded both U5a and U5b subclades. German samples included U5a2a, U5a2c3, U5b2 and U5b2a2.

The same observations are valid for the Neolithic and Chalcolithic periods too, with U5a1 being found in Russia and

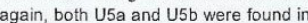
Germany, although with a much higher proportion of U5b this time - especially U5b2a, which was found both among farmers and fisher-gatherers. What's interesting is the appearance of isolated U5a1 samples in Catalonia and Portugal, both circa $3000 \mathrm{BCE}$.

Mesolithic Europeans would have belonged essentially to Y-haplogroup I, with R1a being present mostly in eastern Europe. The rare Y-haplogroup C was also found, and haplogroup $\mathrm{F}$ could also have been there. Five Mesolithic U5 samples, all dating from c. 8,000 years ago, were tested for both mitochondrial DNA and Y-chromosomal DNA. An individual from leon in nom

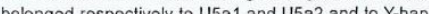

U5b1b1: signature of the extreme nomads

U5b1b1 arose approximately 10,000 years ago, over two millennia after the end of the Last Glaciation, when the Neolithic http://www.eupedia.com/europe/Haplogroup_U5_mtDNA.shtml 